Historic, Archive Document

Do not assume content reflects current scientific knowledge, policies, or practices. 
$a$ SDII

142

United States
Department of
Agriculture

Forest Service

Rocky Mountain

Forest and Range

Experiment Station

Fort Collins

Colorado 80526

General Technical

Report

RM-GTR-257

Sorsts al

\section{National Proceedings: Forest and Conservation Nursery Associations} 1994

\section{coth I}


Abstract-Landis, T.D.; Dumroese, R.K., tech. coords. 1994. National Proceedings, Forest and Conservation Nursery Associations. Gen. Tech. Rep. RM-GTR-257. Fort Collins, CO: US Department of Agriculture, Forest Service, Rocky Mountain Forest and Range Experiment Station. 320 pp.

This proceedings is a compilation of 43 papers which were presented at the regional meetings of the forest and conservation nursery associations in the United States in 1994. The combined Southern and Northeastern Forest Nursery Association Conference was held in Williamsburg, VA on July 11-14, 1994, and the combined Western Forest Nursery Association and the Forest Nursery Association of British Columbia meeting was held in Moscow, ID on August 15-19, 1994. The subject matter ranges from seed collection and processing, through nursery cultural practices, to harvesting storage, and outplanting.

Keywords: bareroot seedlings, container seedlings, nursery practices, reforestation.

Note: As part of the planning for this symposium, we decided to process and deliver these proceedings to the potential user as quickly as possible. Thus, the manuscripts did not receive conventional Forest Service editorial processing, and consequently, you may find some typographical errors. We feel quick publication of the proceedings is an essential part of the symposium concept and far outweighs these relatively minor distractions. The views expressed in each paper are those of the author and not necessarily those of the sponsoring organizations or the USDA Forest Service. Trade names are used for the information and convenience of the reader, and do not imply endorsement or preferential treatment by the sponsoring organizations or the USDA Forest Service

The policy of the United States Department of Agriculture Forest Service prohibits discrimination on the basis of race, color, national origin, age, religion, sex, or disability, familial status, or political affiliation. Persons believing they have been discriminated against in any Forest Service related activity should write to: Chief, Forest Service, USDA, PO Box 96090-6090, Washington, DC 20090-6090. 
USDA Forest Service

General Technical Report

RM-GTR-257

\title{
National Proceedings: Forest and Conservation Nursery Associations
}

\author{
Thomas D. Landis and R. Kasten Dumroese, \\ Technical Coordinators
}

This Proceedings contains the papers presented at two meetings. The combined Southern and Northeastern Forest Nursery Association Conference was held in Williamsburg, VA on July 11 14, 1994, and the combined Western Forest Nursery Association and the Forest Nursery Association of British Columbia meeting was held in Moscow, ID on August 15-19, 1994.

Funding for this publication was provided as a technology transfer service by State and Private Forestry, USDA Forest Service. 



\section{Table of Contents}

\section{Southern and Northeastern Forest Nursery Associations}

Reforestation Trends in the Eastern United States

Clark W. Lantz

Chemical Alternatives to Methyl Bromide

W. A. Carey

Organic Soil Amendments as Potential Alternatives to Methyl Bromide for Control of Soilborne Pathogens in Forest Tree Nurseries

M. E. Kannwischer-Mitchell, E. L. Barnard, D. J. Mitchell, and S.W. Fraedrich

Basamid Use and Results in the Hayward State Nursery

J. E. Borkenhagen.

Bareroot Seedling Culture Without Fumigation: Experience at Armintrout's Nursery

David Armintrout

Genetic Improvement of Southern Hardwoods-1994 Update

R. C. Kellison

Hardwood Production Techniques at Midwestern Nurseries

A. F. Stauder, III

Weed Control in Southern Hardwood Nurseries

D. B. South

Soil Fertility and Management for Culturing Hardwood Seedlings

C. B. Davey

Undercutting in Loblolly Pine

Jim Rakestraw and George Lowerts

Undercutting in Loblolly and White Pine Seedbeds

Thomas A. Dierauf

The Use of the IDS-Treatment on Southern Pine Seeds and its Effect on Seed Cost and Efficiency in the Seed Bed

J. B. McRae, U. Bergsten, and S. Lycksell.

Nurseries and the Worker Protection Standard - A Discussion

J. D. Artman

Permethrin Nursery Spray Protects Pine Seedlings Against Regeneration Weevils

T.C. Tigner. 


\section{Western Forest and Conservation Nursery Association and Forest Nursery Association of British Columbia}

Developing Container Conifer Seedling Specifications...A Balanced Approach?

Eric van Steenis

Long-term Stock Type Trial Results in B.C.: Did Stock Performance Meet Today's Standards?

Rob Bowden, R.G. Scagel....

Container Optimization-Field Data Support Container Innovation

David A. Bainbridge

Nursery Growing Density and Container Volume Affect Nursery and Field Growth of Douglas-fir and Lodgepole Pine Seedlings

David G. Simpson

Summer Plant Culling Criteria of Interior Spruce: Keeping the Bad and Throwing the Good?

Erica L McClaren, Marek J. Krasowski, and Christopher DB Hawkins....

Effects of Contrasting Fertilizer Regimes on Greenhouse Growth and Outplant Performance of Containerized Jack Pine

G.S. Henderson

Five Year Field Performance of Short Day Nursery Treated Engelmann Spruce Seedlings in the Nelson Forest Region of British Columbia

Tracy L Story, Christopher F Thompson, and Christopher DB Hawkins

Conserving Threatened Rare Plants: Some Nursery Strategies

John L. Edson, David L. Wenny, Annette Leege-Brusven, Richard L. Everett,

and Douglass M. Henderson.....

Microcomputer Order Processing and Inventory Control

David L. Wenny and Linda Geer....

Steam Sterilization of Growing Media

John W. Bartok, Jr.

Use of Frost Fabric as a Seedbed Mulch and Frost Protection Method

Randy D. Moench

Nursery Regimes Affect Seedling Size and Outplanting Performance of $1+0$ Ponderosa Pine John Sloan

Machine Vision Inspection System for Packing House Quality Control Michael P. Rigney and Glenn A. Kranzler....

Selecting and Calibrating Low-Volume Sprayers

John W. Bartok, Jr. 
The Effects of Keithia Blight on Outplanting Performance of Western Redcedar Container Seedlings at Two Reforestation Sites in British Columbia-Preliminary Results

David Trotter, Gwen Shrimpton and Harry Kope

Influence of Soil Fumigation and Fungicide Application on Outplanted Ponderosa Pine Seedlings

D.S. Page-Dumroese and A.E. Harvey.

Abscisic Acid Analogs Reduce Planting Stress in Newly Planted Seedlings

Steven C. Grossnickle and Raymund S. Folk

Rapid Assessment of Nursery Stock Viability Using a Portable Gas Analysis System:

A Component of Ontario's Seedling Quality Assessment Program

Stephen J. Colombo, Colin W.G. Templeton and P. Sampson.

Sprinkler Irrigation Management and Scheduling for Diverse Container-Grown Plants

Richard Regan

Use of Container Stock in Mine Revegetation

Jane Rodgers

Protocols for Mass Micropropagation of Antelope and Desert Bitterbrush

Annette Leege-Brusven, John L. Edson, David L. Wenny and Min Hironaka

Impact of Aphid Damage in a Bareroot Nursery and Seed Source on Survival and Growth of Outplanted White Fir Seedlings in the Sierra Nevada

John D. Stein

The Operational Seedling Testing Program at Weyerhaeuser

Y. Tanaka, P. Brotherton, S. Hostetter, S. Dyce, D. Chapman, J. Belanger, B. Johnson and S. Duke ..... 256

Can Foliage Water Content Measurements Replace Freezer Tests in Determining a Safe Lifting

Time For Frozen Storage of Conifer Seedlings?

M.J. Krasowski, A. Caputa, and C.D.B. Hawkins

Short Day Nursery Treatment Promotes Photosynthesis in Interior Spruce Seedlings:

Summary of Poster

C.D.B. Hawkins, R. Y.N. Eng and M.J. Krasowski

Grading Specifications of Ponderosa Pine Seedlings at Lucky Peak Nursery

John Sloan

Propagation of Juniperus for Conservation Planting

Bert Cregg, Scott Lee, Ted Hovland, Clark Fleege, and John Gleason

Cleaning Hardwood and Shrub Seed

Robert P. Karrfalt....

Improving Conifer Seedling Quality with CONFER

D. Bradley Smith, Eric Lloyd and Greg O'Neill . 


\section{Minutes}

Western Forest and Conservation Nursery Association:

1994 Business Meeting

\section{Listing of Participants}

Southern and Northeastern Forest Nursery Associations Meeting 289

Western Forest and Conservation Nursery Association and Forest Nursery Association of British Columbia Meeting 307 


\title{
Southern and Northeastern Forest Nursery Associations
}

\author{
Williamsburg, Virginia \\ July 11-14, 1994
}

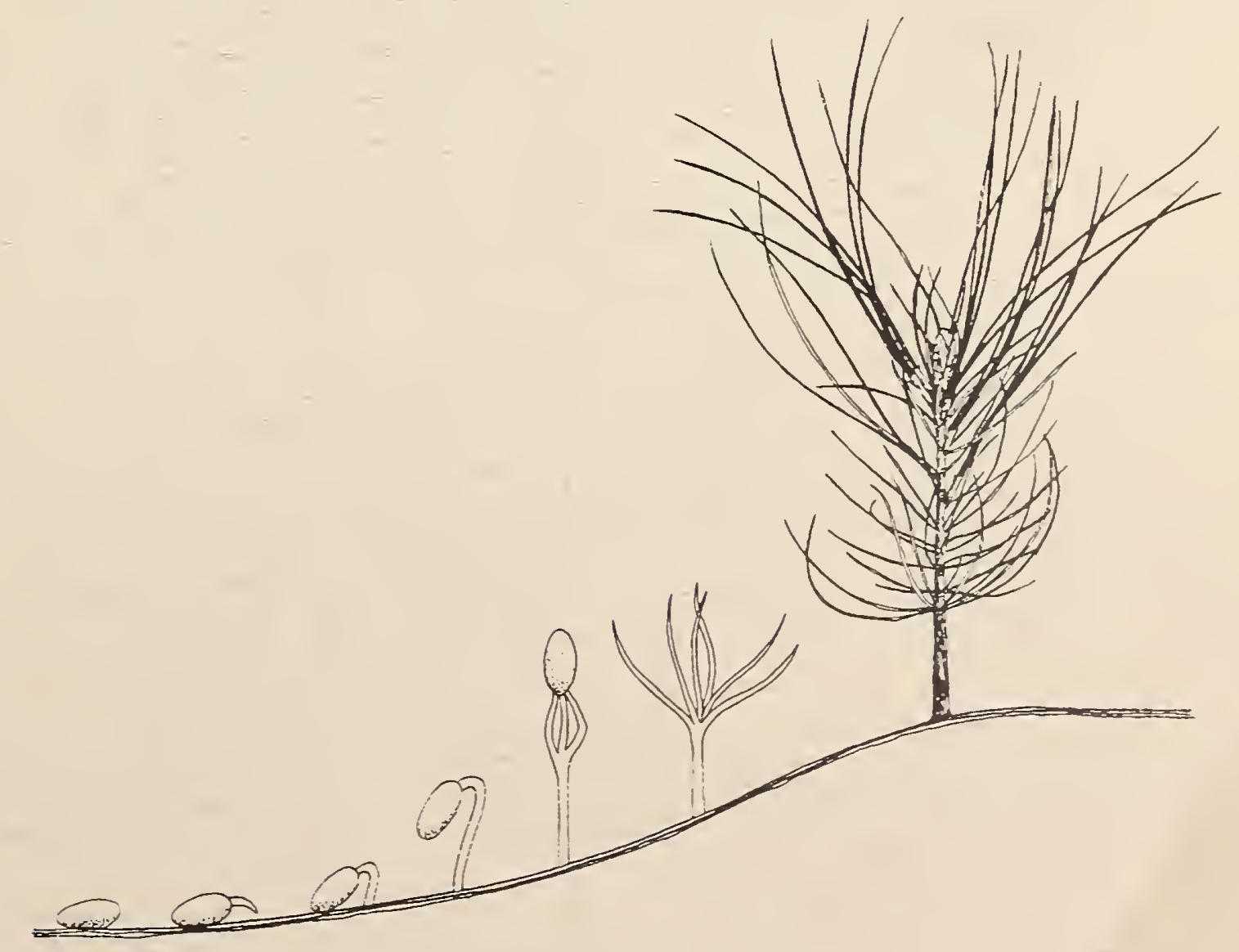





\title{
Reforestation Trends in the Eastern United States ${ }^{1}$
}

\author{
Clark W. Lantz ${ }^{2}$
}

Abstract-Private, non-industrial forest land in the eastern US must compensate for the vast amount of federal land currently under environmental restrictions in the West. As the demand for wood continues to increase nationwide, the eastern US will be in a favorable position to supply much of this wood. Unfortunately, reforestation is falling behind in the South. An average of only one half of the acres harvested is being replanted Southwide.

Suggestions are included for closing the reforestation "gap," for improving seedling quality, and for coping with change within the forestry community.

\section{THE DEMAND FOR WOOD}

With the current environmental restrictions on timber harvesting in the western US, our wood-using industries must find other sources of wood.

Many companies have turned to overseas sources of wood.

Fortunately, the eastern US has a great deal of hardwood timber in the North and large volumes of softwood timber in the South (USDA Forest Service 1990).

Forest industry, particularly in the South, is in a favorable position to satisfy much of this demand. More and more of the timber must be taken, however from private, non-industrial land. The pressure will be on the private, non-industrial forest landowner (PNIF) to supply more and more timber-both softwoods and hardwoods. Environmental restrictions in the East, while not as dramatic as these in the West, appear to affect much of the public timber supply. These restrictions will likely focus timber production on fewer acres where wood can be grown at maximum production rates (USDA Forest Service 1993).

\section{REFORESTATION RATES}

If a reliable, long-term timber supply is to be assured in the South, reforestation rates must be improved. Currently only
$50 \%$ of the acres harvested in the South are replanted. This percentage of harvested acres replanted ranges from a low of 22 in one state to a high of 93 in another state (see table 1).

Although natural regeneration will keep many acres in production, often these acres will not reach full potential. In some cases it will take several years to reach full stocking. Natural seeding from residual or adjacent seed trees may result in low quality trees compared to genetically improved seedlings that could be planted and would grow $10-15 \%$ more wood per acre per year than naturally regenerated stands.

'Lantz, C.W. 1994. Reforestation Trends in the Eastern US. IN: Landis, T.D.; Dumroese, R.K., tech. coords. National Proceedings, Forest and Conservation Nursery Associations. Gen. Tech. Rep. RM-257. Fort Collins, CO: U.S. Department of Agriculture, Forest Service, Rocky Mountain Forest and Range Experiment Station: 1-3. 
In some areas, where there is no natural seed source present, the area will often revert to a "brush field." Low quality hardwoods, greenbriar, honeysuckle and/or kudzu will take over, requiring substantial site preparation work to establish trees. This results in delayed production as well as additional cost.

\section{CLOSING THE REFORESTATION "GAP"}

Closing the reforestation "gap" (the difference between acres harvested and acres planted) will require a wellcoordinated program in 2 areas:

\section{- Education of PNIF landowners.}

\section{- "Fine-tuning" the reforestation system.}

Education of PNIF landowners is largely a continuing education challenge to state service foresters, extension foresters, county agents and industrial "LAP" foresters. Information can be transferred via workshops, shortcourses, field days, demonstration plantings and publications. One of the most effective methods is a demonstration area where local people can see the results of good reforestation work accomplished by one of their neighbors.
Table 1. Reforestation in the South.

$\begin{array}{lcccc}\text { Season } & \begin{array}{c}\text { Acres } \\ \text { Harvested }\end{array} & \begin{array}{c}\text { Acres } \\ \text { Planted }\end{array} & \begin{array}{c}\text { Percent } \\ \text { Planted }\end{array} \\ 1988-89 & 3,675 & & 2,290 & 62 \\ 1989-90 & 3,660 & 1,912 & 52 \\ 1990-91 & 2,667 & 1,709 & 64 \\ 1991-92 & 3,038 & 1,721 & 56 \\ 1992-93 & 3,392 & 1,691 & 50 \\ 1993-94 & * 4,066 & 1,696 & 42\end{array}$

"Fine-tuning" the reforestation system involves emphasis on teamwork and coordination within the organization. The system is only as effective as its "weakest link." Neither the tree improvement section nor the nursery section, nor the management section are independent units. All must work together as a team for the most effective results. A plantation monitoring system is one way to require involvement from all of these units. When plantation survival and growth are assessed on a periodic basis, participation is mandatory from nursery managers as well as management foresters. This requires teamwork from the entire organization.

Our reforestation accomplishments in the South have come about through the spirit of teamwork developed through the federal and state reforestation programs, the landowner assis- tance programs developed by forest industries, and the nursery and tree improvement cooperatives. Technical assistance provided by the state forestry agencies to PNIF landowners is a critical link in the reforestation system. Often the county forester is the only professional source of information on species, seed source and reforestation techniques available. Likewise, the seedlings storage and delivery system is unique to the state forestry agencies and it is essential for maximum seedling survival and growth. No other organization has the capability to provide this service.

\section{IMPROVING SEEDLING QUALITY}

Higher quality seedlings will survive and grow better than nursery-run seedlings. Remember-it costs no more to plant a high-quality, genetically im- 
proved seedling than a grade 2 , unimproved seedling. The difference will be higher survival, faster growth, and a more valuable tree at the end of the rotation.

Higher quality seedlings do not happen by accident. We have learned several important lessons in the last few years:

- Start with high-quality, genetically improved seeds. Make sure the seed source is well-adapted to the planting site.

- Be sure that the nursery soil has sufficient organic matter content. Most of our coarsetextured nursery soils should have at least $11 / 2 \%$ organic content $-2 \%$ is even better. Fine-textured soils need higher organic levels. When we lose methyl bromide as a fumigant, higher organic contents will help to provide a buffer against soil pathogens.

- Sow the seeds with a precision sower at low (15-22/square foot-loblolly) density.

- Install life history plots to monitor the seedling crop. Dig seedlings and examine the roots at regular intervals. Build a data base of seedling morphology at specific times during the growing season. Use this as a "yardstick" to compare seedling development through the year.
- Use undercutting, wrenching and lateral root pruning to reduce shoot growth and shape a more compact, fibrous root system.

- Use lots of T-L-C in the lifting of the seedlings.

- Ship only the large caliper, high quality seedlings with well developed first order lateral roots.

- Be sure that the seedlings are well cared for during shipping, storage and planting.

- Inspect the planting operation to be sure that the vendor is planting the seedlings correctly.

\section{HOW CAN A "TIMBER BEAST" SURVIVE IN THE TIME OF ECOSYSTEM MANAGEMENT?}

- Have patience. Reorganization and downsizing have happened before-they will happen again-life goes on!

-Speak up. When "new concepts" contradict past experience and reliable data we need to set the record straight. History and experience are just as important as new ideas.

- Be a mentor. Get to know a young person. Share your thoughts with them. Invite them to discuss their thoughts with you. Both of you will benefit.
- Keep your sense of humor. Some things are not all that serious - or important. Some things are not worth giving $100 \%$ of your time and energy.

- Take time for yourself. Go for a walk. Read a good book. Learn a new language. Go fishing!

- Be optimistic about the future. Every tree that we plant takes in carbon dioxide, ties up carbon, produces oxygen - in addition to producing future wood products, reducing erosion, providing wildlife habitat, and just generally improving our quality of life.

\section{REFERENCES}

USDA Forest Service 1990. An analysis of the timber situation in the U.S.: 1989-2040 Rocky Mountain Forest and Range Experiment Station, Ft. Collins, Co. G.T.R. RM199. 269pp.

USDA Forest Service 1993. RPA assessment of the Forest and Rangeland situation in the U.S.: 1993 Updated. Forest Resource Rept. No. 27. $75 \mathrm{pp}$. 


\title{
Chemical Alternatives to Methyl Bromide ${ }^{1}$
}

\section{W. A. Carey²}

\begin{abstract}
Three soil fumigants were evaluated at a nursery in Georgia and one in South Carolina. Seedbed density and seedling development were compared among plots treated with tarped and not tarped dazomet at 140 and $280 \mathrm{lbs} / \mathrm{ac}$, tarped and not tarped chloropicrin at 125 and $250 \mathrm{lbs} / \mathrm{ac}$, tarped MC33 at $350 \mathrm{lbs} / \mathrm{ac}$ and non-fumigated plots. Differences among treatments occurred only in South Carolina where both initial seedbed density and harvested seedlings differed with treatments. Among harvested seedlings, the high rate of dazomet and chloropicrin were not significantly different from MC33 but the low rates and controls were inferior. In a second study at the South Carolina nursery, dazomet (150 and $300 \mathrm{lbs} /$ ac tarped and not tarped), MC33 (350 lbs/ac tarped), 1,3-D (290 lbs/ac tarped), metham-sodium (400 lbs/ac tarped and not tarped), dazomet (150 lbs/ac) plus chloropicrin (115 lbs/ac tarped), and metham-sodium plus chloropicrin (400 and $115 \mathrm{lbs} / \mathrm{ac}$ tarped) were evaluated with respect to weed control. MC33 and 1,3-D had the best herbicidal activity.
\end{abstract}

Keywords: Fumigation, Pinus taeda, seedling quality, weeds control.

\section{INTRODUCTION}

Methyl bromide (MBr) fumigation of soils controls a broad spectrum of fungi, nematodes, insects, and weeds (Thompson, 1991). Because all these taxa contain potentially destructive pests of forest tree seedlings, $\mathrm{MBr}$ fumigation, with $2 \%$ or $33 \%$ chloropicrin, has become almost universal in southern nurseries (South, 1992, Carey, 1991). Virtually all southern nurserymen fumigate and very few install control-plots for evaluating pest problems (Carey and Kelley, 1993). Straightforward comparisons between fumigated and nonfumigated productions are rare. Comparisons to the pre-fumigation era are also complicated because the nursery industry itself has shifted most production to sandier soils during the time that fumigation has been extensively practiced (South and Davey, 1983). Handweeding cost provided adequate, reliable estimates for the economic benefits of $\mathrm{MBr}$ (South and
Gjerstad, 1980) and although alternative herbicides have reduced its importance for pine seedlings (South, 1992) the replacement in hardwood seedling production has been less effective (Stone, 1991). The sporadic occurrence (even in the absence of fumigation) of soil born insects and diseases further complicates estimates for the benefits of fumigation where non-fumigated comparisons are rare. Nevertheless, substantial savings are usually projected (South and Gjerstad, 1980) or

\footnotetext{
'Carey, W.A. 1994. Chemical Alternatives to Methyl Bromide. IN: Landis, T.D.; Dumroese, R.K., tech. coords. National Proceedings, Forest and Conservation Nursery Associations. Gen. Tech. Rep. RM-257. Fort Collins, CO: U.S. Department of Agriculture, Forest Service, Rocky Mountain Forest and Range Experiment Station: 4-11.
}

${ }^{2}$ Auburn University School of Forestry, $108 \mathrm{M}$. White Smith, Auburn, AL 36849-5418. 
assumed (Stone, 1991) for $\mathrm{MBr}$ fumigation. In fact, forest tree nurseries had the largest projected benefit per acre or per pound of $\mathrm{MBr}$ used of all crops that utilized significant quantities (Anonymous, 1993).

In response to rumors of the regulatory disfavor of $\mathrm{MBr}$, during the summer of 1992 , the Auburn University Southern Forest Nursery Management Cooperative (AUSFNMC) planned small plot trials to evaluate alternative fumigants.

With the first fumigation scheduled for the fall of 1992, the delusion of being ahead of the learning curve lasted only a few days. In November $1992 \mathrm{MBr}$ was listed as a potential ozone depleter. Under the authority of the Clean Air Act, the EPA has now assigned a phase-out schedule with production termination for the year 2001. Before our first trials were finished we began to test additional fumigants and a few nurseries have now initiated production scale trials primarily comparing chloropicrin, dazomet or 1,3dichloropropene with MBr. Like signs in store windows that count down the days to Christmas it seem only fair to warn nursery managers that there are only six more $1+0$ crops before 2001.

\section{ACKNOWLEDGEMENTS}

Westvaco Corporation and International Forest Seed Com- pany provided space and took care of all the non-fumigation practices required for the commercial production of pine seedlings at nurseries, respectively, in Summerville, SC and Statesboro, GA.. The cooperation of Hendrix \& Dail, Inc. who provided the equipment and application expertise was critical to the study and the contribution of Basamid ${ }^{\circledR}$ (dazomet) by BASF and all other fumigants by Hendrix \& Dail is gratefully acknowledged.

\section{MATERIALS AND METHODS}

\section{Fumigation Treatments:}

The fumigation treatments utilized these products; $\mathrm{MC} 33=$ MBC- $33^{\circledR}(67 \% \mathrm{MBr}+33 \%$ chloropicrin), Triform ${ }^{\circledR}$ (70\% 1,3 dichloropropenes $+30 \%$ chloropicrin), Dazomet is Basamid ${ }^{\text {}}$ ( $99 \%$ ai), Metham-sodium is
Sectagon- $42^{\circledR}(42 \%$ ai), Chloropicrin is $\mathrm{HDPic}^{\circledR}$ (96.5\% ai).

Table 1 lists the 11 fumigation treatments used on beds subsiquently sown with pine seed. Each treatment was randomly assigned to positions within each of five blocks. The same relationship of treatments within blocks was used at both nurseries but at Statesboro a double-bed column contained each block and treatment plots were $68 \mathrm{ft}$ long separated by $5 \mathrm{ft}$ buffers. At Summerville blocks were at right angles to beds and each bed contained five $140 \mathrm{ft}$ long treatment plots separated by $5 \mathrm{ft}$ buffers.

At Statesboro, fumigation treatments were applied October 21 and 22, 1992 to nursery beds but not tractor paths (wheel ruts). Post-treatment soil samples were

\section{Table 1. Fumigation treatments applied to loblolly pine production beds in Statesboro, GA and Summerville, SC.}

$\begin{array}{llll}\text { Compound } & \text { Rate }^{1} & \text { Application } & \text { Seal }^{2} \\ \text { None } & \text { None } & \text { None } & \text { Water } \\ \text { None } & \text { None } & \text { None } & \text { Plastic } \\ \text { Dazomet } & 140 & \text { Rototilled } & \text { Water } \\ \text { Dazomet } & 140 & \text { Rototilled } & \text { Plastic } \\ \text { Dazomet } & 280 & \text { Rototilled } & \text { Water } \\ \text { Dazomet } & 280 & \text { Rototilled } & \text { Plastic } \\ \text { Chloropicrin } & 125 & \text { Injected } & \text { Water } \\ \text { Chloropicrin } & 125 & \text { Injected } & \text { Plastic } \\ \text { Chloropicrin } & 250 & \text { Injected } & \text { Water } \\ \text { Chloropicrin } & 250 & \text { Injected } & \text { Plastic } \\ \text { MC33 } & 350 & \text { Injected } & \text { Plastic }\end{array}$

\footnotetext{
1 Pounds per acre.

${ }^{2}$ Water seals are the irrigation equivalent of 0.25 inches of rain.
} 
collected November 10, 1992 and March 5, 1993 before the treated bed structure was disturbed. The Summerville fumigation was March 18, 1993. Pretreatment soil samples were collected and fumigation treatments applied after the field was disced but before beds were formed and both the bed and future tractor paths were treated.

Treatments for a second study, installed at Summerville in the fall of 1993, are listed in Table 2. The treatments were arranged at a randomized complete block with four blocks and plots were $12 \mathrm{ft}$ by $110 \mathrm{ft}$ and separated by $5 \mathrm{ft}$ buffers. The area was disced and then fumigated, respectively, on October 24 and 26, 1993. Dazomet was rototilled into the soil in two sixfoot-wide strips and the surface of all non-tarped plots was compacted ("power-rolled") using a drum roller. All other chemicals were injected and tarped in single 12-foot-wide strips.

\section{Seedilings:}

A single loblolly pine (Pinus taeda) half-sib seedlot was sown in each nursery on April 14 (27 days after fumigation) at Summerville and May 14 (201 days after fumigation) at Statesboro. Beds were stabilized with a synthetic resin at Summerville and with pinebark mulch at Statesboro.
Numbers of live seedlings (seedbed density) and dead seedlings (damping-off) were determined 35 days after sowing at both nurseries. Two one-footwide sections across nursery beds were delineated near the center of each of replicate plot and these were resampled throughout the study. Seedbed densities were determined again at both nurseries September 810, 1993 and January 2-5, 1994.

In January 1994, seedlings from the four center drills of each seedbed-density-plot were carefully removed from the soil and a random subsample of 25 of these seedlings was taken.

Rootcollar diameters were used to determine numbers of culls (< $3.25 \mathrm{~mm})$ and number one $(>$ $4.76 \mathrm{~mm}$ ) and number two (3.26 to $4.75 \mathrm{~mm}$ ) seedlings per plot. Above and below ground portions of seedlings were separated and each sub-sample was dried to a constant weight. Seedling parameters were calculated both on a mean seedling and a per square foot basis. Mean size and mass values for a 25 seedling replicate were multiplied by plot seedbed density to obtain area values. Seedling height was assessed only for Statesboro seedlings because Summerville seedlings were top-clipped (August 5 and September 16).

\section{Weeds:}

The second fumigation trial Summerville was placed in an area with a persistent infestation of nutsedge (Cyperus spp.), a weed not adequately controlled by alternative herbicides. Because this area was not put into seedling production, differences in weed control were assessed without the subsequent application of herbicides. Weed data only from this fumigation are

Table 2. Fumigation treatments applied to soil not subsequently used for seedling production (Summerville, SC).

\begin{tabular}{|c|c|c|c|c|}
\hline & Chemical & $\begin{array}{l}\text { Rate } \\
\text { (lb/ac) }\end{array}$ & $\begin{array}{l}\text { Application } \\
\text { Method }\end{array}$ & $\begin{array}{l}\text { Soil } \\
\text { Seal }\end{array}$ \\
\hline 1 & MC33 & 350 & Injected & Tarped \\
\hline 2 & Triform & 290 & Injected & Tarped \\
\hline 3 & Dazomet & 300 & Rototilled & Tarped \\
\hline 4 & Dazomet & 300 & Rototilled & Power-roll \\
\hline 5 & Dazomet & 150 & Rototilled & Tarped \\
\hline 6 & Dazomet & 150 & Rototilled & Power-roll \\
\hline 7 & Metham-sodium & 400 & Injected & Tarped \\
\hline 8 & Metham-sodium & 400 & Injected & Power-roll \\
\hline 9 & $\begin{array}{l}\text { Dazomet + } \\
\text { Chloropicrin }\end{array}$ & $\begin{array}{l}150 \\
115\end{array}$ & $\begin{array}{l}\text { Rototilled } \\
\text { Injected }\end{array}$ & Tarped \\
\hline 10 & Metham-sodium+ & 400 & Injected & \\
\hline & Chloropicrin & 115 & Injected & Tarped \\
\hline 11 & Control & 0 & NA & NA \\
\hline
\end{tabular}


presented here. Percentages of ground covered by weeds for each treatment plot was estimated April 12 and all weeds within a randomly selected foursquare-foot area near the center of each plot were counted May 10. 1994. Weeds were categorized as either "spring" or "summer" weeds and nutsedge (Cyperus spp.) was enumerated separately.

\section{RESULTS}

\section{Seedling quality:}

At Summerville, numbers of live seedlings differed significantly between fumigation treatments 35 days after sowing (Table 3). Subsequent mortality was negligible $(0.4$ seedling per foot) and seedbed densities in May strongly predicted those of September $(r=0.95, p=0.0001)$ and January $(r=0.93, p=0.0001)$. However, the effect of fumigation treatment was not significant in in January $(p=0.30)$.

At Statesboro, numbers of damped-off seedlings did not differ among fumigation treatments 35 days after sowing (Table 3). Although the mean seedlings per square foot in June decreased from 23 to 20.6 from June to January. Fumigation treatment effects (in contrast to the trend at Summerville) increased moderately over the same period ( $p$ for June $=0.15$ and for January $=0.08$ ). Correlations for June plot densities $(\mathrm{N}=55)$ with those of September $(r=0.95$, $\mathrm{p}=0.0001)$ and January $(\mathrm{r}=0.93$, $\mathrm{p}=0.0001$ ) were significant.

Among dazomet treatments $(\mathrm{N}=20)$, seedling diameters in plots receiving $280 \mathrm{lbs} / \mathrm{ac}$ were larger $(p=0.03)$ and there was more shoot $(p=0.0001)$ and root $(p=0.009)$ mass than at the 140 lbs/ac rate. Among chloropicrin treatments $(\mathrm{N}=20)$, seedlings in plots treated with $250 \mathrm{lbs} / \mathrm{ac}$ produced more root mass per seedling $(p=0.05)$ and per square $\mathrm{ft}(\mathrm{p}=0.02)$ than those treated with $125 \mathrm{lbs} / \mathrm{ac}$. Tarping did not significantly effect seedling size or mass either in non-fumigated plots or those fumigated with dazomet or chloropicrin. Therefore, tarped and not-tarped treatments were combined for the analysis presented in Table 4. Among the five fumigation treatments (two rates each of chloropicrin and dazomet and one of MC33 and control), plots fumigated with MC33 or the high rates of chloropicrin or dazomet produced larger seedlings than those not fumigated or fumigated with low rates (Table 4).

Among dazomet or chloropicrin fumigations $(\mathrm{N}=20)$, no measured seedbed or seedling parameters differed either with rate of fumigant or tarping. Among non-fumigated plots $(\mathrm{N}=10)$, seedlings were taller $(p=0.02)$ and had more stem mass $(p=0.02)$ among non-tarped plots. However, seedbed density and seedling root mass was not significantly larger among tarped compared to non-tarped plots. There were no significant differences among Statesboro seedlings in size or mass attributable to the five fumigant by rate treatments (Table 4).

\section{Weeds:}

Weed cover by plot and numbers of all weeds and of nutsedge per frame $\left(4 \mathrm{ft}^{2}\right)$ are presented in Table 5. In May, percentage weed cover differed $(p=0.0001)$ between treatments. MC33 always had the fewest weeds and the 1,3-D and the metham-sodium plus chloropicrin were almost as good. These three treatments and the tarped metham-sodium and the dazomet plus chloropicrin were not significantly different.

In addition to nutsedge, pigweed (Amaranthus spp.), dogfennel (Eupatorium capifillifolium), and horseweed (Coneza canadensis) were common in the May survey and these (exclusive of nutsedge) were analyzed together as "summer-weeds". Other weeds were analyzed together as spring weeds. Summer weeds did not differ between treatments $(p=0.58)$. Spring weeds differed significantly for treatment effects $(p=0.0001)$ with the tarped dazomet treatments and the nontreated control having significantly more weeds than other treatments (Table 5). 
Table 3. Seedlings per square foot by nursery, date, and treatment.

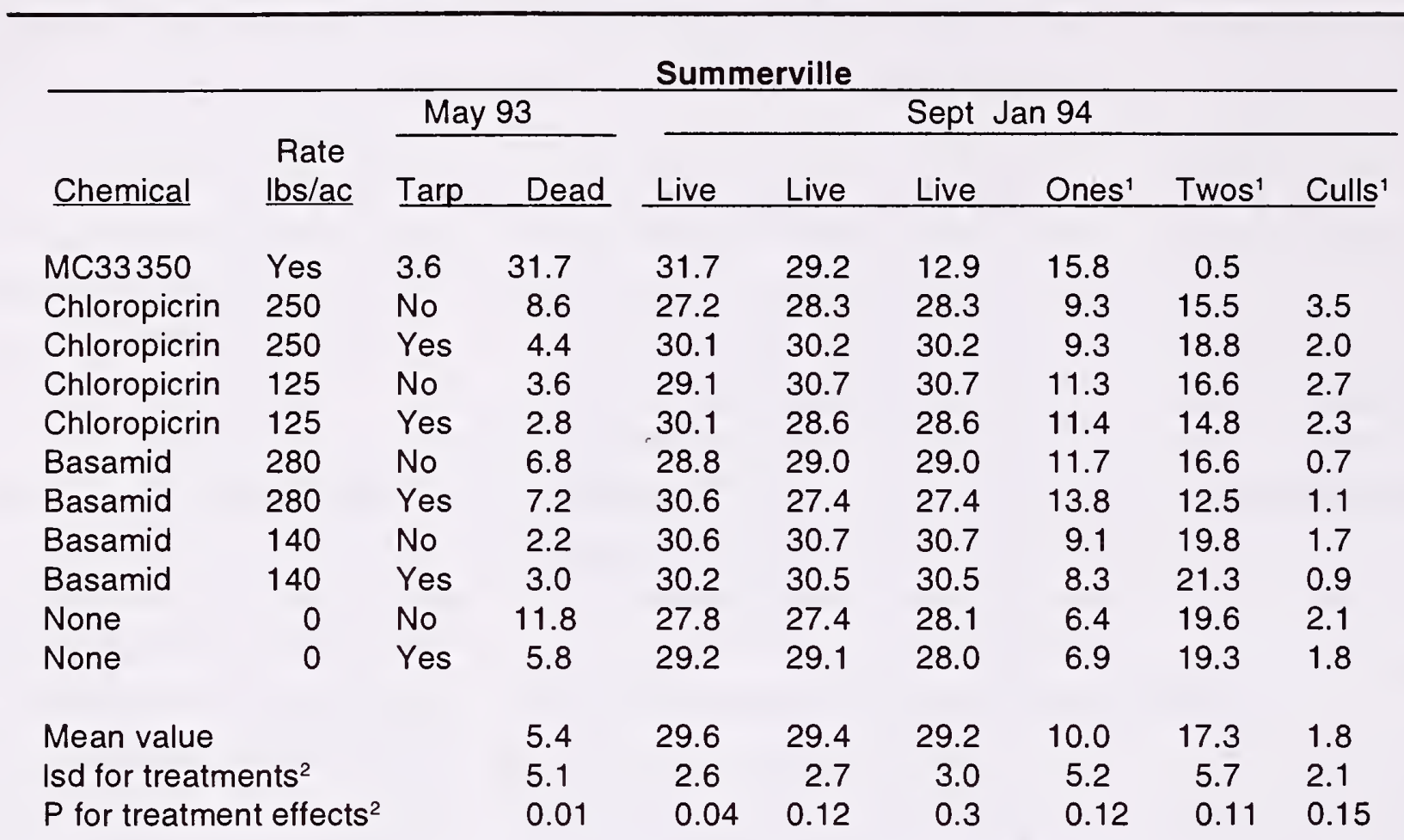

Statesboro

\begin{tabular}{|c|c|c|c|c|c|c|c|c|c|}
\hline \multirow[b]{2}{*}{ Chemical } & \multirow{2}{*}{$\begin{array}{r}\text { Rate } \\
\text { lbs/ac }\end{array}$} & \multicolumn{2}{|c|}{ June 93} & \multicolumn{5}{|c|}{ Sept Jan 94} & \multirow[b]{2}{*}{ Culls } \\
\hline & & $\underline{\text { Tarp }}$ & Dead & Live & Live & Live & Ones ${ }^{1}$ & Twos 1 & \\
\hline MC33 & 350 & Yes & 0.60 & 23.3 & 19.7 & 20.3 & 7.7 & 10.8 & 1.7 \\
\hline Chloropicrin & 250 & No & 0.60 & 24.1 & 20.7 & 22.1 & 9.1 & 11.8 & 1.1 \\
\hline Chloropicrin & 250 & Yes & 0.40 & 25.1 & 21.6 & 22.6 & 10.2 & 9.5 & 2.8 \\
\hline Chloropicrin & 125 & No & 0.20 & 21.8 & 18.9 & 19.9 & 10.1 & 8.6 & 1.1 \\
\hline Chloropicrin & 125 & Yes & 0.40 & 22.9 & 19.5 & 21.0 & 9.0 & 9.8 & 2.1 \\
\hline Basamid & 280 & No & 0.60 & 23.6 & 19.7 & 20.7 & 7.3 & 11.7 & 1.6 \\
\hline Basamid & 280 & Yes & 0.40 & 21.7 & 19.5 & 19.2 & 8.9 & 8.2 & 2.1 \\
\hline Basamid & 140 & No & 0.40 & 21.5 & 18.2 & 18.6 & 8.1 & 8.9 & 1.6 \\
\hline Basamid & 140 & Yes & 0.40 & 21.4 & 19.1 & 19.3 & 7.3 & 9.1 & 2.9 \\
\hline None & 0 & No & 1.20 & 23.6 & 20.0 & 20.8 & 8.2 & 10.2 & 2.3 \\
\hline None & 0 & Yes & 0.00 & 23.9 & 20.7 & 21.5 & 8.3 & 10.4 & 2.7 \\
\hline \multirow{2}{*}{\multicolumn{2}{|c|}{$\begin{array}{l}\text { Mean value } \\
\text { Isd for treatments }{ }^{2}\end{array}$}} & & 0.47 & 23.0 & 19.7 & 20.6 & 8.6 & 9.9 & 2.0 \\
\hline & & & 1.02 & 2.81 & 2.19 & 2.59 & 3.16 & 3.0 & 1.88 \\
\hline \multicolumn{2}{|c|}{$P$ for treatment effect ${ }^{2}$} & & 0.70 & 0.15 & 0.06 & 0.08 & 0.61 & 0.25 & 0.49 \\
\hline
\end{tabular}

1 Seedling rating where ones, two and culls have ground line diameters, respectively of $4.76 \mathrm{~mm}$, $4.75 \mathrm{~mm}-3.26 \mathrm{~mm}$, and $3.25 \mathrm{~mm}$.

2 Statistics from SAS ANOVA. 1 


\section{DISCUSSION}

The herbicidal activities of the fumigants was assessed within seedbeds but standard herbicide applications controlled weeds to the extent that production was not effected. Non-soil associated disease and insect problems were likewise expected to be controlled by standard practices. We expected that any important differences between fumigants would be measured for seed efficiency and seedling quality due to soil-pests other than weeds. The economic aspects of seed efficiency (thit is, the number of plantable seedlings culls omitted produced per unit of pure live seed) have been addressed by South (1987) who showed that small changes had significant economic impacts.

Non-significant differences between tarped and not tarped applications of dazomet or chloropicrin were somewhat surprising. Plastic tarps increase effective concentrations of MC2 or MC33 (Munnecke and Van Gundy, 1979). However, MBr boils at $4.6^{\circ} \mathrm{C}$ and is more physically active than most other fumigants at normal soil temperatures. Dazomet, applied as a granular product evolves its fumigant in contact with soil moisture. Our estimates for soil fungi (data not presented) indicate that much of its activity can occur after tarps would normally

Table 4. Seedbed densities and seedling size and mass by fumigant rate and nursery.

\begin{tabular}{|c|c|c|c|c|c|}
\hline \multicolumn{6}{|c|}{ Summerville (271 days after sowing). } \\
\hline Fumigant & $\begin{array}{c}\text { Rate } \\
\text { (lbs/ac) }\end{array}$ & $\begin{array}{l}\text { Seedlings } \\
\left(/ \mathrm{ft}^{2}\right)\end{array}$ & $\begin{array}{l}\text { Diameter } \\
(\mathrm{mm})\end{array}$ & $\begin{array}{l}\text { Shoot } \\
\text { (gm OD) }\end{array}$ & $\begin{array}{c}\text { Root } \\
\text { (gm OD) }\end{array}$ \\
\hline MC33 & 350 & $29.2 \mathrm{a}^{1}$ & $4.70 \mathrm{a}$ & $2.45 a b$ & $0.78 \mathrm{a}$ \\
\hline Chloropicrin & 250 & $29.6 \mathrm{a}$ & $4.56 \mathrm{abc}$ & $2.38 a b$ & $0.76 a b$ \\
\hline Chloropicrin & 125 & $29.2 \mathrm{a}$ & $4.40 \mathrm{~cd}$ & $2.22 \mathrm{bc}$ & $0.67 \mathrm{~b}$ \\
\hline Basamid & 280 & $28.2 \mathrm{a}$ & $4.68 \mathrm{ab}$ & $2.57 \mathrm{a}$ & $0.82 a$ \\
\hline Basamid & 140 & $30.6 \mathrm{a}$ & $4.44 \mathrm{~cd}$ & $2.00 \mathrm{c}$ & $0.69 \mathrm{~b}$ \\
\hline None & 0 & $28.1 \mathrm{a}$ & $4.21 \mathrm{~d}$ & $2.00 \mathrm{c}$ & $0.68 \mathrm{~b}$ \\
\hline \multicolumn{2}{|c|}{ Mean value } & 29.1 & 4.48 & 2.26 & 0.73 \\
\hline \multirow{2}{*}{\multicolumn{2}{|c|}{$\begin{array}{l}\text { Isd for treatments }{ }^{2} \\
P \text { for treatment effect }\end{array}$}} & 2.3 & 0.23 & 0.28 & 0.08 \\
\hline & & 0.19 & 0.001 & 0.001 & 0.001 \\
\hline
\end{tabular}

Statesboro (250 days after sowing).

\begin{tabular}{lccccc}
\hline Fumigant & $\begin{array}{c}\text { Rate } \\
(\mathrm{lbs} / \mathrm{ac})\end{array}$ & $\begin{array}{c}\text { Seedlings } \\
\left(/ \mathrm{ft}^{2}\right)\end{array}$ & $\begin{array}{c}\text { Diameter } \\
(\mathrm{mm})\end{array}$ & $\begin{array}{c}\text { Shoot } \\
(\mathrm{gm} \mathrm{OD})\end{array}$ & $\begin{array}{c}\text { Root } \\
(\mathrm{gm} \mathrm{OD})\end{array}$ \\
\hline MC33 & 350 & $20.32 \mathrm{abc}$ & $4.52 \mathrm{a}$ & $3.31 \mathrm{a}$ & $0.93 \mathrm{a}$ \\
Chlorpicrin & 250 & $22.37 \mathrm{a}$ & $4.63 \mathrm{a}$ & $3.40 \mathrm{a}$ & $1.00 \mathrm{a}$ \\
Chlorpicrin & 125 & $20.47 \mathrm{abc}$ & $4.71 \mathrm{a}$ & $3.40 \mathrm{a}$ & $1.05 \mathrm{a}$ \\
Basamid & 280 & $19.95 \mathrm{bc}$ & $4.60 \mathrm{a}$ & $3.37 \mathrm{a}$ & $1.02 \mathrm{a}$ \\
Basamid & 140 & $18.99 \mathrm{c}$ & $4.53 \mathrm{a}$ & $3.22 \mathrm{a}$ & $0.97 \mathrm{a}$ \\
None & 0 & $21.16 \mathrm{ab}$ & $4.47 \mathrm{a}$ & $2.86 \mathrm{a}$ & $0.94 \mathrm{a}$ \\
& & & & & \\
\hline Mean value & 20.6 & 4.58 & 3.25 & 0.99 \\
Isd for treatments & 1.93 & 0.28 & 0.52 & 0.15 \\
P for treatment effect & 0.012 & 0.52 & 0.21 & 0.61 \\
& & & & \\
\hline
\end{tabular}

${ }^{1}$ Means followed by the same letter not significantly different (alpha $=.05$ ).

2 "Isd" and "P" values from SAS GLM. 
Table 5 . Weeds by fumigant and date on ground not cultivated after a fall fumigation.

\begin{tabular}{|c|c|c|c|c|c|c|}
\hline Fumigant & $\begin{array}{l}\text { Rate } \\
\mathrm{Ib} / \mathrm{ac}\end{array}$ & $\begin{array}{l}\text { Chl. } \\
\text { lb/ac }\end{array}$ & Tarp & $\begin{array}{l}\text { Cover \% }{ }^{1} \\
\text { (May) }\end{array}$ & $\begin{array}{c}\text { Numbers² } \\
\text { (April) }\end{array}$ & $\begin{array}{c}\text { Nutsedge } \\
\text { \#'s }\end{array}$ \\
\hline $\mathrm{MBr}$ & 235 & 115 & Yes & $29 \mathrm{c}$ & $8.5 \mathrm{c}$ & $0.25 \mathrm{c}$ \\
\hline $1,3-D$ & 290 & 0 & Yes & $35 \mathrm{c}$ & $14.5 \mathrm{c}$ & $2.00 \mathrm{c}$ \\
\hline Dazomet & 300 & 0 & Yes & $95 \mathrm{a}$ & $101.5 \mathrm{a}$ & $36.70 \mathrm{abc}$ \\
\hline Dazomet & 300 & 0 & No & $65 \mathrm{~b}$ & $79.3 \mathrm{ab}$ & $63.52 \mathrm{a}$ \\
\hline Dazomet & 150 & 0 & Yes & 95 a & $82.8 \mathrm{ab}$ & $29.75 a b c$ \\
\hline Dazomet & 150 & 0 & No & $70 \mathrm{~b}$ & $81.8 \mathrm{ab}$ & $56.75 \mathrm{a}$ \\
\hline Dazomet & 150 & 115 & Yes & $46 \mathrm{c}$ & $55.0 \mathrm{abc}$ & $47.25 \mathrm{abc}$ \\
\hline Metham-sodium & 400 & 0 & Yes & $36 \mathrm{c}$ & $28.5 \mathrm{c}$ & $10.25 b c$ \\
\hline Metham-sodium & 400 & 0 & No & 90 a & $35.2 \mathrm{bc}$ & $5.75 a b c$ \\
\hline Metham-sodium & 400 & 115 & Yes & $38 \mathrm{c}$ & $17.3 \mathrm{c}$ & $5.50 \mathrm{bc}$ \\
\hline \multirow[t]{2}{*}{ Control } & 0 & 0 & No & $100 a$ & $91.8 \mathrm{a}$ & $31.75 \mathrm{abc}$ \\
\hline & & Isd & & 16.22 & 44.21 & 38.22 \\
\hline
\end{tabular}

${ }_{1}$ Percentage of ground covered by weeds on Apr. 12, 1994.

${ }^{2}$ Number of weeds in four square foot frame on May 10, 1994.

be removed. Chloropicrin is liquid at normal soil temperatures which evaporates slowly (boiling point $112^{\circ} \mathrm{C}$ ) to produce a gas heavier than air. It seems possible that chloropicrin evaporated and subsequently diffused slowly enough without tarping to achieve a large percentage of that effective concentration produced under plastic. Differences between effective concentration of the high and low rates of dazomet or chloropicrin indicate that measured variables (seedling and fungi but not weeds) were sensitive to treatment differences.

Seedling sizes and masses differed between fumigation treatments only at Summerville where all differences followed the same pattern. Seedlings did not differ significantly between the MC33 or the high rate of chloropicrin or dazomet but these were significantly larger than seedlings from plots treated with the low rates which did not differ from non-fumigated controls. Final seedbed densities did not differ among treatments but sizes and masses were negatively correlated with plot densities.

The effects of seedbed density on loblolly pine are well documented (South, et al. 1990). Density differences at the two nurseries result largely from sowing rates and complicate inferences for fumigation treatment effects. At Summerville, the 30 seedlings $/ \mathrm{ft}^{2}$ at the first survey changed negligibly before harvest but at Statesboro, the initial $23 / \mathrm{ft}^{2}$, was to $20 / \mathrm{ft}^{2}$ during that period due to causes not $(p=0.14)$ associated with fumigation treatments. Differ- ences in seedbed densities, between treatments, increased but remained non-significant at Statesboro and decreased at Summerville.

Non-significant differences for seedling growth among treatments at the Statesboro nursery could be attributable either to environmental conditions unfavorable for diseases controlled by fumigation or just the chance "escape" of the study area from a normally sporadic pathogen development.

Not surprisingly, estimates of weed cover in April and numbers of weeds per sample plot in May indicate essentially the same relative herbicidal activities for the fumigant treatments. It seems unfortunate that MC33, which will soon be unavailable, was the best fumigant tested but 
1,3-D was almost as good.

Although increasing the concentration of chloropicrin usually decrease the herbicidal activity of $\mathrm{MBr}$, it significantly (in April) enhanced the activity of dazomet and insignificantly that of Metham-sodium. Dazomet had the least herbicidal activity of the fumigants.

Nutsedge is currently one of the most difficult weeds to control in southern pine nurseries. Although plants per treatment are presented in Table 3 with a multiple means comparison (Duncan's for SAS ANOVA) it's logical to believe that tuber producing plants will not (as required by these statistics) be normally distributed. Nutsedge plants differed significantly between treatments for non-parametric statistics also (SAS NPAR1WAY) but multiple comparisons are difficult. Anyway, no treatments were significantly different from the control.

As a part of these studies that will be presented later, soil samples were collected each time seedlings were surveyed and subsequently plated on media selective for the development of Fusarium (Nash and Snyder, 1961), Rhizoctonia (L. J. Herr, 1973) and Trichoderma (Elad et al, 1981). Numbers of fungi identified on selective media did not differ significantly among blocks or rows for pretreatment soil samples but all fumigation treatments significantly reduced populations. The assessed fungal "groups" were differentially affected by fumigants and subsequently recovered to prefumigation levels at different rates.

\section{LITERATURE CITED}

Anonymous. 1993. The biologic and economic assessment of methyl bromide. USDA NAPIAP. 99 pp.

Carey, W. A. 1991. Insect and disease problems on hardwoods in southernnurseries. In Proceedings. Nursery pest management workshop. Athens, TN July 30-Aug 1.

Carey. W. A. and W. D. Kelley. 1994. Seedling production trends and fusiform rust control practices at southern nurseries, 1981-1991. South. J. Appl. For. 17:207-211.

Elad, Y. I. Chet and Y. Henis. 1981. A selective media for improving quantitative isolation of Trichoderma spp. from soil. Phytoparasitica 9:59-67.

Herr, L. J. 1973. Disk-plate method for selective isolation of Rhizoctonia solani form soil. Can. J. Microbiol. 19:1269-1273.

Munnecke, D. E. and S. D. Van Gundy. 1979. Movement of fumigants in soil, dosage responses, and differential effects. Ann. Rev.

Phytopathol. 17:405-429.

Nash, S. M. and W. C. Snyder. 1961. Quantative estimates in plate counts of

propagules of the bean root rot fusarium in field soils. Phytopathology 52:567-572.

South, D. B. and D.H. Gjerstad. 1980. Nursery weed control with herbicides or fumigation: an economic evaluation. SJAF $4: 40-45$.

South, D. B. and C. B. Davey. 1983. The southern forest nursery soil testing program. Alabama Agricultural Experiment Station Circular 265. 38 pp.

South, D. B., H. S. Larsen, J. N. Boyer and H. M. Williams. 1990. Seed spacing and seedling biomass: Effect on root growth potential of loblolly pine. New Forests 4:179-192.

Stone, J. M. 1991. Hardwood pest problems weeds, grasses $\&$ herbicide controls. $\underline{\text { In }}$ Proceedings. Nursery pest management workshop. Athens, TN July 30-Aug 1.

Thompson, W. T. 1991. Agricultural chemicals. Book III Miscellaneous agricultural chemicals. 1991-1992 revision. Thompson Publications. Fresno, CA. 


\title{
Organic Soil Amendments as Potential Alternatives to Methyl Bromide for Control of Soilborne Pathogens in Forest Tree Nurseries ${ }^{1}$
}

\author{
M. E. Kannwischer-Mitchell², E. L. Barnard², D. J. Mitchell ${ }^{3}$, and S.W. Fraedrich ${ }^{4}$
}

Abstract -In a multi-year project, pine seedlings are being grown in nurseries in Florida and South Carolina to evaluate the effects of organic amendments on the development of disease and potential management of plant pathogens over time without the use of soil fumigants. Seedling survival, plant quality and outplant performance are being evaluated. The study in South Carolina is currently in its first year and the study in Florida is midway through its second year. Although pathogenic fungi, including species of Fusarium, Macrophomina, Pythium, and Rhizoctonia, and plant parasitic nematodes (Mesocriconema, Paratrichodorus, and Tylenchorenchus spp.) have been detected, no serious disease development has been observed. At the end of the first growing season in the Florida nursery, seedlings from fumigated plots were taller than plants from control plots. The sizes of seedlings from amended plots, however, did not differ from sizes of plants from either fumigated or control plots.

Keywords: pine bark, compost, Pinus elliottii var. elliottii Engelm., Pinus taeda L.

\section{INTRODUCTION}

Over the past several decades, forest tree nurseries, like many agricultural production systems, have relied primarily on fumigation with methyl bromide for the management of soilborne plant pathogens and other pests. The planned elimination of the use of methyl bromide in the near future has emphasized the need to evaluate other potential pest management strategies

(Civerolo, et al. 1993). The

Technology Development

Project reported on herein is funded by the U.S. Forest Service (Region 8 , Forest Health) to evaluate the comparative development of disease and the potential management of soilborne pathogens in forest tree nurseries without the use of fumigants and with the addition of organic amendments to the soil. The effects of soil organic amendments on plant pathogens and on the control or suppression of disease have been reviewed by Hoitink and Fahy (1986). Organic amendments have been shown to control by chemical inhibition of pathogens and by antagonism or suppression of pathogens by organisms associ-

'Kannwischer-Mitchell, M.E.; Barnard, E. L.; Mitchell, D. J.; Fraedrich, S.W. 1994. Organic Soil Amendments as Potential Alternatives to Methyl Bromide for Control of Soilborne Pathogens in Forest Tree Nurseries. IN: Landis, T.D.; Dumroese, R.K., tech. coords. National Proceedings, Forest and Conservation Nursery Associations. Gen. Tech. Rep. RM-257. Fort Collins, CO: U.S. Department of Agriculture, Forest Service, Rocky Mountain Forest and Range Experiment Station: 12-15.

${ }^{2}$ Florida Division of Forestry, FDACS, P.O. Box 147100, Gainesville, FL 32614-7100..

${ }^{3}$ University of Florida, Gainesville, FL 32611.

${ }^{4}$ SEFES, PO Box 70, Olustee, FL 32072. 
ated with or favored by the organic amendments. In the present study, pine seedlings are being grown under standard nursery conditions in Florida and South Carolina in soils receiving no treatment (control), methyl bromide treatment, pine bark amendment, and aged or composted organic amendments. The study is in its initial year in South Carolina and in the second year in Florida.

\section{MATERIALS AND METHODS}

Field tests were initiated in May 1993 in a slash pine (Pinus elliottii var. elliottii Engelm.) nursery compartment at the Florida Division of Forestry's Andrews Nursery in Chiefland, Florida. Soil treatments included an application of methyl bromide (67\% methyl bromide plus $33 \%$ chloropicrin) at 392 $\mathrm{kg} / \mathrm{ha}$ (350 lbs/A), pine bark, composted yard waste, and a control without treatment. Each organic amendment was applied in a 2.5 - and 5.0-cm-thick layer with a manure spreader and tilled into the soil to a depth of $15-20 \mathrm{~cm}$. Plots were arranged in a split block design with four replications of each treatment. Each plot was three seedbeds wide by $36.6 \mathrm{~m}$ (120 ft) long, and plots were separated by fumigated buffer areas. Seedling stand counts were made in three permanent subplots ( 31 $\mathrm{cm} \times 123 \mathrm{~cm}$ ) that were established approximately $123 \mathrm{~cm}$ apart in the center of the middle bed of each plot. Soil samples were taken from each plot prior to treatment, at planting, and when seedlings were lifted. Each soil sample consisted of a bulk of 20 cores (2.5-cm-diam) from the top $15 \mathrm{~cm}$ of soil. Soil dilutions were plated in potato dextrose agar amended with $1 \mathrm{ml}$ Tergitol NPX, 0.1 g streptomycin sulfate, and $0.5 \mathrm{~g}$ chlortetracycline hydrochloride per liter (Steiner and Watson 1965) to establish background fungal counts and in $1 / 10$ th-strength tryptic soy agar plus $50 \mathrm{mg}$ cycloheximide per liter to quantify bacteria and actinomycete populations. The following media were used to isolate specific plant pathogenic fungi: Komada's medium for Fusarium spp., Phytophthora selective medium (PAR) for species of Pythium and Phytophthora, tannic acid benomyl agar (with 2 mg metalaxyl / L substituted for pyroxychlor) for Rhizoctonia spp., and Macrophomina semiselective medium (MP) for the isolation of Macrophomina phaseolina (Singleton, Mihail and Rush (eds.) 1992). Standard chemical soil nutrient analyses and nematode assays also were performed.

\section{Plant samples were taken} from each plot $3 \mathrm{wk}$ after planting (40 seedlings per plot), at midseason (10 seedlings per plot) and at lifting in Jan. 1994 (10 seedlings per plot). Whole small seedlings or roots and stems of larger plants were plated on potato dextrose agar amended with $0.1 \mathrm{ml}$ Tergitol NPX, $0.25 \mathrm{~g}$ ampicillin and 0.01 $\mathrm{g}$ rifampicin per liter to determine the fungi associated with plants from the various treatments. Additional seedlings were taken to measure plant growth parameters and for chemical tissue analyses. Seedlings exhibiting disease symptoms also were examined and plated on selective media as they were observed. Fungi isolated from plants are being evaluated in growthroom tests to determine their pathogenicity.

To assess their field survival and growth, seedlings from the various treatments were planted on an operationally cutover and bedded, flatwood forest site. Fifty seedlings from each plot were planted at a $1.23 \times 3.1 \mathrm{~m}(4$ $x 10 \mathrm{ft}$ ) spacing in each of three replicated rows at the outplanting site. Plant growth will be evaluated on a yearly basis.

This year the project is continuing at the Andrews Nursery with the same treatments superimposed on the plots. Sampling is being conducted as described for 1993. A similar trial has been established in 1994 at the International Paper Company Nursery in Bleinheim, SC. In this nursery, the study was initiated with loblolly pine (P. taeda L.) in a field in the third consecutive year of production following fumigation. Treatments are 
fumigation with methyl bromide, $2.5 \mathrm{~cm}$ of pine bark, $2.5 \mathrm{~cm}$ of aged hardwood bark (bark was piled on site for $4 \mathrm{mo}$ ), and a nontreated control. Amendments were applied as described above. Plots were three plant beds wide

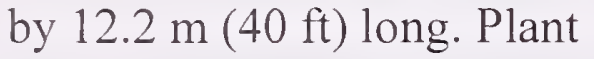
survival and growth characteristic will be measured. Seedling samples will be plated at midseason (August) and at the time of lifting (December) to determine the fungi associated with the plant roots.

\section{RESULTS AND DISCUSSION}

Plant pathogenic fungi detected by soil plating and isolated from seedling roots from the 1993 study at Andrews Nursery include: Pythium myriotylum, Athelia rolfsii, Macrophomina phaseolina, Fusarium spp., Rhizoctonia sp., Phoma sp., Alternaria sp., and Aspergillus sp. Ring

(Mesocriconema spp.), stubby root (Paratrichodorus spp.), and stunt (Tylenchorenchus spp.) nematodes also were detected in soil from Andrews Nursery.

Despite the detection of these potential plant pathogens little disease was observed in the field after the first year of the study. Seedling densities in each treatment remained fairly constant from June to the end of the growing season (Fig. 1). After the completion of germination, seedling density was significantly greater in the fumigated treatments than in the nontreated

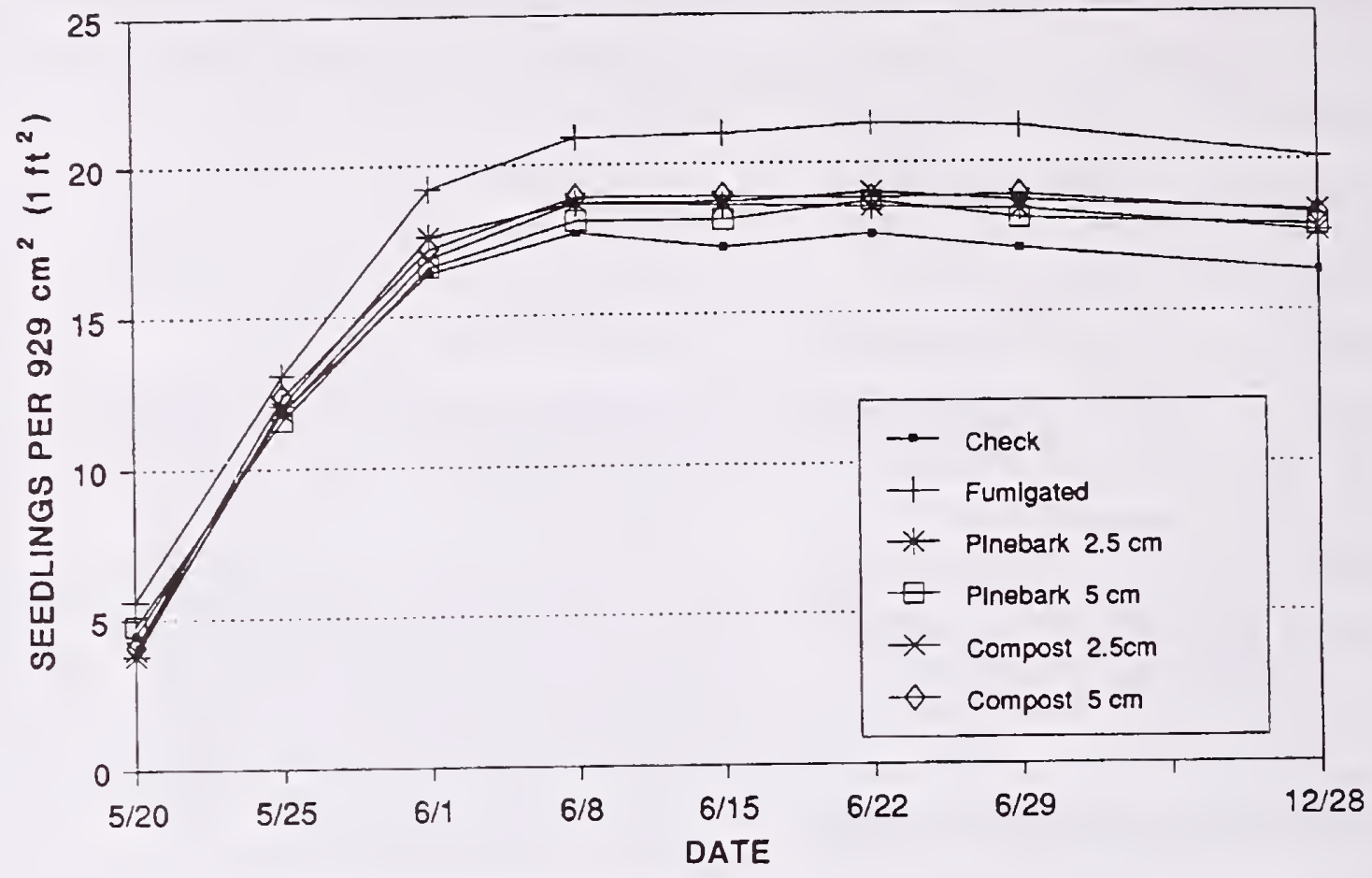

Figure 1. Slash pine seedling density over time at Andrews Nursery, Chiefland, Florida in 1993. Numbers of plants in fumigated plots were significantly greater $(P<0.05)$ than in control plots. Plant densities in plots with organic amendments did not differ from those in either the fumigated or control plots.

Table 1. Effects of soil treatments in 1993 on slash pine seedling morphology at the time of lifting at Andrews Nurserv in Chiefland, Florida.

\begin{tabular}{|c|c|c|c|c|c|}
\hline \multirow[b]{2}{*}{ Treatment } & \multirow{2}{*}{$\begin{array}{l}\text { Height }^{a} \\
(\mathrm{~cm})\end{array}$} & \multirow{2}{*}{$\begin{array}{l}\text { Stem }^{\mathrm{a}} \\
\text { Diameter } \\
\text { (mm) }\end{array}$} & \multicolumn{2}{|c|}{ Dry Weight ${ }^{b}$} & \multirow[b]{2}{*}{$\underline{S R}^{c}$} \\
\hline & & & Shoots & Roots & \\
\hline Check & $19.5 x^{d}$ & $4.6 x$ & $5.8 x$ & $2.4 x$ & 2.4 \\
\hline Fumigated & $25.2 y$ & $4.9 x$ & $7.1 x$ & $2.5 x$ & $2.9 x$ \\
\hline Pine bark $2.5 \mathrm{~cm}$ & $21.8 x y$ & $4.5 x$ & $6.0 x$ & $2.2 \times$ & 2.8 \\
\hline Pine bark $5 \mathrm{~cm}$ & $22.5 x y$ & $4.4 x$ & $6.0 x$ & $2.4 x$ & $2.4 x$ \\
\hline Compost $2.5 \mathrm{~cm}$ & $23.6 x y$ & $4.7 x$ & $7.0 x$ & $2.4 x$ & 2.9 \\
\hline Compost $5 \mathrm{~cm}$ & $21.1 x y$ & $4.6 x$ & $5.6 x$ & $2.2 x$ & \\
\hline
\end{tabular}

aalue is an average from 50 seedlings.

b $V$ alue is an average from 20 seedlings.

'Represents the ratio of average dry shoot weight to average dry root weight. dValues followed by the same letter are not significantly different $(P<0.05)$. 
controls $(\mathrm{P}<0.05)$, while there were no differences among plant densities in amended treatments and those from either the fumigated or the control plots.

When plant growth parameters were compared at the end of the season (Table 1.), plants from the fumigated treatment were taller than all other plants except those from the treatment with $2.5 \mathrm{~cm}$ of composted yard waste $(\mathrm{P}<0.05)$. Seedlings in plots with $5 \mathrm{~cm}$ of pine bark and $2.5 \mathrm{~cm}$ of composted yard waste also were taller than the control seedlings. No differences were observed in stem diameters, shoot weights, root weights, or the shoot/root ratios among plants from any of the treatments.

These field tests for the evaluation of the development of disease without the use of soil fumigation have been established in areas that already had been in plant production without fumigation for several years to increase the likelihood of detection of plant pathogen populations that may already have started to build up. The study will be continued over several years to simulate what may happen over time without fumigation and to assess the long term effects that organic amendments may have on any developing disease problems caused by soilborne plant pathogens. Results also may be useful in assessing the economic feasibility of using organic amendments in the large scale production of pine seedlings.

\section{ACKNOWLEDGEMENTS}

We thank the following cooperators in this project: Mr. Steve Gilley of the Florida Division of Forestry's Andrews Nursery, Mr. Ken Woody of International Paper Company, and JSC Container Corporation of America. The technical assistance of Mr. Ernie Ashe, Florida Division of Forestry and Ms. Patricia Rayside, University of Florida, was greatly appreciated.

\section{LITERATURE CITED}

Civerolo, E.L., et al (eds.). 1993. Alternatives to Methyl Bromide: Assessment of Research Needs and Priorities. U. S. Dept. Agric. Proceedings, U.S.D.A. Workshop on Alternatives to Methyl Bromide. Arlington, VA. 85 pp.

Hoitink, H.A., and P.C. Fahy. 1986. Basis for the control of soilborne plant pathogens with composts. Ann. Rev.

Phytopathol. 24:93- 114.
Singleton, L.L., J.D. Mihail, and C.M. Rush (eds.). 1992. Methods for Research on Soilborne Phytopathogenic Fungi. APS Press, St. Paul. MN. 265 pp.

Steiner, G.W., and R.D. Watson. 1965. Use of surfactants in the soil dilution and plate count method. Phytopathology 55:728-730. 


\section{Basamid Use and Results in the Hayward State Nursery ${ }^{1}$}

\section{J. E. Borkenhagen²}

Abstract-Basamid soil fumigation was compared to three different soil fumigants and two formulations of essentially the same product as Basamid under operational conditions. Basamid in this study was equal to or superior to any of the fumigants tested, provided certain specific application techniques were followed. The results presented here are from red pine seedbeds; however, in other tests not reported here on other species and transplants, the results are comparable.

Keywords: Basamid, application techniques, seedbeds.

\section{INTRODUCTION}

In 1962 we began testing and comparing various soil fumigants at the Hayward Nursery. We were looking for a soil fumigant that was relatively easy and safe to apply that would give consistent control of soil-borne pathogens and also give reasonable weed control.

The fumigants that were tested were Vapam, Methyl Bromide (MC-2), Trizone, Mylone 85W, Mylone 50D, and Basamid. In the initial trials Mylone 50D and $85 \mathrm{~W}$ were used. These two fumigants have been taken off the market and Basamid has taken their place. Basamid (Dazomet) breaks down into methylisothiocyanate just as Mylone did. There are two main differences when comparing Mylone and Basamid, those being Basamid is $99 \%$ active ingredient and is granular like salt or sugar while the Mylone is more of a powder formulation.

In our tests we found Basamid to be comparable to Mylone 50D. Both of these products were very easy to apply, relatively safe for the applicator, and gave the desired control of the pests we were targeting. Trizone, MC-2, and Vapam controlled targeted pests but were more time-consuming and costly, harder to handle, and somewhat more dangerous to apply. When using any of the products tested, we found that method and care in application were very important if satisfactory results were to be obtained.

\section{TRIAL AREA AND DESIGN}

The trial areas used for this study were operational seedbeds at the Hayward State Nursery. The soil at the nursery is a sandy loam with an average $\mathrm{pH}$ of 5.8 , silt clay $14 \%$, organic matter $2.4 \%$, and exchange capacity of $5.4 \mathrm{me} / 100 \mathrm{~g}$. The fumigants used were ones that we had been using at the nursery that had shown promise. All fumigants were applied in an operational manner. The trials were not set up to be completely.statistically sound but rather to give us an idea of how these particular

\footnotetext{
'Borkenhagen, J.E. 1994. Basamid Use and Results in the Hayward State Nursery. IN: Landis, T.D.; Dumroese, R.K., tech. coords. National Proceedings, Forest and Conservation Nursery Associations. Gen. Tech. Rep. RM-257. Fort Collins, CO: U.S. Department of Agriculture, Forest Service, Rocky Mountain Forest and Range Experiment Station: 16-18.
}

${ }^{2}$ Wisconsin DNR, Hayward State Nursery, Hayward, Wisconsin. 
fumigants would perform under true operational conditions. The seedling densities were arrived at from the regular tree inventory procedures at the nursery.

\section{SOIL CONDITIONS}

A cover crop of buckwheat had been growing on all trial areas. The cover crop was plowed under and disked early in July. The area was left fallow until fumigation the first week in August. By this time the cover crop is quite well deteriorated as is called for by the fumigant labels. We have to fumigate at the Hayward Nursery during the first week in August in order to ensure that we have soil temperatures of 50-60 degrees $F$. as is required for good fumigation results. In all trials nothing was done to the soil prior to application with the exception being that Mylone $85 \mathrm{~W}$ was applied and just water-sealed in which case we disked the soil before application.

\section{METHODS AND RATES OF APPLICATION}

Mylone and Basamid were applied at 250 pounds of active ingredient per acre based on past results. Rototilling was used over other forms of incorporation for the same reason. The fumigated areas were left undisturbed until seeding in early October. At that time a light shallow mechanical raking was done to prepared the seedbeds.

\section{Mylone $85 \mathrm{~W}$}

In the first method of application, the soil was worked up by disking immediately before application. 250 pounds of active ingredient per acre was applied with a Gandy fertilizer spreader and the fumigated area was immediately water-sealed with two hours of irrigation to incorporate the fumigant and form a seal.

In the second method of application, the soil was not worked up prior to spreading 250 pounds of active ingredient per acre with a Gandy fertilizer spreader. Immediately after application, the Mylone was roto-vated to a depth of 5-6 inches, rolled and water-sealed for two hours.

\section{Mylone 50D}

The first method used no soil preparation immediately prior to application. 250 pounds of active ingredient per acre was applied with a Gandy spreader. The fumigant was immediately rotovated to a depth of 5-6 inches and water-sealed for two hours.

The second method was the same as for the first except that the area was rolled immediately after roto-vating before the two hour water seal.

\section{Vapam}

50 gallons of product was mixed with 50 gallons of water and applied with a blade-type injector to a depth of 8-10 inches at 50 gallons per acre of active ingredient. The area was then immediately covered with a polyethylene tarp for 48 hours. Two weeks after application the area was worked with a springtooth harrow to vacate the fumigant.

\section{Trizone}

This is a gas and was applied under a polyethylene tarp to an area that had been worked up immediately before application of the Trizone at a rate of 200 pounds per acre of product. The soil was not disturbed until the time of seeding.

\section{Methyl Bromide (MC-2)}

The MC-2 was applied under a polyethylene tarp to soil in good tilth at the rate of 435 pounds of product per acre. The soil was not disturbed until the time of seeding .

\section{Basamid}

Basamid was applied with a Gandy spreader at the rate of 250 pounds of active ingredient per acre. The fumigated area was roto-vated, rolled, and watersealed for two hours. The soil was not disturbed until the time of seeding.

Soil samples were taken from all fumigated areas before seeding and tested for presence of the fumigant. All samples indicated that sufficient evacuation of the fumigant had occurred and the areas could be 
seeded to trees. Before seeding in early October, all areas were worked up to a depth of 1-2 inches to provide a satisfactory bed for seeding. After seeding, an application of the pre-emergent herbicide, Dacthal $75 \mathrm{~W}$, was applied at 8 pounds of active ingredient per acre.

\section{RESULTS AND DISCUSSION}

All of the fumigants used except the Mylone $85 \mathrm{~W}$ produced projected shipping densities of 30-35 trees per square foot (Table 1). The Dazomet (Mylone, Basamid) fumigants produced better results as the method of application increased in intensity. Mylone 50D and Basamid were equal in their effects and produced 36 trees per square foot at shipping time which was 1 tree more than the target high of 35 per square foot. Our results indicate that to gain the most from Basamid or Mylone 50D, they require rotovating, rolling, and a two-hour water seal. For some unknown reason, Mylone $85 \mathrm{~W}$ did not perform well for us. We did not pursue this any further because of the availability of Mylone 50D. In later years we used Basamid due to the fact that Mylone 50D was not available. We have found that this product works as well as the Mylone 50D did under the conditions at Hayward.

We believe if we could get the Basamid in to a depth of 8-10 inches, we would obtain better control of certain soil-borne pathogens that do give some problem at times in certain other species. We will be running tests this summer on various types of equipment to see if we can increase the depth of application in the Basamid.

\section{CONCLUSION}

Basamid soil fumigant does a very good job of fumigating the soil at the Hayward Nursery. It was at least equal to all other fumigants tested. The Dazomet fumigants must be thoroughly incorporated into the soil, rolled, and water sealed for two hours to get optimum results. To ensure good weed control, we used an application of Dacthal $75 \mathrm{~W}$ at 8 pounds of active ingredient per acre over the newly seeded beds. The main reason for doing this is due to the need to fumigate in August to have optimum soil temperatures at Hayward. With this early fumigation, some weed seeds are blown and washed into the fumigated area and cause weed problems in the fall or spring if a pre-emergent herbicide is not applied.

Table 1. Wisconsin Hayward State Nursery.

\section{Summary of Fumigation Results \\ 1962 to Present in 1-0 Red Pine \\ (Desired seedlings per square foot $=30-35$ at shipping)}

\begin{tabular}{|c|c|c|c|c|}
\hline \multicolumn{2}{|c|}{ Active Ingredient } & Method of Application & \multicolumn{2}{|c|}{$\begin{array}{l}\text { Trees/Square Foot } \\
\text { End of First Year }\end{array}$} \\
\hline Control & None & None & 22 & $(18)$ \\
\hline Mylone $85 \mathrm{~W}$ & $250 \mathrm{lbs}$. & Spread with Gandy and water sealed & 29 & $(24)$ \\
\hline Mylone $85 \mathrm{~W}$ & $250 \mathrm{lbs}$. & Spread with Gandy, rototilled and water sealed & 35 & (28) \\
\hline Vapam & $45-50$ gals & Injected under poly tarp and covered 48 hours & 40 & $(32)$ \\
\hline Trizone & $200 \mathrm{lbs}$. & Injected under poly tarp and covered 72 hours & 42 & (34) \\
\hline MC-2 & 435 lbs. & Injected under poly tarp and covered 48 hours & 43 & (35) \\
\hline Mylone 50D & $250 \mathrm{lbs}$. & Spread with Gandy, rototilled and water sealed & 43 & (35) \\
\hline Mylone 50D & $250 \mathrm{lbs}$. & Spread with Gandy, rototilled, rolled \& water sealed & 44 & (36) \\
\hline Basimid & $250 \mathrm{lbs}$. & Spread with Gandy, rototilled, rolled \& water sealed & 44 & (36) \\
\hline
\end{tabular}

() Projected shipping density @ 2-0 


\section{Bareroot Seedling Culture Without Fumigation: Experience at Armintrout's Nursery ${ }^{1}$}

\section{David Armintrout ${ }^{2}$}

At Armintrout's Nursery, we had a long history of using methyl bromide for soil fumigation. In the 1950's we fumigated by hand, using large 4 mil sheets of plastic and 100 pound cylinders of methyl bromide which were placed on scales and the desired weight was released. Later, these plastic tarps were "flipped", and the process was repeated on the adjacent ground. By the time I became involved, the only difference was that we used individual small cans of gas. In the 1970's, commercial applicators using the continuous tarp method, did our fumigation. Then in the 1980's, we bought the equipment, were trained and certified, and again, did our own fumigation.

I was never totally satisfied with fumigation. Damping- off disease could still be a problem. Certain weeds were actually stratified by the fumigation and germinated with a vengeance when present in the soil. Weed seeds either blew into the seedbeds, or were carried in with the irrigation water. There seemed to be a nutrient tie-up, especially with spruce. The cost of fumigation was a concern, as was the extra work and the disposal of the plastic.

I never considered raising seedlings without fumigation until after the herbicide Goal became a part of our routine. At first, we only experimented with Goal, then as our confidence in it grew, we expanded its use to the entire seeding. Then we experimented with growing seedlings without fumigation. Again, we started small, with the trees that we thought would have the best chance, which was Scotch pine. We were successful, which led us to keep expanding the ground that we didn't fumigate. Eventually, we stopped fumigating entirely, and sowed over 20 acres of conifers in the spring, without fumigation.

We only sow our seedbeds on ground that is relatively clean. Land that has been bare fallowed works very well. We use a program of preventative fungicide spraying and the herbicide Goal. All I can say is that it works for us. My advice to anyone in making any changes in their growing routine, is to start small and experiment, then expand on that.

'Armintrout, D. 1994. Bareroot Seedling Culture Without Fumigation: Experience at Armintrout's Nursery. IN: Landis, T.D.; Dumroese, R.K., tech. coords. National Proceedings, Forest and Conservation Nursery Associations. Gen. Tech. Rep. RM-257. Fort Collins, CO: U.S. Department of Agriculture, Forest Service, Rocky Mountain Forest and Range Experiment Station: 19.

${ }^{2}$ Armintrout's, West Michigan Farms, Inc., 1156 Lincoln Road, Allegan, MI 49010. 


\title{
Genetic Improvement of Southern Hardwoods-1994 Update ${ }^{1}$
}

\author{
R. C. Kellison²
}

Abstract-Hardwood tree improvement programs have been in progress since the late 1950's. Because of the low emphasis given to hardwood plantations during the ensuing years, however, only marginal genetic gain has been achieved with indigenous hardwoods. A number of exotic species, especially Eucalyptus spp. and Alnus glutinosa, have been extensively tested, but they almost completely failed under the extensive silviculture provided them.

Strong emphasis has recently been placed on the need for intensively managed hardwood plantations. To accomplish that objective, the genetics program for sweetgum and sycamore has been intensified. That involvement includes clone banking of genetic selections from open-pollinated progeny tests that were established from 1966 to 1981, and the creation of elite populations. The open- and controlpollinated progeny from these populations will be greenhouse and field tested as seedlings and as rooted cuttings. Advances in molecular genetics will allow genetic gains to be obtained from these populations in about half the time that would be required from a conventional tree improvement program.

\section{BACKGROUND}

Interest in genetic improvement of the southern hardwoods had its origin in the late 1950's and early 1960's. It stemmed from the emphasis being given to the genetic improvement of the southern pines. The difference was that the southern pines were being planted on a large scale which begged for a genetic improvement program. More than two million acres of pine seedlings were planted annually during the height of the Soil Bank Program in 1958 and 1959 (McCleary 1992). In contrast, almost no hardwoods were being planted on a commercial scale. The few thousand seedlings being planted consisted primarily of black walnut and yellowpoplar, almost none of which survived to age five.

\section{A few hardwood enthusiasts} within the membership of the $\mathrm{N}$. C. State-Industry Tree Improve- ment Program, which devotes its activities to pines, expressed the need to initiate hardwood tree improvement programs with selected species. This activity gained momentum for species such as red maple (Acer rubrum), yellow-poplar (Liriodendron tulipifera), cherrybark oak (Quercus falcata var. pagodafolia), sweetgum (Liquidambar styraciflua) and sycamore (Platanus occidentalis).

\footnotetext{
'Kellison, R.C. 1994. Genetic Improvement of Southern Hardwoods-1994 Update. IN: Landis, T.D.; Dumroese, R.K., tech. coords. National Proceedings, Forest and Conservation Nursery Associations. Gen. Tech. Rep. RM-257. Fort Collins, CO: U.S. Department of Agriculture, Forest Service, Rocky Mountain Forest and Range Experiment Station: 20-25.
}

${ }^{2}$ North Carolina State University, Raleigh, North Carolina. 
The result of the emphasis on hardwood genetics began to take its toll on the Tree Improvement Program. The solution was to form a separate universityindustry cooperative which resulted in the formation of the Hardwood Research Cooperative on July 1, 1963.

At about the same time other organizations began hardwood tree improvement programs in the U. S. South. Among those organizations were the U. S. Forest Service, Tennessee Valley Authority, Texas A \& M University, Mississippi State University, University of Tennessee, and a number of state forest services. However they, like the N. C. State Hardwood Cooperative with its industrial members, were not planting hardwoods on a scale that would justify the tree improvement investment. The exceptions were a number of organizations in the Mississippi Delta, such as Crown Zellerbach Corp., who were planting cottonwood (Populus deltoides) on a commercial scale. Those industrial organizations depended upon the USDA Forest Service, Stoneville, Mississippi for their hardwood genetics research.

\section{"Silage" Cellulose}

Another major effort of the 1960's was the "Silage" Cellulose Project at Athens, Georgia. Headed by Dr. Robert McAlpine of the U. S. Forest Service and Dr. Klaus Steinbeck, University of Georgia, the project focused on sycamore although a number of other species such as sweetgum and yellow-poplar were also evaluated. The concept was to plant the trees at close spacing, ranging from 2,000 to 6,000 trees per acre. The trees, without genetic improvement, were intensively managed with the idea that they would be harvested at about five years of age. The large financial investment was to be partially offset by managing for two or more coppice crops in addition to the seedling crop (McAlpine, et al. 1966).

Despite some major advancements on hardwood plantation forestry resulting from the "Silage" Cellulose Project, the concept had a reasonably short life. The reason was that pulp mills could not use the material in their normal furnish because of the high bark content associated with the small stems and intact crowns of the juvenile trees.

\section{Industrial Hardwood Plantations}

Enough encouragement was achieved from the Instant Cellulose Project to cause a number of forest industries to pursue hardwood plantation research and development. Among the organizations with the greatest success were Westvaco Corp., Wickliffe, KY, International Paper Co., Natchez, MS, and Union Camp Corp., Franklin, VA. Other organizations with smaller hardwood plantation programs were Brunswick Pulp Land Co., Brunswick, GA, Federal Paper Board Co., Bolton, NC, Hammermill Paper Co., Selma, AL, Scott Paper Co., Mobile, AL and Weyerhaeuser Co., New Bern, NC. Collectively, these organizations established about 100,000 acres of hardwood plantations, primarily of sweetgum and sycamore, from about 1970 to 1985. Adding to this total was the work on cottonwood in the Mississippi Delta by, especially, Crown Zellerback Corp. (now James River Corp.), St. Francisville, LA.

\section{Evaluation of Exotic Hardwoods}

In addition to indigenous species, a major effort was made by the Hardwood Research Cooperative on evaluation of exotic species. Foremost among those species or species groups were Eucalyptus and Alnus glutinosa. The eucalypts are indigenous to Australia, and a few of the adjacent Polynesian islands. When planted in the Tropics and Subtropics throughout the world, however, the species when properly matched to site, have a wood production rate several times greater than that of the same species planted within their indigenous environment in Australia. The outstanding performance of selected species such as $E$. grandis, $E$. urophylla and their hybrid where heights of 100 feet in 10 years 
can be obtained, caught the attention of forest industry executives in the southern United States. Those executives, on a periodic basis, would command their forestry organizations to evaluate the eucalypts, or even to plant them on a semicommercial scale. This exercise became common enough, and the failures frequent enough, that the N. C. State University Hardwood Cooperative began a systematic testing program of the eucalypts in 1971 (Hunt and Zobel 1978). The objective was to determine whether some species and sources were adaptable enough to tolerate the extremes in winter temperatures common to the southern United States. This effort led to the testing of 101 species of the Eucalyptus genus, involving 560 sources, until the program was finally terminated in 1985. The consensus from this major effort in which replicated plantings were installed south of a line from Charleston, SC to Shreveport, LA was that none of the species or sources was suited for commercial forestry in areas where winter temperatures frequently drop below $20^{\circ} \mathrm{F}$. The only area where some success was achieved in introducing eucalypts to the South was south of Tampa, FL, and even there frost damage and kill have not allowed the eucalyptus plantation program to prosper.
European black alder (Alnus glutinosa) was introduced many years ago to colonize the coal spoil banks common to West Virginia, Pennsylvania, Ohio, Indiana and Illinois. The relatively good performance of that species on those marginal sites gave promise that it would be a good species for plantation forestry for fiber production. Numerous sources of the species were obtained from its European locales as well as from the exotic plantations in the mid-west. Like the performance of eucalypts, the early results were impressive (Goncalves and Kellison 1980). With time, however, usually within five years from field planting, the trees began to fade and die. The apparent cause of the decline and mortality was the warm temperatures and high humidities common to the South. The trees continued to respire even at night, using up the carbohydrates that had been manufactured from photosynthesis by day.

\section{Quality Hardwoods}

Most of the research and development work on southern hardwoods was for fiber production. Some organizations, however, were active during this period on the genetic and silvicultural improvement of quality hardwoods. Among the major contributors were the USDA Forest Service, Tennessee Valley Authority and North Carolina Forest Service.

\section{Energy Plantations}

Following the oil crises of 1973 and 1975 , major efforts were made by a number of federal agencies, most notably by the Department of Energy, to grow woody biomass for energy production. The industrial hardwood plantation programs in the South were used as examples of what could be reasonably expected from intensively managed stands where biomass (energy) was the objective. Grants were obtained by the University of Florida, University of Georgia, University of Houston, Mississippi State University, North Carolina State University, Texas A \& I University, and perhaps other public and private agencies for biomass production.

About 1985, the industrial and the biomass plantation programs in the South drew to a halt because of the relatively low wood yields being obtained from the commercial stands. This limitation was compounded by the relatively high cost of plantation establishment, being twice that for establishing a comparable pine plantation and sometimes exceeding $\$ 500$ per acre for establishing the stand and controlling the competition for the first two years. 


\section{THE PRESENT}

At about the same time that the other forest industries were abandoning the concept of hardwood plantations, Scott Paper Co. began an initiative to produce biomass to source a cogeneration plant at Mobile, AL. Subsequent pulping trials proved the wood to be suited for the manufacture of market pulp and tissue at the Mobile pulp mill. The result was establishment of several thousand acres of plantations, primarily of sycamore, to be harvested on a five-year rotation. Subsequent results from these plantations showed that the wood yields culminate at ages greater than five years, probably at ages 8 to 10 years for sycamore, and 10 to 12 years for sweetgum.

Since that time there has been a groundswell of interest in plantation hardwoods, involving especially sweetgum and sycamore. Intensive trials involving the application of high levels of fertilizers on an annual or biannual basis, in company of a weed-free environment, are being installed on the lands of 7 cooperators at 12 locations extending from Virginia to Mississippi. Preliminary estimates are that four cords/acre/ year can be achieved from such plantations on the best upland (pine) sites. The bottomland (hardwood) sites are being excluded from this effort because of periodic flooding which restricts the availability of the wood during periods of inclement weather, and because the bottomland sites are more prone to environmental regulation than are the upland sites.

\section{HARDWOOD TREE IMPROVEMENT- THE SECOND COMING}

\section{Seed Orchards and Seed Production}

Integral to any intensively managed hardwood plantation program is tree improvement. Use is being made of the 149 superior phenotypes of sycamore and the 129 selections of sweetgum that were initially used for establishment of clonal seed orchards (Table 1) and clone banks within the Hardwood Research Cooperative.

Table 1. Hardwood seed orchards by species, clone and acreage in the N. C. State Cooperative Hardwood Research Program.

\begin{tabular}{|c|c|c|c|}
\hline Species & Orchards Estab. & Acres & Clones Grafted \\
\hline Sycamore & 7 & 14 & 130 \\
\hline Sweetgum & 4 & 29 & 57 \\
\hline Yellow-Poplar & 1 & 6 & 22 \\
\hline Green Ash & 1 & 2 & 10 \\
\hline Water-Willow Oak & 1 & 2 & 14 \\
\hline
\end{tabular}


Table 2. Open-pollinated seed lots of five southern hardwoods obtained from above average phenotypes in the N. C. State Hardwood Research Program.

Species N Number of "Mother Trees" Tested

Sycamore $\quad 589$

Sweetgum 324

Green Ash 163

Water-Willow Oak 48

Black Walnut 38

State Hardwood Cooperative trials. In addition, 74 selections of sweetgum and 33 selections of sycamore have been contributed by the Western Gulf Hardwood Tree Improvement Program (Texas A\&M), Mississippi State University and the University of Georgia (Table 3).

These populations have been divided into a Gulf Coastal source and an Atlantic Coastal Plain source. A central clone bank of all select trees in each major subdivision has been established, the one for the Gulf Coast at St. George, SC on lands of the South Carolina State Commission of Forestry, and the one for the Atlantic Coastal Plain at Goldsboro, NC on lands of the North Carolina Division of Forest Resources. In addition, supplemental clone banks have been established on lands of industrial cooperators to assure preservation in case of a catastrophic event.

\section{Breeding Plan}

The breeding plan being established for these two species (sweetgum and sycamore) is to increase the population size for each species to 400, 200 for each major province. These added selections will come from commercial plantations of the two species in the respective provinces. The populations in each of the major subdivisions will be broken into breeding groups of 50 trees each. The best 10 trees of the 50 will be identified as an elite population, based on progeny test data, and other information available. The elite population will be cross bred using a half diallel, minus selfs. In addition to the control-pollinated progeny tests emanating from the intercrossing, about 40 progeny of each cross will be evaluated for asexual propagation (rooting ability and plantlet performance). The latter exercise is being done because it is contemplated that future plantations of sweetgum and sycamore will be from vegetative propagules.

The remaining 40 selections of each breeding unit will be evaluated by open-pollinated progeny tests. The parent trees and their progeny showing superior performance (backward and forward selection) will be moved into the elite population, whereas the clones performing poorly will be excluded from further consideration.

\section{Molecular Genetics}

The progress that has been made in molecular genetics in recent years will allow genetic improvement of the southern hardwoods to be accomplished

Table 3. Genetic selections of sweetgum and sycamore made from provenance and progeny tests of various agencies across the South.

\begin{tabular}{|c|c|c|c|c|c|c|c|c|}
\hline & NCS & & Texa & & Miss 5 & tate & U. of & \\
\hline & S-gum & Syc & S-gum & $\underline{S y c}$ & S-gum & $\underline{S y c}$ & $\underline{\text { S-gum }}$ & $\underline{S y c}$ \\
\hline Atl. Coast & 122 & 53 & -- & -- & -- & -- & 15 & -- \\
\hline Gulf Coast & 154 & 57 & 59 & 33 & - & 10 & -- & -- \\
\hline Total & 276 & 110 & 59 & 33 & -- & 10 & 15 & -- \\
\hline
\end{tabular}


in about half the time that would be required for a conventional breeding program. With the advent of genetic mapping, qualitative trait loci (QTL's) can be identified on the chromosomes that account for a large part of the variation associated with a given trait, such as wood specific gravity or rooting ability. The value of the system is that the QTL's can be identified in newly germinated seeds. Research is still needed to correlate the stability of the QTL's over time and in different environments but, if the results are as expected it will be feasible to screen, in the laboratory, multitudes of plants that once could have been evaluated only by long-term field testing.

Hardwood genetics, involving molecular genetics, is only one part of a plantation silvicultural regime. Such material will have to be evaluated for genotype/ environment interaction. and for clonal response to differences in manufacturing processes. Results have shown that $E$. grandis, E. urophylla and their hybrid pulp differently even when two clones of the same species have near-identical wood specific gravity values (Zobel et al. 1983). To determine the cause of this favorable difference, anatomical and chemical analyses of the wood from the different clones will have to be researched.

\section{Further Testing of Exotics}

A final research need is to assess additional species and hybrids for plantation use in the South. Good success has been had in the Pacific Northwest by using the hybrid of Populus deltoides and P. trichocarpa. When moved to the South, however, the hybrids are extremely susceptible to Melampsora spp. rust. This leaf disease is more damaging to some clones than to others, so the probability exists that some clones will be resistant or tolerant to the malady. Additionally, the probability exists that an exotic species such as one of the eucalyptus species can be found that will be tolerant to the winter temperature extremes common to the South.

The future is bright for plantation management of the southern hardwoods. We need now to take advantage of the research opportunities available so that the U. S. South can continue to effectively compete with foreign competitors who benefit from plantation yields that are several times greater than the best we have heretofore been able to produce in domestic plantations.

\section{LITERATURE CITED}

Goncalves, Paulo de Souza and R.C. Kellison. 1980. Potential of black alder in the South. School of For. Resources Tech. Rept. No. 62. North Carolina State University, Raleigh. 31 p.

Hunt, R. and B. J. Zobel. 1978. Frost hardy eucalypts grow well in the Southeast. South. Jour. App. For 2(1):6-10.

MacCleery, D. W. 1992. American Forests: A history of Resiliency and Recovery. USDA Forest Service FS-540, Wash., DC. 59 p.

McAlpine, R. G., C. L. Brown, A. M. Herrick, and H. E. Ruark. 1966. "Silage" sycamore. Forest Farmer 26(1):6-7. $16 \mathrm{p}$.

Zobel, B. J., E. Campinos, Jr. and Y. K. Ikemori. 1983. Selecting and breeding for desirable wood. Tappi 66:7073. 


\title{
Hardwood Production Techniques at Midwestern Nurseries ${ }^{1}$
}

\author{
A. F. Stauder, IIII,3
}

Abstract-Hardwood seedling nurseries throughout the Midwest play a vital role in assisting area landowners with their conservation programs. Proper seedling production techniques are necessary to produce quality seedlings that will survive and grow to maturity. These techniques differ somewhat from those in other areas of the country.

The nurseries across the Midwest consist mainly of governmental, state and federal, operations. A very limited number of private or industry nurseries are located throughout the area. Approximately 24 million hardwood seedlings of over 75 species are produced in the Midwest states, including Illinois, Indiana, Michigan, Minnesota, Missouri, and Wisconsin.

\section{SEED COLLECTION}

As previously mentioned, over 75 species of hardwood species are produced at nurseries in the Midwest. The largest component of the total seedling production are black walnut and oak species. Because of the large, bulky size of the seed from many hardwood species, special handling problems exist. The large seed is difficult to collect, transport, process and sow. For these reasons most nurseries plant as much of their needed seedbeds as possible during the fall months.

Seed is obtained in one or more of several methods:

1) Nursery staff collections.

2) Department of Corrections inmate collections.

3) Other organization personnel collections such as district. foresters or wildlife biologists.

4) Donations.
5) Purchase from seed dealers.

6) Purchase from private individuals.

Most seed is collected by nursery staff or more so by the purchase from private individuals. The main problems from seed collected by private individuals or seed dealers is the unknown seed source. Buyers must make absolutely sure of the seed source of the seed before it is collected and purchased. For these reasons many states have established seed collection zones to insure as much as possible that local seed is being obtained.

Of the Midwestern states, Indiana has probably the most intensive seed purchase program. All seed is purchased on a live

'Stauder, A. F. 1994. Hardwood Production Techniques at Midwestern Nurseries. IN: Landis, T.D.; Dumroese, R.K., tech. coords. National Proceedings, Forest and Conservation Nursery Associations. Gen. Tech. Rep. RM-257. Fort Collins, CO: U.S. Department of Agriculture, Forest Service, Rocky Mountain Forest and Range Experiment Station: 26-30.

2International Paper, Bullard, Texas.

${ }^{3}$ The author wishes to express his appreciation to the nursery managers from the Midwest states who provided slides for the presentation and input regarding their management activities. 
seed basis, where price is determined for the individual full seed. This requires cut tests on each seedlot, but does insure the quality of the seed. Most of the other nurseries purchase seed on a per pound basis while adhering to specific quality standards.

\section{SEEDBED PREPARATION}

Seedbed areas are typically levelled, subsoiled, and disced prior to forming the seedbed. Most of the nurseries fumigate their seedbed areas. The preferred method is contract fumigation performed by a licensed professional contractor; although some operations still fumigate using their own nursery personnel and equipment. Fumigation is performed to control weed seeds, pathogens and detrimental fungi pests. The fumigation activities are usually performed in late summer, which allows for higher soil temperatures and to allow ample time to prepare the area for fall sowing.

Seedbeds are formed in several ways. The Whitfield bed shaper is used as well as several types of shaper tillers. A new machine, the FOBRO tiller shaper is currently being introduced at some facilities. It provides a one pass method to the bed shaping process. The choice of method and equipment depends on the nursery manager, the soil type, and the area where the nursery is located.

\section{SEED SOWING}

Most nursery operations sow as much seed as possible in the fall months. Sowing at this time provides natural stratification and eliminates the need for winter storage of the seed. Some exceptions to the fall sowing are species such as sumac, black locust, and redbud which require no stratification or can be scarified using an acid or hot water treatment.

For heavier seeded species, most operations have developed and built a sower specific to their needs (Figure 1). These machines use a belt or chain driven system with a hopper to sow the seed at the desired rate. Black walnut probably presents the most problems for the nursery manager, simply because of its large seed size. Iowa uses a modified fertilizer spreader which drops the seed into preformed furrows made into the formed beds. Some nurseries dehusk the black walnut seed while others sow the seed directly in the seedbed with the husk attached. Removing the husk does allow the nursery personnel the ability to float the seed to remove some of the empty seed before planting. However, most nurseries report good results in both cases.

For small seed, several different machines have been used. Currently several operations use a Love Ojyord seeder or a Whitfield seeder. The sowers can accurately be calibrated using seed purity, seed germination and expected seed efficiency information.

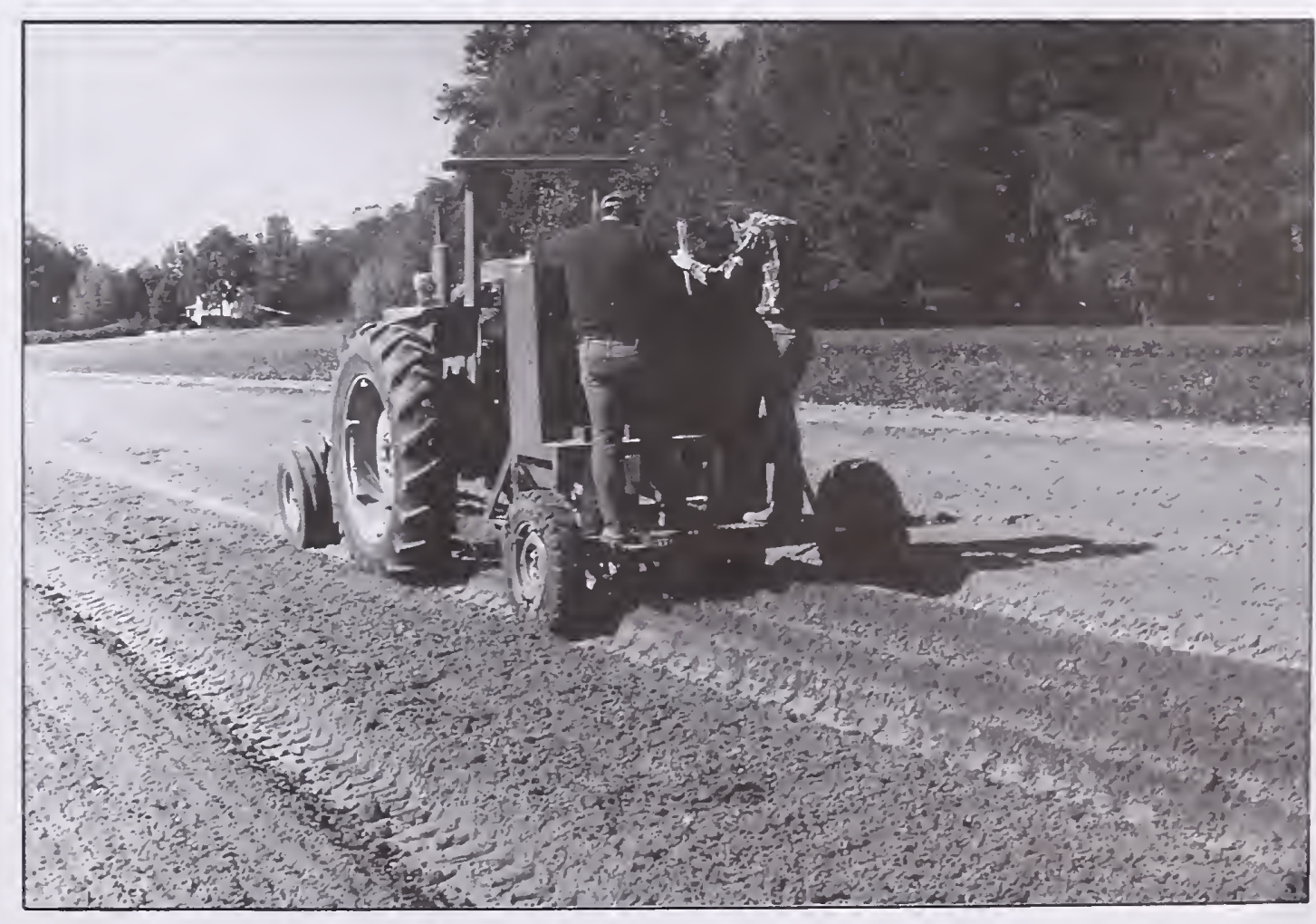

Figure 1. Sower for use with large hardwood seed. 
One problem inherent throughout the area is that of predicted seed efficiency. Hardwood seed is much more variable than the seed of conifer species. Seed crops are very sporadic for most heavy seeded species, and the seed variability and performance may fluctuate greatly from year to year. Seed efficiencies generally range from 20 percent to 85 percent depending on the species, the year collected, and the duration of storage. By using a five year moving average, nursery managers can partly overcome the yearly fluctuations in predicting seed efficiencies.

Several different types of seedbed mulch are used throughout the Midwestern nurseries. Examples of the materials used are sawdust, sand, bark, wood chips, and hydromulch. Nurseries such as those in Iowa use local material such as ground corn cobs. The main purpose of any mulch is to provide protection and insulation to the newly planted seed until germination.

Probably one of the most innovative use of mulch is that of using a green overwinter mulch. Two different methods can be used and example of those are at the nurseries in Indiana and Illinois (Wichman 1993, Stauder 1993). The Indiana operations actually plant winter wheat in the same drill while planting the seed. The wheat germinates and grows throughout the winter providing excellent protection to the stratifying seed. This method provides several advantages, such as:

1) Seed insulation from extreme cold.

2) Protection from predators.

3) Delayed spring germination to reduce frost damage.

\section{4) Seedbed protection from washing.}

The main disadvantage is that the wheat must be sprayed with a herbicide to kill it before the seed germinates. The herbicides used are Roundup before the tree seed germinates or Fusilade if germination has begun.

The nurseries in Illinois operationally use hydromulch. In addition, spring oats are added at a ratio of approximately 50 pounds per acre to the hydromulch mix. The oats germinate in the fall and usually grow to six or seven inches before repeated frosts or freezing temperature kill the oats; however, the oats continue to provide protection and insulation to the stratifying seed after planting.

In the northern part of the Midwest area many nurseries rely on persistent winter snow cover. Snow has excellent insulation properties and provides good physical protection for the seedbed. However, snow cover is not very dependable throughout the central and southern part of the range.

\section{CULTURAL PRACTICES}

Hardwood seedlings generally require approximately one inch of rainfall or irrigation per week for a sandy loam soil. Of course this amount will vary depending on soil type and region. Sandier soils especially in the southern areas, obviously, will require more moisture than heavier textured soils.

Fertilization occurs throughout the growing season. Soil tests are required each year to determine the need for pre-plant fertilizers or lime. The optimum soil $\mathrm{pH}$ to produce hardwood seedlings is from 6.0 to 6.5 . Most operations apply approximately 150 pounds of actual nitrogen per acre per year to produce a quality crop. Several different types of nitrogen are used; these include ammonium nitrate, ammonium sulfate, ammonium phosphate, and calcium nitrate.

Root morphology has become an ever increasingly important concern among nursery managers. Research has clearly shown that quality seedlings must have a minimum number of first order lateral roots to insure survival and excellent growth (Schultz 1989). Therefore most nursery managers have begun to under- 
cut their hardwood seedlings. For 1-0 seedlings undercutting is usually performed after the second flush is completed for the oak species and July for black walnut. The remaining hardwood species are undercut in mid to late summer when 80 percent of the seedlings have attained 80 percent of the target height. For 2-0 seedlings, undercutting usually begins after the first flush in the spring when the new leaves reach 85 percent of full size. Hardwood seedlings are usually cut to a depth of seven to eight inches below the root collar.

Some nurseries such as those in Wisconsin top prune hardwood seedlings. The 2-0 hardwood seedlings are top pruned, if necessary, to a height of 12 to 14 inches during late summer or early fall. Some extremely fast growing species such as sycamore, elderberry or sumac may need to be top pruned during the first year of growth to control height. No major problems have been observed by top pruning alternate branching species; however, nursery managers do not top prune opposite branching species, such as green ash or white ash, because severe forking may result.

A few nurseries practice lateral pruning on hardwood seedlings; however, the practice is not widely used or accepted. Because of the large size of the hardwood seedling, lateral pruning is difficult in many cases.

\section{LIFTING AND PACKING}

Seedling lifting generally begins in the late fall months depending on the area. Nurseries are currently using several types of lifting machines, either homemade or industrial manufactured, with the FOBRO Lifter Shaker preferred by many nursery managers (Figure 2). Nursery personnel at most nurseries attempt to lift as many seedlings as possible during the fall, since the ground may freeze for extended periods during the winter. The seedlings are lifted, then placed into cold storage as soon as possible. Many nurseries store seedlings bareroot on open carts or boxes in the cooler. Since hardwood seedlings are deciduous, they possess no leaves to transpire and dessicate the seedling. The main factor in storage is to maintain the temperature at approximately 34 degrees $\mathrm{F}$ and to maintain a high humidity in the cooler. In some cases the seedlings are stored just below freezing which allows the seedlings to be stored for a longer duration. These trees are stored awaiting grading and packing during the winter months when lifting cannot occur due to frozen ground or severe weather.

Once seedlings are lifted and stored, the next step is the grading process. Most nurseries grade seedlings in a building

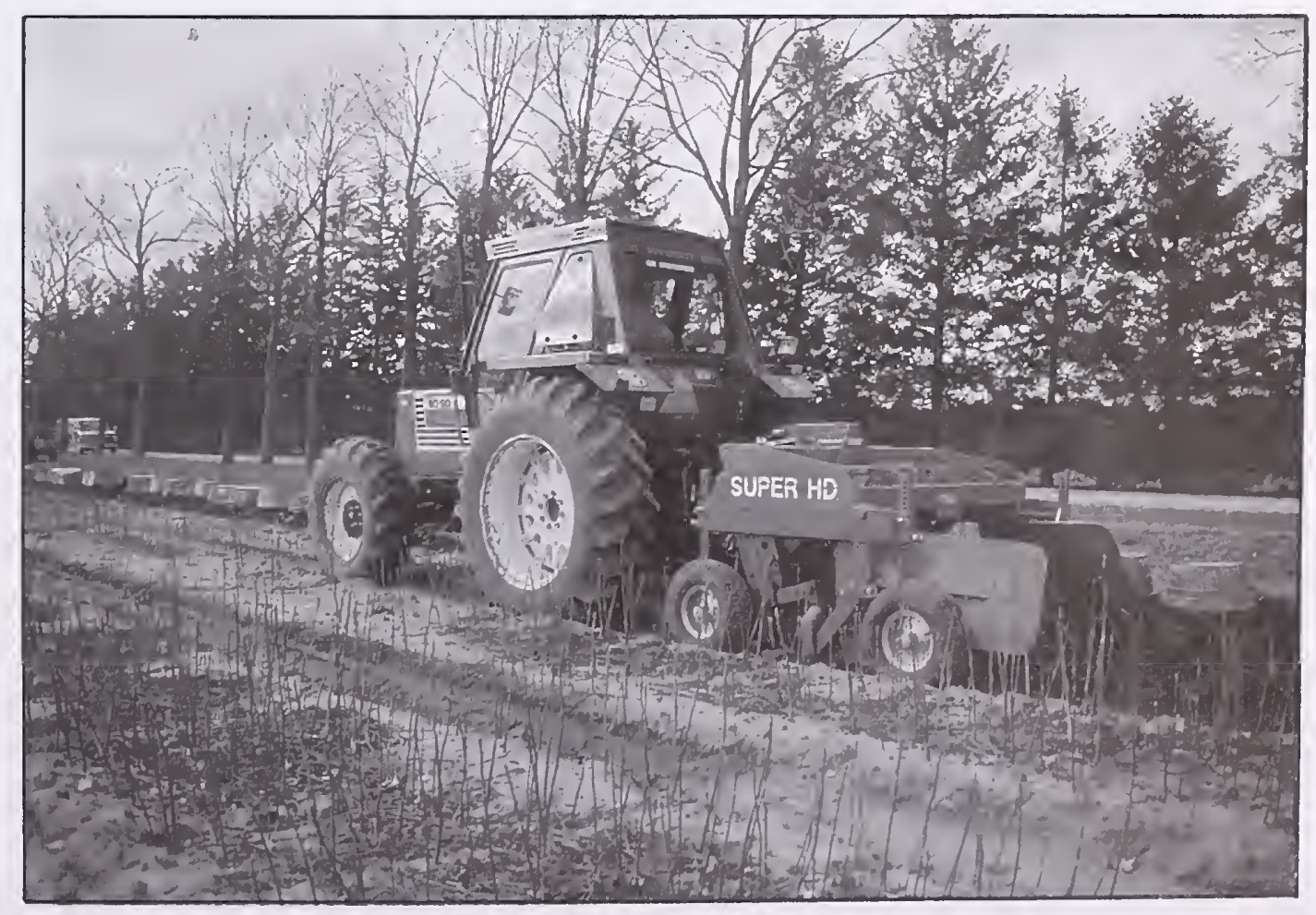

Figure 2. Hardwood seedling lifter. 
where cull seedlings are separated from the quality plant material. Each operation has its own grading specifications, but a general rule is for seedlings to possess at least 0.25 inches diameter and 12 inch height. Root systems are extremely important, and seedlings should possess at least a six inch taproot with a minimum of five first order lateral roots.

Several different types of packing systems are used throughout the Midwest. Seedlings are wrapped in bales, placed in boxes or packed in 3ply kraft bags for transport to the planting site. Packing mediums also vary; these include sphagnum moss, peat moss, synthetic gel, or no medium. Several operations using bags do not use a packing medium. Since the lifted hardwood seedlings have no leaves to cause water loss through transpiration, seedlings have actually been stored for several months with no detrimental effects.

\section{SHIPPING}

Like most other nurseries throughout the United States, operations throughout the Midwest depend on the landowner or purchaser to pick up their seedlings. Seedlings are also sent to the landowner using parcel post or a commercial package delivery company. In most cases seedlings arrive at their destination in excellent condition.

\section{CONCLUSION}

Hardwood seedling nurseries throughout the Midwest provide valuable tree and shrub seedlings for conservation purposes. These operations play a vital role in landowners' goals of proper land stewardship.

\section{LITERATURE CITED}

Schultz, R.C., and J.R. Thompson. 1989. Nursery cultural practices that improve hardwood seedling root morphology In Proc. Northeastern Area Nurserymen's Conference. pp. 17-39.

Stauder, A.F., III. 1993. The use of green overwinter mulch for the Illinois State Nursery Program. In Proc. Northeastern and Intermountain Forest and Conservation Nursery Assoc. Aug. 2-5. pp. 51-54

Wichman, J. 1993. Use of wheat as a living mulch to replace hydromulch for fall sown seedbeds. In Proc. Northeastern and Intermountain Forest and Conservation Nursery Assoc. Aug. 2-5. pp. 55-56. 


\title{
Weed Control in Southern Hardwood Nurseries ${ }^{1}$
}

\author{
D. B. South ${ }^{2}$
}

Abstract - In the South, most nursery managers have relied on methyl bromide for weed control in hardwood seedbeds. When methyl bromide is no longer available, handweeding times will likely increase unless management regimes adapt to the change. Some nursery managers will increase use of both sanitation practices and herbicides. Although several herbicides are registered for use on hardwoods, some can injure seedlings when applied to seedbeds. Grasses can be effectively controlled with selective herbicides. Many small seeded broadleaf weeds can be suppressed with preemergence herbicides. Information on registered herbicides for hardwoods is provided.

Keywords: herbicides, fumigation, integrated pest management.

\section{INTRODUCTION}

Hardwoods are a small proportion of the seedlings grown in forest tree nurseries. In the South, they represent less than $2 \%$ of the total seedling production. Less than half the forest tree nurseries grow hardwoods. In 1992, total production from 10 nurseries was less than 10 million seedlings (Table 1). Developing an efficient weed management program for individual species can be difficult when so few seedlings are produced (Stone 1991). For these reasons, weed control research in seedbeds has concentrated on Pinus
Table 1. Hardwood seedling production from ten nurseries in 1992. (Nurseries include Miller, International Paper, Scott Paper (Alabama), Flint River (Georgia), Champion, Piedmont, Westvaco (South Carolina), Pinson (Tennessee) and Indian Mound (Texas).

\begin{tabular}{lrc}
\hline Group & Production & Acres \\
unspecified & $3,498,000$ & 8.0 \\
oaks & $1,500,750$ & 5.6 \\
sycamore & $1,397,400$ & 5.0 \\
lespedeza & $1,194,000$ & 2.2 \\
dogwood & 662,700 & 3.4 \\
sweetgum & 430,950 & 1.6 \\
maple & 258,100 & 0.5 \\
green ash & 167,050 & 0.7 \\
yellow poplar & 90,000 & 0.1 \\
black walnut & 49,000 & 0.1 \\
mulberry & 39,030 & 0.1 \\
persimmon & 24,500 & 0.04 \\
crab apple & 17,300 & 0.04 \\
& & \\
Total & $9,329,050$ & 25.0 \\
& & \\
\hline
\end{tabular}

'South, D.B. 1994. Weed Control In Southern Hardwood Nurseries. IN: Landis, T.D.; Dumroese, R.K., tech. coords. National Proceedings, Forest and Conservation Nursery Associations. Gen. Tech. Rep. RM-257. Fort Collins, CO: U.S. Department of Agriculture, Forest Service, Rocky Mountain Forest and Range Experiment Station: 31-37.

${ }^{2}$ Auburn University Southern Forest Nursery Management Cooperative, Auburn University, Alabama. 
species. However, weed diversity and numbers are often higher in hardwood seedbeds due to higher soil alkalinity and greater irrigation and fertilization. Without herbicides, handweeding often exceeds 200 hours/acre. Although a nursery may only grow about 2.5 acres of hardwoods, handweeding times for this area may exceed that for the entire conifer crop. For example, an acre of untreated hardwoods at the Norman Nursery in Oklahoma exceeded 1,600 hours of handweeding in 1981 (Abrahamson 1987).

Efficient weed management systems for hardwoods involve a combination of methods which often include fumigation, herbicides, and various nonchemical techniques. Inefficient systems usually rely on just one or two methods of weed management.

\section{SOIL FUMIGATION}

Nursery managers have often relied on methyl bromide fumigation to reduce weed populations in their hardwood seedbeds. A main advantage of methyl bromide is that it can be used prior to sowing many hardwood species. However, after the year 2001, methyl bromide will no longer be available. Some managers will switch to fumigants that are weak on weeds. Possible alternatives include chloropi- crin and dazomet. Although both can control certain soil borne pests, neither is effective in controlling nutsedge. Most other annual weeds can be controlled with herbicides (South and Gjerstad 1980; Garrett et al. 1991).

Few hardwood nurseries have problems growing endomycorrhizal crops when fumigating with $98 \%$ methyl bromide (Campbell 1992). However, fumigation with 300 lbs/acre of chloropicrin may retard growth of certain endomycorrhizal hardwoods. In the past, fumigation that included chloropicrin at 115 to $150 \mathrm{lbs} /$ acre reduced growth of some species (e.g. sweetgum and dogwood). This resulted due to a lack of viable endomycorrhizal spores (South et al. 1980). In fact, in 1994, one nursery in Georgia had stunted corn due to effective fumigation with $33 \%$ chloropicrin and 66\% methyl bromide. Some managers may use other fumigants such as dazomet or 1,3-dichloropropene for beds to be sown with dogwood or sweetgum.

\section{HERBICIDES}

To control weeds without injuring hardwood seedlings, either the herbicide must be totally selective such as fluaziflop-butyl (see Table 2 for common names) or the herbicide must be applied in a suitable manner. Selectivity is based on physiological or morphological differences between crop and weed. For example, a physiological difference between broadleaves and grasses is the basis of selectivity for sethoxydim and fluaziflop-butyl. As a result, handweeding grasses should no longer be necessary.

Morphological differences between crop seed and weed seed can also be used to provide some selectivity. Large seeded species such as oak, walnut, pecan, hickory tolerate preemergence herbicides that are toxic to small seeded species. For example, oxyfluorfen at 0.5 $\mathrm{lb}$ ai/acre can be applied after sowing without injury to walnut, pecan, hickory and oak. Although not currently labeled, this is potentially a useful treatment for several large seeded hardwoods.

Differences in plant size can also be used to achieve selectivity. Some herbicides (like trifluralin, oryzalin, prodiamine and napropamide) are active mainly on seed germination. These herbicides can be applied once hardwood seedlings have germinated and have developed a few true leaves. The herbicide is toxic to small hardwood seed such as sycamore if applied at time of seeding, but when applied after the seedlings are establish, the chance of injury is greatly reduced. Although these herbicides will not control emerged weeds, they will help 
Table 2. Common and trade names of herbicides registered for hardwoods.

Trade name

Common name

\section{Company}

VERY SELECTIVE GRASS HERBICIDES

$\begin{array}{lcc}\text { Acclaim } & \text { fenoxaprop-ethyl } & \text { Hoeschst } \\ \text { Fusilade } & \text { fluaziflop-butyl } & \text { Zeneca } \\ \text { Vantage } & \text { sethoxydim } & \text { BASF }\end{array}$

CAN BE SELECTIVE WHEN SPRAYED OVER

ESTABLISHED HARDWOODS

Barricade

Dacthal

prodiamine

DCPA

Devrinol 50-DF

Treflan 4EC

trifluralin than liquid formulations. Herbicide injury still occurs if granules lodge in the foliage or are not completely washed off with irrigation. Therefore, it is important for most granules to be applied to dry foliage.

A final way to provide selectivity is to ensure the herbicide does not come in contact with crop foliage. This can be done with either directed applications by hand or by using shields to apply herbicides between drill rows. Most foliar active herbicides should be directed away from the crop and toward the weeds. A number of nursery managers have applied glyphosate to weeds between seedling drills.

\section{WEED CONTROL TREATMENTS USED BY MANAGERS}

Sandoz

DowElanco

DowElanco

DowElanco

$\begin{array}{lcc}\text { TO AVOID INJURY, DO NOT APPLY TO SEEDBEDS } & \\ \text { Casoron } & \text { dichlobenil } & \text { Uniroyal } \\ \text { Derby } & \text { metalachlor+simazine } & \text { Ciba } \\ \text { Gallery } & \text { isoxaben } & \text { DowElanco } \\ \text { Kerb } & \text { pronamide } & \text { Rohm and Haas } \\ \text { Pendulum } & \text { pendimethalin } & \text { Cyanamid } \\ \text { Pennant } & \text { metalachlor } & \text { Ciba } \\ \text { Princep } & \text { simazine } & \text { Ciba } \\ \text { Predict } & \text { norflurazone } & \text { Sandoz } \\ \text { Snapshot } & \text { oryzalin+benefin } & \text { DowElanco } \\ \text { Surflan } & \text { oryzalin } & \text { DowElanco } \\ \text { XL } & \text { oryzalin+benefin } & \text { DowElanco }\end{array}$

NOT SELECTIVE BUT CAN BE DIRECTED

$\begin{array}{lcc}\text { Basagran T/O } & \text { bentazon } & \text { BASF } \\ \text { Lescogran } & \text { bentazon } & \text { Lesco } \\ \text { Finale } & \text { glufosinate - ammonium } & \text { Hoechst } \\ \text { Roundup } & \text { glyphosate } & \text { Monsanto }\end{array}$

keep subsequent weed seed from germinating. This technique is used successfully by several nursery managers in the South.

With some herbicides, formulation will affect selectiv- ity. Formulating herbicides as granules is a common practice to reduce the potential injury. When applied to dry foliage, herbicides granules of oxyfluorfen and oxadiazon may be less phytotoxic to foliage
Commonly used weed control practices were determined by surveying 17 hardwood nurseries. Methyl bromide fumigation was used at most (15) of the nurseries. To suppress hardwood diseases, 10 managers used methyl bromide with $33 \%$ chloropicrin.

Ten nursery managers used no herbicides at time of sowing. Some were afraid that herbicides could result in seedling injury. Trifluralin was the most popular preemergence herbicide and was used after sowing at 5 nurseries. Two nurseries had good results 
when testing oxyfluorfen on large seeded species such as oaks, persimmons, and hickories. One applied EPTC as a pre-plant incorporated treatment.

Managers at 12 nurseries used postemergence herbicides (applied postemergence to the crop). Selective grass herbicides were the most popular. Sethoxydim was used at 9 nurseries and 3 others used fluaziflop-butyl. It was surprising that neither of these herbicides were used at 4 nurseries. Apparently some managers either do not mind handweeding grasses or they are afraid to use any herbicide on hardwoods. Two nurseries used granular herbicides (Rout ${ }^{\text {}}$ or $\left.\mathrm{OH}-2^{(}\right)$) to a limited extent.

Napropamide and/or oryzalin were used at 4 nurseries. These herbicides can be applied to seedbeds after germination of hardwoods is complete (South 1984; Warmund et al. 1980). These herbicides do not have contact activity and therefore are not generally phytotoxic to emerged seedlings or weeds (Everest et al. 1989; Skroch 1994). However, since a nursery in New York sued the chemical company due to injury to Douglas-fir, nursery managers in the southern U.S. can no longer legally apply oryzalin to seedbeds. One sure way to reduce the number of registered herbicides is to file suits (or claim damages) against chemical companies. Fortunately, prodiamine is now registered and can be used in place of oryzalin (South 1992).

The following edited comments are from nine of the nursery managers:

\section{\#1 Either EPTC (pre-plant incorporated) or trifluralin (post sowing) is likely to damage chinese elm and river birch, but no problem with large seeded oaks and black walnut. No damage with fluziflop-butyl. Rout ${ }^{\circledR}$ (postemergence) does not hurt oaks.}

\#2 Trifluralin (applied just after sowing) caused some damage to sycamore.

\section{\#3 No problems with} sethoxydim or trifluralin. Oryzalin slightly damaged dogwood, sycamore sweetgum and maple. $\mathrm{OH}-2^{\circledR}$ injured deciduous magnolias, maples, dogwood and sweetgum.

\#4 Sethoxydim caused slight burn on shumard oak and mulberry.

\#5 Wild cherry seedlings were burnt by sethoxydim.
\#6 If sprayed early, dogwood seems sensitive to sethoxydim.

\#7 Sethoxydim leaf burn was greater on white oaks than on red oaks.

\#8 Do not use trifluralin (applied just after sowing) on sycamore; ground line lesions and root damage.

\#9 Oxyfluorfen can be used on large seeded oaks, persimmons, and hickories. Use surfactant rather than oil when using sethoxydim or fluaziflop-butyl. Using a crop-oil can damage hardwoods. Shrub lespedaza can be treated with 2,4-D amine.

Several managers have observed foliar burn after using Poast ${ }^{\circledR}$. In some cases, this resulted from the addition of a crop-oil. Under some environmental conditions, using a crop-oil concentrate injures newly emerged tissue. In fact, various brands of crop-oil were being used with Poast ${ }^{\circledR}$. This is one reason why this product is no longer registered for ornamentals. Vantage ${ }^{\circledR}$ is a new formulation of sethodydim which is registered for hardwoods and already comes with its own surfactant. Therefore Vantage ${ }^{\circledR}$ does not require the addition of a crop-oil. The label for Fusilade $2000^{\circledR}$ states "do not use a crop oil concentrate." 


\section{SUGGESTED HERBICIDE REGIME}

As a general rule, granular fertilizers are more expensive than liquids or powders. For example, a pound of napropamide could cost $\$ 10$ as a powder but $\$ 30$ as a granular. Granular fertilizers that have been used in $1+0$ seedbeds include Rout ${ }^{\circledR}(3 \%)$, Ronstar ${ }^{\circledR}$ $(2 \%)$, OH- $2^{\circledR}(3 \%)$, Treflan $^{\circledR}$ $(5 \%)$, Pennant ${ }^{\circledR}(5 \%)$ and Devrinol $^{\circledR}(5 \%)$. A few other granular herbicides that are used on liner stock but seldom used on $1+0$ seedbeds include $\operatorname{Betasan}^{\circledR}(7 \%)$, Casoron ${ }^{\circledR}(4 \%)$ and Lasso II ${ }^{\circledR}(15 \%)$. Although effective weed control can be obtained with granular herbicides (Reeder et al. 1992), some nursery managers choose not to use granular formulations due to the added expense.

Due to the numerous species involved, a single herbicide regime for all hardwood species is unlikely. However, the regime in Table 3 can be used for a variety of species. It should be used in conjunction with an effective sanitation program. The program relies on use of a grass herbicide

(fenoxaprop-ethyl, fluaziflopbutyl, sethoxydim) in conjunction with a few other herbicides (napropamide, prodiamine, trifluralin) to control germination of small seeded broadleaf weeds. Emerged weeds are controlled with either handweeding or directed applications of glyphosate or glufosinate-ammonium.

Although DCPA has been approved for use in nurseries by the US Forest Service and is currently used in some hardwood nurseries (Garrett et al. 1991; Porterfield et al. 1993), the Auburn University Southern Forest Nursery Management Cooperative does not recommend using this herbicide. According to EPA, the acid metabolites of DCPA are the most commonly detected pesticide in drinking water wells. The metabolites were found in about $6.4 \%$ of community water systems and $2.5 \%$ of rural domestic wells. We believe nursery managers should be pro-active and not use DCPA, atrazine, alachlor, simazine, bentazon, and prometon (all have been found in well water). Nursery managers should restrict their use to herbicides that have little chance of leaching into groundwater. Such herbicides include oxyfluorfen, fluaziflop-butyl, glyphosate and prodiamine. 
Table 3. A sample herbicide regime for fall sown hardwoods.

Time of

Application

Fall

Fall

Barricade

or

Treflan

March Treflan

Spring

Vantage or

Fusilade or

Acclaim

April Devrinol

Spring Roundup or

Finale

May Barricade or

Devrinol

June

Devrinol

Summer

\section{Comments}

Sow species that can be sown in the fall. This results in quicker canopy closure in the spring and gives hardwoods a jump on the weeds.

Apply after sowing to large seeded hardwoods.

Apply after sowing small seeded hardwoods but before mulching. Mulch soon after application and irrigate to reduce volatilization. Do not apply to sycamore.

Handweed winter weeds and apply soon after weeding. Apply $1 / 2$ inch of irrigation after application to reduce volatilization.

Apply after grasses have emerged. Use of crop-oil may cause foliar injury.

Handweed prior to application. Apply after complete emergence of hardwood seedlings.

Use directed applications to perennial weeds.

Apply one month after April treatment. Handweed prior to application.

Apply one month after May treatment. Handweed prior to application.

Apply as needed to control grasses.

Fusilade or Acclaim

For Devrinol 50WP, use 3 pounds product/acre/application

For Barricade CFG, use 1 pound product/acre/application

For Vantage, use 2.25 pints/acre/application

For Fusilade 2000, use 2.5 pints/acre/application

For Acclaim, use 1.5 pints/acre/application

For Treflan 4E, use 1 quart/acre/application 


\section{LITERATURE CITED}

Abrahamson, L.P. 1987. Forest tree nursery herbicide studies at the Oklahoma forest regeneration center. P. 49-57 in Proc. Intermountain Forest Nursery Association, Oklahoma City. USDA Forest Service, General Technical Report RM-151.

Campbell, S.J., Jr. 1992. Hardwood culture. P. 91-95 in Proc. Southern Forest Nursery Association. Pine Mountain, Georgia. Georgia Forestry Commission, Macon, GA.

Everest, J.W., C.H. Gilliam, and K. Tilt. 1989. Weed control for commercial nurseries. Alabama Cooperative Extension Service, Auburn University Alabama. Circular ANR-465. 13 p.

Garrett, H.E., R.C. Stenberg, Jr., G.S. Cox, R.J. Mitchell, and W.G. Young. 1991. A case for herbicidal weed control in forest nurseries. CP. 83-101 in Chemical Vegetation Management, J.E. Kaufman and H.E. Westerdahl (eds.) Plant Growth Regulator Society of America.
Porterfield, J.D., J.D. Odell, and G.R. Huffman. 1993. Effects of a DCPA/napropamide herbicide tank mix on germinants of seven hardwood species in tree nursery beds. Tree Planters' Notes 44:149153.

Reeder, J.A., C.H. Gilliam, G.R. Wehtje, and D.B. South. 1992. The effects of selected herbicides on propagation of chestnut oaks in containers. P. 325-329. in Proc. International Plant Propagators Society. Ocean City, MD.

Skroch, W.A. 1994. Weed control suggestions for christmas trees, woody ornamentals, and flowers. NCSU. North Carolina Cooperative Extension Service. 100 p.

South, D.B. 1984. Chemical weed control in southern hardwood nurseries. South. J. Appl. For. 8:16-22.

South, D.B. 1992. Prodiamine: a herbicide for pine and hardwood nurseries. South. J. Appl. For. 16:142-146.

South, D.B. and D.H. Gjerstad. 1980. Nursery weed control with herbicides or fumigation an economic evaluation. South. J. Appl. For. 4:40-45.
South, D.B., D.H. Gjerstad, and S.J. Campbell. 1980. Comparison of methyl bromide and herbicide effects on endomycorrhizal formation, seedling production, and weed control in sweetgum seedbeds. European Journal of Forest Pathology 10(6):371-377.

Stone, J.M. 1991. Hardwood pest problems weeds, grasses, and herbicide controls. P. 1721 in Proc. Nursery Pest Management Workshop. Athens, Tennessee. USDA Forest Service, Region 8, Atlanta, GA.

Warmund, M.R., C.E. Long, and W.A. Geyer. 1980. Preemergent herbicides for seeded nursery crops. HortScience 15:825-826. 


\title{
Soil Fertility and Management for Culturing Hardwood Seedlings ${ }^{1}$
}

\section{B. Davey ${ }^{2}$}

\begin{abstract}
Nursery production of hardwood seedlings and cuttings is different than the production of pine seedlings in several important ways. Hardwoods need approximately twice as much water and significantly more of most nutrients, especially nitrogen and calcium. Hardwoods are generally produced from open-pollinated, wild seed. This results in large within-seed source variability in seedling size and vigor. Seed orchard seed has tended to reduce this variability some and to increase the average seedling size. Hardwoods are particularly sensitive to soil physical properties. Soil compaction, which results in high soil bulk-density, is very deleterious. This is due to impeded root growth and impaired gas and water movement in the soil. Some hardwoods are ectomycorrhizal, some are endomycorrhizal, and a few can be either or both. Most hardwoods must be grown at a much lower seedbed density than most pines. When this fact is coupled with higher irrigation and fertilization costs per acre, the cost per seedling becomes much higher for hardwoods than pines.
\end{abstract}

Keywords: mycorrhizae, nitrogen fixation, irrigation, fertilization, lime, temperature.

\section{INTRODUCTION}

The nursery manager who has devoted his or her career to the production of pine seedlings and is suddenly confronted with the need to produce hardwoods finds that it is a completely different world. This is true in several respects. We have already heard about the differences in weed control between pines and hardwoods. Now, let us consider various aspects of soil management necessary for the production of quality hardwood seedlings. Topics for consideration will include: water, nutrients, soil testing, soil physical properties, mycorrhizae, seedbed density, and vegetative

propagation.

\section{Water}

The first rule in growing hardwoods is to separate them from the pines. The reason for this is that hardwoods require almost twice as much water as pines and if you try to use one irrigation schedule for both you will either drown the pines or desiccate the hardwoods. This fact was demonstrated dramatically with a single collection of green ash seed. Because of a study we wanted to run in two nurseries, this seedlot was carefully mixed and divided in half with one half going to each nursery. About a month after the seed had been planted, I called both managers to see how the crop was developing. The first manager said that it had been an excellent seedlot and that if anything our seedbed density

'Davey, C.B. 1994. Soil Fertility and Management for Culturing Hardwood Seedlings. IN: Landis, T.D.: Dumroese. R.K., tech. coords. National Proceedings, Forest and Conservation Nursery Associations. Gen. Tech. Rep. RM-257. Fort Collins, CO: U.S. Department of Agricuiture, Forest Service, Rocky Mountain Forest and Range Experiment Station: $38-49$.

${ }^{2}$ Soil Science and Plant Pathology, North Carolina State University, Raleigh, North Carolina. 
was bit high. The second manager said that the seedlot had been bad and that he estimated only about $3 \%$ germination. This prompted a visit to the second nursery. There I found that the green ash seed had been planted in one bed in the middle of a field of loblolly pine beds. The pines were growing beautifully and the green ash was exactly as described - very sparse. Subsequent observations have confirmed that whereas pines may do well with about one inch of water per week, hardwoods need about two inches per week. This is especially critical during germination and emergence of the hardwoods. These general amounts of water include rain plus irrigation and must be used only as a general guide. If a nursery receives a big rain of four inches in a few hours, that does not mean that no irrigation will be needed for two weeks. Interestingly, over the years, I have had more trouble getting people to use less water than to use more water. In some nurseries, I have wondered why there weren't cattails growing in the beds. The bottom line on this is that irrigation needs to be done correctly and hardwoods do demand more water than pines.

\section{Nutrition and Soil Fertility Macro-elements}

In the sections that follow, I will attempt to not only give some notion about hardwood seedling nutrition but also for some key nutrients, how hardwoods differ from pines. However, it must be recognized that soil fertility is only one significant factor in a suite of three factors. The other two are soil physical factors and soil biological factors. Although we will stress fertility management, it cannot be considered in a vacuum. Thus the other two legs of our three-legged stool will also be covered.

There are sixteen elements that are known to be essential for the growth of all tree seedlings and one additional one for the growth of nitrogen-fixing species. Of these elements, four come from the atmosphere and the rest from the soil. These essential elements are conveniently divided into two groups, those that are needed in the plant in fairly large amounts (called macro-elements) and those that are needed in very small amounts (called microelements). The micro-elements have sometimes been called the minor elements, but that gives the false impression that they are somehow less important than the macro-elements. They are all absolutely essential for tree growth.

Carbon $(\mathrm{C})$, hydrogen $(\mathrm{H})$ and oxygen $(\mathrm{O})$ come from the atmosphere as water, oxygen, and carbon dioxide. They are the elements that are needed in largest amounts for tree growth. However, we seldom include them in a discussion of fertility management. For this discussion we will assume that there will be adequate air and water to take care of those needs.

\section{Nitrogen (N)}

Hardwood seedlings come in two groups in regard to their $\mathrm{N}$ needs. The first group, which include a majority of hardwoods require a source of fertilizer $\mathrm{N}$. They need about $50 \%$ more $\mathrm{N}$ than most pines. Thus, they are heavy $\mathrm{N}$ feeders. The second group of hardwoods associate with certain microbes, form nodules on their roots, and provide their own N. Certain leguminous species, such as black locust, associate with bacteria called Rhizobium. while other species such as alders, Russianolive, or casuarina associate with an actinomycete called Frankia. The result is the same in both cases. The microbes live in nodules on the plant roots and convert atmospheric $\mathrm{N}$ into forms that the plant can use. In practice, we usually do not apply fertilizer- $\mathrm{N}$ to the $\mathrm{N}$-fixing species until the middle of June. If they are well nodulated and growing up to expectations, we continue to refrain from fertilizing with $\mathrm{N}$. However, if there is a lack of nodulation and growth is subpar, we simply pick these species up on the regular $\mathrm{N}$ 
fertilization schedule for the rest of the growing season. A lack of nodulation may occur in the year following soil fumigation.

Nitrogen is needed for growth. But sometimes it can also stimulate seed germination. Studies by Auchmoody (1982) suggested that certain recalcitrant seed can be stimulated to germinate through the action of nitrate. He applied either urea or calcium nitrate to cherry (Prunus pennsylvanica) seed and observed a strong germination stimulation. Rates of application of $50 \mathrm{lbs}$. N/acre (56 kg N/ha) were effective. Since both nitrogen sources were equally effective, he concluded that the stimulation was related either to the direct action of the applied nitrate in the calcium nitrate or to nitrate derived from the urea via nitrification. Both phosphorus $(\mathrm{P})$ and potassium $(\mathrm{K})$ were included in the treatments but neither stimulated germination above that produced by the $\mathrm{N}$ alone.

Some authors have shown a strong clonal response to fertilization. Curlin (1967) grew 22 clones of cottonwood (Populus deltoides Bartr.) cuttings, using a single rate of ammonium nitrate fertilization. He found a strong clonal response to the fertilizer in plant height, diameter, and volume. Since most hardwood seed being planted today is still open-pollinated, this strong interaction manifests itself in large seedling-to-seedling variation in growth. The small amounts of improved seed from hardwood seed orchards which have been available for planting almost always show a reduction of variation in seedling size. Until we have genetically uniform seed or use clonal vegetative propagation (Ike,1969), real uniformity among hardwood seedlings will be very difficult to achieve.

The potential advantages of slow-release fertilizers in forestry have been recognized for more than 25 years (Hauck, 1967). One early study of the effect of slow release magnesium ammonium phosphate (MagAmp) and coated oxamide was carried out with tulippoplar (Liriodendron tulipifera) seedlings (White and Ellis, 1965). The authors reported an increase in $\mathrm{N}$ uptake but a decrease in survival. They also found that high rates of $\mathrm{N}$ application depressed potassium uptake. Deines (1973) compared ammonium nitrate, urea, and sulfur-coated urea (SCU) on the growth of sycamore (Platanus oxidentalis) and sweetgum (Liquidambar styraciflua) seedlings in two nurseries which had contrasting soils. Seedling growth, when evaluated at the same rate of $\mathrm{N}$ application, was better with urea than either the SCU or the ammonium nitrate. He cautioned, however, that the SCU had been applied in one preplant application, whereas the other two sources had been split into five equal applications during seedling growth.

The first in-depth evaluation of slow release fertilizers in hardwood nursery production was conducted by Villarrubia (1980). He evaluated both soluble and slow release $\mathrm{N}$ sources over a range of application rates on sweetgum and green ash seedlings. The soluble $\mathrm{N}$ sources were ammonium nitrate (AN), ammonium sulfate (AS), sodium nitrate ( $\mathrm{SN}$ ), and urea $(\mathrm{U})$ and the slow release $\mathrm{N}$ sources were isobutylidene diurea (IBDU) and two slowrelease forms of sulfur-coated urea (SCU). They were called SCU-11 and SCU-24. The numbers represent the dissolution percentages in water after seven days. Thus, the SCU-24 released its $\mathrm{N}$ approximately twice as rapidly as the SCU-11. Rates of fertilization were the equivalent of 200,300 , and 400 lbs. N/acre with the slow release forms being incorporated with the soil prior to planting the seed. The soluble forms were topdressed during seedling growth.

Height growth for both species was greatest with SCU24 (Fig. 1). This was followed by a group consisting of $\mathrm{AS}, \mathrm{U}$, SCU-11, and AN. These were followed considerably by IBDU and lastly by SN. Since most of the better performing $\mathrm{N}$ sources contained sulfur (S), a second 
experiment was conducted using AS, U, and U plus elemental S $(\mathrm{U}+\mathrm{S})$ at the same rate of $\mathrm{S}$ as is in the AS. Results were clear, with both height and root collar diameter being significantly greater with the $\mathrm{S}$-containing forms (AS and $U+S)$ than with the $U$. This response is likely to be soil-specific. However, note the comments on phosphorus below, where $\mathrm{S}$ again becomes an important consideration.

The $\mathrm{N}$ sources had large effects on soil acidity. At the beginning of the study (before any $\mathrm{N}$ fertilizer was applied), the soil in the plots ranged from $\mathrm{pH}$ 5.6 to $\mathrm{pH}$ 6.5. By September, across all plots, the SN plots averaged above $\mathrm{pH} 7$ while the AS plots were all near $\mathrm{pH} 4.5$.

Results showed that there were no differences in seedling growth attributable to $\mathrm{N}$ rate. Thus, the lowest rate tested (200 lbs. N/acre) was adequate and represented a considerable reduction in fertilizer costs, since the highest rate had been the standard for the nursery where the tests were run. Growth response to $\mathrm{N}$ source formed two distinct groups with AS, SCU24, AN, SCU-11, and U being better than IBDU or SN. The AS and SCU-24 gave the best early and rapid growth. This reduced weeding costs due to rapid shade development. Neither source nor rate of $\mathrm{N}$ application affected seedbed density of either species.

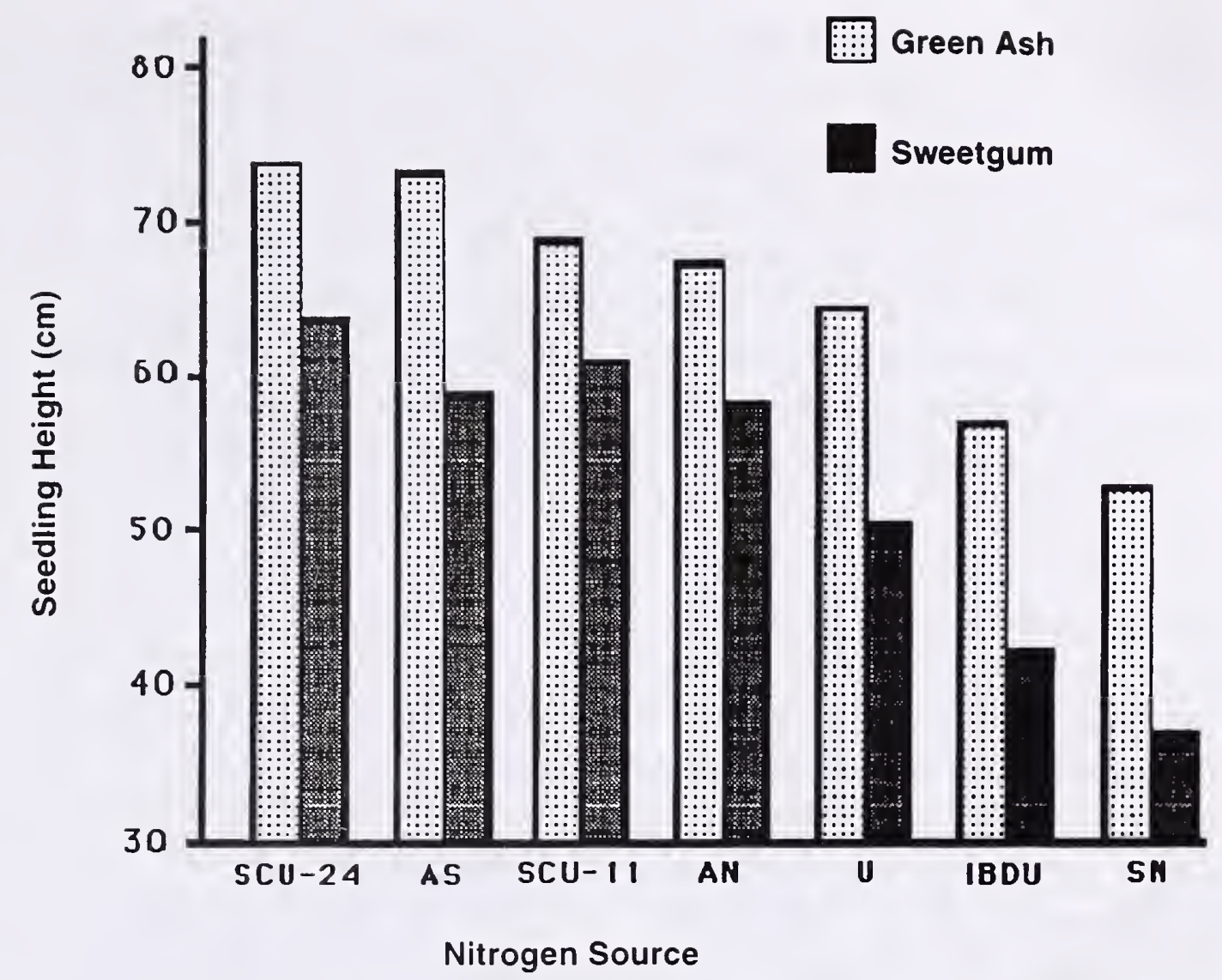

Figure 1. Effect of nitrogen source on height of green ash and sweetgum seedlings at lifting (data summarized from Villarrubia, 1980).

The fact that the slow release forms of $\mathrm{N}$ were as effective as the soluble forms, and that they were applied all in one application at the beginning of the season, seemed to offer some advantage. However, an assessment of the cost of the materials made it at least as economical to use the soluble forms, even when the added cost of fuel and labor for repeated application were included. In addition, the soluble forms offer the advantage of being flexible in the amount used in any given year. This allows adjustment for yearto-year climatic variation. Currently, several nurseries are doing custom application of soluble $\mathrm{N}$ fertilizers that are composed of ammonium nitrate and urea, with varying amounts of ammonium sulfate or ammonium thiosulfate added.

Finally, the soluble forms offer the possibility of following the results of Ingestad (1989) and progressively increasing the rate of application over the growing season. This may also reduce the total amount of fertilizer needed since quite small application rates are used early in the season. This could have been one reason for the low rate being the best in Villarrubia's (1980) study. He used three different application rates; a light rate in June, a moderate rate in July, and a heavy rate in August. 


\section{Phosphorus (P) and sulfur (S)}

In times past, we used ordinary superphosphate (OSP) (0-20-0) as our source of $\mathrm{P}$. Today we use either triple superphosphate (TSP) (0-46-0) or diammonium phosphate (DAP) (18-46-0). All three are acceptable sources of $\mathrm{P}$, but there has been one major change associated with switching away from OSP, and it has nothing to do with $\mathrm{P}$. In the manufacturing of OSP, phosphate ore is reacted with sulfuric acid and the resulting OSP contains plenty of S. In the production of TSP, phosphate ore is reacted with phosphoric acid. Finally, DAP is produced by reacting ammonium hydroxide with phosphoric acid. Thus, neither TSP nor DAP contain any $\mathrm{S}$. As long as OSP was being used nurseries seldom had need for any $\mathrm{S}$ additions. Since the switch to TSP and DAP, there has been a frequent need for added $\mathrm{S}$. This is now provided through the use of ammonium sulfate as an $\mathrm{N}$ source, gypsum (calcium sulfate) as both a calcium and S source, or the application of elemental S to the soil. Both the ammonium sulfate and elemental S will acidify the soil. Thus, they need to be used with some caution. Gypsum has essentially no effect on soil acidity. All of these sources of $\mathrm{P}, \mathrm{S}$, and calcium can be used, when appropriate, on hardwoods. Hardwoods tend to use somewhat more $\mathrm{P}$ than conifers.
Lamar and Davey (1988) inoculated green ash seedlings in a nursery with three VAM fungi and had a non-inoculated control. They found that the P content of the foliage was considerably higher than typical coniferous seedlings. There were significant differences among all three VAM fungi and they were all better than the non-inoculated control. This study is described in more detail below, under the topic of mycorrhizae.

\section{Potassium (K)}

Since $\mathrm{K}$ is not a structural element in any seedlings and since nearly all sources of $\mathrm{K}$ are quite soluble, the only real difference between hardwoods and conifers is that hardwoods use somewhat more $\mathrm{K}$ than conifers. However, the difference is usually less than a $25 \%$ increase for the hardwoods.

\section{Calcium (Ca)}

Hardwoods tend to use more of almost all nutrient elements than pines, but this is especially true for $\mathrm{Ca}$. According to Gosz (1984), the relative nutrient use by trees in general is $\mathrm{N}>\mathrm{K}>$ $\mathrm{Ca}>\mathrm{P}=\mathrm{Mg}=\mathrm{S}>\mathrm{Fe}=\mathrm{Mn}$. However, some hardwoods, such as poplars, use more $\mathrm{Ca}$ than any other nutrient on the list. In general, hardwoods use about twice as much $\mathrm{Ca}$ as pines.

\section{Magnesium (Mg)}

According to a review by Leaf (1968), hardwoods tend to use from $50 \%$ to $200 \%$ as much $\mathrm{Mg}$ as pines. Sources of $\mathrm{Mg}$ include dolomitic lime, Epsom salts (magnesium sulfate), and a mixture of potassium sulfate and magnesium sulfate which is known by at least three different commercial names. These include: Sul-Po-Mag, K-Mag, and sulfate of potash - magnesia. They are all essentially the same product and may be interchanged without risk.

\section{Micro-elements}

Much less is known about hardwood seedling nutrition in regard to the micro-elements than is known about the macro elements. Table 1 presents a set of generalizations digested from the extensive reporting of Stone (1968) in regard to microelement concentrations in the foliage of many species of trees.

In Stone's (1968) original tables, a wider range of values for all of these elements can be found. However, the values in Table 1 represent fairly typical ranges for pine and hardwood seedlings. 
Table 1. Ranges in the foliar concentrations of the micro-elements considered "adequate" for growth of pines and hardwoods.

\section{Element}

\section{Boron \\ Copper}

Iron

Manganese

Molybdenum

Zinc

\section{Pines \\ (foliar concentration in ppm.}

$15-40$
$4-8$
$25-75$
$100-400+$
$0.04-0.10$
$30-50$

$30-60+$

$5-15$

$80-90$

$200-1,000+$

$0.05-0.30$

$25-50$

\section{Soil Testing}

\section{Although not restricted to} hardwood seedling production, it is useful to mention problems and benefits associated with soil testing. Analyzing foliage for nutrients or soil for total nutrients, while requiring good analytical chemistry, is very little trouble. On the other hand, attempting to chemically simulate in a few minutes what tree seedlings (or any other crop) will be able to extract from a soil over a whole growing season is very complex. Over the years, a number of extracting solutions has been developed for this purpose. Some are as simple as hot water which is used to extract available boron and some are quite complex, such as the Mehlich 3 extractant. The best extractant to use in any given region is still a matter for some debate. Most extractants have been named for their developer and this causes problems with pride, if not chemistry. Some typical extractants are known as
Bray 1, Bray 2, Mehlich 1, Mehlich 2, Mehlich 3, Morgan, Olsen, and Truog. All but the Olsen extractant were developed for acidic soils such as exist in nearly all nurseries represented at this meeting. The Olsen extractant was developed specifically for alkaline soils.

The second aspect of the soil testing process is determining the amount of the various elements in the extract. Again, that is very routine chemistry. Finally, once we have the soil test data in hand, we get to the really tricky part of the process and that is interpreting the results in relation to the growth of some specific crop. In many states, a great deal of effort has gone into the process of correlating crop growth and yield with specific soil test levels and developing guidelines for correcting deficiencies or maximizing yield without wasting money or risking environmental pollution. Unfortunately, nearly all soil testing facilities have been developed for agronomic crops. Some work has been done with orchard tree crops, but that is about as close as we get to forest tree seedlings. One nursery manager once told me that his state soil testing lab could give him very precise suggestions for his cover crop but had no idea what to tell him about his trees.

Finally, different soil testing labs use very different ways of reporting the results that they obtain. Some express values as pounds per acre, some as parts per million, some as milliequivalents per 100 grams of soil, some as an index value, and some are based on a volume of soil rather than a weight of soil. By the time you consider all the different extractants that might be used and all the different ways in which the results may be reported, it becomes a nightmare trying to do anything on a regional basis.

Because of the apparent babel created by the use of various soil extractants and the variety of ways of reporting results of soil analysis, a special committee, within the Auburn Nursery Co-op, was set up to try to deal with this confusion. The first decision was to select one laboratory to do all testing. This would at least eliminate the myriad of methods and results expression. No state lab was in a position, logistically or legally, to run soil tests for land owners across states from Texas to 
Virginia. Consequently one commercial lab was selected and most nurseries with in the Co-op and several outside the Co-op have used this lab since the fall of 1981. By having all of the interpretation done at one location, we have built up a very substantial data bank, both in terms of soil test values, and more importantly, in terms of efficient soil management. Many nurseries in the southern region have reached the point of routine fertilization with only occasional significant adjustments of specific nutrients, soil acidity, or organic matter. The hope has been from the beginning that we could improve seedling quality and at the same time reduce seedling production costs.

\section{Soil Physical Properties}

\section{Texture}

Soil texture is an important criterion when selecting a nursery site. Ideally, pine nurseries should be located on fine sands. Coarser sands have low water and nutrient-holding capacities. Hardwood nurseries should be located on loamy sands. Finer textured soils may be fertile and hold water well but they often present severe difficulties during lifting. Root loss is often extreme and the resulting survival of seedlings in the field is reduced. There are a very few nurseries located on almost pure silt ( $<5 \%$ clay) on loess soils near the Mississippi River that seem to have the best of both conditions. However, just a little more clay $(5-10 \%)$ and these soils become nearly useless for seedling production.

\section{Bulk density and soil compaction}

The emergence of germinated seed from soil is affected by mechanical resistance of the soil to seedling root penetration, and by restriction of the exchange of oxygen and carbon dioxide in the seed zone (Chancellor, 1977). He reported that emergence of cotton seedlings, which are very similar to many hardwood seedlings, was directly related to air permeability of the soil and inversely related to mechanical impedance. These effects restrict root extension in the soil and as a consequence of that, the availability of water to the developing seedling. During germination and emergence, nutrient availability is not a significant problem since the very young plant is still depending on the seed for nutrients and energy. Once germination and emergence are completed and the seed energy has been used, nutrient availability becomes an additional concern. Chancellor (1977) concluded that when water is at all limiting, soil compaction reduces water and nutrient uptake. Compaction reduces seedling survival in the seedbed.

Most problems related to mechanical impedance in the nursery are related to soil compaction caused by equipment travel. The nursery manager should instruct all equipment operators to use only the paths between beds, with almost no exceptions. I have observed poor growth of cover crop in a field that had been in seedlings the year before. The poor growth was easily identified as tractor traffic diagonally across the field during lifting. Even one or two passes with a tractor leaves compaction that is difficult to totally erase during the next cycle of land preparation. The susceptibility of soil to compaction is directly related to the moisture content up to near saturation. Unfortunately, the soil is frequently very moist during the lifting season. The compacting force of a tractor tire destroys the large pores in the soil and these pores are primarily responsible for air entry into the soil and carbon dioxide escape.

Compaction leads to a high soil bulk density. The bulk density of a soil is related to its texture and organic matter content. Mitchell, et al. (1982) subjected loblolly pine seedlings to growth in a forest soil which had been compacted to various imposed bulk densities up to $2.0 \mathrm{~g} / \mathrm{mL}$. This was done in a greenhouse where other conditions could be kept constant. Root and top growth were not greatly affected until a bulk density of 1.5 was reached. All 
higher bulk densities had strong, increasingly deleterious, effects on root growth, nutrient uptake, and top growth. At bulk densities of 1.9 and 2.0, growth nearly ceased. No comparable study with hardwood seedlings is known but practical observation has shown the general concept to hold. In one nursery in Virginia. high bulk density caused by equipment compaction has been found to be directly detrimental to sweetgum seedling growth in an otherwise excellent soil. There is an inverse relation between seedling growth and soil bulk density. Since soil compaction is never uniform, it also leads to increased variability in seedling size and quality.

Each soil has a natural bulk density and it is affected by both texture and organic matter content. Sands have a naturally higher bulk density than clays. Daddow and Warrington (1983) have provided a very useful guide to growth-limiting soil bulk densities as influenced by soil texture. Their results show that texture must be considered when trying to decide whether excessive compaction has occurred to any given soil.

\section{Temperature}

Mycorrhizal and non-mycorrhizal green ash seedlings were grown at various root temperatures $\left(7.5^{\circ}-20^{\circ} \mathrm{C}\right)\left(45^{\circ}-68^{\circ} \mathrm{F}\right)$ to determine temperature effects on leaf area. seedling height. and biomass production (Anderson et al. 1987). Leaf area was greater in mycorrhizal than non-mycorrhizal seedlings at all temperatures and the relative difference was greater at low temperatures. Phosphorus concentrations in roots and leaves did not differ between mycorrhizal and nonmycorrhizal seedlings. However, because of the significantly greater growth of the mycorrhizal seedlings, the $P$ content of the mycorrhizal seedlings was always higher. The authors concluded that the mycorrhizal fungus used as inoculum (Glomus etunicatum) actively stimulates green ash growth at moderately low root temperatures.

Soil temperature also directly influences all reactions in the soil. There is a general temperature quotient, $\mathrm{Q}_{10}=2$, which indicates that for every $10^{\circ} \mathrm{C}$ $\left(18^{\circ} \mathrm{F}\right)$ increase or decrease in temperature, reaction rates will either double or be cut in half. For most chemical reactions this holds for all temperatures above freezing. For biological systems, the quotient only holds within the temperature range in which any given organism will grow reasonably well. However, it does help us understand some of the nutrient and organic matter dynamics in the soil. For example, organic matter breaks down much more rapidly in southern nurseries than it does in those in the northeast. Not only does the soil reach somewhat higher temperatures in the south. it remains well above freezing for most (in some locations, all) of the year. Thus, $\mathrm{Q}_{10}=2$ tells us that the oxidation of soil organic matter will be considerably greater in the south. And in fact it is greater. The equilibrium organic matter content of sandy nursery soils in the south is generally well below $2 \%$. By contrast, the nursery soils of the Pacific Northwest frequently have equilibrium organic matter levels around $8 \%$. One might expect that because of higher temperatures during the growing season, growth (photosynthesis) should be much higher in the South. Actually, it is much higher - but unfortunately-so is respiration. Thus net growth is not as much higher than might be thought at first. In fact, most of the greater growth in the South can be attributed to a longer growing season rather than to a warmer one.

Red oak seedlings were grown in a greenhouse at varying day/night soil temperatures (Larson,1970). No single temperature was optimum for root growth but roots grew well at a constant $24^{\circ} \mathrm{C}\left(75^{\circ} \mathrm{F}\right)$. There was some decrease in root growth at $18^{\circ}$ and $29^{\circ} \mathrm{C}\left(64^{\circ}\right.$ and $84^{\circ} \mathrm{F}$ ). Shoot growth remained favorable at $29^{\circ} \mathrm{C}$ but was severely limited below $18^{\circ} \mathrm{C}$ regardless of a favorable air temperature. The total daily degree hours of soil heat was found to be more important for seedling growth than the difference between day and night temperatures. 


\section{Rooting depth}

Rooting depth of seedlings is directly related to seedling growth. Soil depth may be actual depth or effective depth. Actual depth may be limited by a physical barrier to root growth, such as an old plow pan, or it may be effectively shallow due to a high water table or lack of oxygen penetration below a certain depth. In the latter cases there is no physical barrier to downward root growth but roots are nonetheless prevented from rooting to the desired depth.

\section{Mycorrhizae}

Most species of trees are either ectomycorrhizal or endomycorrhizal. A few species, however, can form either type. This was postulated by Lodge (1985) to offer possible advantages to those species when outplanted on variable sites. Eastern cottonwood is one species which can form both types. The results of Lodge's study showed that endomycorrhizae were prevalent on both dry and wet soils whereas ectomycorrhizal seedlings were the norm on moderately moist sites. Fine soil texture and elevated levels of soil $\mathrm{P}$ and $\mathrm{K}$ were all positively correlated with ectomycorrhiza formation and negatively correlated with endomycorrhiza formation. Evidence was found for antagonism among ecto- and endomycorrhizal fungi. In addition to cottonwood, oaks and some leguminous tree species can form either type. In general, where the option exists, superior growth of the seedlings is associated with the formation of ectomycorrhizae. However, with all known tree species, growth of mycorrhizal seedlings of either type significantly exceeds the growth of non-mycorrhizal seedlings. Also, within either type, there are important interactions between tree species and mycorrhizal species. This probably even extends to the genotype of both. However, this has not been well investigated. Tree genotype and fungus species interactions were studied for Douglas-fir by Lambeth (1979) in the phytotron and found to be important.

The effect of soil fumigation on subsequent pine seedling growth and ectomycorrhiza development has been studied fairly extensively. Snyder (1984) studied these factors as they affect sweetgum seedling growth and endomycorrhiza development. Fumigation was with $350 \mathrm{lbs}$./acre of MC-2. The concern was that while the inoculum of ectomycorrhizal fungi is air-borne and soil reinfection is fairly rapid after fumigation, endomycorrhizal fungi have spores that are only soil-borne. Thus, if fumigation damages them significantly, reinoculation can be a slow process. Snyder's results showed that sweetgum seedlings that were grown on first year, spring-fumigated soil were smaller in root collar diameter (RCD) and had lower mycorrhizal infection through much of the growing season than seedlings grown on non-fumigated soil. By lifting time, there was no significant difference in RCD's, but mycorrhizal development was still low. Graded seedlings were outplanted and after a year in the field those seedlings that had been grown on the non-fumigated soil did have larger RCD's than those grown on the fumigated soil.

One possible way to increase the endomycorrhizal inoculum in the soil might be through the growth of cover crops between fumigation and the seedling crop. This was investigated by testing both one summer and several winter cover crops and comparing them with summer fallow. Soil potassium level dropped significantly after the summer fallow and the subsequent sweetgum crop had the lowest mycorrhizal infection. The summer cover crop did not influence the mycorrhizal development of the winter cover but the winter cover did influence the subsequent sweetgum seedling crop. The best result was with a winter cover crop of rye and the poorest following lupine. Sweetgum seedlings grown after a summer cover crop of sudax were significantly taller then those grown after a fallow treatment. In a second study, sweetgum seedlings were 
grown in soil which had produced a crop of ectomycorrhizal water/willow oaks the previous summer. Mycorrhizal development was lower in those sweetgum seedlings than in any of the previous tests following endomycorrhizal cover crops. Thus, the possibility exists that a single crop of ectomycorrhizal seedlings may significantly lower the inoculum potential of endomycorrhizal fungi. Further elucidation is needed on that subject.

There has been some evidence that high soil fertility, especially high phosphorus levels will reduce or even eliminate mycorrhiza development. Also, there has been speculation that vesicular-arbuscular mycorrhizal (VAM) fungi that might be effective in the high fertility environment of the nursery would not be functional in the low fertility environment of forest plantings. In order to study these potential problems, Lamar and Davey (1988) isolated three VAM fungi from roots of green ash trees in a low fertility (5-7 ppm P) forest soil and used them for inoculation of green ash seedlings in a high fertility (148 ppm P) nursery soil. Inoculation with these fungi significantly increased seedling heights, RCD's, dry matter accumulation, and phosphorus uptake, relative to control seedlings. Control seedlings received the same treatments except for the VAM fungal inoculation. Seedbeds had been fumigated with MC-2 at $300 \mathrm{lbs} / \mathrm{acre}$. There was a significant positive correlation between foliar P concentration and percent root infection. These results provide evidence that there are VAM fungi that are capable of functioning effectively under either high or low soil fertility. That should be good news to those nursery managers producing planting stock in fertile nursery soil for outplanting in infertile forest soil. The authors concluded that the growth stimulation was probably eventually limited by the low potassium level in the nursery soil being used rather than by excessive $\mathrm{P}$ accumulation.

\section{Facultative relationships}

Some few tree species have the ability to form either ecto- or endomycorrhizae. It has been postulated that such an ability should offer some ecological advantage. Cottonwood (Populus deltoides) is one such species. A series of experiments were run with cottonwood to define this possibility (Lodge, 1985). Endomycorrhiza infection occurred under very dry or very wet conditions while ectomycorrhiza formation predominated under moderate moisture levels. Soil properties that were positively correlated with ectomycorrhiza formation and negatively correlated with endomycorrhiza formation were fine texture, potassium level, and phosphorus level. Lodge (1985) found evidence for antagonism between ectomycorrhizal and endomycorrhizal fungi.

\section{Seedbed Density}

Hardwood seedbed density varies by species, but it is almost always considerably lower than the conifers (longleaf pine is an exception). Then, since we irrigate and fertilize on an area basis, and the need for both water and fertilizer is greater on an area basis than for pines, the cost per seedling goes up considerably. Typically, the relative cost for nitrogen fertilizer for a single hardwood seedling is approximately 2.5 times as high as for one pine seedling. Likewise, the cost for water is about 3.3 times as great. Thus, it should be no surprise that the price to the purchaser is at least three times as high for hardwoods as it is for pines.

\section{Vegetative Propagation}

For several tropical hardwoods, it has been found advantageous to grow seedlings in the nursery and then just immediately before or after lifting, remove the top, leaving a root system with a stem about 6 inches $(15 \mathrm{~cm})$ long. This is often called a "false cutting" because it looks like a cutting after planting in the field but it has the advantage of having a fully developed root system. 
Such trees can be produced as bare-root stock and survive very well where there is no dormant season. In the nursery, such planting stock can be grown either from seed or vegetatively produced from true cuttings. This last technique allows taking maximum advantage of any superior trees.

In more temperate regions, vegetative propagation has usually involved growing several coppice rotations on established root systems. The sprouts are then converted into true cuttings for establishment in the field. The fertility management of such cutting gardens in the nursery varies somewhat from seedling production. First the plant density is greatly reduced while the root systems are greatly enlarged. The frequency of fertilization of such trees can be reduced while the size of individual fertilizations can be increased over those typical for seedling production. Total nutrient demands for such trees are usually 10 to $25 \%$ greater than for seedlings of the same species. Superior selections of several hardwood species can be advantageously propagated by this method. These commonly include various poplars, ash, and sycamore.

\section{LITERATURE CITED}

Anderson, C.P., E.1.Sucoff, and R.K.Dixon. 1987. The influence of low soil temperature on the growth of vesiculararbuscular mycorrhizal Fraxinus pennsylvanica. Can. J. For. Res. 17:951 -956.

Auchmoody, L.R. 1982. Fertilization of young Allegheny hardwoods. Ph.D. dissertation. North Carolina State University. Raleigh, NC, 75 p.

Chancellor, W.J. 1977. Compaction of soil by agricultural equipment. Univ. Calif., Div. Agr. Sci. Bull. 1881. 53 p.

Curlin, J.W. 1967. Clonal differences in yield response of Populus deltoides to nitrogen fertilization. Soil Sci. Soc. Amer. Proc. 31 :276-280.

Daddow, R.L. and G.E. Warrington. 1983. Growthlimiting soil bulk densities as influenced by soil texture. USDA For. Serv., Fort Collins, CO. Water System Development Group, WSDGTN-00005. 17 p.

Deines, J. 1973. The effect of fertilization on the growth and development of 1-0 sycamore (Platanus occidentalis L.), sweetgum (Liquidambar styraciflua L.), and green ash (Fraxinus pennsylvanica Marsh.) seedlings. M. S. thesis, North Carolina State University, Raleigh, NC, 80p. Ike, A.L. 1969. The influence of soil texture on the growth of American sycamore (Platanus occidentalis L.). Ph.D. dissertation, North Carolina State University, Raleigh, NC, 71 p.

Ingestad, T. 1989. Defined nutrient additions to plants - a theory and its application. Proc. Marcus Wallenbery Found. Symp. 6:5-19.

Lamar, R.T. and C.B.Davey. 1988. Comparative effectivity of three Fraxinus pennsylvanica Marsh. vesicular-arbuscular mycorrhizal fungi in a high phosphorus nursery soil. New Phytol.109:171 -181.

Lambeth, C.C. 1979. Interaction of Douglas-fir (Pseudotsuga menziesii (Mirb.) Franco) fullsib families with field and phytotron environments. Ph.D. dissertation, North Carolina State University, Raleigh, NC, 83 p.

Larson, M.M. 1970. Root regeneration and early growth of red oak seedlings: influence of soil temperature. For.

Sci. 16:442-446.

Lodge, D.J. 1985. The ecology of ecto- and endomycorrhizal fungi associated with eastern cottonwood roots. Ph.D. dissertation, North Carolina State University, Raleigh, NC, 201 p. 
Mitchell, M.L., A.E.Hassan,

C.B.Davey, and J.D.Gregory. 1982. Loblolly pine growth in compacted greenhouse soils. Trans. Amer. Soc. Agr. Eng. 25:304-307, 312.

Snyder, C.S. 1984. Sweetgum seedling growth and endomycorrhizal development as affected by soil fumigation and cover crops. Ph.D. dissertation. North Carolina State University, Raleigh, NC, 68 p.

Villarrubia, J.M. 1980. Effect of nitrogen rate and source on growth and performance of Liquidambar styraciflua (sweetgum) and Fraxinus pennsylvanica (green ash) seedlings in a Virginia nursery. Ph.D. dissertation, North Carolina State University, Raleigh, NC, 91 p.

White, D.P. and B.G.Ellis. 1965. Nature and action of slowrelease fertilizers as nutrient sources for forest tree seedlings. Quart. Bull. Mich. Agr. Exp. Sta. 47: 606-614. 


\title{
Undercutting in Loblolly Pine ${ }^{1}$
}

\author{
Jim Rakestraw and George Lowerts ${ }^{2}$
}

Abstract-Undercutting has been demonstrated in many species to be an effective method to control seedling height, manipulate root system morphology, and alter seedling physiology. Similar results have been demonstrated in loblolly pine undercutting research at Union Camp. Apparently, the moisture stress condition of the seedlings at the time of undercutting plays a very important role in the response achieved.

Keywords: Pinus taeda L., undercutting, nursery.

\section{SUMMARY OF REPORTED UNDERCUTTING EFFECTS}

Undercutting is defined as the physical manipulation of roots while the seedling is still in the nursery bed. This procedure has been used since the late nineteenth century (Racey and Racey 1988). Summer or early fall undercutting has become a standard procedure in southern pine (Pinus spp.) nurseries (SAF Tech. Comm. 1932, Hastings 1948, Johansen 1955, Shipman 1958, Shoulders 1959, 1965). The objectives and methods of undercutting vary somewhat with area regeneration concerns but generally undercutting is practiced to maintain a balance between shoot and root growth, and to modify the form and function of the root system.
Most cultural treatments which sever the roots of a seedling during the growing season will reduce shoot growth (Duryea 1984). Undercutting has been demonstrated to be an effective method to control the shoot growth of the southern pines (Darby 1962, Shoulders 1963, Tanaka et al. 1976, Dierauf and Olinger 1982). Similarly, intensive nursery bed root manipulation of radiata pine (P. radiata D. Don) in New Zealand has been shown to decrease height growth, increase root system fibrosity and root growth rates (Cameron 1969, Rook 1971, Sweet and Rook 1972, van Dorsser and Rook 1972, Benson and Shepard 1977, Bacon 1979, Escobar et al. 1977).
The effect of undercutting on diameter has been inconsistent in many species. In loblolly pine, some studies reported a decrease in diameter with undercutting (Tanaka et al. 1976, Dierauf and Olinger 1982) while others report undercutting has no effect (Shoulders 1963, Venator and Mexal 1981). Undercutting will reduce diameter depending on the severity and frequency of the treatment and the physiological status of the seedling at the time of undercutting (Racey and Racey 1988). Since undercutting will reduce height growth and may reduce diameter growth, seedlings must be given sufficient individual space to allow for maximum diameter growth (van Dorsser 1981) and Jakabffy (1969) indicates that to be

\footnotetext{
${ }^{1}$ Rakestraw, J.; Lowerts, G. 1994. Undercutting in Loblolly Pine. IN: Landis, T.D.; Dumroese, R.K., tech. coords. National Proceedings, Forest and Conservation Nursery Associations. Gen. Tech. Rep. RM-257. Fort Collins, CO: U.S. Department of Agriculture, Forest Service, Rocky Mountain Forest and Range Experiment Station: 50-55.
}

${ }^{2}$ Technical Department, Forest Resources Group, Union Camp Corporation, Savannah, GA. 
successful root manipulation requires sowing to be sparse and uniform. For example, large and vigorous longleaf pine ( $P$. palustris Mill.) seedlings were produced when undercutting at a seedbed density of $20 / \mathrm{ft}^{2}$ compared to $40 / \mathrm{ft}^{2}$ (Johansen 1955, Shipman 1958). In a review of 162 papers involving root manipulation, Racey and Racey (1988) conclude "there is no evidence that undercutting or wrenching are as effective at higher seedbed density". Clearly, undercutting is only effective with lower seedbed densities.

Once undercut, the physiological balance and form of the seedling is altered. Root wounding results in reduction of photosynthetic output, preferential transfer of assimilates from foliage to roots, increased water stress compensated by increased stomatal resistance, and massive root proliferation including lateral root development (Davey 1964, Rook 1971, Wardlaw 1976, Bacon and Bachelard 1978, Stupendick and Shepard 1980, van Dorsser 1981). The recovery period after root pruning in radiata pine seedlings was characterized by decreased stomatal resistance, increased photosynthetic output, and proliferation of new roots (Stupendick and Shepard 1980). Since shoot growth is reduced and root growth stimulated, the root:shoot ratio in undercut seedlings is increased, resulting in better seedling "balance" (Benson and Shepard 1977,
Mexal 1982, van Dorsser 1981, Venator 1983, Mexal and Fisher 1984).

Properly done, undercutting has the potential to produce a seedling in "balance" with a nutrient-charged, fibrous root system and a shoot with enhanced stomatal resistance. Such a seedling will probably survive and recover more quickly from planting shock than an untreated seedling. Survival of undercut seedlings has been reported to be enhanced due to the relative large and active root system which allows rapid contact with soil moisture and nutrient reserves (Rook 1969, Bacon and Hawkins 1977, Benson and Shepard 1977). Undercut radiata pine seedlings were able to maintain active root growth during drought compared to intact seedlings (Rook 1969, van Dorsser 1981). Undercutting was credited with improving the survival of loblolly pine on droughty sites from 70 to 907 , (Tanaka et al. 1976).

Undercutting has also been reported to enhance the early growth of seedlings in some species. Early growth of undercut seedlings was greater than non-treated controls in radiata pine (van Dorsser and Moberly 1969), white spruce (Pica glauca (Moench) Voss), and Douglas-fir (Pseudotsuga menziesii (Mirb.) Franco). Presumably, the robust root system created by undercutting allows for a seedling to rapidly overcome planting shock and commence height growth. Current information is insufficient to support a similar claim for southern pine species.

\section{UNDERCUTTING RESEARCH AT UNION CAMP}

\section{Since 1984, Union Camp} Corporation has conducted a series of undercutting trials in loblolly pine to assess impact of undercutting timing, frequency, seedbed density, water stress, and equipment on seedling characteristics and 1st year field performance. Seedling characteristics typically examined include height, root collar diameter (RCD), and oven dry (O.D. ) tap and lateral root weight. Undercutting research has been conducted at all three company nurseries located at Bellville, Ga., Capron, Va., and Union Springs, Ala. . Described below are the results from several studies which demonstrate the effect of undercutting timing, frequency, and seedbed density on loblolly pine seedling morphology and field planting performance .

\section{In 1988, a factoral study} consisting of all combinations of July, August, and September undercuttings was installed in two single-family loblolly seedlots at our Bellville, Ga. nursery to determine the optimum time of undercutting. The same nursery fertilization, irrigation, herbicide, and pesti- 
cide treatments were applied to both the undercut and control seedlings of each family. The July cutting was applied at a depth of 3 inches, the August cutting at a depth of 5 inches, followed by the last undercutting in September at 6 inches. Seedlings were lifted and graded in November 1988. Surviving seedbed density for both families was approximately $23 / \mathrm{ft}^{2}$. For each family, a subset of grade 1 (4.8-5.5mm RCD) seedlings from each treatment group were field planted on November 18 , 1988. First year height and survival measurements were obtained in February 1989.

When graded at the time of lifting, both families responded in similar fashion to undercutting. For all seedling variables studied, the undercutting-family interaction was not significant. Undercutting reduced seedling height (Table 1). Significant treatment effects occurred in July $(\mathrm{P}=0.0005)$, August $(\mathrm{P}=$ $0.0001)$, and September $(\mathrm{P}=$ $0.0373)$. The greatest reduction in height occurred with more frequent undercutting treatments. Other treatment combinations were not significantly different. Diameter was smaller in all undercutting treatments compared to control trees but this difference was not significant. Similarly, tap root weight (O.D.) was lower in the undercut seedlings but this difference was not significantly different. Compared to control seedlings, lateral root weight (O.D.) was increased by undercutting for all treatments with the August treatment being significantly different $(\mathrm{P}$ $=0.0019$ ).

In 1989, a study was installed to determine the effect of seedbed density on undercutting effects. This study was installed at the Union Springs, Ala. nursery at seedbed densities of $15 / \mathrm{ft}^{2}$ and $23 / \mathrm{ft}^{2}$. Two undercutting treatments were applied, the first in July at a depth of 5 inches and the second in August at a depth of 6-7 inches. Undercutting reduced both seedling height and diameter compared to control seedlings. However, diameter was significantly $(\mathrm{P}=$ $0.0001)$ greater in the lower seedbed density. Tap root and lateral root weight (O.D.) were also significantly greater in the low seedbed density $(P=0.0001$, $\mathrm{P}=0.0004$, respectively). Seedling height was not affected by seedbed density.
Seedling survival and growth in the field is the final and best test of undercutting success. In the 1988 study, control seedlings not undercut and seedlings undercut once in July, August, and September were field planted. All seedlings, both with and without undercutting, were grade one at the time of planting. Survival and height growth were assessed one year after planting. Time of undercutting was not significant for height and survival. Although not significant, undercut seedlings demonstrated greater height and survival one year after planting than control seedlings. Undercut seedlings averaged $54.4 \mathrm{~cm}$ tall with $91 \%$ survival compared to control seedlings which averaged $52.8 \mathrm{~cm}$ with $90 \%$ survival. Survival effects may have been more dramatic if the trees were planted on a droughty site or rainfall was insufficient.

Table 1. Seedling height $(\mathrm{cm})$, root collar diameter $(\mathrm{mm})$, and oven-dried tap and lateral root weight $(\mathrm{g})$ for all combinations of July, August, and September undercuttings at time of lifting.

\begin{tabular}{lccccc}
\hline & & & \multicolumn{2}{c}{$\begin{array}{c}\text { Root } \\
\text { Weight }\end{array}$} \\
\cline { 3 - 6 } Date & Height & Diameter & & Tap & Lateral \\
July (J) & 40.2 & 4.8 & .40 & .50 \\
Aug. (A) & 39.8 & 4.8 & .41 & .51 \\
Sep. (S) & 40.9 & 4.8 & .41 & .52 \\
J,A & 39.0 & 4.8 & .39 & .54 \\
J,S & 39.1 & 4.8 & .39 & .53 \\
A,S & 38.6 & 4.7 & .39 & .56 \\
J,A,S & 38.6 & 4.7 & .39 & .56 \\
Control & 43.2 & 5.0 & .44 & .48 \\
& & & & & \\
\hline
\end{tabular}


Perhaps more important than morphological changes are alterations in seedling physiology due to undercutting. The concentration of soluble sugars in the tap roots of undercut seedlings was found to be $43 \%$ higher than in control seedlings. Similarly, undercutting increased soluble sugar content of lateral roots by nearly $25 \%$. Undercut loblolly pine seedlings have also demonstrated, at least temporary, osmotic adjustments that may help them better withstand drought stress compared to control seedlings.

Since drought conditions cannot be created in the field on demand, a greenhouse study was utilized to determine if undercut trees were physiologically prepared to meet drought conditions. Control and undercut seedlings were tagged and potted in sand. Seedlings were watered only when potted and again three weeks later. Three months later, $80 \%$ of the undercut seedlings were still alive compared to only $20 \%$ of the control seedlings.

Undercut and control seedlings were also placed in aerated hydroponic systems containing various amounts of polyethylene glycol (PEG) to induce moisture stress. Three PEG levels were tested, $0 \%, 10 \%, 17 \%$, which correspond to osmotic potentials of approximately $-3,-5$, and -8.5 bars. PEG induced moisture stress substantially increased cell osmotic response to undercutting. Undercutting increased the tension required to remove water from cells by only $5 \%$ in $0 \%$ PEG but increased it by over $30 \%$ in PEG induced moisture stress compared to control seedlings.

\section{UNION CAMP'S USE OF UNDERCUTTING IN LOBLOLLY PINE}

Undercutting is used at all Union Camp nurseries in combination with root wrenching and lateral root pruning. The seedlings produced have root systems that have been manipulated to enhance survival and perhaps initial growth. The lack of a significant single family undercutting interaction permits one root management protocol for all loblolly pine single families. Control of seedbed density is critical for producing seedlings with the desired diameter. Undercutting will not be as effective with high seedbed densities . The results of Union Camp undercutting research are not entirely uniform. Variation exists in some studies repeated over a period of years. Although the conclusions achieved still indicate the value of undercutting, the strength of the response does vary. Apparently, the moisture stress condition of the seedlings at the time of undercutting plays a very important role in the response achieved. Research efforts are currently underway to help us better understand the relationship of water stress at the time of undercutting and seedling response. Ultimately, nursery irrigation regimes may be altered to produce the best physiologic response in undercut seedlings.

\section{LITERATURE CITED}

Bacon, G.J. 1979. Investigations into radiata pine establishment on the Queensland granite belt. A review of findings and the literature. Dep. For. Queensland Res. Pap. No. 12. $75 \mathrm{p}$.

Bacon, G.J., and E.P. Bachelard. 1978. The influence of nursery conditioning treatments on some physiological responses of recently transplanted seedlings of Pinus caribbea Mor. var. hondurensis B \& G. Australian For. Res. 8:171183

Bacon, G.J., and P.J. Hawkins. 1977. Studies on the establishment of open root caribbean pine planting stock in southern Queensland. Australian For. 40:173-191.

Benson, A.D., and K.R. Shepard. 1977. Effects of nursery practice on Pinus radiata seedling characteristics and field performance: II. Nursery root wrenching. New Zealand J. For. Sci. 7:68-76. 
Cameron, R.J. 1969. The effect of wrenching on root systems of $P$. radiata seedlings. $P$.

117-119 in: Forest Nursery and Establishment Practice in New Zealand. For. Res. Instit. Symp. No. 9.

Darby, S.P. Jr. 1962. Intensified nursery practices - the key to high-quality custom-grown field-graded forest tree seedlings. Tree Planters' Notes 52:7-11

Davey, C.B. 1964. Root pruning in forest nursery management. P. 38-42 in R.G. Hitt, ed. Proc. Region 8 For. Nurserymen's Conferences.

Dierauf, T.A. and H.L. Olinger. 1982. A study of undercutting, lateral root pruning and top clipping in loblolly pine nursery beds. Virginia Div. For. Occas. Rep. 58. 6p.

\section{Duryea, M.L. 1984. Nursery} cultural practices: Impacts on seedling quality. P. 143-164 in M.L. Duryea, and T.D. Landis, eds., Forest Nursery Manual: Production of Bareroot Seedlings. Martinus Nijhoff/Dr. W. Junk, Boston. $385 \mathrm{p}$.
Escobar, R.R., B.X. Espinosa, and V.G. Medina. 1977. Efectos de poda y descalce de raices en el desarrollo de pino insigne (Pinus radiata D.

Don). Boletin de Investigacion, Centro de Ciencias Forestales, Universidad de Concepcion. No. CCF-1 20p.

Hastings, W.G. 1948. Revolutionizing nursery practice. J. For. 21:180-182

Jakabffy, E. 1969. Rationalizing open ground nurseries: Undercutting and some suitable sowing methods. Sver. Skogsvardsforb. Tidskr. 67:425-440.

Johansen, R.W. 1955. M.S. Thesis, North Carolina State University, Raleigh, N.C.

Mexal, J.G. 1982. Growth of loblolly pine seedlings. III. Response to competition and undercutting. Weyerhaeuser Tech. Rep. No. 050-1422/4.

Mexal, J.G. and J.T. Fisher. 1984. Pruning loblolly pine seedlings. P. 75-83 in C.W. Lantz, ed. Proc. 1984 South. Nursery Conference 224p.
Racey, J.E. and G.D. Racey. 1988. Undercutting and root wrenching of tree seedlings: An annotated bibliography. Ontario Min. Nat. Res. For. Res. Rep. No. 121.79p.

Rook, D.A. 1969. Water relations of wrenched and unwrenched Pinus radiata seedlings on being transplanted into conditions of water stress. New Zealand J. For. 14:50-58.

Rook, D.A. 1971. Effect of undercutting and wrenching on growth of Pinus radiata D. Don. seedlings. J. Appl. Ecol. $8: 477-490$

Shipman, R.D. 1958. Planting pine in the carolina sandhills. USFS Southeastern For. Exp. Stat. Pap. 96. 43p.

Shoulders, E. 1959. Root pruning boosts longleaf survival. Tree Planters' Notes 36:15-19.

Shoulders, E. 1963. Root pruning southern pines in the nursery. USDA For. Serv., Southern For. Exp. Sta., New Orleans, Louisiana, Res. Pap. SO-5.

Shoulders, E. 1965. Root pruning in southern pine nurseries. Tree Planters' 70:12-15 
Society of American Foresters, New York Section, Committee on Technical Practices. 1932. Technical forest practices in New York reforestation work. J. For. 58:528-531.

Stupendick, J.T. and K.R.

Shepard. 1980. root regeneration of root-pruned Pinus radiata seedlings. II. Effects of root-pruning on photosynthesis and translocation. New Zealand J. For. Sci. 10:148158.

Sweet, G.B. and D.A. Rook. 1972. Inhibitor levels associated with growth in seedlings of Pinus radiata. New Phytol. 72:1107-1111.

Tanaka, Y., J.D. Walstad, and J.E. Borrecco. 1976. The effect of wrenching on morphology and field performance of Douglas-fir and loblolly pine seedlings. Can. J. For. Res. 6:211-218.

van Dorsser, J.C. 1981. Seedling conditioning. P. 128-142 in Forest Nursery and Establishment Practice in New Zealand. New Zealand For. Serv., For. Res. Instit., Rotorua. FRI Symp. 22. van Dorsser, J.C. and B.W.A. Moberly. 1969. Conditioning of autumn-sown Pinus radiata planting stock. New Zealand For. Serv., For. Res. Instit., Rotorua. Establishment Rep. 6 (unpubl.). 20p. As cited in Duryea (1984), above.

van Dorsser, J.C. and D.A. Rook. 1971. Conditioning of radiata pine seedlings by undercutting and wrenching: description of methods, equipment, and seedling response. New Zealand J. For. 171:61-73.

Venator, C.R. 1983. Effect of lateral root pruning on development of nursery-grown longleaf pine seedlings. Tree Planters' Notes 88:17-19.

Venator, C.R. and J.G. Mexal. 1981. The effect of wrenching and planting date on the survival of loblolly seedlings. U.S.D.A. For. Serv., Gen. Tech. Rep. S0-34. p.20-24

Wardlaw, I.F. 1976. Assimilate partitioning: cause and effect. P. 381-391 in Wardlaw, I.F. and J.D. Passioura, eds., Transport and transfer processes in plants. Academic Press, New York, 484p. 


\title{
Undercutting in Loblolly and White Pine Seedbeds ${ }^{1}$
}

\author{
Thomas A. Dierauf ${ }^{1}$
}

\begin{abstract}
In seven studies installed in six different years, undercutting loblolly pine seedlings has had little effect on survival for our sandy New Kent and Sussex nurseries. For six studies, survival improvement ranged from +2 to -1 percentage points and averaged only one percentage point. White pine survival, on the other hand, was improved considerably by undercutting. Survival increases ranged from 13 to 20 percentage points for five studies, and averaged 18 points.
\end{abstract}

\section{INTRODUCTION}

We have installed seven undercutting studies in loblolly pine and five in white pine. There were two early studies in loblolly pine, in 1977 and 1982 , and the results were published in 1982 and 1988 in Occasional Reports \#58 and \#72. The other five undercutting studies in loblolly pine and the five studies in white pine were installed between 1988 and 1991. These will soon be published in Occasional Reports \#115 and \#116.

For the proceedings of this conference, I have repeated the information presented in these four occasional reports that deals with study procedures and field results. I have omitted information on the effect on root collar diameter and top length in the seedbed.

\section{LOBLOLLY STUDIES}

\section{Study}

A study to test the effects of undercutting, lateral root pruning and top clipping was installed in loblolly pine seedbeds at the New Kent Nursery in the summer of 1977 . The following seven undercutting treatments were replicated in three different seedbeds (the three seedbeds were in different nursery blocks). Seedbed plots were 20 feet long.

$\begin{array}{ll}\text { 1. Control } & \text { not undercut } \\ \text { 2. Undercut } & \text { Aug. } 8 \\ \text { 3. " } & \text { Aug. } 8 \text { \& Sept. } 1 \\ \text { 4. " } & \text { Aug. 8, Sept. 1, \& Oct. } 4 \\ \text { 5. " } & \text { Sept. } 1 \\ \text { 6. " } & \text { Sept. 1 \& Oct. } 4 \\ \text { 7. " } & \text { Oct. } 4\end{array}$

Each plot was divided in half to produce two ten-foot-long subplots, and each subplot was again divided in half to produce two five-foot-long sub-subplots. Lateral root pruning was done each time undercutting was done. The lateral pruning was done first, with undercutting following immediately. Top clipping was done on half of each subplot (sub-subplot). All top clipping was done on September $1^{\text {st }}$. The experimental design was, therefore, a splitsplit-plot with undercutting treatments assigned to main plots, lateral pruning to subplots, and top clipping to subsub plots.

The undercutting was done at a depth of about 5 inches, and was followed immediately by irrigation. This worked satisfactorily in a preliminary test of the undercutter when the soil was moist. However, when the first undercutting treatment was

\footnotetext{
'Dierauf, T.A. 1994. Undercutting in Loblolly and White Pine Seedbeds. IN: Landis, T.D.; Dumroese, R.K., tech. coords. National Proceedings, Forest and Conservation Nursery Associations. Gen. Tech. Rep. RM-257. Fort Collins, CO: U.S. Department of Agriculture, Forest Service, Rocky Mountain Forest and Range Experiment Station: 56-72.
}

${ }^{2}$ Virginia Department of Forestry, Charlottesville, Virginia. 
applied on August $8^{\text {th }}$, the soil was drier and looser than it was during the preliminary test (the soils at the New Kent Nursery are loamy sands and sands with typically close to 90 percent sand in the topsoil). There were many fissures running across the beds after undercutting, and in one of the three seedbeds, the roots were dragged and the seedlings leaned at about a 45 degree angle after undercutting. The seedlings in all three seedbeds quickly wilted and the terminals drooped. They did not fully recover by the next morning. We learned from this experience and made sure the soil was moist, irrigating if necessary, before undercutting on September $1^{\text {st }}$ and October $4^{\text {th }}$. No wilting or leaning occurred following these later undercuttings.

Lateral root pruning was done to a depth of 3 to 4 inches, using coulters running midway between each row of seedlings (seedbeds contain eight rows of seedlings and are separated by paths 2 feet wide).

Top clipping was done at a height of 7 inches with hand shears. When the clipping was done on September $1^{\text {st }}$, the proportion of seedlings clipped on a plot was strongly affected by whether or not the plot had been undercut on August $8^{\text {th }}$. The August $8^{\text {th }}$ undercutting reduced height growth, so that consider- ably fewer seedlings were tall enough to be clipped on these plots.

The August $8^{\text {th }}$ undercutting caused scattered seedling mortality in the seedbed in which the seedlings were dragged. Obviously, the soil was too dry when the undercutting was done.

On December 6 $6^{\text {th }}$, a 3-inch wide (one square foot) sample across the bed was lifted from the central portion of each subsubplot. It was noticed while lifting the samples that seedlings undercut on August $8^{\text {th }}$ were harder to pull; they had more lateral roots resulting in a denser root system. The September $1^{\text {st }}$ and October $4^{\text {th }}$ undercuttings did not noticeably alter root system morphology.

Seedlings were selected for planting in the field from the same samples that were lifted and measured to evaluate seed-

Table 1. Average survival by treatment after the second season in the field.

Undercutting

Clipped Not Clipped

Means

1. Not Undercut

88

83

2. Aug. 8

3. Aug. 8 , Sept. 1

92

4. Aug. 8, Sept. 1, Oct. 4

5. Sept. 1

95

92

6. Sept. 1, Oct. 4

82

7. Oct. 4

97

Means

90 bed treatments. Lateral root pruning had no measurable effect in the seedbeds, so lateral pruned and unpruned seedlings were combined for field planting. Therefore, 14 treatments were planted in the field ( 7 undercutting $\times 2$ top clipping = 14 treatments). There were six samples (from six different subsubplots) from which to select seedlings for each treatment planted in the field. Representative samples were obtained by taking proportional numbers of seedlings from each diameter class from each of the six samples per treatment.

The seedlings were planted on December $14^{\text {th }}$ on a well-drained upland site on the AppomattoxBuckingham State Forest in the central piedmont. The winter of 1977-78 broke records for cold temperatures and the seedlings turned brown, but most of them recovered. 
Overall survival for all treatments was 89,88 , and 81 percent after one, two, and three seasons in the field. The big drop between the second and third sea'son was due to girdling by mice, which was not evenly distributed over the plots. Survival after the second season in the field, therefore, is summarized in Table 1. Undercutting and top clipping had no consistent effect on survival. ${ }^{3}$

This effect of undercutting and top clipping on height growth is shown in Table 2. After three seasons in the field, undercut seedlings averaged about .4 foot taller than check seedlings ${ }^{4}$. Top clipped seedlings averaged about .1 foot taller than unclipped seedlings, but this difference was not statistically significant.

\section{Study}

This study was installed at the New Kent Nursery during the summer of 1982. The following undercutting treatments were replicated by 10 -foot plots in three different seedbeds, each located in a separate nursery block.

$\begin{array}{ll}\text { 1. Control not undercut } \\ \text { 2. Undercut } & \text { July } 20 \\ \text { 3. “ } & \text { July } 20 \text { \& Aug. } 19 \\ \text { 4. “ } & \text { Jul } 20, \text { Aug } 19, \text { \& Sep } 21 \\ \text { 5. “ } & \text { Aug. } 19 \\ \text { 6. “ } & \text { Aug. } 19 \text { \& Sept. } 21 \\ \text { 7. “ } & \text { Sept. } 21\end{array}$

Table 2. Average height by treatment after three seasons in the field.

\begin{tabular}{lcccc} 
Undercutting & Clipped & & Not Clipped & \\
\cline { 1 - 1 } & & & \\
1. Not Undercut & 4.9 & & 4.5 & 4.7 \\
2. Aug. 8 & 5.3 & 5.0 & 5.2 \\
3. Aug. 8, Sept. 1 & 5.0 & 5.1 & 5.0 \\
4. Aug. 8, Sept. 1, Oct. 4 & 5.4 & 5.0 & 5.2 \\
5. Sept. 1 & 4.8 & 4.8 & 4.8 \\
6. Sept. 1, Oct. 4 & 5.2 & 5.2 & 5.2 \\
7. Oct. 4 & 5.4 & 5.1 & 5.3 \\
& & & \\
Means & 5.1 & 5.0 &
\end{tabular}

We attempted to undercut at a depth of about 5 inches, although the actual undercutting depth varied between $4 \frac{1}{2}$ and $51 / 2$ inches, on all three dates. After the first undercutting, on July $20^{\text {th }}$, there was a delay of $1 / 2$ hour for one replication and $2 \frac{1}{2}$ hours for the other two replications before irrigation water was applied. In the two replications that went $2 \frac{1}{2}$ hours before irrigation, the taller seedlings wilted, and some seedlings were leaning as much as 90 degrees. For the later undercuttings, on August 19th and September 21st, irrigation closely followed undercutting and no wilting occurred. Even after the visible wilting following the August $19^{\text {th }}$ undercutting, no mortality was observed. The seedlings in all the plots were operationally topclipped on August $11^{\text {th }}$ and
September $7^{\text {th }}$, to an average height of about 8 inches.

On December $17^{\text {th }}$, we lifted a 6-inch-wide sample (2 square feet) across the bed in the center of each plot. Each sample was counted into three piles as it was lifted, so that seedlings from each drill row were evenly spread over the three piles. One pile was randomly selected for planting. The other two piles were put in storage until January, when root collar diameters were measured and seedlings separated into $1 / 32^{\text {nd }}$-inch diameter classes.

Later in the afternoon of the day we lifted the seedlings, seedlings were selected for planting in the field. We had three lots of seedlings from each treatment, one from each seed-

${ }^{3}$ Survival percents were transformed to arc sine and an ANOVA was made. Neither undercutting or top clipping significantly affected survival.

${ }^{4}$ An ANOVA was made of mean heights after three seasons in the field. The effect of undercutting was significant (probability of a larger $F=.036)$, but top clipping and the interaction of undercutting and top clipping were not. 
bed replication ( $1 / 3$ of the 2 foot square sample lifted from each plot). These three lots, for each treatment, were successively counted into four piles of $20+$ seedlings each, which gave us the seedlings we needed for four replications in the field. This sorting procedure ensured that we selected about the same number of seedlings from each seedbed replication for each field replication.

The study was planted on December $21^{\text {st }}$, in four randomized blocks with a 20 seedling row of each treatment in each block. The site was a gentle upper slope on typical welldrained soil in the central piedmont.

\section{Average survival dropped} only one percentage point between the end of the first and third seasons. After three seasons, average survival for the six undercutting treatments was less than one percentage point higher than for the control (Table 3). The only statistically significant difference is between the July $20^{\text {th }}$ and August $19^{\text {th }}$ undercutting treatments (Treatments 2 and 5).

After three seasons in the field, seedlings from the six undercutting treatments averaged .1 feet taller than seedlings that were not undercut (Table 3).

Table 3. Average survival and height after three seasons in the field.

$\underline{\text { Treatment }}$

1. Not Undercut

2. July 20

3. July 20 , Aug. 19

4. July 20 , Aug. 19, Sept. 21

5. Aug. 19

6. Aug. 19, Sept. 21

7. Sept. 21

Means

Survival percents were transformed to arc sine and an analysis of variance carried out. The overall $F$ for treatments was not statistically significant (probability of a larger F =.355). Duncan's New Multiple Range Test was used to test for differences among individual treatments, and survival percents in Table 3 not followed by the same letter are significantly different at the 0.05 level.

\section{Study}

Seedlings were undercut four times on the following dates:

$\begin{array}{ll}\text { Sussex } & \text { New Kent } \\ \text { July } 27 & \text { August } 1 \\ \text { August } 19 & \text { August } 22 \\ \text { September } 16 & \text { September } 12 \\ \text { October } 5 & \text { October } 5\end{array}$

Undercutting was applied to a 20 -foot-long section of seedbed in four widely separated seedbeds at each nursery. We used a homemade, stationary blade for the undercuttings. The target depth was $5 \frac{1}{2}$ inches for all undercutting. The last three feet of each 20-foot-long undercut plot was laterally pruned using a flat-blade spade to cut straight down midway between each drill row. Lateral pruning was done just before undercutting. All plots were irrigated for an hour before pruning and again for one to two hours after pruning to prevent, or at least minimize, wilting.

Seedlings were lifted on March $6^{\text {th }}$ at New Kent and March $13^{\text {th }}$ at Sussex. We lifted a $11 / 2$-foot-wide sample across the bed, from the center of each 3 foot plot that was both undercut and laterally pruned. The sample was taken from drill rows two through seven. A short distance past the undercutting plot, we lifted a comparable sample of unpruned check seedlings.

We sorted through the seedlings from each sample (two treatments from each of eight 
Table 4. Average survival at age one, two, and three and average height at age three.

\begin{tabular}{|c|c|c|c|c|}
\hline & \multicolumn{3}{|c|}{ Survival at Age } & \multirow{2}{*}{$\begin{array}{l}\text { Height at } \\
\text { Age } 3\end{array}$} \\
\hline & 1 & 2 & 3 & \\
\hline Check & 95.6 & 95.6 & 95.6 & 5.12 \\
\hline Pruned & 98.1 & 98.1 & 98.1 & 5.39 \\
\hline
\end{tabular}

seedbeds) and picked out all seedlings between 4.5 and $6.5 /$ 32 -inch root collar diameter. Then we counted these into piles of ten seedlings each and randomly selected two piles of ten to combine for a 20 seedling row in the field. The seedlings were planted on the AppomattoxBuckingham State Forest by seedbed location, with the two treatments from each seedbed location (check and root pruned) randomly assigned to each of eight blocks.

Survival didn't change between age one and age three, and root pruned seedlings survived 2.5 percentage points better than unpruned seedlings and were .27 feet taller at age three (Table 4). The survival difference was not statistically significant, but the height difference at age three was (probability of a larger $F=$ .173 and .032 respectively).

\section{STUDIES}

In 1989, we installed two studies, a main study and a pilot study, installed at both nurseries, using a recently purchased Summit undercutter.

\section{Main Study}

Seedlings were undercut once, twice, or four times, and for the two and four cut treatments, we undercut at either a constant or increasing depth, giving a total of seven treatments:

\section{Undercut once, in July, at 3- inch depth}

2. Undercut once, in October, at 5-inch depth

3. Undercut twice, in July and September, at 3- and 5-inch depths

4. Undercut twice, in July and September, at 5-inch depths

5. Undercut four times; in July, August, September, and October; at 3-, 4-, 5-, and 5 -inch depths

6. Undercut four times; in July, August, September, and October; at 5-inch depths

7. Check, not undercut.

The actual undercutting dates were:

$\begin{array}{ll}\text { Sussex } & \text { New Kent } \\ \text { July } 24 & \text { July } 26 \\ \text { August } 15 & \text { August } 16 \\ \text { September } 13 & \text { September } 14 \\ \text { October } 10 & \text { October } 12\end{array}$

Undercutting treatments were applied to entire beds, using the seven interior beds of two ninebed sections at Sussex and one nine-bed section at New Kent. These three sections provided three replications of the seven treatments.

Lateral pruning was done by hand right after the undercutting, using a flat-blade spade pushed straight down midway between the drill rows and outside the outer drill rows. Lateral pruning was done in three plots, each two feet long, within each undercut bed.

Seedbeds were irrigated before and after undercutting. Our intention was to prevent wilting, and we were generally successful, although we had some slight wilting at times.

We lifted the seedlings at Sussex on December $5^{\text {th }}$, lifting a 4-square-foot sample (one foot wide across the bed) from each of the three lateral pruning plots in each seedbed. The seedlings were kept in cold storage until December $21^{\text {st }}$, when they were separated by root collar diameter. Small seedlings (below 4/ 32) were discarded, and proportional numbers of seedlings from each diameter class from each of the three samples were selected for four 20-seedling rows in the field. This was done separately for each of the seven treatments of each of the two seedbed replications. 
The seedlings at New Kent could not be lifted until January $8^{\text {th }}$, because the seedbeds had been frozen continuously since early in December. We measured and selected the seedlings for planting the same day, following the same procedures in lifting, measuring, and selecting seedlings as we did at Sussex.

The seedlings were planted on the Appomattox-Buckingham State Forest in the central piedmont of Virginia on January $9^{\text {th }}$. We installed four randomized blocks, with a 20 -seedling row of each of the seven treatments from each of the three seedbed replications in each block, for a total of 1,680 seedlings.

After one season in the field, average survival among the six root pruning treatments ranged from 97.1 to 98.8 percent while survival of unpruned check seedlings was 96.2 percent (Table 5). After three seasons, survival ranged from 94.5 to 96.7 among root pruned treatments and was 91.2 for check seedlings. Between the first and third season, cronartium fusiform killed 26 seedlings, 1.5 percent, and this mortality was not evenly distributed over the seven treatments (Table 5). Treatments involving four prunings and the check treatment suffered the most mortality from fusiform, which should be coincidental and not related to treatments.

An analysis of variance was performed on average survival percent at age three, after transforming to arc sine percent. The main effects of root pruning and seedbed iocation, and their interaction, were not significant (probability of a larger $\mathrm{F}=.37$, .08 , and .51 respectively). Orthogonal comparisons were made among root pruning treatments, and none were significant. The comparison of the check with the average of the six root pruning treatments came close (probability of a larger $\mathrm{F}=.053$ ). If the effect of the root pruning treatments are based on survival after one season, which may be more realistic considering the uneven mortality caused by rust; the improvement from root pruning is considerably less, 1.7 versus 4.3 percentage points (Table 5).

\section{Pilot Study}

We installed some small plots to see what might happen if we started undercutting in late June, when the seedlings were only two or three inches tall. We undercut a 20 foot section of seedbed at Sussex at a depth of about 1.5 inches on June $20^{\text {th }}$. Undercutting was repeated on July $26^{\text {th }}$ at 4 inches, August $15^{\text {th }}$ at 5 inches, September $13^{\text {th }}$ at 4.5 inches, and finally a fifth undercutting was done on October $11^{\text {th }}$, at 5 inches. A small plot was lateral pruned by hand as in the main study.

We undercut a 20 foot section in each of two seedbeds, side by side, at New Kent, on June $26^{\text {th }}$ at a depth of 3 inches. One bed was undercut a total of five times

Table 5. Average survival at age one and three, mortality caused by Fusiform rust between age one and three, and average height at age three.

\begin{tabular}{|c|c|c|c|c|}
\hline \multirow[b]{2}{*}{ Treatment } & \multicolumn{2}{|c|}{ Survival Percent } & \multirow{2}{*}{$\begin{array}{l}\text { Mortality } \\
\text { from } \\
\text { Fusiform }\end{array}$} & \multirow{2}{*}{$\begin{array}{c}\text { Height } \\
\text { at } \\
\text { Age } 3\end{array}$} \\
\hline & Age 1 & Age 3 & & \\
\hline 1. July, 3" & 97.5 & 94.6 & 1.7 & 5.8 \\
\hline 2. Oct., 5" & 97.9 & 96.7 & .8 & 5.8 \\
\hline 3. July \& Sept., 3 \& 5" & 98.3 & 95.4 & 1.2 & 5.6 \\
\hline 4. July \& Sept., $5^{\prime \prime}$ & 98.8 & 96.2 & .4 & 5.6 \\
\hline 5. July, Aug., Sept., Oct.; 3, 4, 5, \& 5" & 97.9 & 95.8 & 2.1 & 5.8 \\
\hline 6. July, Aug., Sept., Oct.; 5" & 97.1 & 94.5 & 2.1 & 5.6 \\
\hline 7. Check & 96.2 & 91.2 & 2.5 & 5.6 \\
\hline
\end{tabular}


and the other three times. Small lateral pruning plots were installed. Pruning dates and depths were July $26^{\text {th }}$ at 4 inches, August $16^{\text {th }}$ at 5 inches, September $14^{\text {th }}$ at 5 inches, and October $12^{\text {th }}$ at 5 inches. Lateral pruning was done immediately before undercutting.

Samples were lifted on the same dates and seedlings were selected for planting following the same procedures as for the main study. The seedlings were planted on January $12^{\text {th }}$ adjacent to the main study, in three randomized blocks, planting a 20 -seedling row of both pruned and unpruned seedlings from each seedbed, for a total of 18 rows.

Survival after one and three seasons and average height after three seasons are shown in Table 6 .

Compared to the main study, unpruned control seedlings survived about the same in both studies (94.4 percent in the pilot study versus 96.2 or 91.2 in the main study after one or three years). However, the root pruned seedlings survived better in the pilot study, 100 percent versus 97.9 or 95.5 in the main study after one or three years. This suggests that starting undercutting about a month earlier than normally done, when the seedling are still very small, might improve survival. There would be risks in starting this early,

Table 6. Average survival percent at age one and three and average height (in feet) at age three.

\begin{tabular}{lcccc}
\hline & \multicolumn{2}{c}{ Survival Percent } & \\
\cline { 2 - 3 } Nursery Treatment & Age 1 & Age 3 & & Height \\
\hline Suse 3
\end{tabular}

because root systems have not yet grown enough to hold the soil together, and the beds could break up badly.

\section{Study}

In addition to the Summit undercutter that we purchased and used for last year's study, we purchased a wrenching attachment for the undercutter and a Summit lateral pruner. We used all of these in this year's study. Identical studies were installed at New Kent and Sussex:

\section{Undercut twice, in early} August and late September, at 3- and 4.5-inch depths
2. Undercut twice, in early August and late September, both times at 4.5-inch depths

3. Undercut once, in early August, at 4.5-inch depth and then wrenched in late September at 4.5 inches

4. Undercut four times; in early August, late August, late September, and late October; at 3-, 4-, 4.5-, and 4.5-inch depths

5. Undercut four times; in early August, late August, late September, and late October; at 4.5 -inch depths

The actual undercutting dates were:

\begin{tabular}{|c|c|c|c|}
\hline \multicolumn{2}{|c|}{ Sussex } & \multicolumn{2}{|c|}{ New Kent } \\
\hline Two Times & Four Times & Two Times & Four Times \\
\hline $\begin{array}{l}\text { August } 1 \& 3 \\
\text {--- } \\
\text { September } 26 \\
\text {--- }\end{array}$ & $\begin{array}{l}\text { August } 1 \& 3 \\
\text { August } 29 \\
\text { September } 26 \\
\text { October } 24\end{array}$ & $\begin{array}{l}\text { August } 7 \& 8 \\
\text { September } 27 \\
\text {-- }\end{array}$ & $\begin{array}{l}\text { August } 7 \& 8 \\
\text { August } 30 \\
\text { September } 27 \\
\text { October } 26\end{array}$ \\
\hline
\end{tabular}


6. Undercut once, in early August, at 4.5-inch depth and then wrenched three times in late August, late September, and late October at 4.5 inches

7. Check, not undercut.

All root pruning treatments included lateral pruning, done just after undercutting or wrenching. Beds were irrigated before (if necessary) and after pruning to avoid (or at least minimize) wilting. Treatments were applied to full-length beds in three different sections at both New Kent and Sussex, 42 beds in all, counting the control beds.

Seedlings were lifted on December $3^{\text {rd }}$ and $4^{\text {th }}$ at New Kent and December $10^{\text {th }}$ at Sussex. We lifted three samples from each seedbed, each sample 3 inches wide across the bed for a one-square-foot sample. The total number of samples lifted was 126: three samples per seedbed times seven treatment beds per section times six sections.

Seedlings were separated by root collar diameter, keeping each sample separate. New Kent seedling were measured on December $4^{\text {th }}$ and Sussex seedlings on December $11^{\text {th }}$. Seedlings smaller than $3.5 / 32^{\text {nds }}$ were discarded, and from the remaining seedlings, proportional numbers of seedlings were randomly taken from each diameter class from each of the nine samples ( 3 samples from each of 3 sections) to obtain 80 seedlings (enough for four 20 seedling rows) from each undercutting treatment from each nursery. To prevent roots from drying while all of this measuring and counting was done, we misted the roots with water frequently and kept them covered with plastic.
The seedlings were planted on December $13^{\text {th }}$ on the

Appomattox-Buckingham State Forest. We installed four randomized blocks, with a 20seedling row of each treatment form each nursery in each block, for a total of 1,120 seedlings.

Survival changed very little between age one and age three (Table 7). Only two seedlings, in the entire study, died during the second season, and one seedling during the third season. An analysis of variance was performed on average survival percent at age three, after transforming to arc sine percent. The main effects of root pruning and nursery, and their interaction, were not significant (probability of a larger $\mathrm{F}=.99, .34$, and .89 respectively). Orthogonal comparisons were made among treatments and none were significant. The one that came closest to being significant was

Table 7. Average survival at age one and three and average height at age three.

Treatment

1. Pruned 2 times, increasing

2. Pruned 2 times, constant

3. Pruned 2 times, wrenched

4. Pruned 4 times, increasing

5. Pruned 4 times, constant

6. Pruned 4 times, wrenched

7. Control

Means

\begin{tabular}{|c|c|c|c|c|c|}
\hline \multicolumn{3}{|c|}{ New Kent } & \multicolumn{3}{|c|}{ Sussex } \\
\hline \multicolumn{2}{|c|}{ Survival } & \multirow{2}{*}{$\begin{array}{l}\text { Height } \\
\text { at } \\
\text { Age } 3 \\
\end{array}$} & \multicolumn{2}{|c|}{ Survival } & \multirow{2}{*}{$\begin{array}{c}\text { Heigl } \\
\text { at } \\
\text { Age }\end{array}$} \\
\hline Age 1 & Age 3 & & Age 1 & Age 3 & \\
\hline 91.2 & 91.2 & 7.0 & 95.0 & 95 & 7.2 \\
\hline 92.5 & 92.5 & 7.2 & 96.0 & 94.8 & 7.2 \\
\hline 93.8 & 92.5 & 7.2 & 93.8 & 93.8 & 7.7 \\
\hline 90.0 & 90.0 & 6.9 & 96.2 & 96.2 & 7.4 \\
\hline 90.0 & 90.0 & 6.7 & 96.2 & 96.2 & 7.3 \\
\hline 95.0 & 95.0 & 6.9 & 95.0 & 95.0 & 7.5 \\
\hline 93.5 & 93.5 & 6.9 & 95.0 & 93.8 & 7.0 \\
\hline 92.3 & 92.1 & 7.0 & 95.3 & 95.0 & 7.3 \\
\hline
\end{tabular}


the interaction between nurseries and two versus four prunings (probability of a larger $\mathrm{F}=.33$ ).

Root pruning did improve height growth slightly, primarily for Sussex seedlings (Table 7). The average difference between pruned (all six treatments combined) and control seedlings at age three was 6.97 versus 6.89 for a difference of .08 feet at New Kent and 7.38 versus 7.00 for difference of .38 feet at Sussex. An analysis of variance was performed on average heights at age three. The main effect of root pruning was not significant (probability of a larger $F=.35$ ), but the main effect of nursery was (probability of a larger $F=.003$ ). The interaction of root pruning and nursery was not significant (probability of a larger $\mathrm{F}=.58$ ). Orthogonal comparisons were made among treatments, and the only significant one was again the overall comparison of $\mathrm{New}$ Kent and Sussex seedlings (probability of a larger $\mathrm{F}=.003$ ).

\section{Study}

This was a comparison of operationally root pruned and unpruned seedlings at the Sussex Nursery. Four sections were involved, and eight of the nine beds in each section were undercut and lateral pruned on August 21 and October 21. The center bed of each section was left unpruned as a check. The seedbeds were irrigated before and after pruning to avoid wilting.
Samples were lifted on January 2,1992. We lifted a total of 16 samples, each sample 6 inches wide across the bed for 2 square feet per sample. In each of the four sections, we lifted two samples from the unpruned center bed and a single sample from each of the pruned beds on either side. Check and pruned samples were paired.

Seedlings for a 20 -seedling row in the field were randomly selected from each of the 16 samples. The seedlings from each paired sample, a pruned and a check, were used to plant a replication in the field. for a total of eight replications. The seedlings were planted on January $6^{\text {th }}$ on the Appomattox-Buckingham State Forest.

Survival after one and two seasons in the field and average height after two seasons is presented in Table 8 . Analyses of variance were performed on second year survival percents (after transforming to arc sine percent) and second year heights. Neither difference was statistically significant (probability of a larger $\mathrm{F}=.346$ and .134 respectively).

\section{WHITE PINE STUDIES}

\section{Study}

This was a small pilot study. We used a flat-blade spade to do the root pruning in small seedbed plots about 2 feet long. We angled the spade, starting midway between drill rows, so as to sever the tap roots at a depth of 5 to 6 inches. The cutting was done from both sides of each drill row. We installed two pairs of plots at each nursery, with the plots of each pair being only a few feet apart. One plot of each pair was root pruned about every three weeks and the other about every four weeks, starting in early June. We made a total of six prunings for the plots root pruned about every three weeks and five prunings for those pruned about every four weeks.

If the soil was dry, we irrigated before pruning, and we always irrigated after pruning. Our objective was to prevent wilting following the pruning.

We lifted the seedlings on January $12^{\text {th }}$ at New Kent and February $22^{\text {nd }}$ at Sussex. Unpruned check seedlings were

Table 8. Average survival at age one and two and average height at age two.

\begin{tabular}{|c|c|c|c|}
\hline & \multicolumn{2}{|c|}{ Survival Percent } & \multirow{2}{*}{$\begin{array}{l}\text { Heigh } \\
\text { in Feet } \\
\text { Age } 2\end{array}$} \\
\hline & Age 1 & Age 2 & \\
\hline Pruned & 96.2 & 95.6 & 3.68 \\
\hline Check & 98.1 & 96.9 & 3.53 \\
\hline
\end{tabular}


lifted adjacent to each pruning plot, starting about 6 inches beyond the point where the root pruning stopped.

Root collar diameters were measured and seedlings separated by $1 / 32^{\text {nd }}$-inch diameter classes. The New Kent seedlings were measured on February $2^{\text {nd }}$ and the Sussex seedlings on February $27^{\text {th }}$. Seedlings for planting in the field were selected proportional to the number of seedlings in each diameter class, discarding all seedlings less than $3 / 32^{\text {nds }}$ - inch diameter. Forty seedlings were selected from each sample, enough for two rows of seedlings in the field.

Two planting installations were made, one on the Appomattox-Buckingham State Forest in the central Piedmont of Virginia and the other on the Page Nelson Tract in Botetourt County, in the Ridge and Valley area of Virginia. Seedlings were planted on March $2^{\text {nd }}$ on the
Appomattox-Buckingham State Forest and on April $6^{\text {th }}$ in Botetourt County.

Root pruning increased survival by about 20 percentage points. Three and four week pruning frequencies gave similar results (Table 9). Analyses of variance were performed on average survival at age three, after transforming to arc sine percent. Separate analyses were performed for the AppomattoxBuckingham State Forest and Botetourt County installations. Root pruning improved survival significantly at both locations (probability of a larger $\mathrm{F}=.004$ and .002 at Buckingham and Botetourt respectively). Seedlings pruned every four weeks rather than every three weeks survived slightly better at both locations, but the differences were not statistically significant. Survival in Botetourt County averaged 23 points better than at the state forest. Root pruning significantly increased average height at age three at Buckingham (probability of a larger $F=.006$ ), but had no effect in Botetourt (Table 9).

\section{Study}

Seedlings were undercut once, three times, or five times. For the three and five cut treatments, we undercut at either a constant or increasing depth, giving a total of seven treatments:

1. Undercut once, in June, at 3inch depth

2. Undercut once, in October, at 5-inch depth

3. Undercut three times, in June, August, and October, at 5-inch depth

4. Undercut three times, in June, August, and October, at 3-, 4-, and 5-inch depths

5. Undercut five times, in June, July, August, September, and October, at 5-inch depth

6. Undercut five times, in June, July, August, September, and October, at 3-. 4-, 5-, 5-, and 5 -inch depths

7. Control, not undercut.

Table 9. Average survival at age one and three and average height (in feet) at age three.

\begin{tabular}{|c|c|c|c|c|c|c|}
\hline \multirow[b]{3}{*}{ Treatment } & \multicolumn{3}{|c|}{$\begin{array}{c}\text { Appomattox-Buckingham } \\
\text { State Forest }\end{array}$} & \multicolumn{3}{|c|}{ Botetourt County } \\
\hline & \multicolumn{2}{|c|}{ Survival } & \multirow{2}{*}{$\begin{array}{l}\text { Height } \\
\text { at } \\
\text { Age } 3 \\
\end{array}$} & \multicolumn{2}{|c|}{ Survival } & \multirow{2}{*}{$\begin{array}{l}\text { Height } \\
\text { at } \\
\text { Age } 3 \\
\end{array}$} \\
\hline & Age 1 & Age 3 & & Age 1 & Age 3 & \\
\hline 3 weeks, pruned & 71.2 & 65.0 & 3.0 & 91.0 & 87.0 & 1.9 \\
\hline 3 weeks, controi & 52.5 & 45.0 & 2.7 & 74.2 & 67.5 & 1.9 \\
\hline 4 weeks. pruned & 70.0 & 57.5 & 3.1 & 93.2 & 92.0 & 2.1 \\
\hline 4 weeks, control & 51.2 & 47.5 & 2.6 & 77.8 & 71.2 & 2.0 \\
\hline
\end{tabular}


The actual undercutting dates were:

$\begin{array}{ll}\text { Sussex } & \text { New Kent } \\ \text { June 20 } & \text { June 26 } \\ \text { July 24 } & \text { July 26 } \\ \text { August 15 } & \text { August 16 } \\ \text { September 13 } & \text { September 14 } \\ \text { October 10 } & \text { October 12 }\end{array}$

Undercutting treatments were applied to entire seedbeds using the Summit undercutter. The seven interior beds of two ninebed sections, one at Sussex and one at New Kent, provided two replications of the seven treatments.

Lateral pruning was done by hand after undercutting, using a flat-blade spade pushed straight down, midway between the drill rows and outside the outer drill rows. Lateral pruning was done in three plots, each 3 feet long, within each undercut bed. Seedbeds were irrigated before and after undercutting in order to prevent wilting.

\section{Seedlings were lifted at} Sussex on January $15^{\text {th }}$ and at New Kent on January $18^{\text {th }}$. We lifted three samples from each seedbed, each sample 6 inches wide for a 2-square-foot sample. These samples were lifted from the center of the three small lateral pruning plots in each seedbed. The seedlings in each sample were measured and separated by root collar diameter. We measured the Sussex seedlings on January $17^{\text {th }}$ and $18^{\text {th }}$ and the New Kent seedlings on January $24^{\text {th }}$ and $25^{\text {th }}$. Seedlings below $4.5 / 32^{\text {nds }}$ inch were discarded, and proportional numbers of seedlings from each diameter class of the three samples from each seedbed were selected for four 20-seedling rows in the field. This was done separately for each of the seven treatments of each of the two seedbed replications.
The seedlings were planted on January $26^{\text {th }}$ on the AppomattoxBuckingham State Forest. We installed four randomized blocks, with a 20 -seedling row of each of the seven treatments from each nursery planted in each block, for a total of 56 rows and 1,120 seedlings.

The New Kent seedlings survived and grew better than the Sussex seedlings (Table 10). Root pruning, combining the six different root pruning treatments, increased survival by 32 percentage points for the Sussex seedlings (74.8 versus 42.5 ) and 7 percentage points for the New Kent seedlings (80.6 versus 73.8). In an analysis of variance, after transforming to arc sine percent, the main effect of pruning and the difference between nurseries were both significant (probability of a larger $F=.004$ and .002 respectively). Orthogonal comparisons were made, and the only signifi-

Table 10. Average survival at age one and three and average height (in feet) at age three, by treatment and nursery.

\begin{tabular}{|c|c|c|c|c|c|c|}
\hline \multirow[b]{3}{*}{ Treatment } & \multicolumn{3}{|c|}{ Sussex } & \multicolumn{3}{|c|}{ New Kent } \\
\hline & \multicolumn{2}{|c|}{ Survival } & \multirow{2}{*}{$\begin{array}{l}\text { Height } \\
\text { at } \\
\text { Age } 3 \\
\end{array}$} & \multicolumn{2}{|c|}{ Survival } & \multirow{2}{*}{$\begin{array}{l}\text { Height } \\
\text { at } \\
\text { Age } 3\end{array}$} \\
\hline & Age 1 & Age 3 & & Age 1 & Age 3 & \\
\hline 1. June only & 80.0 & 72.5 & 2.9 & 83.8 & 81.2 & 2.9 \\
\hline 2. Oct. only & 73.8 & 70.0 & 2.5 & 80.0 & 80.0 & 3.0 \\
\hline 3. June, Aug., Oct., increasing & 81.2 & 78.8 & 2.9 & 83.8 & 80.0 & 3.1 \\
\hline 4. June, Aug., Oct., constant & 81.2 & 81.2 & 2.8 & 86.2 & 81.2 & 2.8 \\
\hline 5. June, July, Aug., Sept., Oct., increasing & 76.2 & 71.2 & 2.7 & 86.2 & 83.8 & 2.8 \\
\hline 6. June, July, Aug., Sept., Oct., constant & 78.8 & 75.0 & 2.7 & 81.2 & 77.5 & 3.1 \\
\hline 7. Control & 43.8 & 42.5 & 2.5 & 76.2 & 73.8 & 2.9 \\
\hline Means & 73.6 & 70.2 & 2.7 & 82.5 & 79.6 & 3.0 \\
\hline
\end{tabular}


cant comparison was between the average of all six pruning treatments and the control (probability of a larger $\mathrm{F}=$ .00004). Increasing the number of cuts and varying pruning depth did not significantly affect survival. When results from the New Kent seedlings were analyzed separately, root pruning did not significantly improve survival (for the comparison between the average of all six pruning treatments and the control, the probability of a larger $F=.21$ ).

Height growth was improved by root pruning the Sussex seedlings, but not the New Kent seedlings (Table 10). In an analysis of variance, the height difference at age three between the Sussex and New Kent seedlings was statistically significant (probability of a larger $\mathrm{F}=$ .00005).

\section{Main Study}

This year we started undercutting much earlier than we had in 1988 and 1989. One treatment started soon after the seedlings had resumed growth in the spring, on March $28^{\text {th }}$, at an undercutting depth of 2 inches. Thereafter, undercutting was done every five weeks, ending on October $24^{\text {th }}$, for a total of seven cuts. Lateral pruning was done immediately after each undercutting, using the Summit lateral pruner. As last year, we used the Summit undercutter. Two additional undercutting treatments were started on May $2^{\text {nd }}$, one treatment starting at a 2 inch depth and the other at a 3 inch depth. Thereafter, they also were undercut and lateral pruned every five weeks until October $24^{\text {th }}$. Two additional undercutting treatments were begun on June $16^{\text {th }}$, one starting at a 2 inch depth and the other at a three inch depth, and they also were retreated every five weeks until October $24^{\text {th }}$. After the initial undercutting, succeeding undercuts were done 1 inch deeper until a depth of 5 inches was reached, which remained the undercutting depth until the final cut. The treatments are listed below.

1. Control, not root pruned.

2. Undercut 7 times, starting on March $28^{\text {th }}$, at depths of 2, 3 , $4,5,5,5$, and 5 inches.

3. Undercut 6 times, starting on May $2^{\text {nd }}$, at depths of 2, 3, 4, 5, 5 , and 5 inches.

4. Undercut 6 times, starting on May $2^{\text {nd }}$, at depths of $3,4,5,5$, 5 , and 5 inches.

5 . Undercut 5 times, starting on June $16^{\text {th }}$, at depths of $2,3,4$, 5 , and 5 inches.

6 . Undercut 5 times, starting on June $6^{\text {th }}$, at depths of $3,4,5,5$, and 5 inches.
The actual dates for undercutting and lateral pruning were:

March 28
May 2
June 6
July 11
August 14
September 19
October 25

This study was installed only at our Sussex Nursery. Undercutting and lateral pruning treatments were applied to entire seedbeds in three different seedbed sections, randomly assigning the treatments to beds three through eight.

Top clipping was added as a treatment, mowing a 40 -footlong plot at a height of 8 inches on July $11^{\text {th }}$ in each root pruned and control seedbed. Half of each 40-foot plot was clipped again on September $19^{\text {th }}$, at a height of 8 to 9 inches. This increased the number of treatments to 18 , six root pruning treatments times three top clipping treatments (unclipped, clipped once, and clipped twice).

We lifted seedling samples on February $14^{\text {th }}$ and $20^{\text {th }}$. From each seedbed, we lifted three samples, each 6 inches wide for a 2-square-foot sample. We took samples from the center of each top clipped plot (clipped once or twice) and a sample of unclipped seedlings adjacent to the top clipped seedlings. This 
was done for the six beds of each of the three sections, for a total of 54 samples.

The seedlings were measured and selected for planting on February $27^{\text {th }}$ and $28^{\text {th }}$. We measured the diameter and top length of each seedling and separated them by root collar diameter, keeping the seedlings from each of the three samples of each treatment separate until we could select seedlings for planting. We needed 80 seedlings from each treatment to plant, for four 20-seedling rows in the field. Seedlings were selected proportional to the number of seedlings in each diameter class. We discarded seedlings below $3.5 / 32^{\text {nds }}$ and calculated the number of seedlings we would need from each diameter class, from each of the three samples in order to obtain the 80 seedlings we needed. To prevent the roots from drying out, while all of this measuring and counting was done, we misted the roots frequently with water and kept them covered

Table 11. Average survival at ages 1, 2, and 3, and average height in feet at age 3 , by root pruning treatment.

\begin{tabular}{|c|c|c|c|c|}
\hline \multirow[b]{2}{*}{ Root Pruning Treatment } & \multicolumn{3}{|c|}{ Survival Percent } & \multirow{2}{*}{$\begin{array}{c}\text { Average } \\
\text { Height } \\
\text { Age } 3 \\
\end{array}$} \\
\hline & Age 1 & Age 2 & Age 3 & \\
\hline Control & 49.2 & 45.4 & 45.0 & 2.1 \\
\hline 7 cuts, 2 inches & 71.7 & 65.4 & 63.8 & 2.4 \\
\hline 6 cuts, 2 inches & 69.2 & 61.7 & 59.6 & 2.2 \\
\hline 6 cuts, 3 inches & 63.2 & 57.8 & 57.3 & 2.2 \\
\hline 5 cuts, 2 inches & 64.2 & 56.7 & 55.4 & 2.3 \\
\hline 5 cuts, 3 inches & 59.6 & 54.6 & 54.6 & 2.4 \\
\hline Means & 62.8 & 56.9 & 55.9 & 2.3 \\
\hline
\end{tabular}

Table 12. Average survival at ages one, two, and three, and average height in feet at age three, by top clipping treatment.

\begin{tabular}{|c|c|c|c|c|}
\hline \multirow[b]{2}{*}{ Number of Clippings } & \multicolumn{3}{|c|}{ Survival Percent } & \multirow{2}{*}{$\begin{array}{c}\text { Average } \\
\text { Height } \\
\text { Age } 3\end{array}$} \\
\hline & Age 1 & Age 2 & Age 3 & \\
\hline 0 & 61.8 & 57.4 & 56.0 & 2.6 \\
\hline 1 & 61.7 & 56.0 & 55.6 & 2.2 \\
\hline 2 & 65.0 & 57.1 & 56.2 & 2.0 \\
\hline Means & 62.8 & 56.8 & 55.9 & 2.3 \\
\hline
\end{tabular}

with plastic. After putting together the 20 -seedling bundles, we pruned the roots to about 6 inches and dipped them in clay.

The seedlings were planted on March $4^{\text {th }}$, in four randomized blocks, with a 20 -seedling row of each of the 18 treatments in each block, for a total of 72 rows and 1,440 seedlings.

Root pruning improved survival an average of 13 percentage points (58.1 versus 45.0), comparing the average of the five root pruning treatments with the control (Table 11). Top clipping had no effect on survival (Table 12). In an analysis of variance of survival at age three, after first transforming to arc sine percent, the main effect of pruning was statistically significant (probability of a larger $F=.007$ ), while top clipping was not (probability of a larger $F=.98$ ). Orthogonal comparisons were made, and the only significant comparison was the average of the five root pruning treatments versus the control (probability of a larger $\mathrm{F}$ $=.0008)$. The differences between 5 and 6 root prunings and starting at a 2 or 3 inch depth (for 5 and 6 prunings) were not significant (probability of a larger $F=.278$ and .625 respectively).

Root pruning increased height at age three (Table 11) but the differences were not statistically significant. Of four orthogonal 
comparisons involving root pruning, the one closest to being significant was the average of the five root pruning treatments versus the control (probability of a larger $F=.075$ ). Top clipping, on the other hand, significantly reduced height at age three as shown in Table 12 (probability of a larger $F=.000000008$ ).

\section{Operational Root Pruning Study}

There were three full sections of 2-0 white pine at Sussex that were not included in the main study. These were operationally root pruned twice, leaving one bed in each section as an unpruned control. Undercutting and lateral pruning were done twice, on March 29th and May $11^{\text {th }}$, both times at an undercutting depth of about 3 inches. At New Kent, five full sections of 2-0 white pine were operationally root pruned three times, leaving one bed in each section as an unpruned control. Undercutting was done three times, on April $12^{\text {th }}$ and $13^{\text {th }}$, August $20^{\text {th }}$ and $21^{\text {st }}$, and October $14^{\text {th }}$. The undercutting depth was 3 inches the first time and $41 / 2$ inches the second and third time. Lateral pruning was done each time undercutting was done.

Seedlings were lifted on February $12^{\text {th }}$ at New Kent and February $14^{\text {th }}$ at Sussex. We lifted 20 samples at each nursery, each sample 6 inches wide for a 2-square-foot sample. Samples were paired, so that a root pruned and control sample were taken side by side in adjacent seedbeds. At New Kent, we lifted two paired samples (4 samples in all) from each of the five sections. At Sussex, we lifted three paired samples from two of the sections and four paired samples from the third section.

The New Kent seedlings were measured on February $13^{\text {th }}$ and the Sussex seedlings on February $15^{\text {th }}$. All seedlings from each sample were measured for root collar diameter and top length, and separated by root collar diameter. We selected 20 seedlings from each sample, proportional to the number of seedlings in each diameter class. This provided enough seedlings for 40 rows in the field, 20 from New Kent, and 20 from Sussex. The roots of the 20 seedling bundles were pruned to about 6 inches and dipped in clay.

The seedlings were planted on the Appomattox-Buckingham State Forest on February $19^{\text {th }}$ in 10 randomized blocks of 4 rows each. The four rows in a block contained a paired sample (root pruned and not root pruned) from each nursery. This provided a total of 40 rows and 800 seedlings.

Root pruning improved survival at both nurseries, but had no effect on height (Table 13). Sussex seedlings survived better than New Kent seedlings. In an analysis of variance for survival at age three, after transforming to arc sine percent, the improvement from pruning was significant and the difference between nurseries was not (probability of a larger $\mathrm{F}=.0002$ and .210 respectively).

Table 13. Average survival at age one, two, and three and average height in feet at age three.

\begin{tabular}{|c|c|c|c|c|c|c|c|c|}
\hline \multirow[t]{3}{*}{ 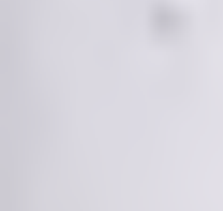 } & \multicolumn{4}{|c|}{ Sussex } & \multicolumn{4}{|c|}{ New Kent } \\
\hline & \multicolumn{3}{|c|}{ Survival } & \multirow{2}{*}{$\begin{array}{l}\text { Height } \\
\text { Age } 3\end{array}$} & \multicolumn{3}{|c|}{ Survival } & \multirow{2}{*}{$\begin{array}{l}\text { Height } \\
\text { Age } 3\end{array}$} \\
\hline & Age 1 & Age 2 & Age 3 & & Age 1 & Age 2 & Age 3 & \\
\hline Control & 52.5 & 49.5 & 48.5 & 2.8 & 51.0 & 47.0 & 46.5 & 3.0 \\
\hline Root pruned & 70.0 & 67.5 & 66.5 & 2.7 & 64.5 & 60.0 & 59.5 & 3.0 \\
\hline Difference & 17.5 & 18.0 & 18.0 & .1 & 13.5 & 13.0 & 13.0 & 0.0 \\
\hline
\end{tabular}




\section{Study}

We root pruned just three times, starting on different dates and at different depths for a total of seven treatments. Root pruning treatments were applied to entire beds in two sections at Sussex and one section at New Kent. The treatments are listed separately by nursery below.

\section{Sussex Nursery}

1. Undercut on Apr. $29^{\text {th }}$, July $16^{\text {th }}$, and Oct. $2^{\text {nd }}$, at $2,4^{1 / 2}$, and $4 \frac{1}{2}$ inch deptns.

2. Undercut on Apr. $29^{\text {th }}$, July $16^{\text {th }}$, and Oct. $2^{\text {nd }}$, at $4,41 / 2$, and $41 \frac{1}{2}$ inch depths.

3. Undercut on May $24^{\text {th }}$, July $16^{\text {th }}$, and Oct. $2^{\text {nd }}$, at $2,41 / 2$, and $4 \frac{1}{2}$ inch depths.

4. Undercut on May $24^{\text {th }}$, July $16^{\text {th }}$, and Oct. $2^{\text {nd }}$, at $4,41 / 2$, and $4 \frac{1}{2}$ inch depths.

5. Undercut on June $19^{\text {th }}$, Aug. $9^{\text {th }}$, and Oct. $2^{\text {nd }}$, at $3,41 / 2$, and $41 / 2$ inch depths.

6. Undercut on June $19^{\text {th }}$, Aug. $9^{\text {th }}$, and Oct. $2^{\text {nd }}$, at $4,41 / 2$, and $4 \frac{1}{2}$ inch depths.

7. Unpruned control.

\section{New Kent Nursery}

1. Undercut on Apr. $11^{\text {th }}$, July $11^{\text {th }}$, and Sept. $11^{\text {th }}$, at $2,41 / 2$, and $4 \frac{1}{2}$ inch depths.

2. Undercut on Apr. $11^{\text {th }}$, July $11^{\text {th }}$, and Sept. $11^{\text {th }}$, at $41 / 2,41 / 2$, and $4 \frac{1}{2}$ inch depths.

3. Undercut on May $9^{\text {th }}$ at 2 inch depth, and then abandoned.
4. Undercut on May $9^{\text {th }}$ at $41 / 2$ inch depth, and then abandoned.

5. Undercut on June $11^{\text {th }}$, Aug. $11^{\text {th }}$, and Oct. $11^{\text {th }}$, at $3,41 / 2$, and $4 \frac{1}{2}$ inch depths.

6. Undercut on June $11^{\text {th }}$, Aug. $11^{\text {th }}$, and Oct. $11^{\text {th }}$, at $41 / 2,41 / 2$, and $4 \frac{1}{2}$ inch depths.

7. Unpruned control.

Treatments three and four at New Kent were abandoned because of insufficient irrigation following pruning, and severe wilting and some mortality occurred.

Lateral pruning was done every time that undercutting was done at both nurseries.

Seedling samples were lifted at Sussex on January $2^{\text {nd }}$.

Samples were 6 inches wide across the seedbed for a 2square-foot sample. We lifted a single sample from each seedbed initially, and realized that we wouldn't have enough seedlings for the field planting. We then lifted another set of samples from one of the two sections, flipping a coin to decide which section to take the second set from. We needed 100 seedlings, enough for five replications in the field, from each of the seven treatments. On January $17^{\text {th }}$, we measured the root collar diameter and top length of every seedling in each sample, and separated by root collar diameter. From the three samples from each treatment, we selected seedlings proportional to the number of seedlings in each diameter class and each sample to obtain the 100 seedlings we needed to plant in the field. We were careful to keep the roots damp while we did all of this measuring and counting. The seedlings were planted on January $22^{\text {nd }}$, on the Appomattox-Buckingham State Forest.

We lifted the New Kent seedlings on January $29^{\text {th }}$. We lifted three samples from each

Table 14. Average survival at age one and two.

\begin{tabular}{lllllll}
\hline & \multicolumn{2}{c}{ Sussex } & & \multicolumn{2}{c}{ New Kent } \\
\cline { 2 - 3 } Treatment & & & & \\
& Age 1 & Age 2 & & & Age 1 & Age 2 \\
\hline 1. Start in April, 2 inches & 88 & 77 & & 86 & 73 \\
2. Start in April, 4 or 41/2 inches & 85 & 78 & & 82 & 71 \\
3. Start in May, 2 inches & 79 & 71 & & -- & - \\
4. Start in May, 4 inches & 85 & 74 & & - & - \\
5. Start in June, 3 inches & 85 & 76 & & 79 & 68 \\
6. Start in June, 4 or 41/2 inches & 82 & 72 & & 81 & 77 \\
7. Control & 63 & 59 & & 57 & 50
\end{tabular}


seedbed, each 6 inches wide across the seedbed for a 2square-foot sample. This gave us a total of 15 samples (two of the treatments had been abandoned, so there were only five treatments left). We measured the seedlings and made up the seedling packages the same day, following the same procedure as for the Sussex seedlings. The seedlings were planted on February $5^{\text {th }}$.

Both the Sussex and New Kent seedlings were planted in the same randomized blocks. There were five blocks, each containing 12 rows of 20 seedlings each, a row each of the seven Sussex treatments and five New Kent treatments.

After two seasons in the field, combining root pruning treatments, root pruning increased survival by 15.7 points ( 74.7 versus 59.0) at Sussex and 22.2 points (72.2 versus 50.0) at New Kent. Sussex seedlings survived slightly better than New Kent seedlings (Table 14). An analysis of variance of survival at age two, after first transforming to arc sine percent, was performed including orthogonal comparisons. The only significant comparison was the average of all root pruning treatments versus the control (probability of a larger $F=.00034)$.

\section{DISCUSSION}

Loblolly seedlings have benefitted only slightly from undercutting. This is hard to explain because multiple undercutting of loblolly seedlings dramatically changed root morphology in ways that might be expected to improve field performance. Multiple undercutting (and lateral pruning) produced more compact root systems with many more fine roots and at least twice as many mycorrhizae (although mycorrhizae were never counted or quantified).

Overall survival improvement from root pruning loblolly seedlings, combining pruning treatments and comparing to unpruned control seedlings, was only $2,1,2,2,0$, and -1 percentage points for six studies (excluding the pilot study beginning when seedlings were only 2 or 3 inches tall). Consequently, we do not root prune loblolly seedlings in the seedbed.

Survival of unpruned control seedlings was very good in all of these studies, leaving little room for improvement by root pruning. Unpruned seedling survival was $88,91,96,96,94,94$, and 97 percent in the seven studies. Had survival been lower, perhaps the improvement from root pruning would have been greater.
One advantage of root pruning is that it controls (reduces) height growth in the seedbed. However, root pruning reduces growth of all seedlings, large and small. We control height growth of loblolly seedlings by top clipping. It reduces growth only for the taller seedlings that are actually clipped. Also, topclipping is a much easier, faster, and cheaper operation than root pruning.

We tried to prevent wilting by irrigating before and after root pruning, but some nurserymen purposely let root-pruned seedlings wilt before irrigating to impose moisture stress.

All of these studies were hand-lifted using reasonable care, but hand-lifting probably does more root damage than careful lifting with a full-bed mechanical lifter. Root pruning makes it easier to hand-lift seedlings. Consequently, we probably caused more root damage to unpruned control seedlings than root pruned seedlings. We hope this was a minor factor, but its effect, if and where it occurred, was probably to favor root pruned over unpruned seedlings.

Root-pruned seedlings are harder to plant with a traditional planting bar, and the more times seedlings are pruned, the harder they are to plant. With loblolly, 
frequent pruning produces a soft, brush-like root system without a single, stiff taproot. The roots hang up on the sides of the planting hole, increasing the amount of folding and making deep planting more difficult. With white pine, frequent pruning produces a rectangular root system, as viewed from above, with short, rigid, spreading, lateral roots that are hard to stuff in a planting slit. The easiest seedlings to plant with a planting bar are medium-sized, unpruned seedlings with a single. stiff, straight, tap root that has been cut to a 5 or 6 inch length by the lifting machine.

Survival improvement from root pruning white pine, on the other hand, was substantial in all five studies. Combining root pruning treatments and comparing to unpruned control seedlings for the five studies, the improvement was 20, 20, 13, 16 , and 19 percentage points (this also combined New Kent and Sussex seedlings). Consequently, root pruning white pine is operational at our New Kent and Sussex nurseries. We never have operationally top clipped white pine seedlings, and the 1990 study suggests that top clipping is of no benefit to white pine.
As the season progresses, it becomes more and more difficult to see the individual drill rows in white pine seedbeds, and thus keep the lateral pruner blades between the rows. We are inclined to omit lateral pruning when the final undercutting is done. 


\title{
The Use of the IDS-Treatment on Southern Pine Seeds and its Effect on Seed Cost and Efficiency in the Seed Bed ${ }^{1}$
}

\author{
J. B. McRae, U. Bergsten, and S. Lycksell²
}

\begin{abstract}
The IDS-treatment ( $I$ = incubation, $D=$ drying, $S=$ separation) is a method to remove filled-dead seed from a seed lot. It is based upon the principle that, when incubated for some period of time and subsequently dried, seeds lose the absorbed water at different rates depending on their viability. Under tightly controlled drying conditions, dead seed and live seed lose water absorbed during the incubation period at different rates, creating the opportunity to make a separation. Contrasting seed lot qualities of loblolly, slash, and pines were submitted to the IDS-treatment. Untreated and treated seeds of the same lot were sown in a split-plot design in two (2) bareroot nurseries. A completely randomized study was established in a container nursery. This seed treatment process may prove helpful for those bareroot nurseries that use precision sowing techniques and most container seedling nurseries. For the seed inventory managers, improving the poor germinating lots of the high genetic value seed, is now a "viable" alternative.
\end{abstract}

Keywords: Pinus taeda L., Pinus elliottii Engelm., IDS

\section{INTRODUCTION}

Nursery managers are always searching for new methods that will lead to improvements in their seedling crops. Experienced growers recognize the importance of seed bed density as it directly influences costs and most importantly seedling quality. In the southern USA, many bareroot nursery managers have employed precision vacuum sowers to accurately place the seed on the nursery beds. This equipment is expensive and consumes more time than drill-type seeders to operate, but the anticipated results appear to be justified as an increasing number of nurseries are employing this method of sowing seed. Integral to the success of using this equipment is the quality of the seed; specifically the percent of full live seed. This characteristic has always been a crucial part of the sowing plan, but now plays even a greater roll as vacuum sowers are designed to strategically place seed to the bed to maximize quality growth.
Container nursery growers have recognized this point for some time. They have observed that a single sown seed to each cavity is the most cost effective method to sow and grow a crop, if all seed germinates. In the northern latitudes where container seedling crops have become the norm, single sown seed (one per cavity) has become a reality with the development of a seed treatment technique called IDS. Virtually all the container seedlings in Sweden are grown from seed that have had all dead and damaged

'McRae, J. B.; Bergsten, U.; Lycksell, S. 1994. The Use of the IDS-Treatment on Southern Pine Seeds and its Effect on Seed Cost and Efficiency in the Seed Bed. IN: Landis, T.D.; Dumroese, R.K., tech. coords. National Proceedings, Forest and Conservation Nursery Associations. Gen. Tech. Rep. RM-257. Fort Collins, CO: U.S. Department of Agriculture, Forest Service. Rocky Mountain Forest and Range Experiment Station: 73-79.

${ }^{2}$ Intemational Forest Seed Company; Swedish University of Agricultural Sciences, Faculty of Forestry, 90183 Umea; respectively. 
seed removed prior to sowing via IDS and other seed conditioning techniques (Bergsten,1991).

The IDS-treatment ( $\mathrm{I}=$ incubation, $\mathrm{D}=$ drying, $\mathrm{S}=$ separation) is a method to remove filled-dead seed from a seed lot. It is based upon the principle that, when incubated for some period of time and subsequently dried, seeds lose the absorbed water at different rates depending on their viability. Under tightly controlled drying conditions, dead seed and live seed lose water absorbed during the incubation period at different rates, creating the opportunity to make a separation. The IDS technique was first developed for Pinus contorta by Simak $(1983,1984)$ and considered a major breakthrough in seed treatment prior to sowing. Subsequent research by his colleagues at the Swedish University of Agricultural Sciences, Umea, Sweden has resulted in the use of IDS as a standard procedure for cleaning Pinus sylvestris (Bergsten, 1983), and Picea abies (Downie and Bergsten, 1990). Also based upon the work at Umea, Vozzo (1994) published successful separations of Pinus roxburghii.
However, the above mentioned species in relation to loblolly (Pinus taeda L.), slash (P. elliottii Engelm. var. elliottii) and longleaf $(P$. palustris Mill.) pines are all small seeded $(70,000$ to $120,000+$ per pound). Until now, separation of commercial size quantities of these larger seeded pines has not been successful (personal communication with Dr. Robert Karrfalt and Dr. Frank Bonner, USDA Forest Service). Small samples of slash pine were successfully separated by Donald, (1985) when he employed the procedures published by Simak, 1983.

The objective of this research is two fold; 1 ) is it possible to successfully separate filled-dead seed from full live seed of loblolly, slash, and longleaf pine? 2) assuming IDS is successful, will nursery managers benefit from sowing the physically improved seed?

To answer these questions, it was necessary to treat good germinating lots $(90 \%$ or better) and marginal germinating lots (approximately 80\%) and sow them in operational bareroot nurseries and in a container nursery.

\section{METHODS AND MATERIALS}

Fifty pound lots of contrasting seed lot qualities of loblolly, slash, and longleaf pines were submitted to the IDS-treatment according to the regimens described by Bergsten (1991). Prior to this treatment, germinations were completed according to ISTA standards to determine the seed quality from which a treatment program for each lot and species was developed. After the IDS treatment, germination tests were completed on all fractions (the flotant as well as the full live seed). Germination counts were made weekly through the fourth week.

\section{Container Nursery Seedlings}

Full live seed via IDS and untreated seed of loblolly and slash were sown to HIKO-93, (40, 5.6 cubic inch cavity) containers. The IDS treated seed (IDS seed) was single sown and the non-IDS treated seed (standard seed) was sown 2 per cavity, the standard sowing activity on April 25, 1994. Ten containers (replications) were randomized within the normal production operations of the respective species at International Forest Seed Company's Odenville, Alabama nursery. After germination was complete, the number of filled and empty cavities were recorded. 


\section{Bareroot Nursery Seedlings}

The IDS seed and standard seed of loblolly and slash were sown at International Forest Seed Company nurseries in Buena Vista, Georgia on April 20, 1994 and Statesboro, Georgia on April 28, 1994. The study design was a splitplot with five replications; the main plots were IDS and standard seed, which were sown at target seed bed densities of 26 and 18 per square foot. All seed was sown with vacuum precision sowers (a LOVE at Buena Vista and a SILVER MOUNTAIN at Statesboro) adjusting the machines for total germination as determined by germination tests and assuming 15\% percent cull rate for all plots during lifting. All seedlings were grown via standard growing procedures. After 60 days, the distance between 100 seedlings in one line of a drill in each plot was measured to determine bed density. Plot means and standard deviations were calculated.

\section{RESULTS AND DISCUSSION}

\section{IDS Treated Seed}

The IDS treatment method employed was successful in separating filled-dead seed of loblolly and slash pines (Table 1). Addition of glycerol, nhexane, and ethanol in varying
Table 1. Percent total germination and vigor of seed prior to and after IDS Treatment expressed as Peak Value'.

\begin{tabular}{|c|c|c|c|c|}
\hline \multirow[b]{2}{*}{ SPECIES } & \multicolumn{2}{|c|}{ PRE IDS } & \multicolumn{2}{|c|}{ POST IDS } \\
\hline & $\begin{array}{l}\text { GERM. }^{2} \\
(\%)\end{array}$ & $\underline{P V}$ & $\begin{array}{c}\text { GERM. }^{2} \\
(\%)\end{array}$ & $\underline{\mathrm{PV}}$ \\
\hline Lob 1 & 92 & 6.0 & 97 & 6.7 \\
\hline Lob 2 & 83 & 3.87 & 97 & 6.5 \\
\hline Slash 1 & 80 & 5.73 & 94 & 6.5 \\
\hline Slash $2^{4}$ & 95 & 6.21 & NA & NA \\
\hline \multicolumn{5}{|c|}{${ }^{1}$ Czabator (1962) } \\
\hline \multicolumn{5}{|c|}{${ }^{2}$ Results of one germination test. } \\
\hline \multicolumn{5}{|c|}{$\begin{array}{l}{ }^{3} \text { Average germination of the seed that separated } \\
\text { into the first two chambers of the sedimentation } \\
\text { flume. }\end{array}$} \\
\hline \multicolumn{5}{|c|}{$\begin{array}{l}{ }^{4} \text { The germination prior to the IDS Treatment was } \\
\text { high and based on this particular seed lot no IDS } \\
\text { Treatment was recommended. }\end{array}$} \\
\hline
\end{tabular}

Table 2. Pounds of seed and mean percent germination of the flotant.

\begin{tabular}{lll}
\hline SPECIES & $\begin{array}{c}\text { WEIGHT } \\
\text { (LBS) }\end{array}$ & $\begin{array}{c}\text { GERM. } \\
(\%)\end{array}$ \\
Lob 1 & 1.5 & 27 \\
Lob 2 & 2.8 & 40 \\
Slash 1 & 4.8 & 32 \\
Slash 2 & NA & NA \\
\hline $\begin{array}{l}\text { Laboratory size samples of longleaf seed submitted } \\
\text { to a preliminary IDS treatment resulted in a success- } \\
\text { ful separation. }\end{array}$ \\
\end{tabular}


amounts to water created solutions with specific gravities equal to that of the filled-dead seed. The high viability full live seed sank and the filled-dead seed (including some weak viable live seed) floated in the solution (Table 2). The seed that floated is referred to as "flotant" since it is primarily filled-dead seed but contains a small portion of live seed.

But to apply the IDS treatment the wing was removed from each seed by hand. The commercial size lots were much too large to do this work; consequently, the longleaf seed was not separated. Additional research should be continued to find a cost efficient method to remove the wing using a "PREVAC" separator (Bergsten and Wiklund, 1987).

\footnotetext{
When comparing seed tests prior to and after IDS treatment, the total percent germination and seed vigor, when expressed as Peak Value (PV) (Czabator, 1962), increased dramatically (Table 1). The PV is the percent germination rate divided by the number of days the seed has been in the germinator at that count. In all but one germination test, the PV was highest after 14 days. The PV moved up (the vigor improved) from 21 to 14 days on the Lob2 seed lot
}

after the IDS Treatment (Table 1). This is an important fact and implies that the IDS treatment process does not negatively influence the vigor of the healthy seed and, in fact, has improved the seed lot as a whole resulting in greater uniformity in the speed of germination (Table 1).

In the sedimentation flume used for the separation step, filled, live seed from Lob2 and Slash1 were separated into all ten chambers and seed from Lob1 settled into the first two chambers of the sedimentation flume. Seed that settled in the third through tenth chamber resulted in germinations of $85 \%$ (slash) and 81\% (loblolly). Each resultant lot was $100 \%$ full, but all the seed did not germinate after the standard 30 day stratification followed by a 28 day germination period. The PV for each, 5.8 (slash) and 5.1 (loblolly), occurred after 14 days in the germinator, just as the seed that settled into the first two chambers. But the PV is noticeably lower. Examining the radiographs revealed a higher proportion of insect damaged and abnormal seeds, $7 \%$ (slash) 14\% (loblolly) in this seed, relative to the seed separated into the first two chambers (maximum 2\% for each species). This is explained as the heavier more vigorous seed sinking immediately and the lighter less vigorous seed sinking more slowly, settling into the last seven chambers. It is reasonable to say that this IDS treatment using the sedimentation flume can separate low vigor seed from higher vigor seed. These results are pioneering for loblolly and slash pine. The less vigorous seed of $P$. sylvestris, $P$. contorta and $A$. picea are separated via similar methods (personal communications, Birger Erikson, Swedish University. Umea, 1994).

\section{Container Nursery Seedlings}

Seed treated with IDS was single sown and untreated (standard) seed was double sown (two per cavity). The number of seedlings per 40 cavity container and the percent full cavities is shown in Table 3 . Filled cavities resulting from

\section{Table 3. Seedlings per 40-cavity tray.}

\begin{tabular}{|c|c|c|c|c|}
\hline \multirow[b]{2}{*}{ Average number per tray } & \multicolumn{2}{|c|}{$\begin{array}{l}\text { LOB } \\
\text { IDS NO-IDS }\end{array}$} & \multicolumn{2}{|c|}{$\begin{array}{l}\text { SLASH } \\
\text { IDS NO-IDS }\end{array}$} \\
\hline & 34 & 67 & 34 & 54 \\
\hline Percent full cavities & 85 & 95 & 85 & 89 \\
\hline $\begin{array}{l}\text { Percent seedlings of } \\
\text { sown seed }\end{array}$ & 85 & 84 & 85 & 68 \\
\hline
\end{tabular}


IDS treated seed were nearly as high as those sown with two standard seed per cavity. However, this result is somewhat disappointing since nearly $95 \%$ full cavities was expected based upon the seed test results (Table 1.) of the IDS seed. However, the percentage of seedlings of sown seed is higher for both species. This fact illustrates the potential seed efficiencies that can be gained from sowing $100 \%$ full live seed.

Reasons for this downfall in germination are not obvious. A review of all our seed handling and nursery procedures did not reveal any clues as to why we only had $85 \%$ of the IDS seed germinate (Table 3). Examining adjacent containers of production run seedlings (containers of test seedlings were completely randomized among the regular crop seedlings) revealed germinations that were also lower than expected for the slash pine lot and one of three loblolly lots. Subsequent inventory reports indicated that only $85 \%$ of the cavities were full for both species. Two other isolated lots of loblolly resulted in $93 \%$ and $94 \%$ full. It may well have been a disease or some local environmental condition affecting germination.

Based on our costs for extra seed and labor to thin the double germinates (two seedlings germinating from the two standard seed sown to a cavity), we determined that the extra revenue gain from the additional seedlings ( $9 \%$ loblolly and 3\% slash Table 3.) would justify the added expense to submit seed to an IDS treatment. Seedling quality will be measured once the crop matures to determine if a difference exists between the seedlings grown from IDS seed and standard seed.

\section{Bareroot Nursery Seedlings}

At each nursery the IDS and standard seed of loblolly and slash were sown with vacuum sowers at two targeted seed bed densities; A low density $\left(18 / \mathrm{ft}^{2}\right)$ and the standard production density of $26 / \mathrm{ft}^{2}$. The objective was to evaluate differences between seed treatments and relate them to seedling quality at lifting. It was thought that the best possibility for significant seedling quality differences would be found in those grown at low densities where they had the space to maximize growth. Seed grown at higher densities tend to produce more cull seedlings, which may interfere with maximizing growth potential.

To make statistically valid evaluations, the actual bed densities should not be different between seed treatments within a targeted sowing density. For all plots, calibrated sowing machines were adjusted to expect a $15 \%$ cull rate at lifting for each specific germination rate and seed size. Theoretically, then, the seedling bed densities are expected to be equal between treatments (IDS seed compared to standard seed) within a targeted density. The actual bed densities 60 days after sowing are presented for each treatment in Table 4. In none of the treatment plots did the actual seedling bed density equal the targeted seedling

Table 4. Number of seedlings per square feet at the two nurseries.

Buena Vista Nursery

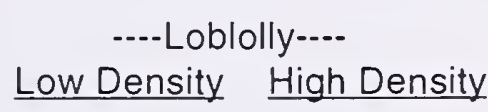

IDS No IDS 16.5 16.3

27.7

29.0

Statesboro Nursery

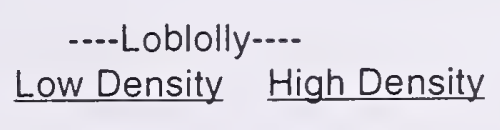

IDS

No IDS
21.8

21.4

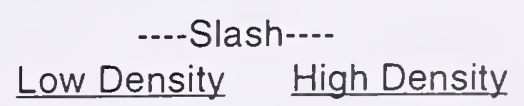

14.2

11.6

20.3

21.8

\begin{tabular}{|c|c|c|c|}
\hline \multicolumn{4}{|c|}{ Statesboro Nursery } \\
\hline -.--Lobloll & -... & ...-.Slash & \\
\hline Low Density & High Density & Low Density & High Density \\
\hline 5.2 & 21.8 & 11.7 & 18.8 \\
\hline 18.5 & 21.4 & 10.6 & 14.7 \\
\hline
\end{tabular}


bed density. The mean density of each plot was determined by measuring the distance between 100 seedlings in one line of a drill in each replication, and mathematically converted to the number of seedlings per square foot. In 1 plot (standard loblolly sown at the Statesboro Nursery) the actual density was only 0.5 feet off the target.

These early results are not surprising to the experienced nursery manager. Due to the many environmental and human management influence upon the seed and the germinates, expected targets are seldom met. However, the actual mean densities in five of eight possible comparisons (two per species at each nursery location) are eqral $(\mathrm{P}=0.05)$ even though they did not equal the targeted density. This implies that although the targeted density was not met, the sowing and germination was still consistent. In most cases, the actual density was much lower than expected. The loblolly sown at $26 / \mathrm{ft}^{2}$ ) at the Buena Vista nursery was slightly higher (average of $2.3 \mathrm{ft}^{2}$ ) than expected.

Reasons for lower than targeted seedling bed densities are many, including heavy rains killing seedlings at the Statesboro nursery very soon after sowing. But in general, it seemed that germination of the IDS seed or the standard seed was not as high as expected. Also, the time required for complete germination of all the viable seed was much longer this year. This affect may well have been due to lower than normal nighttime and daytime temperatures experienced during much of the spring. Bed densities were operationally checked to insure an adequate job of sowing, but extensive data collection was not practical. Since the bed densities were not accurately (collecting statistically ample data) measured to allow statistical comparisons of densities at time of sowing and after germination, the effects of lower seedling bed densities are confounded. Seed quality would have certainly suffered if we had taken hours worth of data prior to mulching the seed.

The seedlings to date are healthy and plans are to continue to evaluate each treatment at harvest. Several linear feet of each plot in each replication will be lifted and precisely counted and evaluated using a computer aided analysis referred to as "machine vision" developed at Auburn University (Wilhoit et.al., 1993). This will enable us to accurately determine bed densities at lifting, as well as the physical qualities of every seedling lifted.

\section{CONCLUSIONS}

1. The IDS treatment employed to separate filled-dead seed from full-live seed of loblolly and slash pines was successful. Increasing the germination percentage as well as removing low viability seed was pioneering work for both species.

\section{Physical qualities and} seedling growth is inconclusive at this time. The number of filled cavities in the container nursery and bed densities at the bareroot nurseries have not provided accurate information to determine if an economic advantage is to be expected from this first crop grown from IDS treated seed. However, the authors anticipate this seed treatment process will prove beneficial for those bareroot nurseries that use precision sowing techniques and all container seedling nurseries. For the seed inventory managers, improving the poor germinating lots of the high genetic value seed, is now a "viable" alternative. 


\section{LITERATURE CITED}

Bergsten, U., 1983. Removal of mechanically damaged and filled-dead seed from a seed lot of Pinus sylvestris. Seminar onmachines and techniques for forest plant production. Czechoslovakia, June 1983: 17pp.

Bergsten, U. and K. Wiklund, 1987. Some physical conditions for removal of mechanically damaged Scots pine seeds by using the PREVAC-METHOD. Scand. J. For. Res. 2:315323.

Bergsten, U. 1991. Removal of dead-filled seeds and invigoration of viable seeds - A review of a seed conditioning concept used on conifers in Sweden. In Edwards, D.G. (ed) "Dormancy and barriers to germination". Proc. Internat.Sympos. IUFRO Project P2.04-00'(Seed Problems). Victoria, British Columbia, Canada. April 23-26, 1991. Forestry Canada, Pacific Forestry Centre, Victoria, B.C.

Czabator, F. J., 1962. Germination Value: an index combining speed and completeness of pine seed germination. For Sci. 8:386-396.
Donald, D.G.M. 1985. The separation of full dead seed from live seed in Pinus elliottii. P. 83-87 in proc. 1985 International Symposium on Nursery Management Practices for the Southern Pine.

Downie, B. and U. Bergsten, 1990. IDS separation of white spruce (Picea glauca Moench/Voss) seed: Why sow dead seed when producing container seedlings? Poster abstract. In "Proceedings of the 11th IUFRO Northern forest silviculture and management working party S1.0512 symposium". Inf. report IV-X-271, Newfoundland and Labrador Region Forestry, Canada.

Simak, M. 1983. A new method for improvement of the quality of Pinus contorta seeds. In: Lodgepole pine: regeneration and management. Gen. Tech. Rep. PNW-157. Portland, OR: U.S. Department of Agriculture, Forest Service, Pacific Northwest Forest and Range Experiment Station: 39-41.

Simak, M. 1984. A method for removal of filled-dead seeds from a sample of Pinus contorta. Seed Science and Technology, 12: 767-775.
Vozzo, J.A. 1994. Application of the incubation, drying and separation method to Pinus roxburghii seeds. USDA Forest Service, Southern Forest Exp. Sta. New Orleans, LA.

Wilhoit, J.H., L.K. Kutz, D. B. Fly, and D.B. South, 1993. Pine seedlings measured with a low cost machine vision system. Highlights of Agricultural Research 40(2):4. 


\title{
Nurseries and the Worker Protection Standard - A Discussion ${ }^{1}$
}

\author{
J. D. Artman²
}

When deliberations began in 1988 regarding the Worker Protection Standard (WPS), there was little doubt that forest nurseries and greenhouses would be included. However, when the proposed Standard included operational forestry, most of the forestry types that screamed did so in terms of the operational forestry inclusion. We thought, if we had any chance at all, it was to reduce the Standard's impact on operational forestry. We even contended that nursery operations were far more akin to traditional agriculture and, therefore, there was some justification for their inclusion, but we failed to see the need for covering site preparation, release and herbaceous operational programs.

We failed in our attempt for an operational forestry exclusion and once a plan had been developed for these programs, we began developing a procedure for dealing with the Standard at
Department of Forestry (DOF) nurseries. Perhaps, a discussion of the procedures developed might be of assistance to others who are facing WPS-related concerns. This discussion involves nurseries only if greenhouses are involved and some additional strategies would be necessary.

Our planning in Virginia involved:

1. Requirements of the Standard.

2. What we use, how we use it and who's involved.

3. Merge \#1 above with \#2 so that we meet the Standard and minimize unnecessary changes within the operation.

Based on the Standard, we knew that there would have to be central location with poster and application and emergency information, decontamination sites, emergency transportation, training, personal protective equipment (PPE), oral notifica- tion and/or posting and differentiation between worker and handler.

Step two involved a look at all products currently used at the nurseries. That included the obtaining of new labels and material safety data sheets (MSDS) for each product with the new WPS wording. Once we had the labels, we knew the restricted entry interval (REI) and personal protective equipment (PPE) required for both handlers and early entry workers. We then examined how each product was used including crop, frequency, rate, method of application and anything else that seemed appropriate.

As we discussed individual products and applications, the most careful analysis involved the actual need to involve workers in a treated area prior to expiration of the (REI). We were extremely fortunate in that we have no use that necessitates 
worker involvement prior to REI expiration. That being the case, our nurseries could be, more or less divorced from the worker side of the WPS.

The Standard requires a substantial amount of training for both early entry workers and handlers. One is exempted from additional training if currently certified through a state's certification program. We had already decided that no workers would be involved and all nursery handlers were already statecertified.

Regarding the "central location" we again lucked out. Each nursery has a place where all employees gather upon arrival in order to discuss work assignments for the day. For our nurseries, that occurs in the grading buildings and that is where our central location will be established. At that place, we will have the required safety poster, a bulletin board showing treatment areas or areas currently under REI and a notebook containing overall procedures relative to the WPS, a listing of chemicals used along with their $\mathrm{REI}$ and required PPE, all product labels, all MSD sheets and the address and phone number of the medical facility that would be used in case of an emergency.

Our decontamination sites are, with one exception, near the central location. We will use the lavatories in the grading buildings at two nurseries and the lavatory in a mechanics shop at one facility. Near the decontamination areas, there will be a container for disposable PPE. It is the responsibility of the handler to clean and replace reusable PPE. A change of required $P P E$ will be available as required.

Application at all three facilities is almost totally done using tractors with enclosed cabs. That exempts the handler from the required $\mathrm{PPE}$. Our handlers do their own mixing/loading and, as such, would wear the appropriate label-specified PPE for the product they are using during the mixing/loading operation. That PPE would be removed prior to reentering the enclosed cab for application.

While everyone is together in the morning, one of the supervisors will briefly cover any maps on the treatment bulletin board. That would involve areas planned for treatment that day as well as other areas currently under an REI. That will serve as our verbal notification as we have opted for that as opposed to field posting. Understand there are some of the more toxic materials for which both posting and verbal notification are required, but none of our products fall into that classification and, as such, we had the option. As a reinforcement of the verbal notification, we will designate treated areas in the field using small, flagged pins. Our intent is to simply keep all people out of flagged areas. The handler making the application will be responsible for placing the field flags during application as well as making sure the treatment bulletin board at the central area is correct regarding his/her application. That same individual will be responsible for removing maps and flags following termination of the REI.

The emergency transportation should not pose a major problem in that any vehicle could be used. The individual driving the affected handler to a medical facility must stop and pick up the WPS notebook at the central location. As mentioned it contains information on the medical facility itself as well as label and MSDS information that would be important for medical personnel as regards treatment.

If we ran into a particular problem, it involved the occasional need to work on irrigation lines while a REI might still be in effect. At this writing, EPA is examining that concern and we will have to work within whatever guidelines are established. It may be well to mention one specific irrigation-type concern as there may be others facing the same problem. Of all products used at our facilities, Goal is used the most and over the most extensive area. The label calls for irrigation following applica- 
tion. Our interpretation of the Standard is that since irrigation is label-specified, the irrigation personnel are handlers and, as such, can work with the actual application. Those individuals must wear the PPE specified on the label for handlers, but it does permit immediate irrigation of the crop following application. This is one example of how we were able to interpret the Standard in order to continue business as usual.

For those among you still wrestling with a nursery procedure regarding this Standard, I suggest you examine your products closely, see what you actually need and whether some applications might be combined. Also look at times of applications. Remember that for a product with a 12-hour REI, an application that terminates at 5:00 PM today will have expired before work begins tomorrow. Perhaps some with a 24-hour REI can be scheduled for Friday afternoon so as to allow the REI to expire over a weekend. Many of us thought that there was simply no way we could operate without involving workers during the REI. As we examined our materials product by product, we soon learned that in no case, with the possible exception of irrigation-type work, was it imperative that workers be involved during the REI. Our final task was to designate, per the Standard, what actually constituted the treatment area.
Dependent upon how and at what pressure materials are applied, the treatment area can vary from the actual treated area alone to the actual treated area plus 100 feet around. Based on our operations, we have standardized our treatment area at the actual site plus 25 feet around. That treatment area will be included on the map at the central location and when the flags are placed in the field.

\section{Certainly we had problems} and will have more in the future, but we believe our procedures meet the intent of the Standard and allow us to produce a crop. I have long felt that the most ingenious among forestry-type people are those associated with nurseries. That ingenuity was obvious as we dealt with DOF nursery personnel. They make their living handling problems; the Standard and its regulations were simply one more concern along the way. Some of the expected trauma was eased when we learned that many of the Standard's requirements were already a part of normal operations. With the recent reprieve on some of the regulations until January 1, 1995, DOF has this growing season to "fine tune" our efforts, while understanding that the label-driven parts of this Standard were fully in effect on April 21, 1994. 


\section{Permethrin Nursery Spray Protects Pine Seedlings Against Regeneration Weevils ${ }^{1}$}

\section{T.C. Tigner ${ }^{2}$}

Abstract-Investigations in 1988 and 1989 demonstrated that several pyrethroid insecticides could protect pine seedlings against regeneration weevils. Permethrin (Pounce) was chosen for further evaluation because of its relatively high efficacy and low mammalian toxicities. Studies in 1990 showed that Pounce 3.2 EC as a $1 \%$ nursery spray protected outplanted seedlings for several months.

Operational use of this treatment has been well received by nursery personnel, tree planters and field foresters for the past four years. Special local need registration of the Pounce nursery spray currently exists in six southeastern states.

'Tigner, T.C. 1994. Permethrin Nursery Spray Protects Pine Seedlings Against Regeneration Weevils. IN: Landis, T.D.; Dumroese, R.K., tech. coords. National Proceedings, Forest and Conservation Nursery Associations. Gen. Tech. Rep. RM-257. Fort Collins, CO: U.S. Department of Agriculture, Forest Service, Rocky Mountain Forest and Range Experiment Station: 83.

${ }^{2}$ Virginia Department of Forestry, Charlottesville, Virginia. 


\section{Western Forest Nursery Association and the Forest Nursery Association of British Columbia}

Moscow, Idaho August 15-19, 1994 



\title{
Developing Container Conifer Seedling Specifications... A Balanced Approach?1
}

\author{
Eric van Steenis ${ }^{2}$
}

Abstract-Seedling morphological specifications give "seedling growing contracts" something legal and binding that can be upheld in a court of law, and help guide the grower in producing stock of reasonable uniformity and quality to ensure a desirable level of plantation survival and establishment. However, seedling specifications should also insure that seedling customers obtain the maximum return from seed supplied, and encourage or allow the seedling growing industry to operate at the highest possible efficiency.

In British Columbia, seedling specifications are set by stock type (species/growing cycle/container type combination), based on what is perceived to be producible by growers at the time, and necessary for proper plantation establishment. In the past, biological and statistical principles were often not considered or adhered to when setting new standards and/or amending old ones. A typical scenario was to generate a caliper distribution for a new stock type, set minimum caliper at a 30\% throw away rate, and target caliper slightly in excess of average. The assumptions being that lower caliper classes are genetically inferior, growers need something to strive for and... "bigger is better".

This presentation is not about seedling physiological quality, but about carbon fixation, as it relates to plants and photosynthesis. Using operational examples, it will attempt to challenge some existing assumptions and present a new way of relating stem caliper specifications to available nursery growing space per seedling.

\section{INTRODUCTION}

Carbon fixation, or biomass production, per unit of growing area, is limited. Growers get paid to fix carbon in a specific way by a specific time. One approach is to imagine the forest seedling crop as a miniature forest, governed by similar principles.
A number of inputs drive the biological systems we refer to as forests or forest seedling crops. Basically, these are light, $\mathrm{CO}_{2}$, water, mineral nutrients, temperature, and time. However, the ultimate driving or controlling factor, the one which in practical terms limits the ability to utilize all others, is light. Assuming all other inputs are not limiting, as we attempt to do in our container growing systems, a seedlings' biochemistry will produce dry matter (fix carbon) at a maximum rate determined by the available light level (quantity and quality) to all photosynthesizing parts. The total accumulation per stem will be a function of the amount of growing (or light capturing) area it is allowed

'van Steenis, E. 1994. Developing Container Conifer Seedling Specifications: a Balanced Approach? IN: Landis, T.D.; Dumroese, R.K., tech. coords. National Proceedings, Forest and Conservation Nursery Associations. Gen. Tech. Rep. RM257. Fort Collins, CO: U.S. Department of Agriculture, Forest Service, Rocky Mountain Forest and Range Experiment Station: 85-92.

${ }^{2}$ Nursery Extension Services, B.C., Ministry of Forests 14275 - 96th Ave., Surrey, B.C. Canada V3V $7 Z 2$ 
to exploit or occupy with its own photosynthetic machinery. Dry matter production is thus limited, rate by available light level and total (per stem) by available growing area (assuming time is constant).

In a mature forest, "productivity" is measured in various ways, one being "stem basal area production" per unit of growing area over time. For a given biological system (set of inputs), productivity is constant per unit of available growing area, hence the productivity per individual tree is a function of its share of the available growing area (assume canopy closure). The more stems/unit of growing area the lower the stem basal area production/stem!

The same principle can be applied to seedling crops. Inputs are limited hence dry matter production is limited. The number of seedlings grown in a set area determines how much dry matter can be produced per seedling. The more seedlings are crammed into a set growing area the smaller (skinnier) they will be.

\section{Stem caliper (diameter)} production does not relate linearly to stem basal area production or its determining factor, available growing area/ stem. E.g. doubling available growing area might lead one to believe you can double stem caliper demand. Wrong! Doubling stem caliper quadruples stem basal area, requiring a

\section{WHY STEM BASAL AREA?}

STEM DIAMETER IS A LINEAR FUNCTION

STEM BASAL AREA IS A SQUARED FUNCTION

(3.14 "RADIUS " RADIUS)

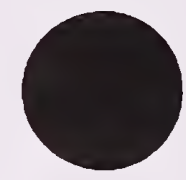

GROWING AREA IS A SQUARED FUNCTION

LENGTH $\times$ WIDTH

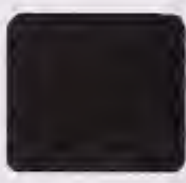

Figure 1

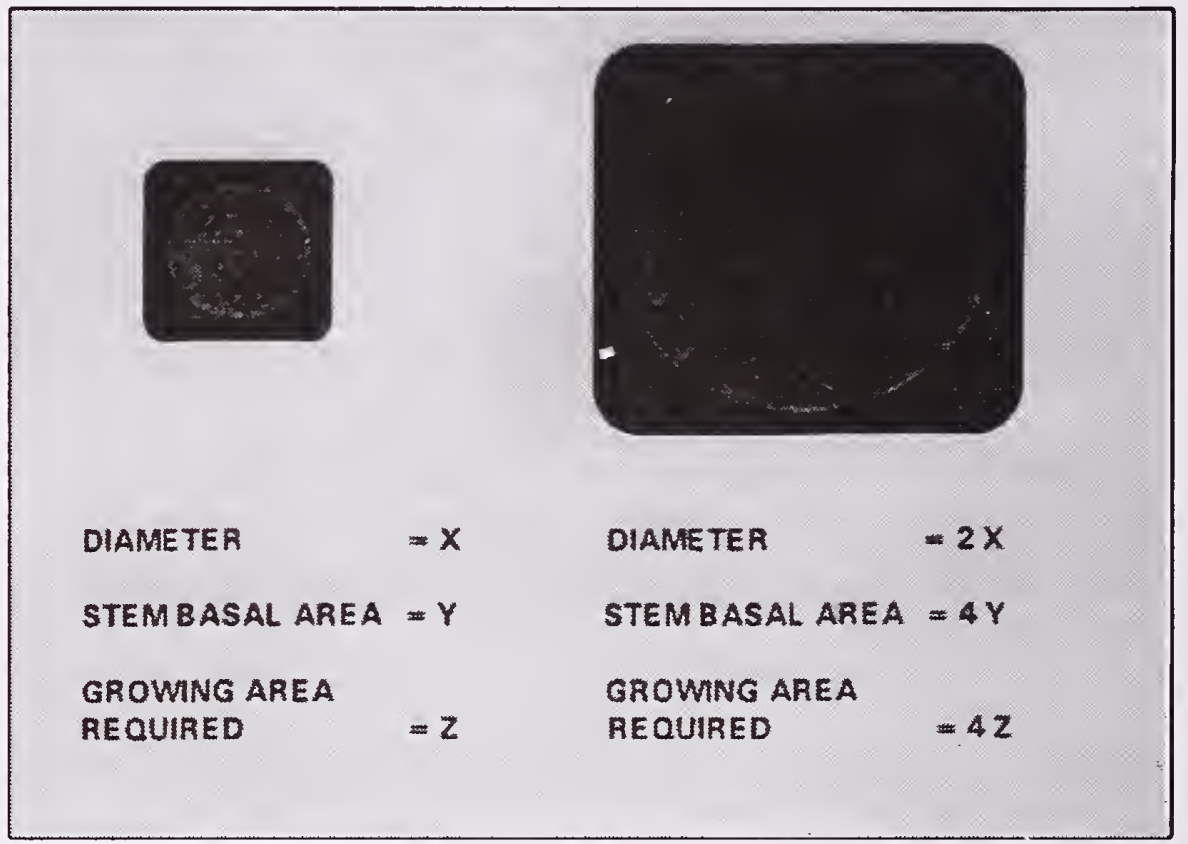

Figure 2

quadrupling of growing area to produce it.

\section{DISCUSSION}

Consider a dozen species, up to 3 growing cycles and 20 different container choices, each combination requiring a separate standard, and the system becomes fairly unwieldy.
Most importantly, field morphological requirements and specific container requirements need to be separated. The choice of specifications for field requirements is basically unlimited, however, what is biologically achievable in a set container type, given the available resources at the nursery, is limited. For instance, field requirements in terms of seed- 
ling morphology and/or physiology can be produced in a variety of containers. e.g. If a $3.0 \mathrm{~mm}$ caliper is the minimum requirement for a snow press area then the container it is grown in is irrelevant. As long as root integrity exists for the particular application, the $3.0 \mathrm{~mm}$ seedling will be as suited for the purpose, regardless of the chosen container. "Creaming" a seedling crop for the larger caliper types only results in the acquisition of rootbound plants at an inflated price. If minimum caliper requirements for field purposes consistently cut too far into a certain seedling crop type then a lower density container (more growing space/seedling) should be utilized (assuming other inputs are not limiting).

Noting the variability in the embling sample (one clone, every plant genetically identical), there is obviously more to variability than genetics! Seed orchard seed crops also show variability distributions similar to "wild" crops. Concern has been expressed regarding crops grown from genetically improved seed... "why are cull rates just as high as in crops grown from wild seed?". There are two possible answers. One, genetically improved seed is not, or two, culling criteria have little or nothing to do with genetics. I would opt for the latter. Growers have enough to strive for without going outside what is biologically achievable.

\section{COMPARISON OF CALIPER DISTRIBUTION FOR 211 AND $3131+0$ LODGEPOLE PINE}

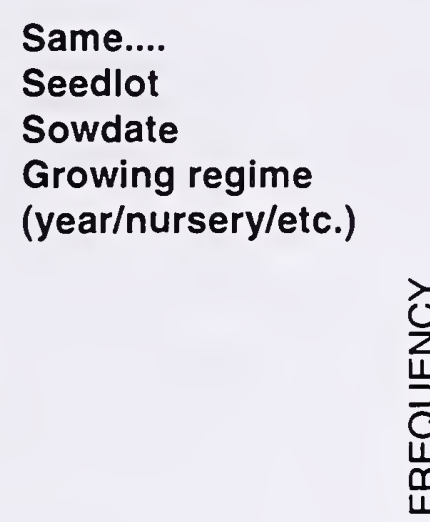

Figure 3

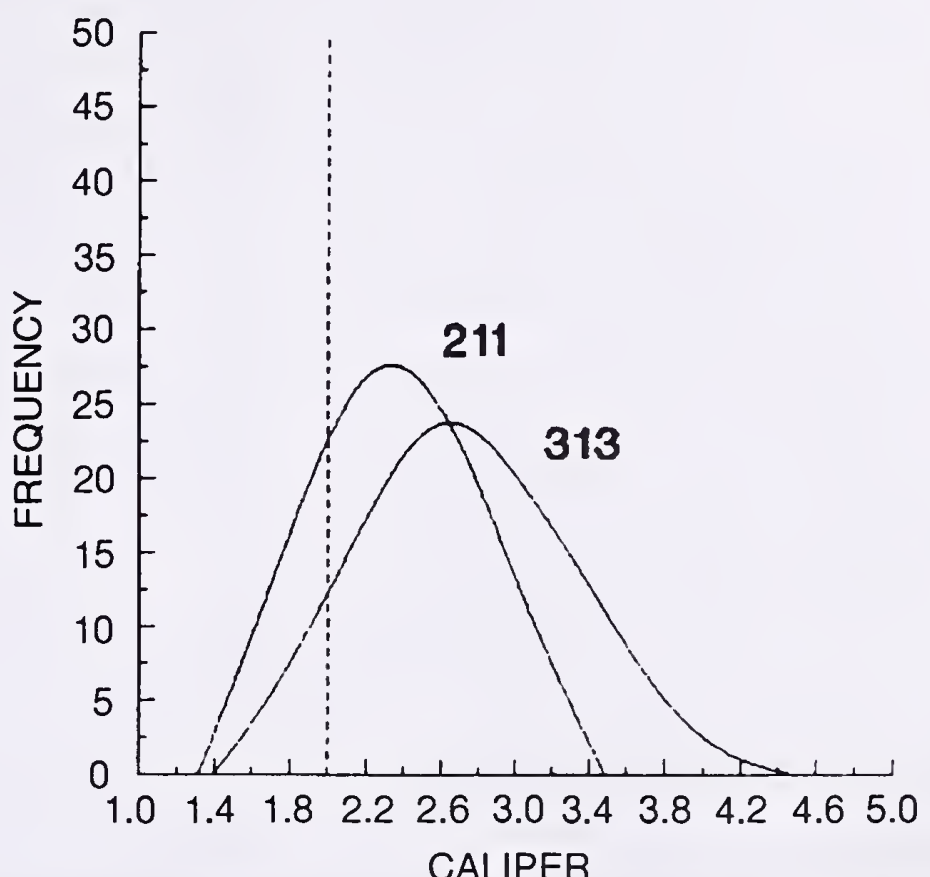

With respect to "bigger is better" we know that within any population there is a degree of variation in size, and the relative growth rate (amount of production per unit of production, e.g. $\mathrm{cm}^{3} / \mathrm{cm}^{3} /$ year for stem volume) of small and large seedlings is basically the same. Larger specimens do not necessarily grow faster but by having a head start may be better able to maintain an advantage. Sort of like interest in the bank or

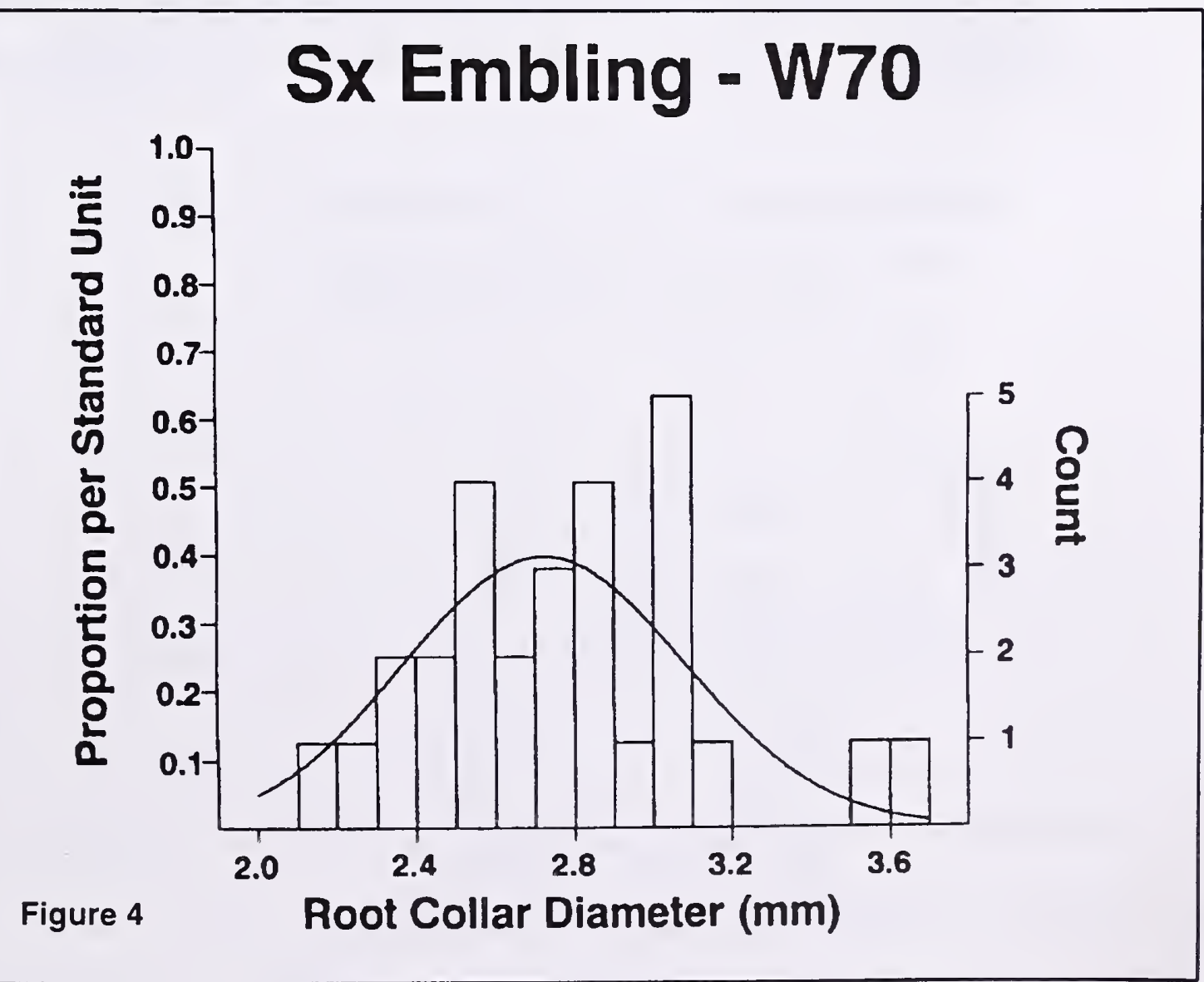


making snowballs. Selecting populations of larger seedlings overall may be the way to apply this principle rather than creaming larger seedlings out of each existing population.

A seedling crop produces a range of stem caliper, due to variability in germination characteristics and growing environment. Variability due to genetics is negligible, hence culling out smaller seedlings on the assumption that they are genetically inferior is not sound practice. So what are we throwing away? Culls created by density dependent competition effects?

Note that there is variability, and the whole population shifts with available growing area/ seedling. Also imagine a $3 \mathrm{~mm}$ diam. min. caliper imposed on these crops and the subsequent cull rates. Would the 412 population contain a higher proportion of genetically inferior seedlings?
Table 1. MINIMUM STEM BASAL AREA REQUIREMENTS FOR $1+0$ CONTAINER WHITE SPRUCE.

B.C. 1994. $\left(\mathrm{mm}^{2}\right)$

$\begin{array}{lll}\text { Block } & \text { \# Cavities } & \text { MSBA Requirement } \\ \text { Type } & \text { Per Block } & \text { Per Block }\end{array}$

$211 \mathrm{~A}$

240

912

$313 A$

198

895

$313 B$

160

723

410

112 (shallow)

550

415B

112 (deep)

690

$412 \mathrm{~A}$

77 (shallow)

544

415D

77 (deep)

619

$615 A$

45

565
By converting minimum stem caliper specs to Minimum Stem Basal Area specs and multiplying by the number of
Comparison of RCD Distribution 412 \& $5121+0$ Sx Seedlings

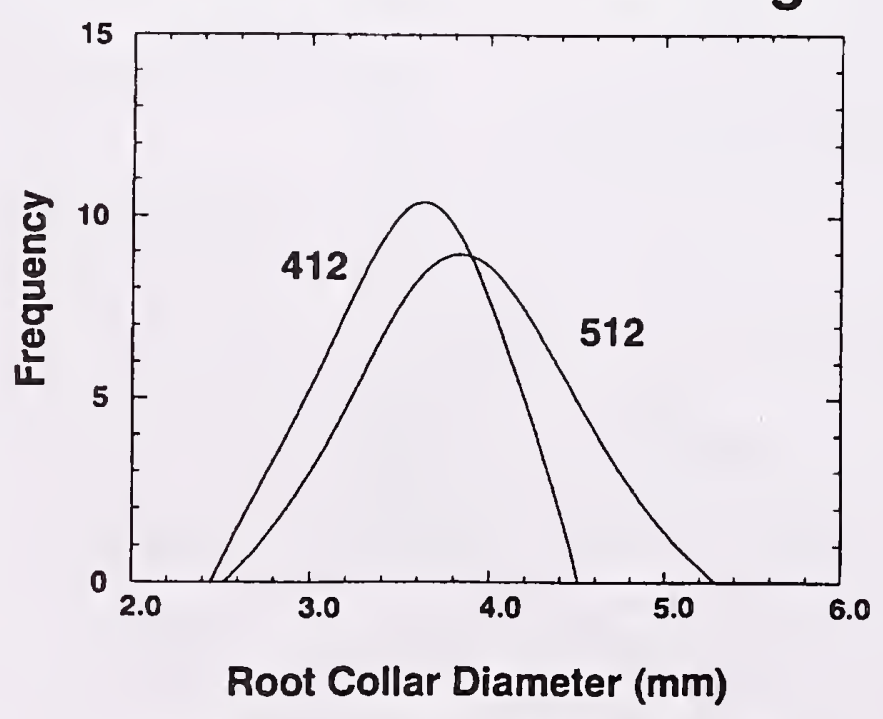

Figure 5 cavities in a block we can generate a current MSBA/Block demand. (block types listed are all the same size).

From the above table one can see that biological demand is not equal across the variety of container types utilized for this species/crop cycle combination. This would not be obvious from looking at stem caliper standards. Can anyone guess which container types might have the highest cull rates? Correct, the $211 \mathrm{~A}$ and $313 \mathrm{~A}$, which are dubbed "poor" containers. The new 410 block is currently looked upon as a "successful" container. Could the "status" of the container have anything to do with the standard imposed on 
it? 410 crops during good years can sometimes be packaged without grading!

Note the shift due to the difference in available growing area per seedling. Curve is similar to caliper distribution but has a wider range due to being a squared function.

Note the similarity, theoretically there should be no shift ie. 512 has a lower production per unit of growing area $(9 \%)$. This lower production in the 512 is likely due to the fact that it takes longer for the seedlings to completely occupy their available growing space. Perhaps $9 \%$ of crop cycle time?
Note that production per stem increases (see Table 2) with increasing growing area per stem while production per block or unit growing area, remains fairly constant for a given set of inputs (Nursery G vs V). Also as growing density increases growing time until canopy closure is reduced perhaps accounting for the reduction in the difference in production per unit growing area $(9 \%$ to $6 \%)$.

\section{PI 211 vs 313A/B mixed:}

This is the same crop used to construct figure 1 . Note the relationship holds up better at these high densities (see Table 3). The time frame from sowing until canopy closure is relatively short compared to total crop cycle growing time.

\section{COULD WE ALIGN EXISTING, OR GENERATE NEW SPECS?}

We know from experience what can be produced in existing crops. Using SBA production per unit of growing area one can extrapolate to new container types (plant densities) to determine what is achievable (other inputs being constant). This could be done with existing specifications to make them fair (relatively speaking) across the variety of container types currently used.

To determine what is achievable with a new stocktype in a new facility (different input levels) one needs to grow some operational crops. From these,
Comparison of SBA Distribution 412 \& $5121+0$ Sx Seedlings

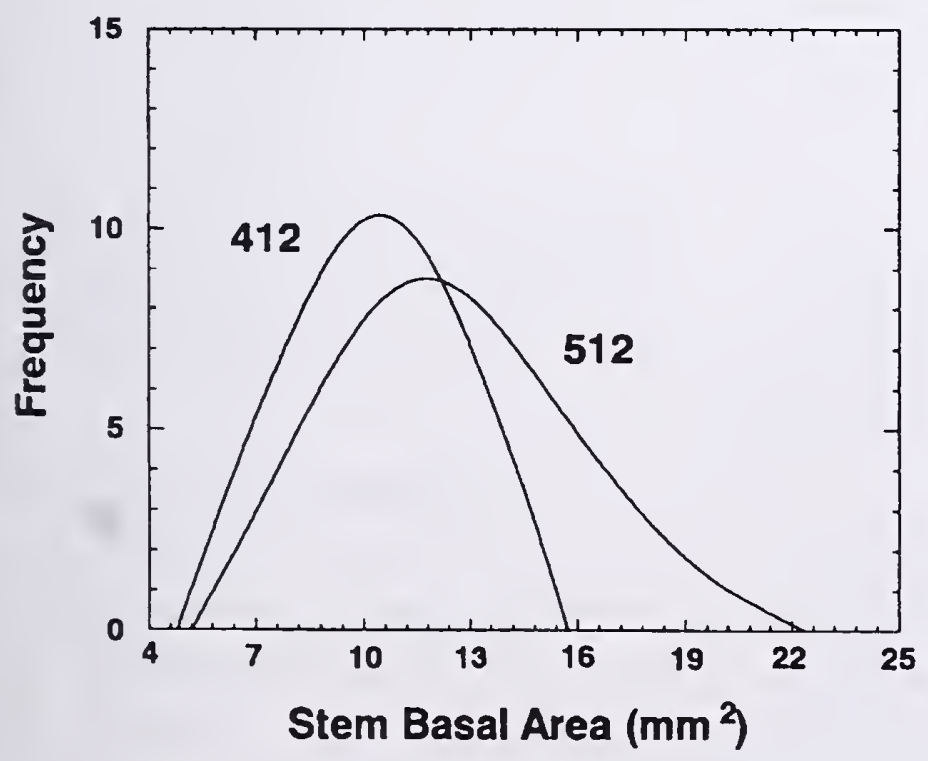

Figure 6. 412 vs 512 SBA (per stem) Distributions
Comparison of SBA/GA Distribution $412 \& 5121+0$ Sx Seedlings

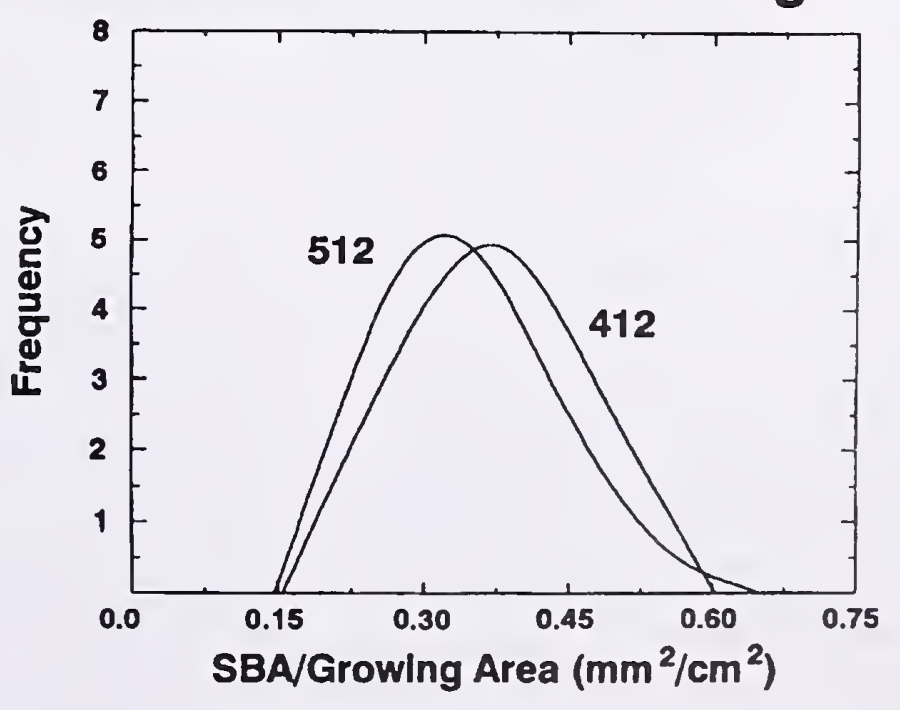


Table 2. White Spruce 1+0 Average Stem Basal Area Production

\begin{tabular}{|c|c|c|c|c|c|}
\hline Block & $\begin{array}{l}\text { \# Cavities } \\
\text { Per } \\
\text { Square } \\
\text { Meter }\end{array}$ & $\begin{array}{l}\text { Availabie } \\
\text { Growing } \\
\text { Area/tree } \\
(\mathrm{sq} \mathrm{cm})\end{array}$ & $\begin{array}{l}\text { Per Tree } \\
\text { (sq mm) }\end{array}$ & $\begin{array}{l}\text { Per Blk } \\
\text { (sq mm) }\end{array}$ & $\begin{array}{l}\text { Per Unit of } \\
\text { Growing Area } \\
(\mathrm{sq} \mathrm{mm} / \mathrm{sq} \mathrm{cm})\end{array}$ \\
\hline $\begin{array}{l}412 G \\
\text { Difference... } \\
512 G\end{array}$ & $\begin{array}{l}366 \\
280\end{array}$ & $\begin{array}{l}27.32 \\
(29 \%) \\
35.26\end{array}$ & $\begin{array}{l}10.13 \\
(18.6 \%) \\
12.01\end{array}$ & $\begin{array}{l}780 \\
(9 \%) \\
721\end{array}$ & $\begin{array}{l}0.37 \\
(9 \%) \\
0.34\end{array}$ \\
\hline $\begin{array}{l}410 \mathrm{~V} \\
\text { Difference... } \\
412 \mathrm{~V}\end{array}$ & $\begin{array}{l}527 \\
366\end{array}$ & $\begin{array}{l}18.98 \\
(43 \%) \\
27.32\end{array}$ & $\begin{array}{l}12.72 \\
(35 \%) \\
17.21\end{array}$ & $\begin{array}{l}1424 \\
(6 \%) \\
1325\end{array}$ & $\begin{array}{l}0.67 \\
(6 \%) \\
0.63\end{array}$ \\
\hline
\end{tabular}

Table 3. Lodgepole pine 1+0 Average Stem Basal Area Production

\begin{tabular}{|c|c|c|c|c|c|}
\hline Block & $\begin{array}{l}\text { \# Cavities } \\
\text { per Growing } \\
\text { square } \\
\text { meter }\end{array}$ & $\begin{array}{l}\text { Available } \\
\text { (sq mm) } \\
\text { Area/tree } \\
\text { (sq cm) }\end{array}$ & $\begin{array}{l}\text { Per Tree } \\
\text { (sq mm) }\end{array}$ & Per Blk & $\begin{array}{l}\text { Per Unit of } \\
\text { Growing Area } \\
(\mathrm{sq} \mathrm{mm} / \mathrm{sq} \mathrm{cm})\end{array}$ \\
\hline 211 & 1130 & 8.85 & 4.34 & 1042 & 0.49 \\
\hline Difference... & & $(34 \%)$ & $(37 \%)$ & $(2 \%)$ & $(2 \%)$ \\
\hline $\begin{array}{l}313 \mathrm{~A} / \mathrm{B} \\
\text { Equal } \\
\text { mix }\end{array}$ & $\begin{array}{l}936 \\
\& \\
764\end{array}$ & $\begin{array}{l}11.89 \\
\text { (ave) }\end{array}$ & 5.94 & 1063 & 0.50 \\
\hline
\end{tabular}

frequency distributions and SBA production capabilities can be determined on average (long term, if possible). Minimum standards can then be generated to reflect biological capability and desired capture limit of variability.

Ideally, seedling customers should take out to the plantation all the biomass produced at the nursery (since they are paying for it all). The key is to select a container/specification combination which will allow all the dry matter produced to be concentrated in the "spec" seedlings, ie. including the dry matter previously contained in "culls". This "optimum" specification for a container type might allow utilization of $95 \%$ of a crop. A crop producible under normal (long term average) conditions.

\section{GRADING!?}

As an industry, we are spending hundreds of thousands of dollars per year grading seedlings. To reduce this cost we are currently also investing large 
sums to develop grading equipment. However, if we succeed in reducing the cost of grading through equipment development there are still the approximately $50+$ million seedlings per year in British Columbia being discarded as "culls". This is an immense waste of seed, seedlings, and growing space possibly making us one of the most inefficient greenhouse growing industries on the globe!

So let's turn the whole concept around. Perhaps, by starting with the final desired product (minimum stem caliper and an acceptable \% cull factor) and designing the growing system to produce it, we could instead ..... eliminate grading, and all the costs and headaches associated with it!? Would it not be nice to just package everything?

\section{DOLLARS RECOVERED PER UNIT OF GROWING AREA}

Costs in a greenhouse operation are calculated on a per unit area basis, ie. facility depreciation, heat, lighting, soil mix, etc. In order for the operation to remain viable, there needs to be a certain amount of monetary input. The break even point for nurseries will differ depending on local situations (weather, labour) but the principle remains. Each square meter under cultivation needs to make a certain return to stay in business.
Hence if stiff specifications (or poor growing techniques) lower the number of saleable units per square meter, the price per unit has to be higher. Competition will take care of the poor growers but specifications will reduce efficiency of even the best.

Basically, the seedling customer is paying for the whole seedling crop, culls included, and chooses (through specifications) which portion to take.

\section{SUMMARY}

1. Attainment of specifications is largely a function of density dependent competition effects.

2. Growing (light capturing) area available per seedling is the main limiting factor in higher density container culture growing regimes.

3. Stem caliper production does not relate linearly to stem basal area production or its determining factor, available growing area/stem.

4. Knowing the biological capability of a system allows realistic determinations of specifications (caliper).

\section{Knowing the customer} specifications demand (caliper) allows development of growing systems with plant densities that will allow them to be achieved.
6. Grading out lower caliper classes (creaming for higher caliper classes) within a seedling crop is an expensive make-work project.

\section{REFERENCES}

Annevelink, E. 1990. Operational Planning in Horticulture: Optimal Space Allocation in Pot-Plant Nurseries Using Heuristic Techniques. J. Agricultural Engineering Res.(1992)51, 167-177.

Boyer, James N.; South, David B. 1986. The Influence of Seedbed Density on Loblolly and Slash Pine Seedling Grade Distributions. Auburn University Southern Nursery Cooperative, Auburn University, AL 36849-4201. November 1986, Number 29.

Decoteau, Dennis R.; Hatt Graham, Heather A. 1994. Plant spatial Arrangement Affects Growth, Yield, and Pod Distribution of Cayenne Peppers. HortScience 29(3):149-151.

Gray, David.; Benjamin, Laurence. 1991. Reducing the Grade-Out Pile. Grower, July 11, 1991.

Hulten, Hakan. 1989. Current Levels of Planting Stock Uniformity and Grading - A Scandinavian View. Forestry Supplement, Vol. 62, 1989. 
Kahn, Brian A. 1990. Reduced Plant Populations Save Seed Costs Without Reducing Yield or Quality of 'Alltop' Turnip Greens. HortScience 25(2):179-180.

Knowe, Steven A.; Foster, Sam

G.; Rousseau, Randall J.; Nance, Warren L. 1994. Eastern Cottonwood Clonal Mixing Study: predicted diameter distributions. Can. J. For. Res. Vol. 24:405-414.

Simpson, David G. 1991. Growing Density and Container Volume Affect Nursery and Field Growth of Interior Spruce Seedlings. Northern Journal of Applied Forestry, Vol. 8, No. 4, 160 - 165.

South, D. B.; Mitchell, R. J.; Zutter, B. R.; Balneaves, John M.; Barber, Brad L.; Nelson, Derek G.; Zwolinski, Janusz B. 1993. Integration of Nursery Practices and Vegetation Management: Economic and Biological Potential for Improving Regeneration. Can. J. For. Res. Vol. 23. 20832092.

Sutherland, D.C.; Day, R.J. 1988. Container Volume Affects Survival and Growth of White Spruce, Black Spruce, and Jack Pine Seedlings: a Literature Review. Northern Journal of Applied Forestry 5(3):185-189.
Sutton, B.C.S.; Grossnickle, S.C.; Roberts, D.R.; Russell, J.H.; Kiss, G.K. 1993. Somatic Embryogenesis and Tree Improvement in Interior Spruce. J. Forestry 91(10):3438.

Rikola, Risto. 1989. Planting Performance of Size graded Scots Pine Seedlings. Forestry Supplement, Vol. 62, 1989. 


\title{
Long-term Stock Type Trial Results in B.C.: Did Stock Performance Meet Today's Standards?'1
}

\author{
Rob Bowden ${ }^{2}$ and R.G. Scagel ${ }^{3}$
}

Abstract-Nursery growers are a part of the system responsible for establishing a free growing crop of trees on a site after harvesting. The seedlings produced, their size, and the condition in which they are delivered to the field can play a large part in the success of the plantation.

This paper briefly outlines the process and legal responsibilities that a forester must follow when preparing a prescription. An integral part of the prescription is the selection of a stock type. The impact of stock type selection on the success of a prescription will be examined using survival and growth results from a 1978 trial established by Forestry Canada near Prince George, British Columbia.

The authors express their thanks to Dr. R. McMinn for the initial trial installation, Marvin Grismer for seedling measurement and Linda Strodeur for assistance in the analysis and report preparation.

\section{INTRODUCTION}

Nurserygrowers are a part of the system responsible for establishing a free growing crop of trees on a site after harvesting. The seedlings produced, their size, and the condition in which they are delivered to the field can play a large part in the success of the plantation.

The forester must prepare a prescription incorporating products that the nursery can produce. The selection of nursery products will be based on cost and performance variables. They must not only survive but attain acceptable growth given the conditions of the site. This must be done to achieve the legal obligations for the establishment of the free growing crop of trees required by law in British Columbia.

Foresters also must develop a prescription that will achieve a variety of goals for the new forest planned for the site. This prescription and goals are based on the ecosystems that occur on the site.
The identification of the ecosystem is the first step in the prescription process. Associated with each ecosystem, there are legally binding standards of reforestation performance (Table1).

One of the basic requirements of the prescription must ensure that a minimum number of wellspaced trees that have attained a minimum height be established on the site within a specified period following harvesting. In B.C., this legal commitment has to be made before approval to harvest will be granted.

'Bowden, R.G.; Scagel, R.G. 1994. Long-term Stock Type Trial Results in B.C.: Did Stock Performance Meet Today's Standards? IN: Landis, T.D.; Dumroese, R.K., tech. coords. National Proceedings, Forest and Conservation Nursery Associations. Gen. Tech. Rep. RM-257 Fort Collins, CO: U.S. Department of Agriculture, Forest Service, Rocky Mountain Forest and Range Experiment Station: 93-98.

${ }^{2}$ Silviculture Branch. BC Ministry of Forest, 990 Fort Street, Victoria BC CANADA V8W 3E7.

${ }^{3}$ Pacific Phytometric Consultants Ltd. 
Table 1. SBSvk-Prince George tree species selection and free growing stocking standard guidelines.

\begin{tabular}{|c|c|c|c|c|c|c|c|c|c|}
\hline \multirow{3}{*}{$\begin{array}{l}\text { Site } \\
\text { series }\end{array}$} & \multirow{2}{*}{\multicolumn{2}{|c|}{ Tree species }} & \multirow{2}{*}{\multicolumn{2}{|c|}{$\begin{array}{l}\text { Stocking standards } \\
\text { (well-spaced/ha) }\end{array}$}} & \multirow{3}{*}{$\begin{array}{l}\text { Regen } \\
\text { delay } \\
\text { (yrs) }\end{array}$} & \multicolumn{2}{|c|}{ Assessment } & \multirow{3}{*}{$\begin{array}{l}\text { Min.tree } \\
\text { height } \\
\text { (m) }\end{array}$} & \multirow{3}{*}{$\begin{array}{l}\text { \%tree } \\
\text { over } \\
\text { brush }\end{array}$} \\
\hline & & & & & & Early & Late & & \\
\hline & Primary & Secondary & Target & Minimum & & (yrs) & (yrs) & & \\
\hline 04 & Sx & $\mathrm{BI}, \mathrm{Fd}, \mathrm{Pl}$ & 1200 & 700 & 4 & 9 & 15 & Sx 1.0 & 150 \\
\hline 05 & Sx & $\mathrm{BI}, \mathrm{P} 1$ & 1200 & 700 & 4 & 9 & 15 & $S \times 1.0$ & 150 \\
\hline 06 & Sx & $\mathrm{BI}, \mathrm{P} 1$ & 1000 & 500 & 4 & 9 & 15 & Sx 0.8 & 150 \\
\hline 07 & Sx & B1. P1 & 1200 & 700 & 4 & 9 & 15 & $S \times 1.0$ & 150 \\
\hline
\end{tabular}

How the forester achieves this free growing crop is of importance to the nurserygrower.

All forest sites in B.C. have been classified according to a variety of site factors including: - climate,

-soils, and

- vegetation present on the site.

This is further broken down based on:

- moisture status of the site, and - nutrient status of the site.

For example, the trial site is located in a very wet $(\mathrm{v})$, cool (k) area within the Sub-Boreal Spruce (SBS) biogeoclimatic zone near Prince George. It is classified as the SBSvk zone. A more detailed classification of this particular site would position it in the 04-07 site series (Figure 1).

Foresters make prescription decisions about the size of planting stock, planting densities, season of planting, site preparation needs, and the year the stock will be planted according to the standards established for each of the site series affected. These decisions are based on the site conditions and costs.

For all of these sites, a set of legal minimum performance standards have also been developed. The reforestation standards for a site dictate the end performance that must be achieved but, as one might imagine, there are a multitude of ways to achieve the results. Consequently, stock type selection is one of the critical choices the forester must make. It is also the choice that is of major importance to the nurserygrower.

Table 1 outlines the species and performance standards that are acceptable for the trial sites northeast of Prince George, based on the location on the edatopic grid.

The standards:

- are broken down for each ecological site series;

- indicate acceptable primary and secondary tree species;

- outline stocking standards that have to be achieved within the free growing time frame; - dictate length of regeneration delay (i.e., the maximum length of time commencing at harvesting by which trees must be established either by planting or natural regeneration); if a forester plans to plant the site, the standards allow up to 4 years following disturbance before the reforesting process must be started;*

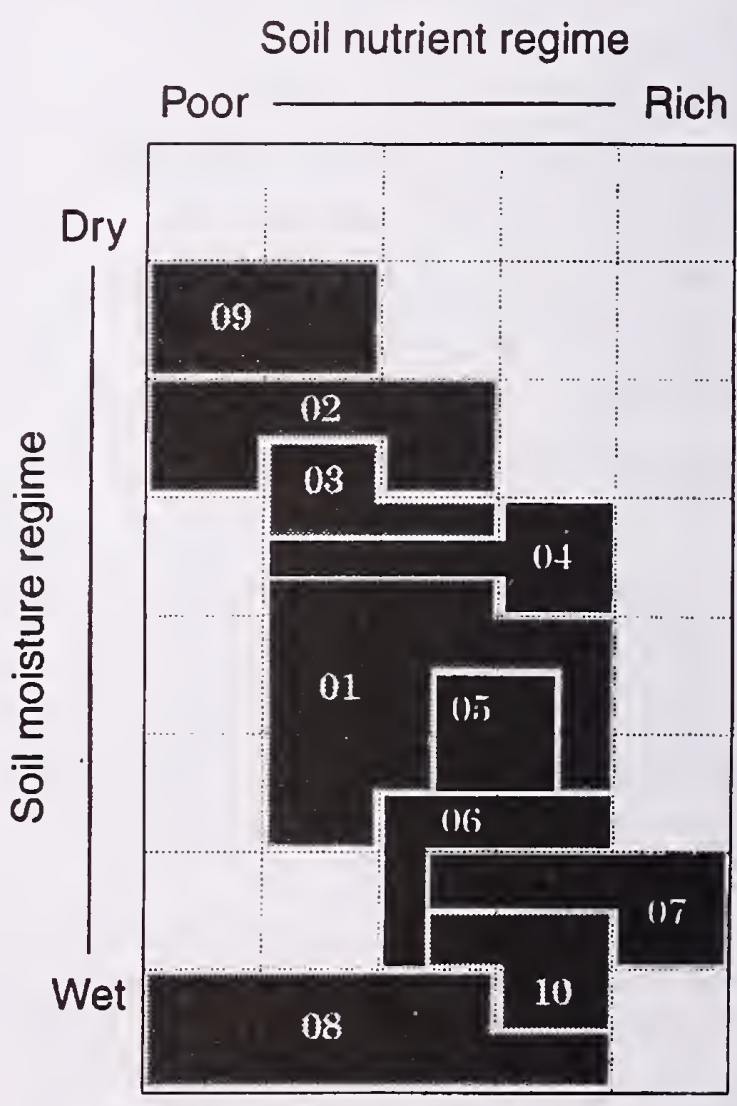

Edatopic Grid SBSvk

Figure 1. 1978 trial location, Prince George, site series edatopic grid. 
- outline free growing assessment-earliest and latest time following commencement of harvesting; and

- dictate minimum tree heights that must be achieved by free growing assessment.

The ability of the different stocktypes are compared in the 1978 trial to the above standards.

(* Leaving reforestation this long can affect the achievement of free growing requirements as is illustrated in the trial results.)

\section{TRIAL OBJECTIVES}

Trials were designed to examine stock type survival and performance under different site conditions.

In 1978 , the container program was still under development and the trial tested newer container stock types against more traditional bareroot options.

While a total of four trials were established, this paper reports the results from one of the representative sitesSevereid. Severeid represents a cross section of the site associations in the subzone (Figure 1).

\section{TRIAL LOCATIONS}

The trials were established in the north central Interior of B.C., north east of Prince George. All four trials were in the SBSvk zone, covering a range of site series.

\section{BACKGROUND ON TRIAL}

The Severeid site was logged in 1974 and planted in 1978. By the time of planting there was significant brush development including Sitka alder, huckleberry, thimbleberry and fireweed.

Discussion will be limited to stock performance on the two largest site series (04 and 07) of the Severeid site. Of the five stock types planted, four have been chosen for analysis because they are still used in B.C. They are also significant in terms of cost. The stock types are $2+1$ bareroot transplants, PSB211 $1+0$ container, PSB312 1+0 container, and PSB415 1+0 container.

A $2+0$ bareroot stock was also planted, however, it suffered close to $80 \%$ mortality in the first two years and it was not measured after that time.

Survival and growth results are presented for each of the remaining four stock types and discussed in terms of whether they would have resulted in the achievement of the free growing obligations by 1994 Ministry of Forests standards for stocking and growth (Table 1).
Two issues are addressed: "Did any or all of the stock types meet the free growing requirements?" Second: "If they did, can we now develop a stock type recommendation for the different site series based on the costs of each of the stock types used?"

\section{Site 1 - 04 Site Series:}

The first site is classified as a 04 site series which is mesic or in the middle of the moisture gradient with a rich nutrient status. The earliest free growing assessment would be year 9 or 1983. The latest assessment would be in year 15 or 1989 .

Figure 2 illustrates the change in stocking for the four stock types relating to time following planting and regeneration delay.

All of the stock types have maintained sufficient survival at the start of the free growing assessment window (5 years after planting - 1983) to achieve the requirements for free growing assessment.

However, mortality is still occurring and by the latest free growing date (1989) the stocking for 211 and $2+1$ stock types has dropped below the minimums outlined in Table 1.

On such a rich site association, it is concluded that the choice of stock type is critical. Extra costs for site preparation and/or re-planting are high and 


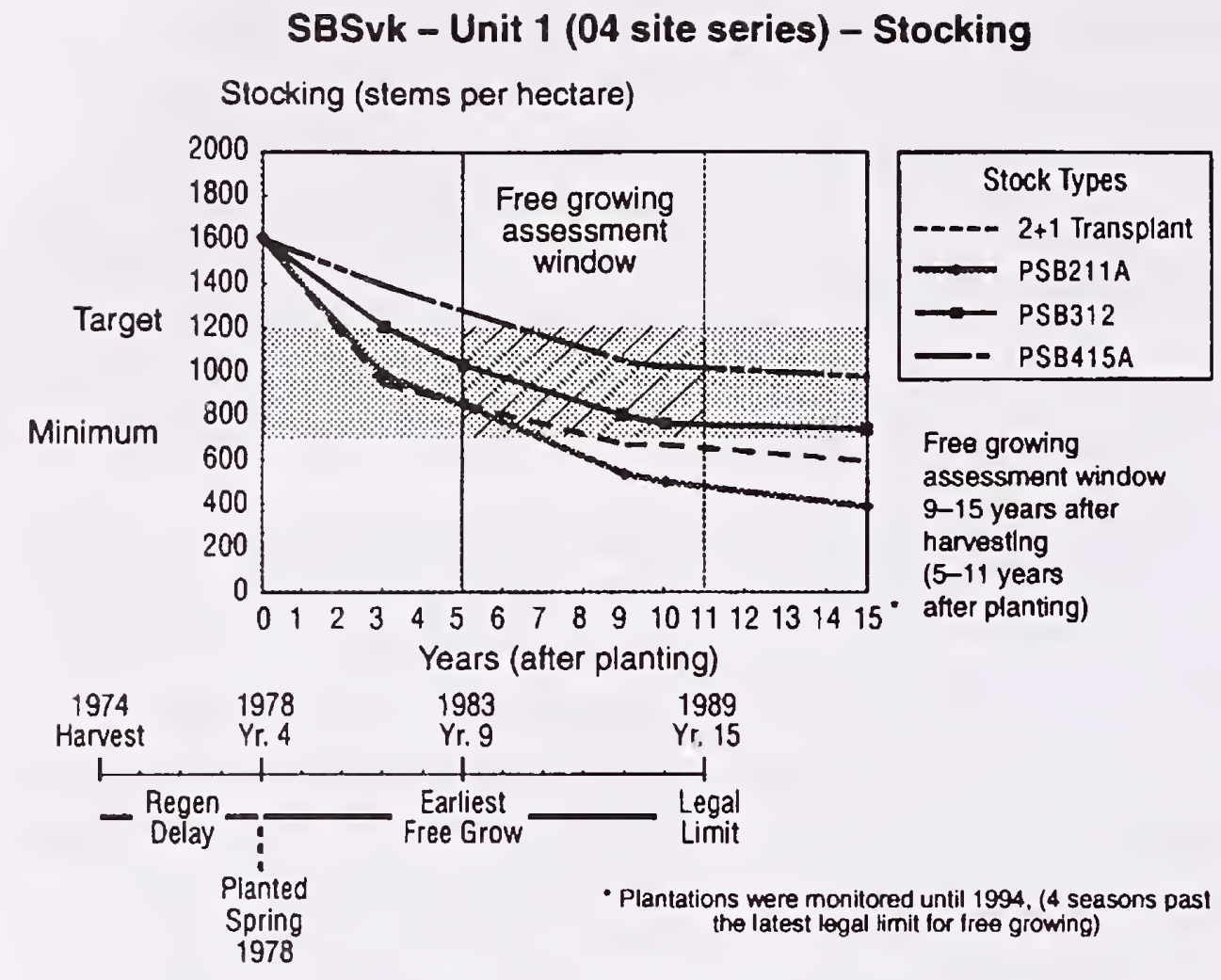

Figure 2. Stocking over time for four stocktypes on the 04 association.

further work will be required to achieve a free growing crop.

Figure 3 displays the number of surviving trees that have reached $1.0 \mathrm{~m}$ in height.

None of the stock type(s) had the minimum number of trees achieve the minimum height requirement during the free growing assessment period.

Both the stocking levels and the fact that these trees must have achieved the minimum height required determines whether the site will be free growing. This did not happen on Site 1.

If the block had been planted right after harvesting, one could (number of free growing trees). have expected the results to have been different. The data suggested that the 415 stock type would have achieved the free growing obligations for Site 1 .

Planting earlier might also have improved survival and growth.

\section{Site 2-07 Site Series:}

On the second site, unit 2 is comprised of an 07 site series, which is wetter than mesic and has a rich nutrient status (Figure 1). All of the stock types maintained at least minimum stocking levels at free growing (Figure 4). Figure 5 shows that stock types 415,211 , and $2+1$ all achieved the free growing minimum heights of 1.0 metre during the free growing assessment period.

\section{Unit 1 (04 site series) - Trees Achieving Free Growing}

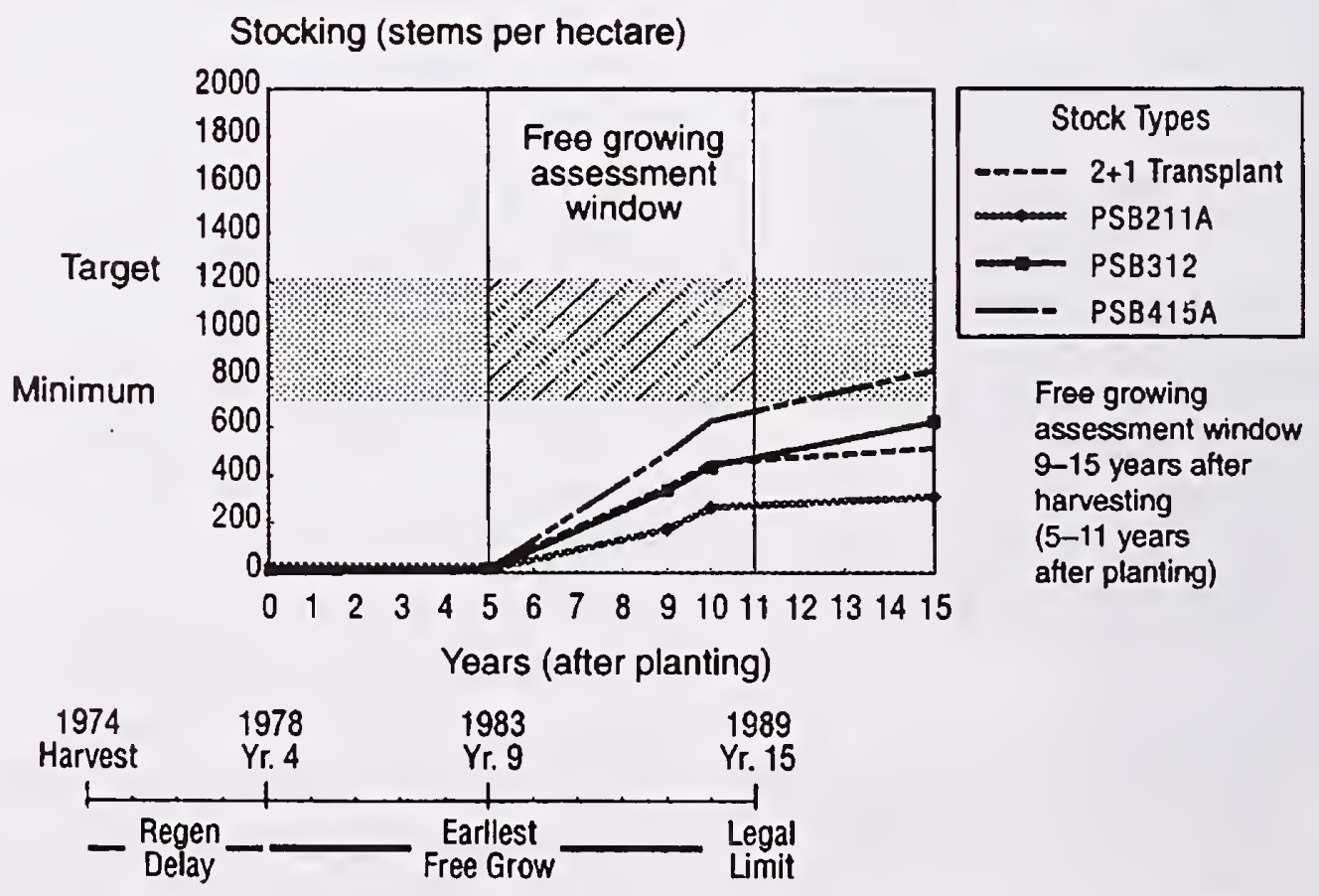

Figure 3. Number of surviving trees by stocktype and over time that have reached the minimum height requirement of 1.0 metres for the 04 association 
The PSB 415 stocking remained above the target number of trees as outlined in the prescription. This is a more expensive stock type than the PSB 312. Therefore, based on this result for this site series, a stock type prescription based on lowest cost (i.e., the site does not require the extra size of a 415 , or the initial planting density may have been reduced on the unit and still satisfied the free growing stocking requirements), could be made.

One point worth noting is that these stock types reached the minimum height requirement at different times. This information could have a major impact on a foresters initial stock type decision.

Trade offs can be made considering cost versus risk of plantation failure and are reflected in the following relationships:

- 211 reaches free growing at year 10 from planting - 312 reaches free growing at year 9 from planting, and - 415 reaches free growing at year 8 from planting.

On Site 2, it can be concluded that stock type selection on this association is not as critical in terms of survival and growth as it was on the 04 association, but may have an impact on the costs of establishment and the amount of time that a licencee carries the legal liability for free growing on the site.

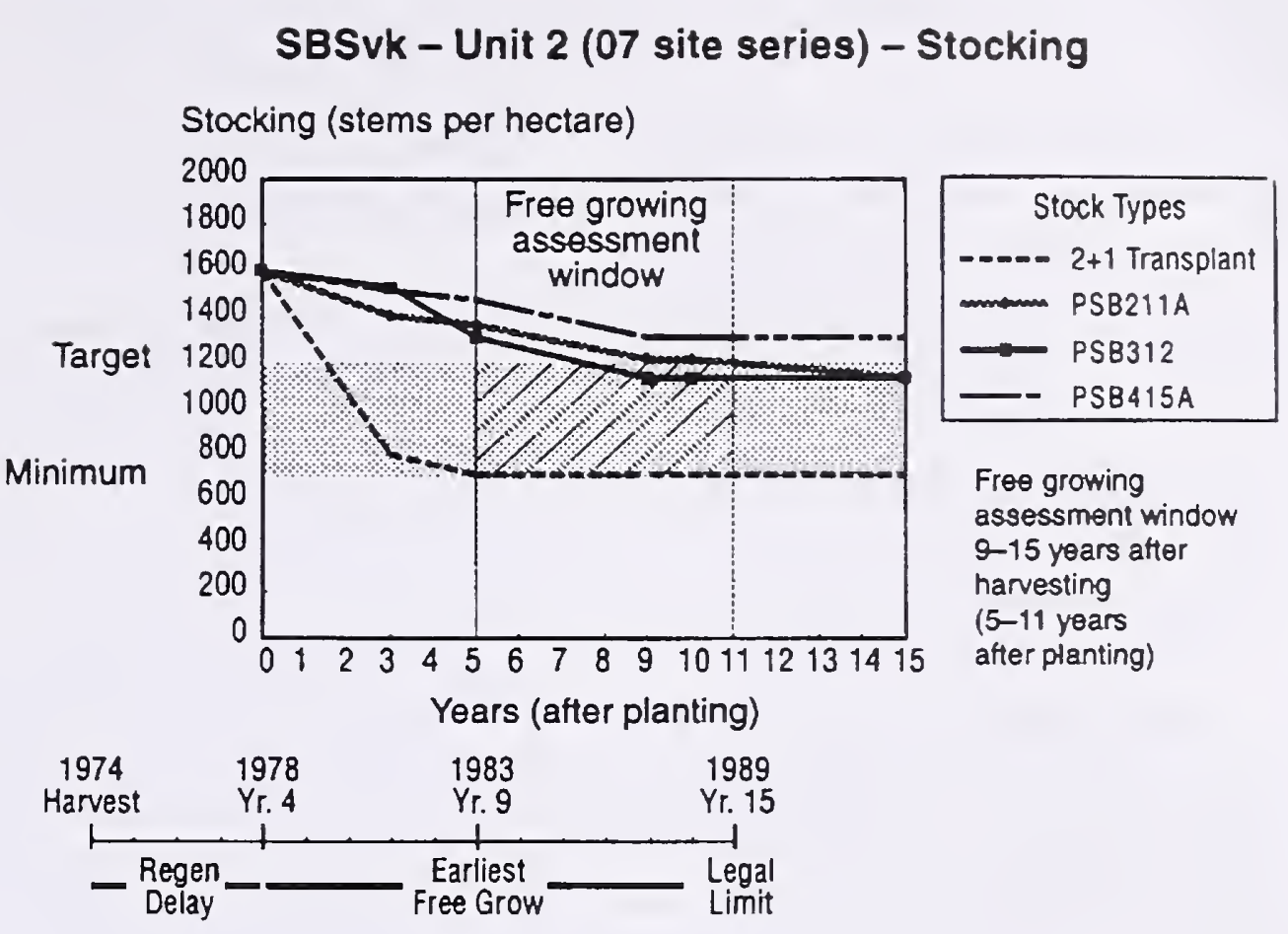

Figure 4. Stocking over time for four stocktypes on the 07 association.

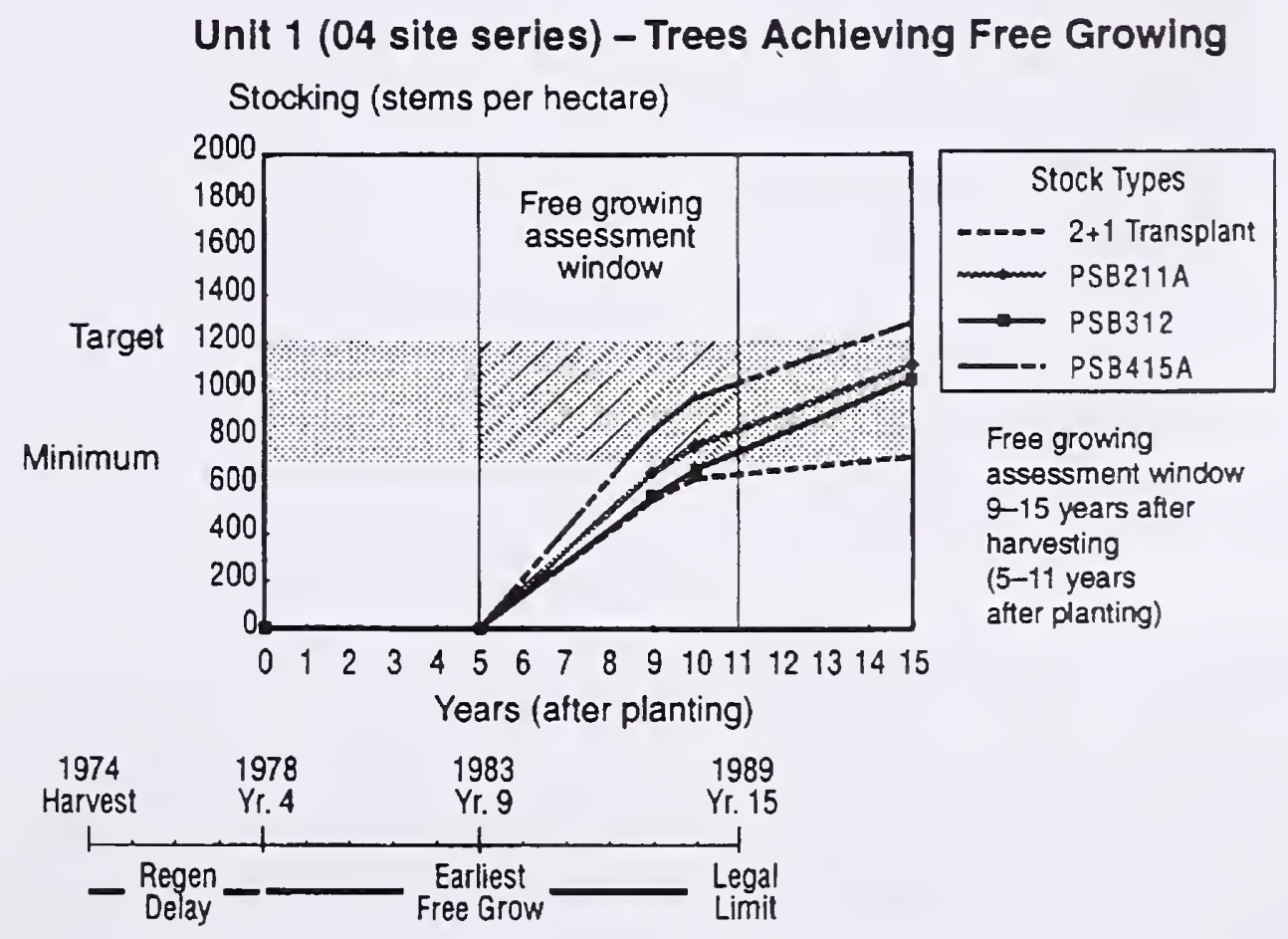

Figure 5. Number of surviving trees by stocktype over time that have reached the minimum height requirement of 1.0 metre on the 07 association (number of free growing trees). 


\section{CONCLUSIONS}

In British Columbia, planting prescriptions, of which a stock

type selection is an integral part, are ecosystem based with a series of legal standards tied to each ecosystem. Trial results such as these serve as a basis upon which to make a cost effective stock type decision.

On the Severeid site there are clear differences in the abilities of the stock types to produce a free growing crop.

Depending on the site conditions, certain stock types may not achieve the basic legal obligations of creating a free growing crop. This failure would result in additional costs for fillplanting or site preparation and planting. All options would require additional expenditure and hold the risk of penalties due to non-conformance with the prescription.

Achievement of free growing obligations can also be jeopardized by delaying planting.

Waiting four years allowed only a maximum of 11 years for those trees to grow to $1.0 \mathrm{~m}$. Results for unit 1 show that for this area of B.C. that was not enough time.

Other factors observed, but not tested for, have affected the results. One of the largest factors observed on these sites was microsite selection. Better microsite selection consistently resulted in an observed improvement in survival and growth.

A lot of factors influence seedling survival and growth but choice of stock type can be critical to plantation success. Given the stock type order the nurserygrower must produce the highest quality planting stock to the specifications set by the forester. Field performance and achievement of legal requirements depend on the stock being able to perform in the field. Delays or problems in stock quality, handling and other site factors may affect success as well. 


\title{
Container Optimization-Field Data Support Container Innovation ${ }^{1}$
}

\author{
David A. Bainbridge ${ }^{2}$
}

\section{INTRODUCTION}

Container planting is essential for successful revegetation or restoration of most dry sites. Therefore, one of the most important choices in developing a planting program is determining the container that best meets biological and bureaucratic requirements and will provide the maximum number of survivors in the field at minimal cost. The primary function of the container is to hold the growing medium, which supplies the roots with water, air, mineral nutrients, and physical support. Although surprisingly little research has been conducted on container considerations for dry sites since (Goor, 1963), evidence suggests that deeper (taller) containers may be beneficial (Bainbridge, 1987; Smith, 1988; Felker et al., 1988; Newman et al., 1990; Holden, 1992).
This study reviews the field experiences of the desert revegetation group at San Diego State University over the last 8 years with transplanted container plants. We have found that excellent seedling survival and growth can be expected even in areas with less than 3 inches [75 $\mathrm{mm}$ ] of rain per year if plants are well prepared and provided with minimal water (2-3 supplemental waterings totalling about 2 quarts) and protection (cages and/or treeshelters).

The most economical method for plant establishment has been outplanting seedlings from relatively small containers (Super-cells or plant bands) with a fast draining high sand content soil mix (limited or no fertilizer). Out-planting before tap root dominance is affected and roots are distorted (often within 3-6 weeks of germination) is desirable for smaller containers. At this stage, the primary leaves may be just emerging with a 12 " shoot and 10-12" roots. Plants should be hardened off in the nursery by gradually reducing water and increasing exposure to full sun before outplanting. Pruning the tops a week before transplanting may be helpful.

Planting dates should be based on plant species characteristics. Mid-summer may be hard on labor but well suited for plant survival and growth. Winter planting, at least for deciduous species such as mesquite, has been less effective. Spring planting appears to be most promising, especially if soil moisture has been recharged.

\section{BIOLOGICALCONSIDERATIONS}

Seedlings destined for dry sites are a root crop and survival on difficult sites is often deter-

'Bainbridge, D.A. 1994. Container Optimization_Field Data Support Container Innovation. IN: Landis, T.D.; Dumroese, R.K., tech. coords. National Proceedings, Forest and Conservation Nursery Associations. Gen. Tech. Rep. RM-257. Fort Collins, CO: U.S. Department of Agriculture, Forest Service, Rocky Mountain Forest and Range Experiment Statıon: 99-104.

²Biology Department, San Diego State University, San Diego, California 92182. 
mined by the ability of the root system to access soil moisture and generate new roots. Many of the containers we use are designed to encourage seedlings to form a good root system and to protect the roots while the seedling is planted. A high root:shoot ratio is desirable, and plants may be pruned before planting to improve this ratio.

The size of the seed or cutting, growth rate, disease sensitivity, temperature preferences and other environmental requirements of the seedling influence container choices. The desired size of the plant at planting, desired growth rate after planting, available irrigation methods and water quality, access to, and environmental conditions at the site all affect container options.

Although container type has traditionally referred simply to volume, it should also include shape. One of the most biologically important container dimensions is height (depth), because of its effect on the water-holding properties of the potting mix. The relation of height to width is the aspect ratio $(\mathrm{AR}=\mathrm{W} / \mathrm{H})$. Aspect ratios of common containers range from 0.14 to 0.85 . The emphasis on deep rooting leads to preference for containers that are tall but narrow.

Seedling size can be increased with larger containers. Containers for desert planting range from less than $10 \mathrm{in}^{3}\left(164 \mathrm{~cm}^{3}\right)$ to more than $850 \mathrm{in}^{3}(14,000$ $\mathrm{cm}^{3}$ ). Larger containers are more expensive to buy and fill, take up more growing space, require longer growing periods for the seedling root system to effectively occupy the container, and are difficult and more costly to handle in the nursery, during shipping and when planting.

While almost any soil mix can work with sufficient attention to water and nutrient management, the key is finding a mix that requires as little attention as possible. Species that tolerate a wide range of soil conditions may require little customizing, but species that are more sensitive can require careful mix development and nursery management. We have found that sand with some perlite or pumice is often a good starting point for desert shrubs.

Growth media in deep containers and containers with a high aspect ratio has different physical properties, water relations, and porosity than in traditional shallow containers. Soil mixes may need to be adjusted to compensate for these changes. Nutrient and water availability should also be tested for different media compositions.

Most species are mycotrophic (Allen, 1991) and pre-inoculation with mycorrhizal (ecto or
VAM) fungi is recommended for planting on large scale, severely disturbed sites where native inocula are likely to be limited. Experimentation may be necessary to develop growth media appropriate for the plant, its microsymbionts, and container characteristics. The VA mycorrhizal fungi are oxygen demanding and often phosphorus sensitive.

Excessive root temperatures (hot or cold) can inhibit or kill roots and root symbionts.

Darker colored containers may reach surface temperatures above $160 \mathrm{~F}$ in the summer in the low desert. Plant bands, which are assembled with heat set glue, can melt and delaminate unless seams are placed to the inside of blocks.

\section{BUREAUCRATIC CONSIDERATIONS}

The potential for delays in delivery, acceptance date, and irrigation and maintenance scheduling must be considered. Cost and availability of the container, soil mix, irrigation, cost of handling and planting, and available growing space are also important. Container seedling quality commonly increases with decreased growing densities so a nursery manager often struggles to minimize spacing without reducing health. Developing a vigorous and 
resilient seedling is critical because survival in the field is the primary goal.

Racks with individual cells are desirable because they can be readily sorted. This is particularly important with poorly understood plant species or low quality seeds. Diseased or otherwise undesirable seedlings and non-filled cells can be removed or replaced. When matched cohorts are needed for experiments these can be selected. Consolidation also saves space in the greenhouse and during storage and shipping.

\section{CONTAINER COMPARISONS}

The best container to use depends on the season, the handling process, the species, and the project. One of the most important considerations is determining which size and depth is most cost-effective, providing the lowest cost per survivor. Bigger containers will be more expensive, both to grow and plant; but may improve survival significantly.

\section{Supercells}

We have extensive experience with the ten cubic inch Supercell (from Stuewe and Sons). They are relatively easy to fill, sort, ship and plant. However, the rigid plastic trays that hold the cells are relatively fragile and easily damaged if they are repeatedly handled while loaded with seedlings. A Supercell weighs approximately $1 / 2$ pound when it is full of sand. A rack of 98 is too heavy for field work and cells are usually transferred to a 5 gallon bucket (with internal rack) which makes handling easier and provides protection from wind and sun.

Seedlings are removed from containers by gently squeezing the supercell or rapping the top of the cell on a hard surface (using momentum to dislodge the plant/soil). Plants with fragile roots can be more gently removed by kneading the cell under water. In general, the sandy soil mixes falls away from the plant and the seedling is effectively bare-rooted.

An experienced planting crew of three (students and desk bound researchers) can plant 150-225 plants per day under typical field conditions using KBC bars. This includes hauling water, watering, and placing grazing protection on the plants. Production decreases rapidly when air temperature exceed $100 \mathrm{~F}$. Inexperienced volunteer teams may plant only half as many plants per day.

Estimated planting cost runs from $\$ 0.50$ to $\$ 5.00$ each depending on species characteristics, number of plants and site characteristics. Total planting costs (after two waterings) may be as high as \$5-10 dollars for each Supercell (including plant cost, planting, plant protection, labor for watering, and administrative costs).

We like Supercells for predictable planting programs where delay is unlikely. Seedlings for some species should be outplanted in 8-12 weeks.

\section{Plant bands}

Plant bands are square tubes made with folded and glued plastic or foil coated cardstock. Standard sizes are available for small orders, but virtually any size can be custom made for larger orders. A wide range of plant band sizes have been tested with generally positive results (up to $3 " x 3 " x 24 "$ inches). Taller plant bands improved survival on a harsh site at Red Rock Canyon State Park, Figure 1. Unfortunately, rabbits learned how to kick over treeshelters and terminated this experiment before the searing dry heat of summer.

Plant bands can be placed on screen, filter fabric or paper. They can be grouped on pallets and banded or set in boxes or beverage crates. They can be stapled together at the top to make filling easier. Although they are discrete units, the loose soil mix we use makes sorting and repacking plant bands difficult.

Plant bands 2"x2"x14" weigh about 2 pounds each and are usually racked in groups of 30 and broken into groups of 3-5 for 


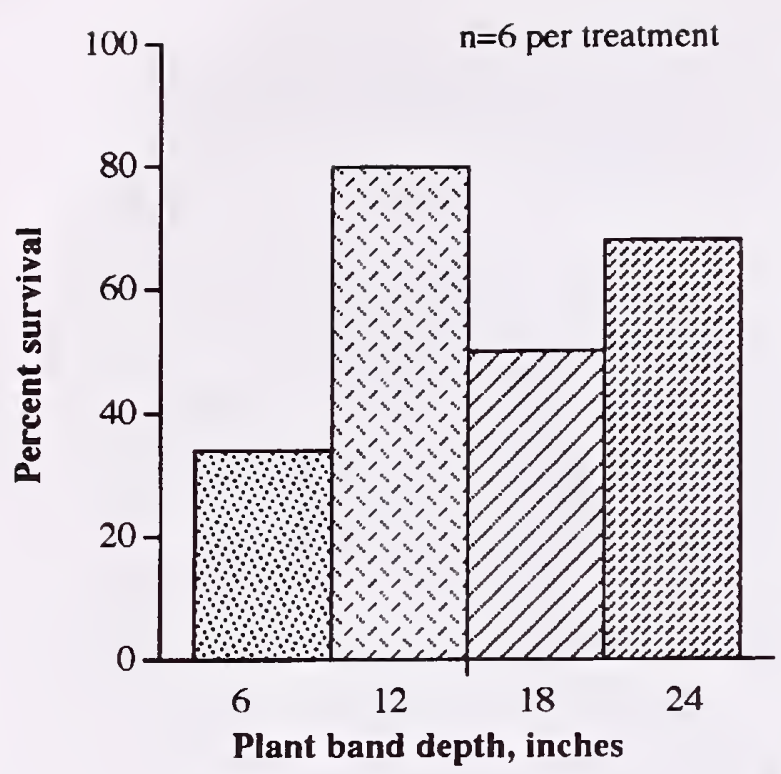

Figure 1. Creosote bush from plant bands, 120 days on a very severe site.

planting. Planting holes are drilled with a drill bit on a gas powered auger (Cannon ${ }^{\mathrm{TM}}$ ). With larger sizes (>2"x2") and a loose mix the plant band can be pulled up over the plant after placing the seedling in the wetted, augered hole. For cohesive soil mixes, root bound plants, and smaller size plant bands, the cardboard should be ripped or cut open. A hooked blade in a razor knife works well The opened cell can be held together as it is placed in the planting hole, which is backfilled loosely as the paper is pulled up. These can often be planted faster than supercells.

Plant bands have been very effective in semi-arid sites (Felker et al., 1988). We feel these are the most flexible and economical containers. A 12$16^{\prime \prime}$ tall, 2-2.5" square cell seems most useful. Plants may be held for more than a year in larger plant bands.

\section{Pipe sections}

Plants have been grown in plastic pipe sections ranging from $3 / 4 " x 30$ " to $6 " x 32 "$. Plant removal is difficult with smaller diameters, and if the pipe must be sawed open it becomes expensive. This has been done in the field with a battery powered circular saw and in the nursery with a larger circular saw. In Australia they used split pipe tied together (Newman et al., 1990), much like the wired lath containers Smith (1950) described. W'ith smooth-walled PVC pipe no cutting is required for most soil mixes. With rougher textured plastic, like drain pipe, the roots become entangled with the plastic container wall. The Center for Arid Lands Restoration at Joshua Tree National Monument has pioneered the development of a Tall Pot made with 32 inch tall, 6 inch diameter PVC pipe (Apache 2729) with a wire mesh base held in by cross wires (Holden, 1992; Rogers, this volume).

The screen at the bottom of the container is removed just before planting. The walls of the pipe are rapped with a hammer to loosen the mix and the container is gently placed in an augered, prewetted hole and partially back-filled. The container is then pulled out (as backfilling continues) by hand or hay hooks inserted in two holes drilled in the top rim. The large volume of soil protects the roots during planting and the fertilizer and water provide conditions for rapid root growth.

Tall pots weigh $30-40$ pounds per container and a large wheeled dolly or handcart is desirable. Planting holes are drilled with a 6 inch bit in the Cannon $^{\mathrm{TM}}$ auger or dug with a post hole digger. A planting crew of 5 people can plant 50 plants per day under average conditions (10 plants per person per day). Planting rates can be much slower in rocky ground. The cost per plant is high ( $\sim 10$ 25 at the nursery gate), but survival is generally excellent and rapid growth is common. Creosote bush (Larrea divaricata) for example, may be 3 feet tall one year after outplanting. Survival on a south facing sandy slope in the low desert from plant bands with several soil mixes is contrasted with tall pots in Figure 2.

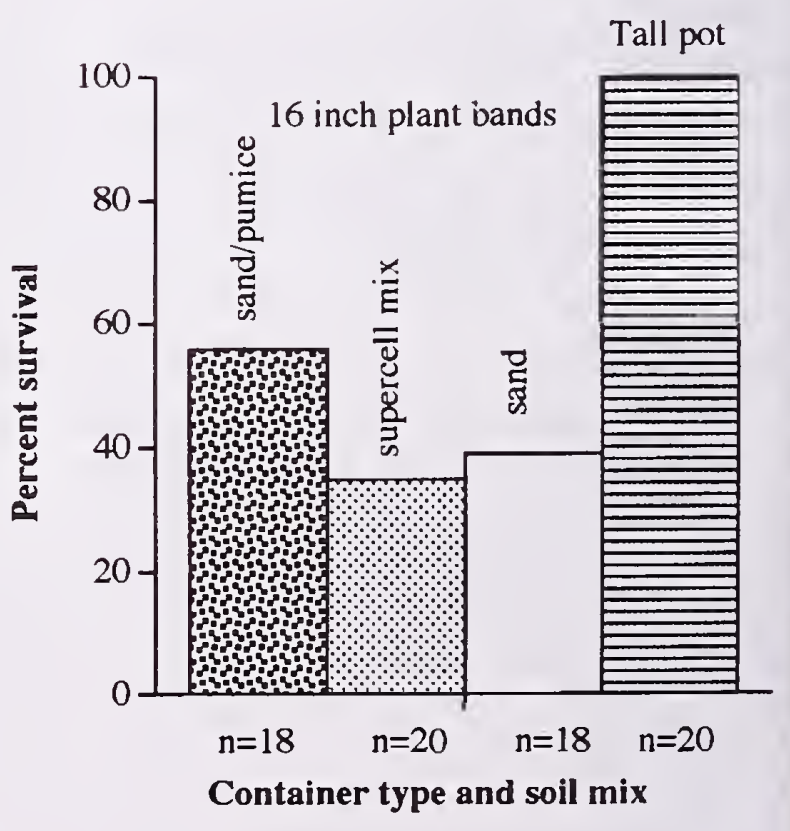

Fig̣ure 2. Creosote bush from plant bands and tall pots after 1 year. 
The L.A. Moran Reforestation Center in Davis, California has developed a 4"x24" smoothwall pipe pot. These Mini-tall pots weigh one third and cost less than half as much as standard tall pots. They should retain many of the advantages of Tall pots while significantly reducing cost and bulk.

Pipe sections are highly recommended for a percentage of total plants for all harsh sites. Tall pots provide a very tough plant with potential for very fast growth. Excellent protection from bureaucratic and biological uncertainty. Container optimization

Table 1. Container planting rate.

Container

Supercell

Supercell jellyroll

Plant band $2 \times 2 \times 14$

1 gallon pot

2 gallon pot

Tall pot

$50-100$ if container must be torn off.

Planting seedlings is an essential part of most revegetation and restoration projects. Planting rates and costs depend on temperature, labor, soil moisture, and site conditions. Typical planting rates for remote sites, hand carried plants, including water, watering and plant protection with academic planting crews are outlined in Table 1.
Container grown seedlings are heavy and awkward to ship and handle in the field, making outplanting expensive (Bainbridge and Virginia, 1990). Removing the seedlings from their containers at the nursery and wrapping them in moist fabric (a technique known as jellyrolling) can make handling less costly. An ice chest holding several hundred jellyrolled plants may weigh only 40 pounds. Planting is faster than from containers and survival compares favorably to containerized plants (Fidelibus, 1994). Jellyrolling may not work as well for species with brittle or easily torn fine roots.

\section{COST PER SURVIVOR}

Costs are commonly underestimated in planning and reviewing projects. Planting small plants in urban areas may cost more than $\$ 15$ each if administration and maintenance costs are included. More accurate cost estimates make it possible to determine the best approach for planting on the basis of cost per survivor. Estimates of these costs are shown in Table 2 for small projects on remote sites. Tree planting crews and larger projects may reduce cost $50 \%$ or more.

\section{SUMMARY AND CONCLUSION}

The smallest container that will work is usually the most cost effective. Under ideal conditions, Supercells can be very successful. In uncertain biological or bureaucratic environments deeper containers such as plant bands (2"x2"x14") are better. Tall pots (6"x32") will have excellent survival and rapid growth even in very difficult conditions. This can be very beneficial when quick visual recovery is important.

Although there is no one container or production system suitable for all conditions and species, seedlings grown in deeper containers improve survival and growth. The cost for 500 surviving plants per acre

Table 2. Container stock, nursery and field (typical).

\begin{tabular}{|c|c|c|c|}
\hline Container & $\begin{array}{l}\text { Cost } \\
\text { nursery }\end{array}$ & $\begin{array}{l}\text { Percent } \\
\text { survival }\end{array}$ & $\begin{array}{l}\text { Relative } \\
\text { cost (plant band }=1 \text { ) }\end{array}$ \\
\hline Supercell & $0.10-1.50$ & 30 & 1.5 \\
\hline Supercell jellyroll & $0.12-1.70$ & 30 & 1.4 \\
\hline Plant band $2 \times 2 \times 14$ & $1.50-3.50$ & 70 & 1 \\
\hline 1 gallon pot & $3.00-5.00$ & 10 & 2 \\
\hline 2 gallon pot & $5.00-10.00$ & 15 & 2.5 \\
\hline $4 \times 24$ Minitall pot & $3.00-5.00$ & 80 & 1.5 \\
\hline $6 \times 32$ Tall pot & $9.00-25.00$ & 95 & 3 \\
\hline
\end{tabular}


can range from $\$ 5-10,000$.

Costs for Tall pot plantings required for fast visual recovery can exceed $\$ 40,000$ acre $^{-1}$. A combination of small through large containers can be used to maximize survival at reasonable cost. This might include 10\% tall pots $(32 \times 6), 20 \%$ mini-tall pots (4x24), $40 \%$ plant bands (2x2x14) and $30 \%$ supercells. At the end of one year in the field the sizes of shoots might be expected to be 4-6 inches for a supercell, 12 inches for plant band, 15 inches for a pipe pot, and 24 inches from a tall pot. This provides a wide range of resilience and survivability. Multiple size classes and more diverse plant architecture can be both biologically and aesthetically important.

\section{ACKNOWLEDGMENTS}

Special thanks to Matt Fidelibus, Robert MacAller, Tom Zink, and Debbie Waldecker, SDSU; Ross Virginia, Dartmouth; Bill Nickels and Laurie Lippitt, California Department of Forestry; Pam Beare, California Department of Transportation; Tom Landis, US Forest Service; Ray Franson, Viceroy Gold/Castle Mountain Mine; Mark Holden, Bob Moon, and Carol Miller, Joshua Tree National Monument; Mark Faull, John Crossman, and Ronie Clark, California State Parks; and Scott Messersmith, Borrego Valley Growers.

\section{REFERENCES}

Allen, M.F. 1991. The Ecology of Mycorrhizae. Cambridge, NY 184p.

Bainbridge, D.A. 1987. Deep containers for revegetation in dry environments. poster presented at the Second Native Plant Revegetation Symposium, SD CA April 1518. reprinted Dry Lands Research Institute, UC Riverside $2 \mathrm{p}$.

Bainbridge, D.A. and R.A. Virginia. 1990. Sonoran Desert Restoration. Restoration and Management Notes. 8(1):3-14.

Felker, P., C. Wiesman and D. Smith. 1988. Comparison of seedling containers on growth and survival of Prosopis alba and Leucaena leucocephala in semi-arid conditions. Forest Ecology and Management 24:177-182.

Fidelibus, M. F. 1994. Jellyrolls reduce outplanting costs in arid land restoration. Restoration and Management Notes. 12(1):87.

Goor, Y.A. 1963. Tree planting practices in arid zones. FAO Forestry Dept. Paper \#16. United Nations, Rome 233p.

Holden, M. 1992. The greening of a desert. American Nurseryman 4/15:22-29
Landis, T. 1990. The Container Tree Nursery Manual. USDA Handbook 6745 volumes.

Newman, R., S. Neville, and L. Duxbury. 1990. Case Studies in Environmental Hope. EPA Support Services, Perth, Australia.

Smith, J.R.S. 1988[1950]. Tree Crops. Island Press, Covelo, CA p. 62. 


\title{
Nursery Growing Density and Container Volume Affect Nursery and Field Growth of Douglas-fir and Lodgepole Pine Seedlings 1
}

\author{
David G. Simpson²
}

Abstract-Douglas-fir and lodgepole pine were grown for a single growing season (24 - 28 weeks) in containers that varied in cell volume from 45 to $120 \mathrm{~mL}$, and at nursery growing densities of 64 to 1111 seedlings per square meter (seedling growing space 9 to $156 \mathrm{~cm}^{2}$ ). Seedlings grown in $45 \mathrm{~mL}$ containers were consistently smaller (shorter; smaller root collar diameter; less dry weight) than seedlings grown in larger (57 - $120 \mathrm{~mL}$ ) containers. At greater nursery growing densities, seedlings were taller, with smaller root collar diameters, and with less root, stem, and foliage dry weight. Maximum crop biomass ( $1.4 \mathrm{~kg}$ per square meter) and maximum seedling basal area production $\left(0.4 \mathrm{~mm}^{2}\right.$ basal area $/ \mathrm{cm}^{2} \mathrm{growing}$ space) was reached at growing densities of aprox. 600 seedlings per square meter. Field growth for 3 years (lodgepole pine) or 4 years (Douglas-fir) suggests that seedlings widely varying in size at planting, grew at similar relative growth rates thus preserving the size ranking of nursery treatments. Comparing the growth of treatments with the smallest and largest seedlings, suggests there is less than a single year time difference for stock to reach a similar size.

\section{INTRODUCTION}

The growing density at which forest tree nurseries grow planting stock has obvious and significant effects on both the cost of growing and the size of the stock. When planting stock is grown in containers, reductions in nursery growing density are usually accompanied by an increase in cell volumes, thus the effects of density and cell volume are often not considered separately. It is widely held that as the growing space avaliable to each plant increases (growing density decreases), larger plants will result. In the production of forest nursery stock, larger size is often equated with an increased morphological quality. It is very common for forest nurseries to grow seedlings and often cull crops to meet some morphological targets thought important by their customers. It is therefore clearly important for nursery managers to understand how both nursery growing density and cell volume affect the growth of their crops. This enables them to produce as many seedlings as possible exceeding the morphological cull levels at the lowest cost. It is equally important for reforestation foresters to know how the field performance potential of planting stock is affected by its physical size (ie. morphological quality) at planting.

This paper thus has the dual objective of firstly examining how nursery growing density and cell volume affects the growth of planting stock in the

'Simpson, D.G. 1994. Nursery Growing Density and Container Volume Affect Nursery and Field Growth of Douglas-fir and Lodgepole Pine Seedlings. IN: Landis, T.D.; Dumroese, R.K., tech. coords. National Proceedings, Forest and Conservation Nursery Associations. Gen. Tech. Rep. RM-257. Fort Collins, CO: U.S. Department of Agriculture, Forest Service, Rocky Mountain Forest and Range Experiment Station: 105-115.

${ }^{2} B C$ Ministry of Forests, Kalamalka Forestry Centre, Vernon BC CANADA V1B 2 C7 Phone: 604-549-5678; Fax: 604-542-2230; Internet-DSIMPSON@GALAXY.GOV.BC.CA 
nursery, and secondly examining how batches of stock of different sizes (due to the nursery treatments) grow in the field following planting (ie. their field performance potential).

\section{METHODS}

\section{Douglas-fir}

Stratified Douglas-fir seed (BC Ministry of Forests registered seedlot 1374) was sown into standard or modified seedling trays used in the production of container-grown forest planting stock. On April 10, 1989 one replicate of the 15 container volume - growing density treatments (Table 2) was sown, and one month later (May 9,1989) two additional replicates of the 15-treatments were also sown. The seedling trays were placed into a glasshouse at the Kalamalka Research Station with daylengths extended to 20 hours and temperature of $20 \mathrm{C}$. Begining on May 1 (April 10th sown seedlings) and May 29 (May 9th sown seedlings), the seedlings were fertilized 2-3 times each week with 9-45-15 to provide $\mathrm{N}$ at $50 \mathrm{ppm}$. On May 26 (April 10th sown seedlings) and on June 21 (May 9th sown seedlings) the fertilizer was changed to 20-20-20 to provide $\mathrm{N}$ at $100 \mathrm{ppm}$. On June 29 the seedlings sown April 10 were moved out-of-doors under extended daylength (20 hours) and natural temperature conditions. From September 1 all seedlings were exposed to a natural photoperiod. Temperature in the greenhouse was maintained near 20C until Oct 11 when it was lowered to $15 \mathrm{C}$ during the days and $10 \mathrm{C}$ at night. On Nov 7 the greenhouse temperature was further lowered to 7C. Fertilization was changed to 9-45-15 on Sept 1 (outside) or Sept 6 (greenhouse) providing $\mathrm{N}$ at $50 \mathrm{ppm}$. In early-December, the seedlings out-of-doors were lifted to cold $(-2 \mathrm{C})$ storage, and between Jan 30 and Feb 28, 1990 the greenhouse grown seedlings were lifted to storage.

From each treatment 150 seedlings (50 per replicate) were outplanted in the field at Miriam Creek April 23-25, 1990. The outplanting site is in the Interior Cedar Hemlock - Shuswap Moist Warm (ICH-mw2) biogeoclimatic sub-zone (Lloyd et al 1990) at an elevation of $800 \mathrm{~m}$. The site is sloped $(5-15 \%)$ with a sandy loam soil and had been clearcut logged in 1988 with the logging debris piled and burnt the same year. The height and stem diameter at root collar of all seedlings were measured at lifting. In addition, the root, foliage and stem dry weights of 45 seedlings from each treatment were measured at lifting. At planting in April 1990 and at the end of the first growing season (Oct 12-13,1990), the height of each planted seedling was measured. Stem diameter at the root collar was not measured at planting, nor at the end of the first growing season. The second (1991), third (1992), and fourth (1993) growing season heights and stem diameters at root collar were measured for all surviving seedlings.

\section{Lodgepole Pine}

Stratified Lodgepole pine (BCMoF registered seedlot 3130) was sown May 7-10,1990 into the 15 container volume and spacing treatments. There were three replications of each treatment consisting of two to four seedling trays. The seedling trays were placed out-of-doors at the Kalamalka Research Station, Vernon BC $(50 \mathrm{~N})$ and the first germinates were observed by May 22nd. Fertilization began June 11 with 9-45-15 being applied at a concentration to provide $75 \mathrm{ppm}$ N. Fertilization was applied two to three times each week. One June 25 the fertilizer was changed to 20-1918 and applied to provide 50 ppm N. Trace elements were applied as STEM at $5 \mathrm{ppm}$. On August 8, due to cool wet weather the seedlings were transfered to a glass house where the natural daylength was extended to 16-hours with high pressure sodium lights (minimum PPFD $200 \mathrm{umol} / \mathrm{m}^{2} / \mathrm{s}$ ) and temperatures were maintained between 15 and 30C. Seedlings were grown under glasshouse conditions until November 7 , whereafter they recieved natural daylengths. Fertilization was terminated on November 13, and on December 14 the glasshouse 


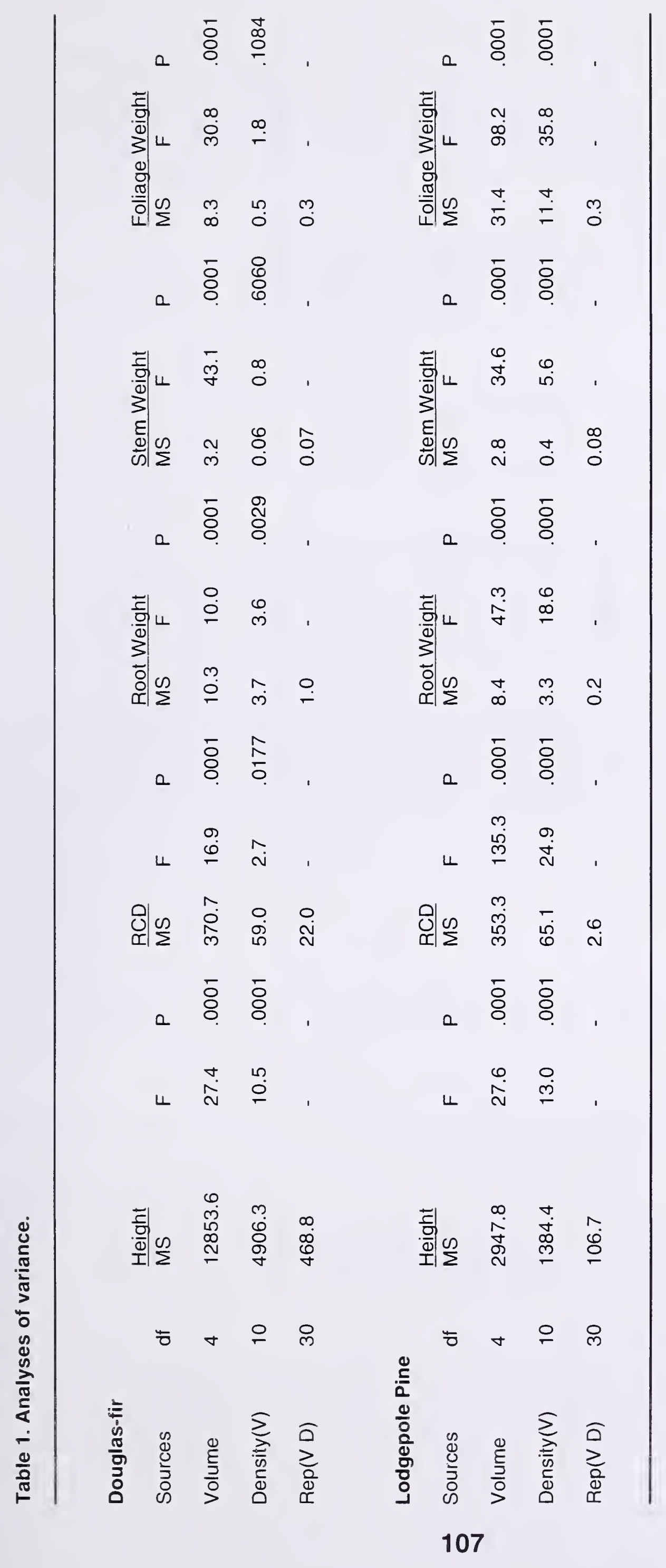




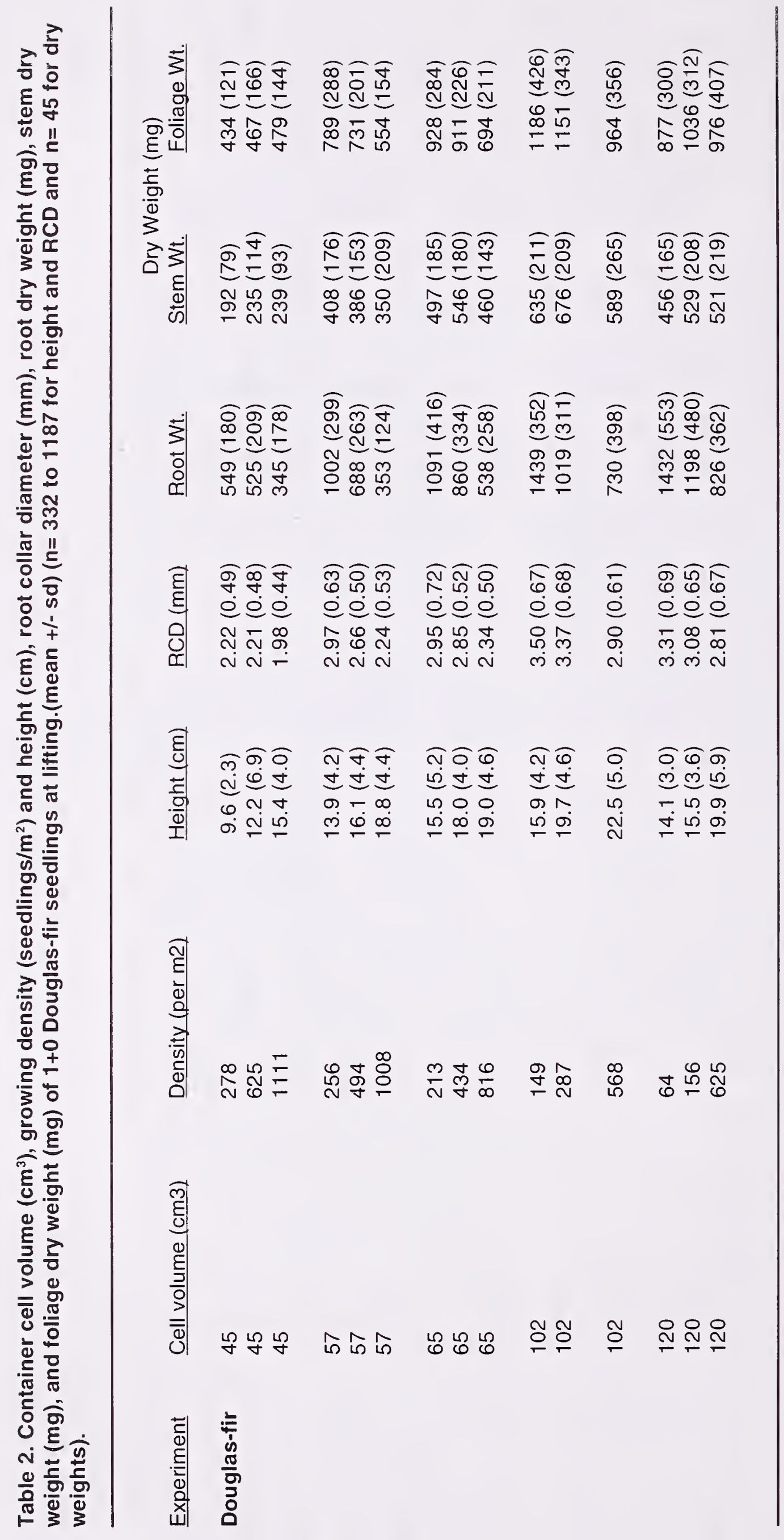


temperature was lowered to $+2 \mathrm{C}$. Seedlings were measured (height, stem diameter at root collar, shoot dry weight, root dry weight) and lifted to cold (-2C) storage January 8-17, 1991.

Outplanting of the seedlings was done May 21-23, 1991. The outplanting site is in the Interior Cedar Hemlock - Shuswap Moist Warm (ICH-mw2) biogeoclimatic sub-zone (Lloyd et al 1990 ) at an elevation of $1100 \mathrm{~m}$. The site is flat with a sandy-loam soil and had been clearcut logged in 1989 and mechanically site prepared in 1990. On June 14,1991 (aprox. three weeks following planting) the heights and stem diameters at root collar of the planted trees were measured (normally these measurements are taken at the time of planting, however due to funding and staff limits the measurements were delayed). Heights and stem diameters at root collar after the first (1991), second (1992), and third (1993) growing seasons were measured for surviving seedlings.

\section{DATA ANALYSIS}

The height and stem diameter at root collar of all seedlings were measured and subject to ANOVA with factors of Cellvolume, Density (Cellvolume), and Rep (Cellvolume Density). The root, foliage and stem dry weights of 45 seedlings from each treatment

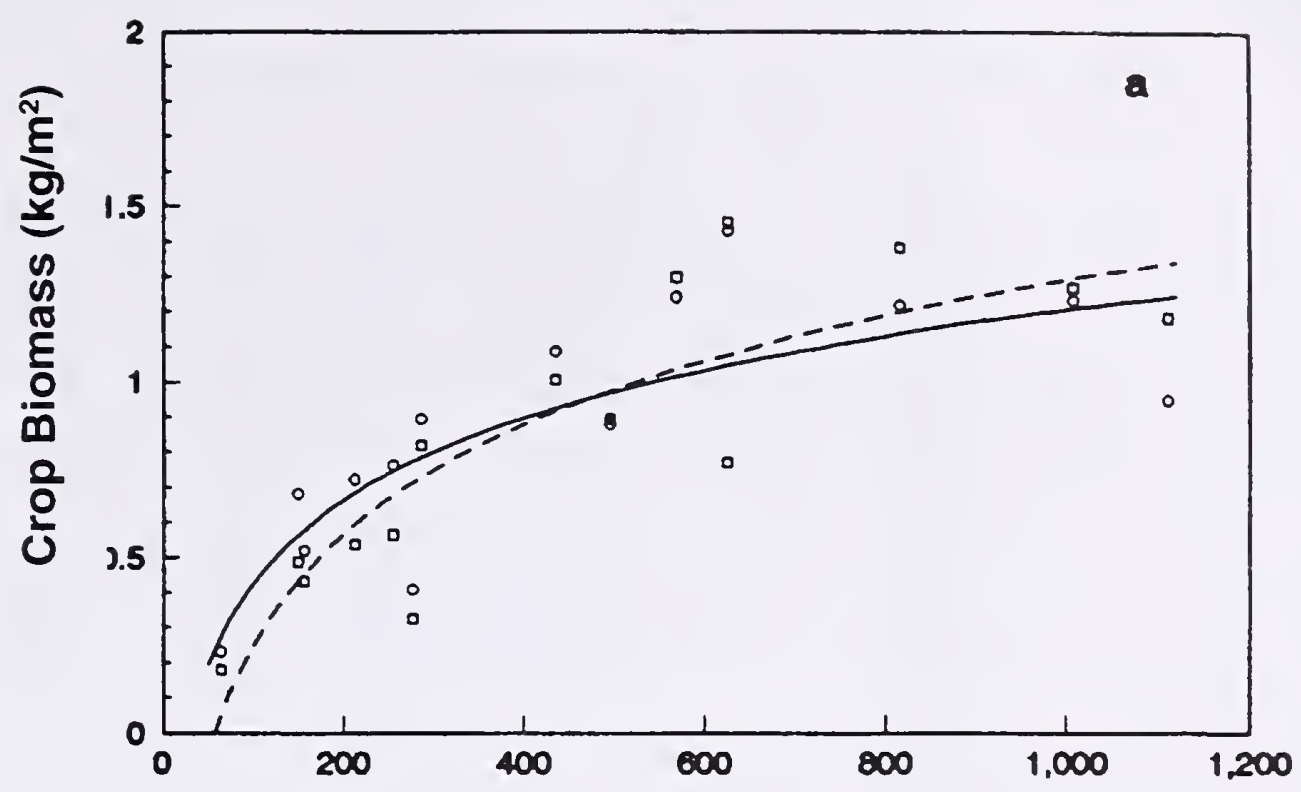

Lodgepole Pine $\longrightarrow$ Douglas Fir ---

Nursery Growing Density (seedlings $/ \mathrm{m}^{2}$ )

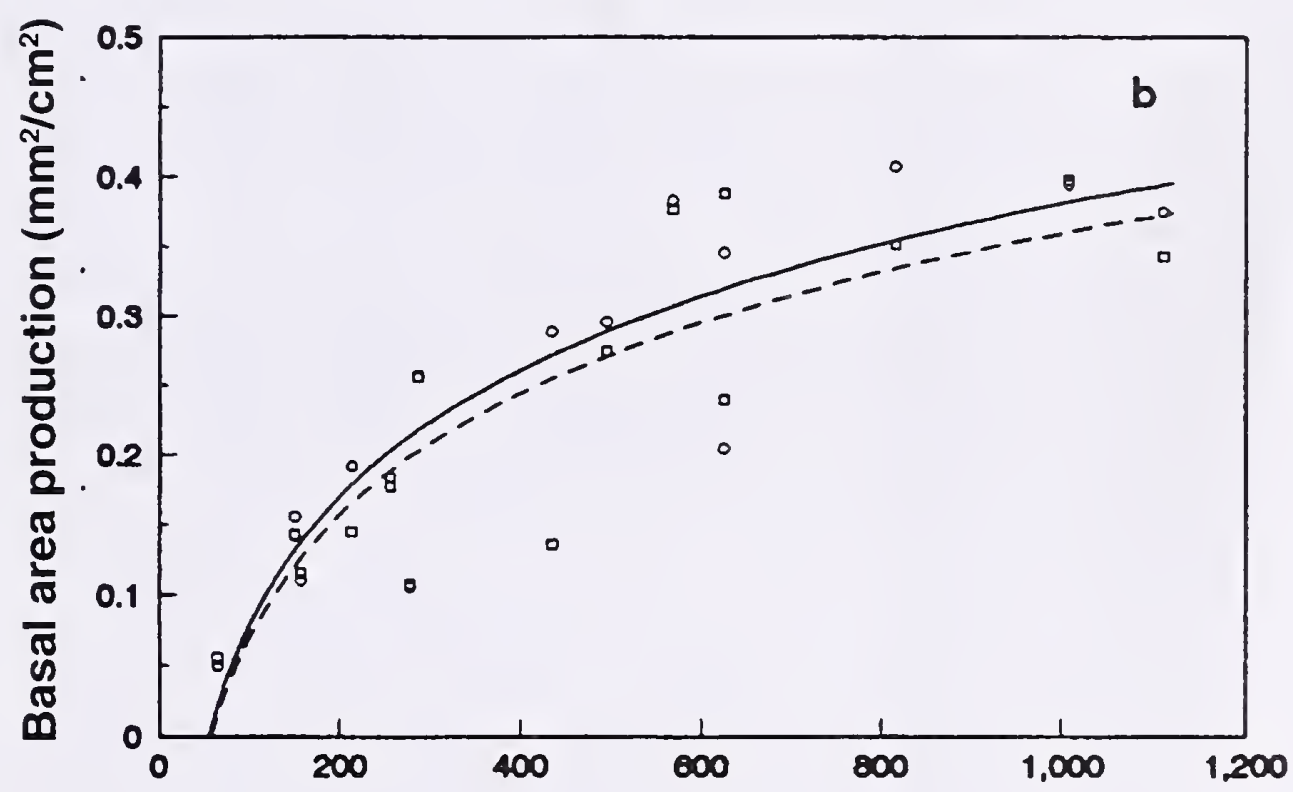

Lodgepole Pine — Douglas Fir - - -

Nursery Growing Density (seedlings $/ \mathrm{m}^{2}$ )

Figure 1. Effect of nursery growing density on (a) crop biomass and (b) stem basal area production of Douglas-fir and Lodgepole pine 


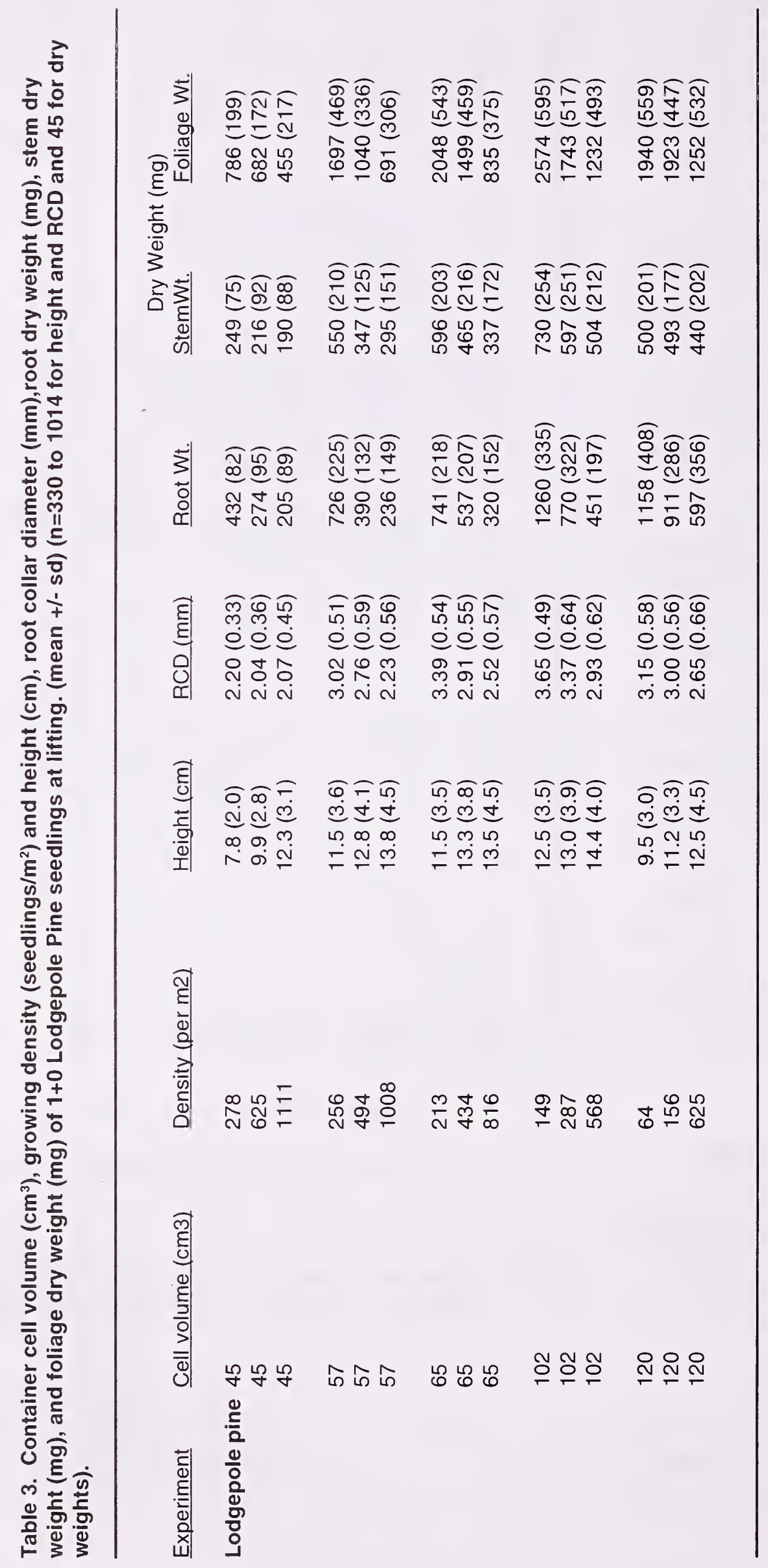


were subject to ANOVA with the same design.

The height and stem diameter of surviving field planted seedlings measured at planting and after each growing season were used to calculate for each seedling a stem volume estimate ( $\mathrm{vol}=1 / 3 *$ basal area $*$ height). The mean annual stem volume relative growth rates (RGR) of each seedling for each growing season was calculated as:

$R G R=\operatorname{Ln}(v o l+1 y r)-\operatorname{Ln}(v o l)$

All field data were subject to ANOVA using the factors Cellvolume, Density (Cellvolume) and Rep (Cellvolume Density).

\section{NURSERY RESULTS}

\section{Douglas-fir}

Both nursery growing density and container volume affected the height, root collar diameter and root dry weight of Douglàsfir seedlings (Table 1). However, only container volume affected stem and foliage dry weights. The design of the experiment does not allow statistical evaluation of interactions between nursery growing density and container volume. However, examination of the data (Table 2) suggests that irrespective of nursery growing density, seedlings grown in the $45 \mathrm{~mL}$ containers were consistently smallest. Likewise, seedlings grown in the $102 \mathrm{~mL}$ containers were generally the largest. Seedlings grown at greater nursery densities were taller, and had smaller root collar diameters and root dry weights. On a crop basis, total crop biomass increased with nursery growing density reaching a maximum of $1.4 \mathrm{~kg}$ dry weight $/ \mathrm{m}^{2}$ at a growing density of 600 seedlings $/ \mathrm{m}^{2}$ (Figure 1-a). Similarly, seedling stem basal area reached a maximum of $0.4 \mathrm{~mm}^{2} / \mathrm{cm}^{2}$ of growing space at a nursery density of 600 seedlings $/ \mathrm{m}^{2}$ (Figure 1-b).

\section{Lodgepole Pine}

Both nursery growing density and container volume affected the height and root collar diameter as well as the root, stem and foliage dry weights of Lodgepole pine seedlings (Table 1). Seedlings grown in $45 \mathrm{~mL}$ containers were consistently smallest, while seedlings grown in 102 or 120 $\mathrm{mL}$ containers were generally largest (Table 3). Seedlings grown at greater nursery densities were taller, and had smaller root collar diameters, as well as smaller root, stem and foliage dry weights. On a crop basis, both total crop biomass and seedling stem basal area increased reaching maximums of $1.4 \mathrm{~kg} / \mathrm{m}^{2}$ and $0.4 \mathrm{~mm}^{2} / \mathrm{cm}^{2}$, respectively, at a nursery density of 600 seedlings $/ \mathrm{m}^{2}$ (Figure 1-b). 


\section{FIELD RESULTS}

\section{Douglas-fir}

In the four growing seasons following planting, seedling height and root collar diameter increased (Figures 2-a, and 2-b). Although the stem volume increased substantially, the stem volume ranking of seedlings from the various treatments did not change over the four years (Figure 2-c) because for each year the annual mean relative growth rate for large and small seedlings were not different. The annual mean relative growth rates (the slope of Figure 2-c) were 1.03 and $1.04 \mathrm{~cm}^{3} / \mathrm{cm}^{3} / \mathrm{yr}$ for the third and fourth growing seasons, respectively.

\section{Lodgepole Pine}

Over the three growing seasons following planting the seedling height and root collar diameter increased (Figures 3-a, and 3-b). However as the annual mean stem volume relative growth rates of large and small seedlings were not different, the stem volume ranking over the three years did not change (Figure 3-c). The annual mean relative growth rates (the slope of Figure 3-c) were $0.98,1.65$ and $1.92 \mathrm{~cm}^{3} / \mathrm{cm}^{3} / \mathrm{yr}$ for the first, second and third growing seasons.
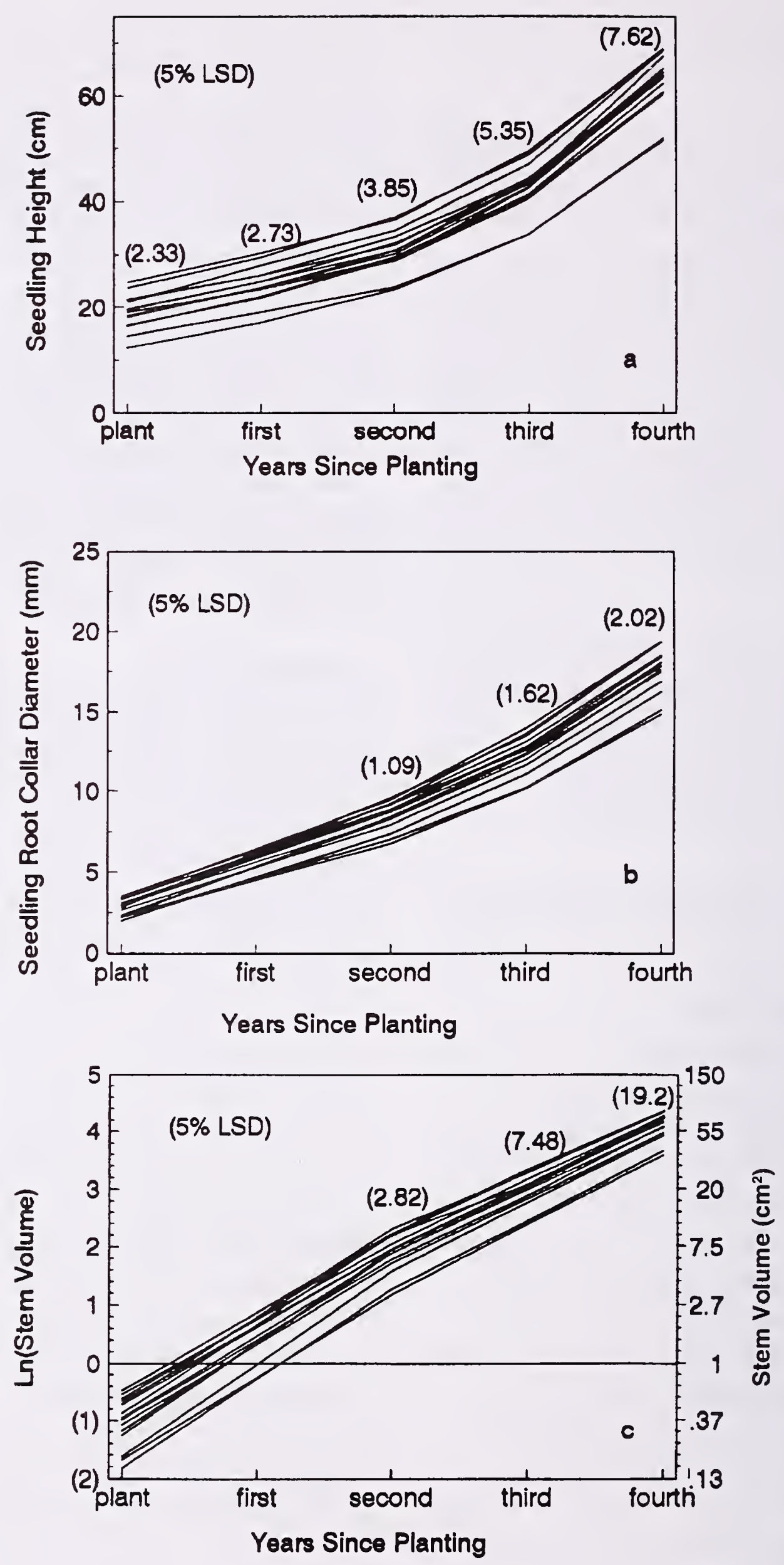

Figure 2. Field height (a), root collar diameter (b) and stem volume (c) of Douglas-fir seedlings 

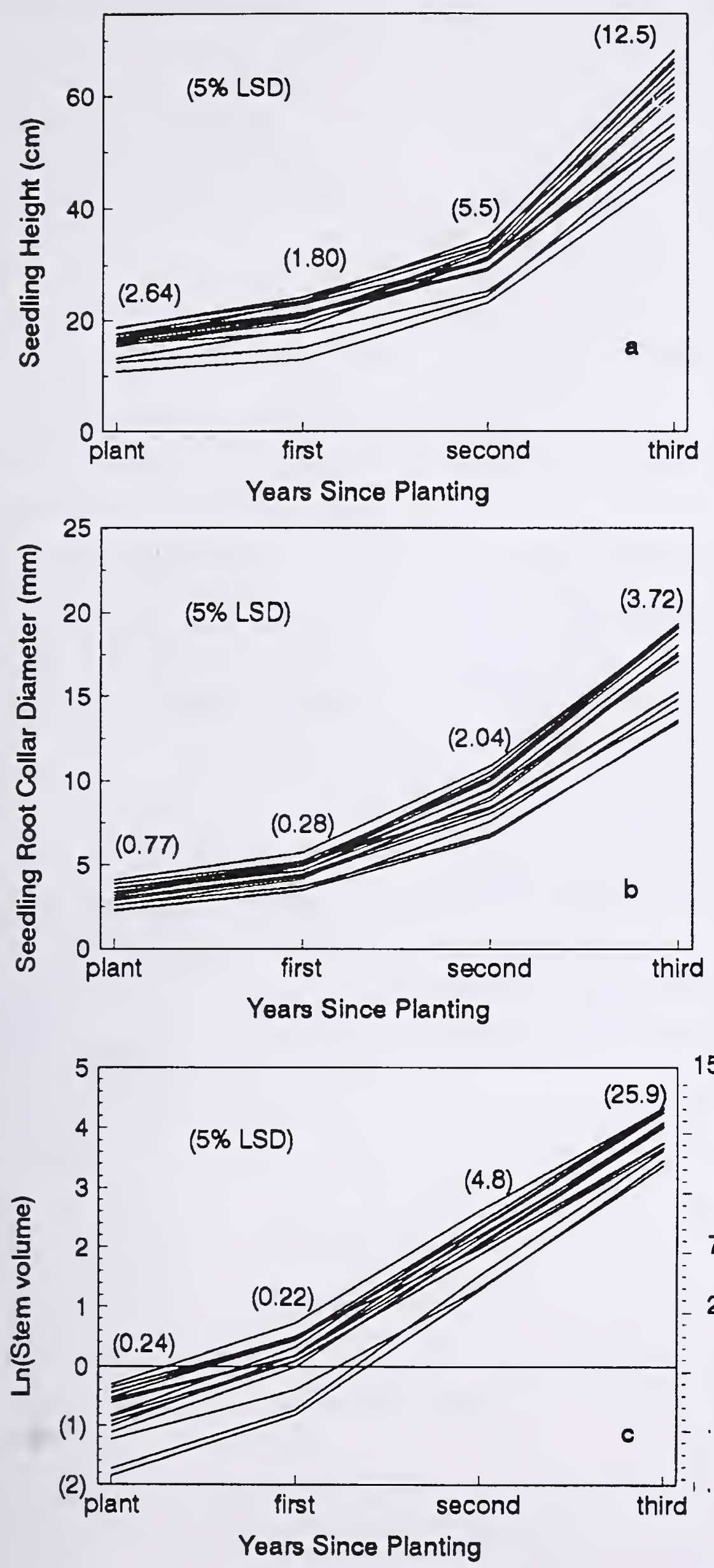

155

55

20

7.5

2.7

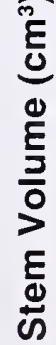

13

\section{DISCUSSION}

The results reported here for Douglas-fir and Lodgepole pine are similar to those reported earlier for interior spruce (Simpson 1991). At greater nursery growing densities, seedlings were taller, with smaller root collar diameters and with less root, stem and foliage dry weight. As might be expected, seedlings grown in the smallest $(45 \mathrm{~mL}$ ) containers were consistently smaller. However, the second largest container $(102 \mathrm{~mL})$ generally produced larger seedlings than the largest $(120 \mathrm{~mL})$ containers. It is unclear if some aspect of container design such as drainage or construction material prevented the seedlings in the largest containers from achieving the greatest growth. Under the cultural conditions used to grow these seedlings, a maximum crop biomass of about 1.4 $\mathrm{kg} / \mathrm{m}^{2}$ was produced. This maximum limit although less than the $9 \mathrm{~kg} / \mathrm{m}^{2}$ reported by Hulten (1989) for Scots pine or 3 $\mathrm{kg} / \mathrm{m}^{2}$ reported by Simpson (1991) for interior spruce occured at a nursery growing density of about 600 seedlings/ $\mathrm{m}^{2}$ as was seen in the earlier studies. At densities less than 600 seedlings $/ \mathrm{m}^{2}$, although larger seedlings result, the

Figure 3. Field height (a), root collar diameter (b) and stem volume (c) of Lodgepole pine seedlings. 
growing area is not fully occupied. At densities greater than 600 seedlings $/ \mathrm{m}^{2}$, as the growing space is fully occupied, the total maximum biomass is now distributed amongst more plants resulting in smaller individuals.

\section{Growing density and cell} volume have been shown here to have fairly similar and predictable effects on the nursery growth of both Douglas-fir and Lodgepole pine. For practical purposes, nursery managers need to know the maximum crop biomass (or stem basal area production) which can be reliably produced with normal cultural conditions for their nursery. With this information in hand, and knowing the morphological targets for their crops (plant weight or root collar diameter), they can then determine an appropriate growing density. With the multitude of container types and configurations commercially available, choosing a container system consistent with a nursery's biological potential becomes somewhat easier.

Although studies relating morphological quality (size) and field performance potential often show inconsistent correlations (Mexal and Landis 1990 and Puttonen 1989, for example), plant size targets and individual tree culling thresholds remain a feature of planting stock production. It is widely believed by purchasers of planting stock that larger trees are of better quality and should therefore result in better field performance. The results reported here support this idea. The field data for both species (Figures 2 and 3) clearly show that smaller trees at planting remain smaller after 3

(Lodgepole pine) or 4 (Douglasfir) years growth on forest sites.

When the growth of the smallest (15.4 cm height, 1.98 $\mathrm{mm}$ RCD) and largest $(19.7 \mathrm{~cm}$ height, $3.37 \mathrm{~mm} \mathrm{RCD)} \mathrm{batches}$ of Douglas-fir are considered, after 4 growing seasons the mean absolute size difference between batches is perhaps 20 $\mathrm{cm}$ in height, $5 \mathrm{~mm}$ in RCD and $40 \mathrm{~cm}^{3}$ for stem volume. This size difference may have some importance for field situations where vegetation competition exists. However, it is important to note that this size difference between treatments reflects a difference in time of perhaps one growing season for the smaller batch to reach the size of the larger (Figure 4). If the added cost of producing larger planting stock can be justified by a one year growth advantage is a matter for purchasers of nursery stock to determine.

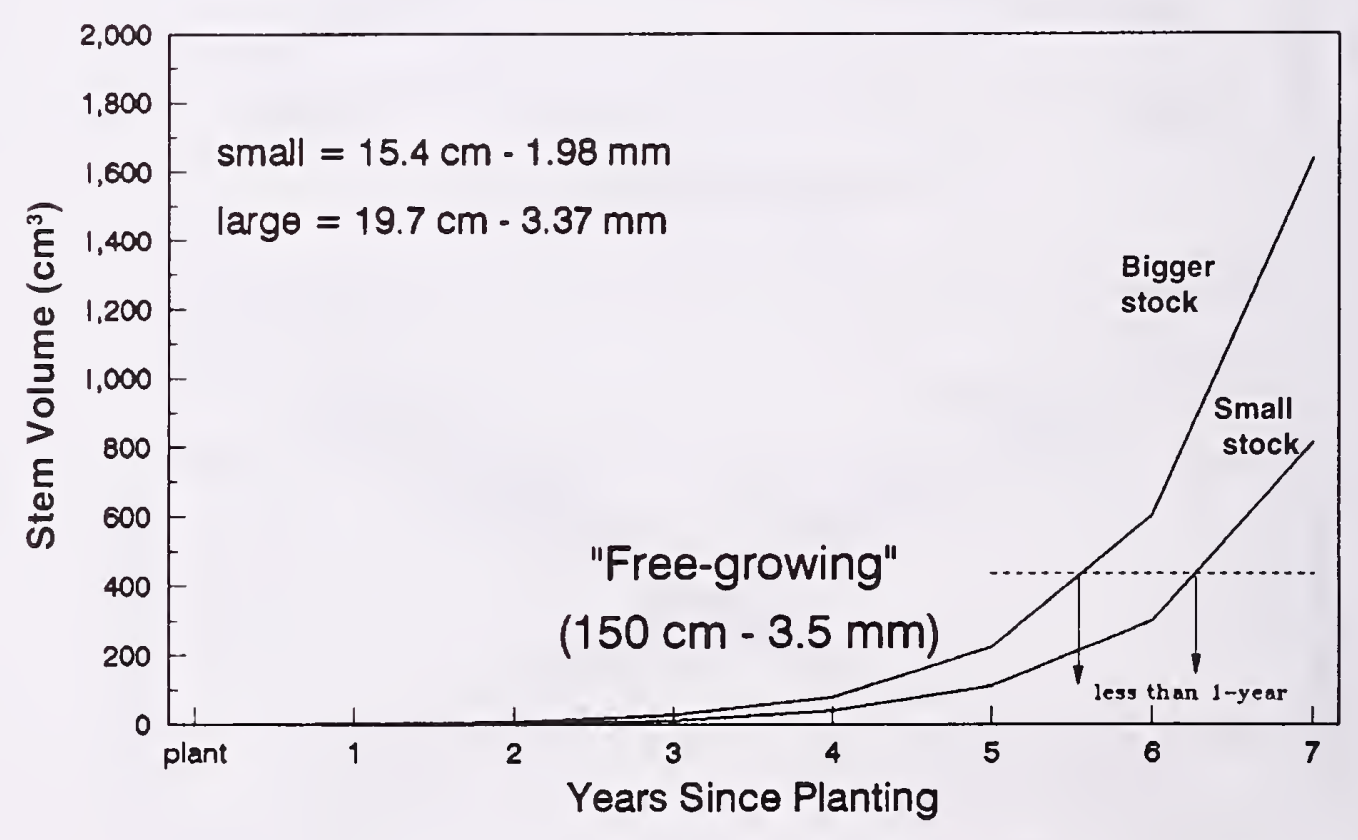

Figure 4. Actual (yrs 1-4) and estimated (yrs 4-7) stem volume growth of small and large Douglas-fir planting stock showing a less than one year time advantage for planting larger planting stock reaching "free-growing" size. 


\section{ACKNOWLEDGEMENTS}

Portions of this work were funded by the Canada-BC FRDA. Without the technical assistance of Sue Matovich, this work would not have been possible. Advice on earlier versions of this manuscript was recieved from Sue Matovich, Eric van Steenis, Pasi Puttonen and Chris Hawkins, all of the $\mathrm{BC}$ Ministry of Forests.

\section{REFERENCES}

Hulten, H. 1989. Current levels of planting stock uniformity and grading - a Scandinavian view. Forestry (Suppl.) 62:112.

Lloyd, D., Angove, K., Hope, G. and Thompson, C. 1990. A guide to site identification and interpretation for the Kamloops Forest Region. BC Ministry of Forests Land Management Handbook No. 23399 p.

Mexal, J.G. and Landis, T.D. 1990. Target seedling concepts: height and diameter. (Chapter 3 Target Seedling Symposium) in Proc. Combined meeting of the western forest nursery assns., August 13-17,1990 Roseburg Oregon. USDA Forest Service Gen. Tech. Rept. RM-200 pp 17 35.
Puttonen, P. 1989. Criteria for using seedling performance potential tests. New Forests 3: 67-87.

Simpson, D.G. 1991. Growing density and container volume affect nursery and field growth of interior spruce seedlings. N. J. Appl. For. 8:160-165. 


\title{
Summer Plant Culling Criteria of Interior Spruce: Keeping the Bad and Throwing the Good? ${ }^{1,2}$
}

\author{
Erica L. McClaren ${ }^{3}$, Marek J. Krasowski ${ }^{4}$, and Christopher D.B. Hawkins ${ }^{4}$
}

\begin{abstract}
Morphological criteria by which spruce nursery stock, or any conifer crop is culled generally raises discussion at the nursery gate. The discussion does not focus on the bulk of the crop but on those seedlings just over or under height and diameter limits. In British Columbia, some workers believe that 'good' small seedlings are being culled in favour of tall 'poor' stock. To address some of these concerns, standard and substandard (culls) blackout treated spruce stock derived from three seed origins (registered natural stand, registered seed orchard and full-sib controlled cross) was summer planted at Red Rock Research Station (RRRS), near Prince George, BC in early July 1993. RRRS is an uncompetitive environment. Very liberal grading criteria were used (the plug must hold together and the seedling should be taller than $9 \mathrm{~cm}$ ) when this crop (16 of the 26 seedlots were of seed orchard origin) was lifted at RRRS. 1752 seedlings were planted and they were monitored during 1993 and into the 1994 season. Height and root collar diameter (RCD) of all seedlings was measured at planting and in September 1993. Seedlings were then classed as 'culls' or 'standards' based on morphology at planting according to B.C. Forest Service (BCFS) seedling specifications for interior spruce (Picea glauca, $P$. engelmannii and their naturally occurring hybrids) summer plant stock. Of the 781 seedlings classified as culls, $8.9 \%$ were underheight, $7.9 \%$ were overheight, $60.3 \%$ had inadequate RCD, $20.5 \%$ were underheight with poor RCD, and $2.3 \%$ were overheight with poor RCD. Survival until June 1994 was excellent: greater than 98 percent regardless of class. Stem volume increment in 1993 was similar between cull and acceptable class seedlings but cull seedlings had significantly greater relative stem volume growth rates. These results raise concerns about present grading criteria for summer planting, particularly for seed orchard stock which tended to have smaller RCD. Further monitoring of the summer planted stock will be necessary to determine whether present grading criteria are in fact too conservative and should include some of the seedlings presently being culled.
\end{abstract}

Growth patterns after planting were also examined in relation to seed origin and nursery treatment. Preliminary conclusions suggest that 1) seed orchard seedlots do not display unusual variability compared to natural stand seedlots, 2) blackout can effectively produce morphologically uniform seedlings suitable for summer planting programs and 3) blackout may promote abnormal terminal bud flushes. The cause and control of the latter issue remains to be ascertained. Otherwise, blackout is an efficient method to deliver quality seed orchard stock to the field for summer planting.

'McClaren, E.L., Krasowski, M.J.; Hawkins, C.D.B. 1994. Summer Plant Culling Criteria of Interior Spruce: Keeping the Bad and Throwing the Good? IN: Landis, T.D.; Dumroese, R.K., tech. coords. National Proceedings, Forest and Conservation Nursery Associations. Gen. Tech. Rep. RM-257. Fort Collins, CO: U.S. Department of Agriculture, Forest Service, Rocky Mountain Forest and Range Experiment Station: 116-129.

${ }^{2}$ Funded by Silviculture and Research Branches of the British Columbia Forest Service.

${ }^{3}$ Coop Student, Simon Fraser University and Red Rock Research Station, RR\#7, RMD\#6, Prince George, BC, Canada, V2N $2 J 5$.

${ }^{4}$ Research Scientists, Red Rock Research Station. 


\section{INTRODUCTION}

Recently, foresters and nursery workers have expressed uncertainties regarding the quality of spruce (Picea sp.) seedlings derived from seed orchard (Class A) seed, as opposed to seedlings from natural stand (wild) seed collections. Their concerns surround the morphology and physiology of interior spruce seed orchard stock as well as the operational feasibility of using this stock in summer planting programs (Hawkins 1993b). During the 1970's, seedlings from the coastal Douglas-fir (Pseudotsuga menziesii (Mirb.) Franco) seed orchard program were regarded with similar scepticism as stock from the interior spruce seed orchard program is presently. However, inquiries into coastal Douglas-fir seed orchards concluded, that no data existed to indicate Class A seedlots were inferior to Class B (natural stand) in terms of nursery performance (Mueller et al. 1981).

Morphologically, spruce seed orchard seedlings are perceived to be tall and spindly with small root collar diameters (RCD) and inadequate root system development (Hawkins 1993b). Additionally, these seedlots are believed to have more height variability than natural stand seedlots (Hawkins 1993b). Physiologically and phenologically, seed orchard seedlings have exhibited developmental variation in timing of budset, development of frost hardiness, and dormancy onset when grown under non-blackout nursery conditions (Hawkins 1993a; Krasowski et al. 1993). Whether this physiological variation is greater than that observed for natural stand collections is unknown (Hawkins 1993a). Logistically, seed orchard stock often fails to meet summer plant deadlines (Hawkins 1993b) due to the difficulty in 'setting' it up for planting. In nursery operations and during field outplanting, it is operationally and economically desirable to have morphologically and physiologically uniform stock (Lang 1989). Consequently, it is pertinent to address these concerns so that B.C.'s interior spruce seed orchard program may fulfil its potential and become a successful and integral component of the intensive provincial regeneration program.

Modified nursery culture may help prevent the undesirable characteristics displayed by some seed orchard stock (Hawkins 1993b). Rather than employing drought and nutrient stressing, common nursery practice to regulate seedling height (D'Aoust and Cameron 1981; Matthews 1981; Johnson 1985), blackout (photoperiod manipulation, short-day treatment or darkout) has proven to be an effective method for height control (Arnott and Mitchell 1981; D'Aoust and Cameron 1981; Hawkins and Draper 1991;
Bigras and D'Aoust 1993). Through simulating a later time in the growing season, blackout enhances morphological uniformity, apical budset, frost hardening and dormancy onset

(Colombo et al. 1981; Silim et al. 1989; Bigras and D'Aoust 1993). In turn, these benefits may increase field survival (Silim et al. 1989). Extremely long blackout treatments, such as $8 \mathrm{~h}$ or shorter daylength nursery regimes, can have negative impacts on post planting phenology and frost resistance (Hawkins and Hooge 1988; Odlum and Colombo 1988; Bigras and D'Aoust 1993). However, moderate blackout treatment (11h to $14 \mathrm{~h}$ ) may prove successful in reducing the morphological and physiological variability of seed orchard seedlots as well as in natural stand and full-sib controlled cross seedlots (Hawkins 1993c; Hawkins and Krasowski 1993).

A trial involving Silviculture Branch, Research Branch and Forest Region staff was established at Red Rock Research Station (RRRS) in February 1993 (Hawkins 1993b). The primary objectives of the trial were to 1) compare the morphological and physiological variability among seed sources (registered natural stand, operational seed orchard and full-sib controlled crosses from the research program) at the nursery and after summer planting and 2) if necessary, make nursery 
culture recommendations that address concerns surrounding seed orchard seed (Hawkins 1993b). This paper will discuss these objectives in light of summer planted seedlings' morphology and growth patterns through the summer of 1993 after planting, survival rates, and bud flush phenologies into the spring of 1994. Additionally, seedlings will be described in terms of the traditional culling criteria outlined by the B.C. Forest Service (BCFS) for summer planted spruce.

\section{MATERIALS AND METHODS}

\section{Nursery}

Seed of 50 spruce (Picea glauca (Moench) Voss, $P$. engelmannii Parry and their naturally occurring hybrids) seedlots from three seed sources (registered natural stand collections, registered seed orchards. and full-sib controlled crosses) was sown on February 17, 1993, into 415B polystyroblocks (Beaver Plastics, Edmonton, $\mathrm{AB}$; $112,105 \mathrm{~mL}$ cavities per container) and cultured at RRRS near Prince George, B.C. (Lat. $53^{\circ} 45^{\prime} \mathrm{N}$, Long. $122^{\circ} 41^{\prime} \mathrm{W}$ ) as described by Hawkins (1993d) and Hawkins and Krasowski (1993).

Seeds were germinated and grown under modified nursery regimes outlined by Draper and Hawkins (1989) and Hawkins and Draper (1991). Blackout was applied to 26 of the 50 seedlots, starting in late May when mean seedlot height was approximately $10 \mathrm{~cm}$ (Hawkins 1993b). Ten of the seedlots were from natural stand collections, six were from seed orchards, and ten were full-sib families. Seedlots originating north of $53^{\circ} \mathrm{N}$ latitude received a $14 \mathrm{~h}$ day whereas those originating south of this latitude received an $11 \mathrm{~h}$ day (Hawkins 1993b). Blackout treatments lasted for 17 days (Hawkins 1993c). Untreated seedlings from the 26 blackout treated seedlots, as well as those from the remaining 24 seedlots, served as controls and received water and nutrient manipulation for height regulation as would be applied in nurseries where blackout was not available.

\section{Summer Plant}

Two grading criteria were used at summer lift: the root plug must hold together (cohesive) and seedlings must be at least 9 $\mathrm{cm}$ tall (Hawkins 1993c). These liberal culling standards, compared to BCFS's regular summer lift 415B stocktype specifications of minimum RCD of 2.6 $\mathrm{mm}$, height between $140 \mathrm{~mm}$ and $280 \mathrm{~mm}$ with a target of 220 $\mathrm{mm}$, cohesive root plugs, and visible terminal bud, were used because of the low number of cavities sown for each seedlot treatment (blackout and control) (Hawkins 1993c).
On July 5, 8, and 15, 1993 (approximately 17 days after removal from short-day treatments), all 26 blackout treated seedlots and their untreated control counterparts were planted into an experimental field at RRRS (Hawkins 1993c). A completely randomized design was established where six randomly selected seedlings from each seedlot treatment unit (STU: a styroblock receiving a specific cultural treatment) were planted in rows, with $30 \mathrm{~cm}$ spacing within and among rows (Hawkins 1993c). Each STU was replicated five or six times depending on the number of blocks sown (Hawkins and Krasowski 1993). In total, 1752 seedlings were planted into the RRRS experimental field.

Height to the nearest $\mathrm{mm}$ and $\mathrm{RCD}$ to the nearest $0.1 \mathrm{~mm}$ were measured at the time of planting and again after the remaining 1993 summer season of growth (September 7). Root and shoot dry weights (to the nearest $\mathrm{mg}$ ) for summer planted stock were estimated at the time of planting by destructively sampling three randomly selected seedlings per STU (Hawkins 1993d). Postplanting survival was assessed in September, October, November, 1993 as well as in May and June 1994. Additionally, bud-flush characteristics were assessed for terminal buds in early June 1994 . Terminal leader buds were subjectively classified as 1) normal, completely flushed and 
extended; 2) none, not flushed at all; or 3) abnormal, partially/ irregularly flushed. Abnormally flushed buds indicated that budbreak had occurred but there was very little extension of the preformed shoot beyond the open bud scales. These seedlings often had a rosette of multiple leaders. Summer planted seedlings will continue to be monitored for the next two to four seasons (Hawkins 1993c).

Mean values were calculated for height, RCD, stem volume, stem volume increment (stem volume in September-stem volume at planting) and relative volume growth were calculated using six seedlings per STU planted into the experimental field at RRRS. Dry shoot and root weight means were calculated using three seedlings per STU. Morphological characteristics were computed by the main factors of interest: seed origin (wild, seed orchard and full-sib controlled cross), seedlot and nursery treatment (control and blackout). Morphologies of all seedlings at planting were subjected to a theoretical cull procedure according to the BCFS specifications already described. This enabled the morphologies and 1993 summer growth of all (substandard or culls included) seedlings and just 'acceptable' (standard) seedlings (after the theoretical cull) to be compared. Culled seedlings were separated into five exclusive cull classes: 1$)$ underheight $(\leq 140$ $\mathrm{mm}$ ) with acceptable RCD; 2) overheight ( $\geq 280 \mathrm{~mm}$ ) with acceptable RCD; 3 ) acceptable height with inadequate $\mathrm{RCD}(\leq$ $2.6 \mathrm{~mm})$; 4) underheight with inadequate $\mathrm{RCD}(\leq 140 \mathrm{~mm}$ and $\mathrm{RCD} \leq 2.6 \mathrm{~mm}$ ); and 5) overheight with poor $\operatorname{RCD}(\geq$ $280 \mathrm{~mm}$ and RCD $\leq 2.6 \mathrm{~mm}$ ). Estimated dry shoot and root weights for culled and acceptable seedlings were obtained by merging mean STU weights from destructively sampled seedlings with mean STU height and RCD values from the planted seedlings. The theoretical cull in this instance was performed on styroblock mean heights and RCDs rather than on an individual seedling basis. Potentially this resulted in some acceptable seedlings being included with the cull seedling weights and vice versa. Postplanting survival as of June 1994 (percentage of living seedlings) was computed for the above cull and acceptable categories.

\section{Statistical Analyses}

General Linear Models procedure (GLM) in SAS (SAS 1988) was used to analyze the significance of seed origin, seedlot and nursery treatment on seedling morphological characteristics, recovery and postplanting survival (ANOVA model presented in Table 1). Analysis of variance was performed on parameters of interest including and excluding theoretically culled seedlings to test if sources changed in significance with all seedlings compared to just the acceptable ones.

SYSTAT's (Wilkinson 1990) Kruskal-Wallis non parametric one-way analysis of variance was used to analyze the frequencies of seedlings in the three apical bud-flushing categories

Table 1. ANOVA model used to compare morphological and growth characteristics of $415 \mathrm{~B}$ seedlings summer planted at RRRS in July 1993. Root and shoot weights were done on STU means: the experimental unit was STyroblock (SO SL PP) with $240 \mathrm{df}$.

$\begin{array}{lrl}\text { Source } & \underline{\text { df }} & \text { Error Term } \\ \text { Seed Origin } & 2 & \text { SL(SO) } \\ \text { SeedLot (SO) } & 23 & \mathrm{SD}(\mathrm{SO} S \mathrm{SP}) \\ \text { PhotoPeriod }^{\mathrm{a}} & 1 & \mathrm{SL}(\mathrm{SO})^{*} \mathrm{PP} \\ \text { SO }{ }^{*} \mathrm{PP} & 2 & \mathrm{SL}(\mathrm{SO})^{*} \mathrm{PP} \\ \text { SL(SO) *PP } & 23 & \mathrm{SD}(\mathrm{SO} \mathrm{SL} \mathrm{PP}) \\ \text { SeeDling (SO SL PP) }^{\mathrm{b}} & \underline{1696} & \end{array}$

Total

1747

a. PhotoPeriod was the nursery treatment of interest.

b. Seedling was the experimental unit. 
according to seedling class (five cull classes and acceptables), nursery treatment (blackout and control) and seed origin. Results were considered statistically significant at alpha $=0.05$.

\section{Equations}

(1) Stem volume $(\mathrm{mL})=$ $1 / 12 \times \pi \times(R C D)^{2} \times$ height where $R C D$ and height are in $\mathrm{cm}$.

(2) Relative Stem volume growth $(\mathrm{mL} / \mathrm{mL} /$ season $)=\log _{10}($ Stem volume in SEP) $-\log _{10}$ (Stem volume at planting).

\section{RESULTS}

\section{Seed Origin}

Seed origin had very little influence on seedling morphology as measured at planting or after a partial summer of field growth (Tables 2, $3 \& 4$ ). Only seedling height at planting was significantly impacted by seed origin (Table 2). Full sib material was taller than seed orchard stock which was taller than the wild seedlots. There were significant interactions between seed origin and nursery treatment for height and stem volume at planting as well as for height in September.

Full-sib seedlings had the greatest mean values for height (Table 4), dry root and shoot weights (Table 3 ). RCD values were similar among seed origins. By September, with the exception of height, seed orchard seedlings exhibited the most desirable characteristics, having the greatest mean values for $\mathrm{RCD}$, stem volume increment and relative stem volume growth (Table 4). In general, relative stem volume growth was greater for seed orchard and full-sib seedlings compared to natural stand seedlings (Figure 1). Hence, at planting and in September seedlings derived from tree improvement seed (full-sib and seed orchard) were larger than seedlings from natural stand collection seed. Post-planting survival was excellent, being greater than 99 percent regardless of seed origin (Table 4).

\section{Seedlot}

Seedlot was a significant source of variation for all morphological parameters in July as well as for height, RCD and stem volume in September (Tables 2, $3 \& 4$ ). There were significant interactions between seedlot and nursery treatment for height in July and for height, RCD and relative stem volume growth in September. Interactions among seedlot and nursery treatment were expected due to the great variability displayed among seedlots in response to blackout application (not presented).

Seedling morphology and survival parameters varied among seedlots of the same seed source as well as among seedlots from different seed sources. As assessed in June 1994, postplanting survival values were high for all seedlots.

\section{Photoperiod}

At planting, nursery treatment (photoperiod = blackout) significantly reduced seedling height, stem volume and shoot weight (Tables 2, $3 \& 4$ ). Height and stem volume were still significantly affected by nursery treatment in September (Table 2). Interactions between nursery treatment and seed origin or seedlot are noted in the previous sections. Relative stem volume growth however, was greater for blackout seedlings than for controls (Table 4). Post-planting survival until early June 1994 was excellent for all seedlings regardless of whether they were blackout treated or controls, culls or acceptables (Table 4).

Blackout treatment however, impacted bud-break characteristics of seedlings in their second year of growth (June 1994) (Table 5). Where controls lowest value for successful flushing was 58 percent in the underheight, poor RCD cull class, the highest successful flushing value for blackout seedlings was 57 percent in the acceptable class (Table 5). In general, more blackout seedlings, all classes included, failed to flush or had funny (unusual form) flushes during their second season than did control seedlings. 
Table 2. Mean square (MS) and probability of $F[P(F)]$ for assessed morphological parameters at planting in July 1993 and a the end of the growing season, September 1993, for all seedlings planted (ALL), acceptable seedlings only (STD), and cull seedlings only (CULL). Sources were considered significantly different at alpha $=0.05$. Abbreviations: HT, height; RCD roo collar diameter; VOL, stem volume; VINC, stem volume increment; and VGRO, relative stem volume growth rate.

\begin{tabular}{|c|c|c|c|c|c|c|c|c|c|c|}
\hline \multirow[b]{2}{*}{ Source } & \multirow[b]{2}{*}{$d f$} & & \multicolumn{3}{|c|}{ July 1993} & \multicolumn{5}{|c|}{ September 1993} \\
\hline & & & $\mathrm{RCD}$ & $\mathrm{HT}$ & VOL & $\mathrm{RCD}$ & HT & VOL & VINC & VGRO \\
\hline \multicolumn{11}{|l|}{ ALL } \\
\hline \multirow[t]{2}{*}{ Seed Origin } & 2 & MS & 0.050 & 95894 & 0.441 & 3.555 & 67367 & 1.851 & 0.516 & 0.070 \\
\hline & & $P(F)$ & .9718 & .0090 & .1963 & .2441 & .0513 & .1544 & .3880 & .6216 \\
\hline \multirow[t]{2}{*}{ SeedLot(SO) } & 23 & $\mathrm{MS}$ & 1.756 & 16454 & 0.252 & 2.370 & 19876 & 0.912 & 0.523 & 0.144 \\
\hline & & $P(F)$ & .0001 & .9991 & .0001 & .0001 & .0001 & .0001 & .0001 & .0001 \\
\hline \multirow[t]{2}{*}{ PhotoPeriod } & 1 & MS & 2.811 & 1621102 & 10.44 & 0.090 & 1618145 & 21.23 & 1.942 & 0.261 \\
\hline & & $P(F)$ & .1260 & .0001 & .0001 & .8371 & .0001 & .0001 & .0204 & .2908 \\
\hline \multirow[t]{2}{*}{ SO*PP } & 2 & MS & 0.611 & 40320 & 0.450 & 2.621 & 51805 & 0.341 & 0.009 & 0.221 \\
\hline & & $P(F)$ & .5852 & .0080 & .0418 & .3016 & .0050 & .2810 & .9733 & .3871 \\
\hline \multirow{2}{*}{$\mathrm{SL}(\mathrm{SO})^{\star} \mathrm{PP}$} & 23 & MS & 1.115 & 6721 & 0.123 & 2.075 & 7862 & 0.254 & 0.313 & 0.223 \\
\hline & & $P(F)$ & 0.0001 & .0001 & .0001 & .0001 & .0001 & .0024 & .0001 & .0001 \\
\hline SeeDling(SO SL PP) & 1696 & MS & 0.294 & 1148 & 0.040 & 0.575 & 1357 & 0.124 & 0.106 & 0.038 \\
\hline \multicolumn{11}{|l|}{ STD } \\
\hline \multirow[t]{2}{*}{ Seed Origin } & 2 & MS & 0.568 & 13986 & 0.081 & 0.989 & 8327 & 0.307 & 0.079 & 0.006 \\
\hline & & $P(F)$ & .4521 & .0558 & .4724 & .5283 & .2434 & .5231 & .7999 & .9179 \\
\hline \multirow[t]{2}{*}{ SeedLot(SO) } & 23 & MS & 0.691 & 4264 & 0.105 & 1.507 & 5538 & 0.460 & 0.350 & 0.067 \\
\hline & & $P(F)$ & .0001 & .0001 & .0001 & .0001 & .0001 & .0001 & .0001 & .0001 \\
\hline \multirow{2}{*}{ PhotoPeriod } & 1 & MS & 0.048 & 596252 & 4.426 & 1.740 & 616508 & 6.779 & 0.258 & 0.085 \\
\hline & & $P(F)$ & .6582 & .0001 & .0001 & .1988 & .0001 & .0001 & .2794 & .2374 \\
\hline \multirow[t]{2}{*}{ SO*PP } & 2 & MS & 0.181 & 12248 & 0.219 & 0.137 & 14727 & 0.382 & 0.026 & 0.005 \\
\hline & & $P(F)$ & .4771 & .0128 & .0177 & .8718 & .0171 & .1615 & .8850 & .9229 \\
\hline \multirow[t]{2}{*}{$\mathrm{SL}(\mathrm{SO}){ }^{*} \mathrm{PP}$} & 23 & MS & 0.237 & 2310 & 0.045 & 0.994 & 3016 & 0.194 & 0.210 & 0.058 \\
\hline & & $P(F)$ & .0353 & .0001 & .0251 & .0025 & .0001 & .0220 & .0070 & .0002 \\
\hline SeeDling(SO SL PP) & 1696 & MS & 0.147 & 632 & 0.027 & 0.483 & 899 & 0.114 & 0.112 & 0.024 \\
\hline \multicolumn{11}{|l|}{ CULL } \\
\hline \multirow[t]{2}{*}{ Seed Origin } & 2 & MS & 0.228 & 71429 & 0.351 & 5.316 & 61303 & 1.959 & 0.651 & 0.092 \\
\hline & & $P(F)$ & .4977 & .0092 & .0223 & .0376 & .0282 & .0405 & .1555 & .4047 \\
\hline \multirow[t]{2}{*}{ SeedLot(SO) } & 23 & MS & 0.317 & 12340 & 0.078 & 1.400 & 14653 & 0.530 & 0.322 & 0.098 \\
\hline & & $P(F)$ & .0193 & .0001 & .0001 & .0003 & .0001 & .0001 & .0001 & .0002 \\
\hline \multirow[t]{2}{*}{ PhotoPeriod } & 1 & MS & 0.822 & 702117 & 3.292 & 1.258 & 686242 & 11.10 & 2.304 & $<.001$ \\
\hline & & $P(F)$ & .1382 & .0001 & .0001 & .4446 & .0001 & .0001 & .0025 & .9667 \\
\hline \multirow[t]{2}{*}{ SO*PP } & 2 & MS & 0.501 & 24558 & 0.230 & 2.688 & 37790 & 0.131 & 0.015 & 0.223 \\
\hline & & $P(F)$ & .2585 & .0159 & .0397 & .2937 & .0033 & .5718 & .9267 & .3065 \\
\hline \multirow[t]{2}{*}{$\mathrm{SL}(\mathrm{SO})^{*} \mathrm{PP}$} & 23 & MS & 0.349 & 4923 & 0.062 & 2.079 & 5090 & 0.229 & 0.201 & 0.179 \\
\hline & & $P(F)$ & .0071 & .0001 & .0006 & .0001 & .0001 & .0029 & .0008 & .0001 \\
\hline SeeDling(SO SL PP) & 1696 & MS & 0.184 & 1448 & 0.027 & 0.585 & 1623 & 0.112 & 0.090 & 0.041 \\
\hline
\end{tabular}

\section{Theoretical Cull}

At planting, the only change in significance levels after theoretically culling seedlings to BCFS was for seed origin which became insignificant as a source of variation for height (Table 2). As mentioned previously, SL and $\mathrm{SL}^{*}$ NT significantly influenced recovery of seedlings. In September, seedlot became a significant source variation for relative stem volume growth after seedlings were culled (Table 2). Additionally, culling created a significant seed origin by nursery treatment interaction for stem volume as well as 
Table 3. Mean square (MS), probability of $F[P(F)]$ and mean shoot and root masses (main effects only) at planting in July 1993.

\begin{tabular}{|c|c|c|c|c|c|c|c|}
\hline \multirow[b]{2}{*}{ Source } & & \multirow[b]{2}{*}{$\mathrm{df}$} & & \multicolumn{2}{|c|}{ All seedlings } & \multicolumn{2}{|c|}{ Standard seedlings } \\
\hline & & & & Shoot & Root & Shoot & Root \\
\hline \multirow{2}{*}{\multicolumn{2}{|c|}{ Seed Origin }} & 2 & MS & 752587 & 23209 & 752999 & 22946 \\
\hline & & & $P(F)$ & . 0920 & .3150 & .0799 & .3218 \\
\hline \multicolumn{2}{|l|}{ SeedLot(SO) } & 23 & $\begin{array}{l}M S \\
P(F)\end{array}$ & 283785 & $\begin{array}{l}19098 \\
0001\end{array}$ & 266408 & 19255 \\
\hline \multirow{2}{*}{\multicolumn{2}{|c|}{ PhotoPeriod }} & 1 & MS & 4732550 & 115 & 4314247 & 195 \\
\hline & & & $P(F)$ & .0001 & .8869 & .0001 & .8540 \\
\hline \multirow{2}{*}{\multicolumn{2}{|c|}{$S O^{*} P P$}} & 2 & MS & 130163 & 31208 & 108623 & 31310 \\
\hline & & & $P(F)$ & .1001 & .0104 & .1463 & .0069 \\
\hline \multirow{2}{*}{\multicolumn{2}{|c|}{$\mathrm{SL}(\mathrm{SO})^{\star} \mathrm{PP}$}} & 23 & MS & 51087 & 5566 & 51919 & 5037 \\
\hline & & & $P(F)$ & .7372 & .7766 & .2015 & .8892 \\
\hline \multicolumn{2}{|c|}{ STyroblock(SO SL PP) } & 238 & MS & 64308 & 7306 & 67314 & 7748 \\
\hline & & & & \multicolumn{2}{|c|}{ All } & \multicolumn{2}{|c|}{ Standard } \\
\hline & & & & $\begin{array}{r}\text { Shoot } \\
\text { (mg) }\end{array}$ & $\begin{array}{l}\text { Root } \\
\text { (mg) }\end{array}$ & $\begin{array}{l}\text { Shoot } \\
\text { (mg) }\end{array}$ & $\begin{array}{l}\text { Root } \\
(\mathrm{mg})\end{array}$ \\
\hline \multirow{3}{*}{ Seed Origin } & Full s & & & 1436 & 376 & 1450 & 382 \\
\hline & Seed & chard & & 1335 & 351 & 1379 & 363 \\
\hline \multirow{2}{*}{\multicolumn{8}{|c|}{ Seedlot ${ }^{1}$}} \\
\hline & & & & & & & \\
\hline \multirow{2}{*}{ Photoperiod } & Cont & & & 1477 & 360 & 1480 & 367 \\
\hline & Blacl & & & 1207 & 357 & 1254 & 366 \\
\hline
\end{tabular}

'Not presented because there are 26 seedlots.

eliminating a significant interaction between nursery treatment and seedlot for RCD and stem volume growth.

In July, mean values for seed origin height, $\mathrm{RCD}$, root weight and shoot weight were increased after culling (Tables $3 \& 4$ ). In September, mean heights and RCDs after theoretically culling (acceptables only) were larger compared to when all seedlings were included. However, pooled stem volume increment and relative stem volume growth values were lower for just the acceptables compared to all seedlings combined (culls + acceptables) (Table 6). In fact, culled seedlings as a class alone had greater relative stem volume growth for each seed origin compared to just acceptables (Figure 1).

Of the 781 seedlings that were classified as culls, 381 were controls and 400 were blackout treated (Table 6). When the 781 culled seedlings were divided into five cull classes, $8.96 \%$ (70) were underheight, $7.94 \%$ (62) were overheight, $60.31 \%$ (471) had inadequate RCD, $20.49 \%$ (160) were underheight with poor RCD and $2.30 \%$ (18) were overheight with poor RCD
(Table 6). Although more blackout seedlings failed to meet minimum height specifications, mean height of this cull class was the same for blackout and control seedlings. The majority of seedlings were culled because of inadequate RCD yet by the end of the summer all five cull classes had RCD above minimum specifications for planting (Table 6). Stem volume increment for the culls was similar to that for acceptable seedlings. Culled and acceptable seedlings had similar root weight values although acceptables had a greater shoot weight value than the cull classes (not presented). 
Table 4. Mean values at planting (July) and after one summer (September) for RCD, height (HT), stem volume (VOL), volume increment (VINC), relative volume growth rate (VGRO) and survival (SURV) by seed origin (SO), photoperiod (PP), classification (CLASS) and major interaction combinations. SO levels, full sib (FSIB), seed orchard (SORC) and natural stand (WILD); PP levels, control (CON) and blackout (BOUT); and CLASS levels, standard (STD) and CULL.

\begin{tabular}{|c|c|c|c|c|c|c|c|c|c|c|c|}
\hline \multirow[b]{2}{*}{ Source } & \multirow[b]{2}{*}{ Level } & \multirow[b]{2}{*}{$n$} & \multicolumn{3}{|c|}{ July 1993} & \multicolumn{5}{|c|}{ September 1993} & \multirow[b]{2}{*}{$\begin{array}{l}\text { SURV } \\
(\%)\end{array}$} \\
\hline & & & $\begin{array}{r}R C D \\
(\mathrm{~mm})\end{array}$ & $\begin{array}{c}\mathrm{HT} \\
(\mathrm{mm})\end{array}$ & $\begin{array}{c}\mathrm{VOL} \\
\left(\mathrm{mm}^{3}\right)\end{array}$ & $\begin{array}{l}R C D \\
(\mathrm{~mm})\end{array}$ & $\begin{array}{l}\mathrm{HT} \\
(\mathrm{mm})\end{array}$ & $\begin{array}{l}\text { VOL } \\
\left(\mathrm{mm}^{3}\right)\end{array}$ & $\begin{array}{l}\text { VINC } \\
\left(\mathrm{mm}^{3}\right)\end{array}$ & $\begin{array}{c}\text { VGRO } \\
\left(\mathrm{mm}^{3} \cdot \mathrm{mm}^{3}\right)\end{array}$ & \\
\hline All & & 1748 & 2.79 & 190 & 0.416 & 3.79 & 188 & 0.754 & 0.339 & 0.261 & 99.5 \\
\hline \multirow[t]{3}{*}{ so } & FSIB & 598 & 2.80 & 202 & 0.437 & 3.83 & 198 & 0.788 & 0.351 & 0.265 & 99.5 \\
\hline & SORC & 432 & 2.79 & 194 & 0.431 & 3.86 & 194 & 0.799 & 0.368 & 0.275 & 99.8 \\
\hline & WILD & 718 & 2.78 & 178 & 0.389 & 3.72 & 178 & 0.699 & 0.310 & 0.249 & 99.2 \\
\hline \multirow[t]{2}{*}{ PP } & CON & 875 & 2.82 & 220 & 0.490 & 3.79 & 218 & 0.863 & 0.373 & 0.253 & 99.7 \\
\hline & BOUT & 873 & 2.75 & 160 & 0.341 & 3.79 & 159 & 0.645 & 0.304 & 0.269 & 99.3 \\
\hline \multirow[t]{2}{*}{ CLASS } & STD & 967 & 3.13 & 199 & 0.522 & 3.94 & 197 & 0.832 & 0.310 & 0.186 & 99.8 \\
\hline & CULL & 781 & 2.36 & 179 & 0.284 & 3.61 & 178 & 0.657 & 0.374 & 0.354 & 99.1 \\
\hline \multicolumn{2}{|c|}{$\mathrm{FSIB}^{*} \mathrm{CON}$} & 300 & 2.83 & 237 & 0.520 & 3.79 & 232 & 0.905 & 0.385 & 0.244 & 99.7 \\
\hline \multicolumn{2}{|c|}{$\mathrm{FSIB}^{\star} \mathrm{BOUT}$} & 298 & 2.76 & 167 & 0.353 & 3.88 & 163 & 0.670 & 0.317 & 0.286 & 99.3 \\
\hline \multicolumn{2}{|c|}{ SORC*CON } & 216 & 2.87 & 231 & 0.535 & 3.81 & 232 & 0.933 & 0.398 & 0.247 & 99.5 \\
\hline \multicolumn{2}{|c|}{ SORC*BOUT } & 216 & 2.71 & 158 & 0.326 & 3.91 & 156 & 0.664 & 0.338 & 0.304 & 100.0 \\
\hline \multicolumn{2}{|c|}{ WILD*CON } & 359 & 2.79 & 200 & 0.438 & 3.78 & 199 & 0.785 & 0.348 & 0.264 & 99.7 \\
\hline \multicolumn{2}{|c|}{ WILD*BOUT } & 359 & 2.77 & 156 & 0.340 & 3.65 & 158 & 0.612 & 0.273 & 0.234 & 98.9 \\
\hline \multicolumn{2}{|c|}{$\mathrm{STD}^{\star} \mathrm{FSIB}^{\star} \mathrm{CON}$} & 174 & 3.09 & 232 & 0.593 & 3.84 & 230 & 0.910 & 0.317 & 0.174 & 100.0 \\
\hline \multicolumn{2}{|c|}{ STD*FSIB*BOUT } & 184 & 3.08 & 176 & 0.446 & 3.95 & 171 & 0.725 & 0.279 & 0.194 & 99.5 \\
\hline \multicolumn{2}{|c|}{ STD*SORC ${ }^{*}$ CON } & 124 & 3.19 & 233 & 0.639 & 3.95 & 231 & 0.985 & 0.346 & 0.171 & 100.0 \\
\hline \multicolumn{2}{|c|}{ STD ${ }^{*}$ SORC ${ }^{\star}$ BOUT } & 105 & 3.11 & 175 & 0.449 & 4.08 & 172 & 0.786 & 0.338 & 0.217 & 100.0 \\
\hline \multicolumn{2}{|c|}{ STD*WILD*CON } & 196 & 3.15 & 207 & 0.549 & 3.90 & 207 & 0.849 & 0.300 & 0.179 & 99.5 \\
\hline \multicolumn{2}{|c|}{ STD*WILD*BOUT } & 184 & 3.17 & 174 & 0.467 & 3.99 & 174 & 0.773 & 0.306 & 0.188 & 98.9 \\
\hline \multicolumn{2}{|c|}{ CULL ${ }^{*} F S I B^{*} C O N$} & 126 & 2.46 & 243 & 0.419 & 3.72 & 235 & 0.898 & 0.479 & 0.341 & 99.4 \\
\hline \multicolumn{2}{|c|}{ CULL*FSIB*BOUT } & 114 & 2.24 & 151 & 0.205 & 3.76 & 148 & 0.583 & 0.378 & 0.434 & 99.1 \\
\hline \multicolumn{2}{|c|}{ CULL ${ }^{*} S O R C{ }^{*} C O N$} & 92 & 2.44 & 228 & 0.396 & 3.63 & 233 & 0.864 & 0.468 & 0.350 & 99.0 \\
\hline \multicolumn{2}{|c|}{ CULL*SORC*BOUT } & 111 & 2.34 & 142 & 0.209 & 3.74 & 140 & 0.548 & 0.339 & 0.386 & 100.0 \\
\hline \multicolumn{2}{|c|}{ CULL *WILD*CON } & 163 & 2.35 & 191 & 0.305 & 3.64 & 189 & 0.709 & 0.405 & 0.366 & 100.0 \\
\hline \multicolumn{2}{|c|}{ CULL*WILD*BOUT } & 175 & 2.35 & 138 & 0.206 & 3.29 & 140 & 0.444 & 0.238 & 0.282 & 98.9 \\
\hline
\end{tabular}

Survival values did not appear to be influenced by cull classification but cull seedlings had fewer individuals with a normal flush (Table 5). Survival was greater than $98.5 \%$ regardless of whether seedlings were culls or acceptables.

There were 967 seedlings classified as acceptable (stan- dard) because they met BCFS summer planting specifications. Of these seedlings, 494 were controls and 473 were blackout treated (Table 6). Although blackout seedlings had smaller mean heights at planting and in September than control seedlings, RCD values were similar between treatments (Table 6). Blackout treated seedlings had a smaller stem volume increment than controls over the summer growth period.

\section{DISCUSSION}

Interior spruce seedlings derived from seed orchard seed have proven to be vigorous growers (Hawkins and 
Table 5. Bud break characteristics of seedlings planted in July 1993 and assessed in June 1994 at RRRS by cull classification and photoperiod. Terminal leader bud break characterized as normal, failed to flush (None) or abnormal rosette - many short leaders (Funny). Abbreviations as in Table 4.

\begin{tabular}{|c|c|c|c|c|c|}
\hline \multirow[b]{2}{*}{ Classification } & \multirow[b]{2}{*}{ PP } & \multirow[b]{2}{*}{$n$} & \multicolumn{3}{|c|}{ Percentage of Seedlings } \\
\hline & & & Normal & None & Funny \\
\hline \multirow{2}{*}{$\mathrm{HT}<140 \mathrm{~mm}$} & CON & 11 & 64 & 27 & 9 \\
\hline & BOUT & 59 & 30 & 24 & 46 \\
\hline \multirow[t]{2}{*}{$\mathrm{HT}>280 \mathrm{~mm}$} & CON & 62 & 79 & 18 & 3 \\
\hline & BOUT & 0 & - & - & - \\
\hline \multirow{2}{*}{$\mathrm{RCD}<2.6 \mathrm{~mm}$} & CON & 265 & 81 & 14 & 5 \\
\hline & BOUT & 206 & 49 & 35 & 16 \\
\hline$H T<140 \mathrm{~mm} \&$ & CON & 26 & 58 & 23 & 19 \\
\hline $\mathrm{RCD}<2.6 \mathrm{~mm}$ & BOUT & 134 & 22 & 39 & 39 \\
\hline $\mathrm{HT}>280 \mathrm{~mm} \&$ & CON & 17 & 76 & 24 & 0 \\
\hline $\mathrm{RCD}<2.6 \mathrm{~mm}$ & BOUT & 1 & 0 & 100 & 0 \\
\hline \multirow[t]{2}{*}{ CULL summary } & CON & 381 & 78 & 16 & 6 \\
\hline & BOUT & 400 & 37 & 35 & 28 \\
\hline \multirow[t]{2}{*}{ STD summary } & CON & 494 & 87 & 11 & 2 \\
\hline & BOUT & 473 & 57 & 27 & 16 \\
\hline \multirow[t]{2}{*}{ TOTAL } & CON & 875 & 83 & 13 & 4 \\
\hline & BOUT & 873 & 48 & 31 & 21 \\
\hline
\end{tabular}

Krasowski 1993). This fact and seed orchard stock's reputation of displaying greater morphological (spindly seedlings) and physiological variation, when compared to natural stand stock, has caused B.C. silviculturists and nursery managers to express concerns regarding the quality and utility of seed orchard seed derivatives. During this study, however, seed origin only influenced seedling height at planting but otherwise had no impact $(\mathrm{P}>0.95)$ on morphological parameters calculated at planting and after the remaining summer of field growth. Further-

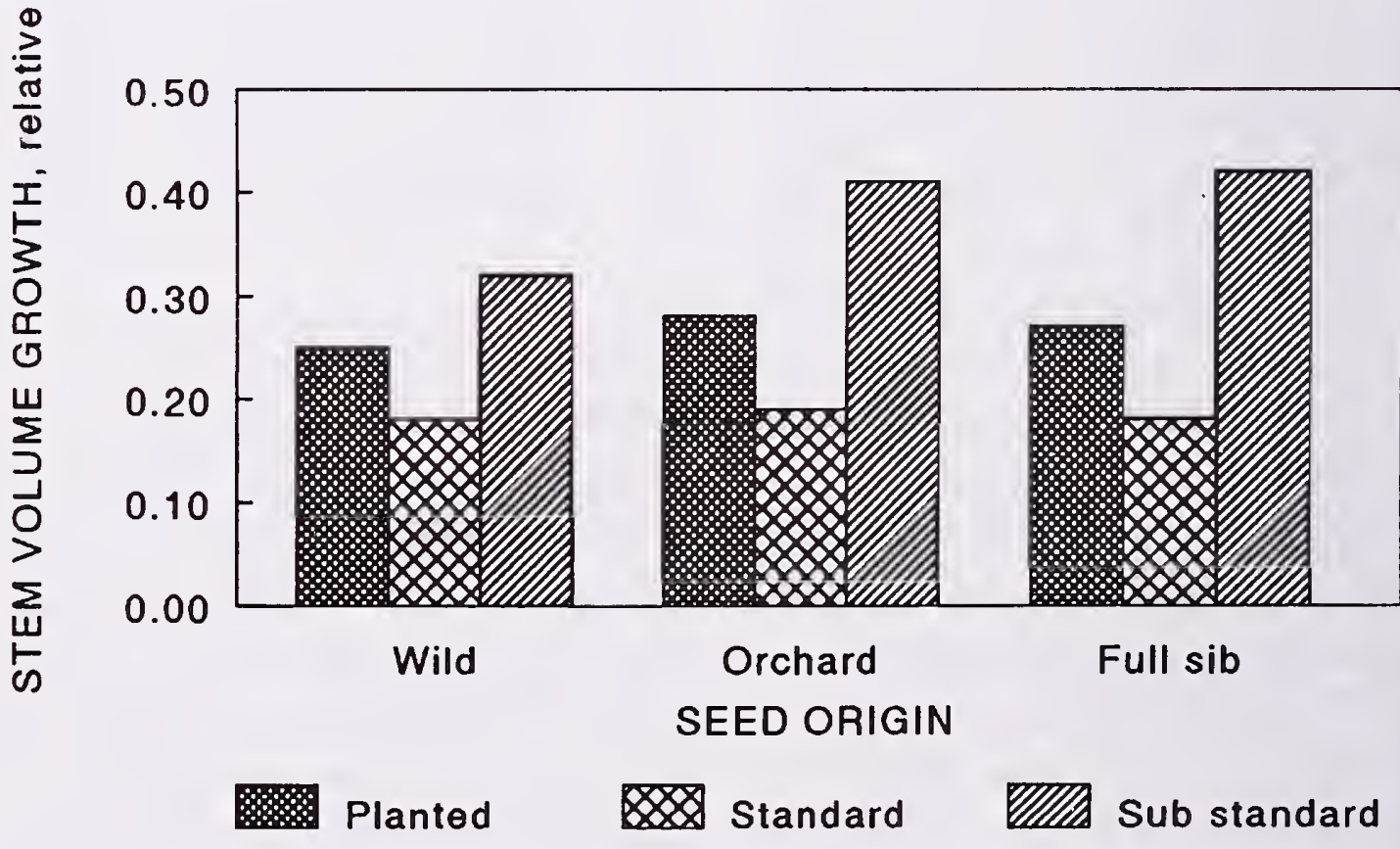

Figure 1. Relative stem volume growth ( $\mathrm{LL} \cdot \mathrm{mL} \cdot$ season) by seed origin for all seedlings planted in July1993, standard seedlings after culling, and for culled sub standard seedlings. 
Table 6. Mean morphological characteristics of summer planted (July) seedlings by cull class and summer growth (September) with respect to classification. Abbreviations as in Table 5.

\begin{tabular}{|c|c|c|c|c|c|c|c|c|}
\hline \multirow[b]{2}{*}{ Classification } & \multirow[b]{2}{*}{ PP } & \multirow[b]{2}{*}{$n$} & \multicolumn{2}{|c|}{ July 1993} & \multicolumn{4}{|c|}{ September 1993} \\
\hline & & & $\begin{array}{l}\mathrm{RCD} \\
(\mathrm{mm})\end{array}$ & $\begin{array}{l}\mathrm{HT} \\
(\mathrm{mm})\end{array}$ & $\begin{array}{l}\mathrm{RCD} \\
(\mathrm{mm})\end{array}$ & $\begin{array}{l}H T \\
(\mathrm{~mm})\end{array}$ & $\begin{array}{r}\text { VINC } \\
\left(\mathrm{mm}^{3}\right)\end{array}$ & $\begin{array}{c}\text { VGRO } \\
\left(\mathrm{mm}^{3} \cdot \mathrm{mm}^{3}\right)\end{array}$ \\
\hline \multirow[t]{2}{*}{$\mathrm{HT}<140 \mathrm{~mm}$} & CON & 11 & 3.00 & 125 & 2.96 & 145 & 0.123 & 0.119 \\
\hline & BOUT & 59 & 2.97 & 125 & 3.51 & 131 & 0.193 & 0.181 \\
\hline \multirow[t]{2}{*}{$\mathrm{HT}>280 \mathrm{~mm}$} & CON & 62 & 3.21 & 302 & 4.01 & 296 & 0.501 & 0.202 \\
\hline & BOUT & 0 & - & - & - & - & & \\
\hline \multirow[t]{2}{*}{$\mathrm{RCD}<2.60 \mathrm{~mm}$} & CON & 265 & 2.26 & 205 & 3.68 & 204 & 0.474 & 0.405 \\
\hline & BOUT & 206 & 2.27 & 163 & 3.76 & 158 & 0.394 & 0.415 \\
\hline $\mathrm{HT}<140 \mathrm{~mm} \&$ & CON & 26 & 1.82 & 118 & 2.96 & 115 & 0.174 & 0.418 \\
\hline $\mathrm{RCD}<2.60 \mathrm{~mm}$ & BOUT & 134 & 2.09 & 118 & 3.25 & 121 & 0.236 & 0.387 \\
\hline $\mathrm{HT}>280 \mathrm{~mm} \&$ & CON & 17 & 2.33 & 303 & 3.67 & 284 & 0.626 & 0.364 \\
\hline $\mathrm{RCD}<2.60 \mathrm{~mm}$ & BOUT & 1 & 2.21 & 365 & 3.61 & 360 & 0.762 & 0.420 \\
\hline \multirow[t]{2}{*}{ CULL summary } & CON & 381 & 2.41 & 217 & 3.66 & 215 & 0.454 & 0.363 \\
\hline & BOUT & 400 & 2.31 & 143 & 3.55 & 142 & 0.312 & 0.371 \\
\hline \multirow[t]{2}{*}{ STD summary } & CON & 494 & 3.14 & 223 & 3.89 & 221 & 0.341 & 0.191 \\
\hline & BOUT & 473 & 3.12 & 175 & 3.99 & 173 & 0.318 & 0.213 \\
\hline \multirow[t]{2}{*}{ TOTAL } & CON & 875 & 2.82 & 220 & 3.79 & 218 & 0.390 & 0.266 \\
\hline & BOUT & 873 & 2.75 & 160 & 3.79 & 158 & 0.315 & 0.285 \\
\hline
\end{tabular}

more, when stock was graded to BCFS specifications the significance of seed origin was completely lost. Nursery treatment and seedlot proved to be the main sources of variation for seedling morphology whether the analysis was performed on the entire, standard, or culled populations. In studies performed by Hawkins (1993a), seed orchard seedlots were found to be within the observable range of height variation for natural stand seedlots and displayed no unusual nursery growth patterns. In fact, Hawkins (1993b) noted that within the nursery there did not appear to be any poor per- forming seed orchard seedlots (all were vigorous) as there were with natural stand seedlots. Likewise, the morphological parameters observed during this study, showed seed orchard seedlots to possibly have more desirable characteristics (greater heights, RCD, shoot and root weights, stem volume increment and relative volume growth) at planting and after a partial field season, than did natural stand collection seedlots. Although natural stand seedlots were better balanced than seed orchard seedlots at planting, these differences were minimal by September.
Blackout is not totally accepted as an appropriate nursery regime. Concerns exist regarding seedling RCD, root mass, susceptibility to reflush after summer planting and altered post planting bud phenology (c.f. Krasowski et al. 1993) as a result of blackout treatment. Overall, blackout stock was shorter than control seedlings. However, blackout seedlings' RCDs were equal to or greater than control seedlings in both the culled and acceptable classes. The dry root weights of blackout treated stock (all seed origins) closely paralleled those of untreated stock, 
indicating that blackout did not reduce seedling root mass. Experiments by Hawkins and Draper (1991) and by Hawkins and Krasowski (1993) have shown some seedlots to actually increase their root mass after removal from blackout in response to blackout treatment. Although this root growth phenomenon was not observed in this experiment, the shorter heights and consequently, smaller shoot weights for blackout treated seedlings, combined with similar RCD and root weights to controls resulted in seedlings with smaller height to $\mathrm{RCD}$ and shoot weight to root weight ratios. These smaller ratios are characteristic of the preferred 'sturdy' morphotype for seedlings (Burdett et al. 1984). The severe blackout treatments used in previous experiments may have resulted in lower quality seedlings and hence, blackout's poor reputation. The moderate regimes used presently, produced morphologically suitable seedlings for summer planting. Nursery treatment did not influence the number of seedlings culled or accepted according to BCFS specifications.

The absence of reflush (data not presented) after planting in July 1993 suggests the blackout treatments administered were sufficient to control nursery seedling height growth while also maintaining bud development (Hawkins 1993b). In June
1994 when apical buds were assessed for flushing characteristics (Table 5) one-third had failed to flush or had broken their apical buds but had not or had only partially extended (1 to $3 \mathrm{~cm}$ ) their preformed leaf primordia. More blackout treated seedlings failed to flush or had unusual terminal bud flushing characteristics compared to control seedlings. Similar results have occurred in studies by Krasowski et al. (1993) for spring planted, blackout treated spruce seedlings.

Krasowski et al. (1993) suggested that buds reactivating growth earlier in the spring are more affected by frost injury. Perhaps this occurred in our experiment. Alternatively, Hawkins and Hooge (1988) have reported greater early-winter terminal bud mortality in blackout treated Sitka-white hybrid spruce seedlings. As suggested by Hawkins and Draper (1991), these differences between control and blackout treated seedlings could possibly be minimized if nursery crop lifting was based on seedlings achieving common physiological requirements rather than aiming for certain developmental goals or meeting time requirements. The timing of bud injury is important to address. If it occurred during the remaining summer after planting it would suggest that summer planting of blackout treated nursery stock should perhaps be reconsidered. However, if the damage occurred during the winter or following spring, it would indicate that some degree of risk involving apical bud injury to seedlings is associated with any planting program, whether it is spring or summer planting.

Culling seedlings at the time of planting to BCFS specifications is a standard nursery practice. However, growth of summer planted seedlings during the partial summer after planting was tested in this experiment in relation to these grading criteria. The majority of seedlings were culled because they had inadequate $\mathrm{RCD}$ and/or were underheight. Of the seedlings culled because of poor RCD, many had RCD between 2.5 and $2.6 \mathrm{~mm}$, just under minimum RCD specifications. It is believed that these seedlings would have reached BCFS RCD specifications if lifting had been delayed a few days or if blackout application occurred when seedlot mean height values were approximately $10 \mathrm{~mm}$ larger than they were in this experiment (Hawkins 1993c). Culls that were underheight $(<140 \mathrm{~mm})$, primarily a result of blackout application, were generally sturdier seedlings with smaller height to RCD ratios than the taller acceptable seedlings. During studies related to planting check, Burdett et al. (1984) concluded that height measurements can be an inadequate estimate of biomass accumulation in newly planted trees. Burdett et al. (1984) 
found that container seedlings with low height to $\mathrm{RCD}$ ratios obtain rapid early height growth compared to taller seedlings with greater height to $\mathrm{RCD}$ ratios which expend more energy towards diameter growth rather than height growth. In other words, stem diameter is added at the expense of height in less sturdy seedlings. Consequently, the sturdier culls may experience more height growth than the less sturdy acceptable seedlings during next season's growth period. Typically, taller trees are less successful than shorter trees on high snowfall sites, droughty sites, and sites prone to vegetation press because often this increase in height is not paralleled with a similar increase in RCD (Hawkins 1993a), i.e. sturdiness.

Further evidence suggesting present summer plant culling standards may be an inappropriate measurement of seedling quality, comes from observations of relative volume growth over the summer. When relative volume growth was examined for all seedlings (before culling), non-culls (standards) and culls (not acceptable), the culls exhibited the greatest values. Relative volume growth measured in $\mathrm{mL} /$ $\mathrm{mL} / \mathrm{season}$, is expected to be greater for the culls which had smaller stem volumes at planting than the non-culls. That is, it is easier for the smaller culls to double their stem volume than it is for the larger acceptable seedlings. However, stem volume increment, the actual amount of volume added over the first growing season, was similar between culled and acceptable seedlings. Thus, the culls greater volume growth was not just because these seedlings started out with smaller volumes than did the non-culls. It was because they expressed more relative volume growth. The effects of culling summer planted trees according to BCFS specifications appear to have decreased rather than increased the growth potential of stock. Consequently, seedlings that were considered 'poor' according to the BCFS standards may prove to be the best performers, assuming they maintain a similar rate of volume growth over the following growing seasons.

While it is presently practical to cull seedlings strictly based on height and RCD measurements, it may be biologically prudent to include height to diameter ratios in the culling criteria. It is recognized that this approach is impractical in our present nursery grading scheme. However, once machine grading is introduced, culling based on heights, root collar diameters and acceptable ratios between the two will be possible. This approach should be implemented at that time.

Thus far, characteristics of concern, suggesting the inferior quality of seed orchard stock compared to natural stand stock, have not been apparent. In fact seed orchard seedlots have displayed favourable morphologies and growth patterns. Blackout treatment, appears to have controlled the morphological variability in all seed sources producing uniform seedlings. Blackout's influence on 1994 apical bud flushing characteristics appears to be negative, however no conclusions on the long term effects of these results can be made until next season's shoot growth is observed.

Between 1985 and 1989, 59\% of all coastal Douglas-fir seed was supplied from seed orchards (El-Kassaby et al. 1992). In New Brunswick, all seed used to produce black spruce (Picea mariana (Mill.) B.S.P.) seedlings for reforestation is obtained from seed orchards (Morgenstern and Park 1991). The interior spruce program in B.C. should be able to meet $60 \%$ of the seed needs by the end of the decade. Hopefully this experiment, further studies and the above information will encourage B.C. foresters and nurseries to become more confident with spruce seed orchard seed and chose to use it in their regeneration programs.

\section{PRELIMINARY CONCLUSIONS}

Seedlings produced from interior spruce seed orchard seed are being met with reluctance by the operational forestry commu- 
nity. These trees are vigorous growers with the reputation of displaying unusual amounts of morphological and physiological variation within and among seedlots. Recent studies have shown nursery treatments, specifically blackout, to be an effective tool for controlling vigorous seedlots. Preliminary conclusions from the summer plant show that seed orchard seedlots are not outliers (unusual) in terms of morphological parameters. In fact, these seedlots possessed more favourable morphological characteristics than did natural stand seedlots. Blackout treatment produced shorter seedlings. They were morphologically uniform and ready for summer planting. Although blackout was observed to have negatively impacted apical bud flushing, the impact this may have on the future performance of seedlings cannot be concluded until further shoot growth data has been collected. According to the present culling criteria, many of the smaller seedlings are unacceptable for planting. However, these seedlings were sturdier and displayed better relative volume growth than did the acceptable seedlings. Consequently, the present method of grading seedlings for summer planting may be too conservative. BCFS specifications may need to be modified to include these more desirable sturdy morphotypes. However, this may not be practical until machine grading is introduced into nurseries. Regardless, seedlings that were culls performed well and the rationale behind morphological specifications should be revisited.

\section{LITERATURE CITED}

Arnott, J.T. \& A. Mitchell. 1981.

Influence of extended photoperiod on growth of white and Engelmann spruce seedlings in coastal British Columbia nurseries. In Proc. Can. Containerized Tree Seedling Symp. J.B. Scarratt, C. Glerum \& C.A. Plexman (editors). Can. Ont. Joint For. Res. Comm. Proc. O-P-10, pp. 139-152.

Bigras, F.J. \& A.L. D'Aoust. 1993. Influence of photoperiod on shoot and root frost tolerance and bud phenology of white spruce seedlings (Picea glauca). Can. J. For. Res. 23:219-228.

Burdett, A.N., L.J. Herring \& C.F. Thompson. 1984. Early growth of planted spruce. Can. J. For. Res. 14:644-651.

Colombo, S.J., D.P. Webb, \& C. Glerum. 1981. Cold hardiness and bud development under short days in black spruce and white spruce seedlings. In Proc. Can. Containerized Tree Seedling Symp. J.B. Scarratt, C. Glerum, and C.A. Plexman (editors). Can. Ont. Joint For. Res. Comm. Proc. O-P-10, pp. 171-176.
D’Aoust, A.L. \& S.I. Cameron. 1981. The effect of dormancy induction, low temperatures and moisture stress on cold hardening of containerized black spruce seedlings. In Proc. Can. Containerized Tree Seedling Symp. J.B. Scarratt, C. Glerum \& C.A. Plexman (editors). Can. Ont. Joint For. Res. Comm. Proc. O-P-10, pp. 153-161.

Draper, D.A. \& C.D.B. Hawkins. 1989. Germination and fertilization regime effects on the growth of container white spruce seedlings at Red Rock Research Station. FRDA Res. Rep. 064. For. Can. and B.C. Min. For., Victoria, B.C.

El-Kassaby, Y.A., D.G.W. Edwards \& D.W. Taylor. 1992. Genetic control of germination parameters in Douglas-fir and its importance for domestication. Silvae Genet. 41:48-54.

Hawkins, C.D.B. 1993a. Variability in spruce seed orchard seedlots. Nursery Extension Newsletter, Silviculture Branch, Victoria, B.C. 6(1).

Hawkins, C.D.B. 1993b. Genetic-induced variation of container nursery-cultured interior spruce in British Columbia. In Proc. 25th Can. Tree Improv. Assoc. Meet., August 1993. Fredericton, NB. J. Laverau (ed.). Natur. Res. Can., Ottawa. 2:115-127. 
Hawkins, C.D.B. 1993c. Summer plant of orchard and natural stand spruce seedlots. Nursery Extension Newsletter, Silviculture Branch, Victoria, B.C. 6(2).

Hawkins, C.D.B. 1993d. Expressed variability of seed orchard seed: cause, control and impact. A pilot nursery study. Unpubl. Work Plan, Res. Branch, Min. For., Victoria, B.C.

Hawkins, C.D.B. \& D.A. Draper. 1991. Effects of blackout on British Columbia spruce seedlots at Red Rock Research Station. FRDA Res. Rep. 170. For. Can. and B.C. Min. For., Victoria, B.C.

Hawkins, C.D.B. \& B.D. Hooge. 1988. Blackout and post planting bud phenology in $\mathrm{S} \times$ S spruce seedlings. In Proc. Combined Meet. W. For. Nurs. Assoc. Aug. 8-11, 1988, Vernon, B.C. T.D. Landis (tech. coord.). USDA For. Serv. Gen. Tech. Rep. RM167. pp.45-49.

\section{Hawkins, C.D.B. \& M.J.}

Krasowski. 1993. Good, bad or ugly: genetic-induced variation of container nurserycultured interior spruce? In Proc. FNABC 13th Annual Meet., September 14, 1993. Courtenay, B.C. pp. 43-50.
Johnson, C.J.S. 1985. How to use seedling quality measurement in container nurseries. In Proc. Intermountain Nurseryman's Assoc. Meet., 1985, Fort Collins, Col. T.D. Landis and J.W. Fischer (editors). USDA For. Serv. Gen. Tech. Rep. RM-125, pp. 84-86.

Krasowski, M.J., T. Letchford \& A.M. Eastham. 1993. Growth of short-day treated spruce seedlings planted throughout British Columbia. B.C. Min. For. and For. Can., Victoria, B.C. FRDA Res. Rep. No. 209.

Lang, H.P. 1989. Risks arising from the reduction of the genetic variability of some alpine Norway spruce provenances by size grading. Forestry 62(Suppl.):49-52.

Matthews, R.G. 1981. Contrasting approaches to containerized seedling production. 1. British Columbia. In Proc. Can. Containerized Tree Seedling Symp. J.B. Scarratt, C. Glerum, and C.A. Plexman (editors). Can. Ont. Joint For. Res. Comm. Proc. O-P-10, pp. 115-122.
Meuller, H., H. Hahn, B. McCutcheon \& C. Bartram. 1981. Review of practices relating to the treatment of seed orchard seed and seedlings. An unpublished report to the Director, Silviculture Branch, Victoria, B.C.

Morgenstern, E.K. \& Y.S. Park. 1991. Breeding of Picea mariana (Mill.) B.S.P.:seed orchard and clonal approaches. Silva Fennica 25(4):280-285.

Odlum, K.D. \& S.J. Colombo. 1988. Short day exposure to induce budset prolongs shoot growth in the following year. In Proc. Combined Meet. W. For. Nurs. Assoc. Aug. 8-11, 1988, Vernon, B.C. T.D. Landis (tech. coord.). USDA For. Serv. Gen. Tech. Rep. RM-167. pp. 57-59.

SAS 1988. SAS/STAT ${ }^{\text {TM }}$ User's Guide, Release 6.03 edition. SAS Institute Inc., Cary, NC, USA. 1028 pp.

Silim, S.N., T. Kannangara, D.P. Lavender \& L. Charleson. 1989. Effects of photoperiod and plant growth regulators upon the growth of coniferous seedlings. Forestry 62(Suppl.):143-148.

Wilkinson, L. SYSTAT: The system for statistics. Evanston. IL: SYSTAT, Inc. 


\title{
Effects of Contrasting Fertilizer Regimes on Greenhouse Growth and Outplant Performance of Containerized Jack Pine ${ }^{1}$
}

\author{
G.S. Henderson, W. Smith, B. Nicks ${ }^{2}$
}

\begin{abstract}
Jack pine seedlings were raised in Jiffy \#165 containers at nine fertilizer regimes to assess whether pre-plant characteristics could be related to subsequent outplant performance. Seedlings received a top dressing of between 0 and $49 \mathrm{mg} \mathrm{N}$ per seedling over a twelve week greenhouse growing period in the summer of 1989. At rotation end, only the two lowest fertilizer regimes, representing less than $4.1 \mathrm{mg} \mathrm{N}$ per seedling,displayed significantly decreased height, diameter, and total dry weight. Toxic growth response to high $\mathrm{N}$ levels was not detected. Three years after planting on a sandy outwash site, seedling stem volume was significantly higher in fertilizer treatments which delivered more than $11 \mathrm{mg} \mathrm{N}$ per seedling. Stem volume increase was $20-58 \%$ more than the conventional regime of $8.1 \mathrm{mg} \mathrm{N}$ per seedling. Field growth was positively related $\left(R^{2}=0.82\right)$ with increasing shoot to root ratios of seedlings at the greenhouse; coeffcient of determination was much weaker with all other preplant seedling parameters. Nitrogen content in seedlings also showed a high positive coefficient of determination $\left(R^{2}=\right.$ 0.71 ) with field performance. The greatest plantation response was evident in seedlings that contained $31 \%$ more nitrogen than conventional seedlings prior to planting. It is postulated that $\mathrm{N}$ content is the more useful predictor of seedling outplant performance as it is a robust measure of pre-plant seedling size and nutrient status. Our results indicate that jack pine seedlings be reared under regimes which deliver more than $11 \mathrm{mg} \mathrm{N}$ per seedling to induce luxury consumption of fertilizer in tissue, which effectively 'loads' seedlings with nitrogen at greenhouse rotation end and stimulates enhanced growth after planting. Additionally, the build up of a nutrient reserve by high fertilizer regimes prior to planting offers a cost-efficient and specialized advantage to jack pine seedlings over site vegetation competing for early establishment in sandy plantations. The utility of high $\mathrm{N}$ fertilizer application in enhancing early field performance of jack pine along with the facility of implementing such luxury consumption fertilizer regimes in the greenhouse suggests that $\mathrm{N}$ content is a beneficial complementary parameter for assessing seedling quality in containerised stock programmes.
\end{abstract}

\section{INTRODUCTION}

The efficient use of $\mathrm{N}$-fertilizer is an important objective in container tree nutrient regimes as it is typically the element most utilized by plants and frequently limits growth of seedlings (Landis 1989).

A wide array of $\mathrm{N}$-fertilizer regimes, however, can produce healthy, plantable, greenhousecultured container tree seedlings.
Scarratt (1986), for example, found that any of 10 different fertilizer treatments applied at 100 ppm $\mathrm{N}$ to jack pine yielded similar seedling morphology, with no apparent advantage conferred by special forestry

${ }^{1}$ Henderson, G.S. 1994. Effects of Contrasting Fertilizer Regimes on Greenhouse Growth and Outplant Peformance of Containerized Jack Pine. IN: Landis, T.D.; Dumroese, R.K., tech. coords. National Proceedings, Forest and Conservation Nursery Associations. Gen. Tech. Rep. RM-257. Fort Collins, CO: U.S. Department of Agriculture, Forest Service, Rocky Mountain Forest and Range Experiment Station: 130-138.

${ }^{2}$ Jiffy Products (NB) Ltd, Shippagan, N.B.EOB 2PO; Mikro-Tek Labs, Timmins, Ont. P4N 7X8; E.B. Eddy Forest Products Ltd., Espanola,Ont. POP 1CO. Canada; respectively. 
mixes or starter and finishing preparations, despite large differences in supplied nutrients. Columbo and Smith (1988) measured greatest shoot, diameter and root dry weight in containerised jack pine which corresponded to $9.19 \mathrm{mg} \mathrm{N} /$ seedling and $1.91-2.33 \%$ foliar $\mathrm{N}$. Timmer and Armstrong (1987) found that $10 \mathrm{mg} \mathrm{N} /$ seedling applied to red pine in An exponential fashion resulted in superior seedling height, dry matter production and root development. Others (Burgess 1990, Troeng and Aczell 1988) have also found advantages in applying fertilizer to seedlings in an exponential fashion during the rapid growth phase, particularly as a means of increasing root development and lowering shoot to root ratios.

However, few container seedling fertilizer programmes are assessed in terms of resultant field performance. Timmer et al. (1991) found that containerised black spruce seedlings raised on an exponential fertilizer regime had significantly greater growth than those on a conventional regime, one year after planting seedlings in pots filled with forest soils. Black spruce seedlings 'loaded' in the greenhouse attained foliar N\% of 2.68 and resulted in significantly greater height and dry matter production one season after outplanting (Timmer and Munson 1991). In a review, Landis (1985) found that while nursery fertilization does not necessarily affect seedling survival after out planting, seedling growth was strongly positively related to pre-plant fertilizer regimes for a variety of coniferous species.In particular, pre-plant foliar $\mathrm{N}$ levels were the best indicators of out plant seedling height development, with Rsquared values reaching 0.84 .

The present investigation follows the field survival and growth of jack pine container seedlings that developed under a variety of nitrogen fertilization treatments.

\section{MATERIALS AND METHODS}

Jack pine (Pinus banksiana Lamb.) seedlings grew in a plastic covered greenhouse at Northern Greenhouse Farms, Iroquois Falls, Ontario, Lat. 48 degrees 46 minutes north, Long. 80 degrees 41 minutes west. The seedlings were sown on June 26, 1989 into Jiffy Forestry Pellets type \#165 (Jiffy Products (N.B.) Ltd., Shippagan, New Brunswick at a density of 910 pellets $/ \mathrm{m}^{2}$. Each pellet was approximately $7.5 \mathrm{~cm}$ in height and $30 \mathrm{~mm}$ in diameter and contained $45 \mathrm{~m}^{3}$ of peat moss amended to a $\mathrm{pH}$ of 4.5 and electrical conductivity of 1.0 millimos. Jiffy pellets are covered by a mesh net which compartmentalizes cavities.

Seedlings developed under natural daylight. Greenhouse conditions ranged from night minimum to day maximum temperatures of 15-20 Celsius.
Twenty-seven trays $(1$ tray $=$ 330 pellets) were arranged on benches in a randomized block design $(8,910$ total seedlings) such that each of nine fertilizer treatments was replicated three times, with each tray representing one treatment.

Seedlings were fertilized using the following treatments of differing concentrations of $\mathrm{N}: 1.0 \mathrm{x}$, water only $(0 \mathrm{ppm} \mathrm{N}) ; 2$. $1 / 2 \mathrm{x},(50 \mathrm{ppm} \mathrm{N}) ; 3.1 \mathrm{x},(100$ ppm N); 4. 1.2x, (120 ppm N); 5. $1.4 \mathrm{x},(140 \mathrm{ppm} \mathrm{N}) ; 6.2 \mathrm{x},(200$ ppm N); 7. 6x, (600 ppm N); 8. $1 / 2 \mathrm{Ex}$ (half exponential rate); and 9. Ex (full exponential rate). $\mathrm{X}$ refers to a rate of $100 \mathrm{ppm} \mathrm{N}$, frequently applied to jack pine seedlings on an operational basis in Northern Ontario. Exponential rates were established using the function of Ingestaad and Lund (1979):

$$
N t=N s\left(e^{n t}-1\right)
$$

where,

$\mathrm{Nt}=$ amount of $\mathrm{N}$ to be added weekly (ppm N)

$N s=\operatorname{start} N(5 \mathrm{ppm} N)$

$r=$ relative addition rate (daily addition rates of $N$ are $6 \%$ for Ex and $3 \%$ for $1 / 2 \mathrm{Ex}$ )

$t=$ frequency of relative addition rate (7 days).

The value for Ns was established from Timmer and Armstrong (1987). Nitrogen was supplied as $12 \% \mathrm{NO}_{3}^{-}, 8 \% \mathrm{NH}_{4}^{+}$, from a water soluble 20-8-20 Plant Products Forestry growing 
-phase mix, applied by a handheld watering can to each tray, starting three weeks after germination and continuing for twelve weeks. A starter fertilizer of 1141-8 (100 ppm N) was applied once every two weeks after germination to all treatments except $0 x$. Fertilizer was applied weekly, with supplemental irrigation as required to prevent seedlings from reaching their wilting point. Seedling germination was considered complete on June 26, based on tested seed viability and vigour.

Fifteen weeks after germination, seedlings were measured and samples collected. Ten seedlings were randomly extracted from each tray and measured for height from root collar to bud tip, root collar diameter, and then oven dried for total dry weight. The first two rows and columns of trays were not sampled to provide a buffer against edge effects. Thirty seedlings per treatment were recorded. Differences between treatments were compared using ANOVA and the Least Significance Difference Test (Snedcor \& Cochran 1980).

Percentage $\mathrm{N}$ in foliage was determined from a composite sample of three randomly selected, then oven dried, seedlings per treatment by the Kjeldahl method (Bremner and Mulvaney 1982) at the Hugh John

Flemming Forestry Complex in Fredericton, N.B.
After measurements, seedlings were moved in trays to an outside holding area in the same design as in the greenhouse to harden and overwinter under snow. No further fertilization was applied prior to shipping seedlings for planting the following spring.

\section{FIELD}

Seedlings were planted on June 14, 1990 by E.B. Eddy Forest Products Ltd. of Espanola, Ontario at the Upper Spanish Forest, Lat. 47 degrees, 28 minutes north, Long. 81 degrees 50 minutes west.

The site is a level, glaciofluvial outwash plain, characterized by deep, rapidly drained coarse sands capped with $20 \mathrm{~cm}$ of well-drained sandy loam. Organic horizons average only $2.5 \mathrm{~cm}$ in thickness. Due to a weakly developed Ae horizon, this soil is classified as Mini Humo-Ferric Podzols (Anon., 1974).

Lesser vegetation includes low-bush blueberry (Vaccinium angustifolium Ait.), trailing arbutus (Epigaea repens L.), wintergreen (Gaultheria procumbens L.), bearberry (Arctostaphylos uva-ursi (L.) Spreng.), and club lichens (Cladina spp.). These species are all indicative of dry, relatively infertile site conditions (Sims et al., 1989).
Seedlings were carefully planted at 2.0 metre spacing within furrows prepared by a TTS Delta hydraulic disc trencher. The experimental design consisted of a randomized complete block having 10 replications of 5-tree row plots for each of the 9 fertilizer treatments. Thus, a total of 50 seedlings from each treatment was planted, for a total of 450 seedlings.

Seedlings were measured annually each fall from 1990 to 1993 for total height and diameter at one-third of stem height. Stem volumes were estimated using the formula for a paracone developed by Forslund (1982) and later verified for jack pine (Forslund and Patterson 1994). Data was examined by one-way ANOVA and Least Significant Difference tests to determine treatment effects.A composite sample of 10 randomly selected, then oven dried, seedlings per treatment were collected for determination of $\%$ foliar $\mathrm{N}$.

\section{RESULTS}

\section{Greenhouse:}

The amount of nitrogen supplied to seedlings by the nine fertilizer treatments ranged from 0 to approximately $49 \mathrm{mg}$ per seedling over the twelve week fertilizer period (Table 1). Approximately $32 \%$ of the fertilizer passed between pellets 
and did not enter into calculations of applied N. The ' $\mathrm{x}$ ' or operational $\mathrm{N}$ level of $100 \mathrm{ppm}$ $\mathrm{N}$ delivered $8.1 \mathrm{mg} \mathrm{N} /$ seedling.

There was no significant increase in seedling height. diameter. shoot dry weight or total dry weight beyond the $1 / 2 x$ fertilizer treatment, corresponding to a rate of $4.1 \mathrm{mg} \mathrm{N} /$ seedling (Table 1). Only the $0 \mathrm{x}$ and $1 / 2 \mathrm{Ex}$ treatments, delivering 0 and $1.6 \mathrm{mg} \mathrm{N}$ per seedling, respectively, were associated with significantly decreased morphology and pronounced deficiency symptoms of stunted growth and needle chlorosis. Seedlings in all other treatments met accepted Ontario Ministry of Natural Resources standards for height and root collar diameter.

Root dry weight showed a decreasing trend as fertilizer application amounts were increased. Significantly lower weights were for seedlings grown at rates of more than 11.4 mg N.

Shoot to root ratios also increased with increasing fertilizer amounts. Ratios ranged from 2.1 at the water only treatment to 7.2 for seedlings in the $6 x$ treatment. Significantly highest ratios were for seedlings in the $2 \mathrm{x}$ and $6 \mathrm{x}$ treatments, which received more than $16 \mathrm{mg}$ $\mathrm{N}$ per seedling.
Foliar $\mathrm{N}$ concentrations in seedling needles increased linearly from $1 \%$ in the wateronly treatment up to a maximum of nearly $3 \%$ for the $2 x$ and $6 x$ treatments (Figure 1). The exception to this trend was the Ex treated seedlings, which showed a slight but non-significant increase in \% $\mathrm{N}$ over seedlings in the higher $\mathrm{N}$-applied $\mathrm{x}$ treatment. This verifies the high fertilizer levels at crop rotation end in the exponential regime and accounts for greener needles heading into the over wintering stage (Table 1).

On the basis of expression of seedling morphology and de- fined in terms of nutrient uptake patterns (Landis 1985), deficiency growth symptoms were evident at an $\mathrm{N}$ applied amount of less than $4 \mathrm{mg}$ per seedling. Optimum-luxury consumption was in the wide range of $4-48$ mg applied $N$ per seedling, as plants were able to uptake additional fertilizer without any reduction in morphology and total biomass. Above applied rates of $16 \mathrm{mg} \mathrm{N}$ per seedling, percentage $\mathrm{N}$ in needles remained stable at 2.9, despite increased availability. Toxic growth response to high $\mathrm{N}$ was not observed and is therefore above $48 \mathrm{mg} \mathrm{N}$ per seedling.

\section{Percent N in Foliage Pre-Plant Levels}

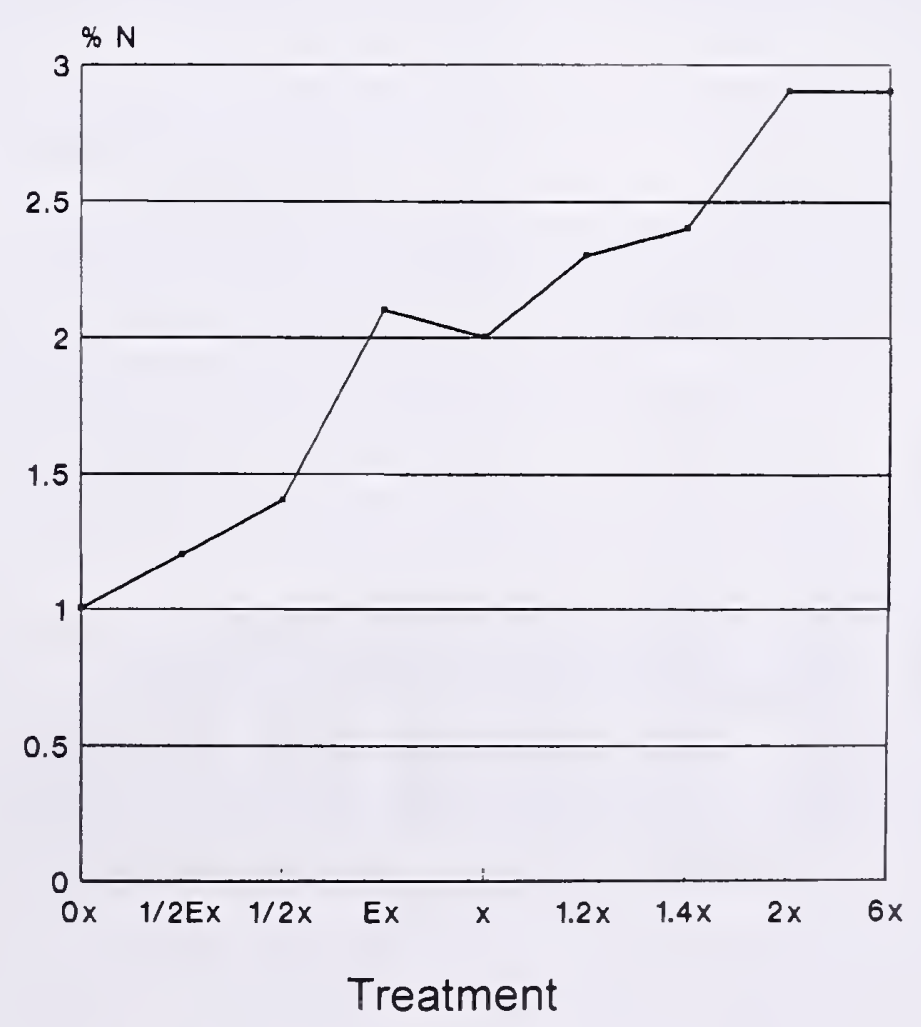

Figure 1 
Table 1. Amount of $\mathrm{N}$ applied by treatment and growth response of seedlings at greenhouse rotation end. Columns followed by the same letter are not statistically different at $\mathbf{p}=\mathbf{0 . 0 5}$.

\begin{tabular}{|c|c|c|c|c|c|c|c|c|c|}
\hline Fertilizer Level & $0 \%$ & 1/2Ex & $1 / 2 x$ & Ex & $x$ & $1.2 x$ & $1.4 \mathrm{x}$ & $2 x$ & $6 x$ \\
\hline $\begin{array}{l}\mathrm{N} \text { applied } \\
\text { (mg/seedling) }\end{array}$ & 0 & 1.6 & 4.1 & 5.9 & 8.1 & 9.7 & 11.4 & $1 \mathrm{C} .2$ & 48.7 \\
\hline Foliar N (\%) & 1 & 1.2 & 1.4 & 2.1 & 2 & 2.3 & 2.4 & 2.9 & 2.9 \\
\hline $\mathrm{N}$ content $(\mathrm{mg})$ & 1.7 & 2.4 & 3.7 & 6.0 & 6.4 & 7.5 & 6.5 & 7.8 & 8.4 \\
\hline Height (mm) & $\begin{array}{l}53.9 \\
\text { (b) }\end{array}$ & $\begin{array}{l}75.3 \\
\text { (b) }\end{array}$ & $\begin{array}{l}106.3 \\
\text { (a) }\end{array}$ & $\begin{array}{l}108.8 \\
\text { (a) }\end{array}$ & $\begin{array}{l}115.9 \\
\text { (a) }\end{array}$ & $\begin{array}{l}124.1 \\
\text { (a) }\end{array}$ & $\begin{array}{l}111.9 \\
\text { (a) }\end{array}$ & $\begin{array}{l}118.5 \\
\text { (a) }\end{array}$ & $\begin{array}{l}118.4 \\
\text { (a) }\end{array}$ \\
\hline Diameter (mm) & $\begin{array}{l}1.0 \\
\text { (b) }\end{array}$ & $\begin{array}{l}1.1 \\
\text { (b) }\end{array}$ & $\begin{array}{l}1.3 \\
\text { (a) }\end{array}$ & $\begin{array}{l}1.4 \\
\text { (a) }\end{array}$ & $\begin{array}{l}1.4 \\
\text { (a) }\end{array}$ & $\begin{array}{l}1.5 \\
\text { (a) }\end{array}$ & $\begin{array}{l}1.4 \\
\text { (a) }\end{array}$ & $\begin{array}{l}1.4 \\
\text { (a) }\end{array}$ & $\begin{array}{l}1.5 \\
\text { (a) }\end{array}$ \\
\hline $\mathrm{Ht}: \mathrm{Dia}$ & $\begin{array}{l}52.5 \\
\text { (c) }\end{array}$ & $\begin{array}{l}66.0 \\
(\mathrm{bc})\end{array}$ & $\begin{array}{l}78.8 \\
(a b)\end{array}$ & $\begin{array}{l}78.1 \\
(a b)\end{array}$ & $\begin{array}{l}79.7 \\
(a b)\end{array}$ & $\begin{array}{l}82.9 \\
\text { (a) }\end{array}$ & $\begin{array}{l}8 \mathrm{LL} \\
(\mathrm{ab})\end{array}$ & $\begin{array}{l}82.3 \\
(a b)\end{array}$ & $\begin{array}{l}80.1 \\
(a b)\end{array}$ \\
\hline Root weight(mg) & $\begin{array}{l}54.0 \\
(a b)\end{array}$ & $\begin{array}{l}57.0 \\
\text { (a) }\end{array}$ & $\begin{array}{l}53.6 \\
(a b)\end{array}$ & $\begin{array}{l}55.1 \\
\text { (a) }\end{array}$ & $\begin{array}{l}53.8 \\
(a b)\end{array}$ & $\begin{array}{l}50.0 \\
(a b)\end{array}$ & $\begin{array}{l}43.8 \\
(a b c)\end{array}$ & $\begin{array}{l}40.2 \\
(\mathrm{bc})\end{array}$ & $\begin{array}{l}35.6 \\
\text { (c) }\end{array}$ \\
\hline $\begin{array}{l}\text { Shoot weight } \\
\text { (mg) }\end{array}$ & $\begin{array}{l}112.3 \\
\text { (c) }\end{array}$ & $\begin{array}{l}141.2 \\
\text { (b) }\end{array}$ & $\begin{array}{l}212.9 \\
\text { (a) }\end{array}$ & $\begin{array}{l}231.2 \\
\text { (a) }\end{array}$ & $\begin{array}{l}268.0 \\
\text { (a) }\end{array}$ & $\begin{array}{l}274.8 \\
\text { (a) }\end{array}$ & $\begin{array}{l}227.1 \\
\text { (a) }\end{array}$ & $\begin{array}{l}228.7 \\
\text { (a) }\end{array}$ & $\begin{array}{l}256.0 \\
\text { (a) }\end{array}$ \\
\hline Shoot:root & $\begin{array}{l}2.1 \\
(\mathrm{e})\end{array}$ & $\begin{array}{l}2.4 \\
\text { (d) }\end{array}$ & $\begin{array}{l}4.0 \\
\text { (cd) }\end{array}$ & $\begin{array}{l}4.2 \\
\text { (bc) }\end{array}$ & $\begin{array}{l}4.9 \\
(\mathrm{bc})\end{array}$ & $\begin{array}{l}5.3 \\
(\mathrm{bc})\end{array}$ & $\begin{array}{l}\text { S. } 1 \\
\text { (bc) }\end{array}$ & $\begin{array}{l}S .7 \\
(a b)\end{array}$ & $\begin{array}{l}7.2 \\
\text { (a) }\end{array}$ \\
\hline $\begin{array}{l}\text { Total weight } \\
\text { (mg) }\end{array}$ & $\begin{array}{l}166.3 \\
\text { (c) }\end{array}$ & $\begin{array}{l}198.2 \\
(\mathrm{bc})\end{array}$ & $\begin{array}{l}266.5 \\
(a b)\end{array}$ & $\begin{array}{l}286.3 \\
\text { (a) }\end{array}$ & $\begin{array}{l}321.7 \\
\text { (a) }\end{array}$ & $\begin{array}{l}324.8 \\
\text { (a) }\end{array}$ & $\begin{array}{l}270.8 \\
(a b)\end{array}$ & $\begin{array}{l}269.0 \\
(a b)\end{array}$ & $\begin{array}{l}291.6 \\
\text { (a) }\end{array}$ \\
\hline
\end{tabular}

\section{Field:}

Seedlings in all treatments had $90 \%$ or greater survival three seasons after planting (Table 2), except seedlings grown without fertilizer that showed a low survival of $70 \%$. Even the small amount of fertilizer of $1.6 \mathrm{mg} \mathrm{N}$ per seedling at the $1 / 2$ Ex treatment increased seedling survival substantially.

Seedling height three years after planting ranged from 11.3 $\mathrm{cm}$ at $0 \mathrm{x}$ to $40.8 \mathrm{~cm}$ at $6 \mathrm{x}$ (Table $2)$. Height was significantly greater with all fertilizer treatments than seedlings grown with water only, but high levels of fertilizer did not significantly improve height over the conven- tional treatment (x). Annual height increment of seedlings in year three did not differ significantly amongst fertilizer treatments, and ranged from 12.8 $15.8 \mathrm{~cm}$. Only the $1 / 2 \mathrm{Ex}$ and $6 \mathrm{x}$ treatments expressed a significantly greater annual height increment than seedlings grown under a water only regime.

Seedling stem volume three years after planting increased with amount of fertilizer applied, resulting in significant increases at the higher treatments of $11 \mathrm{mg}$ $\mathrm{N} /$ seedling or greater (Figure 2). Lowest response was for wateronly seedlings at $4.1 \mathrm{~cm}^{3}$ which was more than a $200 \%$ reduction in growth below the conventional $\mathrm{x}$ fertilization level of 8.1 mg $N$ per seedling. By contrast, the $2 \mathrm{x}$ and $6 \mathrm{x}$ treatments increased stem volume by 43 and $58 \%$, respectively, over the conventional $\mathrm{x}$ treatment, to a maximum of $11.7 \mathrm{~cm}^{3}$ at the $6 \mathrm{x}$ treatment level.

Three years after planting, fertilized seedlings in all treatments reduced to a relatively level nitrogen concentration of between 1.58 and $1.73 \%$ (Figure 1). This is a considerable reduction from pre-plant levels that reached as high as $2.9 \%$. 
Table 2. Third year post plant growth response of seedlings. Columns followed by the same letter are not statistically different at $p=0.05$.

$\begin{array}{llllllllll}\text { Fertilizer level } & 0 x & 1 / 2 E x & 1 / 2 x & \text { Ex } & x & 1.2 x & 1.4 x & 2 x & 6 \% \\ \text { stem volume (cu.cm) } & 4.1(\mathrm{a}) & 6.4(\mathrm{~b}) & 7.1(\mathrm{~b}) & 7.7(\mathrm{c}) & 7.4(\mathrm{c}) & 7.7(\mathrm{c}) & 8.7(\mathrm{~d}) & 10.6(\mathrm{~d}) & 11.7(\mathrm{~d}) \\ \text { Ht.increment (cm) } & 11.3 & 15.7 & 13.5 & 12.8 & 14.1 & 111 & 13.2 & 13.3 & 15.8 \\ & (\mathrm{a}) & (\mathrm{ab}) & (\mathrm{ab}) & (\mathrm{ab}) & (\mathrm{ab}) & (\mathrm{ab}) & (\mathrm{ab}) & (\mathrm{ab}) & (\mathrm{b}) \\ \text { Helght (cm) } & 18.6 & 32.9 & 32.2 & 33.5 & 36.9 & 32.9 & 37.5 & 40.2 & 40.8 \\ & (\mathrm{a}) & (\mathrm{b}) & (\mathrm{b}) & (\mathrm{b}) & (\mathrm{bc}) & (\mathrm{b}) & (\mathrm{bc}) & (\mathrm{c}) & (\mathrm{c}) \\ \text { Survival \% } & 70 & 98 & 94 & 90 & 96 & 90 & 94 & 94 & 90\end{array}$

Stepwise linear regression between pre-plant seedling characteristics and stem volume three years after planting (Table 3) shows a strong positive relationship with $\% \mathrm{~N}\left(\mathrm{R}^{2}=0.84\right)$, $\mathrm{N}$ content $\left(\mathrm{R}^{2}=0.72\right)$ and shoot to root ratios $\left(R^{2}=0.85\right)$. Root weight also showed a high $\mathrm{R}^{2}$, at 0.75 , but this is clearly intercorrelated with shoot to root ratios. Much weaker $\mathrm{R}^{2}$ values were obtained for pre-plant seedling height, diameter, and total dry weight (Table 3).

\section{DISCUSSION}

$\mathrm{N}$ content of pre-plant seedlings is considered as the primary causative factor in increasing stem volume after planting (Figure 3), despite its lower $\mathrm{R}^{2}$ value than both $\% \mathrm{~N}$ and shoot to root ratios. $\mathrm{N}$ content combines foliar $\mathrm{N} \%$ multiplied by seedling total dry weight and is therefore a more robust measure of seedling $\mathrm{N}$ status than $\% \mathrm{~N}$ alone.

High shoot to root ratios with increasing fertilization application rates at the greenhouse are expected; as $\mathrm{N}$ availability increases, shoots develop preferentially over roots. This trend was also evident in Timmer and
Munson (1991). Further, \% N and shoot to root ratios are themselves highly inter-related at the greenhouse $\left(\mathbb{R}^{2}=0.87\right)$. Salonius and Beaton (1994) discovered that three years after planting, seedling shoot to root ratios converged to a common value on the same site. Therefore, shoot to root ratios are considered an expression of 
Table 3. Coefficient of determination $\left(\mathbf{R}^{2}\right)$ of pre-plant seedling characteristics with third year post plant stem volume.

\begin{tabular}{lllllllll}
\hline$\% \mathrm{~N}$ & $\mathrm{~N}$ content & $\begin{array}{l}\text { shoot } \\
\text { root }\end{array}$ & height & diameter & $\begin{array}{l}\text { height } \\
\text { diameter }\end{array}$ & $\begin{array}{l}\text { root } \\
\text { weight }\end{array}$ & $\begin{array}{l}\text { shoot } \\
\text { weight }\end{array}$ & $\begin{array}{l}\text { total } \\
\text { weight }\end{array}$ \\
0.84 & 0.72 & 0.85 & 0.58 & 0.61 & 0.56 & 0.75 & 0.44 & 0.33
\end{tabular}

cultural practices at the greenhouse only and are not a reliable predictor of field performance.

The result of this study agrees with earlier reports (e.g.Timmer and Munson 1991) which also relates high pre-plant $\mathrm{N}$ to improving out plant performance. Greatest enhanced growth occurred in seedlings that received more than $11 \mathrm{mg} \mathrm{N}$ at the greenhouse, or between 40 $600 \%$ more $\mathrm{N}$ than conventionally applied. The wide range of increased $\mathrm{N}$ rates is indicative of the plasticity of jack pine in accommodating fertilizer without adverse effects. The highest regime, at $48 \mathrm{mg} \mathrm{N} /$ seedling, however, did not significantly improve seedling out plant volume over the lower applica-

\section{Stem Volume vs. N Content Jack Pine}

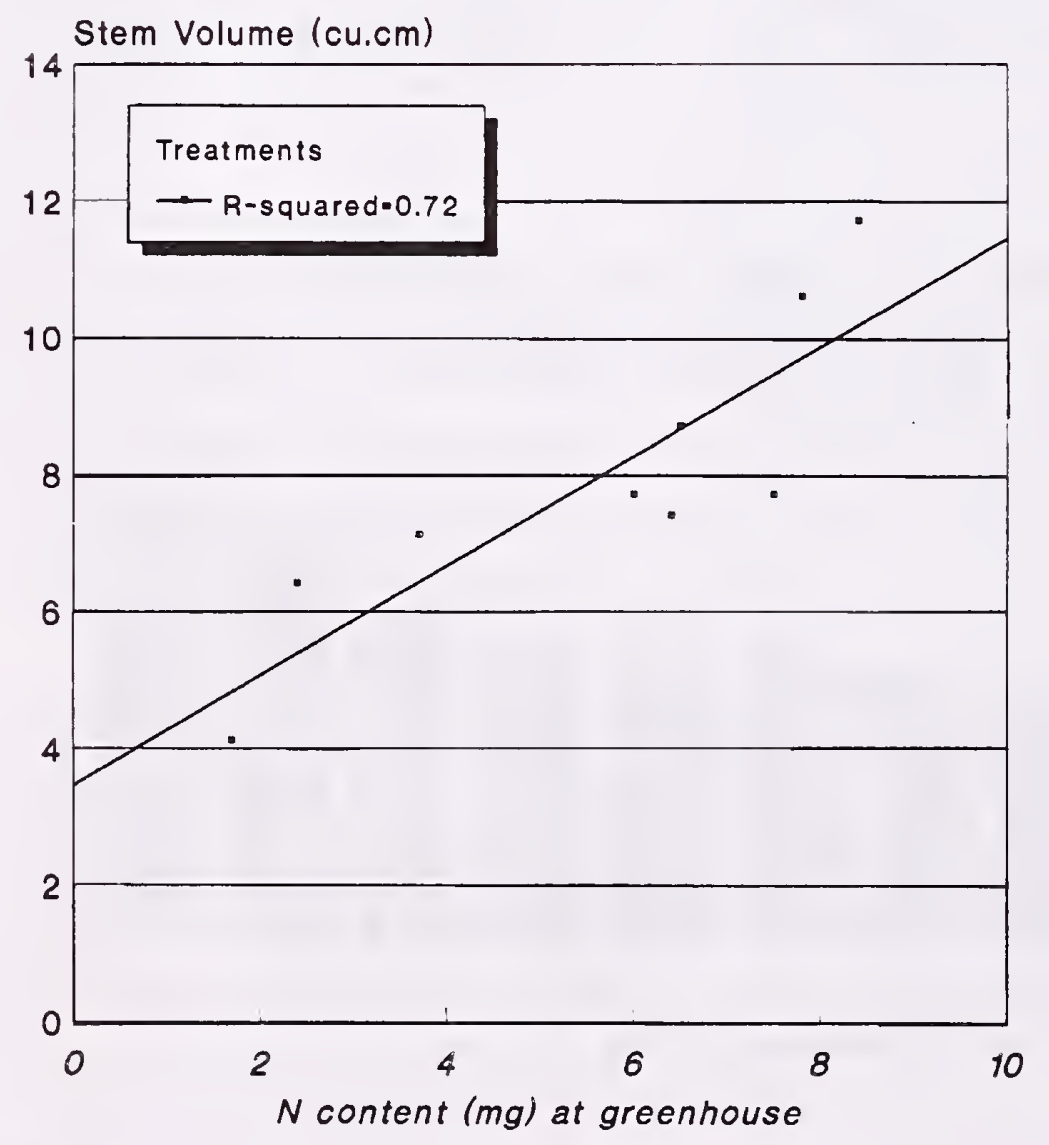

Figure 3

tion rates of 11-16 $\mathrm{mg} \mathrm{N} / \mathrm{seed}$ ling. Further, shoot to root ratios were dangerously high (7:2).

For jack pine, therefore, we have identified the optimum luxury consumption level of applied nitrogen at the greenhouse to be 11-16 mg N/seedling, based on morphology at the greenhouse and then superior response in the field. This nitrogen amount is higher than reported values by Columbo and Smith (1988) and Timmer and Armstrong (1987) for red pine, although these studies evaluated crop response at the greenhouse only. Our N percentage values were also higher - at 2.4-2.9 however, budgetary restrictions prevented large collections that would provide more accurate windows of $\% \mathrm{~N}$ and $\mathrm{N}$-content values.

Timmer et al. (1991) suggests that exponential feed programmes at the greenhouse may be optimum for developing a more physiologically acclimatized seedling and also effectively 'loads' the seedling with high $\mathrm{N}$ prior to planting. Our two exponential treatments may have accomplished this if trees were grown for several more weeks or, with a higher start $\mathrm{N}$ value. 
It is clear that high pre-plant $\mathrm{N}$ greatly benefitted seedling outplant performance. Timmer and Munson (1991) suggest that $\mathrm{N}$ is a stored nutrient reserve which can be tapped by seedlings soon after planting. Munson and Bernier (1993) recorded a rapid decline in $\mathrm{N}$ of black spruce seedlings in the first year after planting. And van den Driessche (1985) found that Douglas-fir seedlings lost all pre-plant $\mathrm{N}$ as well as $\mathrm{P}$ and $\mathrm{K}$ in the first two months after planting. The implication is that $\mathrm{N}$ reserves are used immediately by seedlings after planting, probably in its first year, and the reserves are shunted towards establishment and growth strategies such as new shoots and roots. This accounts for the early differences in stem volume between treatments, evident by second year measurements. The advantage of high $\mathrm{N}$ reserves, therefore, is conferred to seedlings as a short term burst of accelerated growth. This initial advantage given to treated seedlings then carries forward through the formative years of plantation establishment.

Another feature of high $\mathrm{N}$ reserves is that it benefits only the seeedling, as opposed to field fertilization which promotes growth of both desired and nondesired species. With field herbicide spraying programes phasing out due to public sensitivity, greenhouse-based techniques such as high $\mathrm{N}$ should become increasingly attractive. Incorporating luxury $\mathrm{N}$ into greenhouse programs is simple and inexpensive, especially when considering that the benefits could be $20-40 \%$ more stem volume development after only 3 years in the ground.

Finally, industry standards in North America presently place a heavy reliance on seedling morphology at the greenhouse, particularly for establishing payment contracts. It is notable that in this study, greenhouse seedling height and stem diameter contributed very little to outplant performance. Given the importance of seedling $\mathrm{N}$ amount in predicting field growth, however, measurement of foliar $\mathrm{N}$ could prove to be a most useful complementary tool for assessing stock quality.

\section{ACKNOWLEDGMENTS}

The authors are grateful for the review comments and encouragement of this study provided by $R$. van den Driessche, V. Timmer and S. Columbo.

\section{REFERENCES}

Anon. 1974. The system of soil classification for Canada. Publication 1455. Can. Dept. of Agriculture.
Bremner, J.M. and C.S. Mulvaney. 1982. Total nitrogen. In, Methods of soil analysis. Part 2., chemical and microbial properties. R.H. Miller, D.R. Keeney and A.L. Page,eds. Madison, Wisconsin: Am.Soc. Agron.Inc. pp.595-624.

Burgess, D. 1990. White and Black spruce seedling development using the concept of relative addition rate. Scand. J. For. Res. 5: 471-480.

Columbo, S.J. and W.A. Smith. 1988. Response of containerized black spruce and jack pine seedlings to fertilization rate and growing medium. Forestry Rep. No.116, MNR, Ont. 15 p.

Forslund, R.R.1982. A geometrical tree volume model based on the location of the centre of gravity of the bole. Can. J. For. Res. 12(2): 215-221.

Forslund, R.R. and J.M. Patterson. 1994. Nondestructive volume estimates of 11 yr-old Jack Pine and Black Spruce using the power function volume model. Submitted for publication.

Ingestaad, T. and A.B. Lund. 1979. Nitrogen stress in birch seedlings. I. Growth technique and growth. Physiol. Plant. 45:137-148. 
Munson, A.D. and P.Y. Bernier. 1993. Comparing natural and planted black spruce seedlings. II. Nutrient uptake and efficiency of use. Can. J. For. Res. 23:2435-2442.

Landis, T.D. 1985. Mineral nutrition as an index of seedling quality. In, Duryea,M.L. (ed). Proceedings: Evaluating seedling quality: principles, procedures and predictive abilities of major tests. Oct.16-18,1984. Oregon State University, Corvalis.USA.

Landis, T.D., R. Tinus, S.E. MacDonald and J.P. Barnett. 1989. Seedling nutrition and Irrigation, Vol. 4, The Container tree nursery. Agric. Handbook. 674

Washington, D.C.: USDA For. Serv. 119 pp.

Salonius, P. and K. Beaton. 1994. Effect of root packing on field performance of container seedllings. Paper at: Making the Grade, IUFRO Symposium, Sault Ste. Marie, Ont. Sept. 11-15.

Scarratt, J.B. 1986. An evaluation of some commercial soluble fertilizers for culture of Jack Pine Stock. Info-Rep. 0-X-377. For. Can. Great Lakes For. Centre.
Sims, R.A., W.D. Towill, K.A. Baldwin and G.M. Wickware. 1989. Field guide to the Forest Ecosystem Classification for Northwestern Ontario. For. Can. Great Lakes Centre. Sault Ste. Marie, Ontario.

Snedcor, G.W. and W.G. Cochran. 1980. Statistical Methods. The Iowa State University Press. Ames, Iowa. USA.

Timmer, V.R. and A.D. Armstrong. 1987. Diagnosing nutritional status of containerized tree seedlings: comparitive plant analyses. Soil Sci. Am. J. 51:10821086.

Timmer, V.R. and A.D. Munson.1991. Site-specific growth and nutrition of planted response. Can. J. For. Res. 21:1058-1065.

Timmer, V.R., G. Armstrong and B.D.Miller. 1991. Steadystate nutrient pre-conditioning and early outplanting prformance of containerized black spruce seedlings. Can. J. For. Res. 21:585-594.

Troeng, E. and L. Aczell. 1988. Growth regulation of Scotts pine seedlings with different fertilizer composition and regimes. New Forests 2:119130.
Van den Driessche, R. Lateseason fertilization, mineral nutrient reserves, and retranslocation in planted Douglas-fir (Pseudotsuga menziesii (Mirb.) Franco) Seedlings. Forest Sci., Vol.31, No. 2:485-496.

Van den Driessche, R. 1980. Effects of nitrogen and phosporus fertilization on Douglas-fir nursery growth and survival after outplanting. Can. J. For. Res.10:65-70. 


\title{
Five Year Field Performance of Short Day Nursery Treated Engelmann Spruce Seedlings in the Nelson Forest Region of British Columbia ${ }^{1,2}$
}

\author{
Tracy L. Story ${ }^{3}$, Christopher F. Thompson ${ }^{4}$, and Christopher D.B. Hawkins ${ }^{5,6}$
}

Abstract-Engelmann spruce (Picea engelmannii Parry) seedlings of seedlot 5261 were subjected to a series of twelve short day treatment combinations ( 4 photoperiods by 3 durations) at Red Rock Research Station (RRRS) and grown under standard operational conditions at Surrey Nursery in 1988. Nursery treatment at RRRS significantly affected seedling morphology. Surrey stock was taller than RRRS stock. The 12 RRRS treatments plus the operational seedlot from Surrey Nursery were planted at Split Creek in the Kettle River Valley on June 13, 1989. At year five, excellent survival rates were still displayed by all treatments. As observed after nursery culture, height and root collar diameter were still significantly affected by nursery treatment after five field seasons. Photoperiod was a more significant factor than application duration. Ranges of height, root collar diameter, and stem volume for all 12 treatments were greater at planting than at year five; treatment differences were diminishing. Small stock at planting was growing at a greater rate than the larger planting stock. No significant growth difference existed between RRRS short day treated seedlings and Surrey operational stock after five seasons. Small, phenological effects from short day treatments were observed in the first year but were not significant. Overall, results suggest, when stock is spring planted from storage, short day nursery treatment is an effective tool to achieve both nursery and field objectives without compromising either.

\section{INTRODUCTION}

Short day treatment also known as photoperiod regulation or blackout is a procedure currently used by northern nurseries to help control height of vigorous conifer seedlings
(Hawkins and Draper 1988,1991; Draper 1989). The cultural strategies simulate a later stage in the growing season. Seedlings are subjected to a shorter day length than the critical day length (Hawkins and Draper 1988; Bigras and
D'Aoust 1993). In addition to achieving height control, seedlings have improved shoot to root ratio, root growth capacity, enhanced frost hardiness, and earlier dormancy through the use of short day treatments (Draper 1989, Hawkins and Draper

'Story, T.L.; Thompson, C.F.; Hawkins, C.D.B. 1994. Five Year Field Performance of Short Day Nursery Treated Engelmann Spruce Seedlings in the Nelson Forest Region of British Columbia. IN: Landis, T.D.; Dumroese, R.K., tech. coords. National Proceedings, Forest and Conservation Nursery Associations. Gen. Tech. Rep. RM-257. Fort Collins, CO: U.S. Department of Agriculture, Forest Service, Rocky Mountain Forest and Range Experiment Station: 139-149.

${ }^{2}$ Funded by Canada-British Columbia Forest Development Agreement (FRDA) I project 1-36 and FRDA II project 034 .

${ }^{3}$ Coop Student, Simon Fraser University and Red Rock Research Station, RR\#7, RMD\#6, Prince George, BC, Canada, V2N 2J5.

${ }^{4}$ Research Silviculturist, Nelson Forest Region, Nelson, BC, Canada, V1L 4C6.

${ }^{5}$ Research Scientist, Red Rock Research Station.

${ }^{6}$ Corresponding author. 
1991). However, short day treatment has potential field liabilities (Hawkins and Hooge 1988, Odlum and Colombo 1988, Salim et al. 1989, Bigras and D'Aoust 1993). Short day treated stock may flush earlier and grow later into the season, thereby increasing the potential for frost damage in the plantation. If severely frost damaged, a plantation may have increased mortality, or reduced early growth, potentially making the plantation unacceptable.

In 1988, no commercial nursery in the central interior of British Columbia had blackout facilities. There were many questions, both from the nursery and the field, surrounding the impact of blackout on conifer seedlings. The apparent benefits of blackout culture coupled with the concerns lead to a major nursery research trial at Red Rock Research Station (RRRS), near Prince George, BC (lat. $53^{\circ}$ $45^{\prime} \mathrm{N}$, long. $122^{\circ} 42^{\prime} \mathrm{W}$, elev. $620 \mathrm{~m}$ ) commencing in 1988 (Hawkins and Draper 1988, 1991). Daylengths of 13, 15, 17, and 19 (ambient) h were applied for 2, 4 and 6 weeks duration to six interior spruce (Picea glauca (Moench) Voss, P. engelmannii Parry and their naturally occurring hybrids) seedlots ranging in latitude from $49^{\circ}-55^{\circ} \mathrm{N}$ (Hawkins and Draper 1988,1991). After short day treatment, seedlings were raised under ambient day length for the rest of the growing season until lift and freeze storage in early November 1988. The results of the nursery trial are reported elsewhere in detail (Hawkins and Draper 1991). Summarizing the nursery phase, photoperiod had a greater impact on seedling morphology than did application duration and seedlots generally responded in a like manner height was proportional to photoperiod.

Five of the six seedlots grown at RRRS in 1988, after overwinter freeze storage, were planted in the spring of 1989 , back in the area where the seed was collected, for observation of phenological abnormalities and long term growth (Draper 1989). All six of the seedlots were also planted in a common garden at RRRS in the spring of 1989 for detailed phenological observations (Hawkins and Draper 1991). Krasowski et al. (1993) reported on establishment of the five seedlots at the widely distributed field sites after the first field season. Generally in the field, treated seedlings were shorter at planting than untreated seedlings but had greater first field season leader increments than did untreated stock. Although significant, the differences between root collar diameters were small. Seedlings exposed to the shortest day for the longest duration tended to have more terminal buds that did not flush. However, significant phenological effects were observed for only one seedlot on two sites with major spring frost events in 1989 (Krasowski et al. 1993). Hawkins and Draper (1991) reported minimal phenological perturbations for the interior spruce seedlots in the common garden at RRRS.

Fifth season (1993) plantation performance of seedlot 5261 established in the Nelson Forest Region of British Columbia in 1989 is described. The emphasis is nursery treatment influences on sapling morphology, condition, and phenology.

\section{MATERIALS AND METHODS}

\section{Plant Material and Nursery Culture}

Engelmann spruce registered seedlot 5261 (Copper Kettle, lat. $49^{\circ} 44^{\prime} \mathrm{N}$, long. $118^{\circ} 54^{\prime} \mathrm{W}$, elev. $1650 \mathrm{~m}$ ) was sown on March 14, 1988 at RRRS in PSB 313B styroblocks (Beaver Plastics, Edmonton, $\mathrm{AB}$ ) and grown under common culture except for the time of blackout (Hawkins and Draper 1991). Starting July 6,1988 , seedlings received a dynamic system of short day treatments (Hawkins and Draper $1988,1991)$ consisting of four photoperiods $(13,15,17$, and 19 (ambient photoperiod) h), each applied for 3 durations (2, 4, and 6 weeks). From November 2 to 4,1988 , seedlings were lifted and placed in frozen cold storage at $-2^{\circ} \mathrm{C} \pm 1{ }^{\circ} \mathrm{C}$ until spring planting in 1989 (Hawkins and Draper, 1991). 
Seedlot 5261 was also grown under operational conditions of water and nutrient regulated culture at the British Columbia Forest Service, Surrey Nursery (lat. $49^{\circ} 4^{\prime} \mathrm{N}$, long. $122^{\circ} 46^{\prime} \mathrm{W}$, elev. $20 \mathrm{~m}$ ) in 1988. Stock was placed in frozen cold storage in the late fall of 1988. This is referred to as the operational stock.

\section{Planting Sites}

Stock of seedlot (SL) 5261 was shipped from storage at RRRS and Surrey Nursery in early June and planted on June 13, 1989, at Split Creek (lat. $49^{\circ}$ $51^{\prime} \mathrm{N}$. long. $118^{\circ} 45^{\prime} \mathrm{W}$ ) in the Kettle River Valley of the Nelson Forest Region. The predominantly lodgepole pine stand was formerly salvage logged because of mountain pine beetle infestation in 1987 and 1988 and was burned in the fall of 1988 (Thompson, 1989). Burning removed the LFH horizon. However, greater than $60 \mathrm{~cm}$ of rooting depth was still observed. This site has a 0-5 percent south western slope and is in the ICHmw2 BEC subzone (Ecosystems of B.C., 1991) at an elevation of 1375 meters.

The site consisted of five blocks with 13 randomized treatment rows in each (Thompson, 1989). Each row was spaced two $m$ apart with 25 seedlings in a row planted one $m$ apart. Good planting quality was maintained by two planters and no planter effects are suspected (Thomp- son, 1989). Of the 13 rows, 12 consisted of RRRS blackout treated stock and one of operational stock from Surrey Nursery. The operational stock was also planted in the area surrounding the research plantation.

On May 8. 1989 all stock grown at RRRS in 1988 (72 treatments). including seedlot 5261. was planted in a common garden at RRRS (Hawkins and Draper. 1991). The design was a randomized complete block. Phenology assessments were done at weekly or more frequent intervals during the active growing season and year end morphologies were measured (Hawkins and Draper, 1991).

\section{Statistical Analysis}

A completely randomized block design incorporating the RRRS nursery culture was chosen for a three-way factorial analysis (Table 1). The design was simplified when the operational seedlot was included in the analysis (Table 2). Analysis of data at the end of nursery culture simplified the initial model further (Table 3).

The Systat Statistical software package (Wilkinson, 1990) was used to compare treatment means. First and fifth year treatment effects on morphological parameters were compared using Systat's hypothesis contrasting procedure (orthogonal contrasts). This procedure was also used to compare photope- riod and duration effects on treated versus operational stock. Percentage data for survival was normalized using an arcsin transformation (Neter and Wasserman, 1974, pp. 508-509). Additionally, Kruskal-Wallis one way analysis was used to determine if class derived sapling forms were significant after five years (NPAR: Systat). Main treatment effects and interactions were considered significant at alpha $\leq 0.05$.

\section{Measurements}

Post-planting assessments of RRRS treated SL 5261, as well as the Surrey stock, began June 14, 1989 (Thompson, 1989). Total height $( \pm 5 \mathrm{~mm})$ and ground level stem diameter (GSD) $( \pm 0.1 \mathrm{~mm})$ were measured on all seedlings in the spring (pre-flush) and fall (postflush) in 1989. Year five measurements and assessments were done in September 1993. Mean values for height and GSD were calculated and analyzed in relation to one of two models (Tables $1 \& 2$ ). Stem volume was calculated as one-third stem basal area at ground level $\mathrm{x}$ height. Seedling condition (vigour) was assessed at the time of each measurement as recommended by Herring and Pollack (1985).

Detailed phenology assessments were done during the first field season starting on June 27. 1989. two weeks after planting. They continued on a fortnightly 
frequency until terminal bud formation was complete, indicating shoot growth had finished (Thompson, 1989). Consult Krasowski et al. (1993) for more details on first year field data collection, analysis and interpretation. Condition codes were used to record foliage damage, leader and/or stem damage, bud phenology, and presence of insects as outlined by Draper (1989). Seedling condition by treatment was recalculated after each fall measurement series. Only first and fifth year results from Split Creek are presented and discussed.

\section{RESULTS AND DISCUSSIONS}

\section{Nursery Morpleology}

The nursery segment for this series of short day treated seedlings was reported by Hawkins and Draper (1991). In brief, the shorter photoperiod treatments significantly reduced crop height (Figure 1, Table 4) for all seedlots including Engelmann spruce, seedlot 5261. Duration main effects on height were not significant. This suggests for the duration and photoperiod combinations tested, application durations greater than two weeks do not increase the height control attained in the crop. Photoperiod and duration effects on mean root collar diameter (RCD) values were significant. Ambient (19 h) and $17 \mathrm{~h}$ photoperiods did not affect RCD with any of the applied duration periods. How-

Table 1. ANOVA model incorporating RRRS nursery design into the field layout.

$\begin{array}{lrl}\text { Source } & \underline{\text { df }} & \text { Error term } \\ \text { Block } & & \\ \text { Photoperiod } & 4 & \text { Tree (B P D) } \\ \text { Duration } & 3 & B^{*} P \\ B^{*} P & 2 & B^{*} D \\ B^{*} D & 12 & \text { Tree (B P D) } \\ P^{*} D & 8 & \text { Tree (B P D) } \\ B^{*} P{ }^{*} D & 6 & B^{*} P{ }^{*} D \\ \text { Tree (BP D) } & 24 & \text { Tree (B P D) } \\ \text { (B } & 140 & \end{array}$

${ }^{1}$ Block is random and Photoperiod and Duration are fixed factors.

Table 2. ANOVA model for the introduction of the operational seedlot with the 12 RRRS treatments of seedlot 5261.

\begin{tabular}{lrl}
\hline Source & df & Error term \\
Block & 4 & Tree (B T) \\
Treatment & 12 & B $^{*} T$ \\
B $^{*}$ T & 48 & Tree (B T) \\
Tree (B T) & 1543 &
\end{tabular}

${ }^{1}$ Block is a random factor and Treatment is fixed.

Table 3. ANOVA model for seedlot 5261 at the end of RRRS nursery culture.

$\begin{array}{lrl}\text { Source } & \text { df } & \text { Error term } \\ \text { Photoperiod' } & 3 & \text { Seedling }\left(P^{*} D\right) \\ \text { Duration } & 2 & \text { Seedling }\left(P^{*} D\right) \\ P^{*} D & 6 & \text { Seedling }\left(P^{*} D\right) \\ \text { Seedling (P D) } 348 & \\ \\ \text { 'Photoperiod and Duration are fixed factors. }\end{array}$

ever when shorter photoperiods (13 and $15 \mathrm{~h}$ ) were combined with longer durations (4 and 6 week), a significant reduction in RCD was observed (Figure 2, Table 4). This indicates the negative impact of excessive photoperiodic reduction. There was no greater control of seedling height but RCD growth was slowed or stopped. The phenomenon is presumedly related to the lost photosynthetic productivity of extreme treatments. It is possible that for SL 5261 a different photoperiod - duration combination would have been more successful in producing the 'ideal' morphotype; possibly a $13 \mathrm{~h}$ photoperiod for one week. 
For spruce, the 'ideal' morphotype would have a shoot to root ratio of about two (Thompson 1985) and a height to $\mathrm{RCD}$ ratio approaching 40 (Burdett et al. 1984).

First year common garden data for seedlings planted at RRRS revealed that short day treatments had little effect on Engelmann spruce, seedlot 5261. The mean height range between photoperiod and duration levels was only 12 and $5 \mathrm{~mm}$, respectively (Hawkins and Draper, 1991). Analysis of GSD increment displayed different trends among the other seedlots of interior spruce (Hawkins and Draper, 1991). The general trend was for short photoperiod treatments to have greater GSD increments. However SL 5261 showed greater diameter increments with increasing photoperiod. It should be noted that RRRS is considered offsite for this seedlot.

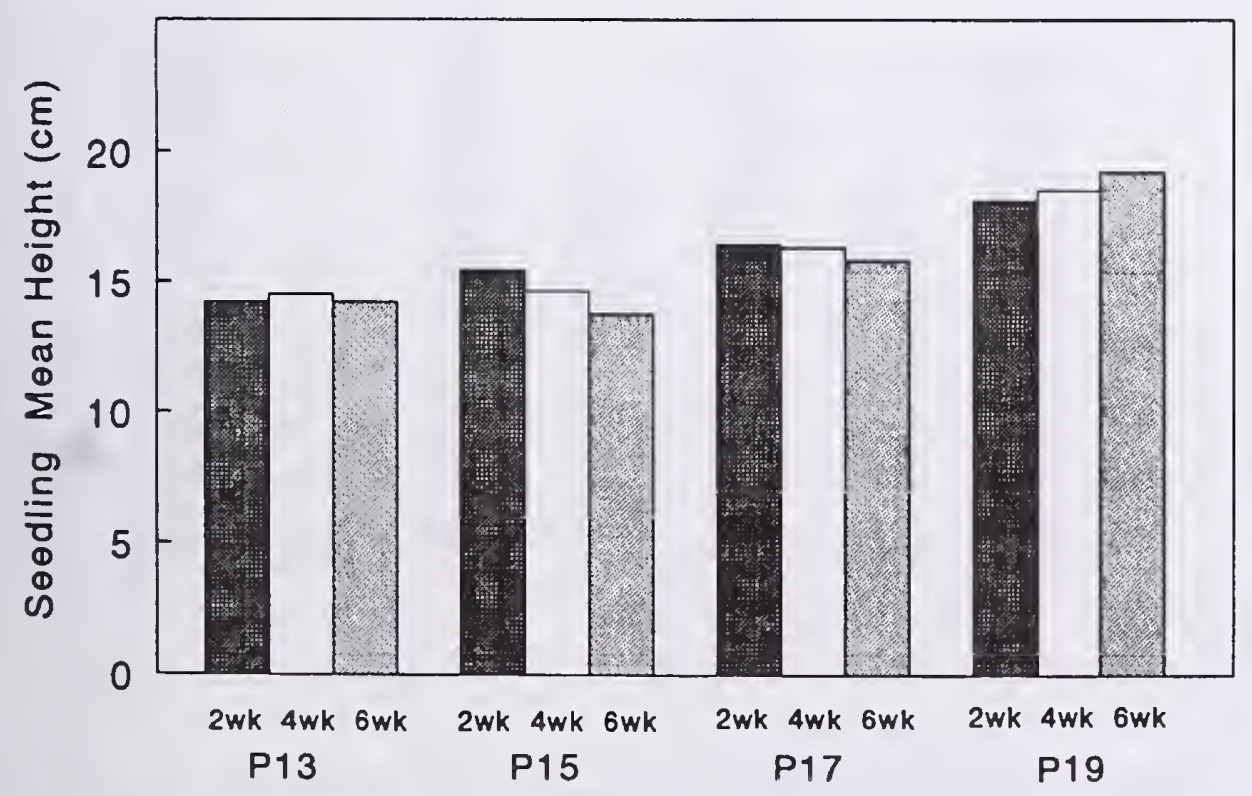

Figure 1. Mean seedling height at the end of nursery culture in 1988 at RRRS by photoperiod and duration. Modified from Hawkins and Draper (1991).

\section{Morphology at Split Creek}

After planting at Split Creek, treatment mean heights were shorter and GSD was greater than sampled in the nursery (Table 4). This reflects i) seedlings were planted deeper than the root collar, and ii) culling at the nursery tended to increase the average diameter of the crop with little effect on height. The mean height after planting of all 13 and $15 \mathrm{~h}$ durations was below the lower limit of $120 \mathrm{~mm}$ for this stocktype as defined by $\mathrm{BC}$ Forest Service seedling growing contract specifications. The operational treatment was significantly taller than all RRRS produced stock, being on average 88 percent $(88.1 \mathrm{~mm})$ taller than stock from the P $15 \mathrm{~h} \mathrm{D} 4$ week treatment. GSD of the operational stock was about the same as that of the tallest RRRS stock.

After the first growing season, height was significantly affected by block, photoperiod and duration (Table 5). Block and duration were also significant for GSD and there were significant $\mathrm{P} * \mathrm{D}$ interactions for both variables (Table 5). The $\mathrm{P}^{*} \mathrm{D}$ interaction for height resulted at a photoperiod of $19 \mathrm{~h}$ where height increased with duration rather than decreasing. The interaction for GSD was caused by the 6 week duration of 15 and $17 \mathrm{~h}$ photoperiods increasing from the 4 week measurement while it decreased in the other two photoperiods. The extreme range between blocks was 0.88 $\mathrm{cm}$ for height and $0.27 \mathrm{~mm}$ for GSD, certainly of no biological interest. Height increased significantly with each photoperiod and increments were similar among photoperiods (Table 5). This suggests short day treatment does not carryover to the field in terms of leader elongation. Krasowski et al. (1993) reported better leader increments for the short day treated stock on other sites in this experimental series. Stock from the short photoperiod treatments were still the shortest after the first season. Photoperiod had no affect on GSD (Table 5) but seedlings treated with the shortest photoperiods had the greatest increments. This suggests a positive field response during the first field season by those seedlings receiving blackout treatment. The operational stock was still significantly taller than any other treatment after 
one year (Tables $5 \& 6$ ). The greater mean height range by photoperiod and duration at Split Creek, 46 and $21 \mathrm{~mm}$, compared to those at RRRS, is within that experienced operationally. This further reinforces the observation the common garden stock was offsite at RRRS. Survival was excellent, greater than 97 percent in all cases except one where it was 93 percent (Table 6).

Height, GSD and stem volume are morphological factors that provide a good estimate of seedling performance after outplanting (Mexal and Landis, 1990). These were used to compare treatment effects after the fifth growing season (Tables $5 \& 6$ ). Photoperiod and duration continue to have significant effects on height (mean range of $\mathrm{P}=49 \mathrm{~mm}, \mathrm{D}=30 \mathrm{~mm}$ ), GSD $(\mathrm{P}=1.1 \mathrm{~mm}, \mathrm{D}=1.2 \mathrm{~mm})$, and stem volume $(P=18 \mathrm{~mL}, \mathrm{D}=15$ $\mathrm{mL}$ ). In general, longer photoperiods combined with shorter durations resulted in taller seedlings with larger GSD and greater stem volume.

The percent extreme range (largest mean - smallest mean) / smallest mean) * 100) for height by photoperiod, duration and 13 treatments was 6,3 , and 13 percent respectively at year five. At planting, these differences were 36,2 and 88 percent. Clearly the shorter stock was growing at a greater rate. A similar trend was observed for GSD. At planting percent ex-
Table 4. Comparison of stock morphology from RRRS and the Surrey Nursery operational seedlot (OPSL) at the end of nursery culture at RRRS (sample) and on measurement after planting at Split Creek (Split). Height (HT), RCD and GSD in $\mathrm{mm}$.

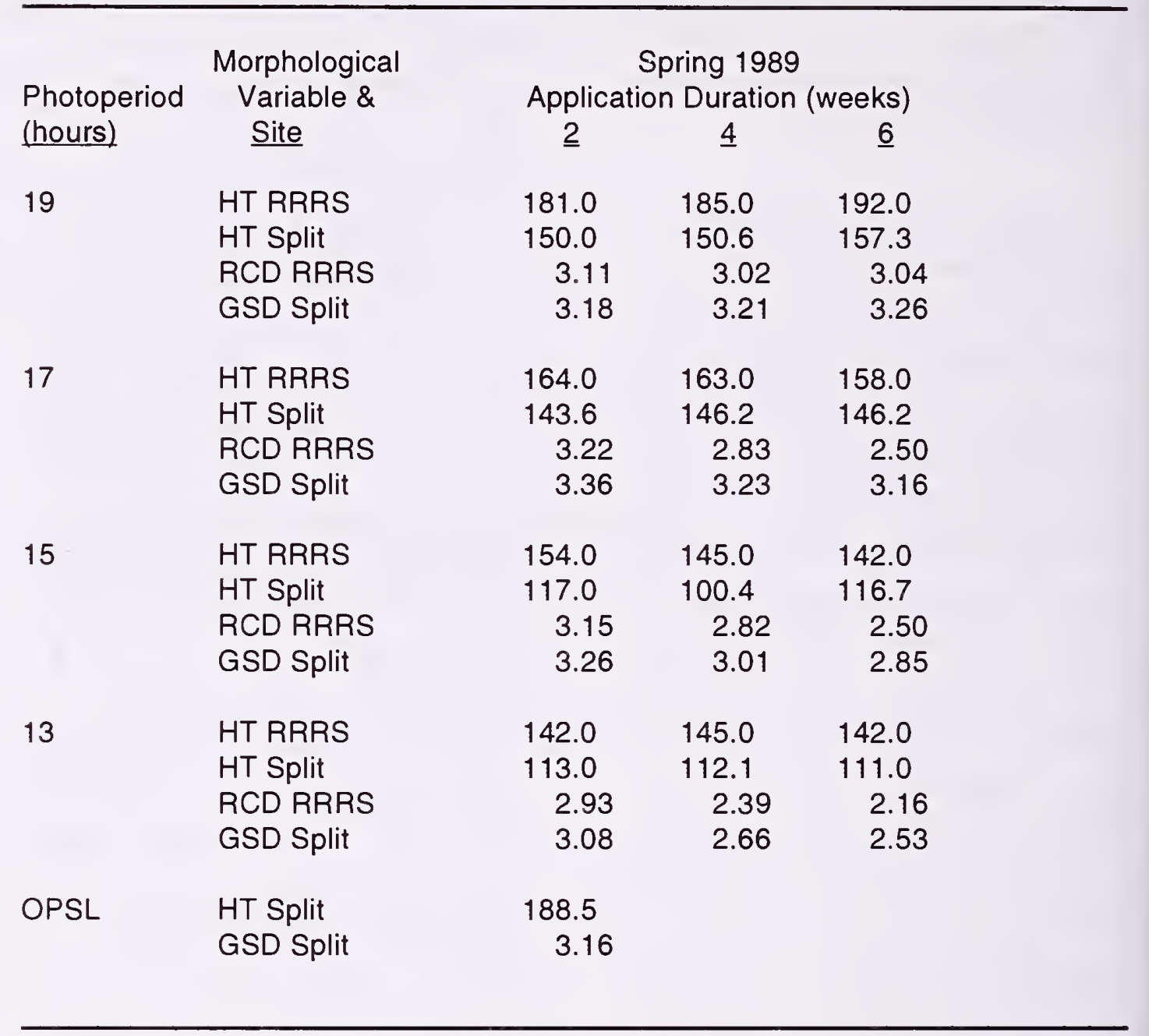

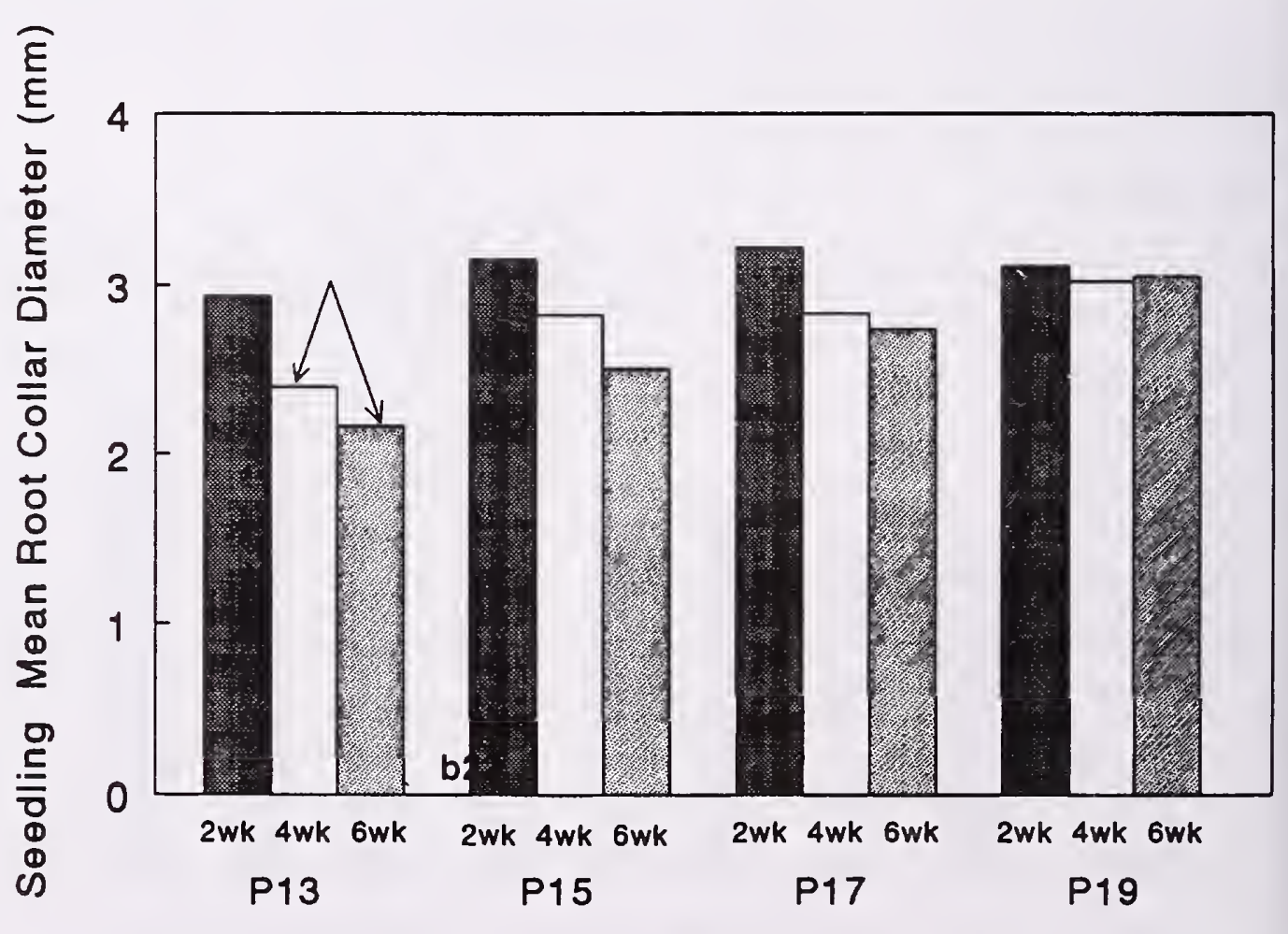

Figure 2. Mean seedling root collar diameter at the end of nursery culture in 1988 at RRRS by photoperiod and duration. Arrows indicate the impact of duration at shorter photoperiods on diameter. Modified from Hawkins and Draper (1991). 
Table 5. Mean height (HT), GSD, stem volume (SVol) and survival (SURV) for each block, photoperiod (h), application duration (weeks) and the operational seedlot (OPSL) after the first (89) and fifth (93) growing seasons. Mean squares (MS) and probabilities ( $\mathrm{Pr}$ ) of significance for variables using the model in Table 1. Means followed by the same letter are not significantly different; LSD at alpha $=0.05$.

\begin{tabular}{|c|c|c|c|c|c|c|c|c|c|c|c|c|c|}
\hline Source & \multicolumn{2}{|c|}{$\begin{array}{c}\text { HT89 } \\
\underline{\mathrm{mm}}\end{array}$} & \multicolumn{2}{|c|}{$\begin{array}{c}\text { GSD89 } \\
\underline{\mathrm{mm}}\end{array}$} & \multicolumn{3}{|c|}{$\begin{array}{c}\text { HT93 } \\
\underline{\mathrm{mm}}\end{array}$} & \multicolumn{2}{|c|}{$\begin{array}{c}\text { GSD93 } \\
\underline{\mathrm{mm}}\end{array}$} & \multicolumn{2}{|c|}{$\begin{array}{c}\text { SVol93 } \\
\underline{\mathrm{mL}}\end{array}$} & & $\begin{array}{c}\text { SURV93 } \\
\%\end{array}$ \\
\hline \multicolumn{14}{|l|}{ Block } \\
\hline 1 & \multicolumn{2}{|c|}{$214.6 \mathrm{~b}$} & \multicolumn{2}{|c|}{$4.71 \mathrm{c}$} & \multicolumn{3}{|c|}{ 896.0ab } & \multicolumn{2}{|c|}{$23.57 a$} & \multicolumn{2}{|c|}{$139.5 a$} & & $97.8 \mathrm{a}$ \\
\hline 2 & \multicolumn{2}{|c|}{$207.0 a$} & \multicolumn{2}{|c|}{$4.66 c$} & \multicolumn{3}{|c|}{$888.1 \mathrm{ab}$} & \multicolumn{2}{|c|}{$23.21 \mathrm{a}$} & \multicolumn{2}{|c|}{$136.3 a$} & & $96.0 \mathrm{a}$ \\
\hline 3 & & $213.6 b$ & \multicolumn{2}{|c|}{$4.73 c$} & \multicolumn{3}{|c|}{$905.1 \mathrm{~b}$} & \multicolumn{2}{|c|}{$24.52 \mathrm{c}$} & \multicolumn{2}{|c|}{$156.8 \mathrm{~b}$} & & $98.5 a$ \\
\hline 4 & \multicolumn{2}{|c|}{$205.8 a$} & \multicolumn{2}{|c|}{$4.56 \mathrm{~b}$} & \multicolumn{3}{|c|}{$\begin{array}{l}907.0 \mathrm{~b} \\
865.6 \mathrm{a}\end{array}$} & \multicolumn{2}{|c|}{$24.05 b$} & \multicolumn{2}{|c|}{$148.8 \mathrm{~b}$} & & $97.2 \mathrm{a}$ \\
\hline 5 & \multicolumn{2}{|c|}{$206.1 \mathrm{a}$} & \multicolumn{2}{|c|}{$4.46 a$} & & $5.6 a$ & & 23.6 & & 137. & & & $97.8 a$ \\
\hline Photop & eriod & & & & & & & & & & & & \\
\hline 13 & & & & & & $5.8 a$ & & 23.6 & & 138. & & & $97.3 b$ \\
\hline 15 & & & & & & $8.0 \mathrm{a}$ & & 23.1 & & 134. & & & $95.7 a$ \\
\hline 17 & & & & & & $1.0 \mathrm{~b}$ & & 23.9 & & 149. & & & $98.1 \mathrm{~b}$ \\
\hline 19 & & $6 d$ & & & & $4.7 b$ & & 24.3 & & 152. & & & $98.9 \mathrm{~b}$ \\
\hline Duratio & & & & & & & & & & & & & \\
\hline 2 & & & & & & $3.1 \mathrm{~b}$ & & 24.4 & & 151. & & & $98.6 a$ \\
\hline 4 & & & & & & $2.9 a$ & & 23.1 & & 136. & & & $96.4 a$ \\
\hline 6 & & & & & & $1.1 \mathrm{a}$ & & 23.7 & & 142. & & & $97.6 a$ \\
\hline OPSL & & & & & & 2.4 & & 23.5 & & 141. & & & 96.7 \\
\hline ANOVA & & Fall & & & & Fall & & & & & & & \\
\hline Source & $d f$ & HT & & GSD & & HT & & GSD & & SVol & & SURV & \\
\hline & & MS & $\mathrm{Pr}$ & MS & $\mathrm{Pr}$ & MS & $\operatorname{Pr}$ & MS & $\mathrm{Pr}$ & Ms & $\mathrm{Pr}$ & MS & $\mathrm{Pr}$ \\
\hline$B$ & 4 & 5441 & .005 & 3.818 & .000 & 824 & .030 & 74 & .020 & $228 * 10^{6}$ & .001 & 0.039 & .614 \\
\hline$P$ & 3 & 181217 & .000 & 0.625 & .193 & 2145 & .001 & 81 & .022 & $268^{*} 10^{6}$ & .001 & 0.173 & .033 \\
\hline D & 2 & 55531 & .000 & 5.970 & .000 & 1585 & .006 & 191 & .001 & $267^{\star} 10^{6}$ & .006 & 0.150 & .080 \\
\hline$B^{*} P$ & 12 & 1359 & .508 & 0.543 & .173 & 498 & .077 & 29 & .317 & $65^{*} 10^{6}$ & .229 & 0.038 & .800 \\
\hline$B * D$ & 8 & 1584 & .366 & 0.276 & .694 & 369 & .290 & 56 & .023 & $98^{*} 10^{6}$ & .054 & 0.065 & .356 \\
\hline$P^{*} D$ & 6 & 17106 & .000 & 2.254 & .000 & 1585 & .001 & 160 & .001 & $295^{\star} 10^{6}$ & .001 & 0.110 & .083 \\
\hline$B^{*} P^{*} D$ & 24 & 3466 & .000 & 0.606 & .048 & 511 & .021 & 51 & .002 & $111^{*} 10^{6}$ & .001 & 0.056 & .533 \\
\hline Error & 1440 & 1450 & & 0.396 & & 305 & & 25 & & $51 * 10^{6}$ & & 0.059 & \\
\hline
\end{tabular}

treme ranges by photoperiod, duration and treatment were 18 , 9 , and 33 percent but had decreased to 5,5 , and 18 percent at year five. These data suggest the effect of nursery treatment is decreasing. Consequently, short day treatments may influence growth patterns of seedlings after nursery culture and in the initial years in the field. However, long term differences among nursery treatments, while statistically significant, are not thought to be biologically sig- nificant by the end of five growing seasons.

At year five, survival was significantly influenced by photoperiod but not by duration (Table 5). Stock raised under the $15 \mathrm{~h}$ photoperiod had significantly lower survival, 95.7 percent, than did stock raised under the other three photoperiods. Rhizina undulata did account for 2.4 percent of the mortality in the P $15 \mathrm{~h}-\mathrm{D} 2$ week treatment. This may have been sufficient to cause photoperiod differences. There was a trend for survival to increase as photoperiod increased towards ambient daylengths. This observation is the opposite of Salim et al. (1989) who postulated that nursery blackout treatment promoted field survival. However, such high percentages, 96 versus 99 percent, may indicate that short day treatments had no effect on seedling survival at this site. Survival of the operational stock was also very good at 96.7 
Table 6. Mean height (HT, mm), GSD ( $\mathrm{mm}$ ), stem volume (SVol, $\mathrm{mL}$ ) and survival (SURV, \%) for all treatment combinations and the operational seedlot (OPSL) after the first (89) and fifth (93) growing seasons.

\begin{tabular}{|c|c|c|c|c|c|c|}
\hline \multirow[t]{2}{*}{$\begin{array}{l}\text { Photoperioc } \\
\text { (h) }\end{array}$} & \multicolumn{3}{|c|}{$\begin{array}{l}1989 \\
\text { Duration (weeks) }\end{array}$} & \multicolumn{3}{|c|}{$\begin{array}{c}1993 \\
\text { Duration (weeks) }\end{array}$} \\
\hline & 2 & 4 & 6 & 2 & 4 & 6 \\
\hline $19 \mathrm{HT}$ & 234.2 & 227.7 & 235.9 & 933 & 905 & 905 \\
\hline GSD & 4.66 & 4.65 & 4.63 & 24.60 & 24.30 & 24.01 \\
\hline SVol & - & - & & 156.8 & 151.3 & 149.6 \\
\hline SURV & 98.4 & 98.4 & 100 & 98.4 & 98.4 & 99.2 \\
\hline $17 \mathrm{HT}$ & 220.6 & 214.7 & 235.4 & 886 & 916 & 932 \\
\hline GSD & 4.69 & 4.59 & 4.86 & 23.17 & 23.8 & 25.01 \\
\hline SVol & - & - & - & 137.5 & 146.8 & 163.7 \\
\hline SURV & 99.2 & 96.0 & 99.2 & 99.2 & 96.0 & 99.2 \\
\hline $15 \mathrm{HT}$ & 220.8 & 174.4 & 189.5 & 953 & 834 & 852 \\
\hline GSD & 4.83 & 4.36 & 4.57 & 24.70 & 21.49 & 22.79 \\
\hline SVol & - & - & - & 160.7 & 113.2 & 127.5 \\
\hline SURV & 99.2 & 96.0 & 93.6 & 98.4 & 96.0 & 92.8 \\
\hline $13 \mathrm{HT}$ & 201.4 & 175.7 & 182.6 & 886 & 876 & 835 \\
\hline GSD & 4.69 & 4.55 & 4.54 & 24.69 & 23.17 & 23.16 \\
\hline SVol & - & - & - & 148.4 & 135.0 & 130.8 \\
\hline SURV & 98.4 & 97.6 & 99.2 & 98.4 & 95.2 & 98.4 \\
\hline OPSL HT & 260.3 & & & 902.4 & & \\
\hline GSD & 4.62 & & & 23.55 & & \\
\hline SVol & - & & & 141.0 & & \\
\hline SURV & 96.7 & & & 96.7 & & \\
\hline
\end{tabular}

percent (Table 5). Overall on this site, survival is not an issue. Seedling condition in the fall of 1989 monitored by Krasowski et al. (1993) suggested that a possible Rhizina infection may have caused the observed mortality rather than exposure to short day nursery treatment.

No differences existed at year five between the Surrey Nursery operational stock and the RRRS stock when orthogonal contrasts were used to compare photoperiod, duration, and all PxD treatments. This suggests the quality of the stock produced at
RRRS was similar to that of stock produced at Surrey Nursery. Performance similarities in stock from the two nurseries also reinforces conclusions at the other trial sites (Krasowski et al. 1993) and in a common garden (Hawkins and Draper 1991). Furthermore, any concerns about research stock produced at RRRS being different from operational stock production should be alleviated by these data.

\section{Phenology and Condition}

In the common garden at RRRS, stock of seedlot 5261 flushed and set lateral buds more rapidly when cultured under a 13 $\mathrm{h}$ photoperiod and 6 week application duration (Hawkins and Draper 1991). Krasowski et al. (1993) reported similar results early in the growing season at Split Creek. The $13 \mathrm{~h}$ photoperiod treated stock also displayed the greatest number of unflushed terminal buds at Split Creek. Phenology class assessments continued during the summer until fall measurements but revealed no further significant treatment differences (Krasowski et al. 1993). There was no earlier flush or later bud set for the short day treated stock 
but it had more terminal buds that failed to flush in the first field season.

Previous studies have observed that short day treated coniferous stock may flush earlier in the spring and grow later into the fall compared to untreated stock (Hawkins and Hooge 1988; Odlum and Columbo 1988; Salim et al. 1989). Higher survival has also been reported for seedlings planted in interior British Columbia when treated with short days in the nursery (Salim et al. 1989). After the first growing season at Split Creek, 5.6 percent of the seedlings had either a forked (multiple) leader, a dead or unflushed terminal bud, a dominant lateral branch, or a combination of these. However, 84 percent of the seedlings that displayed first year form problems were unaffected at year five. A damaged apical bud caused by early or late frost when the bud was active and susceptible to freezing could result in forking or lateral dominance (Carey 1978). At year five, 10.4 percent of all seedlings showed possible form defects although statistical analysis using Kruskal-Wallis by nursery photoperiod or duration and field block determined that defect could not be attributed to any of the independent variables. This level of forking is probably a function of interactions of genotype and environment, and can be regarded as an endemic level of forking. Experience with other plantations suggest that it will probably have little subsequent effect on plantation quality.

\section{SUMMARY AND CONCLUSIONS}

While shorter seedlings, such as those produced by the photoperiod treatments in this trial, may have early advantages over taller seedlings, these were not demonstrated by seedlot 5261 at Split Creek. The seedlings in this trial overcame any possible size disadvantages, demonstrating that blackout produced seedlings are physiologically equal to and possibly superior to those from operational nursery regimes. It remains to be seen whether this more rapid early growth is continued past five years. This trial demonstrates that if blackout treatments are used to achieve operational morphological criteria, the stock thus produced are not physiologically disadvantaged. For seedlot 5261, the nursery treatment with the greatest height and second largest root collar diameter at year five was the intermediate photoperiod (P $15 \mathrm{~h}$ ) and the shortest duration (D 2 week). This was the nursery treatment suggested as being the best to attain nursery objectives and to have minimal impacts in the field (Hawkins and Draper 1991). It is also closest to current operational treatments. In fact, at year five, this treatment combination resulted in the second largest stem volume (Table 6). There were no significant differ- ences between the operational stock from the Surrey nursery and the RRRS nursery treated stock. This has two major implications:

i) similar five year performance was achieved even though RRRS short day stock was significantly smaller at planting than Surrey nursery operational stock suggesting that

a) blackout culture may be less stressful than nutrient and water culture or

b) given time in a similar environment the genotype of various nursery treatments will be expressed in a like manner; and

ii) stock produced at RRRS is comparable to operational stock and field results using RRRS stock are therefore applicable.

Concerns over altered bud phenology in response to shortened photoperiods were not realized on this site. However seedlings receiving the extreme nursery treatments had more terminal buds that failed to flush. Similar effects were also observed in stock subjected to extreme treatment during the first field season in the common garden at RRRS. When moderate treatments were used; longest possible day applied for the shortest duration to attain nursery objectives, 15-h for 2 weeks in this case; field performance was not negatively influenced and was possibly influenced positively. 
Results may vary year to year as climate, site conditions, and stock type are not constants. The genetic component is constant but environment and presumably its interaction with genotype is dynamic. Similarly, conclusions obtained may be different if short day treatments were applied in different years, at different times, or if the plantat:on was established in different seasons. However, preliminary analysis of different interior spruce seedlots established on different sites after winter freeze storage suggests the success of short day treatments is probably quite broad (EP 1042 unpublished data). The results suggest the culture is appropriate for vigorous seedlots when applied judiciously. Furthermore, low phenological alterations, high survival, and good growth were observed for these treatments 5 years after spring planting from freeze storage.

\section{LITERATURE CITED}

Bigras, F.J. and A.L. D'Aoust. 1993. Influence of photoperiod on shoot and root frost tolerance and bud phenology of white spruce seedlings (Picea glauca). Can. J. For. Res. 23:219-228.

Burdett, A.N., L.J. Herring and C.F. Thompson. 1984. Early growth of planted spruce. Can. J. For. Res. 14:644-651.
Carey, J.C. 1978. Plant Physiology. Second Edition, Wadsworth Publishing Co., Inc., Belmont, California.

Draper, D.A. 1989. Working Plans. Unpublished Work Plan, FRDA 1.36, EP 1042, Res. Branch, BC Ministry of Forests (BCMoF). Victoria, BC.

Draper, D.A. and C.D.B. Hawkins. 1989. Germination and fertilization regime effects on the growth of container white spruce seedlings at Red Rock Research Station. FRDA Res. Rep 064. For. Can. and BCMoF, Victoria, BC.

Fernandez, G.C.J. 1992. Residual analysis and data transformations:Important tools in statistical analysis. HortScience 27:4

Hawkins, C.D.B. and D.A. Draper. 1988. Height control of interior spruce by means of photoperiodic induction. In Proc. Combined Meet. Western Forest Nursery Associations, Aug. 8-11, Vernon, BC. T.D. Landis (editor). U.S. Dep. Agric. For. Serv. Gen. Tech. Rep. RM-167, pp.45-49.
Hawkins, C.D.B. and D.A. Draper. 1991. Effects of black-out on British Columbia seedlots at Red Rock Research Station. FRDA Res. Rep. 170. For. Can. and BCMoF, Victoria, BC.

Hawkins, C.D.B. and B.D. Hooge. 1988. Blackout and post-planting bud phenology is Sxs spruce seedlings. In Proc. Combined Meet. Western Forest Nursery Associations, Aug. 8-11, Vernon, BC. T.D. Landis (editor). U.S. Dep. Agric. For.Serv. Gen. Tech. Rep. RM-167, pp.54-56.

Herring, L.J. and J.C. Pollack. 1985. Experimental design protocol for forest vegetation management research: Level B trials, BCMoF RR84013HQ (unpubl.) pp.61, Victoria, $\mathrm{BC}$.

Krasowski, M.J., T. Letchford, and A. Eastham. 1993. Growth of short day treated spruce seedlings planted throughout British Columbia. FRDA Res. Rep. 209. For. Can. and BCMoF, Victoria, BC.

Meidinger, D. and J. Pojar. 1991 Ecosystems of B.C. February, 1991. (Special Rep. Series 6). $\mathrm{BCMoF}$, Victoria, BC. 
Mexal, J.G. and T.D. Landis. 1990. Target seedling concepts: Height and diameter. $\ln$ Proc. Combined Meet. Western Forest Nursery Associations, Aug.13-17, Roseburg, Oregon. R. Rose, S.J.

Campbell, and T.D. Landis (editors). U.S. Dep. Agric. For. Serv. Gen. Tech. Rep. RM-200, pp.17-35.

Neter, J. and W. Wasserman. 1974. Applied Linear Statistical Models. Richard D. Irwin, Inc., Illinois, 508p.

Odlum. K.D. and S.J. Colombo. 1988. Short day response to induce budset prolongs shoot growth in the following year. In Proc. Combined Meet. Western Forest Nursery Associations, Aug. 8-11, Vernon, B.C. T.D. Landis (editor). U.S. Dep. Agric. For. Serv. Gen. Tech. Rep. RM167, pp.57-59

Salim, S.N., T. Kannangara, D.P. Lavender, and L. Charleson. 1989. Effects of photoperiod and plant growth regulators upon the growth of coniferous seedlings. Forestry 62 (Suppl.):143-147.
Thompson. B.E. 1985. Seedling morphological evaluation what you can tell by looking. In Proc. Evaluating Seedling Quaility: Principles, Procedures and Predictive Abilities of Major Tests. M.L. Duryea (editor). For. Res. Lab., Oregon State Univ., Corvallis, OR. pp. 59-71.

Thompson, C. 1989. Field testing of growing stock in the Nelson Forest Region. Unpublished Progress Report FRDA Project 1.36.01., Res. Branch, BCMoF, Victoria, B.C.

Wilkinson, L. 1990. SYSTAT. Evanston, Illinois: SYSTAT, Inc., 1990. 


\title{
Conserving Threatened Rare Plants: Some Nursery Strategies ${ }^{1}$
}

\author{
John L. Edson², David L. Wenny², Annette Leege-Brusven², Richard L. Everett ${ }^{3}$, \\ and Douglass M. Henderson ${ }^{4}$
}

\begin{abstract}
The legacy of the 1992 Earth Summit and the mandates of the Convention on Biodiversity have influenced the propagation of threatened and endangered native plants. Minimum viable population guidelines, appropriate gene pool sampling, micropropagation techniques, and strategies for returning propagules to the environment guide the development of conservation plans. The rare Pacific Northwest endemics Phlox idahonis, Douglasia idahoensis, and Hackelia venusta; oceanic island megararities; and once-abundant but now uncommon plants were evaluated for both ex situ plant recovery programs and other propagation opportunities. Micropropagating seed conserved scarce germplasm of rare Astragalus, Carex, and Lepidium species. The strategy of first propagating the common species, Astragalus aquilonius, was successful in culturing the closely related rare species $A$. amblytropis. Nurserymen can participate in species recovery programs, propagate regional rarities to promote conservation education, and prevent further decline of once-abundant native plants.
\end{abstract}

\section{INTRODUCTION}

In the 1970's, botanists became aware that rare plant populations were declining in many parts of the world. Regions of high endemism particularly vulnerable to loss of diversity include remote oceanic islands, areas with Mediterranean climates such as South Africa and Western Australia, and parts of both the wet and dry tropics. Rising concern over species' decline resulted in global action which produced the Convention on Biodiversity at the Earth Summit, sponsored by the United Nations Commission on Environment and Development, in Rio de Janeiro, Brazil in 1992. The Convention, ratified in 1993 and implemented in 1994, requires the signatory nations, including the United States of America, to develop National Conservation Strategies. Strategy goals include conducting national biological surveys to determine the life forms at risk, developing and executing appropriate in situ (on-site) and ex situ (off-site) conservation plans, and monitoring the biota. The Federal Native Plant Conservation Committee (representing seven federal agencies) and the Center for Plant Conservation (CPC - a private consortium of botanic gardens) are cooperating to conserve the flora of the United States (CPC 1994).

Charles Darwin noted over 150 years ago that rarity precedes extinction (Darwin 1858). While not all rare plants are threatened, most threatened

'Edson, J.L.; Wenny, D.L.; Leege-Brusven, A.; Everett, R.L.; Henderson, D.L. 1994. Conserving Threatened Rare Plants: Some Nursery Strategies IN: Landis, T.D.; Dumroese, R.K., tech. coords. National Proceedings, Forest and Conservation Nursery Associations. Gen. Tech. Rep. RM-257. Fort Collins, CO: U.S. Department of Agriculture, Forest Service, Rocky Mountain Forest and Range Experiment Station: 150-157.

2University of Idaho Forest Research Nursery, Moscow, Idaho 83844-1137.

${ }^{3}$ Forestry Sciences Laboratory, Pacific NW Research Experiment Station, Wenatchee, Washington.

${ }^{4}$ Department of Biological Sciences, University of Idaho, Moscow, Idaho. 
plants are almost always rare. Hence it is natural to ask whether rare species are threatened. Although many factors influence rarity (Harper 1981, Rabinowitz 1981), the greatest threats to small plant populations are human activity and random environmental events such as drought, seed predation or pollination failure (Menges 1992). Protecting habitat is the primary and necessary goal of conservation, and ex situ conservation cannot substitute for habitat protection. Ex situ action becomes appropriate, however, when habitat management alone cannot prevent species' decline. This paper focuses on the ex situ conservation of threatened flora and describes how nursery managers and plant propagators can apply new strategies to conserve rare plants.

\section{EX SITU CONSERVATION METHODS}

A multidisciplinary team (including taxonomists, ecologists, geneticists, population biologists, propagators, and habitat restorationists) identifies the risks, assesses the threats, and selects the criteria for species selection. Botanic Gardens Conservation International recommends working first with species directly threatened, followed by species in habitat under threat of disturbance, rare plants not under threat, wild relatives of crop plants, and other categories (BGCI 1993).
The Center for Plant Conservation, at the Missouri Botanic Garden in St. Louis, lists in descending order of priority: highly endangered species, those rapidly declining from human causes, unique species, species with potential for recovery, and useful genetic material (CPC 1991). After generating a consensus plan, team members capture the genetic variation with seed or vegetative parts, preserve the germplasm, and propagate plants for reintroduction or introductions to new sites.

For most species, a nearly complete sample of the genome can be captured. CPC guidelines recommend collecting seed from up to 5 populations per species, 50 individuals per population, and up to 20 seed per individual if that is less than $20 \%$ of the seed available from that individual (Falk 1992, Guerrant 1992). Vegetative propagation would require more individuals to be sampled to approach the genetic variation provided by seed.

The primary ex situ technologies involving nurseries are: storing germplasm from threatened habitat in seed or gene banks, growing living collections, and micropropagating rare plants in tissue culture laboratories. Seed banks store orthodox seed (seed which survives below freezing temperatures) of species primarily from the temperate zone and dry tropics. Viable seed dried to an equilibrium moisture content of about $5 \%$ and stored in low relative humidity (15\%) at $-20^{\circ} \mathrm{C}$ can potentially remain viable for up to 200 years.

Although requiring more space and more expensive to maintain than seed banks, living collections preserve germplasm when seed cannot be stored below freezing (recalcitrant seed), as is the case with many species from the wet tropics and a few from the temperate zone. Nurseries in botanic gardens, arboreta, universities, and other plant research facilities maintain living collections for research and conservation education.

Micropropagating rare plants in vitro, by both seed and vegetative means, is increasingly used to conserve rare species. Micropropagation requires only small amounts of material and therefore minimizes damage to the species. A useful strategy to avoid wasting valuable rare material is to develop a propagation protocol for a close relative and then apply it to the threatened species. Seed is the preferred choice of plant material since the sterile environment of in vitro seed culture can often enhance germination success over conventional propagation (Fay 1992). When seed is unavailable, in short supply, or cannot be germinated readily (unviable, dormant, damaged by disease or insect, etc.), vegetative micropropagation techniques are appropriate 
(Hartmann et al. 1990). The potential explant (starting material) for a propagation trial could consist of a shoot tip, shoot segment, leaf, petiole, flower, or embryo. Culture involves destroying surface microorganisms and placing the decontaminated explant on a sterile gel medium containing mineral nutrients, vitamins, and carbohydrates. To increase plant numbers, plant growth regulators supplement the medium to induce multiple bud development on the explants. The microshoots elongate after transfer to a hormone-free medium and, after excision from the explant, may root in the sterile laboratory environment or in a high-humidity propagation area. Finally, plantlets (micropropagated plants) are hardened in a greenhouse.

To persist, a species must have a minimum viable population large enough to minimize the chance of extinction from random catastrophe for a long time (Menges 1992). A rule of thumb suggests a plant species with 5 or fewer distinct populations or less than 1,000 individuals in total may become extinct if a chance event causes a population crash (Falk 1992). Nurserygrown plants can be reintroduced to re-establish the species where it has declined or been extirpated (Maunder 1992). Planting stock, however, should be free of disease and pests to prevent introduction of pathogens to the sites. Although of increasing importance in North America, reintroduction techniques are still experimental.

\section{APPLICATIONS AND DISCUSSION}

We now examine how species of varying degrees of rarity (moderately rare endemics of the Pacific Northwest, extreme rarities on oceanic islands, and once-abundant but now uncommon plants) could be considered for ex situ plant recovery programs and other propagation opportunities. We also cite examples where micropropagating seed and vegetative parts conserves scarce germplasm.

\section{Pacific Northwest rarities}

Idaho phlox (Phlox idahonis), one of the state's rarest vascular plants, is restricted to a small region of northern Idaho and is therefore considered a narrow endemic species (Moseley and Crawford 1993). Recent popülation monitoring of Idaho phlox revealed eight occurrences in four metapopulations, with several hundred to many thousand individuals per occurrence, and a total of about 10,000 individuals. Since the populations appear stable and Potlatch Timber Corporation (which owns most of the phlox habitat) plans to prevent decline of this species, ex situ conservation is unnecessary.
Douglasia idahoensis was described as a new Idaho endemic species in 1981 (Henderson 1981). About as abundant as Idaho phlox, $D$. idahoensis numbers about 9,000 individuals but is more widely distributed in 24 known populations, some containing fewer than 50 individuals (USDAFS 1993). Although these demographics indicate no immediate threat, climate warming could result in a rapid decline of this Pleistocene relict since it is confined to northeasterly aspects on subalpine peaks and therefore lacks upslope refugia. The species should be carefully monitored and ex situ action taken quickly if population declines are observed.

Hackelia venusta or showy stickseed (Boraginaceae), an herbaceous biennial endemic to the Washington Cascades (Hitchcock and Cronquist 1973), exists as one population with fewer than 500 individuals in habitat degraded by human activity. In cooperation with the Forestry Sciences Laboratory at the Pacific Northwest Experiment Station and the Wenatchee National Forest, we micropropagated 10 clones of $H$. venusta from shoot tips. The explants multiplied rapidly producing an average of 3 new microshoots per explant per month on MS medium (Murashige and Skoog 1962) containing low levels of the cytokinin benzyladanine (BA) 
from 0.05 to $0.1 \mathrm{mg} / \mathrm{l}$. Microshoots of all 10 clones rooted, at rates from $90-100 \%$, on a culture medium containing the natural auxin indoleacetic acid (IAA) at $0.5 \mathrm{mg} / \mathrm{l}$ (Fig. 1). The rooted microshoots were acclimatized and grown in Rootrainer containers for ease of plug extraction (Fig. 2). Pest and disease-free plantlets will be introduced at four suitable sites with initial plantings of 500 plantlets per site.

\section{Megararities}

Human activities have pushed some naturally rare plants to extreme rarity. If the genetic base of a very rare plant is narrow, a species recovery program may not be useful. Nurseries, however, can play other important conservation roles.

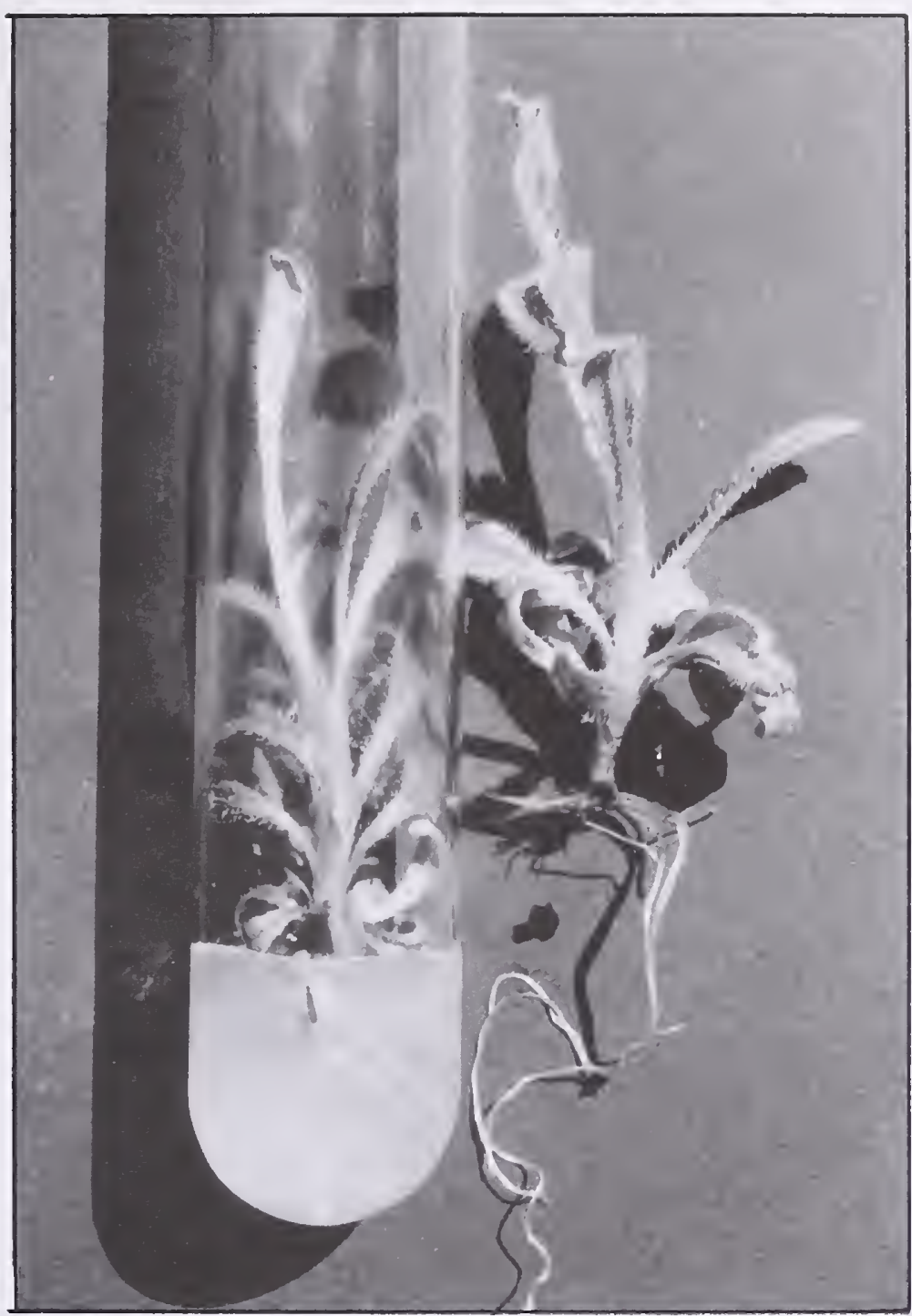

Figure 1. In vitro rooted plantlets of

Hackelia venusta ready for acclimatization.

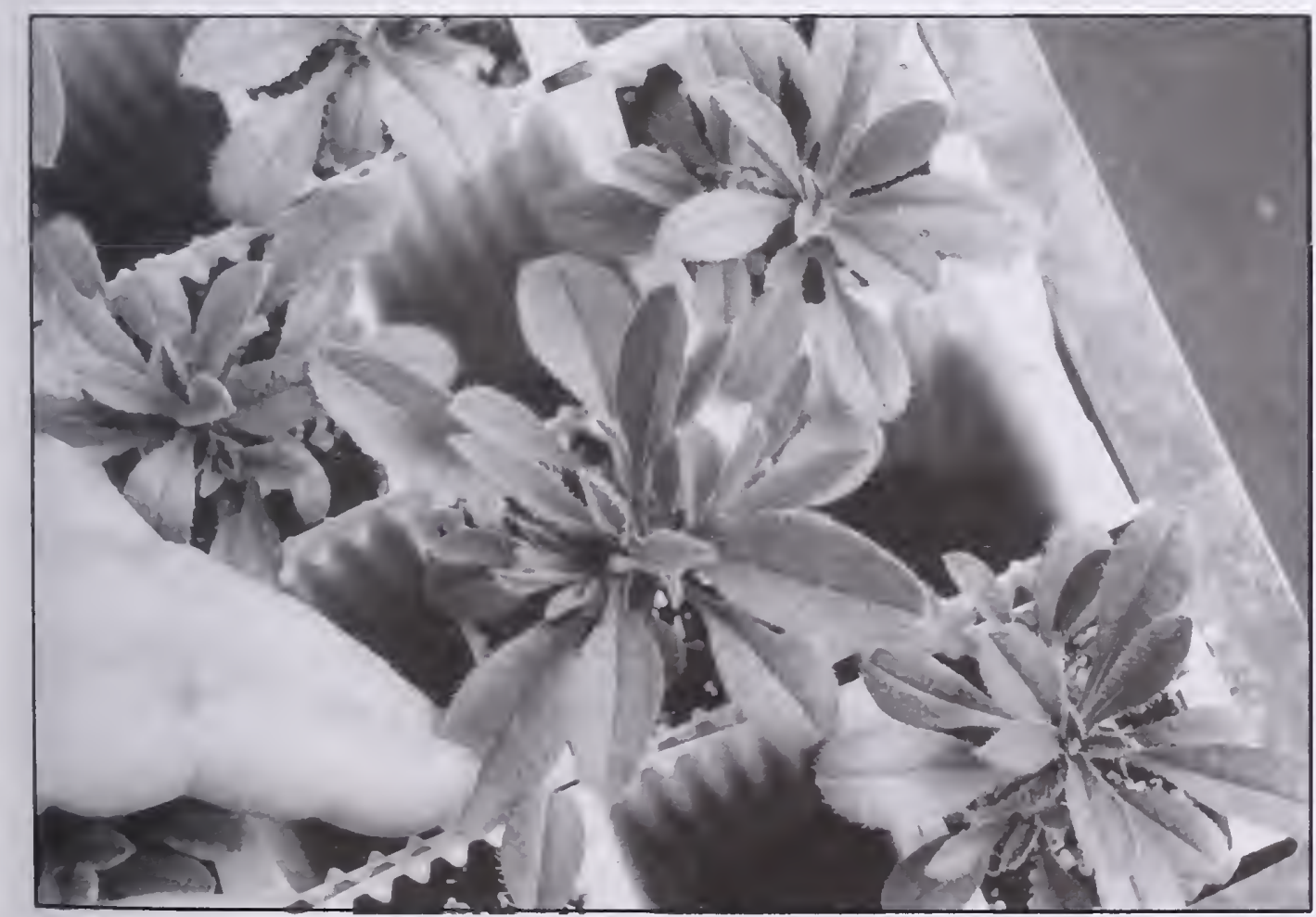

Figure 2. Fully-hardened plantlets of Hackelia venusta for introduction to a forest site.

\section{Tecomanthe speciosa}

(Bignoniaceae), a woody vine species, exists as a single genotype in subtropical forest on a remote offshore island in northern New Zealand (Wilson and Given 1989). Introduced goats which damaged the island vegetation have been removed but no seedling regeneration has occurred. Fortunately, cuttings taken from the wild plant have produced many plants which produce viable seed in cultivation on the mainland. Increasing popularity of this species as a garden ornamental 
has at least delayed its extinction, and propagation of this megararity has developed public interest in conserving native flora of the region. It is presently unknown whether there is sufficient variation in the population of cultivated plants to allow recovery of this species, and there is a risk of contaminating the wild site with the garden fungus Phytophthora cinnamoni on reintroduced nursery plants (Maunder 1992).

Sophora toromiro, a leguminous tree, was once found in volcanic craters on Easter Island. Overcutting reduced the population to 1 tree by 1917 which was last seen by the Heyerdahl expedition in 1955 (Christensen and Schlatzer 1993). Mature specimens were found growing in an arboretum on mainland Chile, and seedlings were reintroduced by the Chilean Forestry and Conservation Agency (Maunder 1992). In addition, Jacobsen and Dohmen (1990) have attempted to increase genetic variation artificially by inducing somaclonal variation in toro miro micropropagules. Equally important for the species survival, the Easter Islanders are likely to protect the reintroductions since toro miro wood was used for wood carving associated with the mythology of the statues (Heyerdahl 1958). Many other countries also propagate "flagship" rarities for both economic and cultural reasons.
Although there are no known megararities in Idaho, the rarest of our plants do provide an opportunity for nurseries to promote conservation in the Interior Northwest. The Idaho phlox grows readily from seed in local gardens, and D. idahoensis has grown successfully in our Moscow greenhouse.

\section{ONCE-ABUNDANT PLANTS IN DECLINE}

At the other end of the rarity spectrum are once-abundant endemics now in decline. Collection of showy natives is a major problem worldwide. The international trade in cut flowers threatens Banksia coccinea (Proteaceae) endemic to Western Australia. Plant families widely threatened include orchids in the wet tropics and temperate forests and bogs, cacti in the Americas, and carnivorous plants in the southeastern USA. Venus Flytrap (Dionaea muscipula), a unique carnivorous species (Ayensu 1981) once relatively abundant, is now threatened by loss of habitat and trade in poached plants (Culotta 1994). The Convention on International Trade in Endangered Species (CITES) controls export of the Flytrap, but the plant is still being dug and traded within the US. The nursery industry could both increase mass propagation to deter digging and support government action to ensure sustainable use of this and other resources.
Idaho's Pacific dogwood (Cornus nuttallii) is a disjunct of the widespread coastal population. Now infected with dogwood anthracnose (Discula destructiva), this outlier population has produced little seed since 1990 , and with fewer than 700 trees remaining the population may be extirpated. Edson et al.(in press) multiplied in vitroderived shoot tips at an average rate of 2.9 microshoots per explant on an agar-based medium containing $1 \mathrm{mg} / \mathrm{l} \mathrm{BA}$, and rooted $50 \%$ of the microshoots after a basal talc dip of $4.5 \%$ IBA. Since no disease resistance has been found, reintroduction would likely fail. Seed banking the genome and storing all the clones in tissue culture are presently the only alternatives to conserve the species.

\section{SEED MICROPROPAGATION}

In vitro germination avoids dampoff and other pathogens of conventional propagation often resulting in higher survival of germinants in culture. Astragalus columbianus (Fabaceae), once thought to be extinct was rediscovered in 1976 (Sauer and Mastrogiuseppe 1979). Untreated seed germinated at $13 \%$ on a propagation bench. Three weeks after scarifying with sand paper, in vitro seed germinated at $92 \%$ on MS medium supplemented with $10 \%$ agar, versus $64 \%$ germination of the scarified ex vitro seed $(\mathrm{p}<0.001)$. Carex hystricina (Cyperaceae), a sedge 
rare in the Pacific Northwest, germinated ex vitro at $27 \%$ with the seed enclosed in the perigynium, the papery covering often left intact when propagating common sedge species (Hurd and Shaw 1992). We compared germination rates, with and without the perigynium present, both in culture and on a propagation bench. Within three weeks of removing the perigynia, the in vitro germination rate of $94 \%$ surpassed that of the conventionally sown seed by $32 \%$ (p < 0.001) (Fig. 3). Lepidium papilliferum (Brassicaceae), an Idaho endemic, germinated at $14 \%$ in vitro versus $0 \%$ ex vitro. After seed dissection, however, $88 \%$ of the embryos produced seedlings.

\section{VEGETATIVE MICROPROPAGATION}

The strategy of first propagating the common species, $A s$ tragalus aquilonius, was successful in culturing the closely related rare species $A$. amblytropis. The two taxa produced an average 1.4 and 1.8 microshoots per explant per culture period ( 3 weeks) on MS medium supplemented with 0.1 $\mathrm{mg} / \mathrm{l} \mathrm{BA}$, rooted at $73 \%$ and $57 \%$ on hormone-free medium, and survived at $92 \%$ and $91 \%$ respectively. Since this protocol also produced similar results with the rare $A$. columbianus, some of the other more than 150 threatened species of Astragalus
Figure 3. In vitro versus ex vitro germination of Carex hystricina with perigynia intact or removed.

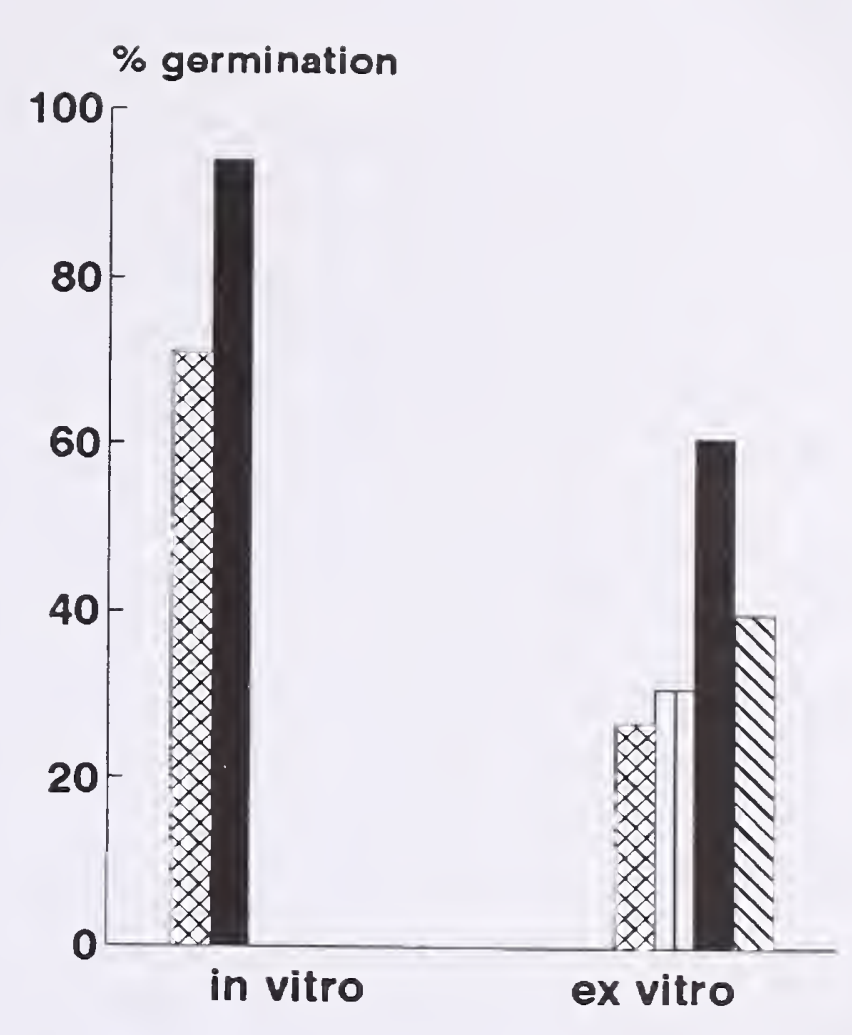

intact-sterile

removed-sterile
I.] intact-unsterile

$\$$ removed-unsterile in the United States (Falk 1993) may also be propagated using this procedure.

\section{Clonal variation can affect} shoot growth and rooting response. The rooting of some $A$. columbianus clones was inhibited at moderate to high levels of IAA. Minimizing the concentrations of plant growth regulators as media supplements may lower the expression of differences between clones, deter callus development, and reduce the chance of genetic change.

\section{CONCLUSIONS}

Using efficient micropropagation strategies, nurseries can better face the challenges of propagating rare plants. In the coming years, as the national biologic survey progresses, we will likely find increased opportunities to participate in plant recovery programs to help avoid extinctions. We can also propagate regional rarities and other threatened endemics for a variety of uses. The positive net effect of these activities will be to promote conservation of our native flora.

\section{ACKNOWLEDGEMENTS}

The Pacific Northwest Experiment Station provided research support for propagating the rare Washington species, and the University of Idaho Research Council furnished a grant for developing strategies for micropropagating rare Idaho endemics. 


\section{LITERATURE CITED}

Ayensu, E.S. 1981. Assessment of threatened plant species in the United States. In: The biological aspects of rare plant conservation. H. Synge (ed.). John Wiley \& Sons: 19-58.

BGCI. 1993. Workshop conclusions of the Third International Botanic Gardens Conservation Congress. Botanic Gardens Conservation News. 2(2): 41-48.

Christensen, S.C. and Schlatzer, G. 1993. Comments on the conservation of Sophora toromiro Skottsb., from Easter Island. Botanic Gardens Conservation News 2(2): 2225.

CPC. 1994. Plant Conservation 8(1): 4 .

CPC. 1991. Genetic sampling guidelines for conservation collections of endangered plants. In: Genetics and conservation of rare plants. D.A. Falk and K.E. Holsinger (ed.). Oxford University Press: 225-238.

Culotta, E. 1994. Vanishing flytraps. Audubon 2: 16-17.

Darwin, C. 1858. The origin of species. Mentor edition (1958), New American Library, New York. 479 p.
Edson, J.L., Wenny D.L., and Leege-Brusven, A. Micropropagation of Pacific Dogwood. HortScience (in press)

Falk, D.A. 1992. From conservation biology to conservation practice: strategies for protecting plant diversity. In: Conservation biology. P.L. Fiedler and S.K. Jain (ed.). Chapman and Hall: 397-431.

Fay, M.F. 1992. Conservation of rare and endangered plants using in vitro methods. In Vitro Cell. Dev. Biol. 28P: 14.

Guerrant, E.O. 1992. Genetic and demographic considerations in the sampling and reintroduction of rare plants. In: Conservation biology. P.L. Fiedler and S.K. Jain (ed.). Chapman and Hall: 298-321.

Harper, J.L. 1981. The meanings of rarity. In: The biological aspects of rare plant conservation. H. Synge (ed.). John Wiley \& Sons: 189-203.

Hartmann, H.T., Kester, D.E., and Davies, F.T. 1990. Plant propagation: principles and practices. Prentice-Hall Inc. $647 \mathrm{p}$.

Henderson, D.M. 1981. A new Douglasia (Primulaceae) from Idaho. Brittonia. 33(1): 52-56.
Heyerdahl, T. 1958. Aku-Aku. Rand McNally \& Co., Chicago. 384 p.

Hitchcock, C.L. and Cronquist, A. 1973. Flora of the Pacific Northwest. University of Washington Press, Seattle, Washington. $730 \mathrm{p}$.

Hurd, E.G. and Shaw, N.L. 1992. Seed technology for Carex and Juncus species of the Intermountain Region. In: Landis, T.D. Proceedings, Intermountain Forest Nursery Association. August 12-16, 1991, Park City, Utah. Fort Collins, Colorado: USDA Forest Service Rocky Mountain Forest and Range Experiment, Station General Technical Report RM-211: 74-83.

Jacobsen, H. and Dohmen, G. 1990. Modern plant biotechnology as a tool for the reestablishment of genetic variability in Sophora toromiro. Courier Forsch. Inst. Senckenberg 125: 233-237.

Maunder, M. 1992. Plant reintroduction: an overview. Biodiversity and Conservation. 1: 51-61.

Menges, E.S. 1992. Stochastic modeling of extinction in plant populations. In: Conservation biology. P.L. Fiedler and S.K. Jain (ed.). Chapman and Hall: 253-275. 
Moseley, R.K. and Crawford, R.C. 1993. Population monitoring and management plan for Idaho phlox (Phlox idahonis). Unpublished report. Idaho Department of Fish and Game, Natural Resource Policy Bureau, Boise, Idaho. 29 p.

Murashige, T. and F. Skoog. 1962. A revised medium for rapid growth and bioassays with tobacco tissue cultures. Physiol. Plant. 15:473-97.

Rabinowitz, D. 1981.'Seven forms of rarity. In: The biological aspects of rare plant conservation. H. Synge (ed.). John Wiley \& Sons: 205-217.

Sauer R.H., Mastrogiuseppe J.D., \& Smookler R.H. 1979. Astragalus columbianus (Leguminosae)- rediscovery of an "extinct" species. Brittonia. 31(2): 261-264.

USDA Forest Service, Boise National Forest. 1993. Conservation agreement for Douglasia idahoensis. Boise, Idaho. $20 \mathrm{p}$.

Wilson, C.M. and Given, D.R. 1989. Threatened plants of New Zealand. DSIR Publishing, Wellington, New Zealand. $151 \mathrm{p}$. 


\title{
Microcomputer Order Processing and Inventory Control ${ }^{1}$
}

\author{
David L. Wenny and Linda Geer ${ }^{2}$
}

The University of Idaho

Forest Research Nursery uses an off-the-shelf database package (REFLEX, Borland Inc.) for processing seedling orders. The Research Nursery grows about 650,000 seedlings annually, comprised of about 48 species or stock types, with 15 shipping dates. Our program has been customized for use by several nurseries faced with similar order processing concerns. We accept orders from landowners for reforestation and/or conservation seedlings on a firstordered-with-payment first-filled basis. Seedlings are held in cold storage until appropriate planting windows are opened across the state. It is imperative to have a flexible, but accurate, system to track the numbers of seedlings available for sale as orders are processed. Quick access to customer records is also important as customers frequently call to make changes to, or inquire about, order status.

\section{ORDER PROCESSING REQUIREMENTS}

1) Record customer data, species and quantities requested, and sales accounting data for numerous clients.

2) Quick access to customer record to enable changes in order.

3) Generate a report showing an up-to-date listing of seedlings sold and of seedlings still available for sale for each species and stock type.

4) Generate a deposit slip (accounting data) for a batch of processed orders.

5) Generate a customer receipt showing species and quantities reserved to fill the order and sales amount received or amount due.
6) Generate a report of all orders for a particular shipping or pickup date.

7) Generate reports of seedlings ordered by species, location (county(s) or state), or other database criteria as desired.

\section{ORDER PROCESSING}

Customers receive a combination catalog/order form by request from the Research Nursery or from local county agents or state agencies. Nursery personnel scan returned orders for completeness, then enter data into the database assigning order numbers and deposit numbers and making any substitutions or refunds as necessary. The database record format is shown as Figure 1. This program calculates certain accounting data and total seedling and stock type sums for management purposes.

\footnotetext{
'Wenny, D.L.; Geer, L. 1994. Microcomputer Order Processing and Inventory Control. IN: Landis, T.D.; Dumroese, R.K., tech. coords. National Proceedings, Forest and Conservation Nursery Associations. Gen. Tech. Rep. RM-257. Fort Collins, CO: U.S. Department of Agriculture, Forest Service, Rocky Mountain Forest and Range Experiment Station: 158-162.
}

${ }^{2}$ Forest Research Nursery, University of Idaho, Moscow, Idaho 83844-1137 
FOREST RESEARCH NURSERY PUBLIC SALE DATEBASE FOR FY94

Order Number: 1

Name: Test Record 1

city: North

county: ID
Date: $9 / 23 / 93$

Address 1: $100 \mathrm{~N}$. Idaho

State: ID

Telephone: 885-8888
Address2 :

Zip code: $\mathbf{8 8 8 8 8}$

No. Customers: 1

Taxable Sales: $\quad \$ 49.00$

Tax Paid: $\$ 2.45$

Exempt sales:

Exempt $\mathrm{S \& H}: \$ 8.50$

Expected Amount: $\$ 59.95$

Amount Paid: $\$ 59.95$

Net Deposit:

$\$ 57.50$

1st Del. Date:

$4 / 11 / 94$

Deposit Number: 1

2nd Del. Date:

Total Exempt: $\$ 8.50$

Amount Due: $\$ 0.00$

Pickup Code:

3rd Del. Date:

\section{Total seedlings: 140}

Total Packages: 0

\begin{abstract}
RL Conifer: 40
ss conifer: 0
\end{abstract}

\section{SS Hdw: 0 \\ s6 Hdw: 100 \\ Misc: 0}

RL CONIFERS

RL White pine:

RL Douglas fir:

RL Grand fir:

RL Ponderosa pine: 20

RL Lodgepole pine:

RL Western larch:

RL Blue spruce:

RL Western redcedar:

RL Norway spruce: 20

SUPERSTOCK CONIFERS

SS Ponderosa:

SS Scotch:

SS Austrian:

Ss Blue:

SS Norway:

SS Larch:

SS Grand fir:

SUPERSTOCK HARDWOODS

Honeylocust:

Rugosa rose:

Honeysuckle:

chokecherry:

Blue oak:

White lilac:

Hybrid poplar:

S6 HARDWOODS \& PACKAGES

S6 Hybrid poplar: 100

s6 sumac:
Black locust:

Siberian pea:

wild apple:

Bur oak:

Syringa:

Sagebrush :

Arctic willow:
Russian olive:

River birch:

Nanking cherry:

sawtooth oak:

Purple lilac:

Sand cherry:

Golden willow:

MISCELLANEOUS SPECIALS

English oak:

Austrian pine:

American plum:
S6 Arctic willow:

IDAHO PACKAGE:
S6 Golden willow:

WILDLIFE PACKAGE:

Figure 1. Database record format. 


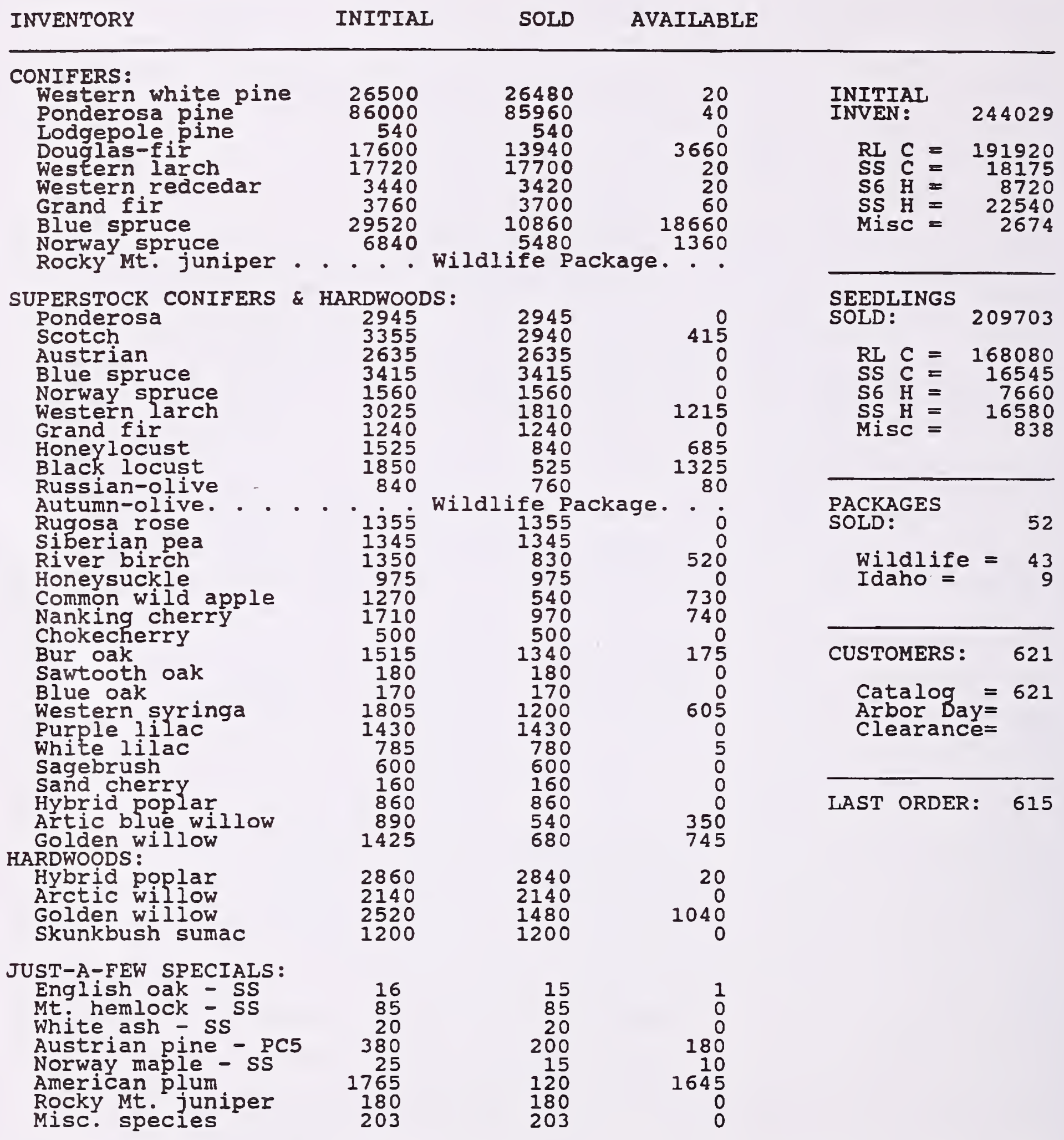

Taxable Sales: $\$$

Tax Paid: \$

EXEMPT TOTAL: $\$$

TOTAL AMOUNT PAID: \$

NET DEPOSIT: $\$$
Exempt Sales: \$

Shipping/Handling: \$

TOTAL AMOUNT DUE: $\$$

Figure 2. Seedling inventory. 
After a batch of orders is processed, a new inventory report (Figure 2) is printed. This report will immediately indicate if seedlings have been oversold or if inventories are low. Appropriate adjustments are then made as necessary. At this time a deposit slip is also generated (Figure 3) showing appropriate financial totals for that batch of orders. The database is then filtered to print customer receipts (Figure 4) or other data as necessary. As shipping or pickup dates approach, the database is queried to determine numbers of customers and quantities of seedlings so that shipping boxes may be prepared in advance. A copy of the receipt is used to fill orders from seedling cold storage just prior to shipment.

This database has proven easy to use by staff personnel without intensive microcomputer training. Additions or deletions are easy to make as the list of species or stock types change annually. The database can be queried to extract other data for management purposes such as distribution of sales, use of seedlings purchased, or preference of species or stock type for a particular planting purpose or location.

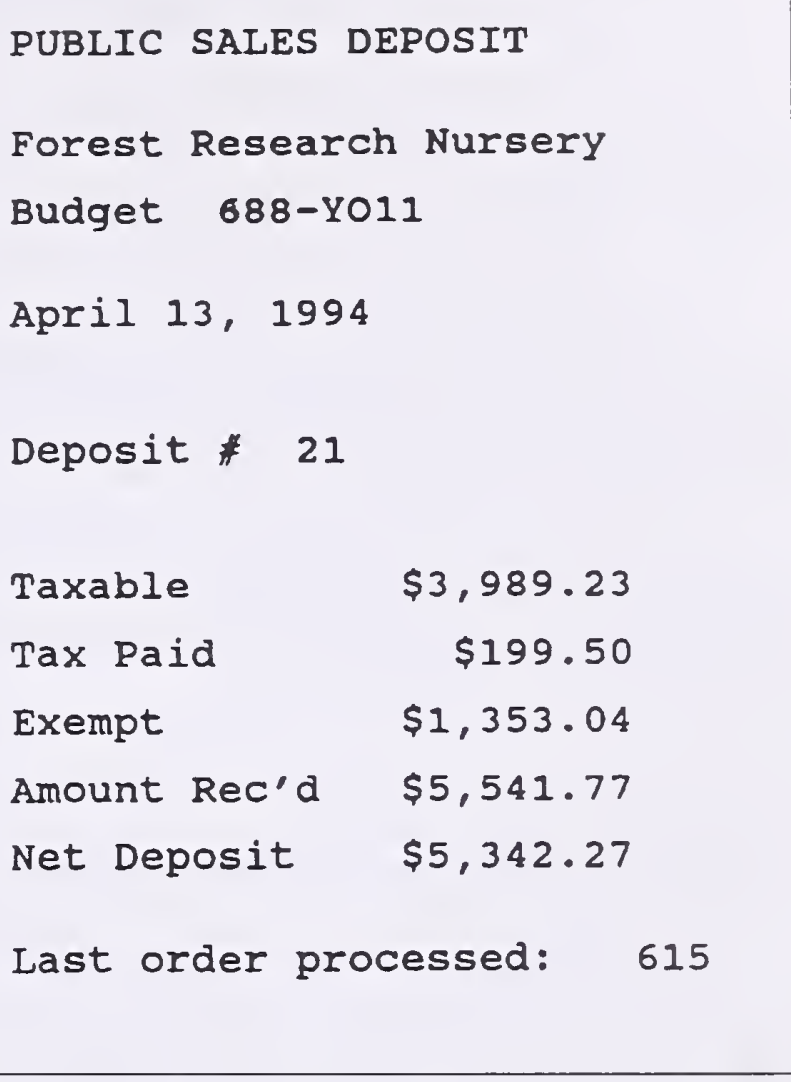

Figure 3. Public sales deposit. 


\section{UNIVERSITY OF IDAHO - FOREST RESEARCH NURSERY}

Order Number: 1

Test Record 1 $100 \mathrm{~N}$. Idaho

North ID
Pickup Code:

Delivery Date 1 :

Delivery Date 3:

Thank you for purchasing seedlings from the University of Idaho Research Nursery. The nursery is dependent upon seedling sales to meet operating expenses and to fund research in nursery management and forest regeneration. We appreciate your concern and efforts toward the protection of our natural resources.

If you are in Moscow, stop by the Nursery. We are open from 7:36 am to 4:00 pm Monday through Friday and visitors are always welcome and appreciated. We're located 2 miles east of Moscow on the Troy Highway (Idaho 8) at the University of Idaho plant Science Farm.

CONIFERS :

Western white pine Ponderosa pine Lodgepole pine

Douglas-fir

Western larch

Western redcedar

Grand fir

Blue spruce

Norway spruce

Rocky Mt. juniper

HARDWOODS :

Hybrid poplar

Arctic willow

Golden willow

skunkbush sumac

JUST-A-FEW SPECIALS:

English oak

Mt. hemlock

White ash

Austrian pine

Norway maple

Misc. species

SPECIAL PACKAGES:

Idaho package:

wildilie package:
SUPERSTOCK CONIFERS:

SS Ponderosa pine

SS Scotch pine

SS Austrian pine

SS Blue spruce

SS Norway spruce

SS Western larch

ss Grand fir

\section{SUPERSTOCK HARDWOODS:}

Honeylocust

Black locust

Russian-olive

100

Autumn-olive

Rugosa rose

Siberian pea

River birch

Honeysuckle

Common wild apple

Nanking cherry

Chokecherry

American plum

Bur oak

Sawtooth oak

Blue oak

Western syringa

Purple lilac

White lilac

Sagebrush

Sand cherry

Hybrid poplar

Arctic willow

Golden willow

Figure 4. Sales receipt. 


\title{
Steam Sterilization of Growing Media ${ }^{1}$
}

\author{
John W. Bartok, Jr. ${ }^{2}$
}

Abstract-With the removal of methyl bromide over the next few years as a treatment agent for soils and growing mixes, other methods will have to be found. Steam offers a good alternative for greenhouse and nursery operations both indoors and in field beds.

The technology has been developed over many years and equipment is available from several manufacturers. The use of aerated steam can reduce energy requirements and speed the sterilization process.

\section{INTRODUCTION}

The Environmental Protection Agency (EPA) has added methyl bromide to the Clean Air Act Class 1 as an ozone depleting substance. This freezes U.S. production and imports from 1994 to 2000 at 1991 levels. By the year 2001, all production will be phased out and other alternatives will have to be used.

Steam has long been considered the best treatment agent for growing media. It will destroy fungi, bacteria, nematodes, insects and most weeds. Its effectiveness is evaluated simply by measuring the medium temperature and the length of contact time.
Steam is also non-toxic so that the soil can be worked immediately after treatment. There is no danger to the workers handling the mix. It can also be used next to living plants without any danger.

The lethal temperatures necessary to eradicate soil pests are shown in Table 1. Good results can be obtained with a temperature of 160 to $180 \mathrm{deg}$. F. for 30 minutes. A probe-type thermometer works well for measuring temperature.

\section{HEAT REQUIREMENT}

The amount of heat needed to raise the temperature of a given volume of growing media depends on the components, its moisture content and the difference between the cold soil temperature and the desired treatment temperature. The heat flow rate needed per minute depends on how quickly the mix must be brought up to the desired temperature. A comparison

Table 1. Temperature necessary to kill soil pests.

$\begin{array}{cl}115 \text { deg.F. Water molds (pythium } & \begin{array}{c}\text { and phytophthora) } \\ \text { Nematodes }\end{array} \\ 120 & \text { Worms, slugs, centipedes } \\ 135 & \text { Most plant pathogenic } \\ 140 & \text { bacteria } \\ & \text { Soil insects } \\ 160 & \text { Most weed seeds } \\ 180 & \text { Few resistant weed seeds } \\ 215 & \text { \& plant viruses }\end{array}$
Agriculture, Forest Service, Rocky Mountain Forest and Range Experiment Station: 163-165.

${ }^{2}$ Natural Resources Mgt. \& Engr. Dept., University of Connecticut, Storrs, CT 06269-4087. 
of the amount of steam needed for different growing mixes is shown in Table 2. For most applications, 30 minutes heating time and 30 minutes of contact time is desirable.

Soil moisture is best at near field capacity. Because it takes about 5 times as many Btu's to heat one pound of water as compared to one pound of soil, very wet soil should be avoided. Real dry soil should also be avoided as it acts like an insulator and restricts heat flow.

When water is heated and turned to steam, 970 Btu's of heat are absorbed in the phase change. The volume also increases 1600 times. When steam is injected into the medium, the 970 Btu's of heat are released as the steam condenses back to wate1. This is what makes steam a much better sterilizing agent than water. Unless the soil has very good porosity, a water treatment system would wet the soil too much.

\section{TYPES OF SYSTEMS}

There are two common methods of steam treatment: free-flowing and aerated.

When steam leaves the boiler it is under slight pressure ( 5 to $15 \mathrm{psi}$ ). As soon as it is released into the growing mix it drops to atmospheric pressure giving up its heat. At this point it is considered free-flowing. As the tem-

Table 2. Amount of steam needed for growing media treatment*.

\begin{tabular}{|c|c|c|}
\hline Growing Media & Free-Flowing Steam & Aerated Steam \\
\hline Soil & $10.8 \mathrm{lb} / \mathrm{cu} \mathrm{ft}$ & $6.3 \mathrm{lb} / \mathrm{cu} \mathrm{ft}$ \\
\hline Soil/peat/sand & 7.5 & 4.4 \\
\hline Soil/peat/perlite & 6.8 & 4.0 \\
\hline Peat/perlite & 9.7 & 5.7 \\
\hline Peat & 11.2 & 6.5 \\
\hline \multicolumn{3}{|l|}{ *Assumes: } \\
\hline \multicolumn{3}{|c|}{ Soil - silty clay loam } \\
\hline \multicolumn{3}{|c|}{ Field capacity moisture content } \\
\hline \multirow{2}{*}{\multicolumn{3}{|c|}{ Saturated steam - 230 deg. F. }} \\
\hline \multicolumn{2}{|c|}{ Aerated steam - 160 deg. F. } & \\
\hline \multicolumn{3}{|c|}{ Soil temperature -60 deg. $F$} \\
\hline \multicolumn{3}{|c|}{ Air -70 deg. F. $-50 \%$ RH } \\
\hline Efficiency & m - & \\
\hline
\end{tabular}

perature drops, it creates a heat zone that advances as the surrounding soil is heated. When one soil particle reaches 212 deg.F, then the steam moves past it to heat the next particle until the whole area is brought up to temperature.

As long as the injection rate does not exceed the condensation rate (about $18 \mathrm{lbs} / \mathrm{hr} / \mathrm{sq} \mathrm{ft}$ of exposed medium surface), blowout, the free escape of steam to the outside does not occur. The medium should be well mixed without clumps, have uniform moisture and be level in the container, bed or bench. Disadvantages of free-flowing steam include over-kill of the microflora because of the high temperature, increase in total soluble salts and changes to the soil structure.

In the aerated steam method, steam from a boiler is combined with air from a high pressure fan to create a 140 to $180 \mathrm{deg}$. F. mix that is forced through the growing media. Radial or backward curved fans with a water static pressure of $20 \mathrm{in}$. to $25 \mathrm{in}$. are commonly used.

Advantages to the aerated steam system include:

1. Up to $40 \%$ less steam is needed as the soil doesn't have to be heated as much.

2. More rapid, even heating because the blower forces the steam through the soil.

3. Microflora survive at the lower sterilization temperature.

4. By turning off the steam and continuing the air flow, the temperature of the soil can be lowered rapidly.

With proper design, the system can be adapted to treat batches or continuous flow. For batch treatment, the air/steam 
mix is typically exhausted into a chamber below a perforated floor of a bin, cart or truck body. A fabric cover is used to hold in the heat but allow the air to escape.

Bed or bench treatment can be done in several ways:

The easiest system to set up but the least effective is to lay perforated pipe on top of the bed. Aluminum, canvas or high temperature plastic pipe is used.

The bed or bench is covered with a canvas cover to retain the steam. Steam injected on the top of the soil only penetrates to about 8 " deep which may not be adequate for some crops.

A better system uses perforated poly pipe buried 12 " or deeper under the top of the bed. This allows the bed to be rototilled or cultivated without disturbing the pipe. Steam injected in the pipe rises toward the surface and gives uniform control throughout the bed.

Steam rakes and blades have been used since the 1950's.

Original development was done in Europe but the technology never was common in the U.S. as chemical sterilants came in about that time. Research on this system is under development at the USDA Forest Service, Missoula, Montana.
With this system the rake or blade is pulled slowly through the soil bed by a winch. Depth is controlled by the angle and length of the tines. Uniformity of treatment is good. A mobile boiler and aerator are needed.
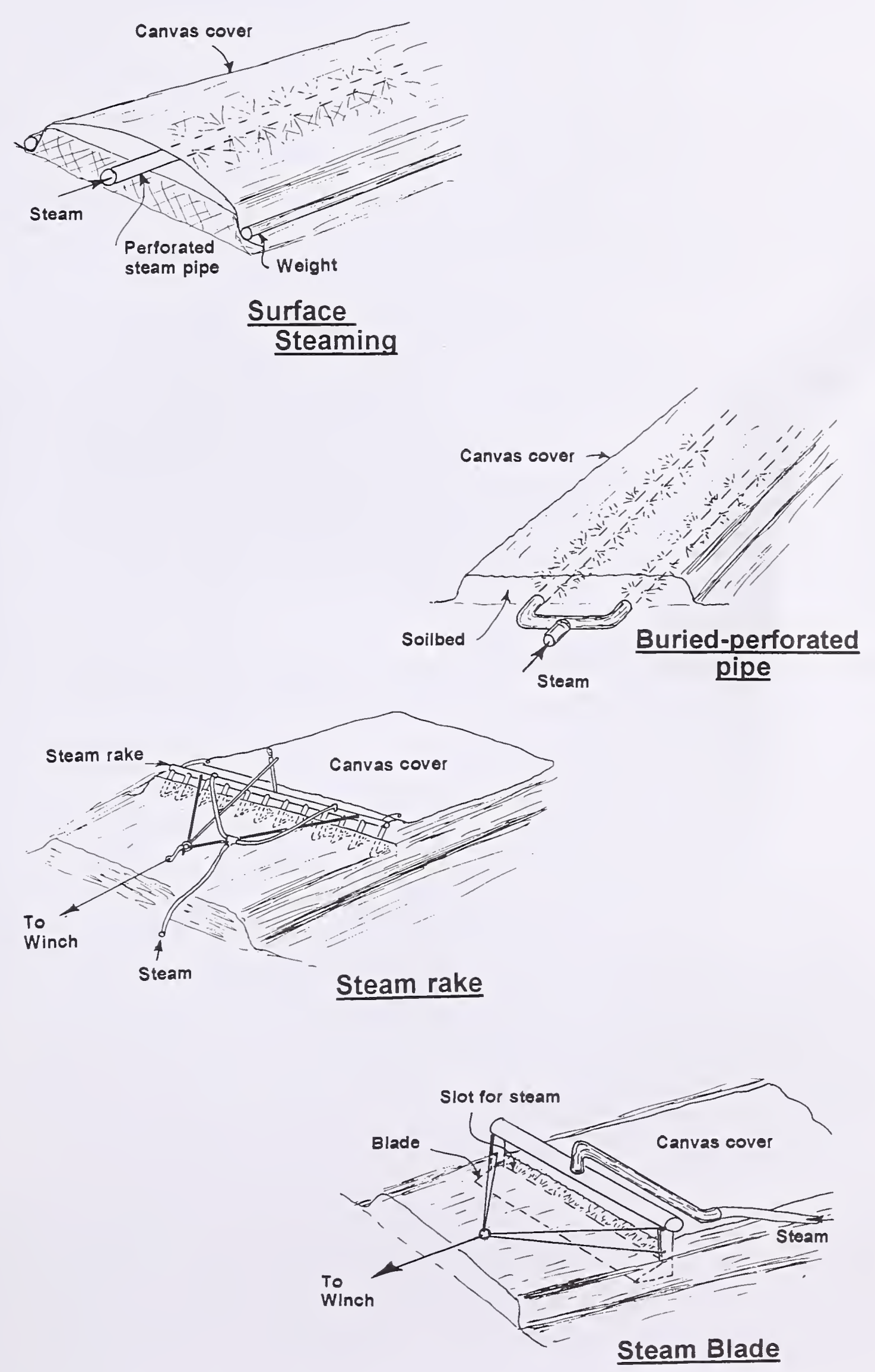


\title{
Use of Frost Fabric as a Seedbed Mulch and Frost Protection Method' 1
}

\author{
Randy D. Moench ${ }^{1}$
}

Abstract-Spring frosts can cause substantial losses to seedling nurseries. Frost fabric - a spunbonded polypropylene product - is found to keep surface soil temperatures above freezing during frost events. It may be an alternative to irrigation and other traditional frost control methods. It is also a satisfactory seedbed mulch. Application and removal methods and equipment have been developed to facilitate use of this fabric on a production basis.

\section{WHY FROST FABRIC?}

The Colorado State Forest Service Nursery produces 2.5 million seedlings annually. Over 35 different species are grown, the majority are produced using bareroot methods. The seed dormancy of most of these species requires fall sowing. This takes place in early October. Seedling emergence occurs from late March through early May depending on species.

Erratic spring weather conditions lead to frequent periods of freezing temperatures. Damage, ranging from slight to catastrophic, often occurs.
Traditional frost control methods such as irrigation have not been effective for the writer. At another nursery, shade frames were found to warm soil surface temperatures as much as $2^{\circ} \mathrm{F}$.

\section{FROST FABRIC DESCRIPTION}

This nursery began evaluating frost fabric as a frost control alternative. This product was originally developed to cover and protect established plants such as tomatoes. The fabric is a light spunbonded polypropylene plastic (Figure 1).

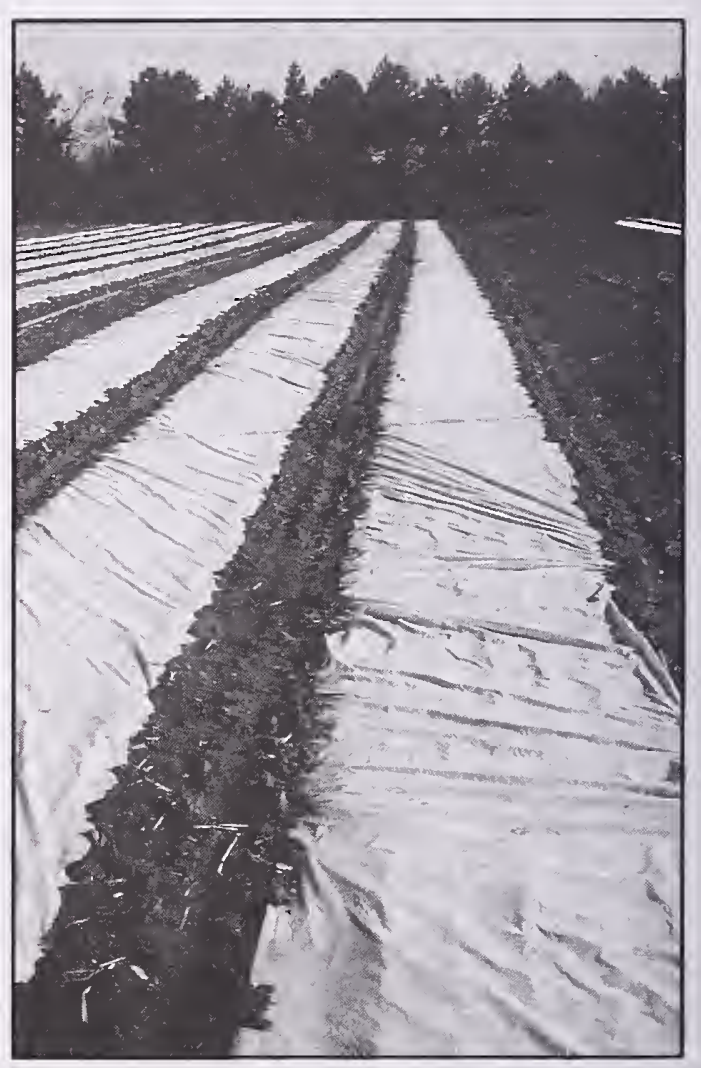

Figure 1. Field covered with frost fabric.

'Moench, R.D. 1994. Use of Frost Fabric as a Seedbed Mulch and Frost Protection Method. IN: Landis, T.D.; Dumroese, R.K., tech. coords. National Proceedings, Forest and Conservation Nursery Associations. Gen. Tech. Rep. RM-257. Fort Collins, CO: U.S. Department of Agriculture, Forest Service, Rocky Mountain Forest and Range Experiment Station: 166-168.

${ }^{2}$ Colorado State Forest Service, Nursery, Building 1060, Foothills Campus, Colorado State University, For Collins, CO 80523. 


\section{FROST BARRIER SPECIFICATIONS}

Spunbonded Polypropylene

1.5 ounces per square yard

Grab Tensile Strenght - 25 LBS.

Trapezoidal Tear Strength (MD-CD)

7.8-6.6 LBS.

Mullen Burst - 48 PSI

Frazier Permeability (cfm / sq. ft.) - 500

Thickness (inches) - 0.011

\section{UV TREATED}

It is UV treated to resist decomposition in sunlight and is reusable. Product cost is under four cents per square foot.

\section{TEST RESULTS}

Initial use of the fabric was for frost control only. In spring, at time of seedling emergence, the nursery's traditional mulch of sudan grass straw was removed and replaced with a covering of frost fabric. 5 foot 3 inch rolls were laid over top of 4 foot wide seedbeds.

Temperature was determined in covered and uncovered areas using a Taylor maximumminimum temperature thermometer. The thermometer was placed flat on the bed surface. Minimum temperature differences between covered and uncovered areas ranged from $4^{\circ}$ to $9^{\circ} \mathrm{F}$. By using frost fabric, soil

Table 1. 1993 Minimum soil surface temperatures with frost fabric covering (fabric) and without (open).

\begin{tabular}{|c|c|c|c|c|c|c|}
\hline \multirow[t]{2}{*}{ Date } & \multicolumn{2}{|c|}{ Fabric } & \multicolumn{2}{|c|}{ Open } & \multicolumn{2}{|c|}{ Difference } \\
\hline & ${ }^{\circ} \mathrm{F}$ & ${ }^{\circ} \mathrm{C}$ & ${ }^{\circ} \mathrm{F}$ & ${ }^{\circ} \mathrm{C}$ & ${ }^{\circ} \mathrm{F}$ & ${ }^{\circ} \mathrm{C}$ \\
\hline $4 / 15$ & $39^{\circ}$ & $4^{\circ}$ & $32^{\circ}$ & $0^{\circ}$ & $7^{\circ}$ & $4^{\circ}$ \\
\hline $4 / 16$ & $36^{\circ}$ & $2^{\circ}$ & $32^{\circ}$ & $0^{\circ}$ & $4^{\circ}$ & $2^{\circ}$ \\
\hline $4 / 19$ & $32^{\circ}$ & $0^{\circ}$ & $28^{\circ}$ & $-2^{\circ}$ & $4^{\circ}$ & $2^{\circ}$ \\
\hline $4 / 20$ & $32^{\circ}$ & $0^{\circ}$ & $25^{\circ}$ & $-4^{\circ}$ & $7^{\circ}$ & $4^{\circ}$ \\
\hline $4 / 21$ & $32^{\circ}$ & $0^{\circ}$ & $28^{\circ}$ & $-2^{\circ}$ & $4^{\circ}$ & $2^{\circ}$ \\
\hline $4 / 23$ & $32^{\circ}$ & $0^{\circ}$ & $28^{\circ}$ & $-2^{\circ}$ & $4^{\circ}$ & $2^{\circ}$ \\
\hline $4 / 26$ & $36^{\circ}$ & $2^{\circ}$ & $30^{\circ}$ & $-1^{\circ}$ & $5^{\circ}$ & $3^{\circ}$ \\
\hline $4 / 28$ & $45^{\circ}$ & $7^{\circ}$ & $41^{\circ}$ & $5^{\circ}$ & $4^{\circ}$ & $2^{\circ}$ \\
\hline $4 / 29$ & $39^{\circ}$ & $4^{\circ}$ & $32^{\circ}$ & $0^{\circ}$ & $7^{\circ}$ & $4^{\circ}$ \\
\hline $5 / 03$ & $36^{\circ}$ & $2^{\circ}$ & $27^{\circ}$ & $-3^{\circ}$ & $9^{\circ}$ & $5^{\circ}$ \\
\hline AVG. & DIFF & & & & $5^{\circ}$ & $3^{\circ}$ \\
\hline
\end{tabular}

Table 2. 1993 Maximum soil surface temperatures with frost fabric covering (fabric) and without (open).

\begin{tabular}{|c|c|c|c|c|c|c|}
\hline \multirow[t]{2}{*}{ Date } & \multicolumn{2}{|c|}{ Fabric } & \multicolumn{2}{|c|}{ Open } & \multicolumn{2}{|c|}{ Difference } \\
\hline & ${ }^{\circ} \mathrm{F}$ & ${ }^{\circ} \mathrm{C}$ & ${ }^{\circ} \mathrm{F}$ & ${ }^{\circ} \mathrm{C}$ & ${ }^{\circ} \mathrm{F}$ & ${ }^{\circ} \mathrm{C}$ \\
\hline $4 / 15$ & $97^{\circ}$ & $36^{\circ}$ & $68^{\circ}$ & $20^{\circ}$ & $29^{\circ}$ & $16^{\circ}$ \\
\hline $4 / 16$ & $90^{\circ}$ & $32^{\circ}$ & $68^{\circ}$ & $20^{\circ}$ & $22^{\circ}$ & $12^{\circ}$ \\
\hline $4 / 19$ & $106^{\circ}$ & $41^{\circ}$ & $79^{\circ}$ & $26^{\circ}$ & $27^{\circ}$ & $15^{\circ}$ \\
\hline $4 / 20$ & $91^{\circ}$ & $33^{\circ}$ & $79^{\circ}$ & $26^{\circ}$ & $12^{\circ}$ & $7^{\circ}$ \\
\hline $4 / 21$ & $97^{\circ}$ & $36^{\circ}$ & $75^{\circ}$ & $24^{\circ}$ & $22^{\circ}$ & $12^{\circ}$ \\
\hline $4 / 23$ & $97^{\circ}$ & $36^{\circ}$ & $75^{\circ}$ & $24^{\circ}$ & $22^{\circ}$ & $12^{\circ}$ \\
\hline $4 / 26$ & $109^{\circ}$ & $43^{\circ}$ & $72^{\circ}$ & $22^{\circ}$ & $37^{\circ}$ & $21^{\circ}$ \\
\hline $4 / 28$ & $113^{\circ}$ & $45^{\circ}$ & $84^{\circ}$ & $29^{\circ}$ & $29^{\circ}$ & $16^{\circ}$ \\
\hline $4 / 29$ & $120^{\circ}$ & $49^{\circ}$ & $90^{\circ}$ & $32^{\circ}$ & $30^{\circ}$ & $17^{\circ}$ \\
\hline $5 / 03$ & $106^{\circ}$ & $41^{\circ}$ & $84^{\circ}$ & $29^{\circ}$ & $22^{\circ}$ & $12^{\circ}$ \\
\hline AVG. & DIFF. & & & & $25^{\circ}$ & $14^{\circ}$ \\
\hline
\end{tabular}

surface temperatures averaged $5^{\circ}$ warmer than uncovered areas. The coldest soil surface temperature in uncovered areas was $25^{\circ}$ with $32^{\circ} \mathrm{F}$ under the fabric (Table 1.)

Maximum soil surface temperatures under the fabric were quite high averaging $25^{\circ} \mathrm{F}$ warmer than uncovered areas. The highest maximum temperature recorded was $120^{\circ} \mathrm{F}$ (Table 2.)
Humidity levels underneath the fabric appeared high as well. While no obvious symptoms of heat damping-off were noted future practice will include irrigating for cooling to reduce these temperatures to sub-lethal readings.

\section{USE AS A SEEDBED MULCH}

Traditional mulching methods at this nursery have been using 
some form of a thick straw mulch. In recent years sudan grass and alfalfa were used for this purpose. The objectives of mulching were to maintain adequate soil moisture for the overwintering process and keeping soil temperatures cool to prevent early germination.

In comparison, frost fabric does an adequate job of moisture retention but may require more frequent irrigation than straw mulch. Seedling germination and emergence seems to occur up to two weeks earlier. However, one can leave the fabric on during emergence where the straw much should be removed.

Nursery soils are sandy clay loams prone to crusting. The fabric keeps the soil surface friable. Fabric has been used with spring sown beds to improve soil surface moisture and seedling emergence.

Application and removal of straw mulches is very labor intensive. Use of fabric mulch has significantly reduced hand labor. Additionally, the UV treated product can be reused, reducing its cost. The initial test sample was used for three successive seasons.

\section{APPLICATION AND REMOVAL EQUIPMENT}

To facilitate using this fabric and further reduce hand labor, Ron Huser and Rex Davidson of the nursery developed and fabricated equipment for the process. The applicator is designed after "weed barrier machines" in common use for conservation tree planting in Colorado (Figure 2).

The edges of the 5 foot 3 inch wide fabric are pushed under and covered by a small layer of soil. Seedbed ends are secured by hand dug trenches. This anchoring method is sufficient to withstand Chinook winds of $90 \mathrm{mph}$.

For reuse the fabric must be rolled up into a tight roll with smooth ends. A machine was developed for this purpose using a hydraulic motor for spooling up the fabric (Figure 3).

\section{POTENTIAL DISADVANTAGES}

Use of frost fabric has improved stand densities, reduced frost damage and improved surface soil moisture and tilth during the critical emergence period. These advantages combined with labor efficiencies has lead to the decision to use this product as the mulching method on all fall sown nursery seedbeds.

Potential disadvantages are also noted. Insect populations seem higher under the fabric. The micro-climate created may increase insect survival. This nursery has never used soil fumigation. While the fabric is quite light seedlings can be bent over from the weight but this seems temporary. The high temperatures were quite surprising. Irrigation for cooling will need to be continued to reduce chances for heat damp-off.

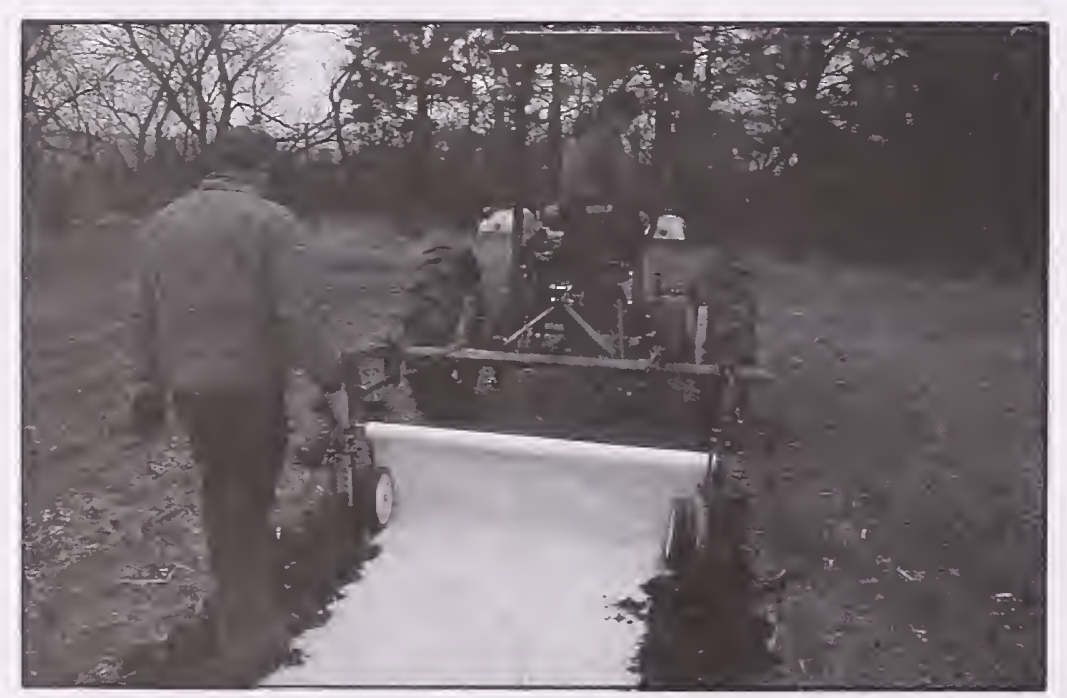

Figure 2. Applicator.

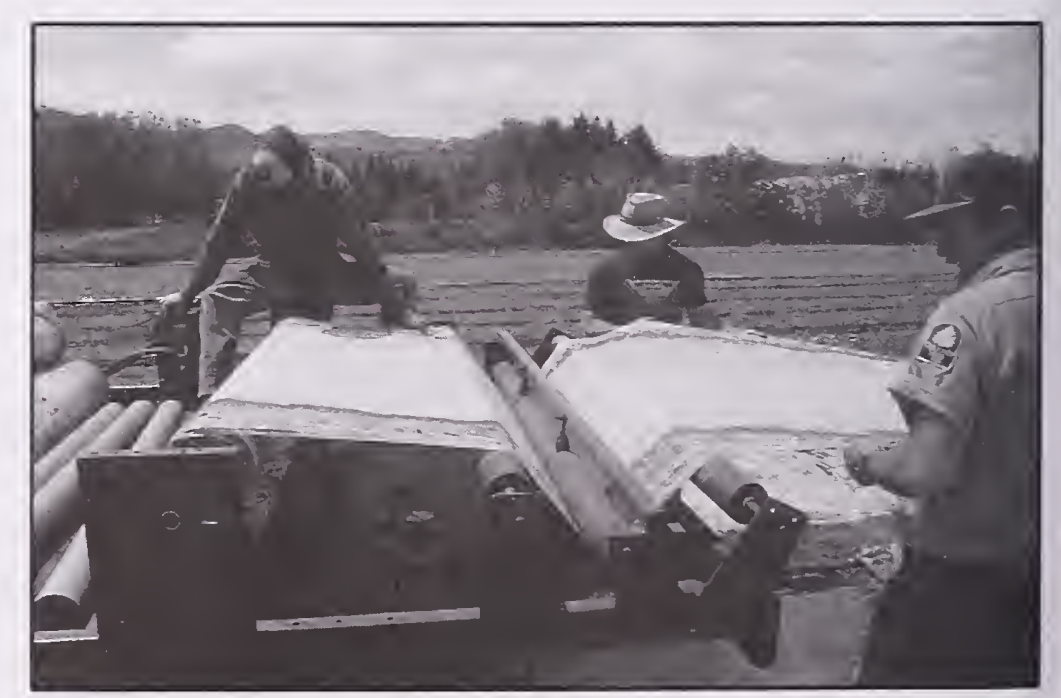

Figure 3. Roller-upper. 


\title{
Nursery Regimes Affect Seedling Size and Outplanting Performance of $1+0$ Ponderosa Pine ${ }^{1}$
}

\author{
John Sloan ${ }^{2}$
}

\section{INTRODUCTION}

Ponderosa pine seedlings are successfully grown to outplanting specifications in two years at Lucky Peak Nursery in Boise. Idaho. Under favorable conditions, these bareroot seedling can grow very large shoots. However, the perception is that after just one year in the nursery, the trees have not grown large enough tops to meet specifications.

Nursery cultural practices can play a big part in seedling morphology and physiology. Fertilization and spacing both influence seedling nutrition. Soil fertility is very important to nursery stock production and, at Lucky Peak Nursery, nitrogen is the nutrient most limiting to growth. Many studies have shown that nitrogen fertilization can increase seedling size (Canham and McCavish 1981, Cochran 1972, Pharis and
Kramer 1964, van den Driessche 1982). Other studies have documented that shoot/root ratios can be adversely affected by overfertilization with nitrogen (Steinbrenner and Rediske 1964. Vlamis and Evans 1957). Increased spacing in the seedbed up to an optimum, increases the size of $2+0$ seedlings (Buse and Day 1989, Mexal 1980, Richards and others 1973, van den

Driessche 1984).

It has been shown that undercutting seedlings in the nursery bed modifies the morphology of planting stock (Aldhous 1972, Buse and Day 1989, Cleary and others 1978, Duryea and Lavender 1982, Hobbs and others 1987, van den Driessche 1983).

The ability to produce $1+0$ ponderosa pine would give Lucky Peak Nursery and their customers more flexibility. It would reduce the lead time required to produce trees for planting after a wild fire or harvesting. One-year-old seedlings cost less to grow, lift, grade, pack, store, ship, and plant. They take less water, fertilizer, weeding, and inventory. It would allow the nursery more frequent opportunities to fallow fields or conduct operations to maintain and improve drainage and soil aeration (Jenkinson and others 1993).

My goal was to produce $1+0$ ponderosa pine seedings that could withstand the harsh conditions of Intermountain planting sites. I chose to modify the seedlings using three cultural practices: fertilization, density management, and root pruning. In this paper, I will compare the morphological characteristics and the outplanting performance of seedlings grown for one year in three regimes of nitrogen fertilization, at four density

\footnotetext{
'Sloan, J. 1994. Nursery Regimes Affect Seedling Size and Outplanting Performance of 1+O Ponderosa Pine. IN: Landis, T.D.; Dumroese, R.K., tech. coords. National Proceedings, Forest and Conservation Nursery Associations. Gen. Tech. Rep. RM257. Fort Collins, CO: U.S. Department of Agriculture, Forest Service, Rocky Mountain Forest and Range Experiment Station: 169-181.
} 
levels, and three regimes of root pruning.

The first objective was to determine the optimum cultural regime to maximize the height, caliper, and root mass of oneyear-old ponderosa pine at Lucky Peak Nursery. A second objective was to compare outplanted $1+0$ seedlings with $2+0$ seedlings of the same seed source.

\section{METHODS}

The seed came from the upper portion of the ponderosa pine's elevation range (elevation 5500 feet or 1676 meters) on the Boise National Forest in central Idaho. The $1+0$ test was sown in nursery beds in close proximity to where the same seedlot was growing as $2+0$ stock. The $2+0$ seedlings had a one-year head start at the time the $1+0$ seedlings were sown. All trees were lifted at the same time.

Differences between treatments were determined using the analysis of variance technique and the Newman-Keuls comparison of means. All statistical differences were at the 95 percent level of confidence.

\section{Nursery Treatments}

The seed for the $1+0$ stock was sown on May 8, 1990. Two experimental blocks were established, each containing three root pruning treatment sections randomly arranged. Within the root pruning sections were 12 randomly arranged fertilizer/ spacing plots, three feet $(.9 \mathrm{~m})$ long. This created 36 different cultural combinations, replicated twice.

\section{Emerged seedlings were} thinned to one of four spacing levels on June 15. The spacing levels included: S1) no thinning: average of 17.7 seedlings per $\mathrm{ft}^{2}$ $\left(190.5 / \mathrm{m}^{2}\right)$, S2) one seedling left where two or more seedlings came up in a clump (doubles): average of 15.1 seedlings per $\mathrm{ft}^{2}$ $\left.\left(162.5 / \mathrm{m}^{2}\right), \mathrm{S3}\right)$ seedlings thinned to $4 \mathrm{~cm}$ spacing: average of 11.1 seedlings per $\mathrm{ft}^{2}$ (119.5/ $\mathrm{m}^{2}$ ), and $\mathrm{S4}$ ) seedling thinned to $6 \mathrm{~cm}$ spacing: average of 8.3 seedlings per $\mathrm{ft}^{2}\left(89.3 / \mathrm{m}^{2}\right)$.

The three fertilizer treatments were: F1) the normal fertilizer applications of presowing treble super phosphate (0-46-0) at 180 lbs/ac $(202 \mathrm{~kg} / \mathrm{ha})(82.8 \mathrm{lb}$. of phosphorus/ac.) and ammonium nitrate (34-0-0) at $120 \mathrm{lbs} / \mathrm{ac}$ $(136 \mathrm{~kg} / \mathrm{ha})(40.8 \mathrm{lb}$. of nitrogen/ ac) and top dressing of ammonium nitrate at $125 \mathrm{lbs} / \mathrm{ac}(140$ $\mathrm{kg} / \mathrm{ha})(42.5 \mathrm{lb}$. of nitrogen/ac) twice, F2) normal presowing rates and twice the normal top dressing of ammonium nitrate (125 lbs/ac 4 times), and F3) normal presowing rates and three times the normal top dressing of ammonium nitrate $(125 \mathrm{lbs} / \mathrm{ac} 6$ times).

The three root pruning treatments were: RP1) no undercut- ting until the lifting date, RP2) seedlings undercut at 8 inches on August 9, and RP3) seedlings undercut at 8 inches on August 9 and undercut at 12 inches on September 25.

Other cultural practices were carried out by nursery personnel as usual. Each plot was lifted as soon as the ground thawed the next spring (March 8, 1991). A sample from the $2+0$ nursery bed was lifted at the same time. Trees were stored in a cooler at $1{ }^{\circ} \mathrm{C}$ until they were measured and again until planting.

\section{Measurements}

Seedlings were randomly selected for each test. From each $1+0$ plot, 15 and 10 seedlings were used for outplanting and root growth capacity tests, respectively. Seedlings from the two blocks were combined to double the number of test trees. The $2+0$ seedlings were divided into three groups based on the seedling caliper at the root collar: large $(7-10 \mathrm{~mm})$, medium(5-7 mm), and small(4-5 $\mathrm{mm}$ ). This was to determine if size or age was responsible for any differences in performance between $1+0$ and $2+0$ seedlings. Height to the nearest $\mathrm{cm}$ and caliper to the nearest $.01 \mathrm{~mm}$ was measured on all trees as was top and root volumes to the nearest $.1 \mathrm{ml}$. Top and root volumes were measured by water displacement on a scale. Shoot/root ratios were based on these top and root volume 
measurements. I maintained the temperatures of air below $15^{\circ} \mathrm{C}$ and water below $10^{\circ} \mathrm{C}$ during sorting and measurements in order to minimize seedling stress. Only seedlings which were damaged in the lifting process or those which lacked a healthy green color were culled. Size was not a factor.

Root growth capacity tests were conducted with the root systems suspended in mist chambers for 14 days. The mist chamber temperatures were maintained at $23^{\circ} \mathrm{C}$.

\section{Outplanting test}

The seedlings were planted April 22, 1991 in three different blocks on a site within the Boise National Forest. The second and third blocks were harsher and drier than the previous one because the soil was shallower. The first block was in a Douglasfir/white spirea (Pseudotsuga menziesii/Spirea betulifolia) habitat type, the second and third blocks supported a Douglas-fir/ elk sedge (Pseudotsuga menziesii/Carex geyeri) habitat type. Seedlings were rolled in wet burlap the day before planting and were acclimated at $50^{\circ}$ for 18 hours.

Seedlings were spaced six feet apart within and between rows. Each planting spot was hand scalped to clear vegetation and debris in a 2-foot square area. The seedlings were side-hole planted in auger holes under good weather conditions for planting. Each block contained 390 randomly arranged seedlings, ten from each nursery cultural treatment combination and the three $2+0$ seedling groups. Each tree planter planted an equal number of seedlings from each treatment.

\section{RESULTS}

\section{1+0 Seedling Size}

Root pruning in the nursery bed tended to reduce seedling height, top and root volume, caliper, shoot/root ratio, and increase root growth potential. Increased nitrogen fertilization in the nursery tended to increase height, caliper, shoot and root volume, and decrease root growth potential. Increased spacing increased height, caliper, shoot and root volume, and shoot/root ratio (Tables 1 and 2).

In figure 1 we see an example of the interaction affect of fertilizer and spacing on root volume. Under the $1 \mathrm{x}$ and $2 \mathrm{x}$ fertilizer regimes, the seedlings responded to each increase in spacing and fertilizer with a larger root volume. However, under the $3 \mathrm{x}$ fertilizer regime root volumes did not increase further and at the wide spacing the root volume began to decline.

Six individual treatments produced seedlings with average heights above $8 \mathrm{~cm}$. These all came from the plots which were not root pruned. Seven treatment

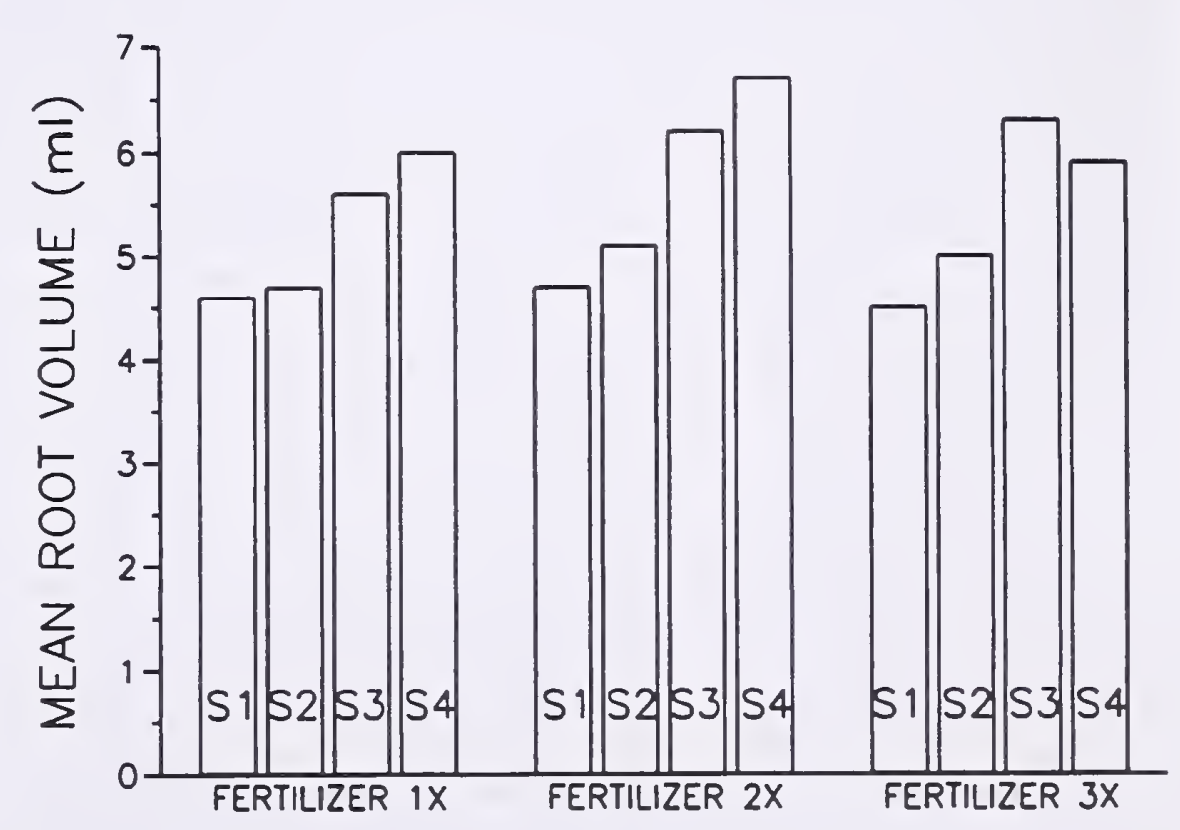

Figure 1. An example of how fertilizer and space affected size (in this case, root volume) of $1+0$ ponderosa pine seedlings. $1 \mathrm{X}$ indicates normal rates of application of ammonium nitrate, $2 X$ indicates twice the normal application of ammonium nitrate, and $3 X$ indicates tree time the rate of ammonium nitrate. $S 1$ plots were unthinned. Successive plots were less dense up to $S 4$ where the seedlings were spaced $6 \mathrm{~cm}$ apart within the rows. 
Table 1. Size and root growth capacity for ponderosa pine seedlings. The $1+0$ seedlings are divided by treatment; the $2+0$ seedlings are divided by size class. Values followed by different letters are significantly different at the 95 percent level of confidence. Values followed by the same letter or no letter are not significantly different.

\begin{tabular}{|c|c|c|c|c|c|c|c|c|}
\hline Treatment & $\begin{array}{l}\text { Mean } \\
\text { Height } \\
(\mathrm{cm})\end{array}$ & $\begin{array}{l}\text { Mean } \\
\text { Caliper } \\
(\mathrm{mm})\end{array}$ & $\begin{array}{l}\text { Shoot } \\
\text { Volume } \\
\text { (ml) }\end{array}$ & $\begin{array}{l}\text { Root } \\
\text { Volume } \\
\text { (ml) }\end{array}$ & $\begin{array}{l}\text { Total } \\
\text { Volume } \\
\text { (ml) }\end{array}$ & $\begin{array}{l}\text { Mean } \\
>\text { no. } \\
\text { Roots } \\
>1.5 \mathrm{~cm}\end{array}$ & $\begin{array}{l}\text { Length } \\
\text { of } 3 \\
\text { Longest } \\
\text { Roots } \\
(\mathrm{cm})\end{array}$ & $\begin{array}{l}\text { Short } \\
\text { Root } \\
\text { Class }\end{array}$ \\
\hline F1 & 7.3ab & $3.9 a$ & $5.3 a$ & $5.2 a$ & $10.5 \mathrm{~s}$ & $7.4 \mathrm{~b}$ & $13.0 \mathrm{c}$ & $4.1 \mathrm{a}$ \\
\hline F2 & $7.7 b$ & $4.1 \mathrm{~b}$ & $6.2 b$ & $5.9 b$ & $12.1 \mathrm{~b}$ & $6.8 b$ & $10.9 b$ & $4.4 b$ \\
\hline F3 & $7.2 a$ & $4.2 \mathrm{~b}$ & $5.9 b$ & $5.9 b$ & $11.8 b$ & $4.1 \mathrm{a}$ & $7.2 a$ & 4.3ab \\
\hline S1 & 7.2 & $3.6 a$ & $4.5 a$ & $4.6 a$ & $5.1 a$ & 5.7 & 10.5 & 4.2 \\
\hline S2 & 7.4 & $3.9 \mathrm{~b}$ & $5.4 b$ & $5.3 b$ & $10.7 \mathrm{~b}$ & 6.3 & 10.8 & 4.3 \\
\hline S3 & 7.7 & $4.3 c$ & $6.5 c$ & $6.2 \mathrm{c}$ & $12.7 \mathrm{c}$ & 5.7 & 10.2 & 4.3 \\
\hline S4 & 7.3 & $4.4 d$ & $6.7 c$ & $6.5 c$ & $13.2 \mathrm{c}$ & 6.7 & 10.0 & 4.3 \\
\hline RP1 & $8.3 c$ & $4.4 a$ & $6.6 \mathrm{c}$ & $6.2 b$ & $12.8 \mathrm{c}$ & $4.0 \mathrm{a}$ & $8.6 a$ & $3.8 \mathrm{a}$ \\
\hline RP2 & $6.5 a$ & $3.8 b$ & $4.9 a$ & $5.3 a$ & $10.2 \mathrm{a}$ & $5.5 b$ & $9.8 a$ & $4.5 b$ \\
\hline RP3 & $7.4 b$ & $4.0 \mathrm{c}$ & $5.8 b$ & $5.5 a$ & $11.3 b$ & $8.7 c$ & $12.7 b$ & $4.4 b$ \\
\hline $1+0$ AVE & 7.4 & 4.0 & 5.8 & 5.7 & 11.5 & 6.1 & 10.4 & 4.3 \\
\hline \multicolumn{9}{|l|}{$2+0$} \\
\hline Small & $9.2 a$ & $3.9 a$ & $8.7 a$ & $5.3 a$ & $14.0 \mathrm{a}$ & $15.1 \mathrm{a}$ & 17.1 & 4.6 \\
\hline Medium & $11.7 \mathrm{~b}$ & $5.3 b$ & $15.9 b$ & $8.9 b$ & $24.8 b$ & $22.6 b$ & 18.3 & 4.9 \\
\hline Large & $16.0 \mathrm{c}$ & $7.7 \mathrm{c}$ & $31.4 c$ & $16.9 \mathrm{c}$ & $48.3 c$ & $21.0 \mathrm{~b}$ & 18.6 & 4.8 \\
\hline
\end{tabular}

combinations produced average calipers above $4 \mathrm{~mm}$. All but one came from plots which were not root pruned. Only four treatment combinations grew seedlings with calipers above $4 \mathrm{~mm}$ and heights above $8 \mathrm{~cm}$. None of the treatments included root pruning; two received $2 \mathrm{x}$ nitrogen and two received $3 x$; spacings included all but the densest one (Table 3).

\section{Comparison of $1+0$ and $2+0$ seedlings}

The average caliper and root volume for the small $2+0$ size class was very close to the average $1+0$ caliper. The average height and shoot volume of the small $2+0$ s were similar to the very largest $1+0$ seedlings. This made the shoot/root ratio of the small $2+0$ seedlings about 50 percent larger than $1+0 \mathrm{~s}$. The trees in the medium and large $2+0$ size classes were larger than those of the small class and the $1+0$ seedlings in every morphological characteristic. Between the three $2+0$ size classes, there was very little difference in shoot/root ratio (Table 2). The root growth capacity was higher for the $2+0$ seedlings but differed little between the size classes (Table 1).

\section{Outplanting}

The overall first-year outplanting survival of the $1+0$ seedlings was 57 percent, compared to 68 percent for the $2+0$ seedlings after one growing season. The $1+0$ survival ranged from 33 to 80 percent for different treatments. For $2+0$ seedlings, the range was from 47 percent (medium size class) up to 83 percent (small size class).

Seedling survival dropped from the first block to the second and fell still more in the third block. The differences were due to shallower soils (Figure 2). At first glance, none of the nursery 
Table 2. Measured means for morphological characteristics of ponderosa pine seedlings planted on the Boise National Forest. The $1+0$ seedlings are divided by treatment; the $2+0$ seedlings are divided by size class. Values followed by different letters arestatistically different at the 95 percent level of confidence.

\begin{tabular}{|c|c|c|c|c|c|c|c|c|}
\hline Treatment & $\begin{array}{c}\text { Shoot } \\
\text { Volume } \\
\text { (ml) }\end{array}$ & $\begin{array}{l}\text { Root } \\
\text { Volume } \\
\text { (ml) }\end{array}$ & $\begin{array}{l}\text { Shoot/ } \\
\text { Root } \\
\text { Ratio }\end{array}$ & $\begin{array}{l}\text { Mean } \\
\text { Height } \\
(\mathrm{cm})\end{array}$ & $\begin{array}{l}\text { Mean } \\
\text { Caliper } \\
(\mathrm{mm})\end{array}$ & $\begin{array}{l}\text { First- } \\
\text { year } \\
\text { Survival }\end{array}$ & $\begin{array}{l}\text { First- } \\
\text { year } \\
\text { Height } \\
(\mathrm{cm})\end{array}$ & $\begin{array}{l}\text { Mean } \\
\text { Growth }\end{array}$ \\
\hline F1 & $5.4 a$ & $5.2 a$ & $1.05 a$ & $7.0 \mathrm{a}$ & $3.5 a$ & 61 & $11.6 a$ & 66 \\
\hline F2 & $6.3 \mathrm{c}$ & $5.7 c$ & $1.10 \mathrm{~b}$ & $7.4 b$ & $3.7 b$ & 58 & $12.4 b$ & 68 \\
\hline F3 & $5.8 b$ & $5.5 b$ & $1.05 a$ & $7.2 a b$ & $3.7 b$ & 53 & $11.5 a$ & 60 \\
\hline S1 & $4.6 a$ & $4.6 a$ & $1.00 \mathrm{a}$ & $6.9 a$ & $3.4 a$ & 58 & 11.3a & 64 \\
\hline S2 & $5.3 b$ & $5.0 b$ & $1.07 b$ & $7.3 b c$ & $3.3 a$ & 57 & $12.3 b$ & 68 \\
\hline S3 & $6.5 \mathrm{c}$ & $6.0 \mathrm{c}$ & $1.08 b c$ & $7.5 c$ & $3.8 b$ & 56 & $12.3 b$ & 64 \\
\hline S4 & $7.0 \mathrm{~d}$ & $6.2 \mathrm{c}$ & $1.12 \mathrm{c}$ & $7.2 b$ & $4.0 \mathrm{c}$ & 56 & $11.5 a b$ & 60 \\
\hline RP1 & $7.1 \mathrm{c}$ & $6.1 b$ & $1.15 \mathrm{c}$ & $8.0 \mathrm{c}$ & $4.0 c$ & 57 & $12.8 \mathrm{c}$ & 60 \\
\hline RP2 & $4.8 a$ & $5.0 \mathrm{a}$ & $0.95 a$ & $6.5 a$ & $3.4 a$ & 54 & $11.0 \mathrm{a}$ & 69 \\
\hline RP3 & $5.7 \mathrm{~b}$ & $5.2 \mathrm{a}$ & $1.09 b$ & $7.2 b$ & $3.5 b$ & 60 & $11.7 b$ & 63 \\
\hline $1+0 \mathrm{AVE}$ & 5.8 & 5.5 & 1.07 & 7.2 & 3.6 & 57 & 11.9 & 65 \\
\hline \multicolumn{9}{|l|}{$2+0$} \\
\hline Small & $7.8 a$ & $5.1 a$ & 1.59 & $9.3 a$ & $3.5 a$ & $83 a$ & $15.3 a$ & $65 c$ \\
\hline Medium & $16.7 b$ & $10.4 b$ & 1.63 & $12.4 b$ & $5.7 \mathrm{~b}$ & $47 b$ & $19.2 a$ & $55 b$ \\
\hline Large & $29.7 \mathrm{c}$ & $17.1 \mathrm{c}$ & 1.75 & $16.3 \mathrm{c}$ & $7.7 \mathrm{c}$ & $73 a$ & $25.2 b$ & $42 a$ \\
\hline
\end{tabular}

treatments seem to have affected the outplanting survival (Table 2). However, in figure 3 we see how the increased root growth potential that came from the root pruning treatments did increase the survival in block III, the harshest one. It appears that the root growth capacity is not a limiting factor in the first two blocks but new root growth was especially important as the site conditions became drier.

Figure 4 shows how the best $1+0$ treatments survival compared to $2+0$ seedling survival. In each of the three blocks the $1+0$ seedlings performed about

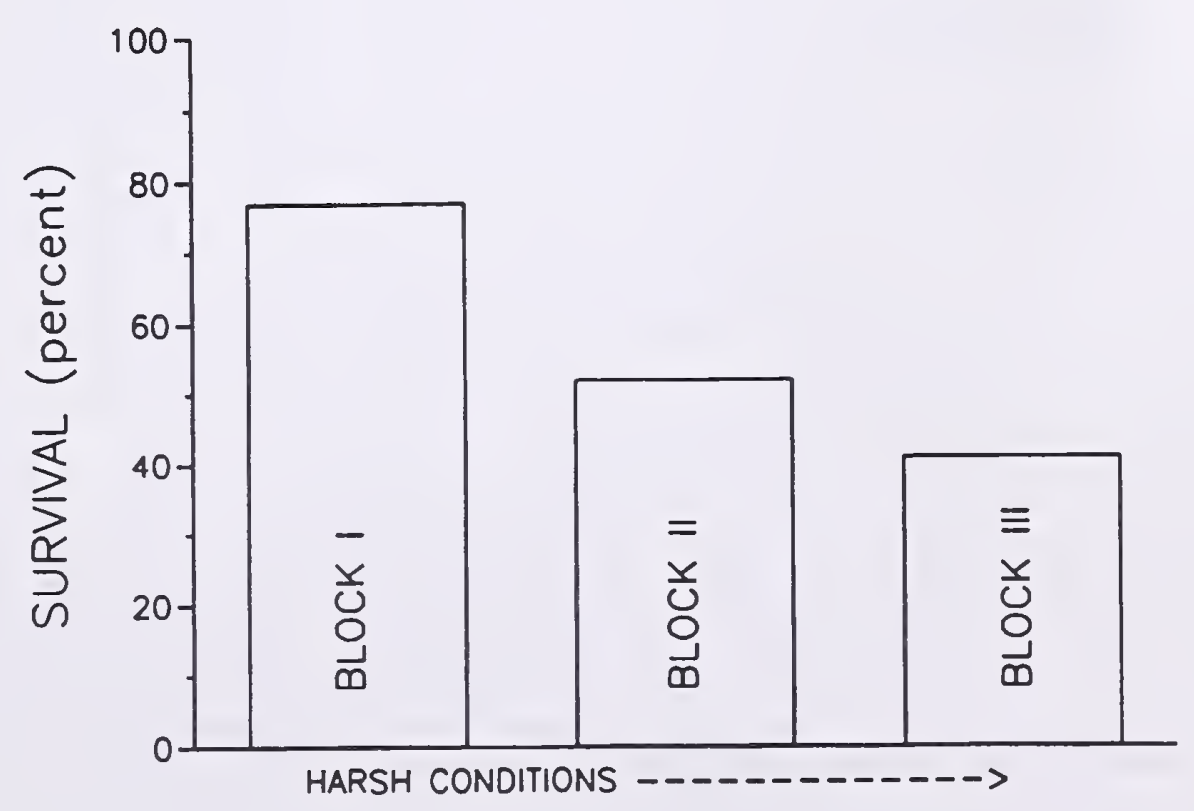

Figure 2. The ponderosa pine seedlings were planted in three blocks on the Boise National Forest. Each successive block was harsher and drier. Figure shows the survival rate of $1+0$ seedlings on the three blocks. 
as well as the $2+0$. Seedling survival reflected the tough conditions of the outplanting site. The spring was wetter than normal but the summer was droughty. At Idaho City, May precipitation was 124 percent of normal. June, July and August precipitation were 72,53 , and 4 percent of normal. A wild fire two years earlier left the site black and the shrubs sprouting vigorously. Ten percent seedling mortality was attributed to pocket gophers.

First-year mean seedling heights showed average height gains for $1+0$ seedlings in the range of 60 to 70 percent of initial heights. The average height gain for the $2+0$ seedlings after the first growing season ranged from 42 percent for the large size class, to 65 percent for the small size class (Table 2).

\section{DISCUSSION}

\section{Nursery treatments effect} on seedling size

Similar to my findings, Pharis and Kramer (1964) saw the root weights of $1+0$ loblolly pine increase with nitrogen fertilization but then decreased when nitrogen was increased further. Others have reported increased seedling caliper and biomass from fertilization but only slight increases in height growth for other conifers (Armson and Sadrieka 1979, Switzer and Nelson 1963, van den Driessche 1982).

Table 3. First year survival and height means for 36 treatment combinations of $1+0$ ponderosa pine planted on the Boise National Forest.

\begin{tabular}{|c|c|c|c|c|c|}
\hline Treatment & $\begin{array}{l}\text { Times } \\
\text { Root } \\
\text { Pruned }\end{array}$ & $\begin{array}{l}\text { Rate of } \\
\text { Fertilizer } \\
\text { (ml) }\end{array}$ & $\begin{array}{l}\text { Seedlings } \\
\text { Spaced }\end{array}$ & $\begin{array}{l}\text { First- } \\
\text { Year } \\
\text { Survival } \\
(\%)\end{array}$ & $\begin{array}{l}\text { First- } \\
\text { Year } \\
\text { Height } \\
(\mathrm{cm})\end{array}$ \\
\hline
\end{tabular}

$\begin{array}{rllllr}111 & 0 & 1 X & \text { no } & 63 & 11.9 \\ 112 & 0 & 1 X & \text { yes } & 47 & 12.4 \\ 113 & 0 & 1 X & 4 \mathrm{~cm} & 33 & 12.5 \\ 114 & 0 & 1 X & 6 \mathrm{~cm} & 57 & 10.5 \\ 121 & 0 & 2 X & \text { no } & 60 & 13.0 \\ 122 & 0 & 2 X & \text { yes } & 69 & 12.9 \\ 123 & 0 & 2 X & 4 \mathrm{~cm} & 72 & 14.0 \\ 124 & 0 & 2 X & 6 \mathrm{~cm} & 61 & 13.8 \\ 131 & 0 & 3 X & \text { no } & 52 & 13.1 \\ 132 & 0 & 3 X & \text { yes } & 47 & 15.8 \\ 133 & 0 & 3 X & 4 \mathrm{~cm} & 59 & 14.1 \\ 134 & 0 & 3 X & 6 \mathrm{~cm} & 63 & 10.2 \\ 211 & 1 & 1 X & \text { no } & 63 & 11.3 \\ 212 & 1 & 1 X & \text { yes } & 66 & 12.6 \\ 213 & 1 & 1 X & 4 \mathrm{~cm} & 50 & 11.0 \\ 214 & 1 & 1 X & 6 \mathrm{~cm} & 69 & 10.9 \\ 221 & 1 & 2 X & \text { no } & 53 & 10.7 \\ 222 & 1 & 2 X & \text { yes } & 43 & 10.6 \\ 223 & 1 & 2 X & 4 \mathrm{~cm} & 52 & 11.8 \\ 224 & 1 & 2 X & 6 \mathrm{~cm} & 66 & 12.5 \\ 231 & 1 & 3 X & \text { no } & 55 & 9.6 \\ 232 & 1 & 3 X & \text { yes } & 43 & 11.4 \\ 233 & 1 & 3 X & 4 \mathrm{~cm} & 55 & 10.3 \\ 234 & 1 & 3 X & 6 \mathrm{~cm} & 38 & 8.4 \\ 311 & 2 & 1 X & \text { no } & 67 & 11.6 \\ 312 & 2 & 1 X & \text { yes } & 80 & 11.3 \\ 313 & 2 & 1 X & 4 \mathrm{~cm} & 70 & 11.4 \\ 314 & 2 & 1 X & 6 \mathrm{~cm} & 63 & 12.6 \\ 321 & 2 & 2 X & \text { no } & 48 & 9.1 \\ 322 & 2 & 2 X & \text { yes } & 63 & 12.4 \\ 323 & 2 & 2 X & 4 \mathrm{~cm} & 55 & 13.6 \\ 324 & 2 & 2 X & 6 \mathrm{~cm} & 52 & 12.6 \\ 331 & 2 & 3 X & \text { no } & 62 & 11.1 \\ 332 & 2 & 3 X & \text { yes } & 55 & 11.7 \\ 333 & 2 & 3 X & 4 \mathrm{~cm} & 62 & 11.6 \\ 334 & 2 & 3 X & 6 \mathrm{~cm} & 40 & 11.1\end{array}$

The increase in seedling size with increased spacing and the slight decrease in height with the widest spacing is consistent with other studies (Baron and Schubert 1963, Edgren 1977, Mullin and Bowdery 1977, Richards and others 1973, Sloan 1992, van den Driessche 1984).
Root pruning reduced the size of the seedlings here as has been documented for conifers in the literature (Bacon and Bachelard 1978, Benson and Shepherd 1977, Hobbs and others 1987, Kainer and Duryea 1990, Venator and Mexal 1981). Although the first root pruning 


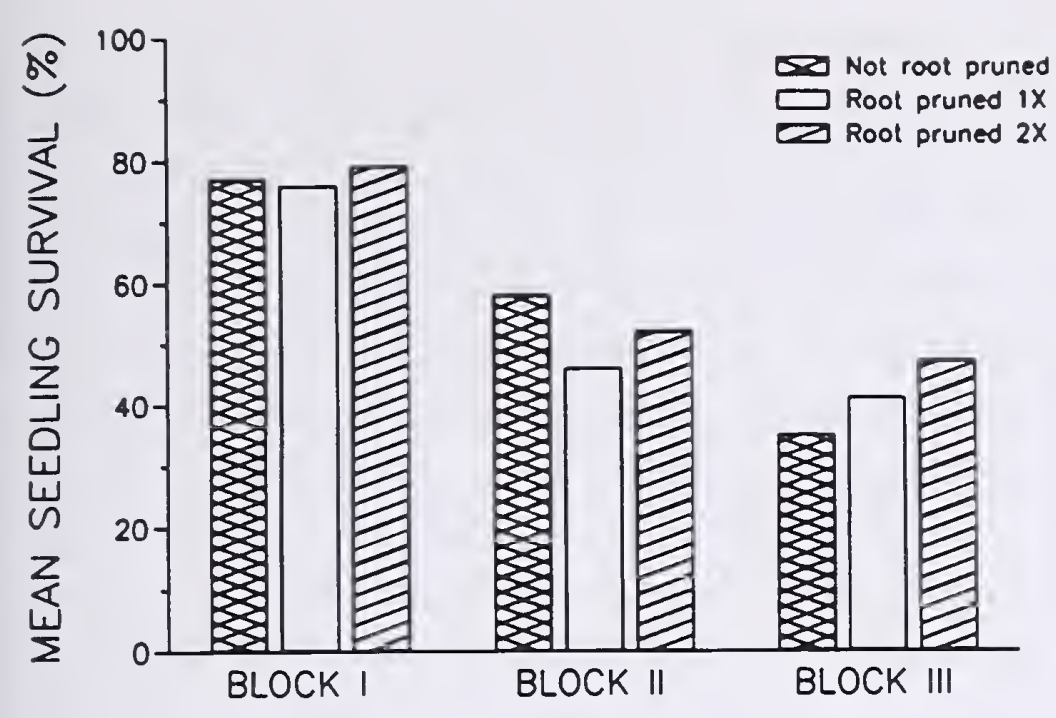

Figure 3. Effect of root pruning treatments on survival in three blocks of $1+0$ ponderosa pine seedlings planted on the Boise National Forest. In the nursery bed, seedlings were root pruned twice, once, or not at all.

treatment in early August was effective in slowing seedling growth and lowering shoot/root ratios, it did not cause the seedlings to set buds. Budset did not occur for all treatments until late September. What is puzzling is the fact that root pruning just once, reduced the seedling size more than root pruning twice (Table 2). Some researchers have recommended that root pruning will be more effective when it is done in conjunction with other cultural treatments including density regulation because root pruning will not be as effective at higher densities (Racey and Racey 1988, O’Neill and others 1988, Edgren 1977, Mullin and Bowdery 1978). I found that even in the densest plots, root pruning improved root growth potential.
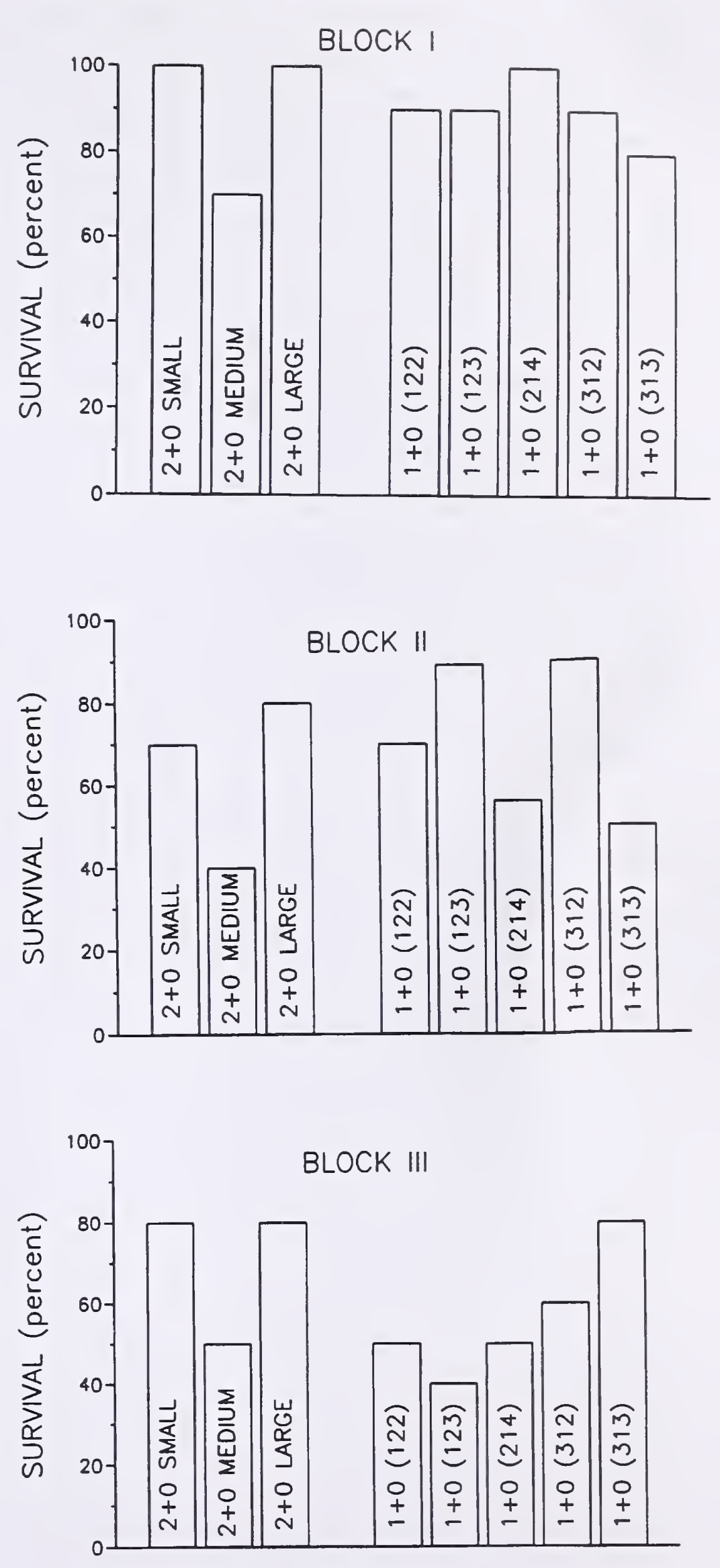

Figure 4. Average heights for ponderosa pine seedlings planted on the Boise National Forest. The first three represent $2+0$ size classes and the last five bars represent selected $1+0$ treatment combinations. See table 3 for interpretation of $1+0$ seedling identification numbers: root pruning treatment, fertilizer treatment, spacing treatment. 
Treatments which increased seedling size tended to also increase shoot/root ratios because they promoted more top growth than root system growth. The reverse is true for treatments which reduced seedling size. This was also shown by Duryea (1984), Duryea and Lavender (1982), Tanaka and others (1976), Stein (1984), and van den Driessche (1983). Racey and others (1983) consider shoot/root ratio to be of little value as an indicator of seedling potential. Shoot/root ratio within a size class is a good indicator of survival potential, especially on droughty sites (Thompson 1985).

The root pruning treatments which reduced seedling growth in the nursery increased root growth potential by allocating some of the energy into storage which would otherwise have gone into growth. Bacon and Bachelard (1978) saw similar results. The opposite was true of the fertilizer treatments: increase in fertilizer increased seedling size and reduced root growth potential. Root growth potential did not change much at the wider spacings even though space increased seedling caliper and shoot and root volumes (Table 2). This agrees with van den Driessche (1984). Wider spacing may provide a possible way to increase seedling size and still maintain root growth potential.

\section{Outplanting test}

As we planted the seedlings into the field, it appeared that the $2+0$ trees would have an advantage over the $1+0$ trees because of their larger size and larger root growth potential. Many of the $1+0$ calipers and heights seemed to be meager, especially for this tough site. However, the $1+0$ seedlings were superior in their even balance between shoots and roots. Although the $2+0$ seedlings had a better average survival rate than the $1+0$ seedlings, some of the $1+0$ treatments had survivals as good or better than the $2+0$ treatments. This agrees with Rose and others (1992) who found that $1+0$ ponderosa pine could perform as well as $2+0$.
I found that root growth potential produced a noticeable influence on field survival only on the harshest block. Much research has examined the relationship between RGP and outplanting performance. Richie and Dunlap (1980) found that 85 percent of the literature reported positive correlations while Richie and Tanaka (1990) found 75 percent.

The larger the $2+0$ size class, the smaller the relative first-year height growth in the field. This was because the root systems of the larger seedlings were not as well balanced to the shoots resulting in more planting stress. The relative height growth of the $1+0$ seedlings was similar to the small $2+0$ size class.

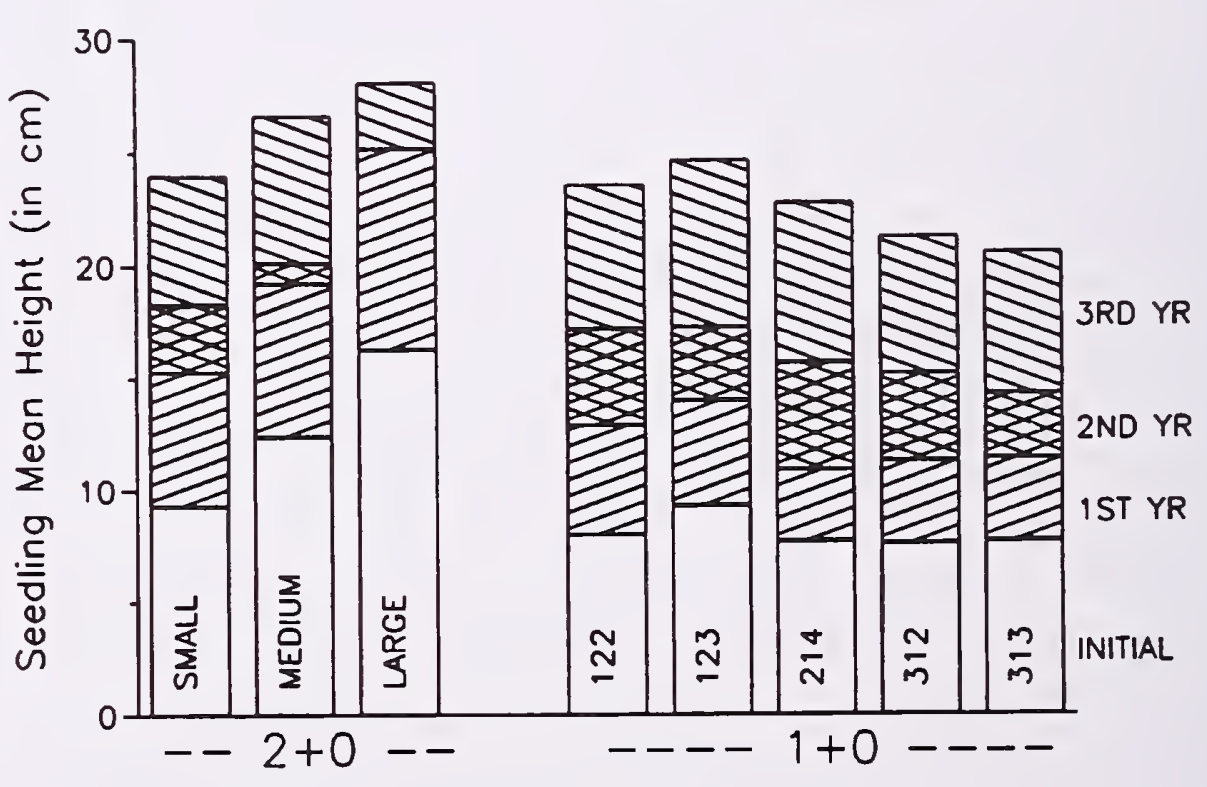

Figure 5. Comparison of survival for ponderosa pine seedlings planted on three blocks in the Boise National Forest. The $2+0$ seedlings are divided into three size classes. The five best $1+0$ treatments are identified in parentheses. The three numbers refer to root pruning, fertilizer, and spacing respectively. See table 3 for interpretation of the treatment codes. 
By the end of the second growing season, nearly all of the differences in height between the $1+0$ treatments had disappeared. Likewise for the $2+0$ seedlings, after two growing seasons there are no longer significant differences in top heights between the three size classes (Figure 6). Because of the dry conditions, many of the large $2+0$ seedlings died back or did not grow much in the second and third seasons. In both cases, many of the smaller seedlings have caught up. Hobbs (and others 1987) also found that morphological differences in ponderosa pine seedlings seen at planting, disappeared four years later.

Several of the treatment combinations produced seedlings that survived better than the $1+0$ average. Of the treatments with the best survival rates, most were root pruned twice. The root pruning and fertilizer treatments had the biggest impacts. The spacing treatment did not seem to matter. This suggests that root growth potential and the balance between top and roots are important to seedling survival. I did not find $1+0$ seedling size to be very important to survival.

Many factors affect seedling survival and growth. As is stated by Mexal and Landis (1990), shoot height is often highly correlated with growth. I found that seedling height after the first growing season was highly correlated to initial shoot length, caliper, shoot volume, and shoot volume. I did not see high correlations between survival and any of the morphological characteristics: shoot volume, root volume, shoot/root ratio, shoot length, or caliper. That does not mean that these characteristics are not important. All must be considered in relation to each other and to the planting site.

Caliper is considered by some to be the best indicator of survival (Cleary and others 1978, Long and Carrier 1993, South and others 1993). Others have shown that root volume is important (Haase and Rose 1993, Long and Carrier 1993, Lopushinsky and Beebe 1976). Rose and others (1991) found that $1+0$ ponderosa pine seedlings with larger root volumes survived better in the field.

The harsh planting site was hard on both the $1+0$ and $2+0$ seedlings. The performance of the small $2+0$ seedlings compared to the large showed that the biggest trees are not the best on tough sites. Although the $1+0$ seedlings had better shoot/root balance, they soon lost their primary needles, leaving them with just one years needles to carry on photosynthesis. The $2+0$ seedlings were sturdier and maintained their previous year's foliage. Short seedlings seem to have an advantage on droughty sites (Hermann 1964 .

Lopushinsky and Beebe 1976,
Tuttle and others 1988, van den Driessche 1991). Taller seedlings have a greater surface for both photosynthesis and for water loss by transpiration (Carlson and Miller 1990).

\section{Lucky Peak Nursery can} produce one year old ponderosa pine with the capability to be successful on Intermountain planting sites. We could possibly improve the size of the $1+0$ seedlings if we sowed the seed earlier in the spring. There was not any one treatment combination that produced seedlings superior to all others.

In the field, survival and growth would have been greater with normal rain during the first growing season or on a more moderate site. A more moderate site would be better for $1+0$ ponderosa pine seedlings of the quality here. For harsh planting sites like this one, I would recommend planting $2+0$ stock tailored to the dry conditions: large root volume, large caliper, high root growth potential, and short top.

\section{SUMMARY}

We grew $1+0$ ponderosa pine seedlings under regimes of three root pruning options, three fertilizer options, and four different spacings in the nursery beds. All three of the cultural practices influenced the seedling 
size at lifting. The largest $1+0$ seedlings were not root pruned, received the medium fertilizer treatment, and grew at $6 \mathrm{~cm}$ apart $\left(8\right.$ seedlings $/ \mathrm{ft}^{2}$ or 89 seedlings $/ \mathrm{m}^{2}$ ), the widest spacing. The largest did not have the highest survival in the field. Treatments which slowed seedling growth in the nursery bed, such as root pruning, tended to increase root growth potential. In the harshest outplanting block, root pruning appeared to improve seedling survival as well.

Overall survival rates were 68 percent for $2+0$ seedlings and 57 percent for $1+0$ on a harsh planting site with shallow soil and a dry first growing season. In a typical year survival would probably have been in the 80 to 90 percent range. However, some of the $1+0$ treatments survived as well or better than the $2+0$.

The $1+0$ seedlings with the greatest initial heights were still the tallest at the end of the first growing season but after three seasons since outplanting, the differences are small.

In order to grow $1+0$ seedings with the best chance of surviving on a harsh site, I would recommend root pruning twice, increasing the target spacing to $4 \mathrm{~cm}$ (11 seedlings $/ \mathrm{ft}^{2}$ or $119 / \mathrm{m}^{2}$ ), and leaving the nitrogen fertilization rates at the current (1X) levels.

\section{LITERATURE CITED}

Aldhous, J.R. 1972. Nursery

Practice. Forestry Commun.

Bull. 43. Her Majesty's

Stationary Office. London. $184 \mathrm{p}$.

Armson, K.A.; Sadrieka, V. 1979. Forest Tree Nursery Soil Management and Related Practices. Ontario Ministry of Natural Resources. 177 p.

Bacon, G.J.; Bachelard E.P. 1978. The influence of nursery conditioning treatments on some physiological responses of recently transplanted seedlings of (Pinus caribaea Mor. var. hondurensis B. and G.) Australian Forestry Research 8: 171-183.

Baron, F.J.; Shcubert, G.H. 1963. Seedbed density and pine seedling graders in California nurseries. Res. Note PSW-31. U.S. Department of Agriculture, Forest Service, Pacific Southwest Forest and Range Experiment Station, Berkley, CA: 14 p.

Benson, A.D.; Shepherd, K.R. 1977. Effect of nursery practice on Pinus radiata seedling characteristics and field performance: II Nursery Root Wrenching. New Zealand Journal of Forestry Science. 7: 68-76.
Buse, Lisa J.; Day, Robert J. 1989. Conditioning three boreal conifers by root pruning and wrenching. Tree Planters' Notes 40(2):33-39

Canham,, A.E.; McCavish, W.J. 1981. Some effects of $\mathrm{CO}_{2}$, daylengh and nutrition on the growth of young forest tree plants: I. In the seedling stage. Forestry 54(2):169-182.

Carlson, William C.; Miller, D. Elaine. 1990. Target seedling root system size hydraulic conductivity and water use during seedling establishment. In: Rose, Robin; Campbell, Sally; Landis, Thomas D. eds. Target Seedling Symposium: Proceedings, combined meeting of the Western Forest Nursery Associations; 1990 August 13-17; Roseburg OR. Gen. Tech. Rep. RM-200. Ft Collins, CO: U.S. Department of Agriculture, Forest Service, Rocky Mountain Forest and Range Experiment Station: 53-66.

Cleary, B.D.; Greaves, R.D.; Owston, P.W. 1978. Seedlings. In: Cleary, B.D.; Greaves, R.D.; Hermann, R.K. eds. Regenerating Oregon's Forests. Corvallis, OR: Oregon State University Extension: 63-97. 
Cochran, P.H. 1972. Tolerance of lodgepole and ponderosa pine seeds and seedlings to high water tables. Northwest Science 46:322-331.

\section{Duryea, M.L. 1984. Nursery} cultural practices: Impacts on seedling quality. In: Duryea, M.L.; Landis, T.D. eds. Forest Nursery Manual: Production of Bareroot Seedlings. The Hague, Netherlands: Martinus Nijhoff/Dr. W. Junk Publishers. p.143-164.

Duryea, M.L.; Lavender, D.P. 1982. Water relations, growth and survival of root-wrenched Douglas-fir seedlings. Can. J. For. Res. 12: 545-555.

Edgren, J.W. 1977. Seedbed density, diameter limit culling, and 2+0 Douglas-fir seedling production. In: Proceedings of the combined meeting, Western Forest Nursery Council and Intermountain Nurseryman's Association, August 10-12, 1976, Richmond, B.C. 9p.

Haase, Diane L.; Rose, Robin. 1993. Soil moisture stress induces transplant shock in stored and unstored $2+0$ Douglas-fir seedlings of varying root volumes. Forest Science 39(2): 275-294.
Hermann, R.K. 1964. Importance of top-root ratios for survival of Douglas-fir seedlings. Tree Planters' Notes 64:7-11.

Hobbs, S.D.; Stafford, S.G.; Slagle, R.L. 1987. Undercutting conifer seedlings: effect on morphology and field performance on droughty sites. Can. J. For. Res. 17: 4046.

Jenkinson, James L.; Nelson, James A.; Huddleston, May E. 1993. Improving planting stock quality - the Humboldt experience. Gen. Tech. Rep. PSW-143. Albany, CA: U.S. Department of Agriculture, Forest Service, Pacific Southwest Research Station: 219p.

Kainer, Karen A.; Duryea, Mary L. 1990. Root wrenching and lifting date of slash pine: Effects on morphology, survival, and growth. New Forests 4:207-227.

Long, Alan J.; Carrier, Byron D. 1993. Effects of Douglas-fir $2+0$ seedling morphology on field performance. New Forests 7: 19-32.
Lopushinsky, W. Beebe, T. 1976. Relationship of shootroot ratio to survival and growth of outplanted Douglasfir and ponderosa pine seedlings. Res. Note PNW-274. Portland, OR: U.S. Department of Agriculture, Forest Service, Pacific Northwest Forest and Range Experiment Station. 7p.

Mexal, J.G. 1980. Seedling bed density influences seedling yield and performance. In: Proceedings of the 1980 Southern Nursery Conference, September.

Mexal, J.G.; Landis, T.D. 1990. Target seedling concepts: height and diameter. In: Rose, Robin; Campbell, Sally; Landis, Thomas D. eds. Target Seedling Symposium: Proceedings, combined meeting of the Western Forest Nursery Associations; 1990 August 13-17; Roseburg OR. Gen. Tech. Rep. RM-200. Ft Collins, CO: U.S. Department of Agriculture, Forest Service, Rocky Mountain Forest and Range Experiment Station: 17-36.

Mullin, R.E.; Bowdery L. 1977. Effects of seedbed density and nursery fertilization on survival and growth of white pine. Tree Planters' Notes 28: 11-13. 
Mullin, R.E.; Bowdery L. 1977. Effects of seedbed density and nursery fertilization on survival and growth of white spruce. For. Chron. 53: 83-86.

Mullin, R.E.; Bowdery, L. 1978. Effects of seedbed density and top dressing fertilization on survival and growth of 3-0 red pine. Can. J. For. Res. 8: 3035.

O'Neill, G.J.; Ditner, M.; Racey, G.D. 1988. Undercutting and wrenching of red pine, white pine and white spruce seedlings. Forest Research Note no. 46. Maple, Ontario: Ontario Ministry of natural Resources: 4p.

Pharis,R.P.; Kramer, P.J. 1964. The effect of nitrogen and drought on loblolly pine seedlings. Forest Science 10: 143-150.

Racey, J.E.; Racey, G.D. 1988. Undercutting and root wrenching of tree seedlings: An annotated bibliography. Forest Research Report no. 121. Maple, Ontario: Ontario Ministry of Natural Resources. $78 \mathrm{p}$.

Racey, G.D.; Glerum, C.; Hutchinson, R.E. 1983. The practicality of top-root ratio in nursery stock characterization. The Forestry Chronicle 59(5): 240-243.
Richards, N.A.; Leaf, A.L.; Bickelhupt, D.H. 1973. Growth and nutrient uptake of coniferous seedlings: Comparison among 10 species at various seedbed densities. Plant Soil 38: 125-143.

Richie, G.A.; Dunlop, J.R. 1980. Root growth potential: It's development and expression in forest tree seedlings. New Zealand Journal of Forest Science 19:213-219.

Richie, Gary A.; Tanaka, Yasuomi. 1990. Root growth and the target seedling. In: Rose, Robin; Campbell, Sally; Landis, Thomas D. eds. Target Seedling Symposium: Proceedings, combined meeting of the Western Forest Nursery Associations; 1990 August 13-17; Roseburg OR. Gen. Tech. Rep. RM-200. Ft Collins, CO: U.S. Department of Agriculture, Forest Service, Rocky Mountain Forest and Range Experiment Station: 37-51.

Rose, Robin; Gleason, John; Sabin, Tom. 1991. Grading ponderosa pine seedlings for outplanting according to their root volumes. Western Journal of Applied Forestry 6(1): 1115. 'ose, Robin; Atkinson, Mary; Gleason, John; Haase, Diane. 1992. Nursery morphology and preliminary comparison of 3-year field performance of $1+0$ and $2+0$ bareroot ponderosa pine seedlings. Tree Planters' Notes 43(4): 153158.

Sloan, J.P. 1992. Effects of seeder design and seed placement on seedling size and cull rates at western forest nurseries. Res. Pap. INT-458.

Ogden, UT: U.S. Department of Agriculture, Forest Service, Intermountain Research Station. 24p.

South, David B.; Mitchell, Robert J.; Zutter, Bruce R.; Balneaves, John M.; Barber, Brad L.; Nelson, Derek G.; Zwolinski, Janusz B. 1993. Integration of nursery practices and vegetation management: economic and biological potential for improving regeneration. Can. J. For. Res. 23: 2083-2092.

Stein, W.I. 1984. Wrenching Douglas-fir seedlings in August: Immediate but no lasting effects. Res. Pap. PNW-317. Portland, OR: U.S. Department of Agriculture, Forest Service, Pacific Northwest Forest and Range Experiment Station. 12p. 
Steinbrenner, E.C.: Rediske, J.H. 1964. Growth of ponderosa pine and Douglas-fir in a controlled environment. Weyerhaeuser Forestry Paper 1: $31 \mathrm{p}$.

Switzer, G.L.; Nelson, L.E. 1963. Effect of nursery fertility and density on seedling characteristics, yield, and field performance of loblolly pine (Pinus taeda L.). Proc. Soil Sci. Amer. 27: 461-464.

Tanaka, Y.; Walstad, J.D.; Borrecco, J.E. 1976. The effect of wrenching on morphology and field performance of Douglas-fir and loblolly pine seedlings. Can. J. For. Res. 6: 453-458.

Thompson, B.E. 1985. Seedling morphological evaluation what you can tell by looking. In: Duryea, M.L. ed., Proceedings Evaluating Seedling Quality: Principles, Procedures, and Predictive Abilities of Major Tests. 1984, October 16-18, Corvallis, OR. Corvallis, OR: Forest Research Laboratory, Oregon State University. 59-71.

Tuttle, C.L.; South, D.B.; Golden, M.S.; Meldahl, R.S. 1988. Initial Pinus taeda seedling height relationships with early survival and growth. Can. J. For. Res. 18:867-871. van den Driessche, R. 1982.

Relationship between spacing and nitrogen fertilization of seedlings in the nursery, seedling size, and outplanting performance. Can. J. For. Res. 12: 865-875.

van den Driessche, R. 1983.

Growth, survival and physiology of Douglas-fir seedlings following root wrenching and fertilization. Can.J. For. Res. 13: 270-278.

van den Driessche, R. 1984. Relationship between spacing and nitrogen fertilization of nutrition and outplanting performance. Can. J. For. Res. 14: 431-436.

van den Driessche, 1991.

Changes in drought resistance and root growth capacity of container seedlings in response to nursery drought, nitrogen, and potassium treatments. Can. J. For. Res. 22: 740-749.

Venator, C.R.; Mexal, J.G. 1981. The effect of wrenching and planting date on the survival of loblolly seedlings. In: proceedings first Biennial Southern Silvicultural Research Conference, Atlanta Georgia. Gen. Tech. Rep. SO34. U.S. Department of Agriculture, Forest Service, Southern Research Station: 20-24.
Vlamis, M.R.; Evans, P.D. 1957. Nutrient responses of ponderosa pine seedlings. Journal of Forestry 55:25-28. 


\title{
Machine Vision Inspection System for Packing House Quality Control'
}

\author{
Michael P. Rigney and Glenn A. Kranzler
}

Abstract-A PC-based machine vision system providing high-speed $(4 / \mathrm{sec})$ measurement of bareroot seedling morphological features has been developed. Designed for quality control and morphological data acquisition by nursery personnel, the system provides a user-friendly, menu-driven graphical interface. The system automatically locates the root collar, measures root collar diameter, shoot height, sturdiness ratio, root mass length, projected shoot and root area, shoot-root area ratio, and percent fine roots. Sample statistics are computed for each measured feature. Measurements for each seedling may be stored for later analysis. Feature measurements may be compared to multi-class quality criteria to easily determine sample quality. Statistical summary and classification reports may be printed to facilitate the communication of quality concerns with grading personnel. System architecture is described, followed by a discussion of software and morphological measurement capabilities. Results from tests comparing measurement differences and variation among repeated manual and machine vision measurements are summarized.

\section{INTRODUCTION}

Over one billion conifer seedlings are produced in the U.S. each year to support reforestation efforts. Most seedlings are graded manually to improve viability after transplanting. Manual grading is labor intensive and subject to human error. The grading task is complicated by the fact that grading criteria change for different species, age classes, seed lots, and customer preferences. Quality control assessments are used to ensure that graded seedlings meet specific grading criteria.
Quality control is performed by sampling seedlings from the grading tables and determining compliance with grading criteria. An accounting system is usually implemented to document deviations, which are then brought to the attention of the grading personnel. The number of specific quality criterion failures per sample might be the full extent of the quality record. Production demands do not allow manual measurement of quality control sample morphology, which may better characterize quality. Morphological statistics from seedling samples could be useful to nursery management as well as customers.

In previous work, we demonstrated the feasibility of using machine vision for tree seedling quality inspection (Rigney and Kranzler, 1988, 1989). Two cameras and a dedicated highperformance machine vision computer were used to automatically locate the seedling root collar and measure stem diameter, shoot height, shoot area, and root area at a rate of 2 seedlings per second. The

\footnotetext{
${ }^{1}$ Rigney, M.P.; Kranzler, G.A. 1994. Machine Vision Inspection System for Packing House Quality Control. IN: Landis, T.D.; Dumroese, R.K., tech. coords. National Proceedings, Forest and Conservation Nursery Associations. Gen. Tech. Rep. RM257. Fort Collins, CO: U.S. Department of Agriculture, Forest Service, Rocky Mountain Forest and Range Experiment Station: 182-191.
}

${ }^{2}$ Biosystems and Agricultural Engineering Department, Oklahoma State University. 
performance of a second prototype was enhanced through the use of backlighting and a single line-scan camera (Rigney and Kranzler, 1992). This system, using a VME bus-based computer and high-performance image processing hardware, achieved increased measurement precision and higher inspection rates (10 seedlings/sec).

An investigation by Hassan et al. (1992) used a machine vision system with $0.5 \mathrm{~mm}$ spatial resolution to evaluate manual sorting in three nurseries (one of which did no sorting). Root collar diameter was the primary grading criterion. Results showed that variations in manual sorting had a significant effect on average root collar diameter and number of plantable seedlings. With respect to seedling misclassification, the authors suggested that the nursery which did no sorting had $2.6 \%$ greater efficiency.

Kutz et al. (1993) describe two-camera and three-camera machine vision systems developed for seedling quality control and research measurement applications. The two and three camera systems provided inspection rates of 5.8 and $15.8 \mathrm{~s}$ per seedling, respectively. Both systems had 0.1-mm resolution for diameter measurement. Root collar location was determined by the operator. Test results showed accurate diameter measurement and high correla- tion between projected area (root or shoot) measurements made by the vision systems and area meter measurements. Low correlation between machine and manual height (needle tip) measurements was observed, however, low correlation was also observed between repeated manual measurements.

In this paper we describe a PC-based machine vision inspection system which provides highresolution imaging, automatic measurement, and quality assessment of conifer seedlings at rates of up to four per second. The system measures ten morphological features, stores measurement data to files, and generates statistical and quality reports, all through a menu-driven, userfriendly interface.

\section{SYSTEM DESCRIPTION- HARDWARE}

\section{Conveyors}

Seedlings are transported through the inspection system on a variable speed conveyor consisting of two sections of conveyor belt aligned end-to-end and powered by a 1-hp motor (Fig. 1). The inspection and sorting conveyors are $46 \mathrm{~cm}$ wide and approximately $2 \mathrm{~m}$ and $1 \mathrm{~m}$ in length, respectively. Singulated seedlings are manually placed on the inspection conveyor, where they accelerate to a belt speed of 1 to $3 \mathrm{~m} / \mathrm{s}$.
Converging guide plates constrain seedling position and ensure oriented passage through the camera field-of-view (FOV). At the inspection area, seedlings cross the gap between the inspection conveyor and the sorting conveyor as they pass between the overhead camera and an apertured lamphouse beneath the conveyors (Fig. 2). A high-resolution shaft encoder (2540 pulses/rev) measures conveyor displacement, ensuring accurate longitudinal measurements independent of belt speed. Cleaning brushes mounted beneath the conveyors prevent the accumulation of debris on the belts.

\section{Camera}

A high-resolution (2048pixel) line-scan camera is mounted above the conveyors in a protective enclosure. The camera mount provides precise manual adjustment in three axes to simplify alignment of the camera FOV with the center of the lamphouse aperture. A through-the-lens viewer enables the operator to see the line-scan FOV at the camera for adjustment of alignment and focus. Live images may also be displayed to assist with camera aiming, focus, and lens aperture adjustment.

Transverse and longitudinal spatial resolutions are independently adjustable. High transverse spatial resolution is important for precise measurement of 


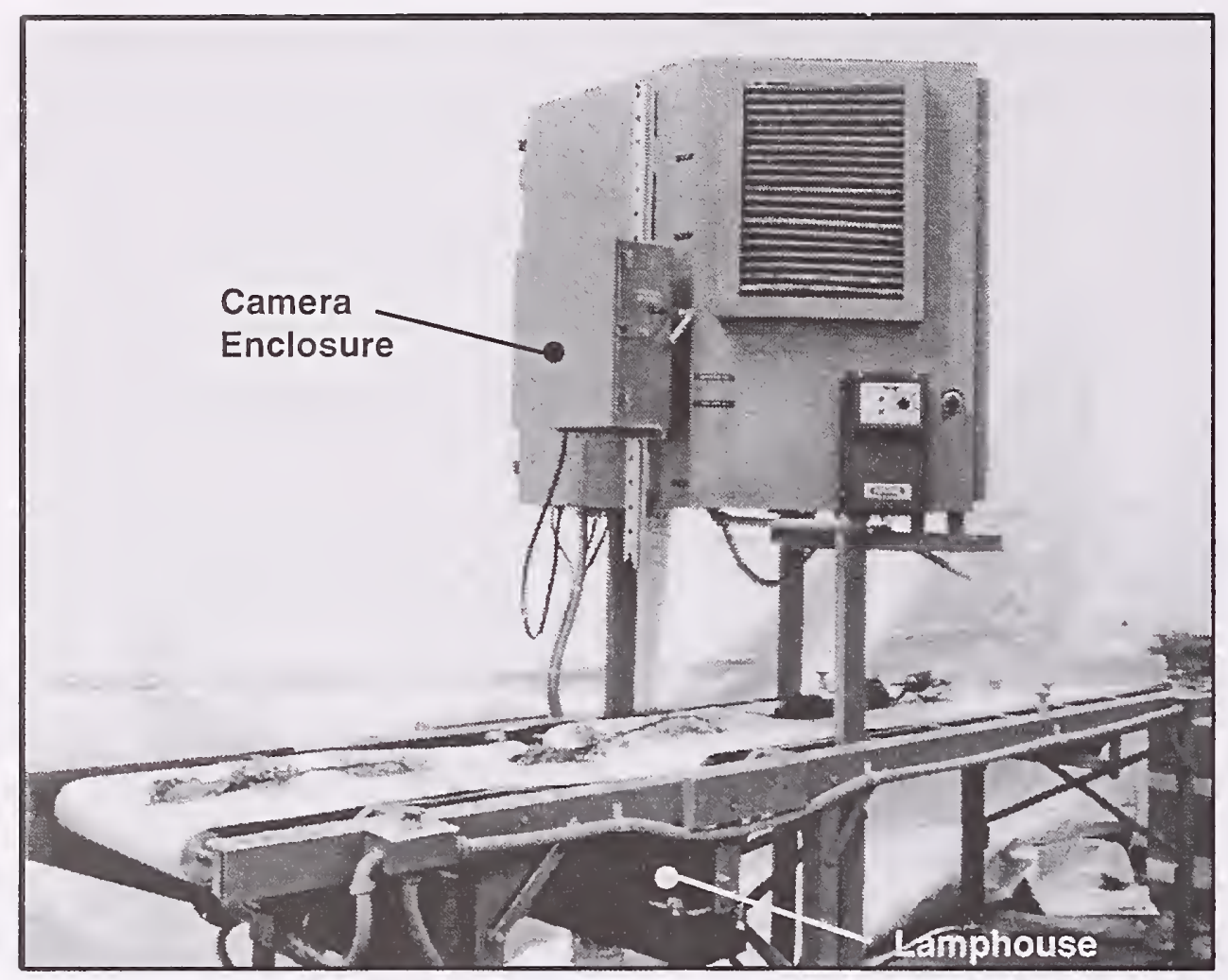

Figure 1. Seedling inspection system.

stem diameter, while much lower longitudinal resolution is sufficient for measurement of seedling height. Transverse resolution is dependent on the camera FOV, which is nominally set to the maximum expected seedling width. The camera FOV is manually adjustable from 10 to $40 \mathrm{~cm}$ (0.05 to 0.20 $\mathrm{mm}$ spatial resolution) by moving the camera and/or changing the camera lens. The camera enclosure is mounted on a precision linear track with integrated clamp for easy positioning.

Longitudinal resolution is controlled by the rate at which line images are acquired from the camera. Line acquisition is controlled by signals from the shaft encoder, which measures conveyor belt displacement.
Longitudinal resolution is software-selectable in the range of 0.5 to $5.0 \mathrm{~mm}$ (nominally 1.0 $\mathrm{mm})$.

\section{Lamphouse}

A high-intensity, high-frequency fluorescent backlight mounted beneath the conveyors is used to obtain high-contrast seedling images. High lamp brightness is needed due to the short exposure time of each line-scan image. A regulated high-frequency power supply with automatic intensity control provides illumination uniformity over the life of the lamp. An "all's well" indicator informs the operator that the lamp and power supply are operating properly. The lamphouse is protected from water and debris by an updraft airstream exiting the lamphouse aperture. Filtered ambient air is provided for lamp cooling and protection.

\section{Computer}

The system is controlled by a $50 \mathrm{MHz}$ 486DX PC. The computer is equipped with a high-capacity hard disk, highdensity floppy disk drive, and an SVGA color monitor. The computer houses a line-scan digitizer card and a shaft encoder interface card.

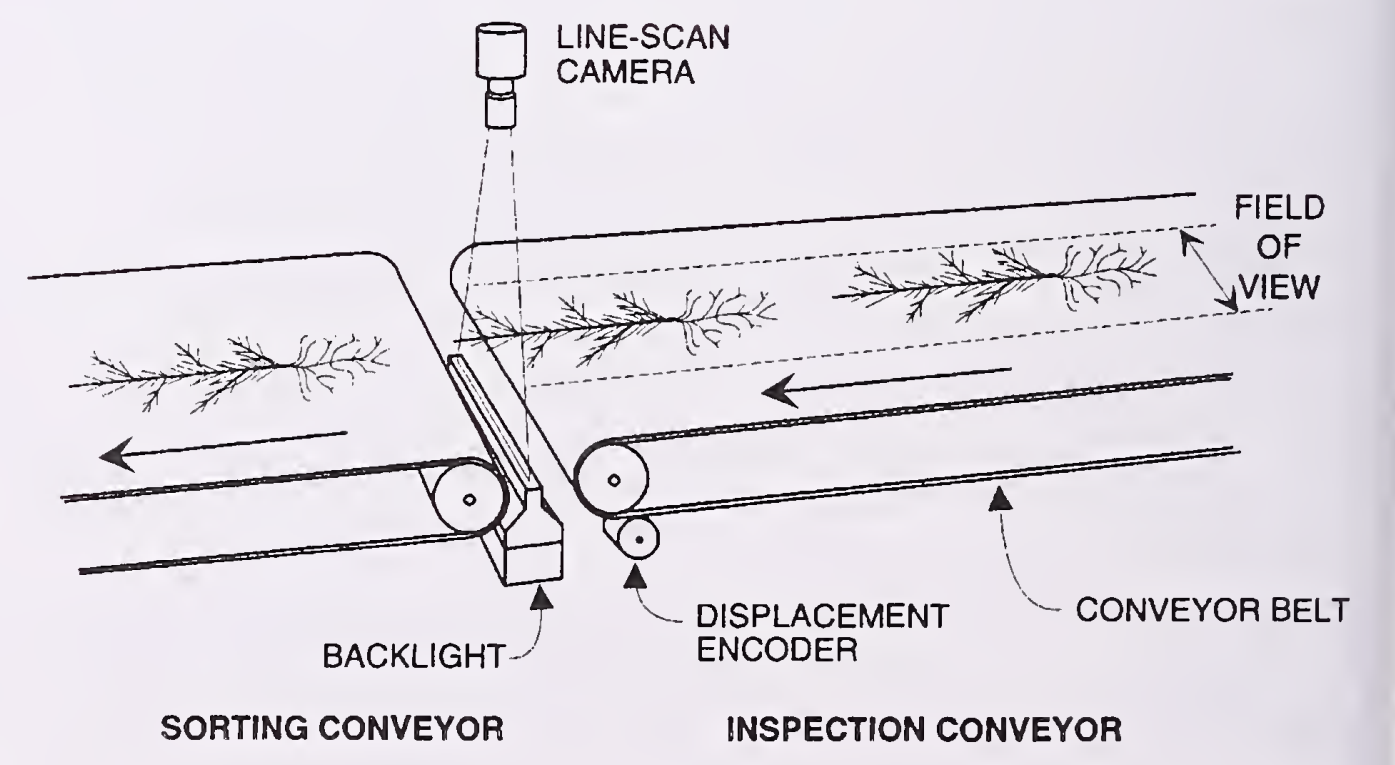

Figure 2. Line-scan inspection configuration. 
The computer and other electrical components are housed in an environmental enclosure mounted above the conveyor (Fig. 3). The keyboard and a trackball pointing device are mounted externally in a protective drawer for easy access. Enclosure cooling is provided by filtered air from the lamphouse blower system.

\section{SYSTEM DESCRIPTION- SOFTWARE}

Software was written in the $\mathrm{C}$ programming language and runs under the Microware OS-9000 operating system. OS-9000 is a real-time, multi-tasking operating system which supports the time-critical needs of the highspeed image processing software. Image processing is performed on a line-by-line basis as data become available from the camera. Measurement data can be written to a DOS-format hard disk partition or 3.5 inch diskettes and may be processed by many popular spreadsheet and statistical analysis programs. Simple statistical analysis of seedling features and compliance with grading criteria are incorporated in the inspection software, as described below.

All program interactions are conducted through a userfriendly, menu-driven graphical user interface. Most inspection system functions are executed by simply selecting a menu item or

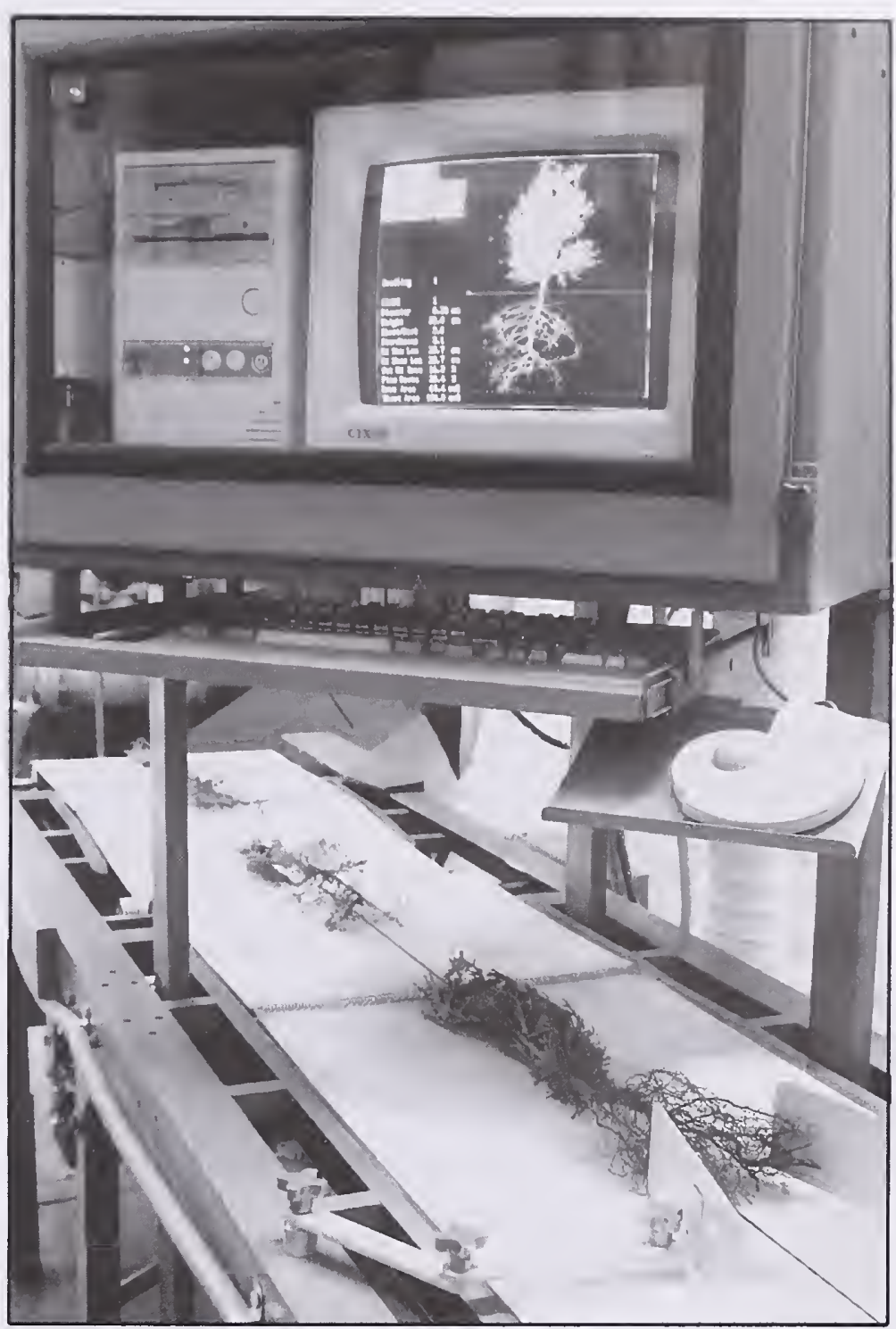

Figure 3. Seedling inspection system showing interactive inspection display.

a filename from a directory. Some selections prompt the user to enter data such as a setpoint or filename. The software supports camera alignment and adjustment, calibration, grading criteria selection, seedling inspection, data storage, statistical reports, and options such as seedling image storage and display.

\section{System Calibration}

The system is calibrated by acquiring several images of a calibration tool (wood dowel) with known diameter and length.
Calibration constants are stored in a file and retrieved each time the inspection system is used. Calibration is only required after changing the lens or camera position. Calibration constants are included in summary reports and may be viewed through a menu selection.

\section{Algorithm Parameters}

Nineteen parameters aflect the behavior of the inspection program. Most parameters control the search for the seedling root collar. Others constrain 
diameter measurement and the search for the seedling top, and define the root zone and maximum fine root width. The parameters are adjusted to obtain the desired measurements or exploit differences between different species or age classes. Parameter tuning may be performed interactively while observing the effects of parameter changes on a seedling image. Algorithm parameters are stored along with grading criteria in a file which is read before inspecting seedlings.

\section{Seedling Features}

Custom image processing software is used to locate the seedling root collar and extract several features which are dependent on root collar location. Locating the root collar is a pattern recognition problem and the most challenging task the system must perform. The seedling features described below are measured after locating the root collar. Several feature measurement algorithms utilize user-defined parameters mentioned above.

\section{Stem diameter. Stem diam-} eter is computed as the average stem width in the root collar zone, corrected for local stem orientation. The size of the root collar zone and its position with respect to the root collar are defined by algorithm parameters. The diameter measurement algorithm discards large line widths in preference to small widths, if width variance exceeds a threshold (example, $0.5-\mathrm{mm}$ ). This procedure reduces errors caused by attached debris which increase the apparent diameter.

2. Shoot height. A seedling top detection algorithm attempts to locate the terminal bud using two algorithm parameters. A width threshold is set to the average terminal bud width. A distance limit is set to the approximate needle length. Height is computed as the distance from the root collar to the seedling top.

3. Sturdiness ratio. Computed as height $(\mathrm{cm})$ divided by diameter $(\mathrm{mm})$.

4. Projected shoot area. Total area above the root collar.

5. Projected root area. Total area below the root collar.

\section{Shoot-root ratio. Projected} shoot area divided by projected root area.

7. Root length. Longitudinal distance from root collar to the end of longest root, which is on the last line in the image. This computation does not take root bending or curvature into account.

8. Root mass length. Distance from the root collar to the first horizontal line which has less than a minimum number of root crossings. The number of crossings is an adjustable algorithm parameter (example, 5 roots).

9. Percentage of root area outside the root zone. Used to detect stiff root laterals or poorly shaped root systems. The root zone is defined as the region within a downward opening $60^{\circ}$ angle, or any other operator-selected angle, with vertex at the root collar. The root area outside the root zone is divided by the total root area to compute this feature.

\section{Percentage of fine roots.} Area of roots with a horizontal width less than or equal to a threshold is determined and divided by the total root area. The width threshold (example, $0.75-\mathrm{mm}$ ) is an adjustable algorithm parameter.

\section{Grading Criteria}

Seedlings may be classified as acceptable or cull by comparing the features described above with user-defined classification criteria. As many as eight acceptable classes may be defined. Seedlings which do not meet all of the criteria for any acceptable class are graded as cull. A given class may be removed from the conveyor at any of eight possible sorting stations. Classification may be based on all, or an operator- 
selected subset, of the criteria listed below:

1. Minimum and maximum diameter.

2. Minimum and maximum height.

3. Minimum and maximum sturdiness ratio.

4. Minimum and maximum shoot area.

5. Minimum and maximum root area.

6. Minimum and maximum shoot-root ratio.

7. Minimum and maximum root length (longest root).

8. Minimum root mass length (5 roots).

9. Maximum percentage of root area outside the root zone.

10. Minimum percentage of fine roots.

These criteria are defined in a grading criteria file which also contains the algorithm parameters. Inspection and modification of the grading criteria are supported by the graphical user interface. Different grading criteria files are typically defined for different seedling types (species, age class. seed lot. customer, etc.) and organized in a hierarchical directory structure for easy access.

\section{Data Files and Summary Reports}

Measured seedling features and compliance with the grading criteria may be stored for each seedling in a user-specified data file. This information is also presented on the monitor as each seedling is inspected.

Inspection results for a group of seedlings are presented in a summary report. The report includes inspection time and date, seed lot and customer identification, calibration constants, algorithm parameters, grading criteria, the data file name, measurement statistics and a classification summary. Measurement statistics include the number of observations, mean, standard deviation, minimum, and maximum for each feature. The classification summary lists, for each class, the number of seedlings which passed the classification criteria and the number which failed. The summary also lists, for each class, how many class failures are attributed to each feature criterion. This information readily tells the operator if, for example, more seedlings are failing due to the diameter or the height criterion. The measurement statistics and classification summary reports may be viewed on the monitor, written to a file. and/or printed.

\section{Seedling Inspection}

The inspection procedure is fast and easy, after the system has been calibrated and a grading criteria file has been created. The operator first selects an existing grading criteria file from a directory. If measurement data and/or a summary report is to be stored in a file, those files must be opened next. Seedlings may then be inspected in either of two modes; interactive or continuous. Seedling images are displayed if the interactive inspection mode is selected. The operator may easily modify algorithm parameters and observe the results. Graphical indicators showing various feature locations (root collar, root zone, seedling top, etc.) are superimposed on the seedling image. The assigned class, value of all measured features, and an indication of which features failed grading criteria are displayed next to the seedling image. Inspection rates are slow (3 seconds per seedling) in the interactive inspection mode, but the system is ready to inspect another seedling as soon as the image of the last seedling is displayed. The continuous inspection mode is much faster (4 seedlings per second), because only seedling data are displayed.

\section{Container Grown Seedlings}

Although developed for bareroot seedlings, the system will locate the root collar, measure diameter, height, sturdiness ratio, 
and foliage area on container grown seedlings. Faster processing speeds could be achieved by exploiting the presence of the plug, and plug integrity inspection could be incorporated. Automated extraction and conveying systems could be integrated with the machine vision system to obtain 100\% product inspection.

\section{SYSTEM PERFORMANCE}

System performance was evaluated first by repeatedly inspecting dowels of known dimension, and second, by inspecting seedlings on which manual measurements were also obtained. Both tests were conducted at a commercial forest nursery. The system was operated at a belt speed of $2 \mathrm{~m} / \mathrm{s}$, with a longitudinal resolution of $1 \mathrm{~mm}$ and a transverse resolution of $0.1 \mathrm{~mm}$.

A test was conducted with wood dowels to determine machine precision and accuracy. Dowels were used because they are relatively uniform in diameter and of fixed length, whereas seedling stems are not uniform in diameter nor of fixed length due to debris, bending, foliage movement, and root movement.

Three 300-mm long dowels having diameters of 6.11, 7.89, and $13.27 \mathrm{~mm}$ were used. The system had been calibrated with the $6.11-\mathrm{mm}$ dowel. Twenty measurements of each dowel were obtained in each of three orientations; aligned with the belt centerline, angled $+/-15$ degrees with respect to the belt centerline, and angled $+/-30$ degrees with respect to the belt centerline. The 15 and 30 degree angles were approximated when placing the dowel on the moving belt.

Table 1 shows system measurement accuracy. The differences between known dimensions and the average machine vision measurement for the 6.11$\mathrm{mm}$ dowel at three orientations are tabulated. The vision system measured diameter slightly larger than actual at unaligned orientations. However, the difference was small, approximately one-third of the camera transverse resolution. Orientation correction applied by the diameter measurement software worked well. Without correction, diameter error would have been $0.94 \mathrm{~mm}$ for the $6.11-\mathrm{mm}$ dowel oriented at 30 degrees. Length measurement error is equal to two image lines for the aligned orientation and increased with orientation angle (as expected), because no orientation correction is applied to length. Area measurement error also increased with orientation angle. However, at 30 degrees the error was only $0.7 \%$ of the dowel area. Data for the 7.89 and 13.27 dowels yielded similar results.

Table 2 shows system measurement precision. The standard deviation for 20 measurements of each feature at three orientations is tabulated. Diameter variation in the aligned orientation is very low $(\mathrm{CV}=$ $0.4 \%$ ). Three standard deviations $(0.06 \mathrm{~mm})$ are less than the camera transverse resolution. Length variation $(\mathrm{CV}=0.6 \%)$ for the aligned orientation is partially due to non-uniform slippage of the dowel as it was transferred from one belt to the other at the inspection area. A

Table 1. System measurement accuracy, average error.

\begin{tabular}{lcccc} 
& \multicolumn{3}{c}{ Tool Orientation } & \\
\cline { 2 - 4 } Feature & Aligned & $+/-15$ Deg. & $+/-30$ Deg. & Units \\
\hline Diameter & 0.0 & 0.03 & 0.03 & $\mathrm{~mm}$ \\
Length & -0.2 & -0.8 & -2.5 & $\mathrm{~cm}$ \\
Area & 0.0 & 0.1 & 0.2 & $\mathrm{~cm}^{2}$ \\
\hline
\end{tabular}

20 obs. for each orientation of $6.11 \mathrm{~mm}$ dia. $\times 300 \mathrm{~mm}$ calibration tool. 
Table 2. System measurement precision, STDEV.

Tool Orientation

\begin{tabular}{llccl} 
Feature & Aligned & t/- 15 Deg. & +/-30 Deg. & Units \\
\hline Diameter & 0.02 & 0.04 & 0.06 & $\mathrm{~mm}$ \\
Length & 0.2 & 0.3 & 0.9 & $\mathrm{~cm}$ \\
Area & 0.2 & 0.2 & 0.3 & $\mathrm{~cm}^{2}$ \\
\hline
\end{tabular}

20 obs. each of $6.11,7.78,13.27 \mathrm{~mm}$ dia. $\times 300 \mathrm{~mm}$ calibration tools.

significant part of the increased variation with orientation angle ( $\mathrm{CV}=3.4 \%$ at $30 \mathrm{deg}$.) is probably due to variation in actual orientation (and thus, the longitudinal projection); the tool was manually placed on the moving belt. Area measurement variation remained relatively constant with increasing orientation angle $(\mathrm{CV}=1.1$ to $1.4 \%)$.

A second test was conducted to compare machine and manual measurements of actual seedlings. One hundred seedlings

Table 3. Machine vs. manual measurement precision.

\begin{tabular}{llllll} 
& \multicolumn{3}{c}{ Machine } & \multicolumn{3}{c}{ Manual } \\
Feature & STDEV & CV\% & STDEV & CV\% & Units \\
\hline Diameter & 0.09 & 1.4 & 0.41 & 6.6 & $\mathrm{~mm}$ \\
Height & 0.8 & 2.7 & 0.7 & 3.0 & $\mathrm{~cm}$ \\
Root Mass Length & 1.4 & 6.6 & 1.1 & 4.8 & $\mathrm{~cm}$ \\
Sturdiness & 0.2 & 3.9 & 0.3 & 7.3 & ratio \\
Shoot/Root & 0.1 & 3.5 & - & - & ratio \\
Fine Roots & 1.2 & 6.0 & - & - & $\%$ \\
Root Area & 1.2 & 2.5 & - & - & $\mathrm{cm}^{2}$ \\
Shoot Area & 2.3 & 1.8 & - & - & $\mathrm{cm}^{2}$ \\
\hline
\end{tabular}

200 seedlings, 4 reps. each of 2-0 ponderosa pine and 2-0 Douglas-fir were measured four times each by the vision system and once each by four different quality control personnel. Manual diameter measurements were obtained with a digital caliper and recorded to the nearest $0.1 \mathrm{~mm}$. Manual height and root mass length measurements were obtained with a meter stick and recorded to the nearest mm. Seedlings were rotated about their longitudinal axis between repeated machine vision measurements.
Table 3 provides a comparison between machine and manual measurement precision. Vision system diameter measurement variation is larger for seedlings than for the wood dowel because: 1) seedlings are not uniform in diameter, 2) the root collar may not be found at exactly the same location during repeated inspections of a seedling, and 3) debris tends to decrease with repeated handling. Still, vision system diameter measurement standard deviation was approximately equal to camera transverse resolution. Machine diameter measurement variation was approximately one-fourth that of manual measurement. Machine and manual measurements had similar variation for height. Vision system measurements showed 50\% less variation in sturdiness ratio compared with manual measurements.

Manual root mass length measurement variation was smaller than that of the vision system. This result is due in part to measurement method. Manual root mass length measurements were obtained with the seedling held in a vertical orientation, such that gravity tended to extend the roots. On the horizontal conveyor belt, however, roots contracted more readily, yielding more variation and a smaller average value (Table 4) for the machine measurement.

Table 4 presents the difference between manual and machine measurements. Machine 
Table 4. Difference between machine and manual measurements.

\begin{tabular}{lccl} 
& \multicolumn{3}{c}{ Machine - Manual } \\
Feature & MEAN & STDEV & Units \\
\hline Diameter & 0.34 & 0.53 & $\mathrm{~mm}$ \\
Height & 3.7 & 2.2 & $\mathrm{~cm}$ \\
Rt. Mass Len. & -1.9 & 2.0 & $\mathrm{~cm}$ \\
\hline
\end{tabular}

200 seedlings, 4 reps.

diameter measurements were, on average, $0.34 \mathrm{~mm}$ larger than manual measurements. This result may be due to debris on the stem and/or the non-contact nature of machine vision measurements. The standard deviation of measurement differences indicates that the two methods could easily differ by one $\mathrm{mm}$. Most of this variation (error), however, may be attributed to the manual measurements, as shown in Table 3.

Machine height measurements were significantly larger than manual measurements (Table 4). This result is partially due to difficulty in locating the terminal bud on many seedlings. The vision system also tended to locate the root collar slightly lower on the stem than the quality control personnel. The difference between manual and machine root collar location was partially responsible for shorter machine measurements of root mass length. Root bending on the conveyor belt, described above, also contributed to shorter root mass length as measured by the machine.

Time measurements indicate that the system can inspect a seedling with a total length of $500 \mathrm{~mm}$ in approximately 0.25 seconds. Shorter seedlings are inspected proportionately faster. Most of the inspection time is consumed by the relatively slow transfer of data from the image digitizer into system memory, rather than image analysis. Recently introduced digitizers operating through VESA or PCI local buses eliminate the data transfer bottleneck and should enable significantly higher inspection rates.

\section{CONCLUSIONS}

A PC-based machine vision inspection system which provides high-resolution imaging, automatic measurement, and quality assessment of conifer seedlings at rates of up to four per second has been described. The system measures ten morphological features, stores measurement data to files, and generates statistical and quality reports, all through a menudriven, user-friendly interface. Performance tests show that machine vision measurement precision is four times greater than that of manual measurements for stem diameter. Machine and manual measurements had comparable precision for shoot height and root mass length. Inspection rates exceed the needs of a quality control system and can be increased by utilizing new digitizer hardware, enabling $100 \%$ production inspection.

\section{ACKNOWLEDGMENTS}

Approved for publication by the Director, Oklahoma Agricultural Experiment Station. This research was supported, in part, under project H-1973. Development of the prototype described in this paper was funded by the USDA Forest Service, Missoula Technology \& Development Center. System performance was tested at the J. Herbert Stone Nursery, Central Point, OR. The authors wish to thank the quality control personnel at the J. Herbert Stone Nursery for their assistance. 


\section{REFERENCES}

Hassan, A.E., A.S. Tohmaz, and J.P. Roise. 1992. Evaluation of manual sorting in three pine nurseries. Transactions of the ASAE, 35(6):1981-1986.

Kutz, L.J., J.H. Wilhoit, and D.E. Fly. 1993. Multiple camera machine vision systems for pine seedling measurements. ASAE Paper No. 933028, ASAE, St. Joseph, MI 49085.

Rigney, M. P. and G. A. Kranzler. 1988. Machine vision for grading southern pine seedlings. Transactions of the ASAE, 31(2):642-646.

Rigney, M. P. and G. A. Kranzler. 1989. Performance of a machine vision based tree seedling grader. ASAE Paper No. 89-3007, ASAE, St.

Joseph, MI 49085.

Rigney, M P. and G. A. Kranzler. 1992. Line-scan inspection of conifer seedlings. Optics in Agriculture and Forestry. SPIE Proceedings, Vol. 1836, pp. 166-174. 


\section{Selecting and Calibrating Low-Volume Sprayers ${ }^{1}$}

John W. Bartok, Jr. ${ }^{2}$

Abstract — Low-volume sprayers are an alternative to hydraulic sprayers for greenhouse and nursery pesticide application. Although more expensive, they provide better coverage with less chemical material. Some low-volume sprayers also reduce application time and therefore labor cost. Proper selection and operation is important for the type of application and crop.

\section{INTRODUCTION}

The most important goal in the application of agricultural pesticides is to get uniform distribution of the chemicals throughout the crop foliage. Underdosing may not give the desired coverage and control needed. Overdosing is expensive as it wastes pesticide and increases the potential for contamination of groundwater.

In the hydraulic sprayer, spray material is carried to the target (plant foliage) by the energy supplied by the pump. Water is the carrier and the pump creates the pressure (40 to 1000 psi). Spray material is usually applied to runoff. Nozzles on a boom or hand held gun direct the spray and break it into small droplets.
In a low-volume sprayer, spray material is injected into a high speed air stream from a blower or compressor. A small pump is used to inject a concentrate pesticide into the air stream. The air stream speed may be up to $200 \mathrm{mph}$. To get good coverage the air within the foliage canopy must be replaced with air that contains the pesticide. Because droplet size is much smaller, less chemical is needed.

One way to distinguish between a hydraulic sprayer and low-volume sprayer is by droplet size. Hydraulic sprayers produce droplets with a 200 to 400 micron diameter (thickness of the human hair $=0.004 \mathrm{in} .=100$ microns. Low-volume sprayers develop a mist (50 to $100 \mathrm{mi}-$ crons) or fog (0.05 to $50 \mathrm{mi}-$ crons). Small droplets from a mist or fog applicator mean more likelihood of the insects contacting the spray material.

One disadvantage to smaller droplets is the greater possibility of drift, especially in outdoor applications. In a $3 \mathrm{mph}$ wind, a 200 micron droplet will be carried about 18 feet, a 50 micron droplet, 178 feet and a 1 micron droplet, 84 miles. For this reason, fog applicators are normally used in greenhouses where the pesticide is contained by the building.

One gallon of spray material will yield 318 million droplets, 300 microns in diameter or 68 billion droplets that are 50 microns in size. Coverage can be more uniform with the smaller droplets.

'Bartok, J.W. Jr. 1994. Selecting and Calibrating Low-volume Sprayers. IN: Landis, T.D.; Dumroese, R.K., tech. coords. National Proceedings, Forest and Conservation Nursery Associations. Gen. Tech. Rep. RM-257. Fort Collins, CO: U.S. Department of Agriculture, Forest Service, Rocky Mountain Forest and Range Experiment Station: 192-195.

${ }^{2}$ Natural Resources Mgt. \& Engr. Dept., University of Connecticut, Storrs, CT 06269-4087 
Water usage with low volume sprayers is reduced from 10 to $60 \%$. This means a smaller tank size can be used and more area can be covered before reloading.

\section{REVIEW}

The following is a review of the different types of lowvolume applicators:

\section{Mist blower}

A small engine and fan creates an air stream with a velocity of 100 to $200 \mathrm{mph}$. Concentrated spray injected into the air stream by a special nozzle is carried to the foliage by the air.

This spraying technique is more complicated than with a hydraulic sprayer. The nozzle should be directed into the plant canopy to get good penetration and coverage, but it should be kept at least 6 feet away from the plants to avoid blast damage. The operator should visualize that all the air within the canopy must be replaced by the air from the mist blower.

\section{Electrostatic sprayers}

Compressed air forms spray droplets and carries them to the plants. In addition, the spray material as it travels through the nozzle is given a static electric charge. This helps to create particles of more uniform size that disperse well because they repel each other.
Charged particles are attracted to leaves, metal and some plastics. Uniform coverage occurs because a charged particle, when it strikes a surface, creates a momentary overcharge that repels other particles. These land elsewhere on the leaf, so there is more uniform coverage.

Several styles of electrostatic sprayers are available. The simplest are backpack-mounted and contain a tank and spray gun. They require an independent air supply to charge the tank. Other units are cartmounted with an integral compressor powered by a gas engine or electric motor. Electrostatic sprayers work best if the spray distance is less than 15 feet.

Field crop sprayers with boom mounted nozzles are available. These reduce chemical usage by 30 to $60 \%$. Water usage is also reduced. After spraying, plants are dry with no visible residue on the plant leaves and there is no runoff.

\section{Thermal foggers}

Designed for greenhouse use, these foggers require a specially formulated carrier that is mixed with the pesticide to improve uniformity of droplet size and distribution of the spray material. The carrier also decreases molecular weight, allowing the particles to float in the air for up to six hours. a disadvantage if you have to get into the greenhouse to care for the plants.
In the operation of a thermal fogger, the pesticide is injected into an extremely hot, fast moving air stream that vaporizes it into fog particles. Moving from one end to the other in the greenhouse, an acre can be covered in as little as $15 \mathrm{~min}$ utes. Using air circulation, such as the horizontal air flow (HAF) system, will give greater uniformity of coverage and better foliage penetration.

Temperature and humidity in the greenhouse also affect the spray droplets. Under high temperatures and low humidity, the spray droplets will tend to fall out of the air quicker and increase the deposits on the upper leaf surface.

Because of the noise associated with the jet engine, hearing protection is recommended with this type of applicator.

\section{Mechanical foggers}

Also called cold foggers, these devices use high-pressure pumps and atomizing nozzles to produce fog-sized particles. Distribution of the spray material is through a hand-held gun or external fan unit.

With the fan unit, the distance and amount of area that can be covered depends on the capacity of the fan. Multiple units or multiple settings may be needed to cover large areas. 
As with other foggers, penetration and coverage may not be as good as with mist or hydraulic sprayers. Small particles don't have the mass or velocity to move into heavy foliage. Still, in most studies, good insect control has been achieved.

Safety is important when using a mechanical fogger employing a high pressure pump. Keep hands and arms away from the outlet because at 2000 to 3000 psi, the spray particle can penetrate the skin very easily.

\section{Calibration}

Low-volume sprayers provide better coverage with less spray material by developing smaller size droplets that are carried to the leaf surface by air movement. The greater uniformity of coverage allows less pesticide to be applied. This may require an adjustment in the rate that is recommended on the label.

When making up a tank mix, both the dosage and water requirement need to be considered. The dosage, the amount of chemical that should be applied to a given area is listed on the label. With most pesticides, a range is given, for example, 4 to $12 \mathrm{oz} / 100 \mathrm{gal}$. Selection of the rate should be made based on the level of infestation, type and maturity of the crop, past experience and other variables. If this is the first time that the pesticide is being used, a dosage in the middle of the range is a good starting point.

The amount of water that is needed to cover the growing area depends on the type of equipment used. With hydraulic sprayers, a rate of 25 to $50 \mathrm{gal} /$ $10,000 \mathrm{sq} \mathrm{ft}$ is common. Lowvolume sprayers use only $1 / 4$ to $2 \mathrm{gal} / 10,000 \mathrm{sq} \mathrm{ft}$.

Most chemical labels state the amount of pesticide to be diluted into 100 gallons of water and not the amount of spray concentrate that is to be applied to a given area. Some labels now list the amount of chemical that should be applied per acre. The instruction manual that comes with each sprayer contains charts or tables that help to guide in determining how much spray material to mix with the water. This is usually based on a 10,000 sq $\mathrm{ft}$ area so must be adjusted to fit the growing area to be sprayed. Also with low-volume sprayers, the rate can frequently be reduced at least $5 \%$ because of not spraying to runoff as with a hydraulic sprayer.

\section{Spraying technique}

The technique by which crops are sprayed is very important. It should be developed to fit the type of equipment that is being used. The compressed air from fans propels the mist or fog into the foliage. With hand held guns, a sweeping motion over the foliage will allow the spray material to penetrate and get to the underside of the leaves.

With fixed fan type units, an air flow pattern needs to be established so that all of the plant canopy receives the pesticide. Location of the unit is important to get good air flow. With both systems, the use of an air circulation system, such as HAF will enhance the movement and distribution of the fog and mist particles. The fan should continue to operate for 30 to 60 minutes after the spraying operation is done.

Observations should be made to see that the sprayer is operating correctly and that good coverage is being obtained. A good way to monitor coverage with a mist sprayer is to use strips of water-sensitive paper (available from Spraying Systems Co., North Avenue at Schmale Rd., Wheaton, IL 60189-7900 or from a local spraying equipment supplier). The paper is attached to representative leaves in the plant canopy. When exposed to spray droplets, stains will appear indicating the size and number of particles that were received by the leaf.

For fog applications, evaluation of coverage can be made using a fluorescent dye in water. Placing representative leaves under an ultra-violet light or black light will show droplet size and distribution. 
Another tool that can help to promote better techniques and coverage is to keep a log of the spraying operations and the results that were obtained. This should include the date, time and location of application, crop and pest, pesticide used, tank mix and an evaluation of the results obtained. Adjustments should be made in subsequent applications to try to improve the application.

\section{Maintenance}

As with any type of spray equipment, maintenance is important to get consistent results. This is particularly true with low-volume sprayers as the nozzle openings are smaller than with hydraulic units. Cleaning with soap and water will remove most of the pesticide residue. Filters and nozzles should be disassembled and scrubbed with a brush.

Thermal foggers require maintenance of the pulse-jet engine after each use. The batteries in the gun of the electrostatic sprayer need to be replaced after 10 to 15 hours of operation. Engine powered units require oil changes and lubrication on a regular basis. With regular maintenance, many years of service can be expected from the equipment that is available today.

Because low-volume sprayers are more complex to set up and operate, a checklist that guides you through the steps should be developed. It should be developed following the steps in the manual, but without all the explanation. Page references are helpful in locating information that is complex. Dilution amounts for that chemicals that are frequently applied could be included. Keep this list with the spray log.

Environmental and safety concerns affect the way that spraying is done. A well calibrated and maintained lowvolume sprayer can achieve good results with less spray material. 


\title{
The Effects of Keithia Blight on Outplanting Performance of Western Redcedar Container Seedlings at Two Reforestation Sites in British Columbia-Preliminary Results ${ }^{1}$
}

\author{
David Trotter ${ }^{2}$, Gwen Shrimpton ${ }^{3}$ and Harry Kope ${ }^{4}$
}

\begin{abstract}
The significance of various infection levels of Keithia blight on 2+0 container western redcedar seedlings after outplanting is examined. Increasing levels of Keithia infection had a negative effect on height and root collar diameter but did not impact survival. Site climate humidity appeared to contribute to the continued severity of the disease. Seedlings sprayed at the recommended nursery rate and timing with mancozeb were larger and had less disease.
\end{abstract}

\section{INTRODUCTION}

Keithia blight is a foliar disease of western redcedar, Thuja plicata Don, and is caused by the fungus, Didymascella thujina (Dur.) Maire. The fungus is an obligate parasite that is endemic to North America and is found throughout the geographical range of western redcedar (Pawsey, 1960; Sinclair et al, 1987). One of the first descriptions of significant $D$. thujina infestations of $T$. plicata was recorded in 1912 to 1915 from northern Idaho (Weir, 1916). It has also been reported on eastern white cedar, Thuja occidentalis L., and on Thuja spp in Europe due to introductions of cedar imported from North America (U.K. Forestry Commission, 1963). Individual trees vary in the degree of infestation and although all age classes are affected, seedlings and young trees are the most susceptible stages (Pawsey, 1962). Keithia blight is considered a two year disease, with infection of individual leaflets occurring in the first growing season, and disease expression and spread developing in the second. Damage is usually minimal on one year old seedlings and if present, it is confined to juvenile and mature leaves on the lower stem. In general, spread of the disease is encourage by mild temperatures and high humidity (H. Kope, pers. comm., Aug. 1994). The ascospores require free water and temperatures above $10^{\circ} \mathrm{C}$ for release and relative humidities above $95 \%$ and $15^{\circ} \mathrm{C}$ for germination. The fungus is not systemic but kills individual leaflets. After several weeks, spores form in structures called apothecia and as they mature they are forcibly ejected up to $5 \mathrm{~cm}$ to adjacent foliage and the infection

\footnotetext{
'Trotter, D.; Shrimpton, G.; Kope, H. 1994. The Effects of Keithia Blight on Outplanting Performance of Western Redcedar Container Seedlings at Two Reforestation Sites in Britsh Columbia-Preliminary Results. IN: Landis, T.D.; Dumroese, R.K., tech. coords. National Proceedings, Forest and Conservation Nursery Associations. Gen. Tech. Rep. RM-257. Fort Collins, CO: U.S. Department of Agriculture, Forest Service, Rocky Mountain Forest and Range Experiment Station: 196-202.
}

2B.C. Ministry of Forests, 14275 96th Ave, Surrey, B.C. V3V 7Z2. Tel (604) 930-3302

${ }^{3}$ B.C. Hydro, Vancouver, B.C.

${ }^{4}$ Applied Forest Science Ltd., Victoria, B.C. 
cycle spreads through the plant.

The ascospores are coated with a very thin and sticky film and once they affix to any surface they are difficult to remove with out damaging them. In addition, ascospores can be either wind or water-borne and are thought to be carried for great distances. Heavy infections of branches can significantly reduce seedling vigor, performance and occasionally survival. However, once seedlings are 4-5 years old they appear to overcome the effects of the disease.

In 1988, the first major Keithia blight infestation of western redcedar in a British Columbia container nursery was recorded and resulted in significant nursery and reforestation site losses. Since then, all coastal nurseries have recorded Keithia blight infestations, primarily in 2+0 container stock. In 1991-92, about one million seedlings were discarded due to the disease. In 1988 at Humbolt Nursery in California, over 60,000 seedlings were rejected due to moderate to heavy levels of Keithia blight (Frankel, 1990). Due to the aggressive nature of the disease, and its effects on outplanting performance, most field staff and administrators are faced with the problem of determining an acceptable level of Keithia blight on seedling stock. In recent years, studies by Natural Resources Canada - Pacific Forestry Center and the B.C. Ministry of Forests have reviewed the epidemiology of the disease, evaluated the available registered fungicides, and assessed outplanting survival. A screening of 5 registered fungicides found that bi-weekly applications of mancozeb through the growing season was effective at protecting seedlings from infection. In 1992, a preliminary outplanting study was initiated to evaluate seedling performance in relation to described levels of Keithia blight infection and site environment (D. Trotter, unpublished data, 1994, B.C. Ministry of Forests). Six sites were selected in five forest districts of coastal B.C. Each site was planted with $2+0$ container seedlings having low $(0-5 \%)$, medium (5-10\%) and high $(>10 \%)$ Keithia blight levels based on initial assessments of the foliage prior to storage and shipment. In addition, the stock was further compromised with the identification of stem lesions caused by the disease. This preliminary survey found that the degree of infection coupled with site characteristics appeared to contribute substantially to seedling survival and the aggressiveness of the disease after outplanting. Overall, seedling performance was compromised with increased site wetness and vegetation competition in conjunction with the degree of Keithia blight infection. Seedlings outplanted on the drier sites performed significantly better and eventually recovered after one year. In contrast, seedlings planted in the wetter sites, regardless of infection level, continued to be affected by the disease even after two field seasons.

In order to aid nursery personnel and field foresters, the following study was initiated to; a) evaluate the efficacy of a nursery fungicide treatment with mancozeb on outplanting, and b) develop grading criteria in relation to field performance and site characteristics.

\section{MATERIALS AND METHODS}

\section{Seedling Source}

This study was initiated at the Surrey Nursery, B.C. Ministry of Forests, which is located $35 \mathrm{~km}$ southeast of Vancouver, British Columbia. Western redcedar seedlings destined for outplanting assessments were selected from $2+0415$ b container stock (527 seedlings per $\mathrm{m}^{2}$ ) grown under operational conditions. After the first growing season, an operational spray program was initiated in which the fungicide, mancozeb was applied bi-weekly at a rate of $2.75 \mathrm{~kg}$ a.i./ha from June to November, 1992. Mancozeb is the recommended control for protecting western redcedar foliage from infection by Keithia blight (Barnett, 1993). Twentyfour containers of this crop were maintained as controls. The treatments were assessed biweekly just prior to the fungicide application. At each assessment. 
10 randomly selected seedlings from each of five styrofoam containers per treatment were evaluated for the number of Keithia blight pustules or apothecia per seedling. At the end of the growing season, seedlings treated with mancozeb had no visible signs of Keithia blight. In contrast, control seedlings had infestations ranging from 0 $100 \%$ of their foliage infected with the disease. In December 1992, the seedlings were categorized based on the percentage of foliage infected and treatment.

The four categories were as follows: 1) $0 \%$ Keithia infection/ mancozeb treatment, 2) $0 \%$ Keithia infection/control, 3) 10\% Keithia infection/control and 4) $50-100 \%$ or $50+\%$ Keithia infection/control. Seedlings were randomly selected from the two treatments, assessed for the total number of visible Keithia pustules and assigned to one of the above categories. Fifty seedlings per category were then bundled into individual wax-coated cardboard boxes, sealed and placed in a freezer storage unit at $-4^{\circ} \mathrm{C}$.

\section{Study Locations}

From previous preliminary outplanting studies, 2 reforestation sites were selected for outplanting of the trial stock (Figure 1).

The Holt Creek site, Duncan District (Lat. N48 $45^{\prime}$, Long. W $\left.124^{\circ} 05^{\prime \prime}\right)$, has predominately coastal Douglas-fir (Pseudotsuga menziesii (Mirib.) Franco) and western hemlock (Tsuga

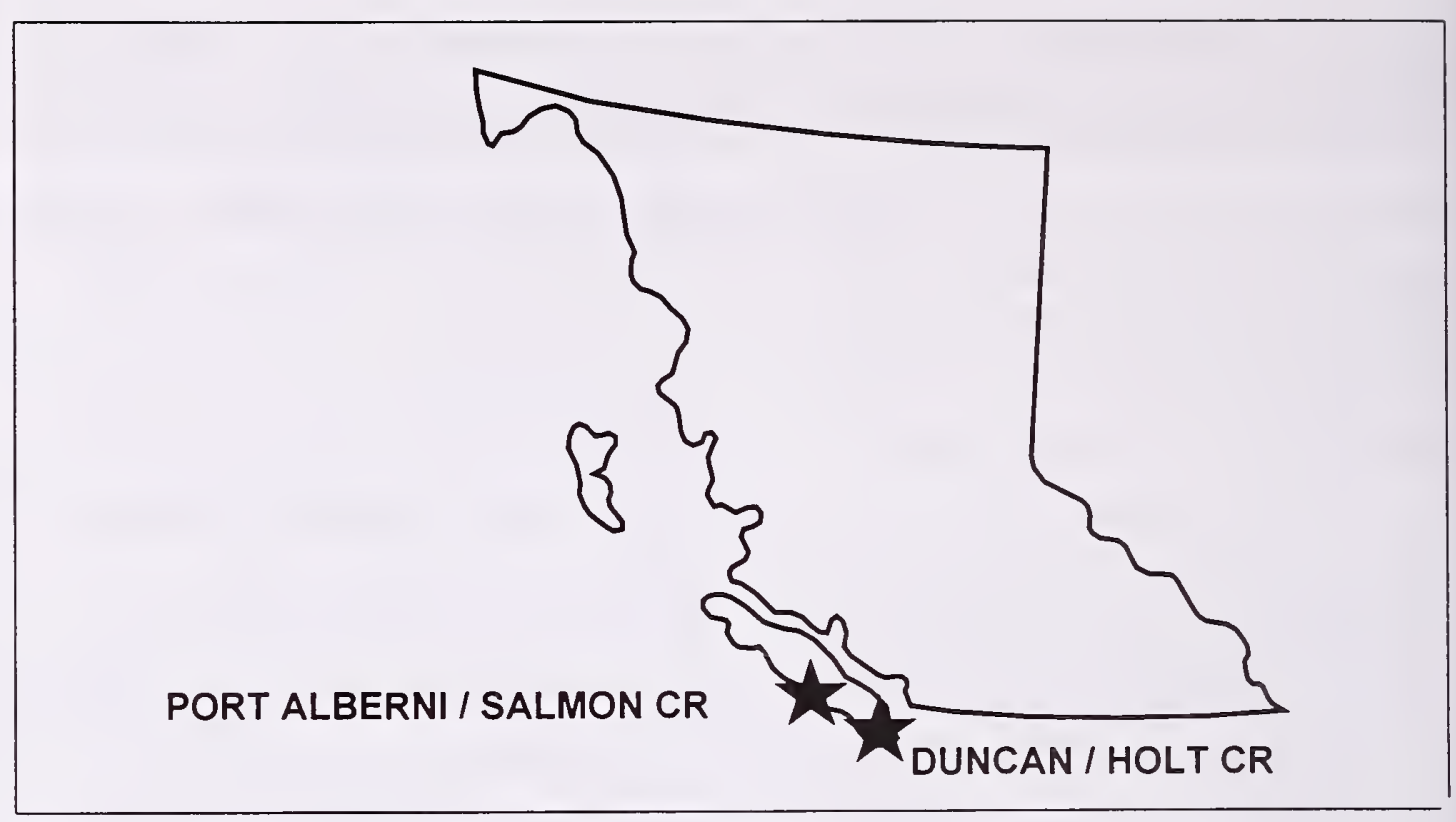

Figure 1. Location of trial outplanting sites in British Columbia.

heterophylla (raf.) Sarg.) in the surrounding forest. The area has warm, dry summers and moist, mild winters with an average rainfall of $1500 \mathrm{~mm} / \mathrm{year}$. The biogeoclimatic zone classification is CWHxm. The Salmon Creek site, Port Alberni District (Lat. N. $48^{0} 59^{\prime \prime}$, Long. W $125^{\circ}$ 34") has a surrounding forest species composition dominated by western hemlock (Tsuga heterophylla), amabilis fir (Abies amabilis (Dougl. ex Loud.) Forbes) and western redcedar (Thuja plicata Donn ex D. Don in Lamb). The site has moist, mild summers and winters with an average rainfall of $2800 \mathrm{~mm} /$ year. The biogeoclimatic zone classification for the site is CWHvh1.

\section{Experimental Design}

The trial seedlings were transported and outplanted at both reforestation sites on April 7-9, 1993. The seedlings were planted in a randomized complete block design with 5 seedlings and replicates respectively per Keithia infection category. The seedlings were positioned in rows with a $1 \mathrm{~m}$ spacing and a 3 $\mathrm{m}$ spacing between treatments. Each seedling was then covered with a $0.75 \mathrm{~cm}$ high plastic mesh tube for protection against animal damage. Seedlings at both sites were examined on October 19 \& 20, 1993 (Fall, 93) and June $1 \&$ 6, 1994 (Spring, 94). Stem heights and root collar diameters were measured at each site. Survival was scored into three categories; dead, unacceptable and acceptable. Seedlings were rated as unacceptable if they were found to be chlorotic and Keithia infections were recorded on both new and old foliage. The degree of Keithia infection was assessed by counting the number of pustules on the four top and bottom branches of each seedling. 


\section{Analysis}

Differences among Keithia infection categories for mean height, root collar diameter and number of pustules were evaluated by analysis of variance and SNK multiple range test at the alpha level of 0.05 .

\section{RESULTS AND DISCUSSION}

The degree of seedling survival for the 4 Keithia infection categories differed depending on initial Keithia infection and trial site. At the Holt Creek site, the Fall 93 assessment found overall only $13 \%$ of the $50+\%$ category seedlings to be unacceptable (Fig. 2). By the Spring 94 assessment, the unacceptable $50+\% /$ control treatment seedlings had died with additional mortality noted in the $0 \% /$ control treatment.

In contrast, the number of acceptable seedlings at the Salmon Creek site decreased significantly with increasing initial Keithia infection (Fig. 3). In addition, dead seedlings were found in all but the $0 \% /$ mancozeb treatment category. By the Spring 94 survey, the unacceptable seedlings had improved and were all rated as acceptable. The reduction in the percentage of dead seedlings in the $10 \%$ /control treatment was due to the appearance of new branchlets emerging from the base of some dead stems.
HOLT CREEK / DUNCAN DISTRICT

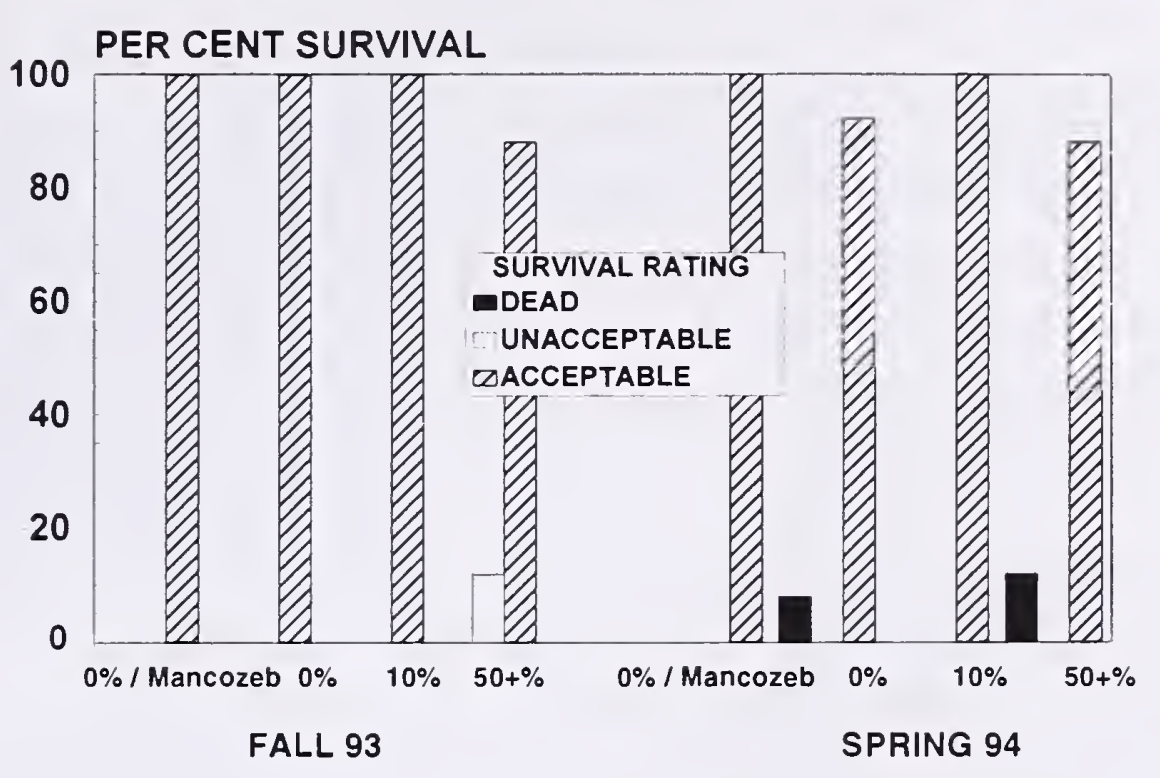

Figure 2. Per cent survival and rating of outplanted seedlings at the Holt Creek site.

\section{SALMON CREEK / PORT ALBERNI DISTRICT}

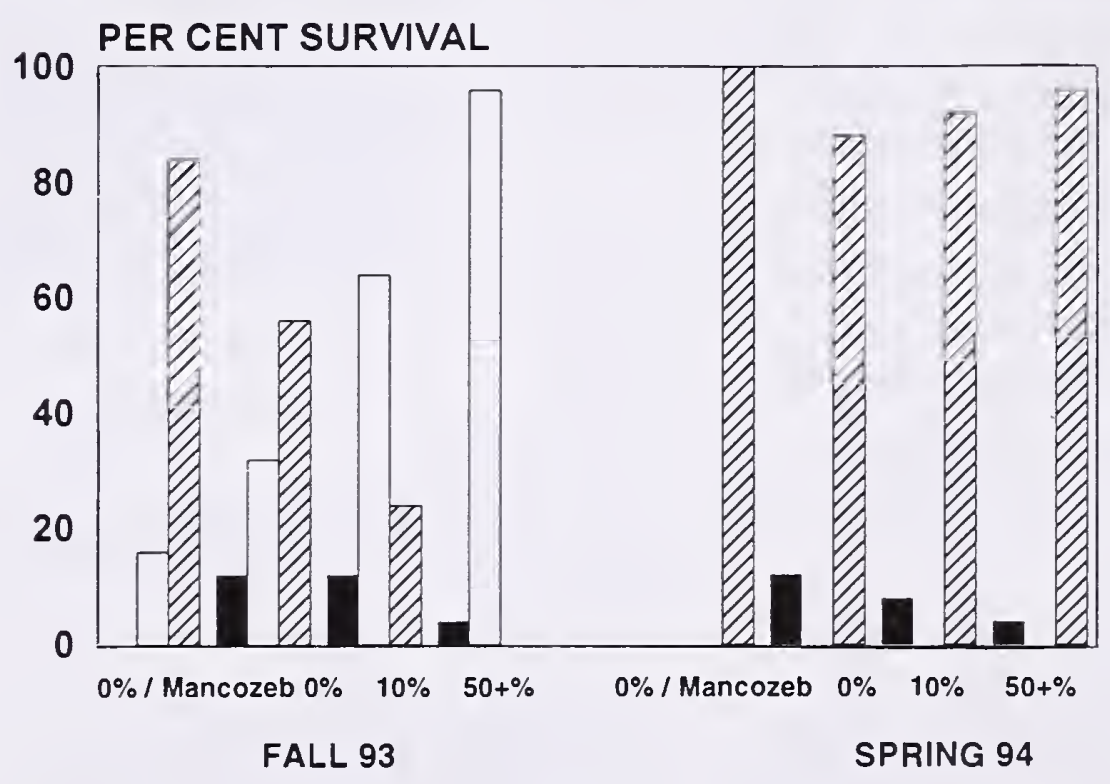

Figure 3. Per cent survival and rating of outplanted seedlings at the Salmon Creek site. 
Both stem height and root collar diameter were significantly impacted by the level of disease. At Holt Creek, stem heights were found to decrease with higher Keithia infection levels while at Salmon Creek there was little difference in seedling heights (Figure 4).

For root collar diameter, the decrease was significant at both sites (Figure 5). In comparison, seedlings from Holt Creek, regardless of infection level, were larger after 14 months than those outplanted at Salmon Creek. At both sites, the seedlings treated with mancozeb were taller and thicker with the largest seedlings located at Holt Creek.

The degree of disease incidence on the foliage of the seedlings was closely correlated to the initial level of Keithia infection and the outplanting site. At Holt Creek, the number of pustules or apothecia found in the Fall 93 assessment was higher on the bottom than top four branches regardless of initial infection level (Figure 6).

Overall, the number of new infections was greater with correspondingly higher initial disease levels. By the Spring 94 survey, the number of infections had decreased in the top foliage and remained constant in the lower branches. Similarly, the seedlings at Salmon Creek were found to have less Keithia infection in the top foliage

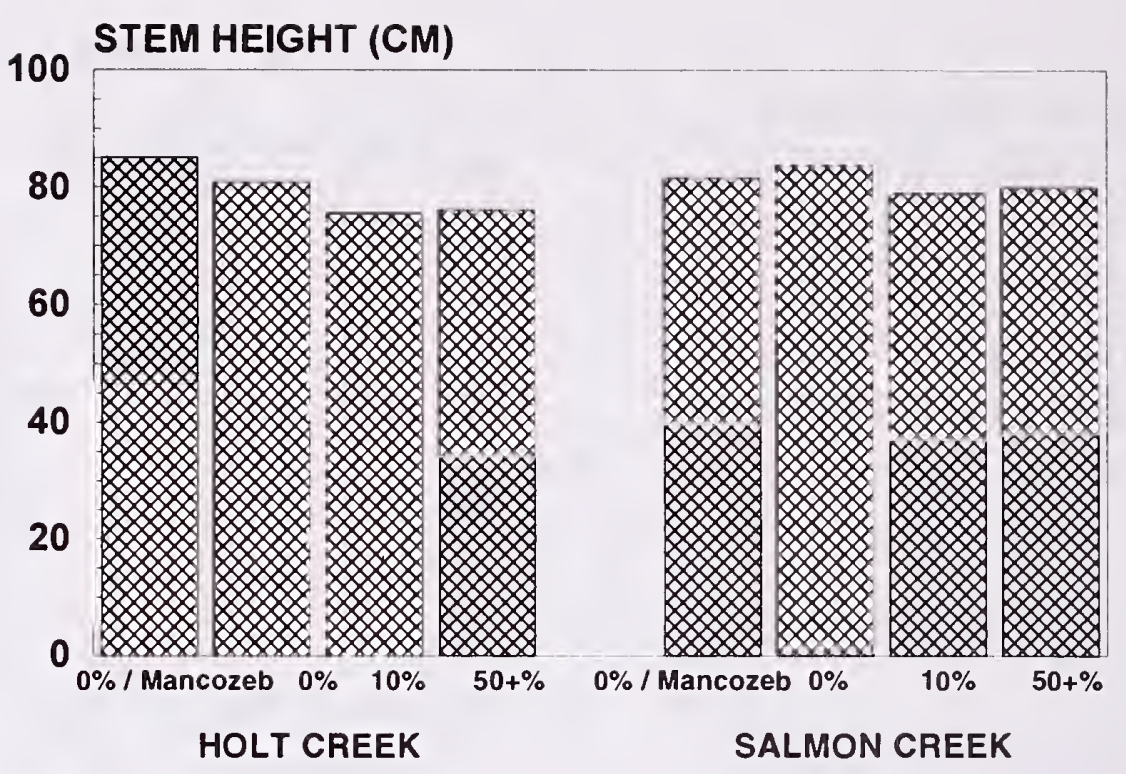

Figure 4. Mean stem height for outplanted seedlings for Spring 94 at both trial sites.

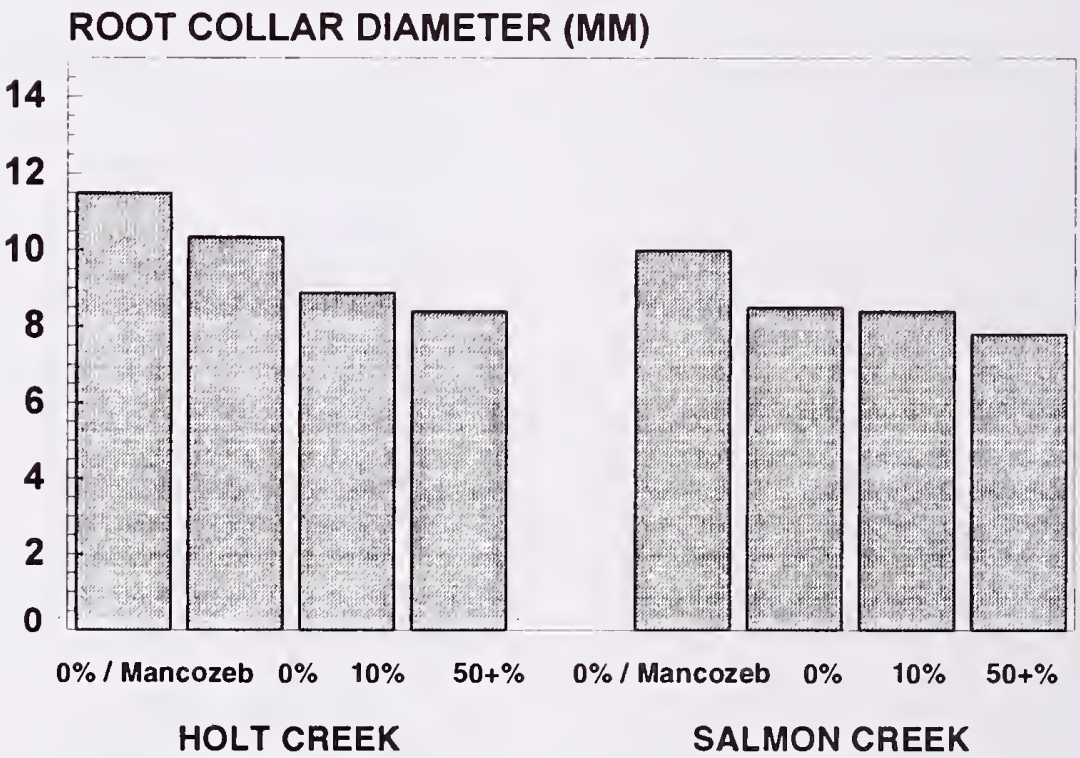

Figure 5. Mean root collar diameter for outplanted seedlings for Spring 94 at both trial sites.

compared to the bottom branches, and that the number of pustules had increased from the initial infection level (Figure 7).

At Salmon Creek, the amount of Keithia infection in the top branches was found to decrease over time but the reverse was observed for the lower branches. Between the two sites and regardless of treatment, the degree of Keithia infection was significantly greater at the Salmon Creek location. In all cases, the $0 \% /$ mancozeb treatment seedlings had significantly less disease than the other treatments. 
The initial degree of Keithia infection coupled with environmental site differences appears to significantly impact on western redcedar seedling growth especially in the first year of outplanting. At both sites, seedling survival was not severely affected but initial seedling ratings were poor at Salmon Creek. Similar observations were reported from an outplanting of moderately infected western redcedar seedlings from Humbolt Nursery in California (Frankel, 1990). Furthermore, both the degree of infection and reduction in seedling growth were greater at the Salmon Creek site. At Hoit Creek, the incidence of disease appears to be in decline across the 4 treatments but its early effects on seedling growth are still evident. The Salmon Creek site has a comparatively wetter climate and thus provides biological conditions conducive to Keithia blight. This is similar to findings by Porter (1957) who found that site microclimate was the chief factor responsible for differences in Keithia infection. Though a spray program with mancozeb can substantially reduce the effects of Keithia blight in the field, wet sites like Salmon Creek still afford an environment better suited for continued Keithia infection. Yet for nursery growers and field foresters, a mancozeb spray program presents a viable avenue to protect

\section{HOLT CREEK / DUNCAN DISTRICT}

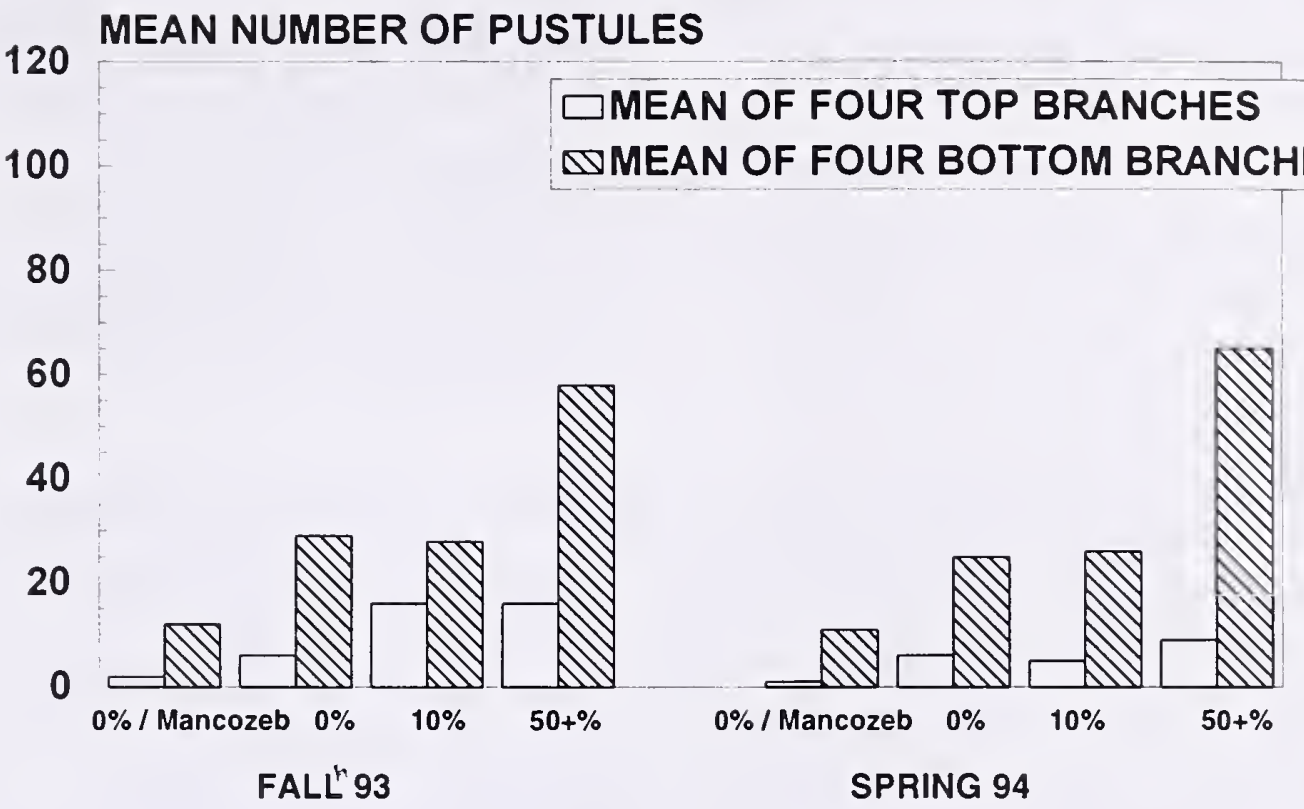

Figure 6. Total mean number of Keithia blight pustules on the four top and bottom branches of outplanted seedlings at the Holt Creek site.

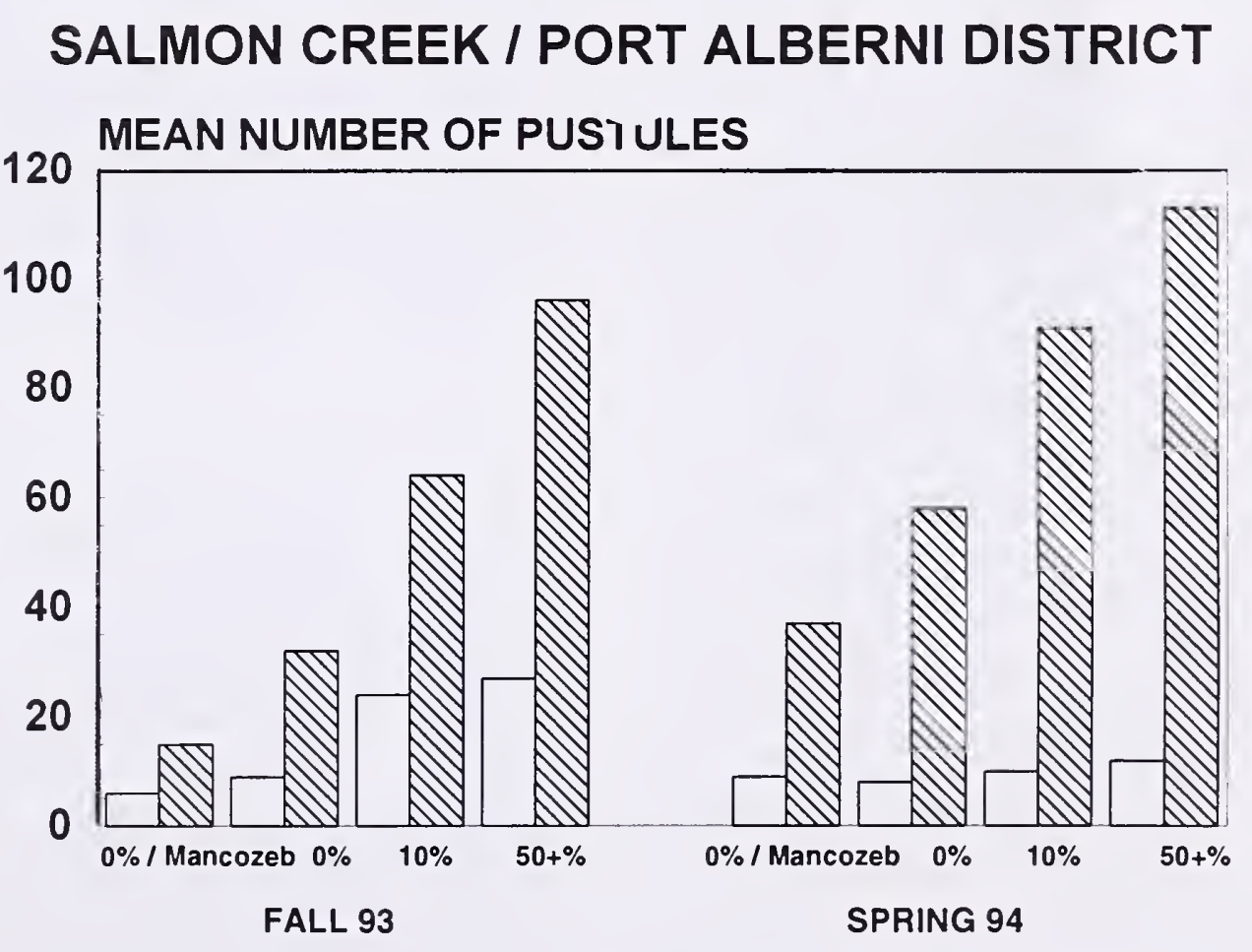

Figure 7. Total mean number of Keithia blight pustules on the four top and bottom branches of outplanted seedlings at the Salmon Creek site. 
and enhance western redcedar seedlings in the nursery and field environments. Also, prior knowledge of the amount of Keithia blight on nursery stock may provide field foresters with some options as to the degree of infection that may be accepted depending on the desired destination. For example, the Holt Creek site presents less of a risk to outplanting performance if a decision is made to accept western redcedar seedlings with small amounts of visible Keithia blight. This would not be the case for a location similar to the Salmon Creek site. Further studies are needed to help develop a greater understanding of the outplanting effects of Keithia blight on container seedlings.

\section{ACKNOWLEDGMENTS}

The authors gratefully acknowledge the contributions made to this study by the following people: S. Clary, J. Dennis, J. Fliczuk, D. Hall, G. Jaggs, K. Kahle, T. Peterson, J.

Sutherland, B. Wilson, C. Wilson and the staff of Surrey

Nursery.

\section{BIBLIOGRAPHY}

Barnett, C. (editor) 1993. Nursery crop production guide for commercial growers. 19931994 edition. British Columbia Ministry of Agriculture, Fisheries and Food, Victoria, B.C. 116pp.

Frankel, S. 1990. Evaluation of fungicides to control cedar leaf blight on western redcedar at Humbolt Nursery. Forest Pest Management Report No. 90-01, USDA Forest Service, Pacific Southwest Region. 4pp.

Pawsey, G. 1960. An investigation into Keithia disease of Thuja plicata. Forestry 33: 174-187.

Pawsey, G. 1962. Rotation sowing of Thuja in selected nurseries to avoid infection by Keithia thujina. Quarterly Journal of Forestry 56: 206210.

Porter, W.A. 1957. Biological studies on western redcedar blight caused by Keithia thujina Durand. Interim Report. Forest Biology Laboratory. Victoria, B.C. Forest Biology Division. Science Service. Department of Agriculture. Ottawa. Canada.
Sinclair, W.A., H.H. Lyon and W.T. Johnson. (editors). 1987. Didymascella leaf blight. in Diseases of Trees and Shrubs. Cornell University Press. Ithaca and London.

U.K. Forestry Commission. 1963. Keithia disease of Thuja plicata. Leaflet No. $43 \mathrm{Her}$ Majesty's Stationary Office, London, England. 7pp.

Weir, J.R. 1916. Keithia thujina, the cause of serious leaf disease of western redcedar. Phytopathology 6: 361-363. 


\title{
Influence of Soil Fumigation and Fungicide Application on Outplanted Ponderosa Pine Seedlings ${ }^{1}$
}

\author{
D.S. Page-Dumroese and A.E. Harvey ${ }^{2}$
}

Abstract - Ponderosa pine (Pinus ponderosa Laws.) was used as a model to determine the effects of soil fumigation and fungicide applications on outplanted stock in moderately-fertile soils of the Intermountain West, U.S.A. Five soil fumigation treatments (Vapam), singularly and in combination with fungicide (triadimefon) applications, were compared to a control. Growth characteristics, nutrition, and ectomycorrhizal colonization were evaluated. Seedling height growth at the end of the fourth growing season was best after spring fumigation. Greatest ectomycorrhizal colonization occurred in the nonfumigated treatment with fungicide applied before planting. Generally, spring or fall soil fumigation treatment, without fungicide applications, produced seedlings with the best growth. These results suggest that soil fumigation applications could improve early performance of ponderosa pine when reforesting sites with abundant, native inoculum. Ponderosa pine planted on moisture or nutrient limited sites, with adequate ectomycorrhizal inoculum, may benefit from elimination of ectomycorrhizae in the nursery.

\section{INTRODUCTION}

Ponderosa pine (Pinus ponderosa Laws.) is an important regeneration species on dry sites in the western U.S.A. (Linhart, 1988). Rapid achievement of full stocking following harvesting is usually a primary objective for managing ponderosa pine, but frequently is difficult to obtain. Most regeneration failures in this region result from long periods of evaporative demand, low soil moisture (Curtis and Lynch, 1957), root disease (Johnson and Zak, 1977), and poor ectomycorrhizal colonization (Harvey et al., 1992). Competition from invading or residual plants after harvest can further reduce amounts of water and nutrients available to conifer regeneration (Miller, 1987; Stewart, 1974). Nonconifer vegetation that competes with tree crops for moisture can increase the risk of regeneration failure and reduce growth of established stands (Boyd, 1985).

On sites with severe competition, common site preparation practices may not be adequate to reduce invading herbaceous species. These sites often must be replanted several times before stocking is adequate for stand development (Coffman, 1982). Alternative methods to reduce seedling mortality and/or increase growth during early years may give foresters valuable options in treating and regenerating such sites. Options could include soil fumigation before planting and/or seedling treatment with fungicides before planting.

\footnotetext{
'Page-Dumroese, D.S.; Harvey, A.E. 1994. Influence of Soil Fumigation and Fungicide Application on Outplanted Ponderosa Pine Seedlings. IN: Landis, T.D.; Dumroese, R.K., tech. coords. National Proceedings, Forest and Conservation Nursery Associations. Gen. Tech. Rep. RM-257. Fort Collins, CO: U.S. Department of Agriculture, Forest Service, Rocky Mountain Forest and Range Experiment Station: 203-213.
}

${ }^{2}$ USDA Forest Service, 1221 South Main Street, Moscow, ID 83843. 
In the western U.S.A., Vapam (sodium-N-methyl-dithiocarbamate) is sometimes used as a soil fumigant. Vapam is amenable for use in field situations since it does not require that the soil be covered with plastic after treatment. Vapam is less volatile than other fumigants, such as methyl bromide. If the soil is moist, tarping is not necessary. While results were preliminary (first year) fumigation with Vapam produced Douglas-fir (Pseudotsuga menziesii var. glauca [Beissn.] Franco) and white pine (Pinus monticola Dougl. ex. D.Don) seedlings with increased root growth and total weight as compared to seedlings planted in non-fumigated soil (Cornwall, 1985; Rainville, 1987). However, changes in plant nutrition or ectomycorrhizal function were not measured.

Soil fumigation has been shown to raise levels of available soil nitrogen $(\mathrm{N})$ and phosphorus (P) and to increase nutrient uptake by seedlings (Benzian, 1965). The relationship of soil nutrient availability to plant uptake following fumigation is unclear, since addition of fertilizer does not give similar growth gains (Rovira and Simon, 1985; Bengtson and Smart, 1981; Rovira, 1976). However, increased availability of $\mathrm{N}$ and $\mathrm{P}$ may be due to loss of viability of microorganisms that tie up nutrients as well as increased nutrient levels from the dead organisms (Alexander, 1977). Soil organic matter content, cation exchange capacity, ectomycorrhizal colonization, and $\mathrm{pH}$ can all be affected by fumigation treatments (Sandler et al., 1988). Many fumigation studies in greenhouses and forest nurseries have shown increased numbers of ectomycorrhizal short roots, increased nutrient uptake (Henderson and Stone, 1970; Marx et al., 1978; Snyder and Davey, 1986) and increased water uptake (Menge, 1982; Zak 1964).

Fumigation also changes the microbial equilibrium of the soil. Parr (1968) suggested the pattern or sequence of reestablishment of fungi in fumigated soil varies considerably and depends on soil chemical and physical properties, as well as on the fumigant itself. In general, microbial numbers decrease after fumigation, but certain species quickly reinhabit the soil, and shortly after treatment overall numbers are usually in excess of untreated controls (Martin and Pratt 1958). Fumigation alters microbe species in favor of fungi normally suppressed by Aspergilli and Penicillia. Actinomycetes have a greater tolerance for fumigation than either fungi or bacteria (Wensley, 1953). One principal recolonizing group in fumigated surface soils is Trichoderma spp. (Danielson and Davey 1969). The antagonism of Trichoderma to certain detrimental fungi may improve growth of outplanted seedlings. For example, Trichoderma viride is antagonistic to Phytophtora, Pythium, Armillaria, Rhizoctonia, and other parasitic fungi (Garrett, 1956; Wright, 1956; Weindling, 1938).

Broad-spectrum fumigants like Vapam have been shown to inhibit the growth of ectomycorrhizal fungi in forest nurseries (Johnson and Zak, 1977; Hacskaylo and Palmer, 1957; Trappe and Strand, 1969). Some fungicides may be more selective than broad-spectrum fumigants. They are generally believed to be less harmful to ectomycorrhizal fungi (Marx and Barnett, 1974). Application of triadimefon, 1-(4chlorophenoxy)-3,3-dimethyl-1(1H-1,2,4-triazol-1-yl)-2butanone (Bayleton ${ }^{\circledR}$ ), a systemic fungicide, does not inhibit short root development (South and Kelley, 1982). In fact, Kelley (1987) noted that after 1 year, greenhouse-grown loblolly pine (Pinus taeda L.) seedlings treated with triadimefon had significantly more ectomycorrhizal short roots that control seedlings. Survival and growth of seedlings treated with triadimefon were similar to control seedlings after outplanting into plantations (Rowan and Kelley, 1986). Twoyear-old loblolly pine seedlings had a similar response (Marx, 1987). These greenhouse studies differ from field nursery tests. Marx et al. (1986) noted that 
growth of loblolly pine in South Carolina was inhibited by the application of triadimefon.

Increases in growth that continue even after competing vegetation has reoccupied the site indicate a basic change in soil/tree root biology. Applying triadimefon in the nursery may encourage faster seedling root colonization by native ectomycorrhizal symbionts after outplanting in a forest site.

Field studies, using planting spot methyl bromide soil fumigation in the western U.S.A., have shown a doubling of survival and growth of outplanted Douglas-fir and ponderosa pine on dry sites in eastern Washington (Klock, 1980). Fumigant-induced changes in soil biology may affect disease resistance, soil nutrient availability, or ectomycorrhizal development (Bengtson and Smart, 1981; Klock, 1980).

This paper examines the impact of planting-site fumigation with Vapam and fungicide application (triadimefon) on ponderosa pine. It considers ectomycorrhizal colonization, seedling growth and nutrition, and soil $\mathrm{N}$ transformations in a moderately fertile, forested environment with high levels of native ectomycorrhizal inoculum.

\section{METHODS AND MATERIALS}

\section{Site Description}

The study was located on the Priest River Experimental Forest $19 \mathrm{~km} \mathrm{~N}$ of Priest River, ID, U.S.A. at an elevation of 1550 $\mathrm{m}$. The previous stand, which consisted of western white pine, Douglas-fir, lodgepole pine (Pinus contorta Dougl. ex Loud.), and western larch (Larix occidentalis Nutt.), was cleared in 1985 and the soil rototilled to a depth of $30 \mathrm{~cm}$. The soil is a coarse loamy, mixed, frigid Typic Xerochrept (Soil Survey Staff, 1975). Mean annual average precipitation and temperature is $84 \mathrm{~cm}$ and $6.6^{\circ} \mathrm{C}$, respectively.

\section{Study Design}

A randomized complete block design was established on this site in 1988, with three replications of five treatments and an untreated control. Treatments consisted of:

(1) spring soil fumigation with Vapam,

(2) fall soil fumigation with Vapam,

(3) fall soil fumigation with Vapam and triadimefon applied to seedlings in the greenhouse before outplanting,

(4) fall soil fumigation with Vapam and triadimefon applied to seedlings in the greenhouse before outplanting, plus 4 additional times during the first growing season,

(5) no soil fumigation and triadimefon applied to seedlings in the greenhouse before outplanting.

Seedlings treated with fungicide before planting had triadimefon applied 3 times at 2week intervals, while actively growing in the greenhouse. The concentration was $1.8 \mathrm{mg}$ active ingredient/seedling mixed with a surfactant (Marx, 1987). Plots were $30 \mathrm{~m} * 30 \mathrm{~m}$ in size with a $1 \mathrm{~m}$ buffer.

\section{Soil Treatment Application}

Fall and spring soil fumigations were achieved by applying $450 \mathrm{ml} / \mathrm{m}^{2}$ Vapam after the soil had been soaked to a depth of 30 $\mathrm{cm}$ by rain. Treated areas were water-sealed to move the Vapam into the soil. Fall fumigation plots were treated the second week of October (1988) and the soil covered with black plastic until 4 weeks before spring planting. Spring fumigation plots were treated with Vapam, at the same rate as the fall fumigation treatments, approximately 6 weeks before planting (1989). The plots were covered with black plastic for 2 weeks, then uncovered for 4 weeks prior to planting to allow dissipation of the fumigant. Plots were tested for remaining fumigant by planting highly sensitive tomato 
plants as an indicator 1 week

before seedlings were

outplanted. Plots were then

planted with 1-year-old con-

tainer-grown ponderosa pine

seedlings on a 1-by-1 m spacing.

\section{Seedling Sampling and \\ Measurements}

Before outplanting, 5 seedling root systems from each treatment were examined for

ectomycorrhizal root tips. Active ectomycorrhizal root tips com-

prised approximately 10 percent of the root system, except the triadimefon treated seedlings which had no active ectomycorrhizal root tips. Monthly during the first and second growing seasons, 5 seedlings from each treatment and replication were carefully excavated. Top height, rooting depth, and root-collar diameter were measured. Tops of seedlings were severed from the roots, dried at $60^{\circ} \mathrm{C}$ for $24 \mathrm{~h}$, weighed, and ground to pass a 20-mesh sieve. Entire seedling tops were analyzed for total $\mathrm{N}$ and $\mathrm{P}$ by Kjeldahl digestion methods using the salicylic acidsodium thiosulfate modification (Bremner and Mulvaney, 1982). They were analyzed on an Alpkem Rapid Flow Analyzer. Calcium (Ca) and magnesium (Mg) were analyzed by atomic absorption spectroscopy, potassium $(K)$ was analyzed by flame emission after samples had been dry ashed at $450^{\circ} \mathrm{C}$ and leached with $2 \mathrm{~N} \mathrm{HNO}_{3}$. After seedling roots were washed, total ectomycorrhizal tips counted with a $20 x$ binocular microscope. Roots were then dried at $60^{\circ} \mathrm{C}$ for $24 \mathrm{~h}$ and weighed.

\section{Soil Sampling and Analysis}

Five $20 \mathrm{~g}$ random soil core samples were collected in each treatment $1 \mathrm{~d}$ before fumigation, and 14 and $45 \mathrm{~d}$ after fumigation. They were sieved to pass a $2 \mathrm{~mm}$ sieve. Control soil samples were collected at the same time as the fall fumigation samples. Ammonium-nitrogen $\left(\mathrm{NH}_{4}-\mathrm{N}\right)$ and nitrate-nitrogen $\left(\mathrm{NO}_{3}-\mathrm{N}\right)$ were analyzed on undried samples in a $1 \mathrm{~N} \mathrm{KCl}$ extract using and Alpkem Rapid Flow Analyzer (Keeney and Nelson, 1982).

\section{Statistical Analysis}

The significance of difference among treatments was tested using a one-way analysis of variance (ANOVA) for a randomized complete block design followed by Scheffe's multiple range test (Scheffe, 1953). A type I error rate of 0.05 was applied.

\section{RESULTS AND DISCUSSION}

\section{Seedling growth characteristics}

After the first growing season, height growth was greatest in the fumigation only treatments, and least in the fall fumigation treatment with continuous triadimefon application (Table 1). Rooting depth was unaffected by these treatments (data not shown). Root-collar diameter was greatest in the fumigation only treatments. Second-year seedling growth was similar to the first year. Seedlings growing in the fumigated treatments had greater height growth, root-collar diameter, and biomass than the other treatments, but, also as with the first-year, the differences were not always significant. By the end of the fourth growing season, seedlings growing in the spring fumigation plots had significantly greater height than those in any other treatments (Table 2).

Spring fumigation before outplanting provided the environment for improved seedling growth. In Vapam treated soil, Trichoderma viride and Penicillium sp. are the dominant recolonizers (Singha, et al., 1979; Corden and Young, 1965). These fungi may act as antagonists against potential pathogens. Fall fumigation may allow recolonization of all species of microbes in the rooting zone before seedling outplanting the following spring. Other investigators have also noted striking increases in seedling height and biomass in fumigated soil, compared to controls that were not fumigated (James et al., 1990; Rainville, 1987; Cornwall, 1985; Klock, 1980; Henderson and Stone, 1970). 
Table 1. Growth characteristics of ponderosa pine as affected by site treatment.

\begin{tabular}{|c|c|c|c|c|c|c|}
\hline \multirow[t]{2}{*}{ TREATMENT } & \multicolumn{3}{|c|}{ Year 1} & \multicolumn{3}{|c|}{ Year 2} \\
\hline & $\begin{array}{l}\text { Height } \\
-\mathrm{cm}-\end{array}$ & $\begin{array}{l}\text { Caliper } \\
-\mathrm{mm} \text { - }\end{array}$ & $\begin{array}{l}\text { Biomass } \\
-\mathrm{g} \text { - }\end{array}$ & $\begin{array}{l}\text { Height } \\
-\mathrm{cm}-\end{array}$ & $\begin{array}{l}\text { Caliper } \\
-\mathrm{mm} \text { - }\end{array}$ & $\begin{array}{l}\text { Biomass } \\
-\mathrm{g} \text { - }\end{array}$ \\
\hline Spring fumigation & $18.1 a^{8}$ & $4.7 a b$ & $6.0 \mathrm{ab}$ & $36.1 \mathrm{a}$ & $12.7 a$ & $49.9 a$ \\
\hline Fall fumigation & $18.1 \mathrm{a}$ & $5.2 a$ & $6.1 \mathrm{a}$ & $33.5 a b$ & $11.9 a$ & $45.7 a b$ \\
\hline Fall fumigation and triadimefon & $17.6 \mathrm{ab}$ & $4.5 a b c$ & $6.2 \mathrm{a}$ & $32.3 b$ & $11.7 \mathrm{a}$ & $41.4 a b$ \\
\hline $\begin{array}{l}\text { Fall fumigation and } \\
\text { continuous triadimefon }{ }^{A}\end{array}$ & $16.8 b$ & $4.6 a b$ & $5.7 a b$ & $32.7 a b$ & $11.8 \mathrm{a}$ & $42.1 \mathrm{ab}$ \\
\hline No fumigation and triadimefon & $17.4 a b$ & $3.8 \mathrm{c}$ & $5.1 \mathrm{~b}$ & $30.8 b$ & $10.0 \mathrm{~b}$ & $34.9 b$ \\
\hline Control & $17.6 \mathrm{ab}$ & $4.4 b c$ & $5.2 b$ & $33.2 \mathrm{ab}$ & $11.8 \mathrm{a}$ & $42.9 \mathrm{~b}$ \\
\hline
\end{tabular}

${ }^{A}$ Continuous triadimefon during year 1 only.

${ }^{8}$ Different letters indicate significant differences $(P \leq 0.05)$ among treatments.

The lack of many significant differences between treatments and controls during the first growing season may be due to outplanting containerized nursery stock with pre-set buds and a high nutrient status (Kozlowski et al., 1973). Although no biomass measurements of herbaceous competition were taken, visual assessment indicated the fumigated plots has substantially less competition than plots that were not fumigated. This may also contribute to growth differences.

By the end of the second year, seedlings that had triadimefon applied, either before planting or continuously, had reduced height growth, root-collar diameter and total biomass compared to the fumigation only treatments. Marx (1987) and Rowan and Kelley (1986) found no significant effects of triadimefon on first-year growth of nurserygrown bareroot loblolly or slash pine (Pinus elliottii Engelm.) seedlings compared to control seedlings. However, Davis (1991) found that triadimefon can act as a potent inhibitor of shoot growth with effects persisting for several years.

Table 2. Height of 4-year-old ponderosa pine seedlings as affected by site treatment.

\begin{tabular}{ll} 
TREATMENT & $\begin{array}{l}\text { Height } \\
-\mathrm{cm}-\end{array}$ \\
\hline Spring fumigation & $\begin{array}{l}74.8 \mathrm{a}^{\mathrm{B}} \\
68.5 \mathrm{~b}\end{array}$ \\
Fall fumigation & $68.5 \mathrm{~b}$ \\
Fall fumigation and triadimefon & $64.9 \mathrm{~b}$ \\
Fall fumigation and continuous triadimefon ${ }^{\mathrm{A}}$ & $60.6 \mathrm{c}$ \\
No fumigation and triadimefon & \\
& $68.1 \mathrm{~b}$ \\
Control & \\
& \\
\hline & \\
&
\end{tabular}

Ectomycorrhizae colonization

There were no significant treatment differences during the first year in total ectomycorrhizal root tips (Table 3). This is consistent with results from the southeastern U.S.A. where increasing rates of triadimefon 


\begin{tabular}{|c|c|c|c|c|}
\hline \multirow[t]{2}{*}{ TREATMENT } & \multicolumn{2}{|c|}{ Year 1} & \multicolumn{2}{|c|}{ Year 2} \\
\hline & $\begin{array}{l}\text { Total } \\
\text { Tips }\end{array}$ & $\begin{array}{l}\text { Tips } / g \\
\text { dry root }\end{array}$ & $\begin{array}{l}\text { Total } \\
\text { Tips }\end{array}$ & $\begin{array}{l}\text { Tips/g } \\
\text { dry root }\end{array}$ \\
\hline Spring fumigation & $30 a^{B}$ & $15 b$ & $32 \mathrm{~b}$ & $3 a$ \\
\hline Fall fumigation & $28 \mathrm{a}$ & $13 b$ & $42 a b$ & $8 a$ \\
\hline Fall fumigation and triadimefon & $31 \mathrm{a}$ & $20 \mathrm{~b}$ & $39 a b$ & $4 a$ \\
\hline Fall fumigation and continuous triadimefon ${ }^{A}$ & $24 a$ & $10 \mathrm{~b}$ & $59 a$ & $8 a$ \\
\hline No fumigation and triadimefon & $49 a$ & $36 a$ & $62 a$ & $9 a$ \\
\hline Control & $32 \mathrm{a}$ & $22 a b$ & $42 a b$ & $5 a$ \\
\hline
\end{tabular}

${ }^{A}$ Continuous triadimefon during year 1 only.

${ }^{\mathrm{B}}$ Different letters indicate significant differences $(P \leq 0.05)$ among treatments.

did not alter first year ectomycorrhizal colonization of feeder roots (Kelley, 1987). However, ectomycor-rhizal root tips per gram of dry roots were significantly greater in the no fumigation, before planting triadimefon application treatment compared to the others. This is probably related to slightly greater number of total ectomycorrhizal tips on these seedlings. In this study, fumigation alone did not improve ectomycorrhizal colonization of ponderosa pine.

By the end of the second growing season, ectomycorrhizal colonization was greatest in the fall fumigation treatment that had triadimefon applied continuously during the first growing season and the no fumigation treatments with triadimefon applied before planting. Fall fumigation alone and fall fumigation treatments with triadimefon applied before planting were not significantly different from these treatments. Soil fumigation has been shown to reduce populations of ectomycorrhizal fungi (Johnson and Zak, 1977). Without reinoculation of seedling root systems, or ample native ectomycorrhizae present, colonization can be slow (Henderson and Stone 1970). In this study, fall fumigation likely allowed mycorrhizal inoculum to recover before planting.

Triadimefon may rid seedlings of non-site-specific ectomycorrhizae early in the first growing season and allow sitespecific ectomycorrhizae to colonize roots vigorously (Harvey et al., 1991; PageDumroese et al., 1990). It ap- pears that maximum seedling growth can be achieved with a moderate number of native ectomycorrhizae.

\section{Seedling nutrition}

Seedling nutrient concentrations did not always correspond to seedling growth characteristics. After the first growing season, seedling $\mathrm{K}$ concentration among treatments was unchanged (Table 4). In the fall fumigation treatment with triadimefon applied before planting, $\mathrm{Mg}$ concentrations were greatest compared to most other treatments, except the no fumigation triadimefon treatment before planting. Results were similar for $\mathrm{Ca}$. Greater concentrations of $\mathrm{Ca}$ and $\mathrm{Mg}$ in triadimefon-treated seedlings may be caused by residual triadimefon and its metabolite triadimenol in the needles. After 
Table 4. Nutrient concentrations of ponderosa pine foliage and stems as affected by site treaiment.

TREATMENT

Spring fumigation

Fall fumigation

Fall fumigation and triadimefon

Fall fumigation and continuous triadimefon ${ }^{A}$

No fumigation and triadimefon

Control

\begin{tabular}{|c|c|c|c|c|c|c|c|c|c|}
\hline \multicolumn{5}{|c|}{ Year i } & \multicolumn{5}{|c|}{ Year 2} \\
\hline $\begin{array}{l}\text { Total N } \\
-- \text { perce }\end{array}$ & $\begin{array}{l}\text { Total P } \\
\text { nt -- }\end{array}$ & $\mathrm{Ca}$ & $\begin{array}{c}\mathrm{Mg} \\
\mathrm{g} / \mathrm{kg}\end{array}$ & $\mathrm{K}$ & $\begin{array}{l}\text { Total N } \\
\text {-- perce }\end{array}$ & $\begin{array}{l}\text { Total P } \\
\text { nt -. }\end{array}$ & $\mathrm{Ca}$ & $\begin{array}{l}\mathrm{Mg} \\
\mathrm{g} / \mathrm{kg}\end{array}$ & $\mathrm{K}$ \\
\hline $0.79 a^{B}$ & $0.10 \mathrm{ab}$ & $2168 a$ & $894 b$ & $5464 a$ & $1.78 \mathrm{a}$ & $0.35 a$ & $1863 c$ & $813 a$ & $5757 a$ \\
\hline $0.81 a$ & $0.10 \mathrm{ab}$ & $2325 a b$ & $905 b$ & $5076 a$ & $1.73 a$ & $0.45 a$ & $1982 b c$ & $823 a$ & $5279 a$ \\
\hline $0.76 \mathrm{ab}$ & $0.09 b$ & $2565 a$ & $1145 a$ & $4937 a$ & $1.72 a$ & $0.36 a$ & $2042 b c$ & $848 a$ & $5416 a$ \\
\hline $0.78 \mathrm{ab}$ & $0.10 a b$ & $2124 b$ & $884 b$ & $5386 a$ & $1.55 b$ & $0.36 a$ & $2241 a$ & $849 a$ & $5528 a$ \\
\hline $0.69 b$ & $0.10 a b$ & $2358 a b$ & $982 a b$ & $5009 a$ & $1.68 \mathrm{ab}$ & $0.37 a$ & $2153 a b$ & $809 b$ & $5484 a$ \\
\hline $0.76 \mathrm{ab}$ & $0.11 a$ & $2045 b$ & $859 b$ & $5146 a$ & $1.77 \mathrm{a}$ & $0.39 a$ & $2021 b c$ & $836 a$ & $5694 a$ \\
\hline
\end{tabular}

${ }^{A}$ Continuous triadimefon during year 1 only.

${ }^{B}$ Different letters indicate significant differences $(P \leq 0.05)$ among treatments.

foliar application of triadimefon, it remains in the sprayed portion of the plant and is usually not redistributed through it, but may move to the leaf margins

(Davidse and DeWaard, 1984). Triadimefon has been shown to reduce transpiration and produce thicker, darker leaves on many plants (Fletcher and Nath, 1984).

Although significant differences in seedling total $\mathrm{P}$ were found during the first-growing season, the actual values differed by very little. By the end of the second year, differences were no longer significant. Because endemic ectomycorrhizae were likely eliminated from the fumigation plots, we expected seedling $\mathrm{P}$ to be depressed (Henderson and Stone, 1970). Apparently, in this soil type, $\mathrm{P}$ was available in sufficient quantity for normal seedling uptake.

Total seedling $\mathrm{N}$ was greatest in the two fumigation-only treatments. During the second- year, fall fumigation treatments with triadimefon applied before planting had the lowest total $\mathrm{N}$ values. This may be due to the plant growth-regulating properties of triadimefon. Wang et al. (1986) reported that triadimefon applications increased the $\mathrm{N}$ nutrition of applied seedlings. However, most differences associated with triadimefon applications have been caused by variations in application rates and frequencies and by variations in environmental conditions.

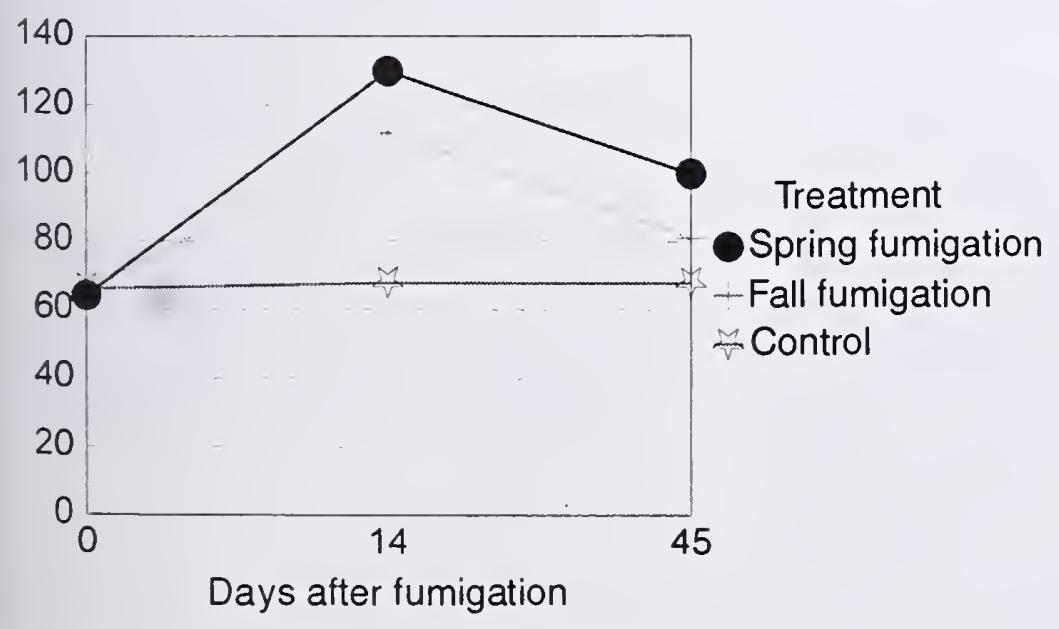

Figure 1. Effect of soil fumigation with Vapam on ammonium-nitrogen levels $(\mathrm{mg} / \mathrm{kg})$.

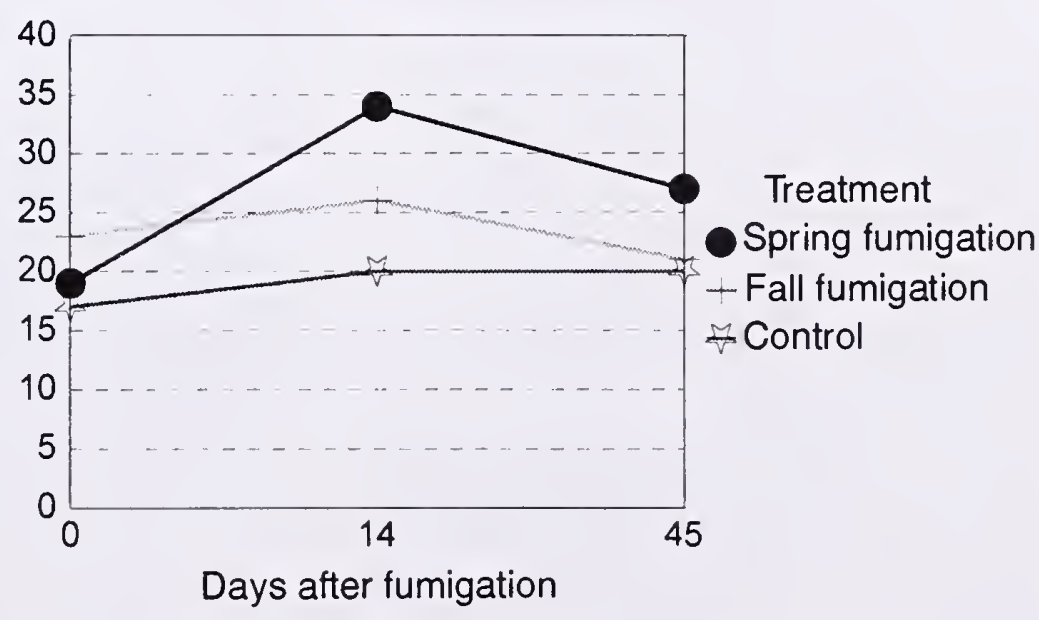

Figure 2. Effect of soil fumigation with Vapam on nitrate-nitrogen levels $(\mathrm{mg} / \mathrm{kg})$. 
Soil $N$ transformations

Although there was an immediate increase in ammonium-N in fumigated soils, levels had dropped off to before fumigation levels by $45 \mathrm{~d}$ after treatment (Fig. 1). Spring fumigation was the only treatment with significantly higher ammonium at planting time. Higher concentrations in the spring fumigation treatment may be attributed to warm soil temperatures immediately after fumigation. The short elapsed time between fumigation and planting in this treatment likely allowed seedlings to capitalize on $\mathrm{N}$ releases. This may have contributed to improved seedling growth in this treatment. Similar results are reported elsewhere (Singha et al., 1979; Munnecke and Ferguson, 1960).

Soil nitrate-N levels followed the same trend as ammonium-N, with the spring fumigation treatment having the highest concentration at planting time (Fig. 2). Other studies have shown that fumigation had a strong, initial effect of depressing nitrification (Singha et al., 1979; Munnecke and Ferguson, 1960). This was apparently not the case here. The toxic effect of Vapam on nitrifiers has been attributed to the highly toxic compound methyl isothiocyanate. Since fumigation rates were relatively low and Vapam was watered into the soil after application, toxicity may have been reduced for this study.

\section{REFERENCES}

Fumigation offers an effective way to rid a site of competition by controlling both vegetation and microorganisms in the rooting zone. This treatment alone may provide an environment for enhanced regeneration performance. Spring fumigation provides the greatest opportunity for improving ponderosa pine seedling growth after outplanting, however fall fumigation was also fairly successful. Fall fumigation may be more effective if seedlings are planted 4 to 6 weeks after fumigation, depending on timing and weather, instead of the following spring. Initial growth increases from fumigation, particularly if conducted in the spring just before planting, appear to last well beyond the first growing season. Eliminating ectomycorrhizae before planting, or during the first growing season, enhanced second year colonization, but seedling growth was not improved over moderate colonization levels. Use of triadimefon to eliminate nursery produced ectomycorrhizae may only be useful if rapid colonization by native ectomycorrhizae is assured by abundant, native inoculum and required for seedling survival.
Alexander, M. 1977. Introduction to soil microbiology. John Wiley and Sons, Inc. New York.

Bengtson, G. W. and Smart, G. C., Jr. 1981. Slash pine growth and response to fertilizer after application of pesticides to the planting site. For. Sci. 27: 487-502.

Boyd, R. J. 1985. Conifer performance following weed control site preparation treatments in the Inland Northwest. In: Weed control for forest productivity in the Interior West. Eds. D. M.

Baumgartner, et. al. 1985. Feb. 5-7. Washington State University. Spokane, WA. pp. 95-110.

Bremner, J. M. and Mulvaney, C. S. 1982. Nitrogen-total. In: Methods of Soil Analysis. Part 2. Agronomy. 9: 595-624.

Coffman, M. S. 1982. Regeneration prescriptions: the need to be holistic. In: Artificial regeneration of conifers in the Upper Great Lakes Region. Eds. G. D. Mroz and J. F. Berner. 1982 October 26-28. Michigan Technological University. Houghton, MI. pp. 190-208. 
Corden, M. E. and Young, R. A. 1965. Changes in the soil microflora following fungicide treatments. Soil Sci. 99: 272-277.

Cornwall, B. J. 1985. Effects of Vapam on growth and rhizoplane microflora of western white pine and Douglas-fir seedlings in mounded forest soils. Master of Science Thesis. University of Idaho, Moscow. 32 p.

Curtis, J. D. and Lynch, D. W. 1957. Silvics of ponderosa pine. Misc. pub. U. S. Department of Agriculture, Intermountain Forest and Range Experiment Station. Ogden, UT. 37 p.

Danielson, R. M. and Davey, C. B. 1969. Microbial recolonization of a fumigated nursery soil. For. Sci. 15: 368380.

Davidse, L. C. and DeWaard, M. A. 1984. Systemic fungicides. In: Advances in plant pathology. Eds. D. S. Ingram and P. H. Williams. Volume 2. Academic Press. pp. 191-257.

Davis, T. D. 1991. Regulation of tree growth and development with triazole compounds. J. Arboriculture. 17: 167-170.
Fletcher, R. A. and Nath, V. 1984. Triadimefon reduces transpiration and increases yield in water-stressed plants. Physiol. Plant. 62: 422-426.

Garrett, S. D. 1956. Ecology of root-inhabiting fungi. Cambridge Univ. Press. Cambridge, England.

Hacskaylo, E. and Palmer, J. G. 1957. Effect of several biocides on growth and incidence of mycorrhizae in field plots. Plant Dis. Rep. 41: 354-358.

Harvey, A. E., Page-Dumroese, D. S., Graham, R. T. and Jurgensen, M. F. 1991. Ectomycorrhizal activity and conifer growth interactions in western-montane forest soils. In: Proceedings-management and productivity of westernmontane forest soils. Comps. A. E. Harvey and L. F. Neuenschwander. 1990 April 10-12; Boise, ID. Gen. Tech. Rep. INT-280. U. S. Department of Agriculture, Forest Service, Intermountain Research Station Ogden, UT. pp. 110-117.

Henderson, G. S. and Stone, E. L., Jr. 1970. Interactions of phosphorous availability, mycorrhizae, and soil fumigation on coniferous seedlings. Soil Sci. Soc. Am. Proc. 34: 314-318.
James, R. L., Metzger, S., and Gilligan, C. J. 1990. Effects of soil fumigation on conifer seedling production at the USDA Forest Service Nursery, Coeur D'Alene, Idaho. Rep. 90-11. Missoula, MT: U.S. Department of Agriculture, Forest Service, Northern Region. Missoula, MT. 18 p.

Johnson, D. W. and Zak, B. 1977. Effects of soil treatments on fungal populations and ponderosa pine seedling survival in an Oregon nursery. Plant Dis. Rep. 6: 43-47.

Keeney, D. R. and Nelson, D. W. 1982. Nitrogen-inorganic forms. In: Methods of soil analysis. Part 2. Agronomy. 9: 643-693.

Kelley, W. D. 1987. Effect of triadimefon on development of mycorrhizae from natural inoculum in loblolly pine nursery beds. South. J. Appl. For. 8: 51-54.

Klock, G. O. 1980. Preplant soil fumigant increases survival and growth of field planted conifer seedlings. For. Sci. 26: 400-402.

Kozlowski, T. T., Torrie, J. H., and Marshall, P. E. 1973. Predictability of shoot length from bud size in Pinus resinosa (Ait). Can. J. For. Res. 3: 34-38. 
Linhart, Y. B. 1988. Ecological and evolutionary studies of ponderosa pine in the Rocky Mountains. In: Ponderosa pine, the species and its management. Eds. D. M. Baumgartner, et. al. 1987. Sept 29-Oct. 1; Spokane, WA. Washington State University Extension Service. Pullman, WA. pp. 77-91.

Martin, J. P. and Pratt, P. F. 1958. Fumigants, fungicide, and the soil. Agricultural and Food Chemistry. 6: 345-348.

Marx. D. H. and Barnett. J. P. 1974. Mycorrhizae and containerized forest tree seedlings. In: Proceedings, North American containerized tree seedling symposium. Great Plains Agricultural Council. Pub. No. 68. Denver, CO. pp. 85-92.

Marx, D. H., Morris, W. G., and Mexal, J. G. 1978. Growth and ectomycorrhizal development of loblolly pine seedlings in fumigated and nonfumigated nursery soil infested with different fungal symbionts. For. Sci. 24: 193203.
Marx, D. H. 1987. Triadimefon and Pisolithus ectomycorrhizae affect second-year field performance of loblolly pine. Res. Note SE-349. U. S. Department of Agriculture, Forest Service, Southeastern Forest Experiment Station. Asheville, NC 6 p.

Menge, J. A. 1982. Effect of soil fumigants and fungicides on vesicular-arbuscular fungi. Phytopath. 72: 1125-1132.

Miller. D. L. 1987. The influence of competing vegetation in ponderosa pine forests. In: Ponderosa pine, the species and its management. Eds. D. M. Baumgartner, et. al. 1987. Sept 29-Oct. 1; Spokane, WA. Washington State University Extension Service. Pullman, WA. pp. 115-120.

Munnecke, D. E. and Ferguson, J. 1960. Effect of soil fungicides upon soil-borne plant pathogenic bacteria and soil nitrogen. Plant Dis. Rep. 44: 552-555.

Page-Dumroese, D. S., Loewenstein, H., Graham, R. T., and Harvey, A. E. 1990. Soil source, seed source, and organic-matter content effects on Douglas-fir seedling growth. Soil Sci. Soc. Am. 54: 229-233.
Parr, J. F. 1968. The soil microbiological equilibrium: nature and duration of changes induced by cultural practices: In: Forest fertilization-theory and practice. TVA. Muscle Shoals, AL. p. 28-37.

Rainville, S. G. 1987. Effect of microsite preparation on the development of conifer seedlings in northern Idaho. Master of Science Thesis. University of Idaho, Moscow.

Rovira, A. D. 1976. Studies on soil fumigation. I. Effects on ammonium, nitrate, and phosphate in soil and on the growth, nutrition, and yield of wheat. Soil Biol. Biochem. 8: 241-247.

Rovira, A. D. and Simon, A. 1985. Growth, nutrition, and yield of wheat in calcareous sandy loams of South Australia: effects of soil fumigation, fungicide, nematicide, and nitrogen fertilizers. Soil Biol. Biochem. 17: 279-284.

Rowan, S. J. and Kelley, W. D. 1986. Survival and growth of outplanted pine seedlings after mycorrhizae were inhibited by use of triadimefon in the nursery. South. J. Appl. For. 10: 21-27. 
Sandler, H. A.. Carroll, R. B.. and Sparks, D. L. 1988. Effects of biocidal treatments on cation exchange capacity and Fusarium blight of soybean in Delaware soils. Agron. J. 80: 8-12.

Scheffe. H. 1953. A method for judging all contrasts in the analysis of variance.

Biometrica. 53: 347-358.

Singha. A. P.. Agnihotri, V. P., and Singh. K. 1979. Effect of soil fumigation with Vapam on the dynamics of soil microflora and their related biochemical activity. Plant and Soil 53: 89-98.

Snyder. C. S., and Davey, C. B. 1986. Sweetgum seedling growth and vesiculararbuscular mycorrhizal development as affected by soil fumigation. Soil Sci. Soc. Am. J. 50: 1047-1051.

Soil Survey Staff. 1975. Soil taxonomy. Agric. Handbook 436. U.S. Department of Agriculture, Washington, D. C.

South. D. B., and Kelley. W. D. 1982. The effect of selected pesticides on short-root development of greenhousegrown Pinus taeda seedlings. Can. J. For. Res. 12: 29-35.
Stewart, R. E. 1974. Foliage sprays for site preparation and release from six coastal brush species. U. S. Department of Agriculture, Forest Service, Pacific Northwest Forest and Range Experiment Station. Portland. OR. 20 p.

Trappe. J. M. and Strand, R. F. 1969. Mycorrhizal deficiency in a Douglas-fir region nursery. For. Sci. 15: 381-389.

Wang. S. Y., Steffens, G. L., and Faust, M. 1986. Effect of paclobutrazol on accumulation of carbohydrates in apple wood. Hort. Sci. 21: 14191421.

Weindling, R. 1938. Association effects of fungi. Chronica Botanica. Waltham, MA.

Wensley, R. N. 1953. Microbiological studies of the action of some selected soil fumigants. Can. J. Bot. 31: 277-308.

Wright, J. M. 1956. Biological control of a soil with Pythium infection by seed inoculation. Plant and Soil. 8: 132-140.

Zak. B. 1964. Fate of mycorrhizae in root disease. Ann. Rev. Phytopath. 2: 377-392. 


\title{
Abscisic Acid Analogs Reduce Planting Stress in Newly Planted Seedlings ${ }^{1}$
}

\author{
Steven C. Grossinickle and Raymund S. Folk ${ }^{2}$
}

Abstract-A research program examined whether specific abscisic acid (ABA) analogs could maintain good water balance of interior spruce seedlings under environmentally stressful conditions, through partial stomatal closure. In addition, the influence of ABA analogs on root growth under optimum conditions was monitored. ABA analogs allowed seedlings to maintain good seedling water balance for extended periods of time, under moderate and severe drought conditions, through greater stomatal closure. ABA analogs caused partial stomatal closure for periods of up to two weeks. Seedlings treated with $A B A$ analogs had the capability to grow an extensive number of new roots, when tested under optimum environment.

\section{INTRODUCTION}

Plants require a continuous movement of water from absorbing roots to transpiring leaves to ensure their survival. The capability of a plant to take up water is influenced by available soil water, root system size and distribution, root-soil contact, and root hydraulic conductivity. Transpiration rates are determined by the degree of stomatal opening (i.e., stomatal conductance), needle area and the atmospheric demand for water (i.e., vapor pressure deficit). A plant will be exposed to water stress if transpirational demands exceed their capability to take up water.
Seedlings can be exposed to water stress shortly after being planted on a reforestation site. This occurs because most reforestation sites can have extreme environmental conditions which alter the sites heat exchange processes and soil water relations (Miller 1983). In addition, newly planted seedlings will have root confinement, poor contact of roots with soil, and possibly low root system permeability which can limit water uptake from the soil (Kozlowski and Davies 1975, Burdett 1990). As a result, newly planted seedlings can be exposed to planting stress, where water loss from the shoot, through transpiration, exceeds water uptake by the root system. Planting stress will decline as seedlings start to develop a root system out into the surrounding soil, enabling them to access available soil moisture.

Abscisic acid (ABA) is a plant hormone that naturally accumulates in plants under drought stress conditions (Zeevaart and Creelman 1988). This accumulation of $\mathrm{ABA}$ initiates the closure of stomata, thereby reducing plant water use under conditions of restricted water availability (Davies and Zhang 1991). Past studies have found that exogenously applied $\mathrm{ABA}$ reduces transpiration in plants by closing stomata

\footnotetext{
'Grossnickle, S.C.; Folk, R.S. 1994. Abscisic Acid Analogs Reduce Planting Stress in Newly Planted Seedlings. IN: Landis, T.D.; Dumroese, R.K., tech. coords. National Proceedings, Forest and Conservation Nursery Associations. Gen. Tech. Rep. RM-257. Fort Collins, CO: U.S. Department of Agriculture, Forest Service, Rocky Mountain Forest and Range Experiment Station: 214-222.
} 
(Mansfield et al. 1978, Davies and Mansfield 1983). As a result, the possibility of using $\mathrm{ABA}$ to control water loss in plants has been considered an attractive nursery cultural regime.

Major limitations have existed for using $\mathrm{ABA}$ within operational forest regeneration programs. The main problems are that natural $\mathrm{ABA}$ is easily degraded in the field (i.e., a very short term effect on stomatal conductance), has poor uptake capability by some plants, and is relatively expensive to synthesize. To address these concerns, scientists at the Plant Biotechnology Institute, National Research Council of Canada, have been developing a series of $\mathrm{ABA}$ analogs. These $\mathrm{ABA}$ analogs are compounds that are chemically related to natural $\mathrm{ABA}$, are biologically active in plants and produce similar physiological responses as natural $\mathrm{ABA}$. The $\mathrm{ABA}$ analogs are chemically simpler to synthesize than natural $\mathrm{ABA}$ and slow release forms may be produced ensuring long term effectiveness. This would allow for a large scale production of a cost-effective, ABA analog-based, antitranspirant product to be developed.

A research program has been initiated with the Plant Biotechnology Institute of the National Research Council of Canada,
DowElanco Canada Ltd., the University of Victoria and the Forest Biotechnology Centre at $\mathrm{BCRI}$ to develop an $\mathrm{ABA}$ analog-based antitranspirant product. This product would help alleviate planting stress that occurs during forest regeneration programs. A research program is underway to determine whether specific ABA analogs can: 1) maintain good seedling water balance under environmentally stressful conditions, through partial stomatal closure, and 2) ensure that root growth capability is maintained under optimum conditions and possibly enhanced under environmentally stressful conditions. Preliminary results from this research program are presented in this paper.

\section{MATERIALS}

\section{Plant material}

Interior spruce (Picea glauca (Moench) Voss x Picea engelmannii Parry ex. Engelm.) seedlings were grown at Pelton Reforestation Ltd. from March through August, 1993, and placed in frozen storage on November 30, 1993. Interior spruce seedlings were a containerized (410B container) $1+0$ stocktype from a single seedlot (seedlot \#4061, Kamloops region, Lat. 51 $19^{\prime} \mathrm{N}$, Long. $\left.119^{\circ} 57^{\prime} \mathrm{W}\right)$. Testing was conducted from January through May 1994. The seedling popula- tion was morphologically screened to ensure a standard height, diameter and root form. Seedlings were removed from frozen storage, allowed to thaw over four days and then ABA analogs were applied.

\section{ABA analog treatments}

Compounds that are structurally similar to abscisic acid (ABA analogs) were produced by the Plant Biotechnology Institute, National Research Council of Canada. Two of these ABA analogs (\#1 and \#5) were applied as a spray-root drench that simulated application through a nursery irrigation system. Seedlings with intact root-soil plugs were placed in a container, and $\mathrm{ABA}$ analog treatments were applied $\left(10^{-3} \mathrm{M}\right.$ concentration in an acetone solvent @1\%) as a top drench. In addition, there were two control treatments; both a water only and acetone only@1\% (not reported). Treated seedlings were kept in the large container where the treatment flowthrough was allowed to be reabsorbed into the plugs over a two day period. This ensured that all of the treatment was taken up by the root plugs and was available to seedlings. During testing, seedlings had their root-soil plugs kept intact. This enabled the ABA treatment to be retained in close contact with the root system. 


\section{METHODS}

\section{Response under low root temperature conditions}

This study determined the needle conductance of seedlings treated with $\mathrm{ABA}$ analogs under low root temperature conditions (i.e., spring conditions). This study also determined the long term effectiveness of $\mathrm{ABA}$ analogs to maintain a reduction in needle conductance.

Needle conductance $\left(g_{w v}\right)$ of seedlings from each analog $(n=8)$ were determined with a LI-COR 6200 gas exchange system. Controlled environment conditions were $22{ }^{\circ} \mathrm{C}$ air temperature, $50 \%$ relative humidity and $16 \mathrm{~h}$ photoperiod at 400 mmol $\mathrm{m}^{-2} \mathrm{~s}^{-1}$. Seedlings were potted in a peat growing media, well watered and grown under these controlled environment conditions with root temperatures maintained at $12{ }^{\circ} \mathrm{C}$. Needle conductance was assessed six times across the 14 day measurement period.

\section{Response to long term moderate drought stress}

This study determined whether ABA analogs enable seedlings to maintain a good water balance, under moderate drought, for extended time periods. Just after ABA analog treatment application, seedlings $(n=25)$ were put through a series of drought cycles. Seedlings were planted in containers containing media of pure sand and placed in the above described controlled environment conditions. These containers were sealed to allow water loss to occur only through needle transpiration. Every four days, each container was watered with $40 \mathrm{ml}$ of water (equivalent to $40 \%$, by weight, of field capacity). This study was conducted over a 12 day period with watering taking place on days 0,4 , and 8 (three four-day cycles). On the first and fourth days of each of the 4-day drought cycles, midday shoot water potential $\left(\mathrm{Y}_{\text {min }}\right)$ readings were taken. These readings corresponded to either periods when seedlings had the maximum or minimum amount of available soil water. For each seedling, these $\mathrm{Y}_{\min }$ readings were used to determine a mean $\mathrm{Y}_{\min }$ for each drought cycle.

\section{Response to rapid severe drought stress}

This study determined how $\mathrm{ABA}$ analogs influence seedling response to severe soil drought. Just after treatment application, seedlings $(\mathrm{n}=25)$ were put through a rapid drought. Each seedling root plug was enclosed in a plastic bag and placed in a darkened chamber with the shoot systems exposed to the above described controlled environment conditions. Seedlings were allowed to dry out through shoot transpiration. The $g_{w v}$ of seedlings from each treatment were measured during each daylight period. At each gas exchange measurement time, seedlings were measured with a pressure chamber to determine daylight shoot water potential (Y). Changes in gas exchange parameters and seedling water stress were determined over time until seedlings reached a $\mathrm{Y}$ of $<-2.0$ $\mathrm{MPa}$.

\section{Root growth capacity}

Seedlings $(\mathrm{n}=25)$ were measured to determine root egress out of the soil plug over 14 days. Root growth capacity was measured on seedlings that were potted in a peat growing media, well watered and grown in the above described controlled environmental conditions.

Root growth was quantified for all roots that developed out of the container plug into the growing media. Total roots were quantified into root length categories of 1 ) new roots $\geq 0.5$ $\mathrm{cm}, 2$ ) new roots $\geq 2.5 \mathrm{~cm}$, and 3) new roots $\geq 5.0 \mathrm{~cm}$. It should be noted that each subsequently smaller root length category contained all roots measured in the longer root length categories (i.e., root category $1=$ categories $1+2+3$, root category $2=$ categories $2+3$ ).

\section{Experimental organization and analysis of data}

Both analogs were tested at the same time within each experimental procedure. Seedlings were set up in a blocked experimental design with all treatments randomized within each block. Where appropriate, 
an ANOVA followed by a Dunnett's test allowed comparisons between the control treatment and each $\mathrm{ABA}$ analog. The rapid drought treatment did not have statistical analysis conducted on results. This was due to differences between treatments in their rate of water loss over time.

\section{RESULTS AND DISCUSSION}

Low soil temperatures are one of the main factors that can cause planting stress in newly planted seedlings. Low root temperatures can restrict water uptake resulting in water stress in spruce seedlings (Kaufmann 1977, Grossnickle 1988). This limitation in seedling water movement may result in a hormonal response, analogous to soil drying, (Davies and Zhang 1991) which reduces stomatal opening.

ABA analog \#1 had superior long-term drought avoidance capability under low root temperature conditions (Fig. 1). On day 1 , this ABA analog reduced $\mathrm{g}_{\mathrm{wv}}$ by $84 \%$ and net photosynthesis was reduced by $50 \%$ (unreported data). On days 3 through $9, \mathrm{ABA}$ analog $\# 1$ reduced $\mathrm{g}_{\mathrm{wv}}$ by $>37 \%$ with only a slight decrease in net photosynthesis (unreported data). Though not significantly different than the control treatment on days 11 and $14, \mathrm{ABA}$ analog $\# 1$ reduced $\mathrm{g}_{\mathrm{wv}}$ by up to $17 \%$.

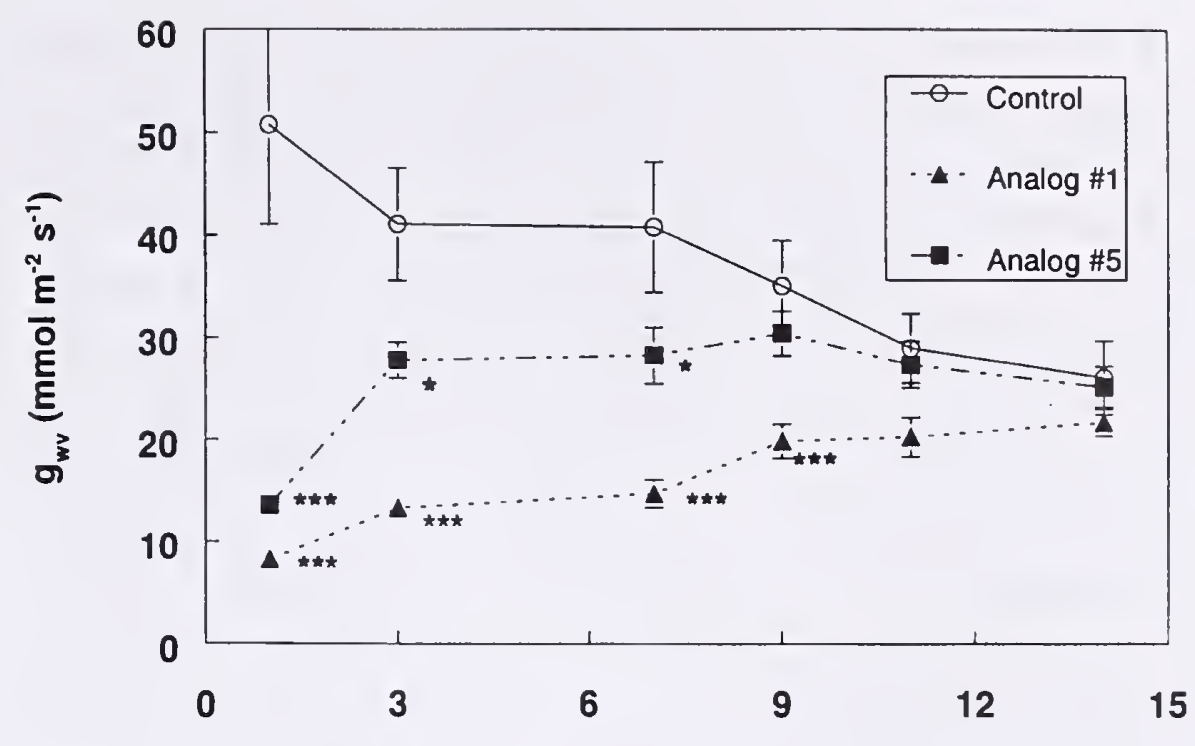

\section{Days}

Figure 1. Needle conductance $\left(g_{w v}\right)$ of interior spruce seedlings, from a control treatment or treated with an ABA analog, in response to low root temperature conditions. Statistical significance of 0.01 $\left(^{\star \star \star}\right), 0.05\left(^{\star \star}\right)$ or $0.10\left(^{\star}\right)$ were determined by an analysis of variance and a Dunnett's test which compared each ABA analog with the control treatment

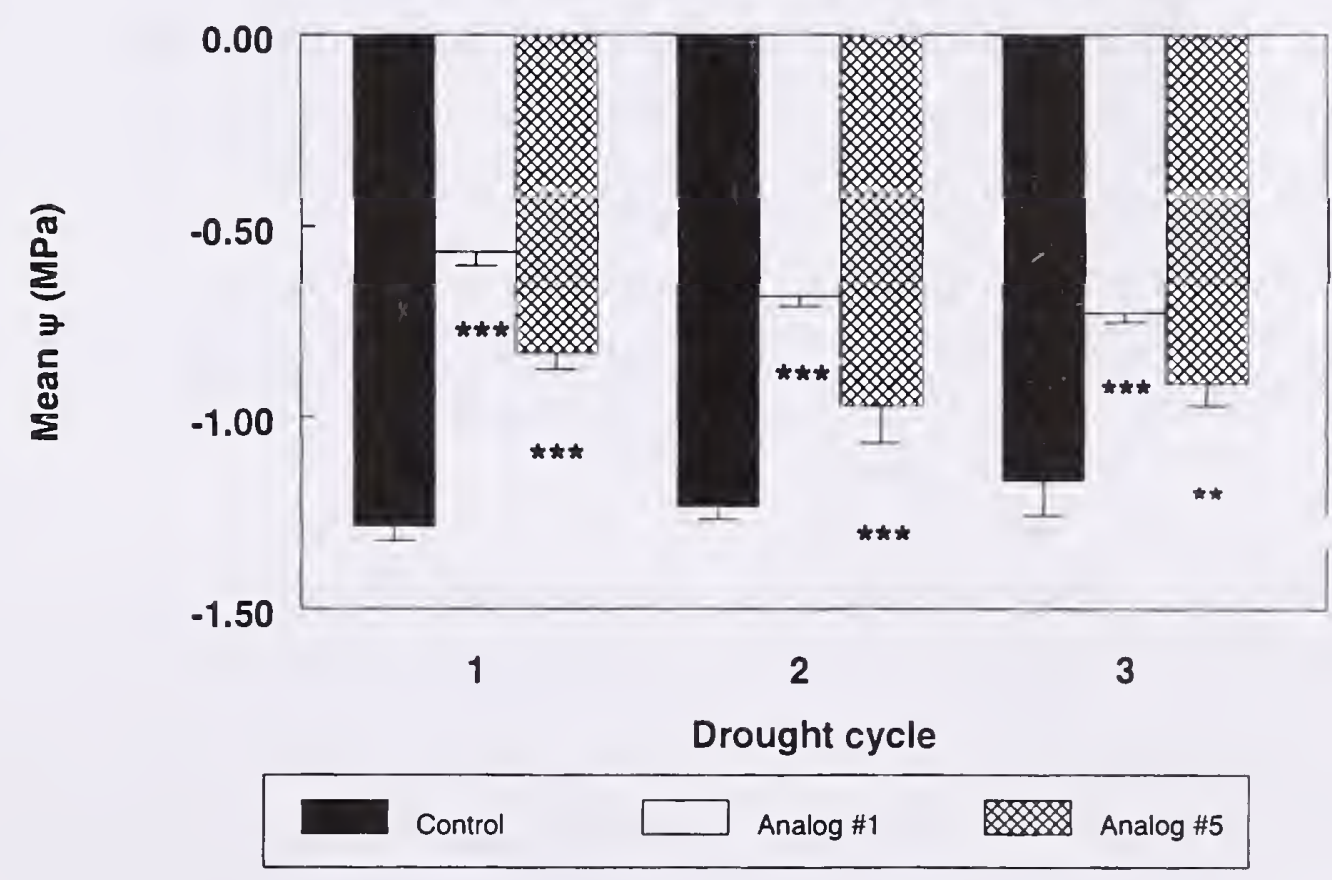

Figure 2. Mean shoot water potential (Y) of interior spruce seedlings, from a control treatment or treated with an ABA analog, over three fourday drought cycles. Statistics as in figure 1. 
ABA analog \#5 had good long-term drought avoidance capability under low root temperature conditions (Fig. 1). This $\mathrm{ABA}$ analog reduced $\mathrm{g}_{\mathrm{wv}}$ from 30 to $67 \%$ for 7 days, with no significant reduction in net photosynthesis (unreported data). By day $9, \mathrm{ABA}$ analog $\# 5$ had $g_{\mathrm{wv}}$ levels that were not significantly lower than the control treatment, though they were all causing at least a $13 \%$ reduction in $g_{w v}$. ABA analog $\# 5$, compared to the control treatment, caused no reduction in $\mathrm{g}_{\mathrm{wv}}$ after day 10.

Exogenously applied ABA can reduce the transpiration, and/ or $g_{w v}$ on a number of woody angiosperm (Davies and Kozlowski 1975a) and coniferous (Blake et al. 1990a, Marshall et al. 1991) species for a limited length of time. Davies and Kozlowski (1975a) found ABA initially reduced transpiration by $60 \%$ and that transpiration slowly returned to normal over a period of three weeks. In addition, preliminary testing of synthetic ABA analogs applied on the leaves or via the substrate, having different chemical structures than those tested here, have also been found to reduce $g_{w v}$ (Blake et al. 1990a) or water consumption (Rademacher et al. 1989) in plants.

Drought stress is the other main factor that can cause planting stress in newly planted seedlings. Newly planted seed- lings can be exposed to drought through limited soil moisture and/or high evaporative demand conditions of the atmosphere. Drought conditions cause seedling water stress by reducing water uptake from the soil (Kaufmann 1979, Grossnickle and Reid 1984, Sands 1984, Brissette and Chambers 1992) and by increasing transpiration as evaporative demand increases (Grossnickle and Reid 1984, Grossnickle and Blake 1987, Livingston and Black 1987, Grossnickle and Arnott 1992).

The result of increased water stress in newly planted seedlings is a reduction in growth (Nambiar and Zed 1980, Margolis and Waring 1986, Livingston and Black 1988, Grossnickle and Heikurinen 1989). As a result. planting stress can be exacerbated by drought conditions that reduce growth and delay a seedling's capability to occupy the site. ABA analogs may provide a means of avoiding moisture stress seedlings can be exposed to after planting on a reforestation site.

\section{ABA analogs \#1 and \#5} caused superior drought avoidance capabilities in seedlings under moderate drought conditions (Fig. 2). Seedlings treated with these analogs had higher mean $Y_{\text {min }}$, ranging from 20 to $60 \%$ higher, in all drought cycles compared to control seedlings. The higher $Y_{\text {min }}$ for seedlings treated with the ABA analogs, compared to the control treatment, thiroughout all of the drought cycles was attributable to lower $g_{w v}$ during the initial stages of each drought cycle (unreported data).

Improvement of drought avoidance under severe drought stress conditions was defined by the length of time interior spruce seedlings maintained nonlethal $\mathrm{Y}(>-2.0 \mathrm{MPa}) . \mathrm{ABA}$ analog \#1 had superior drought avoidance capability (Fig. 3). This analog reduced $g_{w v}$ and resulted in nonlethal $\mathrm{Y}$ being maintained over $400 \%$ longer than the control treatment. ABA analog \#5 had good drought avoidance capability. This ABA analog reduced $g_{w v}$ which resulted in nonlethal $\mathrm{Y}$ being maintained over $150 \%$ longer than the control treatment.

Seedlings treated with ABA analogs were capable of avoiding drought stress in either the moderate or severe drought stress experiments. Seedlings treated with $\mathrm{ABA}$ analogs, compared to control seedlings, had reduced transpirational water loss through reduced $g_{w v}$, which resulted in higher shoot $Y$ values over extended time periods. Exogenous application of ABA to conifer seedlings can reduce transpiration and maintain more favorable shoot water potentials under drought conditions (Davies and Kozlowski 1975b, Marshall et al. 1991). In addition, exogenous application of 
certain $\mathrm{ABA}$ analogs can reduce transpiration and improve water use efficiency in black spruce (Picea mariana (Mill.) B.S.P.) seedlings under drought (Blake et al. 1990a).

Improved root growth, in newly planted seedlings, will enhance the ability of seedlings to overcome planting stress and become established. Newly planted spruce seedlings that are able to develop root systems out of the container plug into surrounding soil will have reduced water stress (Grossnickle and Reid 1984). Seedlings in the control treatment, and seedlings treated with $\mathrm{ABA}$ analogs \#1 and $\# 5$ were able to develop over 85 new roots $\geq 0.5 \mathrm{~cm}$ in length (Fig.4). Trials comparing laboratory measured root growth capacity with field survival, found greater than $80 \%$ survival in interior spruce seedlings that produce $>10$ new roots (Burdett et al. 1983, Burdett 1987 ,

Simpson 1990, Simpson et al. 1994). This $\geq 0.5 \mathrm{~cm}$ measurement length is an indication of the potential number of locations on a root system that can grow new roots. ABA analogs can cause a reduction in $g_{n v}$ and subsequently a reduction in net photosynthesis under optimum environmental conditions (Grossnickle and Folk, unreported data). It has been shown that new root growth in conifers is supported by current photo assimilated carbohydrates (van
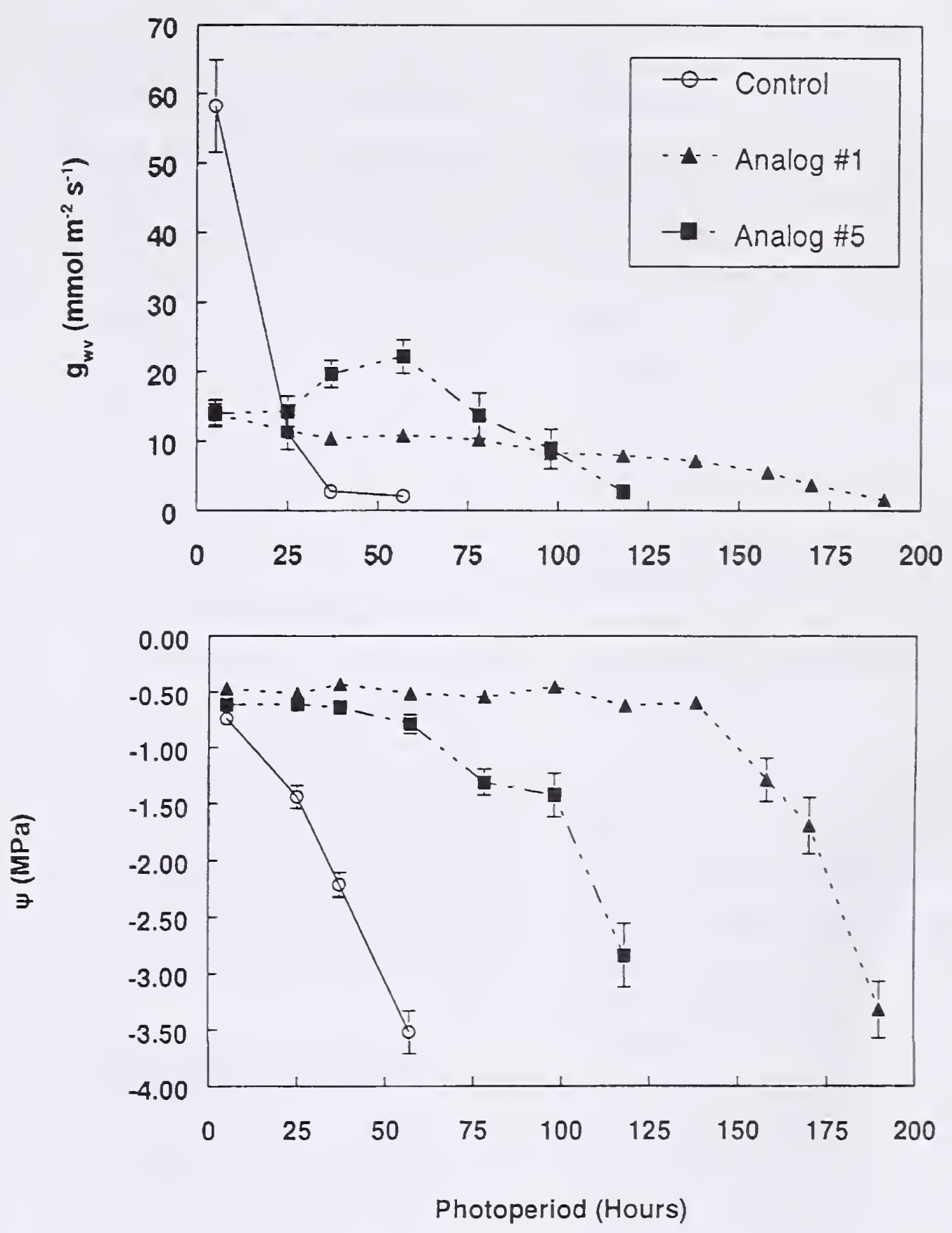

Figure 3. Needle conductance $\left(g_{w v}\right)$ and shoot water potential $(Y)$ of interior spruce seedlings, from a control treatment or treated with an $A B A$ analog, over a severe drought cycle.

den Driessche 1987). However, current photosynthates in spruce seedlings have not been strongly related to new root production (Philipson 1988, Thompson and Puttonen 1992). Previous work also found that exogenous application of certain $\mathrm{ABA}$ analogs had no effect on the root development of conifer seedlings (Blake et al. 1990b). Seedlings treated with $\mathrm{ABA}$ analogs had the capability to grow an extensive number of new roots, when tested in this optimum environment.

Seedlings in the control treatment were able to develop around 70 new roots $\geq 2.5 \mathrm{~cm}$ in length. and of these new long roots. 42 were $\geq 5.0 \mathrm{~cm}$ in length (Fig. 4). For the longer root 
length categories, $\mathrm{ABA}$ analogs $\# 1$ and \#5 resulted in approximately a $10 \%$ and $35 \%$ increase in the $\geq 2.5 \mathrm{~cm}$ and $\geq 5.0 \mathrm{~cm}$ root length categories, respectively. These measurement lengths are an indication of the ability of a root system to develop roots out into the soil and quickly become established.

Root growth results from the reported study indicate that $\mathrm{ABA}$ analog \#1 increased the number of long roots $(>5.0 \mathrm{~cm})$. However, additional testing of interior spruce seedlings did not find a positive influence of $\mathrm{ABA}$ analogs on the growth of longer roots when seedlings were tested at a phenological stage having low root growth capacity (unreported data). This indicates the need to further define how ABA analogs influence root growth during different phenological stages that are related to the times of year when seedlings are planted on reforestation sites.

\section{CONCLUSIONS}

Results from this research program have found that specific ABA analogs allow seedlings to maintain good water balance under environmentally stressful conditions through partial stomatal closure. These ABA analogs can cause partial stomatal closure for a period of over two weeks. In addition, $\mathrm{ABA}$ analogs maintain root growth capability, under optimum conditions, at levels that are conducive to seedling survival and growth when planted on reforestation sites. These results provide evidence that an ABA analog-based antitranspirant product can be developed to help alleviate planting stress in seedlings.

\section{ACKNOWLEDGMENTS}

This research program is funded by the National Research Council of Canada biotechnol-

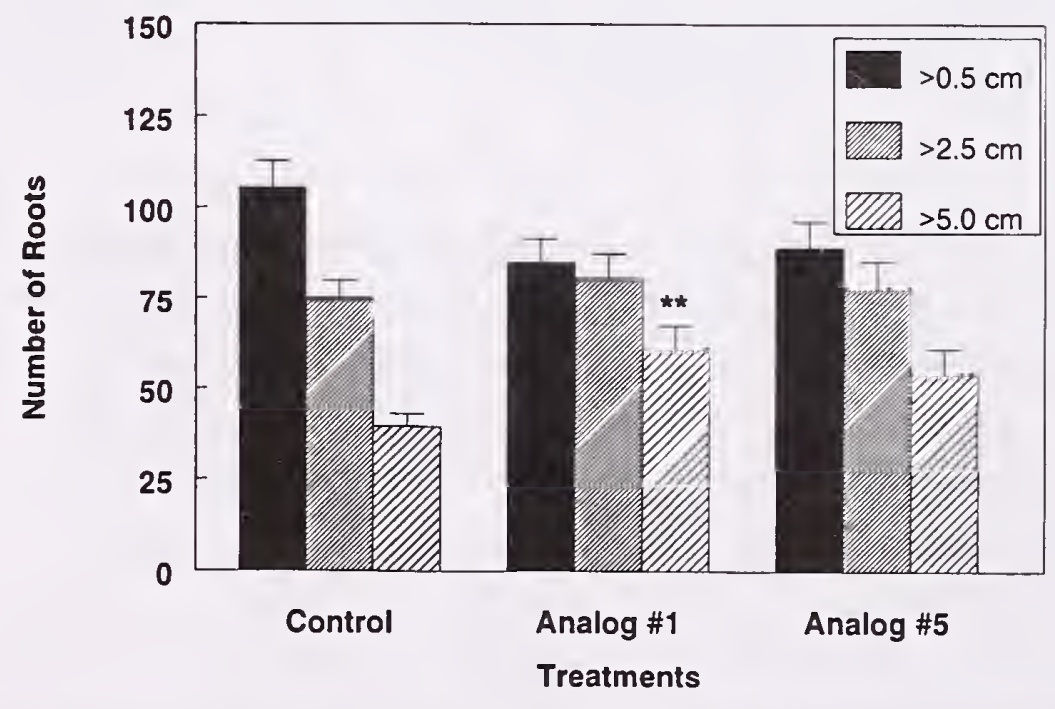

Figure 4. Root growth capacity of interior spruce seedlings, from a control treatment or treated with an $A B A$ analog. Each subsequently smaller root length category contains all roots contained in the longer root length categories. Statistics as in figure 1.

ogy contribution program in joint partnership with DowElanco Canada Ltd. All collaborators in this research program thank Pelton Reforestation Ltd. for providing consultation during development of this program and for seedlings used in the experiments.

\section{REFERENCES}

Blake, T.J., W. Tan and S.R. Abrams. 1990a.

Antitranspirant action of abscisic acid and ten synthetic analogs in black spruce.

Physiol. Plant. 80: 365-370.

Blake, T.J., E. Bevilacqua, G.A. Hunt and S.R. Abrams. 1990b. Effects of abscisic acid and its acetylene alcohol on dormancy, root development and transpiration in three conifer species. Physiol. Plant. 80: 370-378.

Brissette, J.C. and J.L. Chambers. 1992. Leaf water status and root system water flux in shortleaf pine (Pinus echinata Mill.) seedlings in relationship to new root growth after transplanting. Tree Physiol. 11: 289-303.

Burdett, A.N. 1987. Understanding root growth capacity: theoretical considerations in assessing planting stock quality by means of root growth tests. Can. J. For. Res. 17: 768-775. 
Burdett, A.N. 1990. Physiological processes in plantation establishment and the development of specifications for forest planting stock. Can. J. For. Res. 20: 415-427.

Burdett, A.N., D.G. Simpson and C.F. Thompson. 1983. Root development and plantation establishment success. Plant Soil, 71: 103-110.

Davies, W.J. and T.T. Kozlowski. 1975a. Effects of applied abscisic acid and plant water stress on transpiration of woody angiosperms. For. Sci. 21: 191-195.

Davies, W.J. and T.T. Kozlowski. 1975b. Effect of applied abscisic acid and silicone on water relations and photosynthesis of woody plants. Can. J. For. Res. 5: 9096.

Davies, W.J. and T.A. Mansfield. 1983. The role of abscisic acid in drought avoidance. In: Abscisic Acid. Ed. F.T. Addicot. Praeger, New York, pp. 237-268.

Davies, W.J. and J. Zhang. 1991. Root signals and the regulation of growth and development in drying soil. Annu. Rev. Plant. Physiol. Plant Mol. Biol. 42: 55-76.
Grossnickle, S.C. 1988. Planting stress in newly planted jack pine and white spruce seedlings. 1. Factors influencing water uptake. Tree Physiol. 4: 71-83.

Grossnickle, S.C. and J.T. Arnott. 1992. Gas exchange response of western hemlock seedlings from various dormancy-induction treatments to reforestation site environmental conditions. For. Ecol. Manage. 49: 177-193.

Grossnickle, S.C. and T.J. Blake. 1987. Comparison of water relation patterns for newly planted bare-root and container jack pine and black spruce seedlings on boreal cut-over sites. New For. 1: 101-116.

Grossnickle, S.C. and J. Heikurinen. 1989. Site preparation: Water relations and growth of newly planted jack pine and white spruce. New For. 3: 99-123.

Grossnickle, S.C. and C.P.P. Reid. 1984. Water relations of Engelmann spruce on a high elevation mine site: An example of how reclamation techniques can alter microclimate and edaphic conditions. Reclam. Reveg. Res. 3:199-221.
Kaufmann, M.R. 1977. Soil temperature and drying cycle effects on water relations of Pinus radiata. Can. J. Bot. 55: 2413-2418.

Kaufmann, M.R. 1979. Stomatal control and the development of water deficit in Engelmann spruce seedlings during drought. Can. J. For. Res. 9: 297-304.

Kozlowski, T.T. and W.J. Davies. 1975. Control of water balance in transplanted trees. Arboriculture, 1: 1-10.

Livingston, N.J. and T.A. Black. 1987. Stomatal characteristics and transpiration of three species of conifer seedlings planted on a high elevation south-facing clear-cut. Can. J. For. Res. 17: 1273-1282.

Livingston, N.J. and T.A. Black. 1988. The growth and water use of three species of conifer seedlings planted on a high elevation south-facing clearcut. Can. J. For. Res. 18: 1234-1242.

Mansfield, T.A., A.R. Weliburn and T.J.S. Moreira. 1978. The role of abscisic acid and farnasol in the alleviation of water stress. Philos. Trans. R. Soc. Lond. Ser. B. 284: 471 482. 
Margolis, H.A. and W.H. Waring. 1986. Carbon and nitrogen allocation patterns of Douglas-fir seedlings fertilized with nitrogen in the autumn. II) Field performance. Can. J. For. Res. 16: 903-909.

Marshall, J.G., J.B. Scarratt and E.B. Dumbroff. 1991. Induction of drought resistance by abscisic acid and paclobutrazol in jack pine. Tree Physiol. 8: 415-421.

Miller, P.C. 1983. Comparison of water balance characteristics of plant species in "natural" versus modified ecosystems. In Disturbance and Ecosystems. Components of Response. Eds. H.A. Mooney and M. Gordon SpringerVerlag, New York, pp. 188212.

Nambiar, E.K.S. and P.G. Zed. 1980. Influence of weeds on the water potential, nutrient content and growth of young radiata pine. Aust. For. Res. 10: 279-288.

Philipson, J.J. 1988. Root growth in Sitka spruce and Douglas-fir transplants: dependence on the shoot and stored carbohydrates. Tree Physiol. 4: 101-108.
Rademacher, W., R. Maisch, J. Liessegang and J. Jung. 1989. New synthetic analogues of abscisic acid: their influence on water consumption and yield formation in crop plants. $\underline{\text { In Structural and Functional }}$ Responses to Environmental Stresses. Eds. K.H. Kreeb, H. Richter and T.M. Hinckley. Academic Publishing, the Hague, pp. 147-154.

Sands, R. 1984. Transplanting stress in radiata pine. Aust.

For. Res. 14: 67-72.

Simpson, D.G. 1990. Cold hardiness, root growth potential and field performance relationships in interior spruce, lodgepole pine, Douglas-fir and western hemlock seedlings. Can. J. For. Res. 20: $566-572$.

Simpson, D.G., C.F. Thompson and C.D. Sutherland. 1994. Field performance potential of interior spruce seedlings: effects of stress treatments and prediction of root growth potential and needle conductance. Can. J. For. Res. 24: 576-586.

Thompson, B. and P. Puttonen. 1992. Patterns of gas exchange, photosynthate allocation, and root growth during a root growth capacity test. Can.

J. For. Res. 22: 248-254. van den Driessche, R. 1987. Importance of current photosynthate to new root growth in planted conifer seedlings. Can. J. For. Res. 17: 776-782.

Zeevaart, J.A.D. and R.A. Creelman. 1988. Metabolism and physiology of abscisic acid. Annul. Rev. Plant Physiol. Plant Mol. Biol. 39: 439-473. 


\title{
Rapid Assessment of Nursery Stock Viability Using a Portable Gas Analysis System: A Component of Ontario's Seedling Quality Assessment Program ${ }^{1}$
}

\author{
Stephen J. Colombo, Colin W.G. Templeton and P. Sampson ${ }^{2}$
}

Abstract-A provincial seedling quality assessment program has provided a coordinated service of standardized nursery stock physiological testing in Ontario since 1992. Testing consists of three related components: (i) Certification, (ii) Problem Stock Testing and (iii) Stress-induced volatile emissions (SIVE) for field identification of problem stock. Certification measures seedling condition and viability prior to shipping. Problem Stock Testing provides a rapid (48-72 hour) assessment of seedling viability, both prior to and after shipping, where concerns over viability exist. Measurement of SIVE by nursery and forestry staff is a new method which places a practical, physiologically-based seedling viability measure for identifying problems, into the hands of field practitioners. Together, these three components of Ontario's seedling quality assessment allow Ontario nurseries to (i) compare the physiological performance of their stock to provincial averages for such attributes as chlorophyll fluorescence and root growth potential, and (ii) judge the effects of modifications in nursery practices in terms of improvements in physiological stock quality. For foresters, testing allows a higher degree of assurance that stock shipped to them for planting meets their viability standards and an objective means of comparing the quality of nursery crops over time and to one another.

\section{INTRODUCTION}

The identification of damaged or non-viable tree seedlings prior to planting is an important step in successful reforestation programs. In many cases, visual symptoms of damaged or dead seedlings may not be evident at the time of planting. Where such damage goes undetected inferior quality stock may be planted, resulting in poor plantation stocking, low rates of growth, or plantation failure. The costs of replacing a failed plantation are often very high, so that a means of identifying low vigour and damaged stock prior to planting is extremely important. This paper describes Ontario's seedling quality assessment program, including the recent introduction of a tool for nursery managers and foresters to rapidly identify stock quality problems at the nursery or the planting site.

\section{SEEDLING CERTIFICATION}

The first component of the provincial seedling quality testing program in Ontario is Seedling Certification. All testing is conducted on a voluntary basis, and can be requested either by the producer or user of stock. For each stocklot to be tested, a sample of 150 seedlings is collected according to prescribed methods. Stock is shipped on ice to one of two

'Colombo, S.J.; Templeton, C.W.G.; Sampson, P. 1994. Rapid Assessment of Nursery Stock Viability Using a Portable Gas Analysis System: A Component of Ontario's Seedling Quality Assessment Program. IN: Landis, T.D.; Dumroese, R.K., tech. coords. National Proceedings, Forest and Conservation Nursery Associations. Gen. Tech. Rep. RM-257. Fort Collins, CO: U.S. Department of Agriculture. Forest Service, Rocky Mountain Forest and Range Experiment Station: 223-229.

${ }^{2}$ Ontario Forest Research Institute, Ministry of Natural Resources, 1235 Queen Street East, Sault Ste. Marie, Ontarıo. Canada P6A 5N5, Tel: 705/946-2981; Fax: 705/946-2030. 
laboratories, one in Timmins, Ontario and one at the Ontario Forest Research Institute in Sault Ste. Marie, Ontario. In 1993, certification involved the application of four tests: 1. Viusal examination of root, stem and bud meristems; 2. Electrolyte leakage from detached shoot tips; 3 . Shoot chlorophyll fluorescence; 4 . Root growth potential. In addition to these tests, selected stock is planted at a controlled site.

\section{Visual Examination}

A sub-sample of the seedlings is examined for external signs of dead or damaged foliage and roots, as well as internally for damage to the terminal bud on the main stem and to phloem and cambium on the roots and stem. Seedlings with evidence of pathogens are forwarded for examination by the Forest Pest Laboratory of the Ontario Forest Research Institute.

\section{Electrolyte Leakage From Detached Shoot Tips}

Plant cells contain large amounts of electrolytes, which are substances that, when dissolved in water, conduct electric current. The main electrolyte in plant cells is potassium. The basis of the electrolyte leakage test is that damaged cells are "leaky", and if placed in water the cell contents, including electrolytes, go into solution. The amount of damage can often be estimated from the electrical conductivity of water into which seedling tissues have been placed. High levels of electrical conductivity usually indicate cell damage (Burr et al. 1990).

For short-needled conifer species this test uses the terminal $2-3 \mathrm{~cm}$ of the main stem shoot from a sub-sample of seedlings. The terminals excised from seedlings are submerged in distilled water in test tubes. Twenty to 24 hours after being placed in water, the electrical conductivity of the solution is measured using a conductivity bridge. After this measurement, the shoot tips are killed by heating in a $90^{\circ} \mathrm{C}$ oven for 4 hours. After an additional 20-24 hours of leaching following killing, the electrical conductivity of the solution is remeasured. Electrolyte leakage is expressed as "relative conductivity", the percentage electrical conductivity before and after killing (relative conductivity $=$ initial conductivity $\div$ killed conductivity). A relative conductivity below $10 \%$ is considered good. Relative conductivity above $20 \%$ usually indicates moderate to high levels of damage. Care must be taken to avoid confusing a high relative conductivity caused by herbicide or fertilizer residues which may be present on foliage with electrolytes leached from damaged cells. In addition, low levels of conductivity for badly-damaged foliage may occasionally occur. For this reason, electrolyte leakage should not be used as the sole criterion of foliage condition. Additional measures, such as chlorophyll fluorescence provide further information on foliage viability.

\section{Shoot Chlorophyll Fluorescence}

Trees require light to carry out photosynthesis. However, a portion of the light absorbed by tree seedling needles is not used in photosynthesis, and is instead re-emitted or fluoresced from the foliage. The amount of light and the pattern over time in which it is fluoresced can be measured using highly sensitive photodetectors (Vidaver et al. 1988, Bolhàr-Nordenkampf 1989). When first illuminated, there is typically an initial increase to a low level of fluorescence, followed within less than one second by a peak fluorescence value being reached. The peak fluorescence is followed within a matter of seconds by a partial reduction and then a secondary peak in fluorescence, after which fluorescence slowly (over minutes) declines. Usually, these fairly complex fluorescence patterns are reduced to one or two mathematical expressions which have been found to relate to foliage condition (for example, Fv/Fmax, maximum fluorescence minus initial fluorescence divided by maximum fluorescence).

Fluorescence can be used to detect healthy, stressed and damaged foliage (Vidaver et al. 


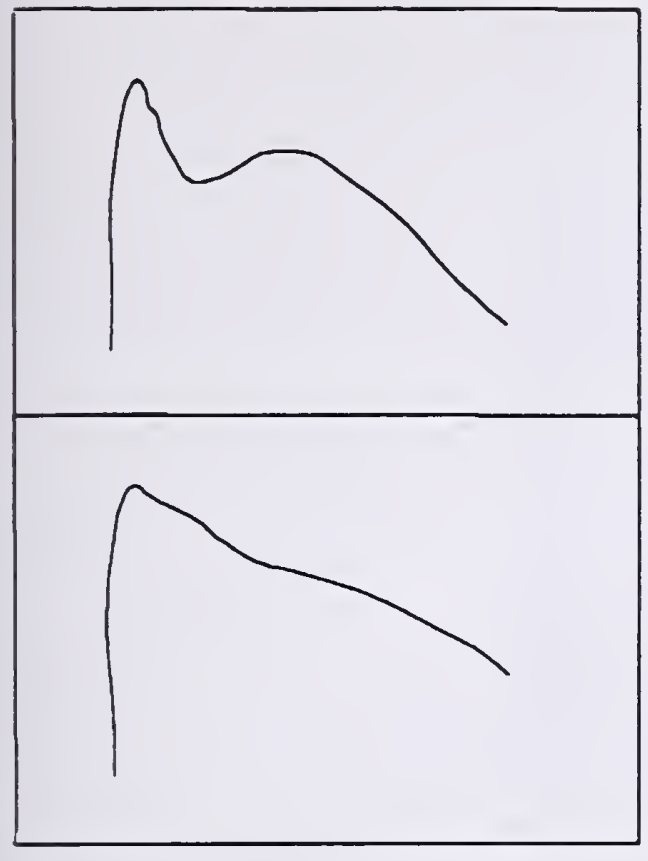

Time

Figure 1. Representative patterns of chlorophyll fluorescence associated with healthy (top) and damaged (bottom) foliage.

1989). Figure 1 shows representative patterns of fluorescence for healthy (top) and stressed (bottom) foliage. Until recently, the operational use of fluorescence for assessment of seedling quality has been limited. However, automated equipment which is easy to operate and which measures and directly computes fluorescence values is now available (Vidaver et al. 1989, Bolhàr-Nordenkampf 1989).

In Ontario, chlorophyll fluorescence is used operationally as a rapid measure of foliage viability. Two days after representative samples from a stocklot have been potted and placed in a controlled environment the seedlngs are measured for fluorescence. The measured fluorescence values are compared to benchmarks for fluorescence established for healthy and damaged foliage of the important conifer species grown in Ontario tree nurseries. When measured fluorescence values fall below thresholds established for that species, the nursery or forester are advised of the possible presence of problems and further testing is usually carried out.

\section{Root Growth Potential}

The ability to produce new roots when placed in an environment favourable for growth is a well established measure of plant vitality (Landis and Skakel 1988). A seven day root growth test for container stock and a 14 day test for bareroot stock has been found to be effective at distinguishing differences between high and low vigour stock lots of all conifer species grown in Ontario. Testing is conducted in a controlled environment exclusively, with artificial lighting to avoid the confounding influence of changing light levels depending on time of year and local weather, as would occur if testing were carried out in a greenhouse.

An important purpose of testing root growth potential is to identify stock lots containing seedlings unable to produce new roots in the favourable test conditions. In most but not all cases, seedlings unable to produce new roots in the test are dead. For seedlings able to produce roots, the patterns of root growth can differ substantially between species and stock type, the results of root growth potential tests are compared only against seedlings of the same species and stock type (Fig. 2). Stocklot condition based on root growth potential is based foremost on the presence of seedlings unable to produce any new roots, and secondarily on the number of seedlings producing only a few versus many new roots (Fig. 2).

\section{Controlled-Site Plantings}

In addition to the above tests, samples from selected stock lots are planted at a weed-controlled site to observe field performance. These test plantings allow longer-term evaluation relating measures of seedling quality to field performance. One of the purposes of these plantings is to develop a data base relating seedling quality measurements to performance potential. Seedlings are remeasured annually for height and survival, and are also available for measurement of postplanting physiological condition. The oldest seedlings in these test plantings will enter their fourth field season in 1995.

\section{PROBLEM STOCK TESTING}

When nursery stock quality is in question, either as a result of problems identified during Certification or due to concerns 


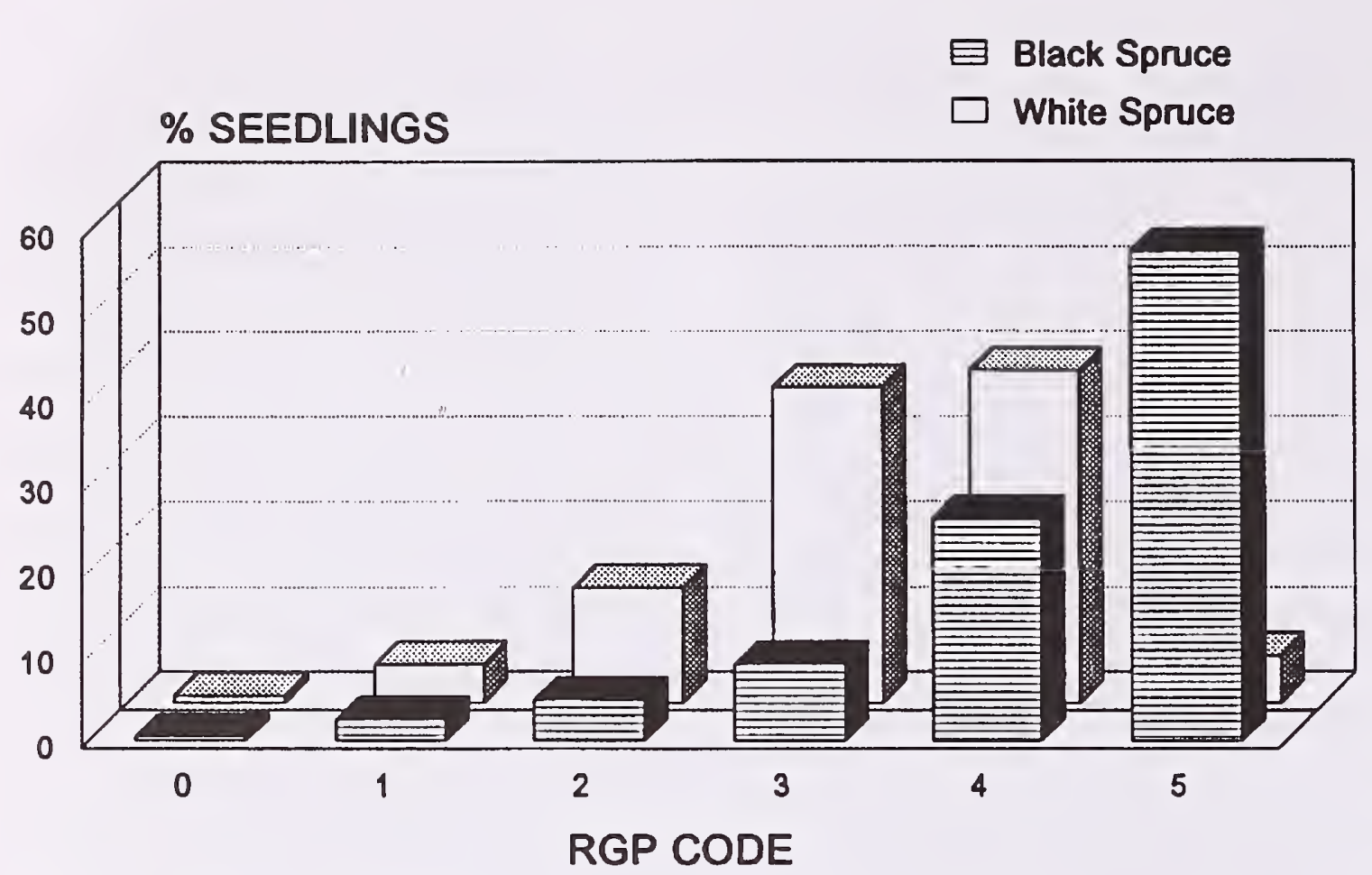

Figure 2. Provincial frequency distributions for white spruce and black spruce bare root seedling root growth potential in Ontario. For each species the graph indicates the average percentage of seedlings expected to fall into a particular root growth potential code for an average stocklot. Root growth potential codes are from Burdett (1979), where $0=$ no new roots initiate, $1=$ some new roots initiated, none $1 \mathrm{~cm}$ or longer, $2=1-3$ new roots $1 \mathrm{~cm}$ or longer, $3=4-10$ new roots $1 \mathrm{~cm}$ or longer, $4=11-30$ new roots $1 \mathrm{~cm}$ or longer, and $5=$ more than 30 new roots $1 \mathrm{~cm}$ or longer.

of nursery managers or foresters, it is tested using Problem Stock Testing. The same four tests are applied in Problem Stock Testing as in Seedling Certification, with additional tests such as photosynthesis, transpiration, and measurement of stressinduced volatiles used depending on the type of damage suspected. However, the primary difference between Certification and Problem Stock Testing is that problem stock is given priority to provide rapid answers where needed. Results of the visual examination, electrolyte leakage and chlorophyll fluorescence are obtained within 48 hours of stock being received for testing. Even within a province as large as Ontario, shipment of stock to the testing facilities can be rapid enough to allow test results to be given in sufficient time to provide a preliminary indication of whether problems warrant suspending shipping or planting operations. When problems are found, stock lots are resampled to confirm whether the initial observations were accurate.

\section{STRESS-INDUCED VOLATILE EMISSIONS (SIVE) FOR FIELD DETERMINATION OF PROBLEM STOCK}

Nurseries and foresters need tools for rapid determination of seedling viability on-site. It has been known for over a decade that stress-damaged nursery stock produces a number of gases, such as ethylene, acetaldehyde and ethanol (Kimmerer and Kozlowski 1982, Johnson and Gagnon 1988). However, the application of this knowledge has been limited by the fact that there was previously no means of measuring stress-induced gases which was rapid, inexpensive, easy-to-use and field portable. A new procedure to address this need, using an 'offthe-shelf' instrument, has been developed at the Ontario Forest Research Institute.

We identified instruments being produced to measure toxic gases in industries such as mining and manufacturing, also capable of measuring stressinduced gases given-off by tree seedlings. The four commercially available systems we have identified all work on the same basic principle: a glass indicator tube packed with a chemical indicator is attached to a manually operated vacuum pump (Fig. 3). A sample of gas is drawn by vacuum through the tube. A chemical indicator packed in the tube reacts by colour change to particular SIVE gases. Different tubes are manufactured for such SIVE gases as ethanol, acetaldehyde and ethylene. The concentration of the gas is shown by the extent of the colour change along the length of the indicator tube (Fig. 4). 
Figure 3. Gastec $₫$

instrument for measuring stress-induced volatile emission, consisting of a glass indicator tube packed with a chemical indicator and a manually operated vacuum pump.

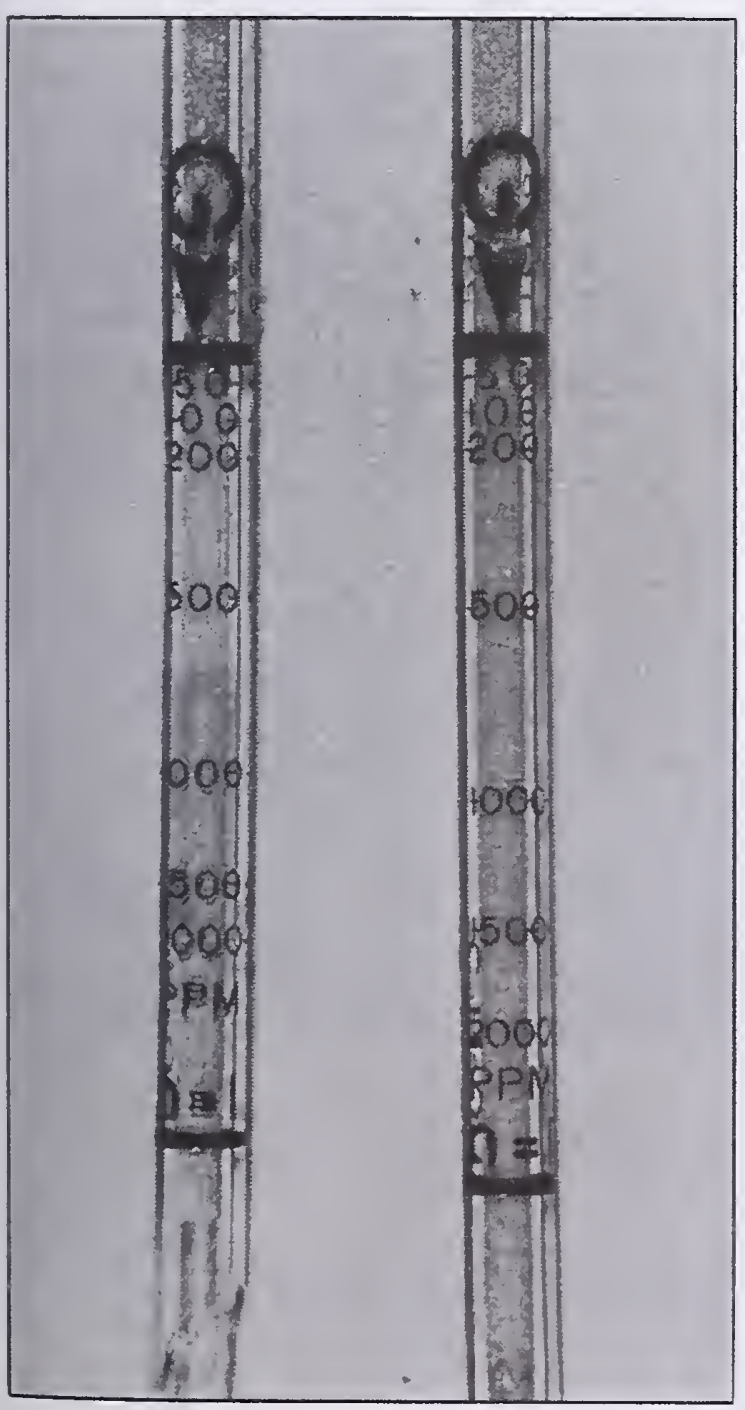

To apply this technique to determine the presence of stressinduced damage to tree seedlings, a sample of trees must be incubated in an air-tight bag to allow the gas to accumulate. Preliminary indications of problems may be obtained by sampling gas directly from shipping packages where the seedlings are already sealed in a plastic bag, if bag temperature is greater than $15^{\circ} \mathrm{C}$. We recommend that a sample of approximately 50 bareroot or 100 container seedlings be placed in a 50 pound, 4 mil plastic bag for 24 hours at $20^{\circ} \mathrm{C}$ prior to being sampled for stress-induced production of gases. Where there are multiple bags or boxes of seedlings sampling may be done for many shipping containers.

Figure 4. Glass indicator tubes for measuring stress-induced volatile emissions. Upon exposure the concentration of stress-induced volatile emission will be shown by the distance along the length of the indicator tube of the colour change of the tube contents.
Correlations have been found between the production of stressinduced volatile emissions and seedling damage for black spruce, Norway spruce, white spruce, red pine, white pine and tamarack. In general, a level of ethanol in excess of $1,000 \mathrm{ppm}$ is associated with significantly reduced root growth potential and increased bud mortality and foliage damage in black spruce (Templeton and Colombo 1994). More precise levels of damage and stress-induced gas concentrations are being investigated for these and other species.

The advantages of the portable gas analysis system are that it is inexpensive (a pump system 
costs approximately $\$ 300$ and each detector tube about $\$ 3$ ), rapid (one measurement takes about 5 minutes), non-destructive (only gases, not the seedlings are used), technically simple to use and interpret (a detector tube is read similar to a thermometer) and portable (the pump system can fit in a car glove compartment or desk drawer).

While the SIVE procedure provides a means of identifying damaged stock, erroneous readings may occasionally occur. For example, false positive values (i.e. stress-induced gases above the critical point produced without damage being present) may occur if bags of seedlings are much more than $20^{\circ} \mathrm{C}$ when gases are measured. False negative values (i.e. stressinduced gases not produced when seedlings are damaged) may occur if damage is so severe that the biosynthetic processes producing the gases are no longer functional (i.e. dead trees do not produce stress gases). For these reasons, we view the use of the portable gas analysis system as the field component of a comprehensive seedling quality testing program.

Forester's interests are best served by using nursery stock which has passed through some form of certification or screening, to detect problems otherwise unsuspected prior to shipping. In Ontario, when the portable gas analysis system detects elevated levels of stress-induced gases after stock has left the nursery, the quality of the nursery stock is usually evaluated further using Problem Stock Testing, as described previously.

\section{CONCLUSIONS}

\section{In 1994, over half of all} nursery stock in Ontario was tested through the Seedling Quality Assessment Project. In so doing, samples representing approximately 60 million seedlings were evaluated (Fig. 5). The testing program is voluntary, with user fees of $\$ 50$ for container stock and $\$ 90$ for bareroot, the price difference being based on the greater space and longer test duration required by bare root seedlings in the root growth testing facility. These prices are subsidized by the provincial government, since, in Ontario, nearly all reforestation, including that conducted by private companies, takes place on public land.

Nurseries can benefit from seedling testing by comparing the physiological performance of their stock to provincial averages for such attributes as chlorophyll fluorescence and root growth potential. Furthermore, nursery managers can evaluate the effects of variations and modifications in nursery practices in terms of improvements in physiological stock quality. To foresters purchasing nursery stock, testing through the type of program in Ontario allows for a higher degree of assurance that stock shipped to them for planting meets their viability targets. Testing information also provides foresters with an objective means of comparing nurseries.

The application of seedling physiological testing in Ontario has made a measureable im-

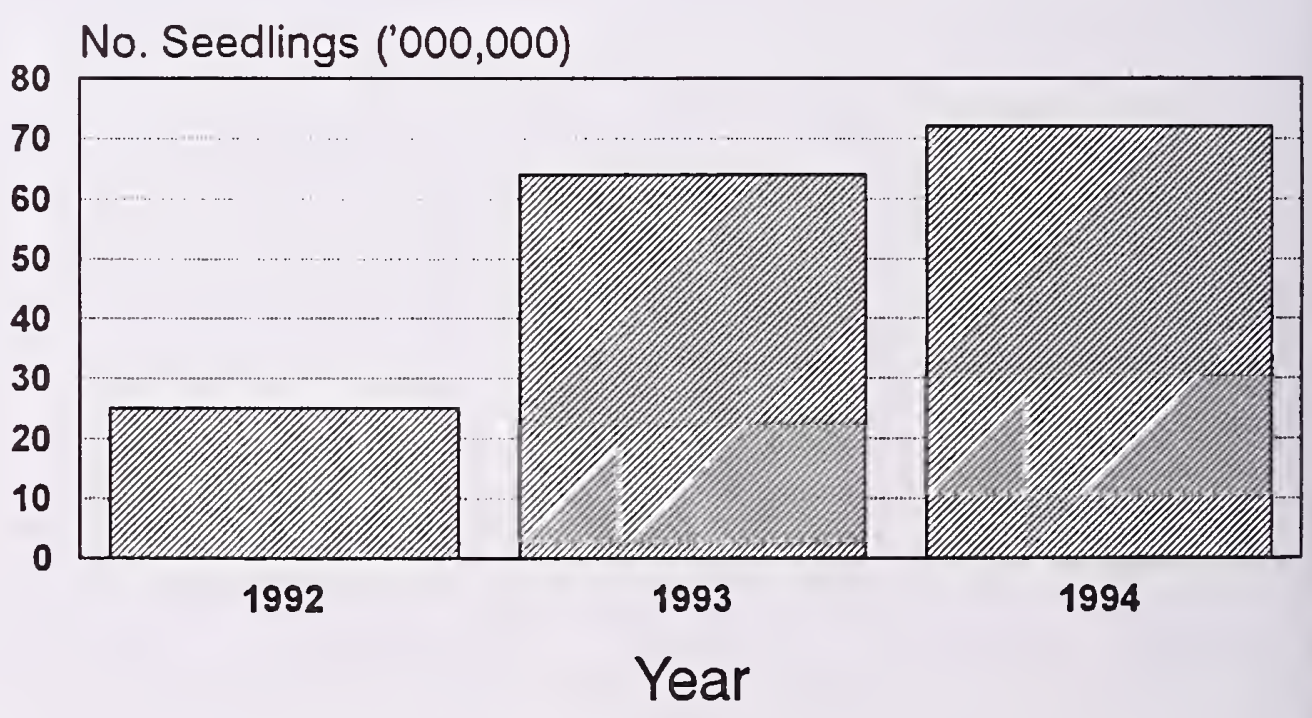

Figure 5. Millions of seedlings represented in stocklots for which quality assessment was conducted from 1992 to 1994 through Ontario's seedling quality assessment program. 
provement in plantation success. In the three years that the program has been offered, cost savings of nearly $\$ 2$ million have been realized by preventing the planting of stock which was already dead or dying. It is our objective to continue to refine the current tests being used operationally in Ontario, to utilize the database of physiological performance to suggest improvements in nursery practices to nursery managers, and to develop new tests with improved accuracy, speed and predictive ability.

\section{REFERENCES}

Bolhàr-Nordenkampf, H.R., Long, S.P., Baker, N.R., Öquist, G., Schreiber, U. and Lechner, E.G. 1989. Chlorophyll fluorescence as a probe of the photosynthetic competence of leaves in the field: a review of current instrumentation. Functional Ecology 3: 497-514.

Burdett, A.N. 1979. New methods for measuring root growth capacity: their value in assessing lodgepole pine stock quality. Can. J. For. Res. 9:63-67.
Burr, K.E., Tinus, R.W., Wallner, S.J. and King, R.M. 1990. Comparison of three cold hardiness tests for conifer seedlings. Tree Physiology 6: 351-369.

Drakeford, D.R. and Hawkins, C.D.B. 1989. The stress induced volatile emissions (SIVE) technique for measuring levels of stress in conifer seedlings. Forestry Canada and B.C. Ministry of Forests, FRDA Report 084.

Johnson, J.D. and Gagnon, K.G. 1988. Assessing freezing damage in loblolly pine seedlings: a comparison of ethane production and electrolyte leakage. New Forests 2: 65-72.

Kimmerer, T.W. and Kozlowski, T.T. 1982. Ethylene, ethane, acetaldehyde, and ethanol production by plants under stress. Plant Physiology 69: 840-847.

Landis, T.D. and Skakel, S.G. 1988. Root growth potential as an indicator of outplanting performance: Problems and perspectives. In: Proceedings, Combined Meeting of the Western Forest Nursery Associations, August 8-11, 1988, Vernon, B.C. U.S.D.A. Forest Service, Gen. Tech. Report RM-167. pp. 106-110.
Templeton, C.W.G. and Colombo, S.J. 1994. A portable system to quantify seedling damage using stressinduced volatile emissions. Can. J. Forest Res. (in review).

Vidaver, W., Toivonen, P., Lister, G., Brooke, R. and Binder, W. 1988. Variable chlorophyll a fluorescence and its potential use in tree seedling production and regeneration. In: Proceedings, Combined Meeting of the Western Forest Nursery Associations, August 8-11, 1988, Vernon, B.C. U.S.D.A. Forest Service, Gen. Tech. Report RM-167. pp. 127-132. 


\title{
Sprinkler Irrigation Management and Scheduling for Diverse Container-Grown Plants ${ }^{1}$
}

\author{
Richard Regan ${ }^{2}$
}

\begin{abstract}
Nurseries are looking at irrigation scheduling to help conserve water and solve environmental concerns regarding water quality and runoff. Irrigation scheduling increases the level of management for nurseries who grow a large number of diverse species. Nursery managers must consider irrigation efficiency, zone irrigation, and crop water requirements.
\end{abstract}

\section{INTRODUCTION}

Forest and conservation nurseries are expanding their product line to include a wider variety of plant species. These species are in demand for planting projects that involve new forest management strategies, riparian revegetation, wildlife habitat enhancement, and recreation and parks. Much of this expansion is with containergrown plants. Nurseries often select new plants that fit into their general mode of operation. This avoids drastic changes in facilities, specialized equipment, and additional capital. Nonetheless, increasing the number of diverse plant species grown will complicate cultural practices and management decisions.
Irrigation is more difficult when you increase the number of plants grown at the nursery. Overhead sprinklers are commonly used to apply water to large areas or zones. If only one plant species is located within a zone, then water can be applied to replace the amount used by the crop. Growers have found that certain plants need more water than others. When several diverse species are located within the same zone, water must be applied to satisfy the needs of the high water use plant. This extra amount of water can be over twice that required by the other plants causing root rot, excessive leaching, and increases surface runoff. This irrigation strategy requires a large supply of water. To comply with irrigation water runoff regulations Oregon nurseries have installed tailwater return systems.

Water supply and environmental issues regarding water quality are concerns of the nursery industries. Nursery managers have an obligation to use irrigation water efficiently. In addition, water costs are increasing and water use regulations are more restrictive. Good irrigation practices and management can conserve water and reduce runoff (Kabashima, 1993). This strategy is based on increasing the water application uniformity and irrigation scheduling.

${ }^{1}$ Regan, R. 1994. Sprinkler Irrigation Management and Scheduling for Diverse Container-Grown Plants. IN: Landis, T.D.; Dumroese, R.K., tech. coords. National Proceedings, Forest and Conservation Nursery Associations. Gen. Tech. Rep. RM257. Fort Collins, CO: U.S. Department of Agriculture, Forest Service, Rocky Mountain Forest and Range Experiment Station: 230-233.

${ }^{2}$ North Willamette Research and Extension Center, Oregon State University, Aurora, Oregon. 
IRRIGATION EFFICIENCY

A major objective of sprinkler system design is to apply water uniformly. In practice, uniformity is never perfect. Distribution pattern efficiency is a measure on how uniformly water is applied to all the containers within an irrigated area (Regan, 1987). It can be estimated either on site using the can test, or by computer software. Good water distribution requires the correct nozzle size, system pressure, and sprinkler spacing. Wind disrupts application uniformity, especially when it is above $8 \mathrm{MPH}$. Low distribution pattern efficiency means that large dry areas exist. Additional irrigation water is applied to compensate for these dry areas resulting in increased use of water, overwatered areas, and excessive runoff.

With container nurseries, most the irrigation water applied through sprinklers is not stored in the root zone. Water stored in the root zone compared to the total amount of irrigation water applied is called the application efficiency and is very low due to water falling outside of the containers. Application efficiency in ornamental nurseries ranges between $15 \%$ to $25 \%$ (Beeson, 1991) and about 40\% for traveling boom irrigated forest seedlings (Dumroese et al., 1991). The application efficiency is best when the plants are small and spaced can-tight, but decreases dramatically when the spacing between containers increases. Water shedding and water holding by dense plant canopies can further reduce application efficiency by preventing water from reaching the container medium surface.

\section{CROP WATER REQUIREMENT}

Crop water requirement is the amount of water needed to replace the water lost from evapotranspiration of a healthy crop. Water use of containergrown plants is strongly influenced by the climate, and by production practices and crop characteristics (Regan, 1991). Daily weather conditions effect the amount of water a plant will use. Most temperate zone plants use more water on hot, dry, and windy days. Variation in water use also exists within the major plant groups (conifer, deciduous, broadleaf evergreen) as well as between the groups (Burger et al., 1987). Crop coefficients are used to adjust irrigation to specific production practices and crop characteristics (Doorenbos and Pruitt, 1977). For example, plants use more water when their spacing is increased and less water is used after summer pruning.
Crop coefficients are different for each growth and development stage of a specific crop. Generally, as plants get larger they require more water (Knox, 1989). During crop establishment water use is low and rather constant. As the crop develops it is influenced by the type of shoot growth and dormancy. Plants that grow continuously (freegrowth) tend to use more water than plants which have only one growth flush (fixed-growth). Plant growth rate also affects crop coefficients with fast growing species using more water (Roberts and Schnipke, 1987). Plant water use declines rapidly with the onset of dormancy and winter acclimation. Comparison of crop coefficients shows the relative difference in water use between plants or crops.

\section{IRRIGATION SCHEDULING}

Irrigation scheduling means applying only the amount of water that is needed, when it is needed. Most container growers irrigate on a daily basis and make adjustments based on crop appearance and time of year. The ideal way to schedule irrigations is by determining how much water the plants are using and then replenish it. This works well if plants with similar crop coefficients have been grouped under the same irriga- 
tion zone. Irrigation can then be scheduled for daily crop water use. If crop coefficients for each diverse species is unknown, past experience can be used to arrange plants by water use. Plants can be grouped into three general water use categories: high, moderate, and low. Each separate irrigation zone should only accommodate one of the water use categories. In addition, all plants within a zone should be at the same stage of production.

When to irrigate is based on the amount of water depleted from the container medium. Frequent irrigations (pulse or daily) that minimizes medium water depletion is considered best for plant growth and irrigation efficiency (Beeson, 1994; Karam et al., 1993). Nursery managers are likely to use container weight measurement to determine percent water depletion. They lift the container and judge the amount of water left in the container by how heavy it is. Moisture measuring technology has not advanced far enough to assist container nurseries. Containers that are allowed to dry down (below $50 \%$ medium water depletion) are very difficult to wet and cause plant stress. In dry containers, water tends to move along the sides of container with less chance of it being stored in the medium.
How much water to apply should be adjusted daily. A standard run time that delivers a specified amount of is budgeted for the weather conditions (temperature, wind, relative humidity, and sunshine) the previous day. This standard irrigation is based on crop water use for the average evapotranspiration at that time of year. This can be done by a irrigation controller operated by a trained irrigator, or by a computer. For example, if the standard amount of water to be applied is 0.4 inches, and yesterday was much cooler than normal, the irrigation budget for today might be $75 \%$ of the standard (0.3 inches). Container medium salinity is maintained by applying additional water to remove these excess salts. It is very important to evaluate how completely the available water is replenished following an irrigation.

\section{REFERENCES}

Beeson, R.C., Jr. 1994. Pulsing microirrigation in containers increases tree growth. HortScience 29(5):443. (Abstr.)

Beeson, R.C., Jr. and G.W. Knox. 1991. Analysis of efficiency of overhead irrigation in container production. HortScience 26(7):848-850.
Burger, D.W., J.S. Hartin, D.R. Hodel, T.A. Lukaszewski, and S.A. Wagner. 1987. Water use in California's ornamental nurseries. Calif. Agri., SeptOct, p. 7-8.

Doorenbos, J. and W.O. Pruitt. 1977. Guidelines for predicting crop water requirements. FAO Irrigation and Drainage Paper, No. 24, Rome, Italy. p. 1-82.

Dumroese, R.K., D.S. PageDumroese, and D.L. Wenny. 1991. Managing pesticide and fertilizer leaching and runoff in a container nursery p. 27 33. In Proceedings: Intermountain Forest Nursery Association Meeting. [Park City, Utah, August 12-16, 1991] USDA Forest Service General Technical Report RM-211, 140 p. Rocky Mountain Forest and Range Experiment Station, Fort Collins, Colo.

Kabashima, J.N. 1993. Innovative irrigation techniques in nursery production to reduce water usage. HortScience 28(4):291-293.

Karam, N.S., A.X. Niemiera, and R. Wright. 1993. Intermittent sprinkler irrigation reduces water loss from container-grown plants. Comb. Proc. Intl. Plant Prop. Soc. 43:240-243. 
Knox, G.W. 1989. Water use and average growth index of five species of container grown woody landscape plants. J. Environ. Hort. 7(4):136-139.

Regan, R.P. 1991. Crop water requirements of containergrown plants. Comb. Proc. Intl. Plant Prop. Soc. 41:229231.

Regan, R.P. 1987. Irrigation practices: Measuring sprinkler system application uniformity. ONW Newsletter 11(1):10-12.

Roberts, B.R. and V.M. Schnipke. 1987. Water requirements of five containergrown Acer species. J.

Environ. Hort. 5(4):173-175. 


\title{
Use of Container Stock in Mine Revegetation ${ }^{1}$
}

\author{
Jane Rodgers ${ }^{2}$
}

\begin{abstract}
Mining reclamation in the desert southwest has been hampered by the difficulties encountered with the climate and soils of the region. Natural recovery is slow, and direct seeding of mined areas has resulted in minimal success. The Silver Bell Mine at Joshua Tree National Monument offers an opportunity to explore the possibilities of revegetating a strip mine and its tailings using potted native plant material. Plants, rebar, wire fencing, and tools were flown into this roadless area by helicopter in February of 1994. A total of 383 plants of 24 species were outplanted using 3 types of containers which varied in depth and volume. Monitoring thus far reveals high survival of the large $(97 \%)$ and mid-size (82\%) pots, and fair survival of the smaller pots (69\%). Continued monitoring over the coming years will examine the success of these various species and pot sizes in desert mine reclamation.
\end{abstract}

\section{INTRODUCTION}

In a cooperative venture with the US Bureau of Mines, Joshua Tree National Monument began exarrining alternate ways to reclaim abandoned mines in the desert southwest. In 1993, vegetation surveys were conducted on old mine sites in the monument to collect information concerning the return of native species to disturbed mine sites versus adjacent undisturbed vegetation communities. As one might guess, results showed significant differences between disturbed and undisturbed sites, as well as between types of disturbance. During these field surveys, an abandoned mine site within the monument was selected for use as a test for mine revegetation using native nursery stock. The Silver Bell Mine in Lower Wilson Canyon, unlike many underground mines in Joshua Tree, is a surface excavation with a large disturbed area and a waste rock overburden. The soil stratum is a mixture of cobble Pinto gneiss and hematite, low in fines with little to no organic matter. Drilling depth was often limited to 15 " with a power auger and/or hand trowels.

\section{METHODS}

The project presented two challenges: transporting planting materials to a roadless site, and finding new container sizes to reduce weight and drilling depth while maximizing root mass.

Our standard container size (Tall Pot) is 30" tall and weighs 45 lbs. In 1987, the Joshua Tree Native Plants Nursery developed the Tall Pot for use in arid lands restoration (Miller et al. 1992). The pot depth allows for uninterrupted growth required by most desert plant taproots, thus maximizing root mass for outplanting in dry conditions. Our success

\footnotetext{
${ }^{1}$ Rodgers, J. 1994. Use of Container Stock in Mine Revegetation. IN: Landis, T.D.; Dumroese, R.K., tech. coords. National Proceedings, Forest and Conservation Nursery Associations. Gen. Tech. Rep. RM-257. Fort Collins, CO: U.S. Department of Agriculture, Forest Service, Rocky Mountain Forest and Range Experiment Station: 234-238. 
with the Tall Pot has been excellent, averaging $88 \%$ survival where used in wilderness areas and for roadside mitigation. Such a cumbersome container, however, would have been too difficult to transport to Silver Bell. The solution was to try three types of pots significantly smaller than our Standard Tall Pot (Table 1), and sling-load them up to the site using a helicopter (Figure 1.) In looking for smaller containers, we found a one-gallon Citrus Pot $^{\mathrm{TM}}$ and four-gallon Tree Pot ${ }^{\mathrm{TM}}$ from Stuewe \& Son, and fashioned the third container by cutting our Tall Pot in half. Each of these had the advantage of being taller and slimmer than typical nursery gallon pots, yet easier to work with than our standard Tall Pot.

In the summer of 1993, the nursery collected seed of 29 different plant species; of these, 24 species were successfully propagated and outplanted at Silver Bell. By early February, nursery stock and planting equipment were sling-loaded up to Silver Bell along with 1500 gallons of water dropped into a port-a-tank. Throughout the month of February, the planting crew worked on benches, small bench slopes, road paths, and a wasterock slope. Digging holes proved challenging, and often our 2-person power auger went astray, jettisoning off large rocks

Table 1. Standard container vs. new containers.

\begin{tabular}{lcccc}
\hline $\begin{array}{l}\text { Container } \\
\text { Size }\end{array}$ & $\begin{array}{c}\text { Height } \\
\text { (in.) }\end{array}$ & $\begin{array}{c}\text { Diameter } \\
\text { (in.) }\end{array}$ & $\begin{array}{c}\text { Volume } \\
\left.\text { (in }^{3}\right)\end{array}$ & $\begin{array}{l}\text { Nursery } \\
\text { Growing } \\
\text { Period }\end{array}$ \\
$\begin{array}{l}\text { Standard } \\
\quad \text { Tall Pot }\end{array}$ & 30 & 6 & 855 & $1 \mathrm{yr}$ \\
$\begin{array}{l}\text { Tree Pot } \\
\text { Half-tall }\end{array}$ & 18 & 7.5 & 601 & 7 mos. \\
Citrus Pot & 15 & 6 & 416 & 6 mos. \\
& 14 & 4 & 231 & 4 mos. \\
\hline
\end{tabular}

encountered in the meager soil stratum. Most of the slope planting used hand trowels and the smallest container stock (Figure 2).

During this time, there were only one or two light showers at the mine with frequent gusty winds prevailing, desiccating much of the stock awaiting outplanting. On February 25 planting was completed and the remaining water used to water the plants a second time (Figure 3). The cumulative precipitation from February through June measures 1.18 inches.

\section{RESULTS AND DISCUSSION}

Since planting, we have monitored the site twice for plant survival and health. Each plant was mapped out, using aluminum tags for identification, and then recorded in our nursery database. On April 1, there was $84 \%$ survival and on June 16 , with increased temperatures, that fell to $77.5 \%$ (Table 2). Numbers are expected to continue decreasing during the hot summer, but we will have a better idea of survival after late summer and spring rains. Thirteen photo points have been established, and will be updated annually for

Table 2. Survival by container size.

\begin{tabular}{lll} 
Container Size & $\underline{04-01-94}$ & $\underline{06-16-94}$ \\
Tree Pot $(n=77)$ & $97 \%$ & $97 \%$ \\
Half-tall $(n=78)$ & $86 \%$ & $82 \%$ \\
Citrus Pot $(n=223)$ & $\underline{78 \%}$ & $\underline{69 \%}$ \\
Overall Survival & $84 \%$ & $77.5 \%$ \\
\hline
\end{tabular}




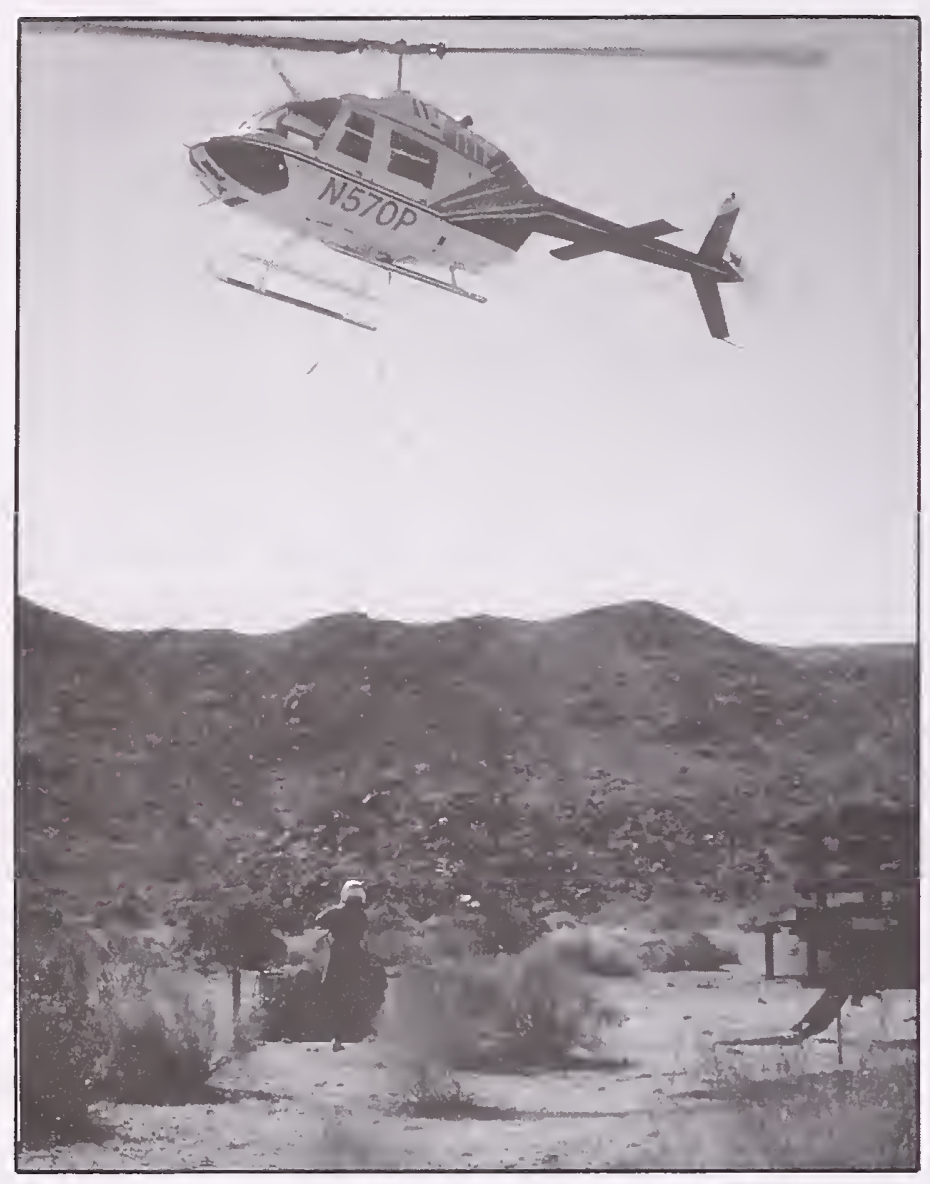

Current trends between species, based on a minimum of six representative outplanted stock, show significant differences in establishment success. Species with less than $70 \%$ survival are as follows: Adenophyllum porophyloides, Cucurbita palmata, Hyptis emoryi, Marina parryi, Pleuraphis rigida, and Senna armata. Those with greater than 90\% survival include: Ambrosia dumosa, Encelia virginensis, Hymenoclea salsola, Isomeris arborea, Sphaeralcea ambigua, and Xylorhiza tortifolia. (See Appendix for complete species list).

\section{Figure 1.}

the next five years, and every five years thereafter, providing us with visual images of the progress of the stock as well as any natural volunteers to the site.

While incoming data provides only a glimpse at the long-term success of this project, mortality percentages already reveal trends among container sizes. Each monitoring of the site for plant survival showed a relationship between plant vigor and container size; on both occasions, highest mortality occurred in the smallest containers. Sloped areas versus flat benches seems to affect small stock survival; on the slopes, where soil is limited, June survival was $63 \%$ as compared to $78 \%$ survival on the flatter areas.

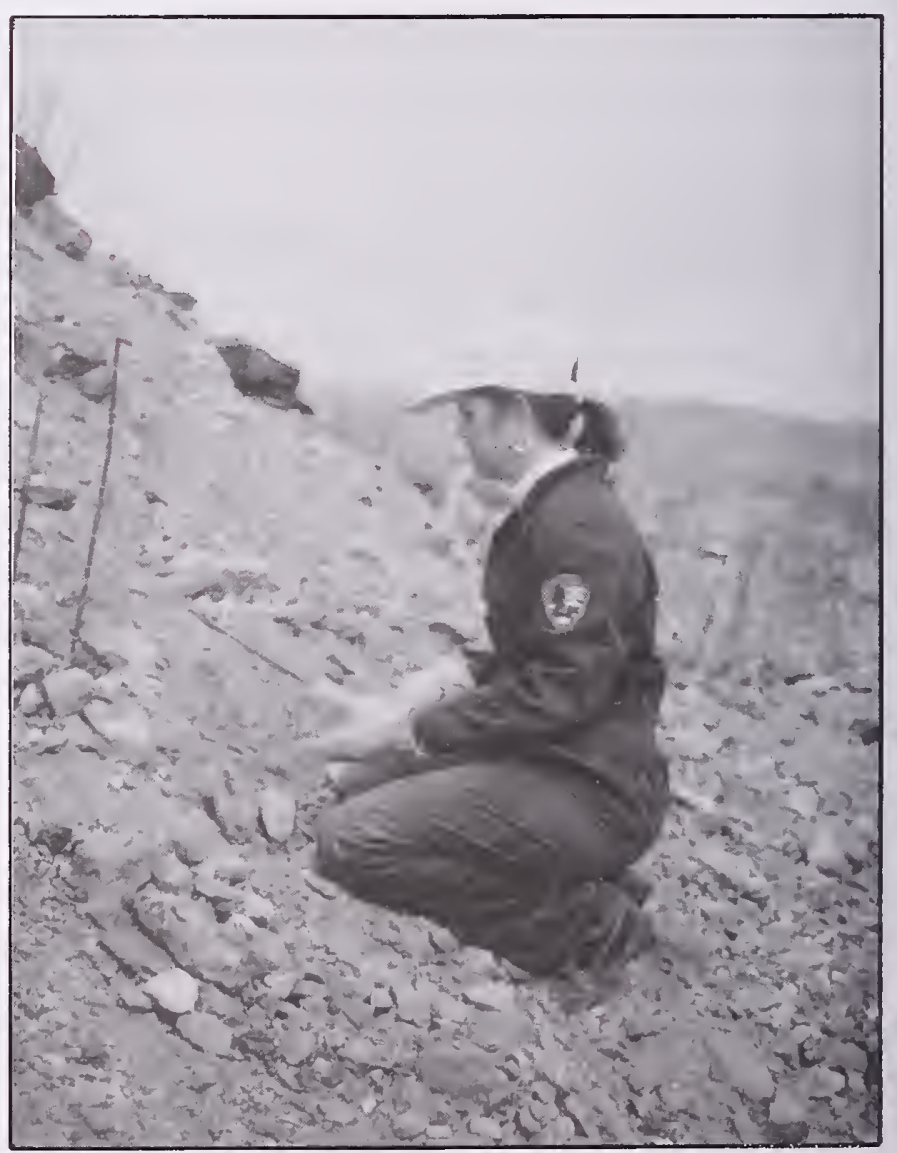

Figure 2. 


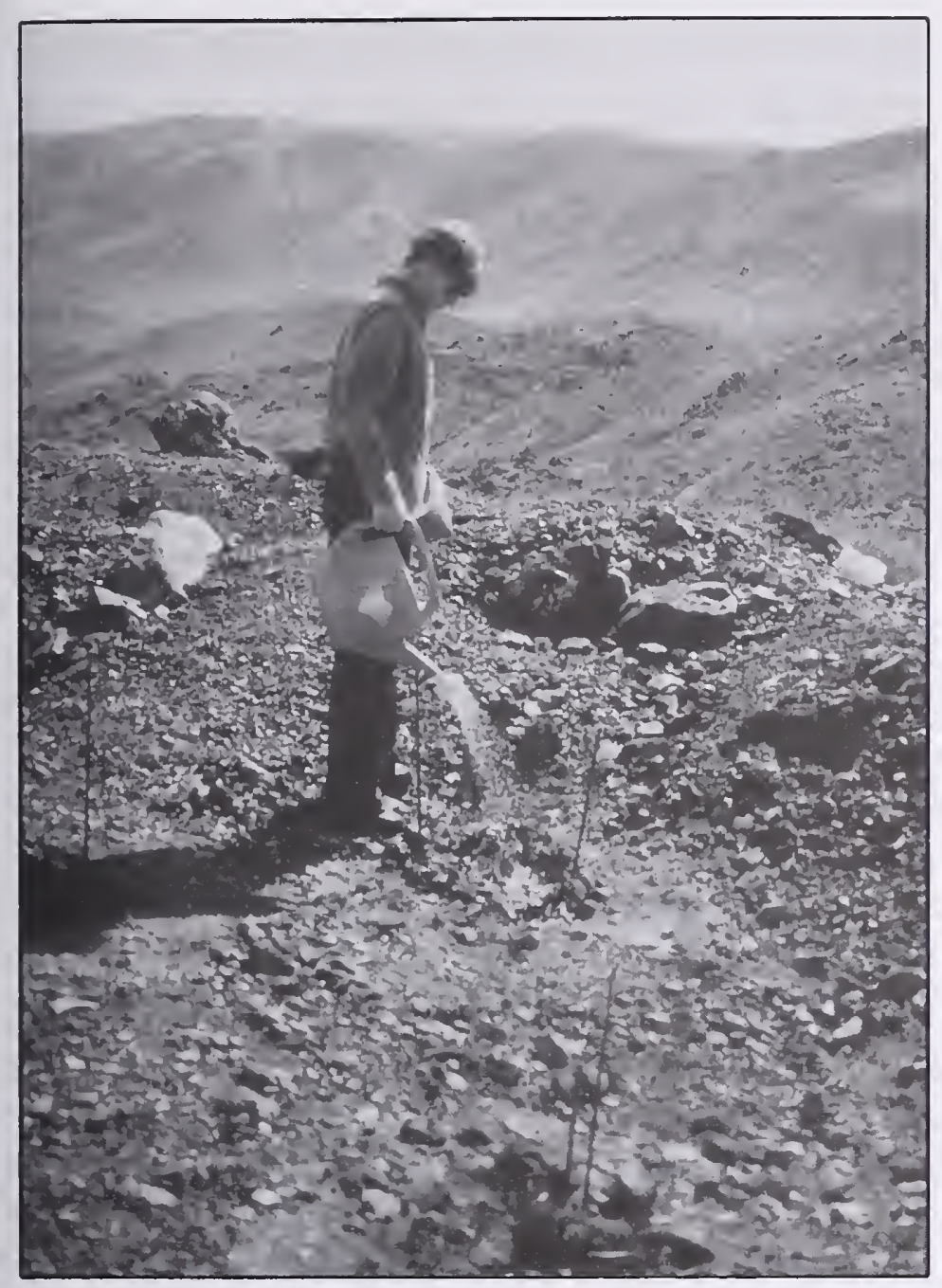

Figure 3.

In summary, high mortality amongst the smaller containers versus the two larger containers may be due to a variety of factors:

- reduced root growth potential, based on container volume

- quantity of fertilizer-enriched nursery soil mixture included with each transplant, based on container volume

- premature outplanting (Pleuraphis rigida)

- shorter growing time in the nursery over 14 inches deep for tap root development and of sufficient volume to allow for maximum fibrous root growth, greatly increase prospects for desert nursery stock survival. With larger and/or more remote areas in need of revegetation, success at the Silver Bell Mine could lead the way in changing rehabilitation methodologies for abandoned mines and other severely disturbed desert sites.

\section{LITERATURE SITED}

Miller, C., and M. Holden. 1992. Propagating Desert Plants. In Proceedings Western Forest Nursery Association Meeting, Stanford Sierra Camp, Fallen Leaf Lake, CA., Sept. 1418, 1992.

\section{ACKNOWLEDGEMENTS}

- due to their small size, the citrus pots were easier to outplant in rockier and thus harsher sites

- differences between species

As monitoring continues, we will have a better idea of optimum container size and species selection for revegetating landscapes such as the Silver Bell Mine. Use of containers smaller than our Tall Pot in arid lands restoration could significantly reduce costs, increase nursery production, and still meet the need for large root mass and deep taproots. These containers,
I would like to recognize the staff at the Joshua Tree Native Plants Nursery for their dedication and enthusiasm for desert protection and restoration. Without their belief in this humble ecosystem, projects of such tremendous challenge and benefit would not exist. 
Scientific Name

Adenophyllum porophyloides Ambrosia dumosa Bebbia juncea Cucurbita palmata Encelia virginensis Eriogonum fasciculatum Erioneuron pulchellum Hibiscus denudatus Hymenoclea salsola Hyptis emoryi Isomeris arborea Larrea tridentata Marina parryi Mirabilis bigelovii Physalis hederifolia Pleuraphis rigida Psorothamnus schottii Salazaria mexicana Senna armata Sphaeralcea ambigua Stephanomeria pauciflora Trixis californica Vigueria parishii Xylorhiza tortifolia

\section{Common Name}

Dyssodia

Burrobush

Sweetbush

Coyote Melon

Brittlebush

Red-top Buckwheat

Fluff Grass

Desert Hibiscus

Cheesebush

Desert Lavender

Bladderpod

Creosote

Marina

Four o'clock

Ground Cherry

Galleta Grass

Purplebush

Paperbag Bush

Desert Senna

Desert Mallow

Desert Straw

Trixis

Parish Vigueria

Mojave Aster 


\title{
Protocols for Mass Micropropagation of Antelope and Desert Bitterbrush ${ }^{1}$
}

\author{
Annette Leege-Brusven², John L. Edson², David L. Wenny² and Min Hironaka ${ }^{3}$
}

Abstract-Vegetative propagation of Purshia tridentata and $P$. glandulosa could potentially capture and multiply valuable genetic traits such as fire resistance and produce plants which reproduce in a shorter time than seedlings. The goal of this research was to develop mass propagation protocols for antelope and desert bitterbrush using micropropagation techniques. Microshoot tips were incubated in vitro on alternative nutrient media supplemented with different levels of cytokinin and auxin growth regulators. An average of 7.9 shoots/explant of $P$. tridentata were produced after 1 month on Woody Plant Medium (WPM) supplemented with $0.1 \mathrm{mg} / \mathrm{l}$ benzlyadenine (BA). P. glandulosa multiplied 5 -fold over 1 month on the same media. Best rooting occurred ex vitro for both species. P. tridentata microshoots rooted at $88.6 \%$ after treatment with Hormex $\# 1(0.1 \%$ IBA $)$ and $P$. glandulosa microshoots rooted up to $78 \%$ after treatment with Hormex®\#3 $(0.3 \%$ IBA $)$. Flowering and fruiting of micropropagated plantlets from both species occurred after one season's growth in the greenhouse. These successful mass propagation systems for bitterbrush could play an important role in range restoration.

\section{INTRODUCTION}

Antelope and desert bitterbrush (Purshia tridentata (Pursh) DC. and P. glandulosa Curran, respectively) are roseaceous, nutritive forage shrubs in the semi-arid rangelands of Utah, Nevada, Idaho and California (Welch et al., 1982). Wild-fires and livestock overgrazing have degraded range habitat and reduced the population of both bitterbrush species. Since efforts to propagate mate- rial for revegetation projects have been hindered by seed dormancy and seed predation (Young and Evans, 1981), vegetatively propagated plants could provide an alternative and more reliable source of planting stock. Micropropagated antelope and desert bitterbrush plants, produced in a relatively short time, could potentially restore damaged habitat with fireresistant, palatable, nutritious and drought-hardy selections.
This paper describes masspropagation protocols for antelope and desert bitterbrush and evaluates the effects of culture media and plant growth regulators on multiplication and rooting.

\section{GENERAL METHODS}

\section{Culture initiation}

Our source of $P$. tridentata and P. glandulosa material was wild seed, collected from rangeland shrubs in southern Idaho

\footnotetext{
'Leege-Brusven, A.; Edson, J.L.; Wenny, D.L.; Hironaka, M. 1994. Protocols for Mass Micropropagation of Antelope and Desert Bitterbrush. IN: Landis, T.D.; Dumroese, R.K., tech. coords. National Proceedings, Forest and Conservation Nursery Associations. Gen. Tech. Rep. RM-257. Fort Collins, CO: U.S. Department of Agriculture, Forest Service, Rocky Mountain Forest and Range Experiment Station: 239-245.
}

2University of Idaho Forest Research Nursery, Moscow, Idaho 83844-1137.

${ }^{3}$ Range Resources, Department of Range Resources, University of Idaho, Moscow, Idaho. 
and Nevada, respectively. Seedlings were grown in pots at the University of Idaho Plant Science greenhouse. Shoot tips of new growth were collected from 2-yr-old containerized seedlings and placed in sterile culture for propagation.

The cuttings were washed in running tap water for $30 \mathrm{~min}$. Leaves were excised from the stems, and the defoliated shoots were agitated for $10 \mathrm{~min}$ in an aerated aqueous solution containing 5 drops of Tween ${ }^{\circledR} 80$ per liter. The stems were then surface sterilized for $15 \mathrm{~min}$ in a continuously stirred $20 \%$ Clorox $^{\circledR}$ bleach solution ( $1 \%$ $\mathrm{NaClO}$ ) and rinsed $3 \mathrm{X}$ in sterile, distilled, deionized water. The stem segments were given fresh basal cuts and placed individually in $25 \times 150 \mathrm{~mm}$ test tubes containing $10 \mathrm{ml}$ of Murashige and Skoog (MS) basal medium (Murashige and Skoog, 1962). These and all subsequent cultures grew on open shelves under an 18-h photoperiod provided by cool-white fluorescent lights $(40 \mathrm{~W})$ which produced approximately 20 umoles $\mathrm{m}^{-2} \mathrm{~s}^{-1} \mathrm{PAR}$ on the leaf surfaces. Diurnal temperatures ranged from $22^{\circ}$ to $27^{\circ} \mathrm{C}$.

To increase the number of microshoots available for experiments, stems were cut into 2node segments and transferred to fresh media monthly until sufficient numbers of uniform healthy microshoot tips were produced.

\section{Selecting a culture medium}

Although MS medium has commonly been used as a substrate for micropropagation, many woody plants grow better on other defined media with lower concentrations of mineral nutrients (Bonga and von Aderkas, 1992) such as Woody Plant Medium (WPM) (Lloyd and McCown, 1980). Hence, we cultured microshoots on MS and WPM media to detect differences in shoot elongation and the number of axillary shoots produced.

\section{Shoot multiplication}

Microplants exposed to potent and high levels of cytokinins in culture media often produce adventitious as well as axillary shoots (Huetteman and Preece, 1993), and adventitious shoot production has been linked to increased rates of somaclonal variation (Pierik, 1987). To decrease the possibility of adventitious shoot formation, thus, maintaining the genotypes of the bitterbrush shoots, the cytokinin benzyladenine (BA) was used at low to moderate levels for shoot multiplication.

\section{Ex vitro rooting}

The effect of several commercial auxin preparations on the rooting of microshoots was assessed after 6 weeks growth under fog humidification on a greenhouse propagation bench. The auxin treatments were either basal talc dips in: Hormex ${ }^{\circledR} \# 1$ $(0.1 \%$ indolebutyric acid (IBA));
Hormex $^{\circledR} \# 3$ (0.3\% IBA); Hormex ${ }^{\circledR} \# 8$ (0.8\% IBA); or Rootone ${ }^{\circledR}$ (0.2\% naphthaleneacetic acid (NAA) plus 4.04\% Thiram $\left.^{\circledR}\right)$; or a 5 -sec dip in a 1:10 solution of Dip ' $n$ Grow $^{\circledR}$ ( $0.1 \%$ IBA and $0.05 \%$ NAA). All microshoots were immersed in $1 \mathrm{~g} / \mathrm{l}$ of the fungicide benomyl for $20 \mathrm{sec}$ before being treated and planted. The treated microshoots were placed on propagation benches under $60 \%$ shade and natural photoperiod. Root zone temperatures varied from $20^{\circ}$ to $22^{\circ} \mathrm{C}$, relative humidity from 86 to $92 \%$, and diurnal air temperatures from $15^{\circ}$ to $25^{\circ} \mathrm{C}$.

\section{PROPAGATION OF PURSHIA TRIDENTATA}

\section{Materials and methods}

Culture medium: 90 microshoots were equally assigned to hormone-free MS, WPM and $1 / 2$ MS. To compare microshoot elongation and new shoot production on the same 3 media containing BA, 450 shoot tips were randomly assigned to WPM, MS or $1 / 2 \mathrm{MS}$, each supplemented with $0.1 \mathrm{mg} / \mathrm{l} \mathrm{BA}$. After 4 weeks, microshoot elongation, the number of new shoots and health scores were recorded for each explant.

Shoot multiplication: 270, 1.5-cm-long microshoot tips were assigned in equal numbers to 9 concentrations of BA ( 0 , $0.025,0.05,0.1,0.2,0.4,0.8$, 


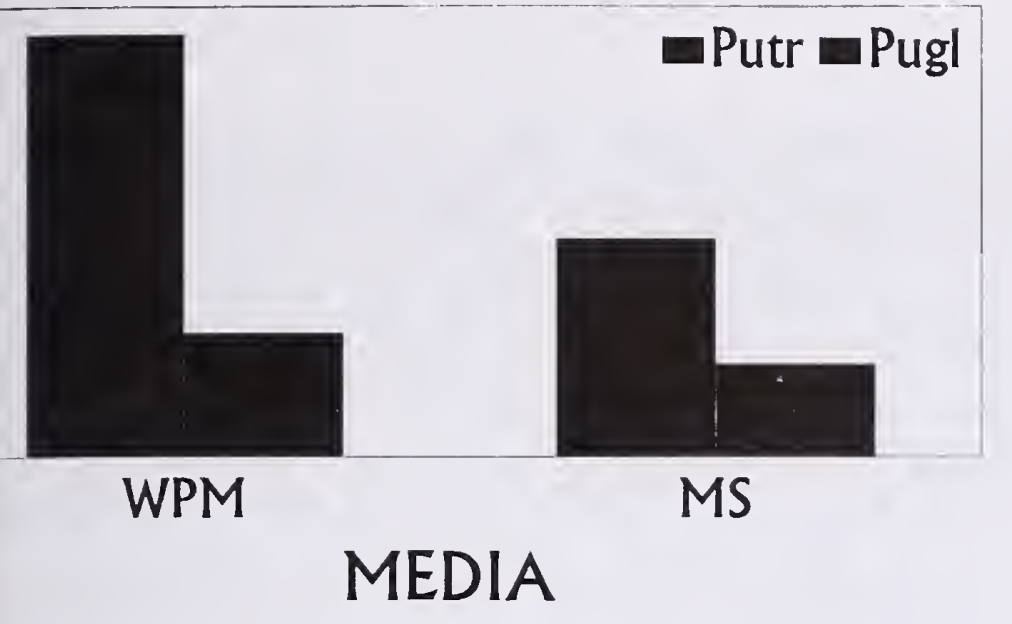

1.6 , and $3.2 \mathrm{mg} / \mathrm{l}$ ) on WPM, arranged in a CR design. After 4 weeks, shoot elongation and counts of all new shoots were recorded.

In vitro rooting: 200 microshoots were assigned to 2 replicates of 4 auxin treatments arranged in a RCB design. The treatments included a 5-sec NAA $(1,000 \mathrm{mg} / \mathrm{l})$ basal dip and culture on hormone-free WPM, and placement on WPM containing $0,0.1$ and $1.0 \mathrm{mg} / \mathrm{l} \mathrm{NAA}$. Rooted microshoots were tallied after 4, 6 and 8 weeks. In a second experiment, $4321-\mathrm{cm}$ long microshoots were either dipped or not dipped in 1,000 $\mathrm{mg} / \mathrm{l} \mathrm{NAA}$ and placed on $1 / 2 \mathrm{MS}$ or WPM.

Ex vitro rooting: $480,1-\mathrm{cm}-$ long microshoots were removed from test tubes and assigned to 3 replicates of a control (no hormone), Hormex ${ }^{\circledR} \# 1$, Rootone ${ }^{\circledR}$ and Dip " $n$ Grow" arranged in a RCB design. The treated shoots were struck into 5-ml capacity miniplug cells containing a 2:1:1 mix of perlite, peat and vermiculite $(\mathrm{v} / \mathrm{v})$.

Acclimatization: 50 -in vitro- rooted microshoots with normal root development were transplanted to $215 \mathrm{cc}$ capacity cells filled with a 1:1:1 mix of perlite, vermiculite, and peat $(\mathrm{v} / \mathrm{v})$. The plants grew under natural light with greenhouse temperatures varying from $15^{\circ}$ to $25^{\circ} \mathrm{C}$ during the growing season. Survival, shoot growth, number of stems, and flowering habit were recorded 1 year later on a random sample of 30 survivors.

\section{Results and discussion}

Culture Medium: After 1 month in culture, the microshoots on BA-free MS, $1 / 2$ MS and WPM elongated an average of only $4 \mathrm{~mm}$ and produced no new shoots. In contrast, microshoots on the same 3 media supplemented with $0.1 \mathrm{mg} / \mathrm{l} \mathrm{BA}$ lengthened rapidly and produced vigorous new shoots. Greatest stem elongation and new shoot production occurred on WPM. The microshoots grew an average of 0.8 and $1.1 \mathrm{~cm}$ taller on WPM versus $\mathrm{MS}$ and $1 / 2 \mathrm{MS}$, respectively $(p=0.0008)$, and developed an average of 5 more new shoots per explant on WPM versus MS ( $p=0.0002)$.
The new shoots on WPM developed normal healthy foliage (mean health score 2.3) versus slightly more chlorotic growth on MS (2.1), and $1 / 2 \mathrm{MS}$ (1.4) media $(p=0.005)$. Because the bitterbrush microshoots grew more vigorously on WPM than on either MS or $1 / 2$ MS, we selected WPM as the medium for subsequent in vitro experiments.

Shoot Multiplication: New shoots developed from axillary nodes and the bases of explants treated with varying levels of BA. In contrast, the explants on BA-free medium were stunted and failed to release axillary shoots. The number of new shoots increased from 0 on hormone-free medium, to a maximum average of 15 , after treatment with $0.8 \mathrm{mg} / \mathrm{l} \mathrm{BA}$, and then declined at higher concentrations of BA. Maximum stem growth $(1.8 \mathrm{~cm})$ occurred with treatment of $0.1 \mathrm{mg} / \mathrm{l} \mathrm{BA}$, and decreased significantly after treatments $>0.2 \mathrm{mg} / \mathrm{l} \mathrm{BA} \mathrm{(} \mathrm{p}=$ $0.0001)$. The difficulty of clearly identifying axillary shoots increased when BA concentrations rose above 0.2 $\mathrm{mg} / \mathrm{l}$, due to shorter stem internodes and increased basal shoot proliferation. Therefore, the maximum shoot count of 15 may include adventitious shoots less desirable for clonal production. The BA level of $0.1 \mathrm{mg} / \mathrm{l}$ resulted in optimal elongation, a moderate number of new shoots 
produced, and reasonable assurance of the axillary nature of the new shoots.

\section{In vitro rooting: NAA} seemed to inhibit normal rooting. Microshoots on NAA-free WPM (control) developed white "normal" roots which penetrated to the bottom of the test tube. Explants on the NAA-supplemented media, however, developed "aerial" horizontal fibrous roots on the surface of the medium and produced few if any normal roots. In the second experiment, $11 \%$ of the NAAtreated microshoots rooted versus $53 \%$ of the non-treated explants $(\mathrm{p}<0.0001)$ after 6 weeks in culture. Rooting was similar on both WPM and $1 / 2$ MS incubation media.

Ex vitro rooting: Microshoots rooted more successfully ex vitro than in vitro (Fig. 1). After 6 weeks, $62 \%$ of the untreated microshoots (control) had rooted versus $88.6 \%$ and $79.0 \%$ of the microshoots treated with Rootone ${ }^{\circledR}$ and Hormex ${ }^{\circledR} \# 1$, respectively. The microshoots treated with Dip 'n Grow ${ }^{\circledR}$ rooted at $65.3 \%$. We infer that a low rate of auxin, applied as either IBA or NAA powder treatment, will likely result in ex vitro rooting at a level sufficient for commercial production.

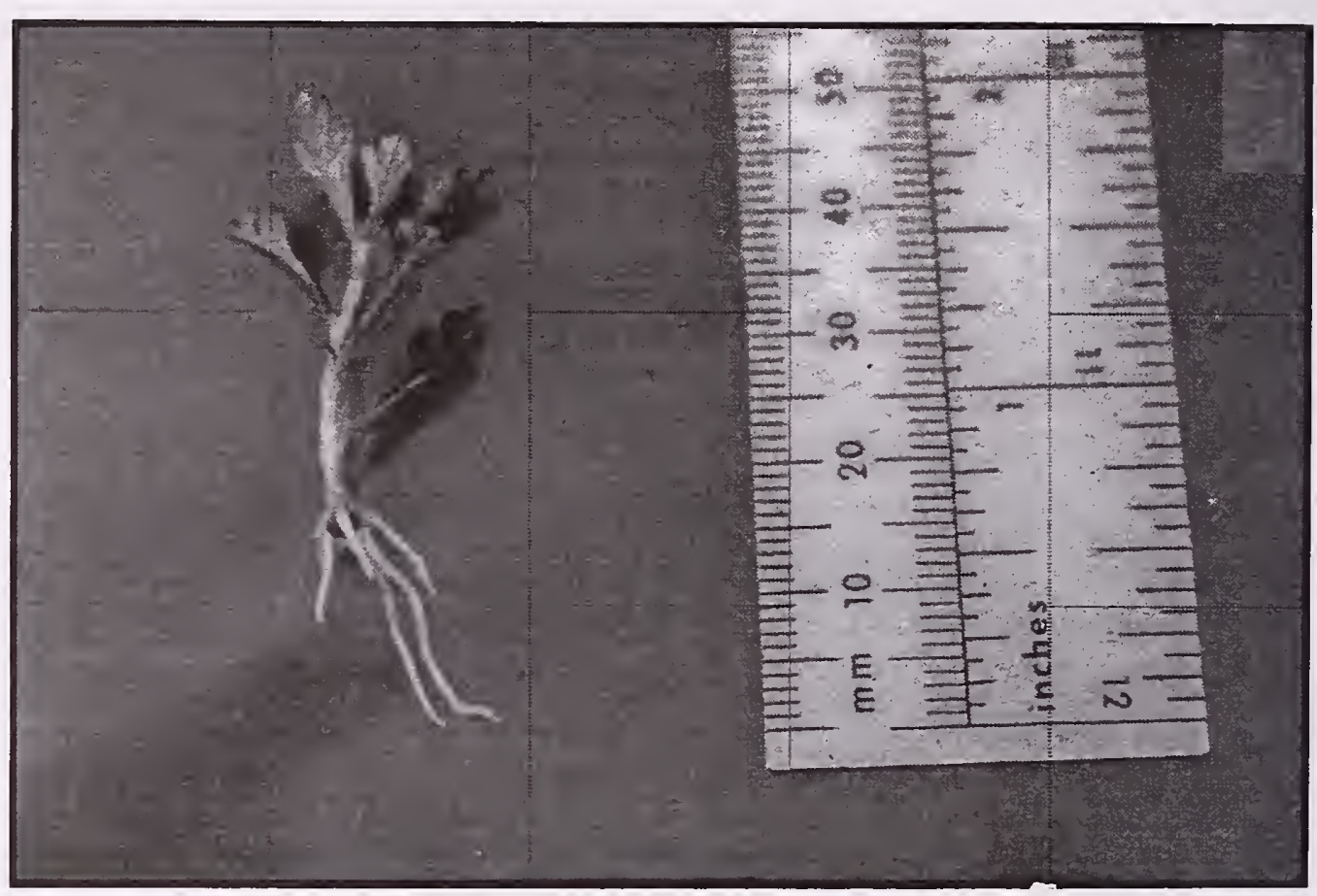

Figure 1. Ex vitro rooted Purshia tridentata plantlet 4 weeks after treatment with $0.1 \%$ IBA.

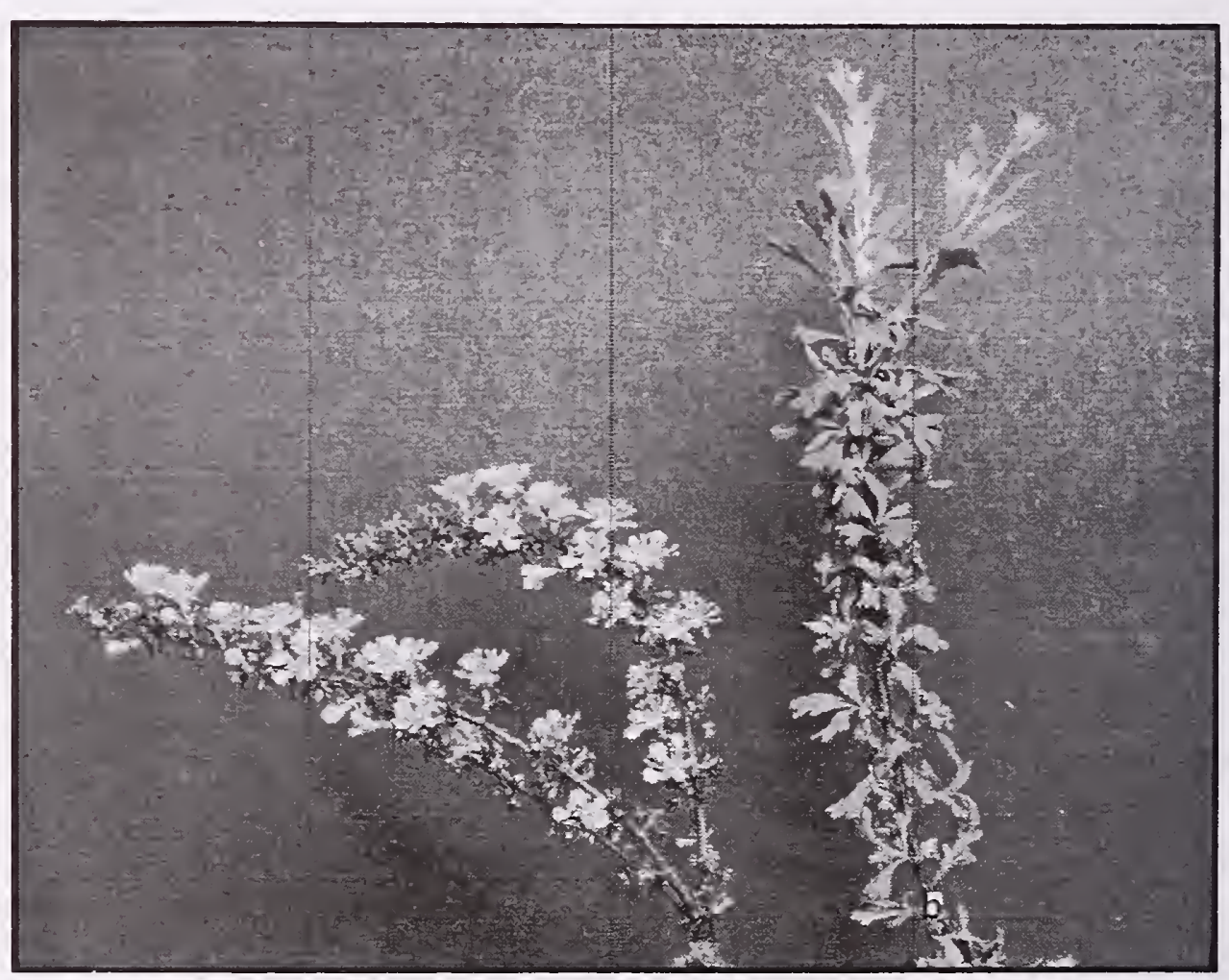

Figure 2. Flowering desert bitterbrush (left) and antelope bitterbrush (right) after 1 year in the greenhouse. 
Acclimatization: Four months after transplant, $85 \%$ of the plantlets remained alive with no subsequent death. By the end of the first year's growth in the greenhouse, the plantlets had produced leaders with an average extension of $16.4 \mathrm{~cm}$. The plantlets bloomed heavily within 1 month of budbreak with an average of 20 flower buds on each leader (Fig. 2). The precocious and prolific flowering of the plantlets suggests that regeneration could occur the first year after outplanting this type of planting stock if conditions are favorable for establishment.

\section{PROPAGATION OF PURSHIA GLANDULOSA}

\section{Materials and methods}

Culture medium: $360,2-\mathrm{cm}-$ long shoot tips were excised and placed randomly on MS or WPM containing $0.1 \mathrm{mg} / \mathrm{l} \mathrm{BA}$. After 5 weeks, we calculated stem elongation and counted the number of axillary shoots produced.

Shoot multiplication: 160 shoot tips were randomly assigned to 24 treatment combinations of $\mathrm{MS}+0,0.05,0.1,0.2$, $0.4,0.9,1.8$ or $3.6 \mathrm{mg} / \mathrm{l} \mathrm{BA}$. Twenty microshoots were used per treatment. After 4 weeks, shoot elongation and the number of axillary bud breaks were recorded for each shoot.

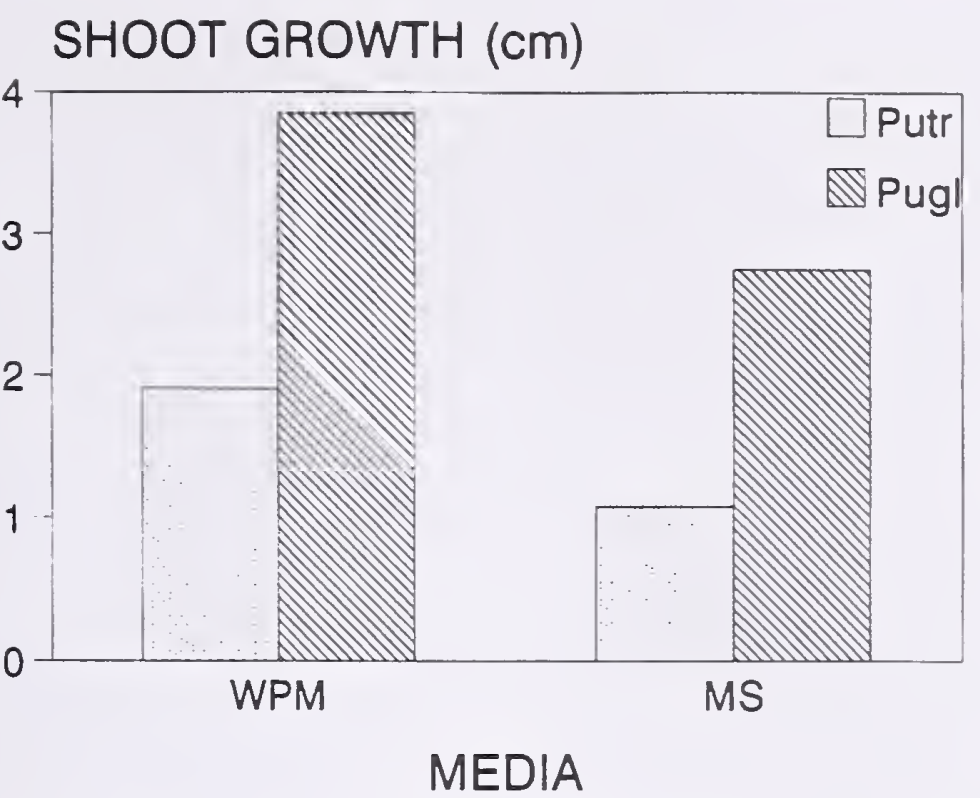

Figure 3. Effect of Woody Plant Medium (WPM) and Murashige and Skoog medium (MS) on shoot elongation of $P$. tridentata (Putr) and $P$. glandulosa (Pugl) microshoots after 4 weeks in culture.

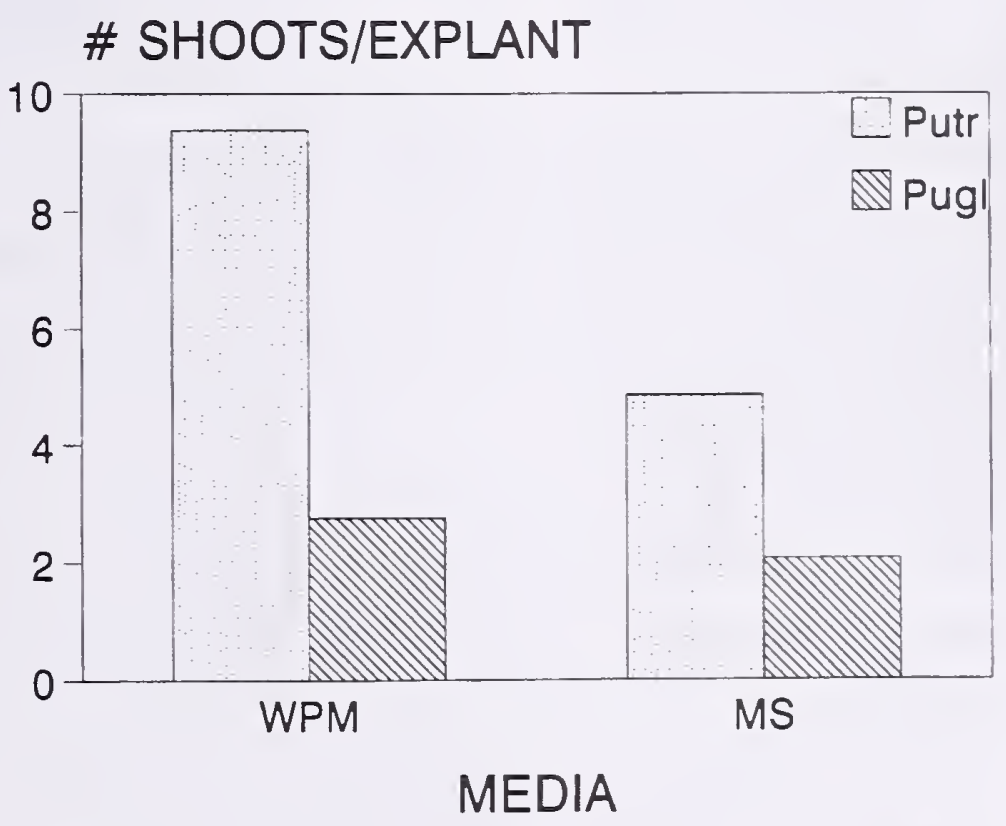

Figure 4. Effect of Woody Plant Medium (WPM) and Murashige and Skoog medium (MS) on shoot production of $P$. tridentata (Putr) and P. glandulosa (Pugl) microshoots after 4 weeks in culture.

In vitro rooting: $216,2-\mathrm{cm}-$ long microshoots were divided among 6 media (MS, $1 \frac{2}{2} \mathrm{MS}$ and WPM supplemented with or without $1 \mathrm{mg} / \mathrm{l} \mathrm{NAA}$ ). Rooting was recorded after 4, 6, 8 and 10 weeks.
Ex vitro rooting: Nonlignified microshoots were cut into 600,3-cm-long shoot tips and 600 stem segments. Forty tips and 40 segments were randomly assigned to each of 5 hormone treatments: a control (no hormone), Hormex® \#3, 
Hormex ${ }^{\circledR} \# 8$, Rootone ${ }^{\circledR}$, and Dip 'n Grow ${ }^{\circledR}$. The experiment was replicated twice in a randomized split-plot design. The explants were struck in 5-ml capacity miniplug cells containing a 1:1 mix of Sunshine $\mathbb{R}$ \#3 and perlite.

Acclimatization: 40 rooted microshoots were transferred from agar medium to $164 \mathrm{cc}$ capacity Ray Leach $\AA$ containers containing Sunshine $\mathbb{}(\# 2$. Observations were made a year later on shoot growth, number and location of branches, and incidence of flowering and fruiting.

\section{Results and discussion}

\section{Culture medium: Stem} elongation and axillary shoot production were enhanced significantly on the WPM $(\mathrm{p}<0.001)$ versus MS medium (3.85 vs. $2.75 \mathrm{~cm}$ and $2.75 \mathrm{vs}$. 2.06 shoots, respectively). $P$. glandulosa microshoots developed taller stems but fewer axillary shoots than $P$. tridentata explants on both media (Figs. 3 \& 4). Using a low level of BA $(0.1 \mathrm{mg} / \mathrm{l})$ would avoid the foliar chlorosis and adventitious shoot production associated with the higher levels of BA in the medium, a distinct advantage when propagating selected genetic traits.

\section{Shoot multiplication:}

Microshoots developed tall, single stems on hormone-free medium (Fig. 5), in contrast to

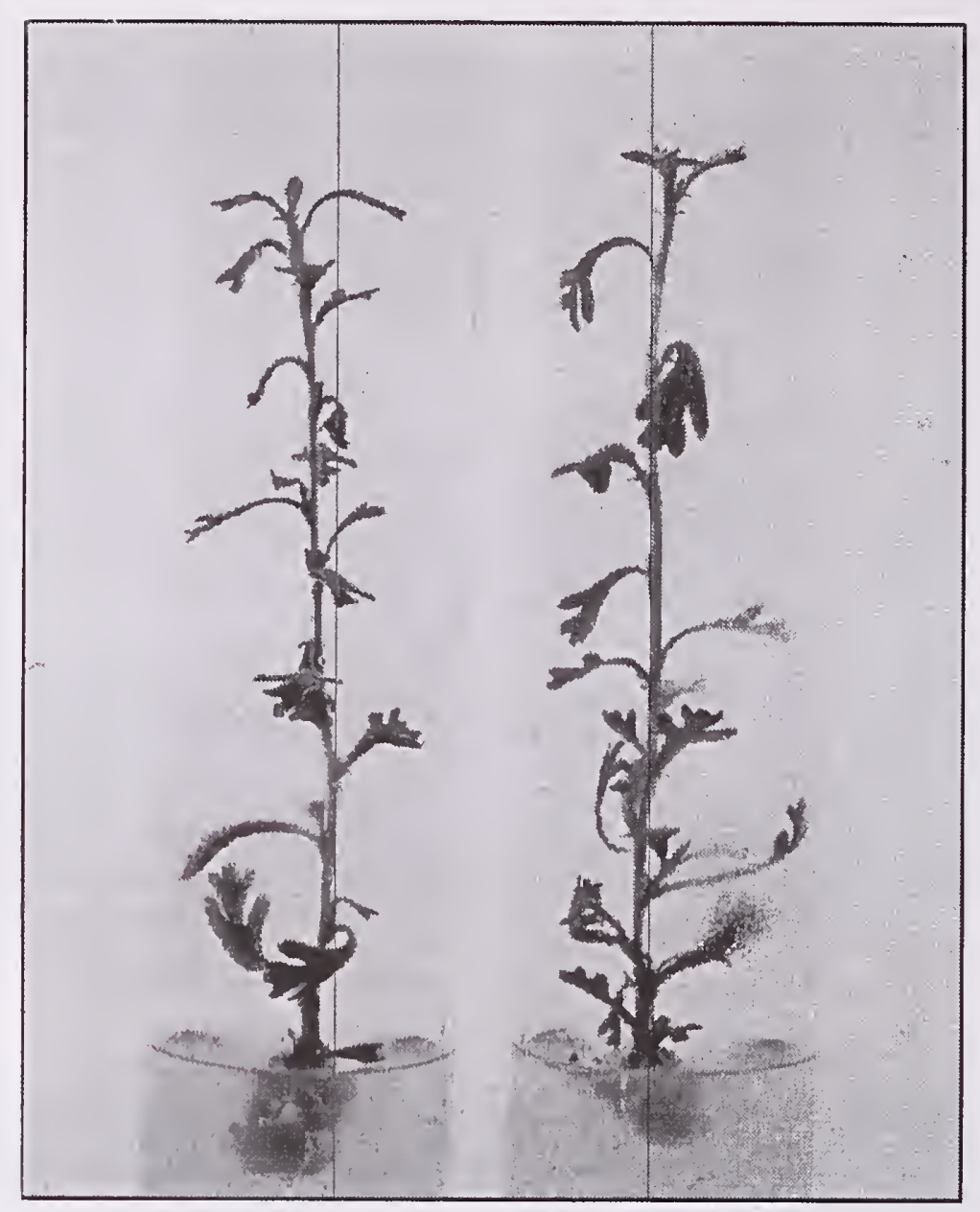
Figure 5. Purshia glandulosa microshoots after 1
month on hormone-free WPM. Note tall,
single stem growth.

the stunted growth of $P$. tridentata on BA-free media. Explants achieved maximum growth with $0.1 \mathrm{mg} / 1 \mathrm{BA}(3.5$ $\mathrm{cm})$ and were shorter with more axillary bud break after treatments $>0.2 \mathrm{mg} / \mathrm{l} \mathrm{BA}$. The number of new shoots increased from 0 on BA-free medium, to a maximum average of 5.0 shoots per explant after treatment with $0.4 \mathrm{mg} / 1 \mathrm{BA}$, and then declined at higher concentrations of BA.

In vitro rooting: The best rooting (44\%) occurred after 10 weeks on WPM $+1 \mathrm{mg} / \mathrm{l} \mathrm{NAA}$ as compared to $0 \%$ and $19 \%$ rooting on NAA-supplemented $\mathrm{MS}$ and $1 / 2 \mathrm{MS}$, respectively. None of the microshoots on MS produced roots, regardless of whether NAA was present or not in the medium. This data suggests the most important factor in rooting is the basal medium. In contrast to the response of $P$. tridentata, NAA did not inhibit rooting.

Ex vitro rooting: Microshoot tips rooted most successfully after they were treated with a low concentration of auxin. After 6 weeks, $28 \%$ of the untreated microshoots had rooted versus $74 \%, 72 \%$, and 


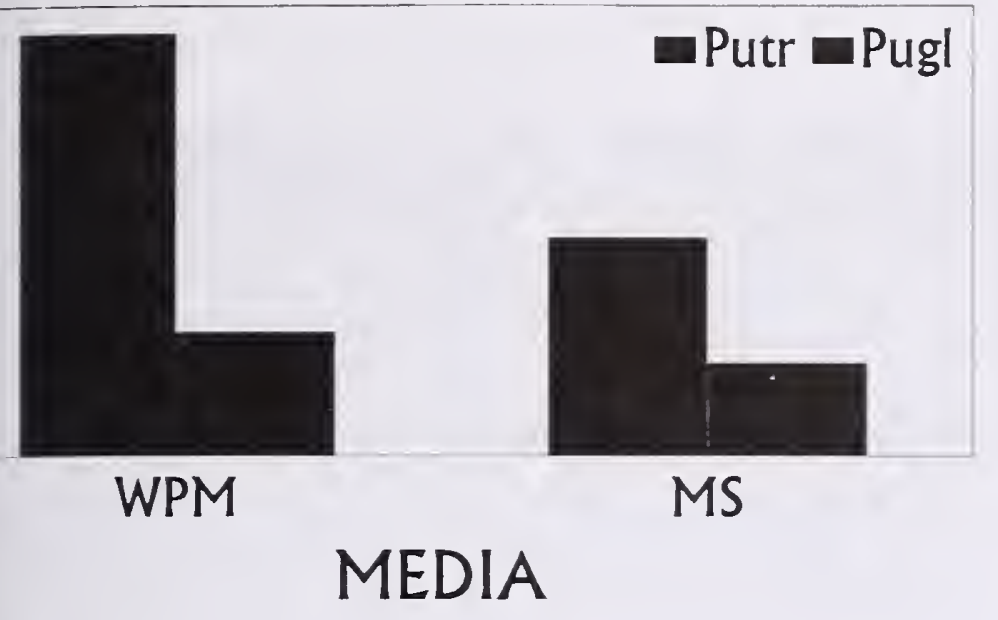

1.6 , and $3.2 \mathrm{mg} / \mathrm{l}$ ) on WPM, arranged in a CR design. After 4 weeks, shoot elongation and counts of all new shoots were recorded.

In vitro rooting: 200 microshoots were assigned to 2 replicates of 4 auxin treatments arranged in a RCB design. The treatments included a 5 -sec NAA $(1,000 \mathrm{mg} / \mathrm{l})$ basal dip and culture on hormone-free WPM, and placement on WPM containing $0,0.1$ and $1.0 \mathrm{mg} / \mathrm{l} \mathrm{NAA}$. Rooted microshoots were tallied after 4, 6 and 8 weeks. In a second experiment, $4321-\mathrm{cm}$ long microshoots were either dipped or not dipped in 1,000 $\mathrm{mg} / \mathrm{l} \mathrm{NAA}$ and placed on $1 / 2 \mathrm{MS}$ or WPM.

Ex vitro rooting: $480,1-\mathrm{cm}-$ long microshoots were removed from test tubes and assigned to 3 replicates of a control (no hormone), Hormex ${ }^{\circledR} \# 1$, Rootone ${ }^{\circledR}$ and Dip " $n$ Grow ${ }^{\otimes}$ arranged in a RCB design. The treated shoots were struck into 5 -ml capacity miniplug cells containing a $2: 1: 1$ mix of perlite, peat and vermiculite $(\mathrm{v} / \mathrm{v})$.

Acclimatization: 50 -in vitro- rooted microshoots with normal root development were transplanted to $215 \mathrm{cc}$ capacity cells filled with a 1:1:1 mix of perlite, vermiculite, and peat $(\mathrm{v} / \mathrm{v})$. The plants grew under natural light with greenhouse temperatures varying from $15^{\circ}$ to $25^{\circ} \mathrm{C}$ during the growing season. Survival, shoot growth, number of stems, and flowering habit were recorded 1 year later on a random sample of 30 survivors.

\section{Results and discussion}

Culture Medium: After 1 month in culture, the microshoots on BA-free MS, $1 / 2$ MS and WPM elongated an average of only $4 \mathrm{~mm}$ and produced no new shoots. In contrast, microshoots on the same 3 media supplemented with $0.1 \mathrm{mg} / \mathrm{l} \mathrm{BA}$ lengthened rapidly and produced vigorous new shoots. Greatest stem elongation and new shoot production occurred on WPM. The microshoots grew an average of 0.8 and $1.1 \mathrm{~cm}$ taller on WPM versus MS and $1 / 2 \mathrm{MS}$, respectively ( $p=0.0008)$, and developed an average of 5 more new shoots per explant on WPM versus MS ( $p=0.0002)$.
The new shoots on WPM developed normal healthy foliage (mean health score 2.3) versus slightly more chlorotic growth on MS (2.1), and $1 / 2 \mathrm{MS}$ (1.4) media $(p=0.005)$. Because the bitterbrush microshoots grew more vigorously on WPM than on either MS or $1 / 2$ MS, we selected WPM as the medium for subsequent in vitro experiments.

Shoot Multiplication: New shoots developed from axillary nodes and the bases of explants treated with varying levels of BA. In contrast, the explants on BA-free medium were stunted and failed to release axillary shoots. The number of new shoots increased from 0 on hormone-free medium, to a maximum average of 15 , after treatment with $0.8 \mathrm{mg} / \mathrm{l} \mathrm{BA}$, and then declined at higher concentrations of BA. Maximum stem growth $(1.8 \mathrm{~cm})$ occurred with treatment of $0.1 \mathrm{mg} / \mathrm{l} \mathrm{BA}$, and decreased significantly after treatments $>0.2 \mathrm{mg} / \mathrm{l} \mathrm{BA} \mathrm{(} \mathrm{p}=$ 0.0001 ). The difficulty of clearly identifying axillary shoots increased when BA concentrations rose above 0.2 $\mathrm{mg} / \mathrm{l}$, due to shorter stem internodes and increased basal shoot proliferation. Therefore, the maximum shoot count of 15 may include adventitious shoots less desirable for clonal production. The BA level of $0.1 \mathrm{mg} / \mathrm{l} \mathrm{re-}$ sulted in optimal elongation, a moderate number of new shoots 
produced, and reasonable assurance of the axillary nature of the new shoots.

\section{In vitro rooting: $\mathrm{NAA}$} seemed to inhibit normal rooting. Microshoots on NAA-free WPM (control) developed white "normal" roots which penetrated to the bottom of the test tube. Explants on the NAA-supplemented media, however, developed "aerial" horizontal fibrous roots on the surface of the medium and produced few if any normal roots. In the second experiment, $11 \%$ of the NAAtreated microshoots rooted versus $53 \%$ of the non-treated explants $(\mathrm{p}<0.0001)$ after 6 weeks in culture. Rooting was similar on both WPM and $1 / 2$ MS incubation media.

Ex vitro rooting: Microshoots rooted more successfully ex vitro than in vitro (Fig. 1). After 6 weeks, $62 \%$ of the untreated microshoots (control) had rooted versus $88.6 \%$ and $79.0 \%$ of the microshoots treated with Rootone ${ }^{\circledR}$ and Hormex ${ }^{\circledR} \# 1$, respectively. The microshoots treated with Dip "n Grow ${ }^{\circledR}$ rooted at $65.3 \%$. We infer that a low rate of auxin, applied as either IBA or NAA powder treatment, will likely result in ex vitro rooting at a level sufficient for commercial production.

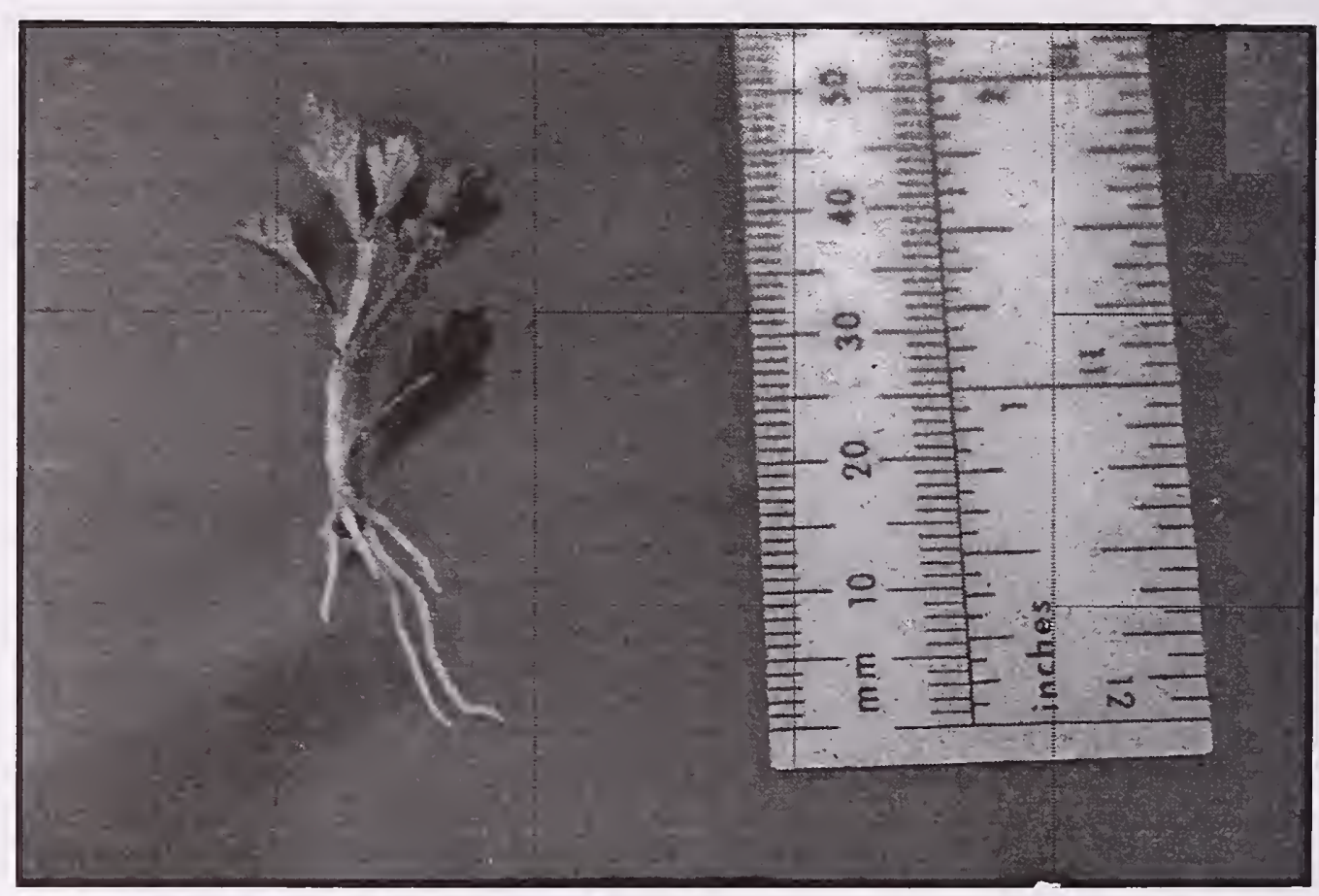

Figure 1. Ex vitro rooted Purshia tridentata plantlet 4 weeks after treatment with $0.1 \%$ IBA.

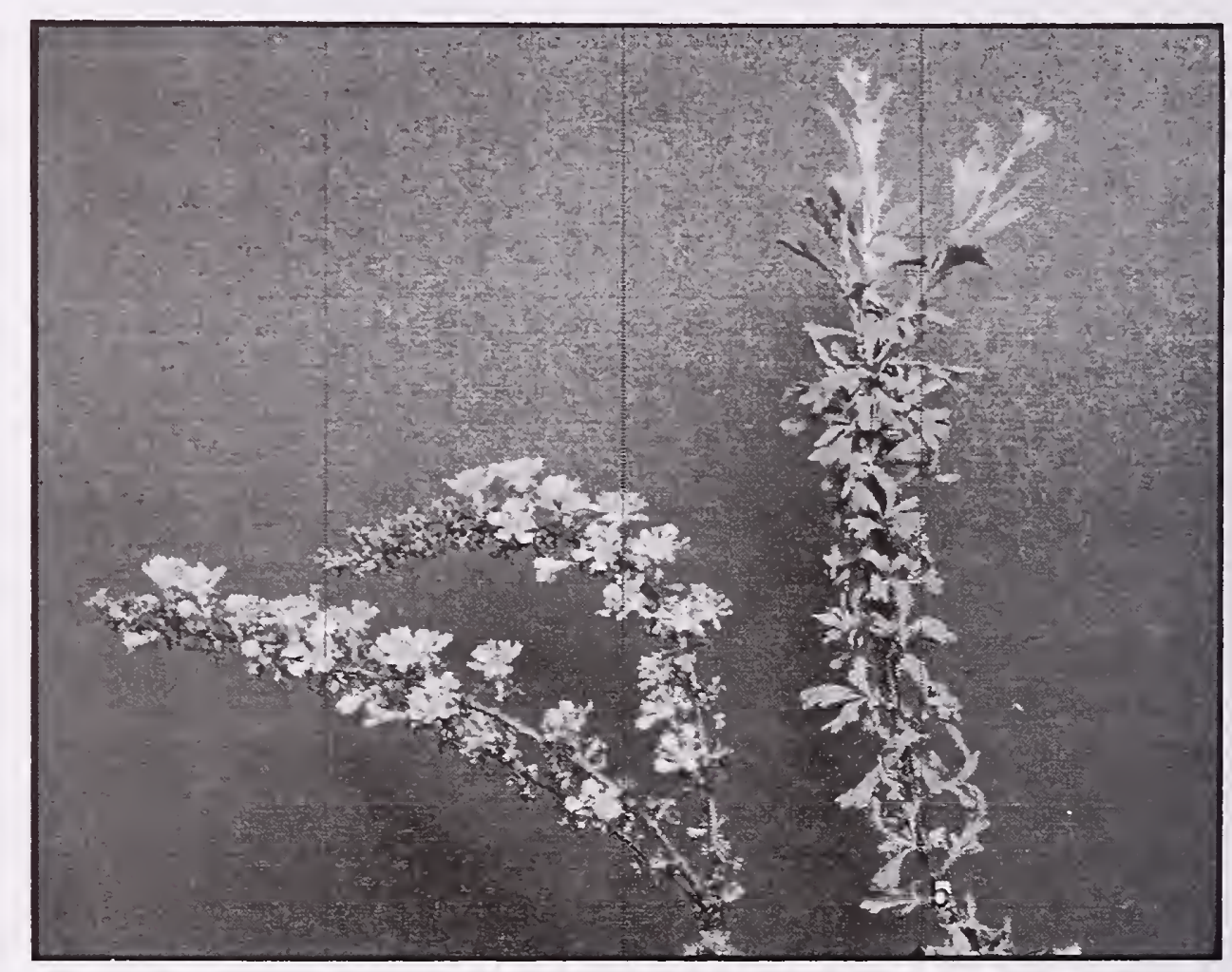

Figure 2. Flowering desert bitterbrush (left) and antelope bitterbrush (right) after 1 year in the greenhouse. 
Acclimatization: Four months after transplant, $85 \%$ of the plantlets remained alive with no subsequent death. By the end of the first year's growth in the greenhouse, the plantlets had produced leaders with an average extension of $16.4 \mathrm{~cm}$. The plantlets bloomed heavily within 1 month of budbreak with an average of 20 flower buds on each leader (Fig. 2). The precocious and prolific flowering of the plantlets suggests that regeneration could occur the first year after outplanting this type of planting stock if conditions are favorable for establishment.

\section{PROPAGATION OF PURSHIA GLANDULOSA}

\section{Materials and methods}

Culture medium: $360,2-\mathrm{cm}-$ long shoot tips were excised and placed randomly on MS or WPM containing $0.1 \mathrm{mg} / \mathrm{l} \mathrm{BA}$. After 5 weeks, we calculated stem elongation and counted the number of axillary shoots produced.

\section{Shoot multiplication: 160} shoot tips were randomly assigned to 24 treatment combinations of $\mathrm{MS}+0,0.05,0.1,0.2$ $0.4,0.9,1.8$ or $3.6 \mathrm{mg} / \mathrm{l} \mathrm{BA}$. Twenty microshoots were used per treatment. After 4 weeks, shoot elongation and the number of axillary bud breaks were recorded for each shoot.

\section{SHOOT GROWTH $(\mathrm{cm})$}

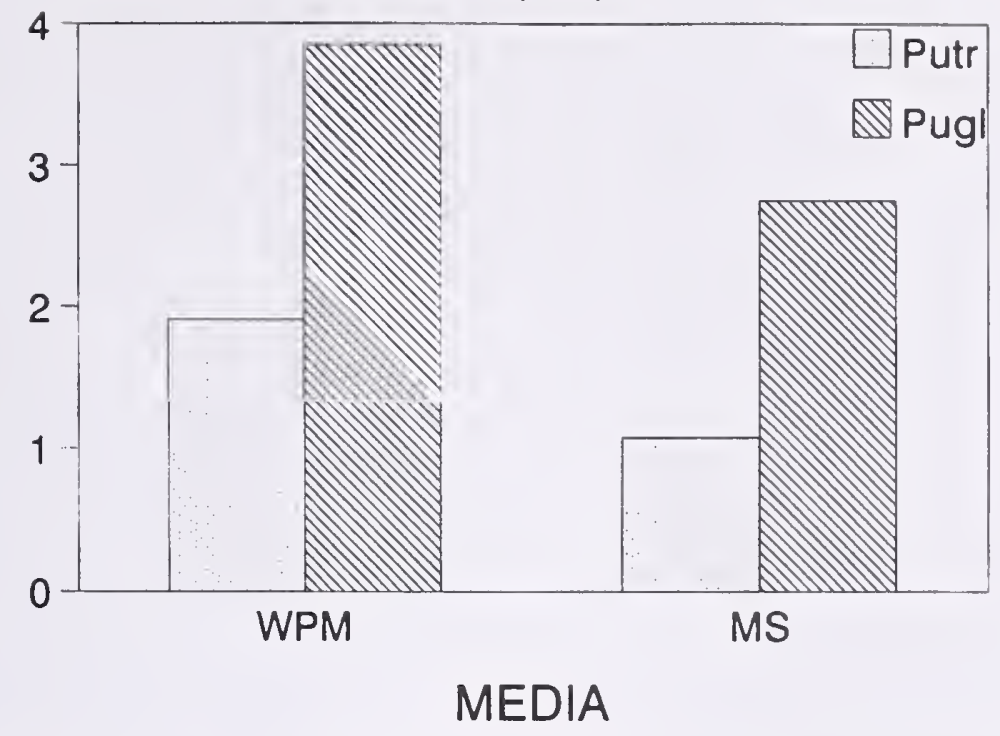

Figure 3. Effect of Woody Plant Medium (WPM) and Murashige and Skoog medium (MS) on shoot elongation of $P$. tridentata (Putr) and P. glandulosa (Pugl) microshoots after 4 weeks in culture.

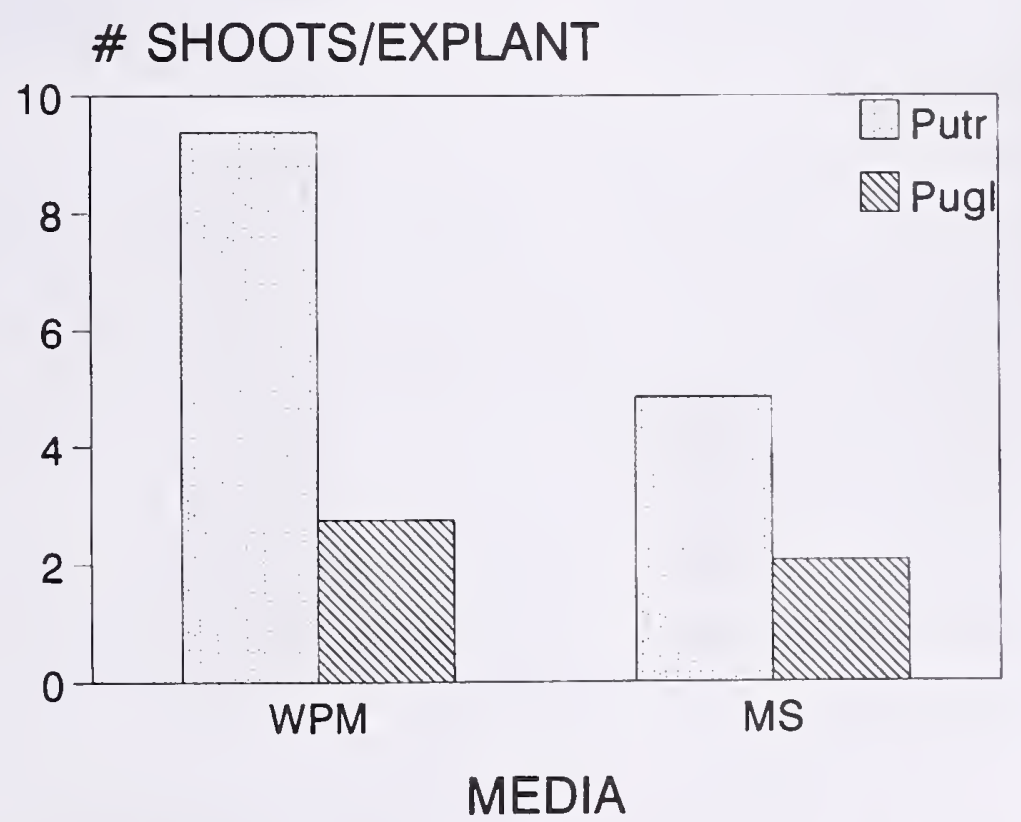

Figure 4. Effect of Woody Plant Medium (WPM) and Murashige and Skoog medium (MS) on shoot production of $P$. tridentata (Putr) and P. glandulosa (Pugl) microshoots after 4 weeks in culture.

In vitro rooting: $216,2-\mathrm{cm}-$ long microshoots were divided among 6 media (MS, $1 / 2 \mathrm{MS}$ and WPM supplemented with or without $1 \mathrm{mg} / \mathrm{l} \mathrm{NAA})$. Rooting was recorded after 4, 6, 8 and 10 weeks.
Ex vitro rooting: Nonlignified microshoots were cut into 600,3 -cm-long shoot tips and 600 stem segments. Forty tips and 40 segments were randomly assigned to each of 5 hormone treatments: a control (no hormone), Hormex® \#3, 
Hormex ${ }^{\circledR} \# 8$, Rootone $\AA$, and Dip "n Grow ${ }^{\circledR}$. The experiment was replicated twice in a randomized split-plot design. The explants were struck in 5-ml capacity miniplug cells containing a 1:1 mix of Sunshine $®$ \#3 and perlite.

Acclimatization: 40 rooted microshoots were transferred from agar medium to $164 \mathrm{cc}$ capacity Ray Leach $₫$ containers containing Sunshine ${ }^{\circledR} \# 2$. Observations were made a year later on shoot growth, number and location of branches, and incidence of flowering and fruiting.

\section{Results and discussion}

Culture medium: Stem elongation and axillary shoot production were enhanced significantly on the WPM $(\mathrm{p}<0.001)$ versus MS medium (3.85 vs. $2.75 \mathrm{~cm}$ and 2.75 vs. 2.06 shoots, respectively). $P$. glandulosa microshoots developed taller stems but fewer axillary shoots than $P$. tridentata explants on both media (Figs. 3 \& 4). Using a low level of BA $(0.1 \mathrm{mg} / \mathrm{l})$ would avoid the foliar chlorosis and adventitious shoot production associated with the higher levels of BA in the medium, a distinct advantage when propagating selected genetic traits.

\section{Shoot multiplication:}

Microshoots developed tall, single stems on hormone-free medium (Fig. 5), in contrast to

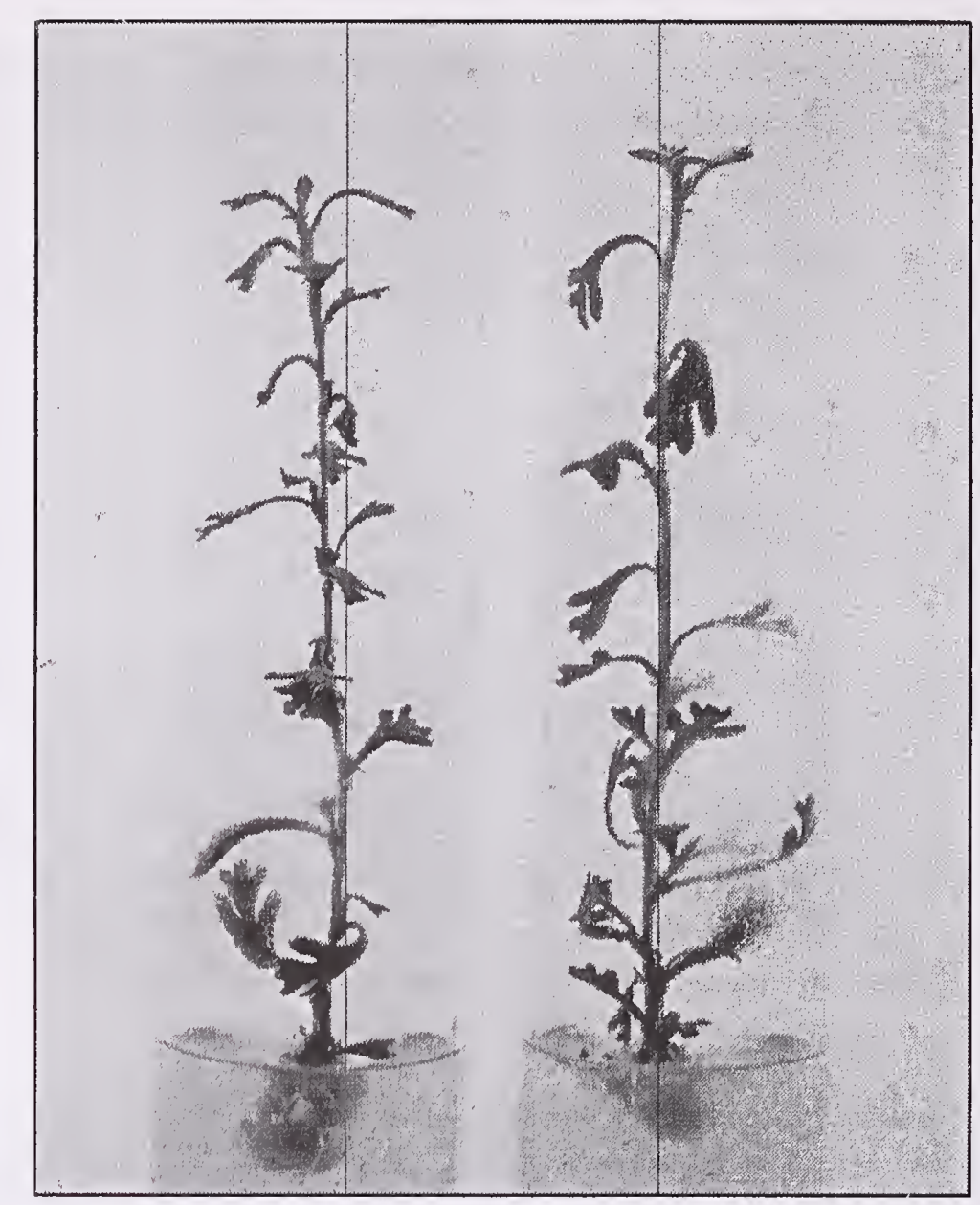

Figure 5. Purshia glandulosa microshoots after 1 month on hormone-free WPM. Note tall, single stem growth. the stunted growth of $P$. tridentata on BA-free media. Explants achieved maximum growth with $0.1 \mathrm{mg} / \mathrm{l} \mathrm{BA}(3.5$ $\mathrm{cm})$ and were shorter with more axillary bud break after treatments $>0.2 \mathrm{mg} / \mathrm{l} \mathrm{BA}$. The number of new shoots increased from 0 on BA-free medium, to a maximum average of 5.0 shoots per explant after treatment with $0.4 \mathrm{mg} / \mathrm{l} \mathrm{BA}$, and then declined at higher concentrations of $\mathrm{BA}$.

In vitro rooting: The best rooting $(44 \%)$ occurred after 10 weeks on WPM $+1 \mathrm{mg} / 1 \mathrm{NAA}$ as compared to $0 \%$ and $19 \%$ rooting on NAA-supplemented MS and $1 / 2$ MS, respectively. None of the microshoots on MS produced roots, regardless of whether NAA was present or not in the medium. This data suggests the most important factor in rooting is the basal medium. In contrast to the response of $P$. tridentata, NAA did not inhibit rooting.

Ex vitro rooting: Microshoot tips rooted most successfully after they were treated with a low concentration of auxin. After 6 weeks, $28 \%$ of the untreated microshoots had rooted versus $74 \%, 72 \%$, and 
$71 \%$ of the microshoots treated with Hormex ${ }^{\circledR}$ \#3, Hormex ${ }^{\circledR}$ \#1 and Dip 'n Grow ${ }^{\circledR}$, respectively. Microshoots treated with Hormex ${ }^{\circledR} \# 8$ rooted at $52 \%$. Explant tips also rooted better than stem segments ( $60 \%$ versus $36 \%$, respectively).

Acclimatization: Four months after transplant, $85 \%$ of the plantlets remained alive with no subsequent death. After 1 year in the greenhouse, the leading shoots had extended an average of $18.0 \mathrm{~cm}$. Eighty-five percent of the plantlets flowered, with the axillary bloom generally extending to the full length of all the stems (Fig. 2).

\section{CONCLUSIONS: THE PROPAGATION PROTOCOL}

1. Initiating and multiplying both bitterbrush species on Woody Plant Medium, supplemented with $0.1 \mathrm{mg} / \mathrm{l} \mathrm{BA}$, provides numerous elongated healthy shoots suitable for multiplication in subculture.

2. Rooting the microshoots in ex vitro conditions with low levels of auxin would lower propagation costs, although untreated microshoots of $P$. glandulosa and $P$. tridentata rooted with moderate success under in vitro conditions ( $44 \%$ and $61 \%$, respectively)
3. Plantlets of both species, transferred to greenhouse conditions, can provide flowering and fruiting plants within 1 year.

We have demonstrated that antelope and desert bitterbrush can successfully be propagated by micropropagation techniques, achieving numbers suitable for commercial production.

With micropropagated antelope and desert bitterbrush, range managers and scientists can potentially:

1. revegetate areas with locally selected genetic stock

2. shorten the time for breeding programs with selected clones

3. outplant material which could rapidly produce seed

4. lower the fire frequency, enhance forage, and increase cover of damaged habitat.

\section{REFERENCES}

Bonga, J.M. and P. von Aderkas. 1992. In Vitro Culture of Trees. Kluwer Academic Publ., Dordrecht, The Netherlands.

Huetteman, C.A. and J.E. Preece. 1993. Thidiazuron: a potent cytokinin for woody plant tissue. Plant Cell, Tissue and Organ Cult. 33:105-119.

Lloyd, G. and B. McCown. 1980. Commercially-feasible micropropagation of mountain laurel, Kalmia latifolia, by use of shoot-tip culture. Comb. Proc. Int. Plant Prop. Soc. 30:421-427.

Murashige, T. and R. Skoog. 1962. A revised medium for rapid growth and bioassays with tobacco tissue cultures. Physiol. Plant. 15:473-97.

Pierik, R.L.M. 1987. In Vitro Culture of Higher Plants. Martinus Nijhoff Publ.,Dordrecht, The Netherlands.

Welch, C.L., S.B. Monsen, and N.L. Shaw. 1982. Nutritive value of antelope and desert bitterbrush, Stansbury cliffrose, and Apachi-plume, p. 173-185 In: A.R. Tiedman and R.L. Johnson (eds.), Proc. Research and Management of Bitterbrush and Cliffrose in Western North America Symposium. Intermtn. Forest and Range Exp. Sta. General Tech. Rep. INT-152.

Young, J.A. and R.A. Evans. 1981. Germination of seeds of antelope bitterbrush, desert bitterbrush, and cliff rose. USDA Science and Education Administration Agricultural Research Results, ARR-W-17. 


\title{
Impact of Aphid Damage in a Bareroot Nursery and Seed Source on Survival and Growth of Outplanted White Fir Seedlings in the Sierra Nevada ${ }^{1}$
}

John D. Stein²

\begin{abstract}
A species of a woolly fir aphid, Mindarus kinseyi Voegtlin (Homoptera: Aphididae), has been responsible for dead apical buds on $25 \%$ to $65 \%$ of the white fir seedlings harvested for outplanting at a bareroot nursery in central California since 1987. In 1990 and 1991, undamaged and damaged progeny from seeds collected at elevations of $1500 \mathrm{~m}$ or higher were outplanted on Iron Mountain in the central Sierra Nevada. Nursery seedlings originating from the Eldorado National Forest that meet or exceed nursery cull standards, despite being injured by $M$. kinseyi, were more vigorous than undamaged Eldorado seedlings during the first year of outplanting. In 1990, the origin of seed sources had a significant effect upon seedling survival during the first field season. The local seed source originating from the Eldorado National Forest, seemed to be better adapted for survival when seedlings were drought stressed. Eldorado seedlings had the highest survival, whereas seedlings from the Klamath and Stanislaus National Forests had the highest mortality. Aphid damage and seed origin in 1990 did not have a significant effect upon growth response; however, in 1991, the interaction of aphid damage and seed origin was important. Aphid-damaged seedlings from the Eldorado and site one of the Stanislaus National Forests grew significantly taller than undamaged seedlings from the Eldorado and the Klamath National Forests. Aphid-damaged seedlings from the Eldorado and Klamath seed sources had significantly more stem volume than undamaged seedlings from the Eldorado and site one of the Stanislaus seed sources. The contrast in the growth response for undamaged and aphid damaged seedlings from the Eldorado may indicate a difference in an induced hardiness.
\end{abstract}

\section{INTRODUCTION}

White fir (Abies concolor [Gord. \& Glend.] Lindl.) is considered not only a commercially viable timber species, but a valuable component and genetic resource of the mixed conifer forests. The present native range of white fir extends west from Colorado and southern Idaho to western California and south to Arizona, New Mexico, and northern Mexico. In the mountainous Pacific Coast region, white fir obtains maximum growth and yield. White fir is a major component of the Sierra Nevada mixed conifer forest and is replaced as a climax species only by western hemlock (Tsuga heterophylla [Raf.]

Sarg.) on wet sites in its northern range (Franklin and Dyrness 1973). Other associated tree species in California and Oregon include grand fir (Abies grandis [Dougl. ex D. Don] Lindl.), Douglas-fir (Pseudotsuga menziesii [Mirb.] Franco),

'Stein, J.D. 1994. Impact of Aphid Damage in a Bareroot Nursery and Seed Source on Survival and Growth of Outplanted White Fir Seedlings in the Sierra Nevada. IN: Landis, T.D.; Dumroese, R.K., tech. coords. National Proceedings, Forest and Conservation Nursery Associations. Gen. Tech. Rep. RM-257. Fort Collins, CO: U.S. Department of Agriculture, Forest Service, Rocky Mountain Forest and Range Experiment Station: 246-255. 
incense-cedar (Libocedrus decurrens Torr.), ponderosa pine (Pinus ponderosa Dougl. ex Laws.), lodgepole pine ( $P$. contorta Dougl. ex Loud.), sugar pine (P. lambertiana Dougl.), Jeffrey pine ( $P$. jeffreyi Grev. \& Balf.), tanoak (Lithocarpus densiflorus [Hook. \& Arn.] Rehd.), California black oak (Quercus kelloggii Newb.), and Pacific madrone (Arbutus menziesii Pürsh) (Laacke 1990).

Considerable effort has been devoted to replanting areas deforested by natural events or timber sales because white fir is recognized as such a valuable tree species in 14 or more forest types in western North America. Restocking efforts are often hindered by many white fir pests. Significant seedling damage and loss of white fir in reforestation areas are often caused by the mountain pocket gopher (Thomomys monticola Allen), brush rabbit (Sylvilagus bachmani [Waterh.]), blacktailed hare (Lepus californicus Gray), mule deer (Odocoileus hemionus [Caton]) and competition from grasses (Agropyron spp.) (Jones 1974). Furniss and Carolin (1977) reported that weevils, Neodiprion sawflies, cutworms, and scarab beetles have caused significant damage to intensively managed regeneration areas.

In 1987. an unknown species of aphid (Mindarus sp.) was damaging white fir seedlings at a bareroot nursery in the central Sierra Nevada (Stein 1990, Stein and Smith 1990, Stein and Haverty 1990). Voegtlin (1995) has since described this new aphid species as Mindarus kinseyi. This aphid was contributing up to $27 \%$ of an increased cull rate and killing terminal buds on seedlings that were eventually shipped to field sites.

This paper reports on the survival and growth response of aphid-damaged seedlings from various seed sources during their first year of establishment in plantations in the central Sierra Nevada.

\section{METHODS}

Two plantation sites were selected on Iron Mountain in Eldorado County, California (Figure 1). The first site was planted at Plum Creek Ridge in 1990. This area had been burned over in 1973 and subsequently used as an outplanting for a white fir provenance study. The second site, established at Plummer Ridge in 1991, was designated a reforestation area after commercial logging. Site preparation consisted of clearing brush and tilling the soil. Seedlings at Plum Creek Ridge were planted with no additional maintenance during the first year. Management of seedlings at the Plummer Ridge plantation included additional weeding, watering, and the application of deer repellent.
White fir $2+0$ bareroot nursery seedlings were randomly chosen from five seed sources in 1990 and again in 1991. In total, seed sources from the two study sites represented seven seed zones on six different national forests in the Cascade-Sierra Nevada of California (Figure 1). This nursery material represented a range of habitats from $1665 \mathrm{~m}$ to $2165 \mathrm{~m}$ (5463-7103 ft) (Table 1). Within each seed source, seedlings were separated into two groups: one with normal seedlings and the other with seedlings that had a dead apical bud resulting from damage by Mindarus kinseyi in the nursery. Seedlings were lifted in mid winter and stored in plastic bags at $0.6^{\circ} \mathrm{C}$ until planting in April or May.

The study was randomized blocks (replications) with a split plot design. Each seed source (main treatment) was randomly located within the blocks and represented by two parallel rows of 10 seedlings (sub-treatment) - one row with normal seedlings and the adjacent row with damaged seedlings exhibiting a dead terminal bud. All rows were perpendicular to the contour of the mountain. Seedlings were spaced $30 \mathrm{~cm}$ within the row and $60 \mathrm{~cm}$ between rows.

Both study sites represented a mixed conifer type of ponderosa pine and white fir $(60: 40)$ with maximum potential growth. It was assumed that the interaction 
Table 1. Seed sources of white fir selected from the Cascade-Sierra Nevada of California for outplanting at the Plumb Creek Ridge and the Plummer Ridge plantations on Iron Mountain ${ }^{1}$

\begin{tabular}{|c|c|c|c|}
\hline $\begin{array}{r}\text { National Forest } \\
\text { (seed source) }\end{array}$ & $\begin{array}{l}\text { Elevation } \\
\text { (m) }\end{array}$ & $\begin{array}{l}\text { Latitude } \\
\left({ }^{\circ} \mathrm{N}\right)\end{array}$ & $\begin{array}{l}\text { Longitude } \\
\left.\qquad{ }^{\circ} \mathrm{W}\right)\end{array}$ \\
\hline \multicolumn{4}{|c|}{ Plumb Creek Plantation } \\
\hline Eldorado & 1665 & 38.80 & 120.50 \\
\hline Klamath & 1665 & 41.63 & 123.17 \\
\hline Lassen & 2165 & 40.38 & 121.63 \\
\hline Sierra & $2165^{\circ}$ & 37.30 & 119.27 \\
\hline Stanislaus & 1665 & 38.28 & 120.00 \\
\hline \multicolumn{4}{|c|}{ Plummer Ridge Plantation } \\
\hline Eldorado & 1665 & 38.72 & 120.25 \\
\hline Klamath & 1833 & 39.60 & 120.87 \\
\hline Plumas & 1833 & 39.88 & 121.23 \\
\hline Stanislaus-I & 1665 & 38.42 & 120.27 \\
\hline Stanislaus-2 & 1833 & 38.00 & 120.07 \\
\hline
\end{tabular}

'The Plumb Creek Plantation was located at $38.42^{\circ} \mathrm{N}, 120.15^{\circ} \mathrm{W}$ (elevation $1947 \mathrm{~m}$ ), and the Plummer Ridge Plantation was located at $38.38^{\circ} \mathrm{N}$, $120.23^{\circ} \mathrm{W}$ (elevation $1833 \mathrm{~m}$ ). Stanislaus-I and Stanislaus-2 are two separate sites from the same National Forest.

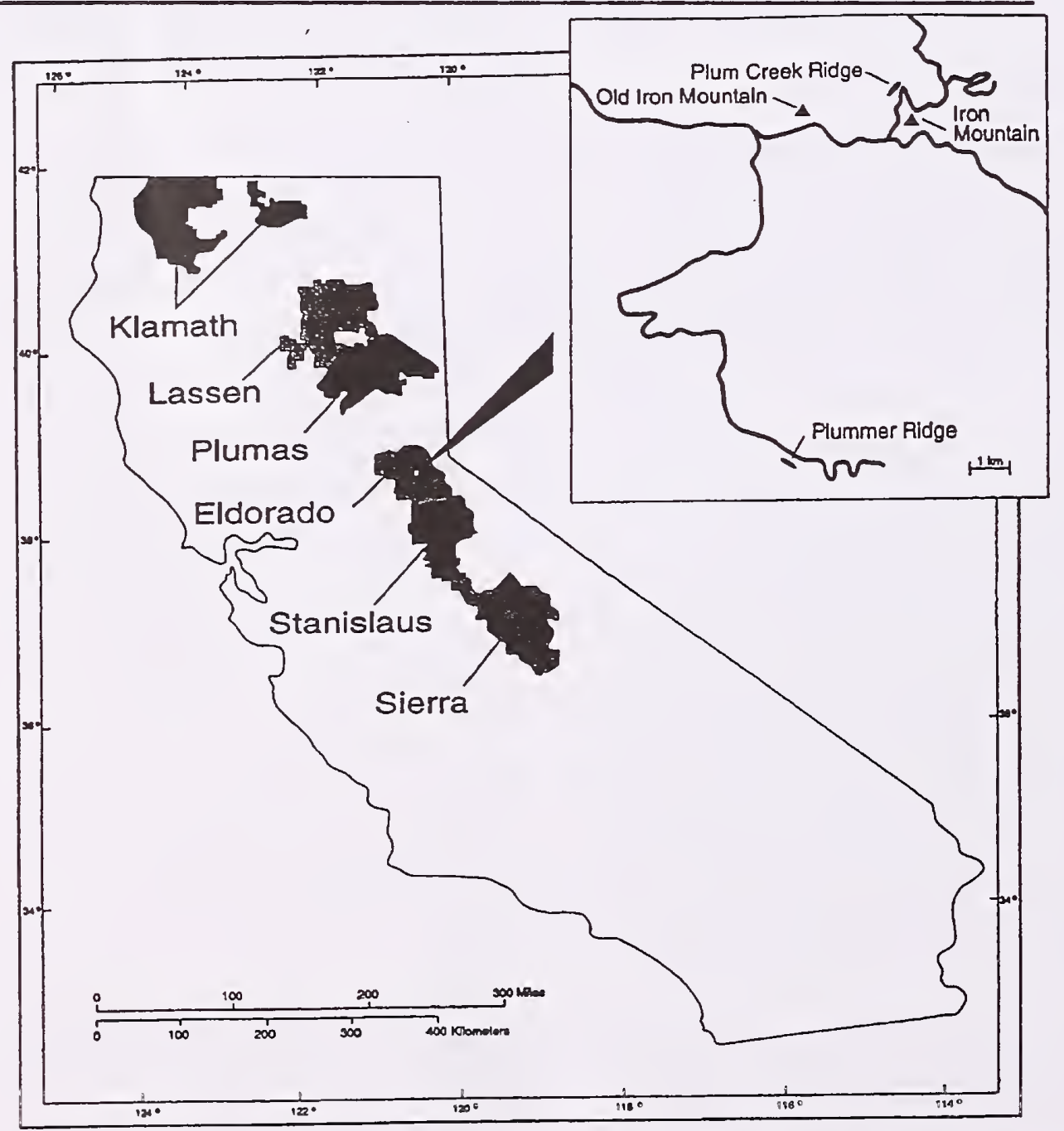

Figure 1. National Forest seed sources and plantation site locations of white fir seedlings in California study. of site with seed source would be minimal during the first year and that growth response due to aphid damage would probably be emphasized in the first year of establishment and survival (Dr. J. Jenkinson, U.S.D.A. Forest Service, Berkeley, CA, personal comm.). First-year survival and growth measurements were recorded from time of planting (April 1990 and May 1991) until cessation of root growth in November. The effect of treatments upon seedling survival was assessed by analysis of variance (ANOVA) with arcsin transformation, where $\mathrm{n}$ is the cell counts of survival (Bishop et al. 1975). The effect of interaction of insect damage by seed source on growth was assessed by a multivariate repeated measures analysis (MANOVA) (Huynh and Feldt 1970, Winer 1971 SAS 1994).

\section{RESULTS AND DISCUSSION}

\section{Seedling mortality}

Seedling survival was dramatically different between the two plantations. Two thirds of the seedlings died at the Plum Creek Ridge plantation in 1990 (Figure 2). It appears that the majority of seedling mortality was caused by lack of soil moisture. Drought conditions have been present in Eldorado County since 1985 . During the two years prior to planting in 1990, annual precipitation averaged $65 \mathrm{~cm}$ below normal (Table 2). With supplemental 


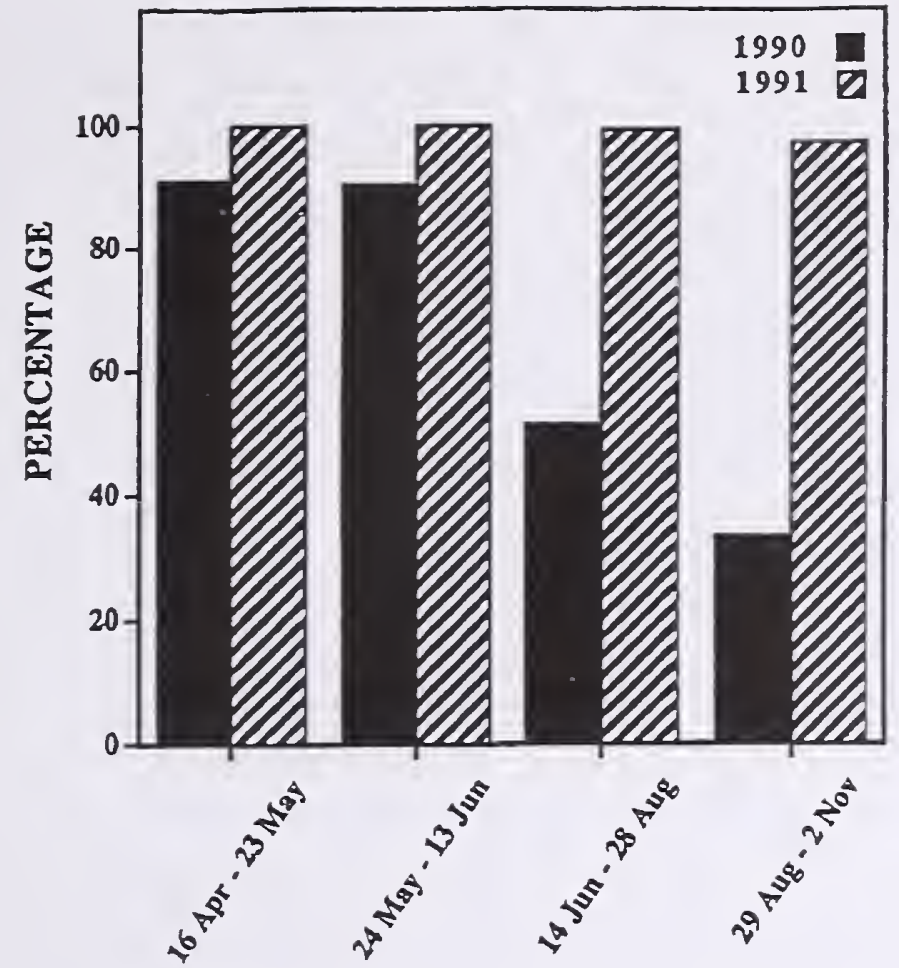

Figure 2. Survival of white fir seedlings during the first-year of outplanting at Plum Creek Ridge (1990) and Plummer Ridge (1991).

watering at the Plummer Ridge plantation during $1991,97 \%$ of the seedlings survived. The $3 \%$ mortality in 1991 was insufficient to detect a statistically significant association with time intervals or seed sources during the first year of outplanting.
During 1990, mortality at Plum Creek Ridge plantation was significantly affected by time (Pillai's Trace $F=339.6$; $\mathrm{df}=3,34 ; \mathrm{p}<0.01)$. The daily mortality rate was bimodal with a peak in May and a resurgence of mortality in August (Figure
3). The accumulative mortality in November represented a $642.2 \%$ increase from the seedling mortality in May. Most of this mortality occurred during late July. In contrast to this fluctuation in seasonal mortality, symptoms known as precursors to declining health remained at low levels. Seedlings with chlorotic foliage represented $<6 \%$ of the overall population throughout the summer and fall.

Damage by $M$. kinseyi in the nursery to the apical bud and the origin of the seed source were independent of seedling survival during the first field season (Figure 4). The main effect of time on seedling mortality at Plum Creek Ridge was significantly different for the five seed sources (Pillai's Trace $F=2.72$; $\mathrm{df}=12,108 ; \mathrm{p}<0.01)$. The Eldorado and Lassen seed sources had significantly more

Table 2. Selected climate data from Iron Mountain covering the summer and winter months'.

\begin{tabular}{|c|c|c|c|c|c|c|c|c|}
\hline \multirow[b]{3}{*}{ Year } & \multicolumn{4}{|c|}{ Summer } & \multicolumn{4}{|c|}{ Winter } \\
\hline & \multicolumn{2}{|c|}{ Precipitation (cm) } & \multicolumn{2}{|c|}{ Temperature $\left({ }^{\circ} \mathrm{C}\right)$} & \multicolumn{2}{|c|}{ Precipitation $(\mathrm{cm})$} & \multicolumn{2}{|c|}{ Temperature $\left({ }^{\circ} \mathrm{C}\right)$} \\
\hline & Total & $\begin{array}{l}\text { Diff. } \\
\text { from } \\
\text { normal }\end{array}$ & Average & $\begin{array}{l}\text { Diff. } \\
\text { from } \\
\text { normal }\end{array}$ & Total & $\begin{array}{l}\text { Diff. } \\
\text { from } \\
\text { normal }\end{array}$ & Average & $\begin{array}{l}\text { Diff. } \\
\text { from } \\
\text { normal }\end{array}$ \\
\hline 1985 & 2.79 & -0.16 & 33.3 & +2.2 & 33.17 & -32.05 & 13.9 & +1.6 \\
\hline 1986 & 0.00 & -2.95 & 32.2 & +1.1 & 47.80 & -17.42 & 14.4 & +2.0 \\
\hline 1987 & 0.74 & -2.21 & 31.7 & +0.6 & 46.51 & -18.72 & 11.9 & -0.5 \\
\hline 1988 & 1.32 & -1.63 & 32.6 & +1.5 & 1.04 & -64.19 & 13.9 & +1.6 \\
\hline 1989 & 3.89 & +0.94 & 30.9 & -0.2 & 0.00 & -65.23 & 12.8 & +0.4 \\
\hline 1990 & 0.38 & -2.57 & 23.6 & -7.5 & 30.02 & -35.21 & 6.2 & -6.2 \\
\hline 1991 & 1.93 & -1.02 & 23.6 & -7.5 & 15.90 & -49.33 & 10.8 & -1.6 \\
\hline
\end{tabular}

'Summer is defined as June, July, and August; winter Is defined as December. January, and February. 


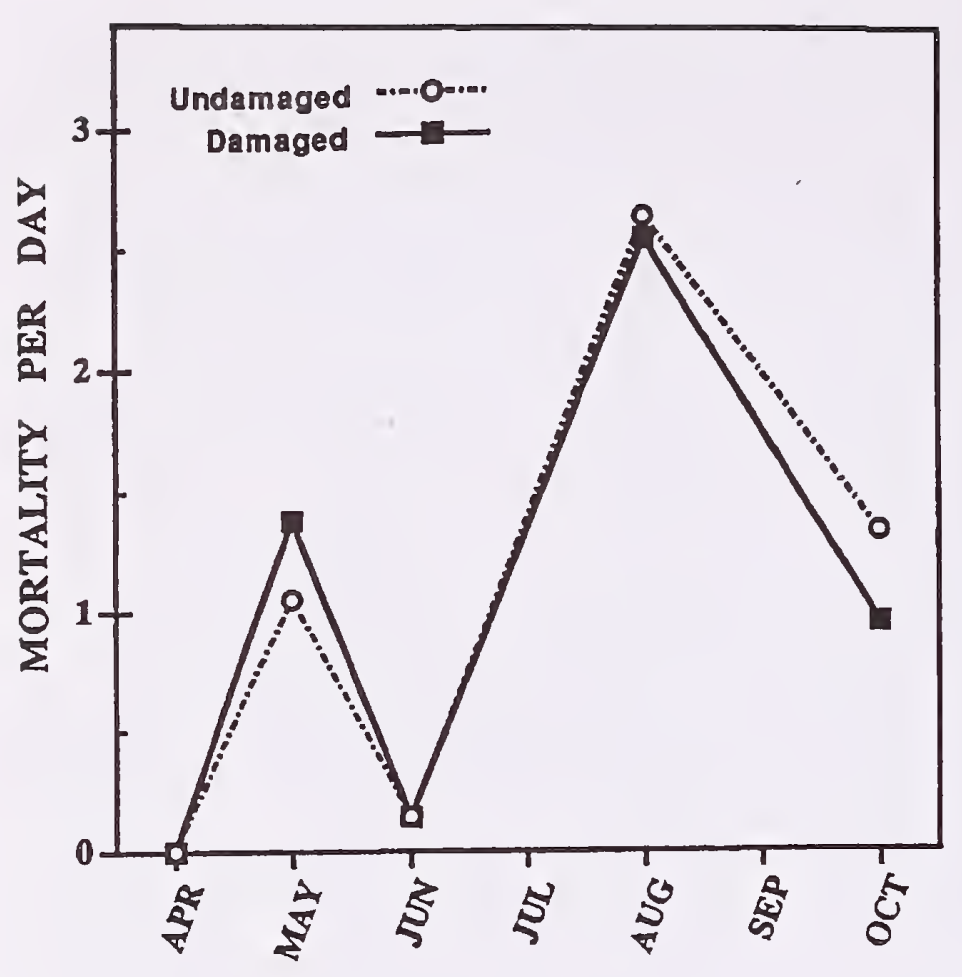

Figure 3. Daily mortality rate of undamaged and Mindarus-damaged white fir seedlings at the Plum Creek plantation in 1990.

live seedlings throughout the growing season than did the seed source from Stanislaus National Forest (Table 3). The Sierra and Klamath seed sources were considered the same as seed sources associated with high or low seedling survival.

\section{Seedling growth}

In general, the positive increase in seedling survival at Plummer Ridge was also reflected in an overall increase in growth five times that of the seedlings at the Plum Creek plantation (Figure 5). At Plum Creek, there was very little increase in diameter, height or volume between summer and fall measurements. There was no significant difference in volume for seed source by sub-treatment interactions for summer or fall measurements (Figure 6). The main effect of sub-treatment and seed source was not significant for height or volume during 1990 at Plum Creek.

At Plummer Ridge, there was an overall growth differential between summer and fall measurements with no significant difference between treatments (Figure 5). There was a significant difference for seed source by sub-treatment interactions for both summer $(\mathrm{F}=3.41 ; \mathrm{df}=4$, $900 ; \mathrm{p}<0.01)$ and fall volume $(\mathrm{F}=3.41 ; \mathrm{d} f=4,900 ; \mathrm{p}<0.01)$ measurements. The undamaged nursery seedlings for Plumas and collection site one of the Stanislaus had significantly less.

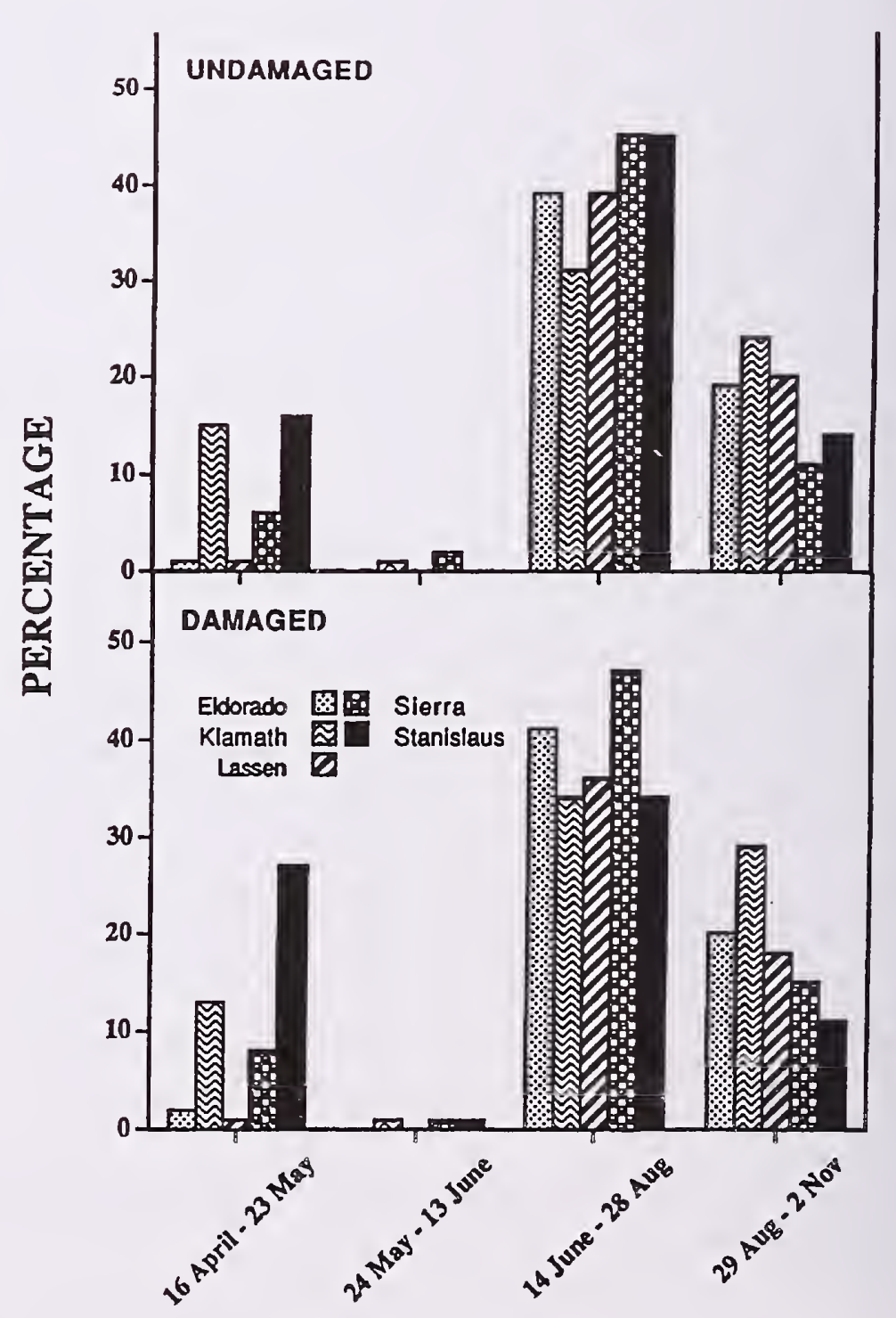


Table 3. Mean percentage (SD) of first year survival for white fir seedling genotypes at Plum Creek Plantation in 1990'.

$\begin{array}{llllll}\text { Genotype } & \underline{\mathrm{n}} & \text { May } & \underline{\text { June }} & \underline{\text { August }} & \text { November } \\ \text { Eldorado } & 20 & 98.5(4.9) \mathrm{a} & 98.5(4.9) \mathrm{a} & 58.5(20.3) \mathrm{a} & 39.0(20.5) \mathrm{a} \\ \text { Klamath } & 20 & 85.5(12.3) \mathrm{bc} & 85.0(11.5) \mathrm{bc} & 52.5(24.9) \mathrm{ab} & 26.0(21.1) \mathrm{b} \\ \text { Lasssen } & 20 & 99.0(3.1) \mathrm{a} & 99.0(3.1) \mathrm{a} & 61.5(25.4) \mathrm{a} & 42.5(25.7) \mathrm{a} \\ \text { Sierra } & 20 & 93.0(9.2) \mathrm{ab} & 91.5(9.9) \mathrm{b} & 45.5(19.6) \mathrm{ab} & 32.5(18.0) \mathrm{ab} \\ \text { Stanislaus } & 20 & 78.5(16.0) \mathrm{c} & 78.0(16.1) \mathrm{c} & 38.5(19.8) \mathrm{b} & 26.0(17.0) \mathrm{b}\end{array}$

1 Multiple comparisons were made with arcsin transformed data. Results are presented with data in the original scale of measurement. Means in columns followed by the same letters are not significantly different with an experimentwise error rate of a = 0.05 , Tukey's hsd procedure (SAS Institute 1994).

stem volume than the undamaged seed sources of the Klamath and collection site two of the Stanislaus, and the damaged seedlings of the Klamath and the Eldorado National Forests in the spring of 1991 (Figure 7). The same significant difference and ranking for seed sources occurred in the fall of 1991. It appears that the same relative differences in growth were maintained for each seed source. Those seedlings that were the largest when planted, remained the largest throughout the first year in the field.

There was an overall disparity in the net growth between plantation sites. Height was 8fold and volume was 12-fold greater at Plummer Ridge than at Plum Creek. The main effect of treatment at Plummer Ridge was not significant for diameter but significant for net height $(\mathrm{F}=$ 9.91; $\mathrm{df}=1,900 ; \mathrm{p}<0.002)$ and net volume $(\mathrm{F}=7.67 ; \mathrm{df}=1,900$; $\mathrm{p}<0.006)$. Seedlings which sustained damage by $M$. kinseyi
PLUM CREEK PLUMMER RIDGE

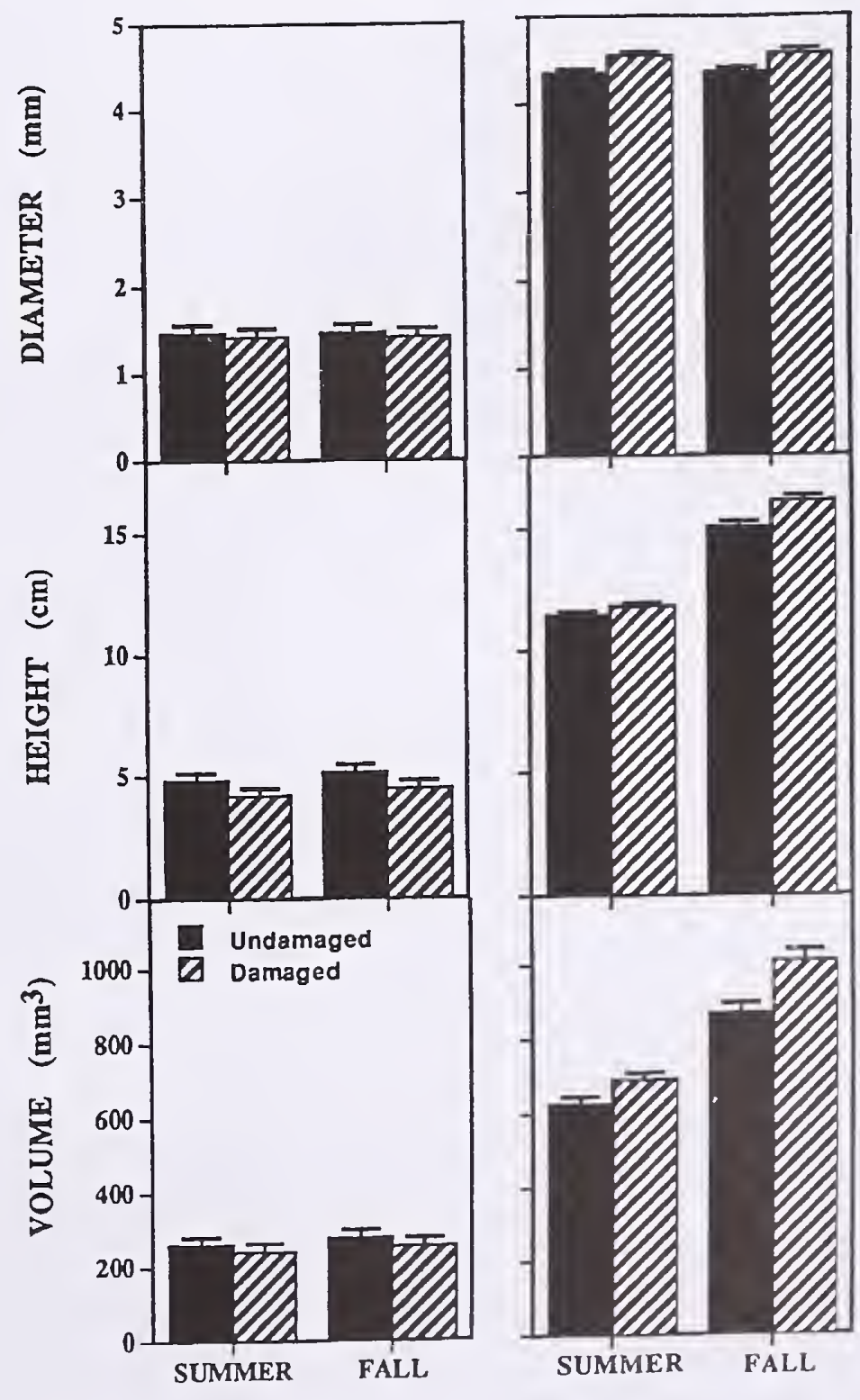

Figure 5. The summer and fall accumulative growth measurements (bars = means + SEM) for undamaged and damaged seedlings at Plum Creek and Plummer Ridge plantations. 


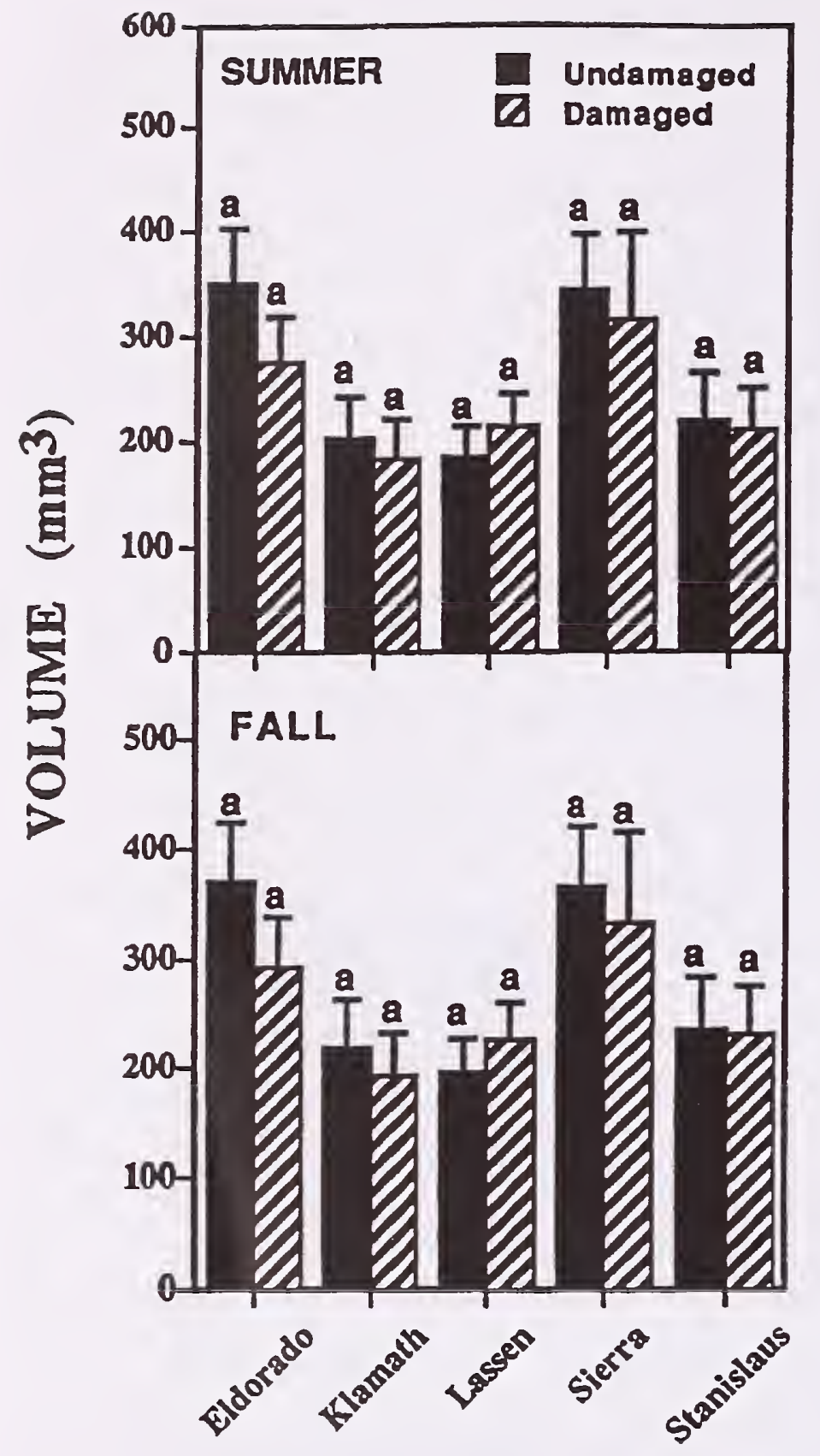

Figure 6. The effect of treatment and seed source upon accumulative seedling stem volume (bars $=$ means + SEM) in the summer and fall at Plum Creek, 1990. Bars with the same letters are not significantly different with an experimentwise error rate of $a=0.05$, Tukey's hsd procedure (SAS Institute 1994).

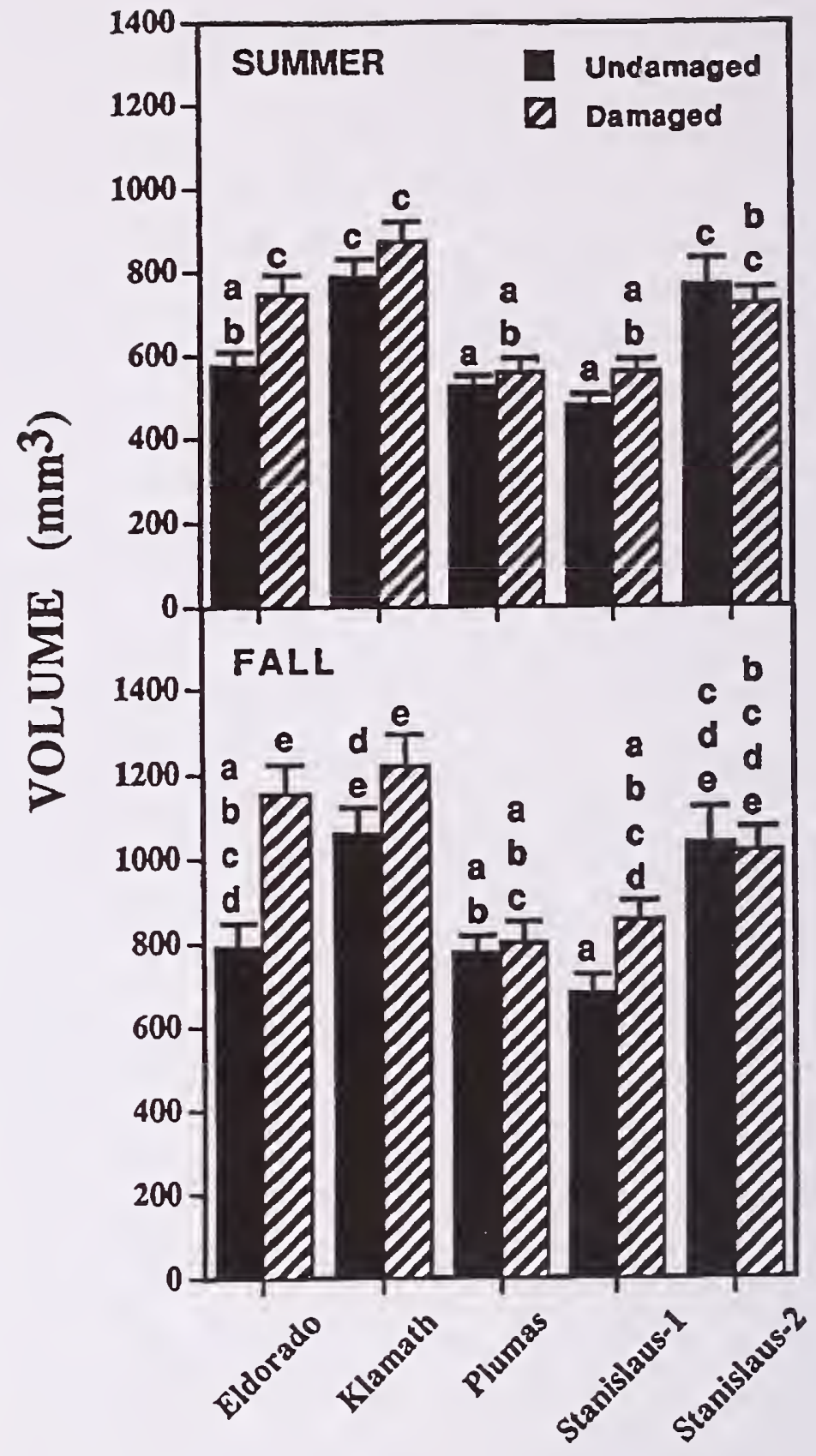

Figure 7. The effect of treatment and seed source upon accumulative seedling stem volume (bars = means + SEM) in the summer and fall at Plummer Ridge, 1991. Bars with the same letters are not significantly different with an experimentwise error rate of $a=0.05$, Tukey's hsd procedure (SAS Institute 1994). Stanislaus1 and Stanislaus-2 are two separate collection sites from the same National Forest. in the nursery grew taller and had more stem volume than undamaged seedlings (Figure 8). The main effect of seed source was not significant for stem diameter or volume at both plantations, but significant for net height $(\mathrm{F}=2.49$; $\mathrm{d} f=4,900$; $\mathrm{p}<0.04$ ) at Plummer Ridge
(Figure 9). Seedlings from the Stanislaus collection site one grew significantly taller than seedlings from the Klamath seed source.

Significant differences occurred at the Plummer Ridge plantation for seed source by treatment interactions for both net height $(\mathrm{F}=2.45 ; \mathrm{df}=4,900$; $\mathrm{p}<0.04)$ and net stem volume $(\mathrm{F}=2.40 ; \mathrm{df}=4,900 ; \mathrm{p}<0.05)$. Undamaged seedlings from the Eldorado and the Klamath National Forests had significantly less net height than aphiddamaged seedlings from the 
Eldorado and collection site one of the Stanislaus National Forests. Aphid-damaged seedlings from the Eldorado and the Klamath seed sources had significantly more net stem volume than undamaged seedlings from the Eldorado and collection site one of the Stanislaus seed sources. Undamaged and damaged seedlings from the Plumas and collection site two of the Stanislaus seed sources were considered the same when comparisons were made for both net height and net volume (Figure 10). The difference that occurs between seed source for net height and net volume indicates that damaged seedlings from the Klamath
Figure 8. Overall first-year net growth (bars = means + SEM) of undamaged and aphid damaged seedlings outplanted on Iron Mountain at Plum Creek (1990) and Plummer Ridge (1991) plantations.

\section{PLUM CREEK}

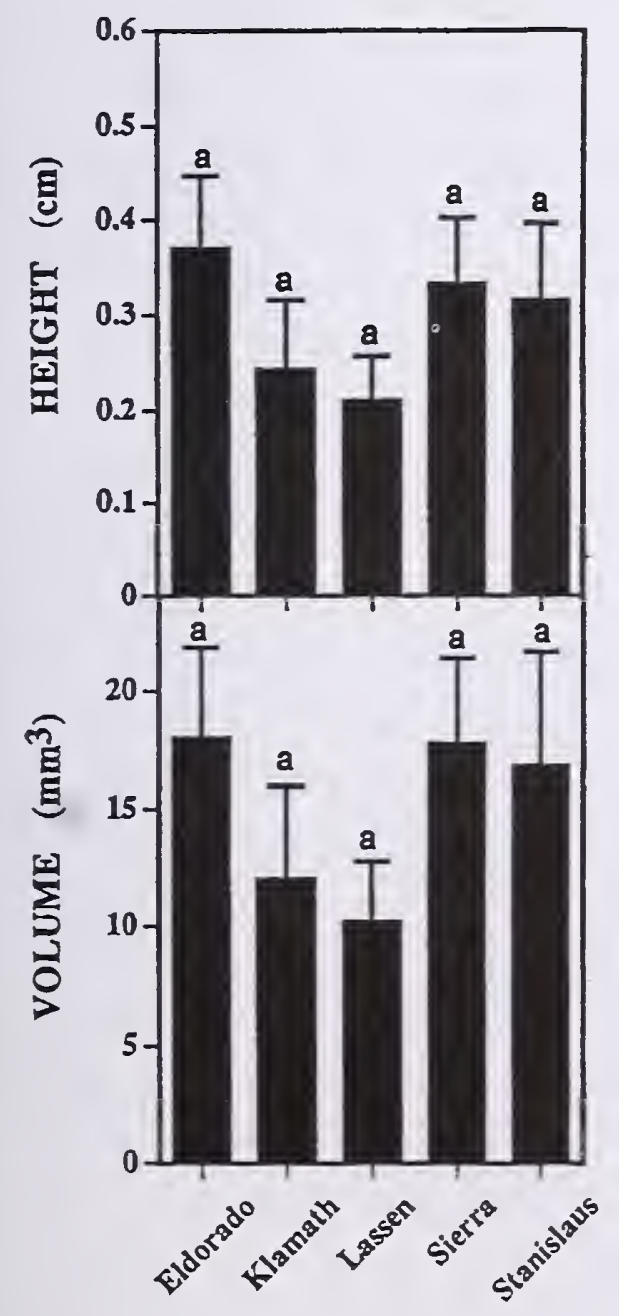

\section{PLUMMER RIDGE}

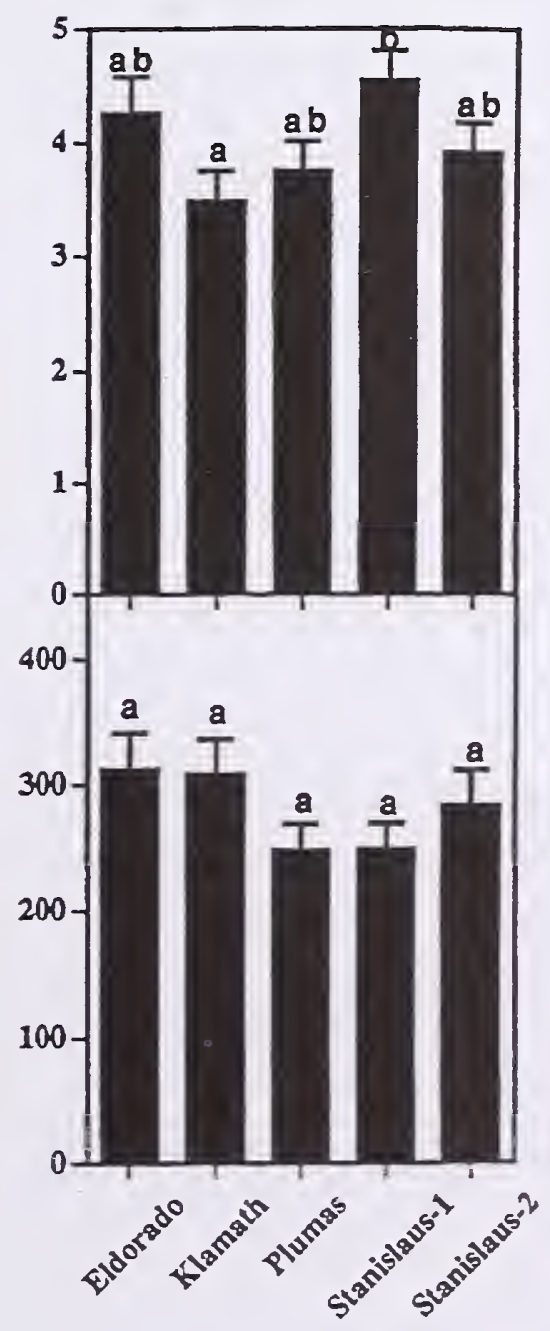

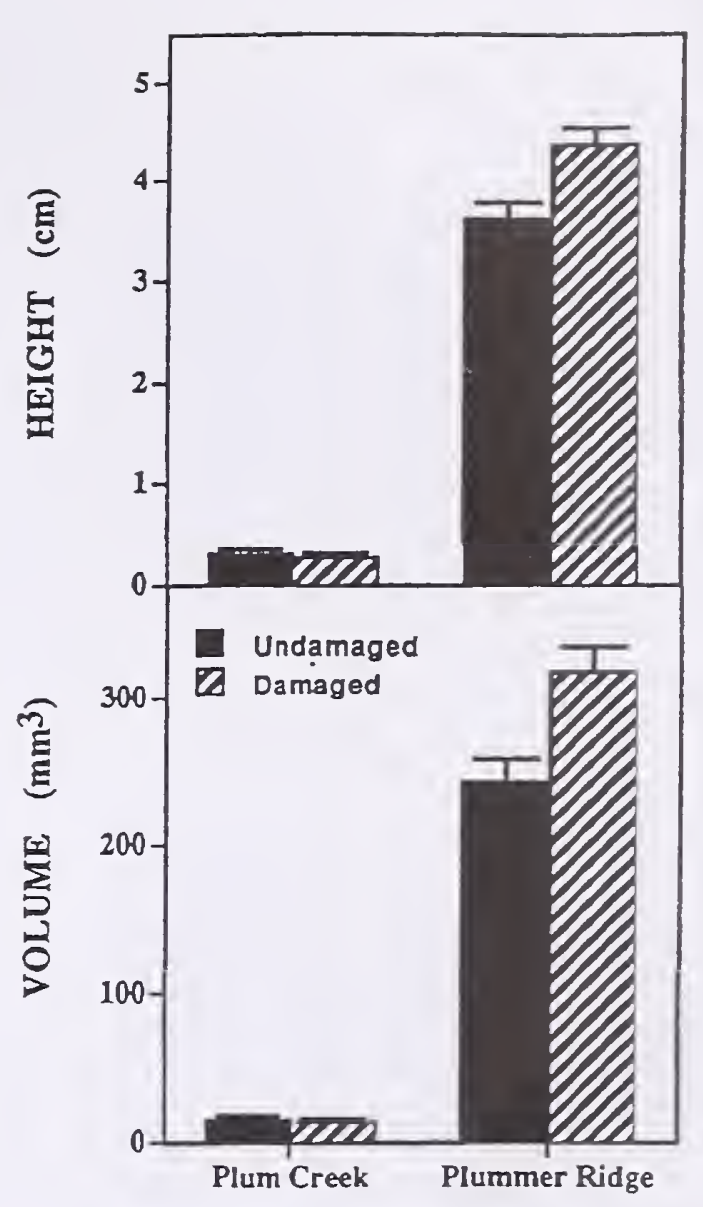

Figure 9. The first-year effect of seed source on net height (bars = means + SEM) and net stem volume at both the Plum Creek and the Plummer Ridge plantation sites. Bars with the same letters are not significantly different with an experimentwise error rate of a $=0.05$, Tukey's hsd procedure (SAS Institute 1994).

Stanislaus-1 and Stanislaus-2 are two separate collection sites from the same National Forest. 


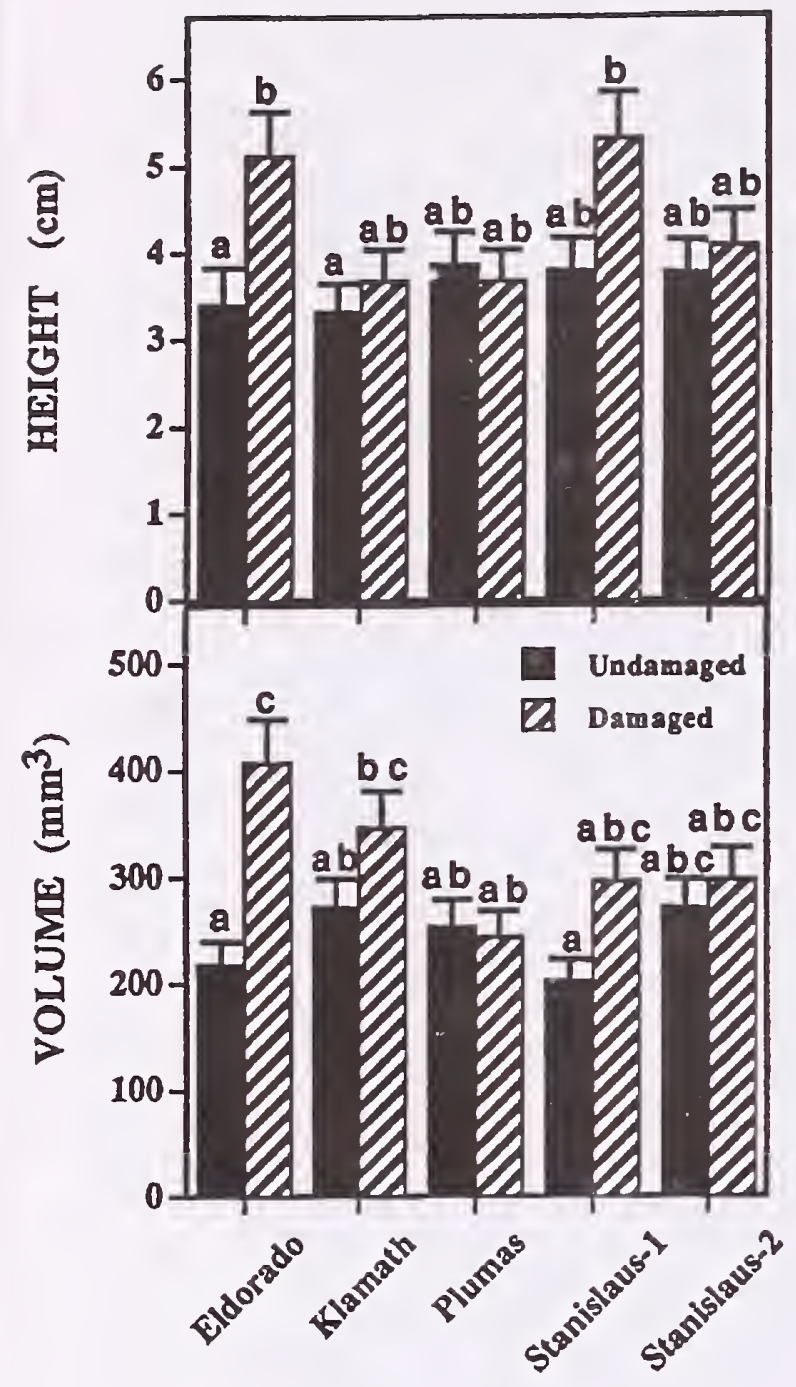

Figure 10. The effect of treatment by seed source interaction on first-year net growth (bars = means + SEM) at Plummer Ridge.

Bars with the same letters are not significantly different with an experimentwise error rate of $a=0.05$, Tukey's hsd procedure (SAS Institute 1994). Stanislaus-1 and Stanislaus-2 are two separate collection sites from the same National Forest.
National Forest developed larger diameters than damaged seedlings from collection site one of the Stanislaus seed source. This may be a manifestation of the residual effect of nursery aphid damage for certain seed sources. Some seed sources with dead apical buds may have reduced shoot elongation and stimulated radial growth during the first year of outplanting. In the case of the Klamath seed source, aphid damage resulted in a shorter seedling with more stem volume.

\section{CONCLUSION}

In 1990, aphid damage to the apical bud while in a bareroot nursery did not influence seedling survival. However, seed origin had a significant effect upon seedling survival during the first field season. The local seed source seems to be better adapted for survival when seedlings were subjected to drought stress. Eldorado seedlings had the highest survival, whereas those from the Klamath and Stanislaus National Forests had the highest mortality. With the majority of the mortality occurring in the May and August, supplemental watering in late April and late July would probably increase first-year survival. It appears that supplemental watering during the summer of 1991 helped increase overall seedling survival to $97 \%$.
Apparently, aphid damage and seed source did not affect growth responses when seedlings were exposed to severe moisture stress in 1990. In 1991, when seedlings maintained reasonable growth, the interactions of aphid damage and seedling origin were important for both height and volume during the first year of outplanting. The relatively poor overall performance of normal seedlings from all the seed sources and the contrasts between normal and damaged seedlings from specific seed sources were unexpected. With seedlings from the Eldorado National Forest, that had been damaged by $M$. kinseyi grew significantly taller and produce more stem volume than normal seedlings. Perhaps seedlings with apical bud abortion from a local seed source, which surpassed the nursery's cull standards, are more suitable for initial growth during their first season in the field.

\section{LITERATURE CITED}

Bishop, Y.M.M.; Fienberg, S.E.; Holland, P.W. 1975. Discrete multivariate analysis: Theory and practice. MIT Press, Cambridge. 557 p.

Franklin, J.F.; Dyrness, C.T. 1973. Natural vegetation of Oregon and Washington. U.S.D.A., For. Serv., Gen. Tech. Rep. PNW-8. 417 p. 
Furniss, R.L.; Carolin, V.M. 1977. Western forest insects. U.S.D.A., For. Serv., Misc. Publ. 1339. 654p.

Huynh, H.; Feldt, L.S. 1970. Conditions under which mean square ratios in repeated measurements designs have exact F- distributions. J. Am. Stat. Assoc. 65:1582-1589.

Jones, J.R. 1974. Silviculture of southwest mixed conifers and aspen: the status of our knowledge. U.S.D.A., For. Serv., Res. Pap. RM-122. 44 p.

Laacke, R.J. 1990. Abies concolor. Pages 36-46 in R.M. Burns and B.H. Honkala, Tech. Coords. Silvics of North America, Vol. 1, Conifers. U.S.D.A., For. Serv., Agric. Handb. 654. 675 p.

SAS Institute. 1994. SAS user's guide: statistics. SAS Institute, Cary, NC.

Stein, J.D. 1990. Biology of a white fir aphid nursery pest: biotype or new species. Page 273 in J.R. Sutherland and S.G. Glover, editors. Proceedings of the first meeting of IUFRO Working Party S2.0709 (Diseases and Insects in Forest Nurseries). Victoria, British Columbia, Canada. August 22-30, 1990. For. Can. Pac. For. Cent. Inf. Rep. BC-X-331. Victoria, B.C. 298 p. (abstr.)
Stein, J.D.; Haverty, M.I. 1990. Insecticides effectively control an aphid pest of white fir seedlings. Tree Planters' Notes 41(4):8-12.

Stein, J.D.; Smith, R. S., Jr. 1990. Diseases and insects in United States forest nurseries. Pages 109-115 in J.R. Sutherland and S.G. Glover, editors. Proceedings of the first meeting of IUFRO Working Party S2.07-09 (Diseases and Insects in Forest Nurseries). Victoria, British Columbia, Canada. August 22-30, 1990. For. Can. Pac. For. Cent. Inf. Rep. BC-X331. Victoria, B.C. 298 p.

Voegtlin, D.J. 1995. Notes on the Mindarus spp.

(Homoptera: Aphididae) of North America with descriptions of two new species. Proc. Entomol. Soc. Washington. (submitted)

Winer, B.J. 1971. Statistical principles in experimental design. 2nd edition. McGrawHill Book Co., New York. $907 \mathrm{p}$. 


\title{
The Operational Seedling Testing Program at Weyerhaeuser ${ }^{1}$
}

\author{
Y. Tanaka, P. Brotherton, S. Hostetter, S. Dyce, D. Chapman, J. Belanger, B. Johnson ${ }^{2}$ and S. Duke ${ }^{3}$
}

\begin{abstract}
The Weyerhaeuser Seedling Testing program was established in 1985 to evaluate root growth potential, greenhouse viability, cold hardiness and morphology of nursery seedlings. This system is designed to identify and minimize the use of poor quality stock and help develop good working relationships with customers. Laboratory test results are compiled as baseline data for interpretation of future test results.
\end{abstract}

\section{INTRODUCTION}

The Weyerhaeuser seedling testing program called the Seedling Testing System (STS) was developed and implemented at the Weyerhaeuser Western Forestry Research Center, Centralia, Washington in 1985. The main purpose of the system is to determine and monitor the quality and condition of planting stock. About 500-800 tests are conducted annually, providing testing services to nine company seedling production facilities in six states (five in the Pacific Northwest and four in the Southeast) and, to a limited extent, to outside customers on a fee basis.
The STS is capable of determining the following four seedling characteristics:

1. Root Growth Potential (RGP) The ability of a seedling to produce new roots in a greenhouse or growth chamber that is conducive to optimum root growth. The RGP is considered to be a good indicator of the general vigor and health of seedlings (Ritchie 1985).

2. Greenhouse Viability $(G V)$ The condition of the bud, stem cambium and foliage of the same seedlings used in the RGP tests determines the viability. A seedling is considered non-viable (likely to perform poorly in the field) if one of the following conditions exists: (1) $50 \%$ or more of the buds are dead (may not apply to pine and some other species), (2) stem cambium tissue is dead around the circumference of the lower $1 / 2$ of the main stem, or (3) $80 \%$ or more of the foliage is damaged (unless there are 5 or more new roots greater than or equal to $1 \mathrm{~cm}$. in length). The GV thus also provides information on the general vigor and health of seedlings.

3. Cold Hardiness $(\mathrm{CH})$ - The ability of a seedling to withstand various levels of subfreezing temperatures, cold

'Tanaka, Y.; Brotherton, P.; Hostetter, S.; Dyce, S.; Chapman, D.; Belanger, J.; Johnson, B.; Duke, S. 1994. The Operational Seedling Testing Program at Weyerhaeuser. IN: Landis, T.D.; Dumroese, R.K., tech. coords. National Proceedings, Forest and Conservation Nursery Associations. Gen. Tech. Rep. RM-257. Fort Collins, CO: U.S. Department of Agriculture, Forest Service, Rocky Mountain Forest and Range Experiment Station: 256-260.

${ }^{2}$ Weyerhaeuser George R. Staebler Forest Resources Research Center, Centralia, WA.

${ }^{3}$ Weyerhaeuser Technology Center, Federal Way, WA. 
hardiness test results are used in the frost control program in the nursery and in various other regeneration decisions (Timmis et al 1994).

\section{Morphology - The external characteristics including} height, root collar diameter. shoot and root dry weights and root to shoot ratio (Thompson 1985).

\section{SEEDLING TESTING PROCEDURES}

\section{Root Growth Potential (RGP) Test:}

Twenty seedlings ( 4 pots of 5 seedlings per pot) from each lot are potted into two gallon pots in a peat:perlite (3:2) mix and grown in a growth chamber for 7 or 14 days or in a greenhouse for 4 weeks. In the growth chamber (7-day and 14-day RGP tests), the root temperature is maintained as close to $20^{\circ} \mathrm{C}$ as possible with a relative humidity of $75 \%+$. The daylength is maintained at 16 hours using high pressure sodium vapor lamps, which provide about $400 \mu \mathrm{E} / \mathrm{m}^{2} /$ sec. at foliage height. In the greenhouse (4-week RGP test), the root temperature is maintained as close to $20^{\circ} \mathrm{C}$ as possible with a relative humidity of $50 \%+$. Seedlings are grown with natural sunlight extended to sixteen hours using cool white fluorescent lamps.
At the conclusion of the tests, new roots longer than or equal to $1 \mathrm{~cm}$. (Figure 1) are counted and the values are then converted into a modified Burdett's (Burdett 1987) root growth index (RGI) using the following scale:

\begin{tabular}{|c|c|}
\hline$\underline{\mathrm{RGI}}$ & $\begin{array}{c}\text { Number of new roots } \\
>1 \mathrm{~cm} .\end{array}$ \\
\hline 0 & No new roots \\
\hline 1 & Some new roots, but none $>1 \mathrm{~cm}$ \\
\hline 2 & $1-3$ \\
\hline 3 & $4-10$ \\
\hline 4 & $11-30$ \\
\hline 5 & $31-100$ \\
\hline 6 & $101-300$ \\
\hline & over 300 \\
\hline
\end{tabular}

The purpose of the conversion to RGI is mainly to minimize the possible biases associated with the use of the mean number of new roots, which sometimes becomes misleading when a few trees produce an unusually large number of new roots.

Using the baseline data and research results, we have determined the threshold RGI value (Ritchie and Tanaka 1990) for three main stock types of Douglas-fir.

\begin{tabular}{lll}
\hline Stock & 14-day & 4-week \\
$\frac{\text { Type }}{1+1}$ & $\frac{\text { RGP }}{3.0}$ & $\frac{\text { RGP }}{4.8}$ \\
$2+0$ & 2.0 & 4.0 \\
MPT $^{\star}$ & 3.0 & 4.0
\end{tabular}

*MINI-PLUG ${ }^{T M}$ transplant, grown in the greenhouse for 5-6 months and transplanted into the nursery bed for one season (Hee et al 1988, Tanaka et al 1988).
This is the value below which the quality of stock is considered to be less than optimum and greenhouse viability is often less than $90 \%$ (Figure 2).

\section{Greenhouse or Growth Chamber Viability (GV) Test:}

$\mathrm{GV}$ is determined using the tops of the same sample seedlings used in the RGP tests and is expressed as a percentage of viable trees. A tree is considered to be dead if one of the following conditions exists:

1. Fifty percent or more of the buds are dead out of ten buds examined (if available). This may not apply to some pine and deciduous species.

2. Stem cambium tissue is dead around the full circumference anywhere on the lower half of the main stem.

3. Eighty percent or more of the foliage is damaged (however, if the number of new roots 1 $\mathrm{cm}$. is five or more, the tree is considered viable).

\section{Cold Hardiness Test:}

Cold Hardiness is estimated using whole-plant freeze tests followed by visual damage assessment. It is expressed as the lethal temperature in ${ }^{\circ} \mathrm{C}$ that kills $10 \%$ and $50 \%$ of a given lot $\left(\mathrm{LT}_{10}\right.$ and $\left.\mathrm{LT}_{50}\right)$. 


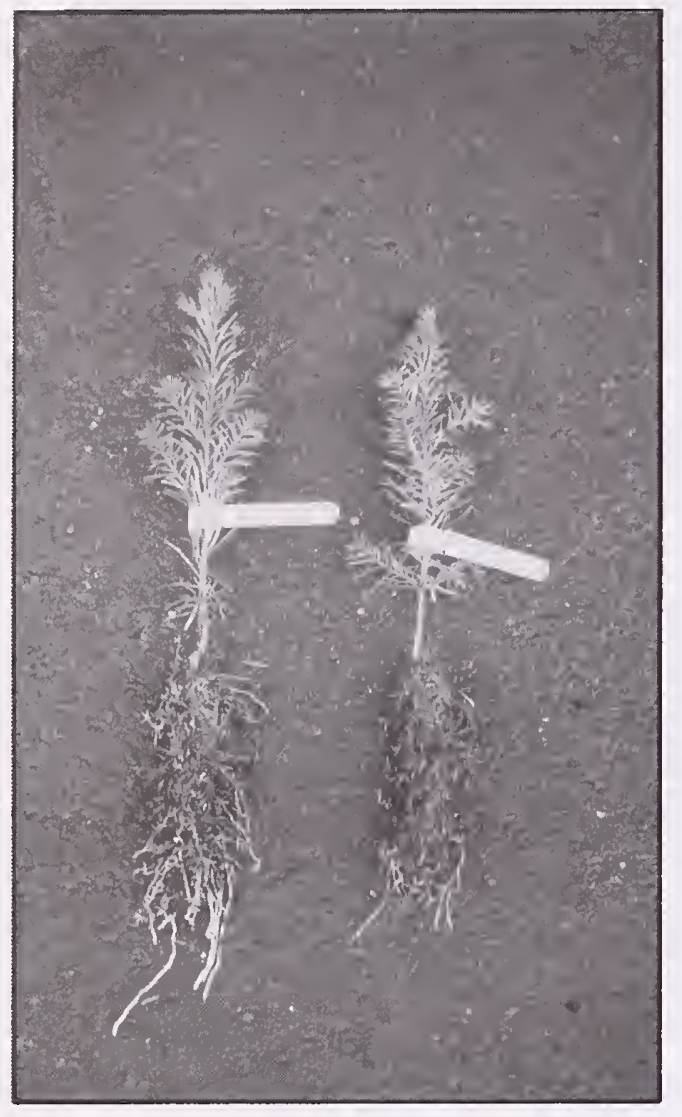

Figure 1. RGP test showing differences in the number of new roots produced by 2 noble fir plugs.

For most stock types, ninety sample trees are divided into 18 groups of 5 trees each. For larger stock types such as $1+1$ and $2+1$, the sample trees are divided into 30 groups of 3 trees each. Each group is potted into a one gallon pot in peat:perlite $(3: 2)$ mix. Pots are placed into insulated boxes to protect the roots from freezing temperatures. Fifteen trees (3-5 groups) are then exposed to four or five sub-freezing temperatures in a controlled freezer (Thermatron, Holland, Michigan). Depending on the lift date, temperatures are selected to bracket the $\mathrm{LT}_{10}$ and $\mathrm{LT}_{50}$. For each exposure, the temperature is lowered at a rate of $5^{\circ} \mathrm{C}$ per hour, held at the test

\section{Root Growth Potential Test Threshold Value}

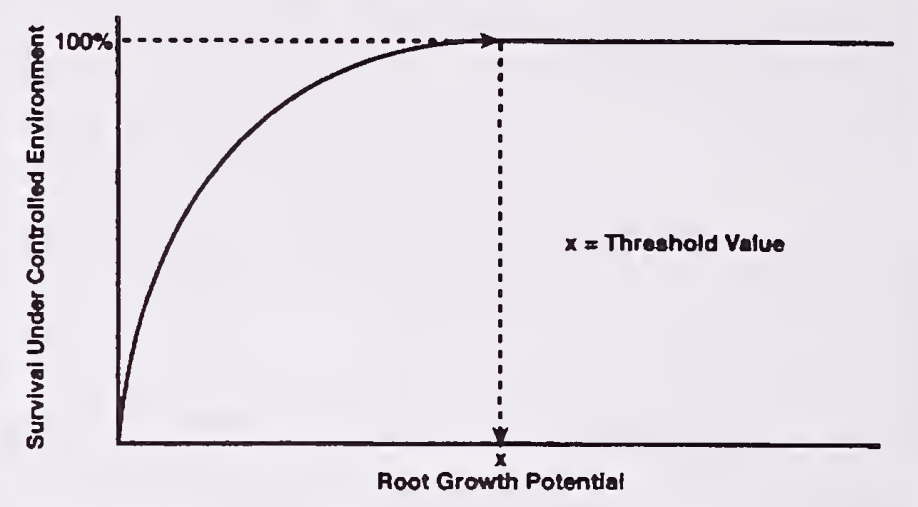

Figure 2. Threshold RGI values are estimated by determining the lowest RGI that still maintains $100 \%$ survival in a controlled environment.

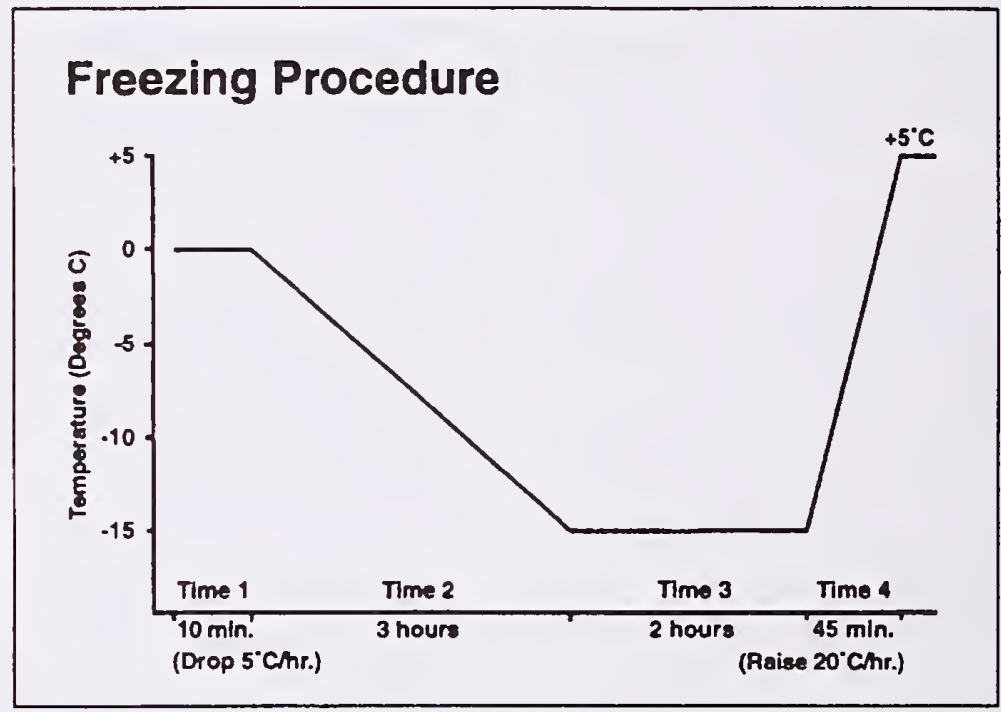

Figure 3. Ramp and hold procedure for exposure to sub-freezing temperatures in the cold hardiness test.

temperature for 2 hours and then raised back to room temperature at a rate of $20^{\circ} \mathrm{C}$ per hour (Figure 3).

Following freezing exposure, trees are moved into a greenhouse. The air temperature is maintained as close to $20^{\circ} \mathrm{C}$ as possible with a relative humidity ranging between $30 \%$ and $70 \%$. The daylength is extended to 16 hours using cool white fluorescent lamps.

Trees are evaluated for cold damage after a seven day incubation period in the greenhouse. A tree is considered to be dead if one of the following conditions exists: (1) $50 \%$ or more of the 10 buds assessed are dead, (2) cambium is dead around the full circumference anywhere on the lower half of the main stem, (3) 
cambium and buds are questionable and needle damage is $80 \%$ or more. (Needle damage is used in combination with the bud and cambium condition, not by itself, in determining mortality of questionable trees.)

\section{Morphology Test:}

Measurements are done on 20 sample seedlings. Tree height is measured in $\mathrm{cm}$. from the root collar (positioned $1 \mathrm{~cm}$. below the cotyledon scar in most species) to the base of the terminal bud. Stem diameter is measured in $\mathrm{mm}$. at the root collar. Shoot and root dry weights are determined in grams after drying them at $70^{\circ} \mathrm{C}$ for at least 48 hours. The 20 samples are weighed in four groups of 5 seedlings, but the results are expressed as the mean weight of the individual tree. Root dry weight is divided by the shoot dry weight to determine the root to shoot ratio.

\section{Reporting}

Through the use of a SASbased (SAS Institute Inc., Cary, NC) computer program, the seedling test results are analyzed and summarized, giving the client information on individual test seedlings as well as the frequencies, means and standard deviations for each parameter tested. Results are often faxed to clients within the same day of assessment to assist in making important management decisions. The seedling testing results are archived, yielding baseline data for each species and stock type combination by nursery and are used for interpretation of test data. Values in the lower quartile of the baseline data or those below threshold value are considered below normal and recommendations may be made to the client depending upon the circumstances. If low values are due to environmental damage (such as a cold event in the nursery), we recommend the seedlings be left in the nursery bed or in storage for recovery. In other situations, a recommendation may be made to increase the number of seedlings planted or to plant the affected stock on a milder site.

\section{CURRENT RESEARCH}

In addition to the above operational seedling testing, research is being conducted in the following areas:

\section{Seedling Testing Field Trial}

Research is being conducted to correlate laboratory seedling testing results after a nursery cold event with actual field performance. The results will allow us to estimate field performance of stock having various levels of RGP and GV under a range of field environments.

\section{Seedling Stress Test}

Tests are in progress to develop a reliable method to quickly evaluate the condition of stock with a suspected quality problem. A shorter test with a three to seven day turn around time would greatly help customers make important regeneration decisions. The feasibility of testing viability under stressful environments is being evaluated for this purpose.

\section{Variable Chlorophyll Fluorescence}

Tests to determine the variable chlorophyll fluorescence profiles of seedlings would provide a rapid and accurate method of assessing seedling damage in a non-destructive manner (Hawkins and Binder 1990). Both non-modulated and fully modulated fluorometers are being tested to evaluate the usefulness of this technique.

\section{CONCLUSIONS}

The Seedling Testing System (STS) provides accurate, repeatable assessment of the quality and condition of planting stock. STS minimizes the utilization of poorer quality stock that might result in regeneration failure, potential crop losses due to pathological problems in the greenhouse and nursery, and provides assistance to the company nurseries in developing good working relationships with outside seedling customers. By tracking the test results of various seedlots, we are able to monitor the progress of our continuing goal to produce high quality seedlings with superior survival and growth potential. 


\section{ACKNOWLEDGMENTS}

We would like to thank the following people for their help and support throughout various phases of the project: Jim Bryan, Steve Altsuler, Jerry Barnes, Tom Daniels, Debbie Johnson, Rod Miller, Mike Pfaff, Tom Stevens, Gale Thompson and Mark Triebwasser for technical advice and assistance, providing testing materials and facilitating outside customer's and bench marking work; Mitch Allen, Byron Carrier, Jim Clarke, Alex Dobkowski, Dick Ford, Greg Jones, Tim Kosderka, Martin Lugas and Chris Sokol for field evaluation and technical advice; Jack Englund, Jim Keeley, Mike McKinnis, Ed McLaughlin, John Wakefield and Doug Waldren for maintenance, repairs and upgrading of testing facilities and equipment; John Browning, Bill Carlson, Will Littke, Gary Ritchie, Roger Timmis and Patty Ward for various technical support and advice; Carol Morehead, Carol O'Brien and Betty Styger for carrying out RGP, morphology and cold hardiness tests and Tina Allen, Donna Loucks, Susan

Sweetingham and Frances Tanaka for preparing reports and literature search. We are particularly grateful to Steve Cafferata, Steve Hee, Tom Terry and Cheryl Talbert whose support and advice have been most helpful in initiating and establishing the Weyerhaeuser seedling testing program.

\section{REFERENCES}

Burdett, A.N., 1987. Understanding root growth capacity: theoretical considerations in assessing planting stock quality by means of root growth tests. Can. J. For. Res. 17:768-775.

Hawkins, C.D.B. and Binder, W.D. 1990. State of the art seedling stock quality tests based on seedling physiology, In: Target Seedling Symposium, USDA Forest Service, Gen. Tech. Rpt. RM-200, pp. 91-121.

Hee, S., Stevens, T., and Walch, D. 1988. Production aspects of mini-plug transplants, In: Proceedings, Combined Meeting of the Western Forest Nursery Associations, USDA Forest Service, Gen. Tech. Rpt. RM-167, pp. 168-171.

Ritchie, G.A. 1985. Root growth potential: principles, procedures and predictive ability, In: Duryea, M.L. ed., Evaluating Seedling Quality: Principles, Procedures, and Predictive Abilities of Major Tests. For. Res. Lab., Oregon State Univ., Corvallis, OR. pp. 93-105.
Ritchie, G.A. and Tanaka, Y. 1990. Root growth potential and the target seedling, In: Target Seedling Symposium, USDA Forest Service, Gen. Tech. Rept. RM-200, pp. 3751 .

Tanaka, Y., Carrier, B., Dobkowski, A., Figueroa, P., and Meade, R. 1988. Field performance of miniplug transplants, In: Proceedings, Combined Meeting of the Western Forest Nursery Associations, USDA Forest Service, Gen. Tech. Rpt. RM167, pp. 172-181.

Thompson, B.E. 1985. Seedling morphological evaluation, In: Duryea, M.L. ed., Evaluating Seedling Quality: Principles, Procedures, and Predictive Abilities of Major Tests. For. Res. Lab., Oregon State Univ., Corvallis, OR. pp. 5971.

Timmis, R., Flewelling, J. and Talbert, C. 1994. Frost injury prediction model for Douglasfir seedlings in the Pacific Northwest, Tree Physiology 14:855-869. 


\title{
Can Foliage Water Content Measurements Replace Freezer Tests in Determining a Safe Lifting Time For Frozen Storage of Conifer Seedlings? ${ }^{1,2}$
}

\author{
M.J. Krasowski ${ }^{3}$, A. Caputa ${ }^{4}$, and C.D.B. Hawkins ${ }^{3}$
}

Several researchers have reported a strong relationship between the frost hardiness of planting stock and its shoot water content (Pellet and White 1969, Rosvall-Åhnebrink 1977, Jonsson et. al. 1981, Colombo 1990, Calmé et. al. 1992). The last cited work was done in Quebec. Calmé et. al (1992) examined the reiationship between shoot water content and injury sustained in a $-10^{\circ} \mathrm{C}$ freezer test by containerized seedlings of three species (Jack pine, white, and black spruce). They reported that frost hardy seedlings had shoot dry to fresh weight ratio of less than 0.3 . Consequently, they suggested that measuring shoot water may rapidly predict seedling frost tolerance. In fact, the dry weight to fresh weight ratio of excised shoot tips (terminal $2 \mathrm{~cm}$ ) has been used operationally in Sweden to determine safe lifting time for storage of conifer seedlings. Seedlings are lifted when the ratio is 0.31 or less (Hultén and Lindell 1980).

The possibility of a simple and rapid test to determine safe lifting time for seedling storage is an exciting one. Unfortunately, there are problems with the reliability of the water content test. Calmé et. all. (1992) reported that photoperiod shortening alone or coupled with moisture stress, and different levels of NPK fertilization had no effect on the relationship between frost tolerance and shoot water content. Non-hardy seedlings had high water content while it was low in the hardy ones. Lindström ${ }^{5}$ (pers. comm. 1994), however, thought cultural treatments may influence the relationship.

In Sweden, seedlots from locations north of the nursery must reach lower water content to be lifted than the local seedlots. The reverse is the case for seedlots south of the nursery (Lindström - pers. comm. 1994). Based on the Swedish perspective, a great deal of experience is required from nursery managers to interpret the water relation based measurement correctly.

'Krasowski, M.J.; Caputa, A.; Hawkins, C.D.B. 1994. Can Foliage Water Content Measurements Replace Freezer Tests in Determining a Safe Lifting Time For Frozen Storage of Conifer Seedlings? IN: Landis, T.D.; Dumroese, R.K., tech. coords. National Proceedings, Forest and Conservation Nursery Associations. Gen. Tech. Rep. RM-257. Fort Collins, CO: U.S. Department of Agriculture, Forest Service, Rocky Mountain Forest and Range Experiment Station: 261-267.

${ }^{2}$ Funded by Research Branch of the British Columbia Forest Service (BCFS)

${ }^{3}$ Research scientists, Red Rock Research Station, RR\#7 RMD\#6, Prince George, B.C., V2N 2J5, phone (604) 963-9651 fax (604) $963-3436$.

${ }^{4}$ Research technician, Red Rock Research Station.

${ }^{5}$ Lindström, A. Swedish University of Agricultural Sciences, Dept. of For. Yield Res., Garpenberg, Sweden 
In British Columbia, safe time to lift for freezer storage is determined by the $-18^{\circ} \mathrm{C}$ test recommended by Simpson $(1985)^{6}$. The test is simple and reliable but results of visual injury assessment are available only after one week. So far, faster methods of injury evaluation have not been operationally adopted in British Columbia.

This report takes advantage of data gathered for other studies in 1991 and in 1994. Foliage water content was monitored in these studies and related to results of the $-18^{\circ} \mathrm{C}$ test. Therefore, our results are not directly comparable to reports based on measurements of shoot water content. We treat this report as a preliminary assessment of the method for more thorough examination, should it be warranted.

\section{MATERIALS AND METHODS}

\section{Plant material and sampling:}

A number of seed sources and treatments were tested. Seedlots and treatments used for testing should be viewed merely as a variety of material available at the nursery. Seed source locations and special cultural treatments are given in the results section.
In 1991, all tests were made on transplants growing outdoors in a nursery bed at Red Rock Research Station. They were either, planted in the spring of 1991, following freezer storage, or sown in the spring, grown in a greenhouse culture, and transplanted into the nursery bed in August. These were not truly cultured seedlings; however, we were interested in the evaluation of end-of-season trends. The 1994 testing was made on current-year sown seedlings growing in a greenhouse culture.

Nine randomly collected seedlings were sampled per seedlot or treatment in 1991, and 15 in 1994. Means of water content measurements and foliage injury in freezer tests are presented here. In most cases, foliage samples for water content determination were taken from seedlings used in the freezer tests. With few exceptions, both procedures were carried out on the same dates.

\section{Freezer tests:}

The standard $-18^{\circ} \mathrm{C}$ freezer test was used as it is done routinely in British Columbia nurseries. Two-thirds of the collected seedlings were frozen while one third served as controls. Evaluation of visible injury was done after one week in a hydroponic culture at forcing conditions.

\section{Water content measurements:}

Four needles were sampled at mid-day from the terminal $2 \mathrm{~cm}$ of each seedling. The needles were placed into numbered glass vials, then weighed (fresh weight) on the laboratory precision balance. In 1991, the needles were processed in pairs two per sampled tree. In 1994, a sample consisted of four needles. After weighing, the leaves were placed on a microwave-safe plastic tray with numbered compartments and microwaved at low power for $10 \mathrm{~min}$. They were weighed, then returned to the microwave for one more minute at low power and weighed again to determine if their dry weight stabilized (no further decline). This was usually sufficient to obtain a reliable dry weight measurement. Dry weight to fresh weight ratios were then calculated.

\section{RESULTS AND DISCUSSION}

\section{Seedlings remaining outdoors in a nursery bed in 1991:}

\section{Seedlot 8791 (latitude 54 $36^{\circ}$ $\mathrm{N}$, elevation $1219 \mathrm{~m}$ )}

Seedlot 8791 was sown in PSB $313 B^{7}$ containers in March 1991 at two different nurseries: Red Rock Research Station (RRRS) and Cowichan Lake

${ }^{6}$ Simpson, D.G. Measuring cold hardiness. Presentation at the Forest Nursery Association of British Columbia Annual Meeting, Sept. 23-26, Duncan, B.C.

${ }^{7}$ All container types mentioned in this report are styroblock containers produced by Beaver Plastic Limited of Edmonton, Alberta. Providing trade names does not constitute endorsement by BCFS. 
Research Station (CLRS).

Following growth at an extended, $23 \mathrm{~h}$ photoperiod, different short day treatments (SDT) were applied at each nursery to induce dormancy. A 14 h photoperiod SDT was applied at RRRS in early July for two weeks. A 10 h photoperiod SDT for three weeks was applied in mid-July at CLRS. The CLRS stock was air shipped to Red Rock and both batches were planted into the nursery bed at RRRS on August 6.

There was a rapid increase in dry weight to fresh weight ratio in RRRS and CLRS seedlings between August 7 and September 10 (Fig. $1 \mathrm{~A}-\mathrm{B}$ ). The first freezer test was made on September 10. On that date, both the RRRS and CLRS seedlings had mean foliage injury greater than $25 \%$. Foliage dry to fresh weight ratio was about 0.42 on September 6 . It obviously stabilized and remained at this value in all measurements after September 6 . Mean foliage injuries in all freezer tests after September 10 were very low (Fig 1A-B).

\section{Seedlot 8779 (latitude}

\section{$55^{\circ} 44^{\prime} \mathrm{N}$, elevation $1067 \mathrm{~m}$ )}

Two stock types were available in seedlot 8779 . One was a 2+0 PSB 415B container type with seedlings sown on June 1, 1990 and grown in Industrial Forestry Services (IFS) greenhouses near Prince George. The other stock was 1+0 PSB 415B sown in February and grown in
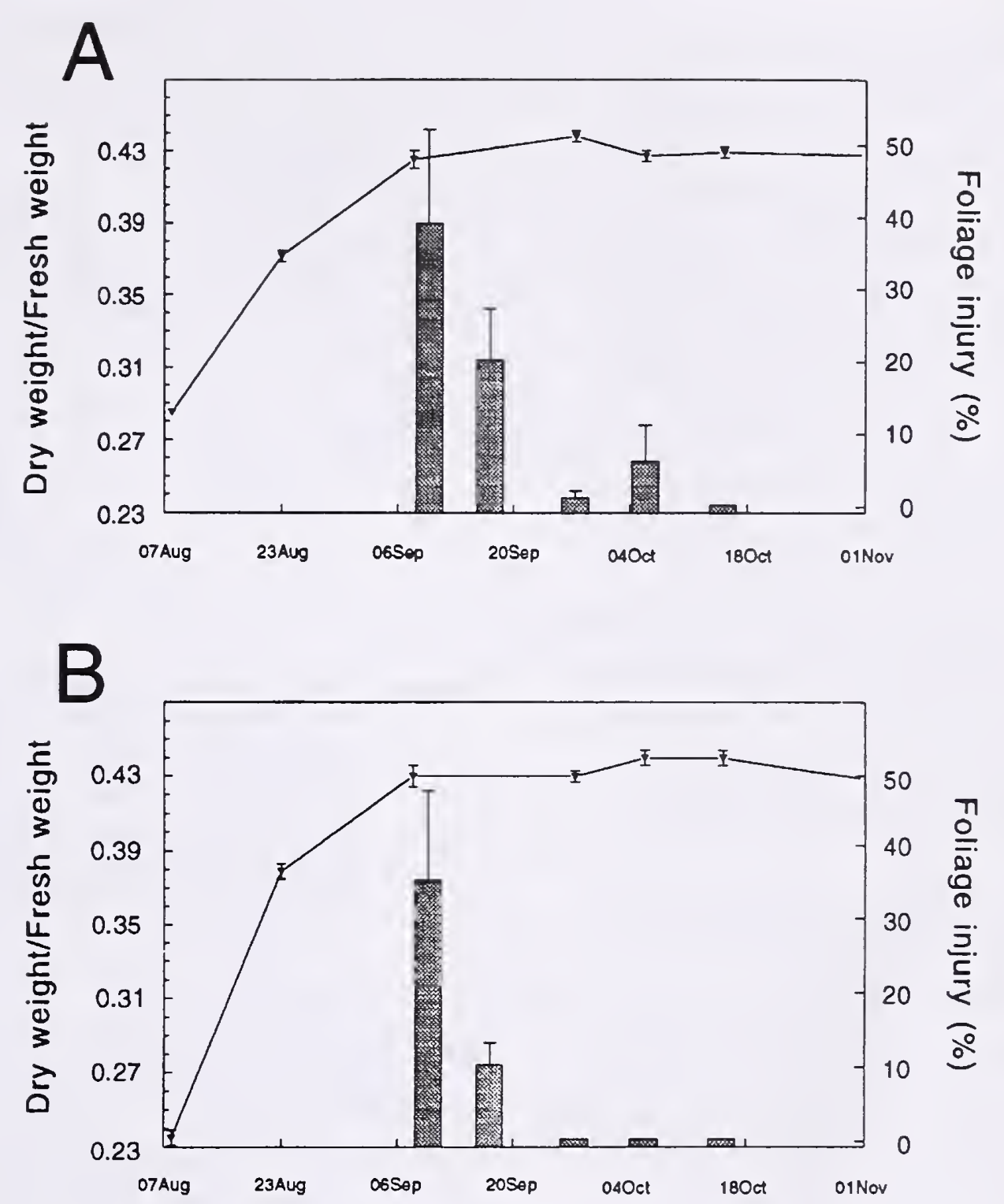

Figure $1 \mathrm{~A}-\mathrm{B}$. Changes in mean foliage water content expressed as a dry to fresh weight ratio (line graph) and mean foliage injuries resulting from $-18^{\circ} \mathrm{C}$ freezer tests for seedlings of seedlot 8791 transplanted in August from greenhouse culture into a nursery bed at Red Rock Research Station. Capped vertical lines show standard errors of the means.

Figure 1A: Stock grown in Red Rock greenhouses prior to transplanting.

Figure 1B: Stock grown in Cowichan Lake Research Station greenhouses prior to transplanting.

the Hybrid nursery greenhouses, near Vancouver. IFS nursery used reduced $\mathrm{N}$ fertilization to induce budset. No particular dormancy induction treatment was applied at Hybrid nursery. Rather, budset was promoted by naturally occurring shorter days at the nursery's latitude, relative to that of the seed source. Both batches were planted at Red Rock on August 6.

The Hybrid stock passed the first freezer test made on September 9 , and was considered ready for lifting. Dry to fresh weight ratio was about 0.42 on that date (Figure 2). It continued to increase until November 
reaching about $0.45-0.46$. Injury in all freezer tests after that date was very low (Figure 2). The IFS stock had $27 \%$ injury and dry/fresh weight ratio of about 0.41 on September 9. It passed the freezer test on September 20. The weight ratio increased, then declined (but not below 0.42) between September 10 and November 1 (Figure 2). The IFS stock was only $2 \%$ above the acceptable injury limit on September 10. Ithis possible that it was ready for lift at that date (visual assessments of injury are not that precise).

\section{Seedlot 1822 (latitude $54^{\circ} 45^{\prime}$ elevation $853 \mathrm{~m}$ )}

PSB 415B 2+0 stock was planted in late May 1991 following freezer storage. It sustained mean foliage injury higher than $30 \%$ in the September 9 test even though foliage dry to fresh weight ratio already reached about 0.43 (not shown). However, the ratio was very stable after that date (0.43-0.44) and foliage injury was minimal or none.

All the above seedlots were from sources north of, and higher in elevation than RRRS. The seed sources were also north of the nurseries where they were grown prior to transplanting into beds at RRRS. It is difficult to judge to what extent the effects of previous growing conditions were nullified by the common post-transplanting conditions at

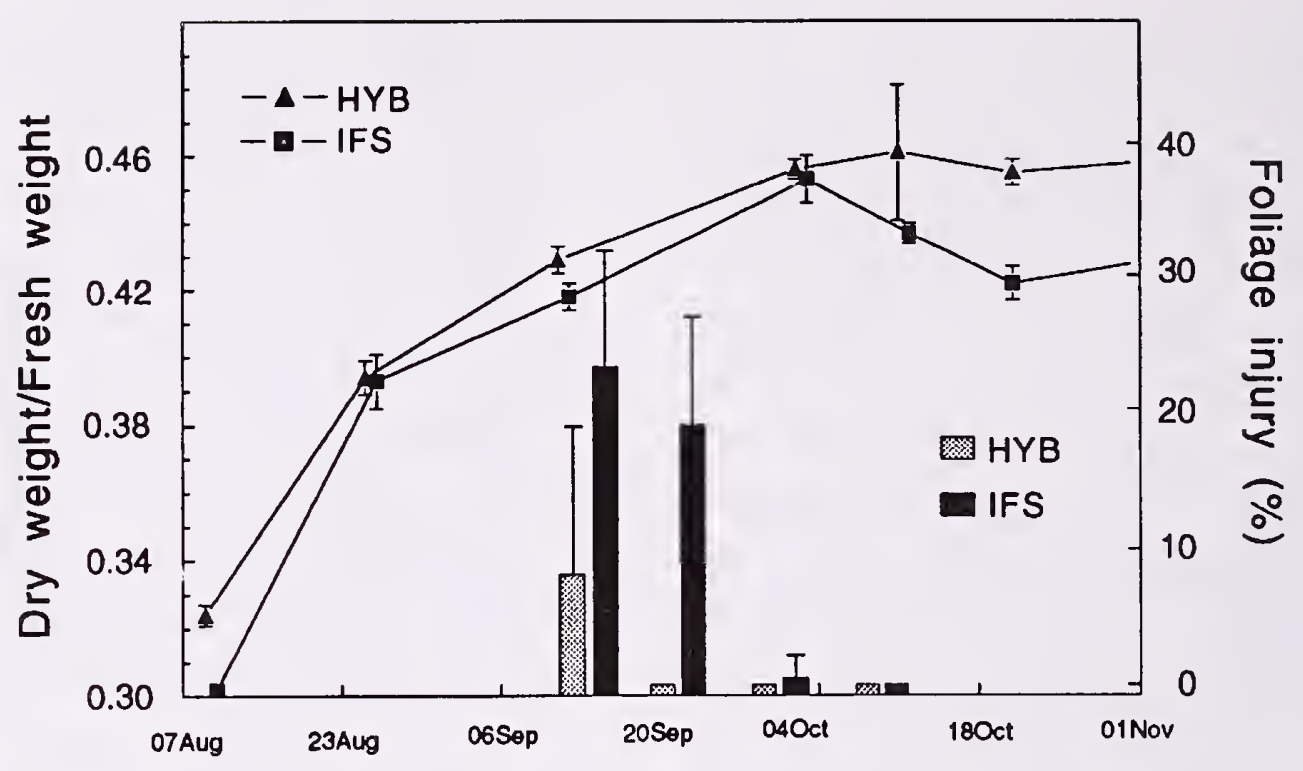

Figure 2. Changes in foliage water content (dry to fresh weight ratio) shown as a line graph, and mean freezer test foliage injury (vertical bars) in seedlings of seedlot 8779 . Seedlings were transplanted into a nursery bed at Red Rock in August 1991 as 2+0 PSB 415B stock grown at Industrial Forestry Services (IFS) nursery and as 1+0 PSB 415B grown at the Hybrid nursery. Capped vertical lines indicate standard errors of the means.

RRRS (latitude $54^{\circ} 45^{\prime} \mathrm{N}$, elevation $620 \mathrm{~m}$ ). For seedlot 8791 , there appears to be very little if any significant effect of previous treatments and nursery of origin. In seedlot 8779 , the difference between stock types (different age and nursery of origin) was both in frost hardening and foliage water content patterns. The latter difference occurred only after late September. It is not certain whether the observed differences were due to the nursery locale (latitude, growing regime), age of stock, or both.

We remind the reader that these are outdoor-grown seedlings and they cannot be compared to greenhouse-grown ones. Nevertheless, the above examples do show close a relation- ship between water (or dry matter) content and frost resistance of spruce seedlings. For these outdoor-located seedlings the threshold value of dry to fresh weight ratio of about 0.42 0.43 appears to be well related to the stage when the seedlings sustain less than $25 \%$ foliage injury in the $-18^{\circ} \mathrm{C}$ test.

\section{4 testing of seedlings from greenhouses:}

This time, container seedlings grown in a greenhouse culture rather than outdoors were studied. Figure 3 A-B shows changes in dry to fresh weight ratio in seedlings of four seedlots ranging widely in latitudes and altitudes of seed sources and either untreated (Figure 3A) or subjected to SDT of $14 \mathrm{~h}$ for two 
weeks in early June (Figure 3B). All seedlings were grown in PSB 415B styroblocks and were sown at the same date in February. Seed source locations are as follows:

Seedlot 30664 latitude $51^{\circ} 36^{\prime} \mathrm{N}$, altitude $480 \mathrm{~m}$;

Seedlot 6863 latitude $54^{\circ} 56^{\prime} \mathrm{N}$, altitude $960 \mathrm{~m}$;

Seedlot 8779 latitude $55^{\circ} 44^{\prime} \mathrm{N}$, altitude $1067 \mathrm{~m}$;

Seedlot 35075 latitude $58^{\circ} 25^{\prime} \mathrm{N}$, altitude $450 \mathrm{~m}$;

Figure 3 shows no obvious stabilization of foliage water content in seedlings of any seedlot whether SDT treated or not, until possibly very late in the season. Therefore, it is necessary to look for threshold values in water content corresponding to the dates when seedlings sustained lower than $25 \%$ foliage damage in freezer tests and were considered ready for lift. Outcomes of freezer tests resulting in injury higher than $25 \%$ are not shown on Figures $3 \mathrm{~A}-\mathrm{B}$ to prevent their overcrowding. Instead, Table 1 presents lift dates determined by freezer tests, mean foliage injury, and mean foliage dry to fresh weight ratios on these dates.

The northernmost seedlot 35075 was ready for lift early. It had consistently lower foliage water content than did other
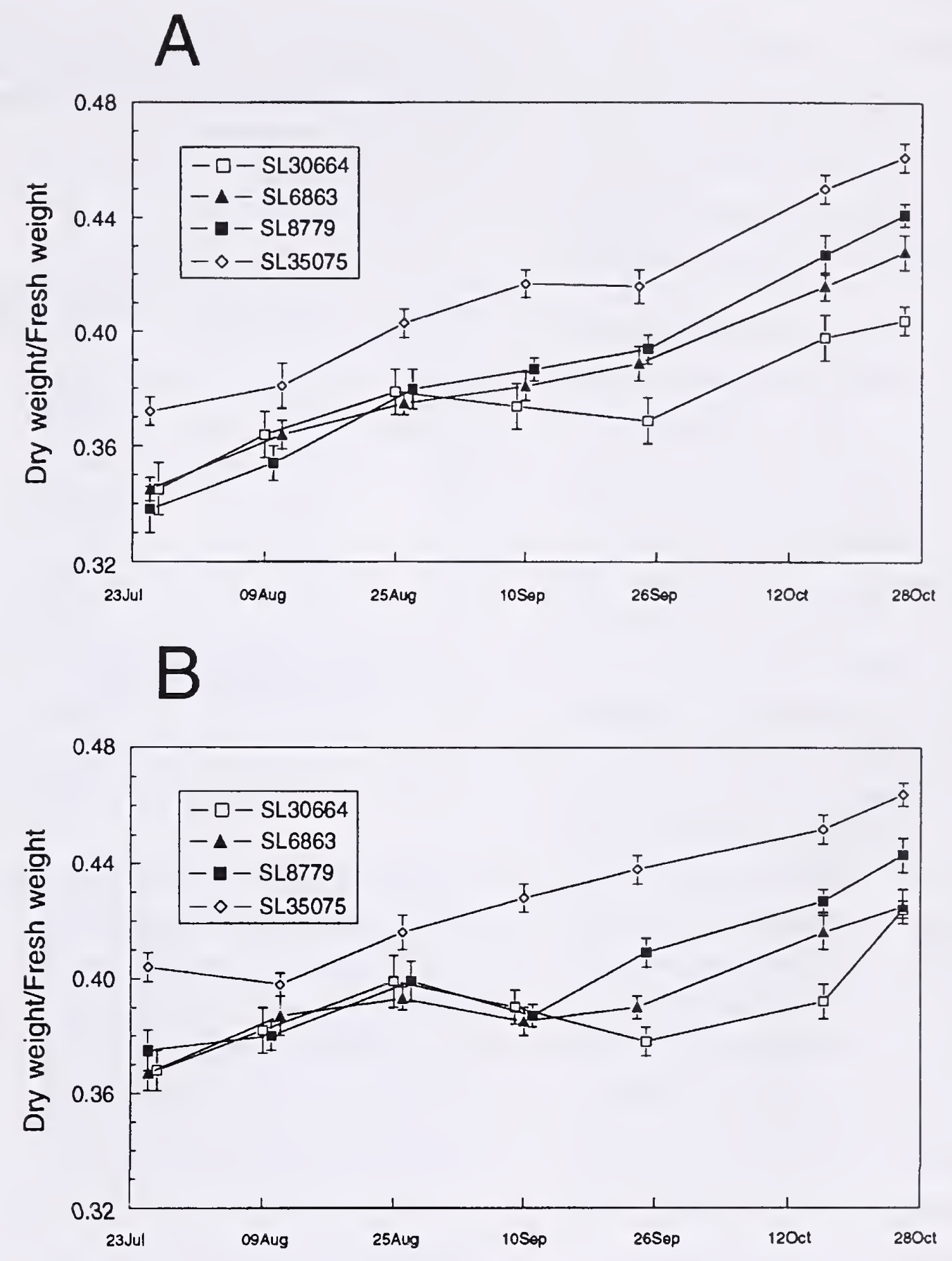

Figure 3A-B. Changes in foliage water content (dry to fresh weight ratio) in seedlings of four different seedlots (SL) of interior spruce toward the end of their first growing season. All seedlings were sown on the same date and grown under a greenhouse culture in PSB 415B containers.

Figure 3A: Seedlings untreated with short day treatment. Figure 3B: Seedlings from a $14 \mathrm{~h}$ short day treatment applied for 2 weeks starting June 9, 1994.

seedlots throughout the observation period, whether short-day treated or not (Figures 3A-B). This is consistent with the earlier discussed effect of seedlot location. The trend is for lower water content (higher dry to fresh weight ratio) in seedlots north of, and for higher water content in those south of the nursery when at similar levels of frost hardiness (Lindstöm, pers. comm. 1994). It is particularly obvious if seedlot 35075 is 
contrasted with seedlot 30664 , which came from a similar elevation but almost seven degrees of latitude south. Seedlot 8779 is an exception to the theory. This seedlot is from north of the nursery and from a higher elevation than all the other seedlots. However, it had a low dry to fresh weight ratio, compared to the other seedlots, when ready to lift as determined by the $-18^{\circ} \mathrm{C}$ test (Table 1 ). Seedlot 6863 can be considered local by latitude but about $300 \mathrm{~m}$ higher in elevation, relative to nursery location. It was ready to lift at about 0.42 dry to fresh weight ratio. In most cases the ratio was higher at ready to lift date in short-day treated than in the untreated seedlings (Table 1) indicating there may be some influence of these treatments on the discussed relationship. The dry to fresh weight ratio separated the seedlots in accordance to the latitude of seed origin in untreated and SDT treated seedlings in late September (Figures 3A-B). By that time, however, some seedlots and treatments would have already been lifted based on the $-18^{\circ} \mathrm{C}$.

\section{SUGGESTIONS AND CONCLUSIONS}

At this time, it is not possible to replace freezer tests with water content measurements to determine safe lifting time for conifer seedlings. The data shows, though, that it would be

Table 1.Mean foliage water content and mean foliage injury (plus and minus standard error) on the date considered safe to lift for seedlings of four seedlots and untreated (UNTR) or treated with a short day (SDT) of $14 \mathrm{~h}$ for 2 weeks in early summer.

\section{Means on that date}

\begin{tabular}{|c|c|c|c|c|}
\hline Seedlot & Treatment & $\begin{array}{l}\text { Date when } \\
\text { ready to lift }\end{array}$ & $\begin{array}{l}\text { Foliage } \\
\text { injury (\%) }\end{array}$ & $\begin{array}{l}\text { Foliage dry: } \\
\text { fresh weight ratio }\end{array}$ \\
\hline 30664 & UNTR & Oct 20 & $12 \pm 3$ & $0.404 \pm 0.005$ \\
\hline 30664 & SDT & Oct 20 & $17 \pm 3$ & $0.424 \pm 0.003$ \\
\hline 6863 & UNTR & Oct 11 & $9 \pm 2$ & $0.416 \pm 0.005$ \\
\hline 6863 & SDT & Oct 11 & $12 \pm 4$ & $0.416 \pm 0.006$ \\
\hline 8779 & UNTR & Sept 19 & $4 \pm 2$ & $0.394 \pm 0.005$ \\
\hline 8779 & SDT & Sept 19 & $22 \pm 6$ & $0.409 \pm 0.005$ \\
\hline 35075 & UNTR & Sept 19 & $4 \pm 2$ & $0.416 \pm 0.006$ \\
\hline 35075 & SDT & Sept 19 & $14 \pm 8$ & $0.438 \pm 0.005$ \\
\hline
\end{tabular}

Note:Seedlings were considered ready to lift once mean foliage damage in a $-18^{\circ} \mathrm{C}$ freezer test was below $25 \%$.

worthwhile to undertake more work in this area as it may be possible to reduce the number of freezer tests. Many issues not addressed by this study must be realized and answered to gain a better understanding of the water content measurement technique.

These are:
1) Are whole shoot or shoot tip based measurements of water content more consistent and better related to seedling frost
3) What is the influence of seedling age and size on the dry to fresh weight ratio of foliage and of shoots? resistance than foliage based measurements? In this report, the dry to fresh weight ratio of foliage at lifting dates was always higher than the shoottip based ratio threshold of 0.31 used for lifting time determination in Sweden.
2) What about the great range of seed source elevation (from sea level to $>1000 \mathrm{~m}$ ) and latitude combinations characteristic of British Columbia seed sources? Does it make the water content measurement test too complicated to interpret for reliable practical use?

4) Should further studies relate directly between weight based measurements and storability rather than be compared to one temperature based freezer test?

5) What technical details could be improved to make the technique more reliable? 
The $-18^{\circ} \mathrm{C}$ test works well in determining safe lift time in British Columbia nurseries. The water content measurement must prove to be equally reliable to be considered useful in practice. If it does so, its low cost, simplicity, and speed will offer real benefits.

\section{LITERATURE CITED:}

Calmé, S., Margolis, H.A., and F.J. Bigras. 1993. Influence of cultural practices on the relationship between frost tolerance and water content of containerized black spruce, white spruce, and jack pine seedlings. Can. J. For. Res. 23: 503-511.

Christersson, L. 1975. Frost hardiness development in rapid- and slow-growing Norway spruce seedlings. Can. J. For. Res. 5: 340-343.

Colombo, S.J. 1990. Bud dormancy status, frost hardiness, short for frozen storage. J. Am. Soc. Hortic. Sci. 115:302-307.

Edwards, I.K. 1989. The effects of mineral nutrition on hardening-off of conifer seedlings. U.S. For. Serv. Rocky Mt. For. Range Exp. Stn. Gen. Tech. Rep. RM-184. pp. 98102.
Glerum, C. 1985. Frost hardiness of coniferous seedlings: principles and applications. In Proceedings, Evaluating Seedling Quality: Principles, Procedures, and Predictive Abilities of Major Tests, 1618 Oct. 1984, Corvallis, Oreg. Edited by M.L. Duryea. Forest Research Laboratory, Oregon State University, Corvallis. pp. 107-123.

Hultén, H., and Lindell, M. 1980. TS-halt ett mått på invintring. Avd. för skogsförnyelse, Sveriges Lantbruksuniversitet, Garpenberg, Sweden.

Jonsson, A., Eriksson, G., Dormling, L., and Ifver, J. 1981. Studies on frost hardiness of Pinus contorta Dougl. seedlings grown in climate chambers. Stud. For. Suec. 157: 1-47.

Pellett, N.E., and White, D.B. 1969. Relationship of seasonal tissue changes to cold acclimation of Juniperus chinensis 'Hetzi' J. Am. Soc. Hortic. Sci. 94:460-462.
Rosvall-Åhnebrink, G. 1977. Artificiell invintring av skogsplantor i plastväxthus. Skogshögskolan, Institution for skogsgenetík, Uppsala, Sweden. No. 27. pp. 153-161.

Timmis, R. 1974. Effect of nutrient stress on growth, bud set and hardiness in Douglasfir seedlings. In Proceedings, North American Containerized Forest Tree Seedling Symposium 26-29 Aug. 1974.

van den Driessche, R. 1980. Health, vigour and quality of conifer seedlings in relation to nursery soil fertility. In Proceedings, North American Forest Tree Nursery Soils Workshop, 28 July - 1 Aug. 1980, Syracuse, N.Y. Edited by L.P. Abrahamson and D.H. Bickelhaupt. College of Environmental Science and Forestry, New York State University, Syracuse. pp. 100120. 


\title{
Short Day Nursery Treatment Promotes Photosynthesis in Interior Spruce Seedlings: Summary of Poster ${ }^{1,2}$
}

\author{
C.D.B. Hawkins, R.Y.N. Eng and M.J. Krasowski ${ }^{3}$
}

The ideal nursery cultural treatment would promote seedling photosynthesis (Ps) and decrease respiration (Rd). Realistically, a treatment promoting Ps and not affecting Rd would be most acceptable. The next best scenario would be for a cultural treatment that did not affect either process.

Blackout is a very powerful nursery cultural tool for controlling the height of interior spruce (Picea glauca, P. engelmannii and their naturally occurring hybrids) in central British Columbia (Hawkins and Draper 1991, Hawkins and Hooge 1988). Hawkins and Draper (1991) suggested that blackout treatments may promote Ps after exposure to shortened days ends. They used changes in plant weight as the basis for their hypothesis. Others (Hawkins and Hooge 1988. Odlum and Colombo 1988, Krasowski et al. 1993) have suggested blackout could also have negative impacts on seedling morphology, physiology and phenology.

In 1993, three photoperiods, ambient about $19 \mathrm{~h}$ (control), 14h and $11 \mathrm{~h}$, were appiied for 17 days at Red Rock Research Station to seedlings of registered BC Forest Service seedlots 6866 and 8779 . Treatment commenced when mean seedlot height was $10 \pm 1 \mathrm{~cm}$. At the end of blackout treatment, all seedlings were returned to ambient photoperiod. At this time, Ps and $\mathrm{Rd}$ assessments started. Assessments were done 4 times over 8 weeks. Ps and Rd were measured with a LiCor 6200 (Lincoln, NB) infrared gas analyzer (IRGA) with a different sample of 36 seedlings for each date. The measurement frequency is approximately one seedling every 6 minutes.

Control Ps was significantly lower on all test dates (Table 1). Photoperiod had no affect on Rd for the dates where $\mathrm{Rd}$ is not shown (Table 1). Seedlot had no affect on Rd but 8779 had greater Ps rates on 30 June and 23 Aug. There was no interaction between seedlot and photoperiod demonstrating the applicability of the results. Increased Ps rates for the short day treatments is further supported by the increased fertigation required by the $14 \mathrm{~h}$ and $11 \mathrm{~h}$ treatment seedlings over the eight weeks of observation.

\footnotetext{
${ }^{1}$ Hawkins, C.D.B. ; Eng, R.Y.N.; Krasowski, M.J. 1994. Short Day Nursery Treatment Promotes Photosynthesis in Interior Spruce Seedlings: Summary of Poster. IN: Landis, T.D.; Dumroese, R.K., tech. coords. National Proceedings, Forest and Conservation Nursery Associations. Gen. Tech. Rep. RM-257. Fort Collins, CO: U.S. Department of Agriculture, Forest Service, Rocky Mountain Forest and Range Experiment Station: 268-270.
}

${ }^{2}$ Funded by Silviculture and Research Branches of the British Columbia Forest Service.

${ }^{3}$ Red Rock Research Station, RR \#7, RMD \#6, Prince George, BC, Canada V2N 2J5, Ph: 604-963-9651 FAX: 604-963-3436 
Table 1. Photosynthesis (Ps) and dark shoot respiration (Rd) of spruce seedlings subjected to shortened days (blackout). Seedlots are pooled and only significant (ANOVA) parameters are presented. On a date, means followed by the same letter are not different.

\begin{tabular}{|c|c|c|c|c|c|c|}
\hline Photoperiod & $\begin{array}{l}30 \text { Jun } \\
\text { Ps }\end{array}$ & $\begin{array}{l}6 \mathrm{Jul} \\
\text { Ps }\end{array}$ & $\mathrm{Rd}$ & $\begin{array}{l}26 \text { Jul } \\
\text { Ps }\end{array}$ & $\begin{array}{l}23 \text { Aug } \\
\text { Ps }\end{array}$ & $R d$ \\
\hline $11 \mathrm{~h}$ & $3.83 a$ & $7.39 a$ & $2.57 a$ & $6.10 a$ & $5.84 a$ & $1.79 \mathrm{a}$ \\
\hline $14 \mathrm{~h}$ & $3.63 a$ & $6.70 b$ & $2.91 \mathrm{a}$ & $6.15 a$ & $5.29 b$ & $1.74 a$ \\
\hline $19 \mathrm{~h}$ & $2.77 b$ & $5.52 c$ & $3.36 b$ & $3.16 b$ & $5.28 b$ & $2.02 b$ \\
\hline
\end{tabular}

Short day treated seedlings were not as tall as ambient photoperiod treated stock. Root collar diameter and root mass were similar among photoperiod treatments at lifting in late October. Short day treated seedlings also developed terminal buds earlier, became glaucous sooner, developed increased frost resistance and were ready for lifting and storage earlier than their ambient treated counterparts. It is hypothesized the increased net photosynthesis provided the energy required to accelerate the observed developmental and physiological changes for these seedlots.

In 1994, one seedlot (30664) was exposed to either a $14 \mathrm{~h}$ or a 19h (control) photoperiod.

Treatment commenced when mean seedlot height was $11 \pm 1$ $\mathrm{cm}$. At the end of blackout treatment, all seedlings were returned to ambient photoperiod. At this time, Ps assessments were started using an EARS plant productivity fluorometer (PPM) (Delft, Netherlands).
Assessments were done periodically in the nursery and after planting on the same sample populations of seedlings (c.f. IRGA). The PPM measured quantum yield (QY) of each seedling. The measurement frequency is approximately one seedling every 20 s. Figure one shows how quantum yield for two populations (efficient and less efficient) is related to Ps. Generally the greater the quantum yield the greater the rate of Ps.

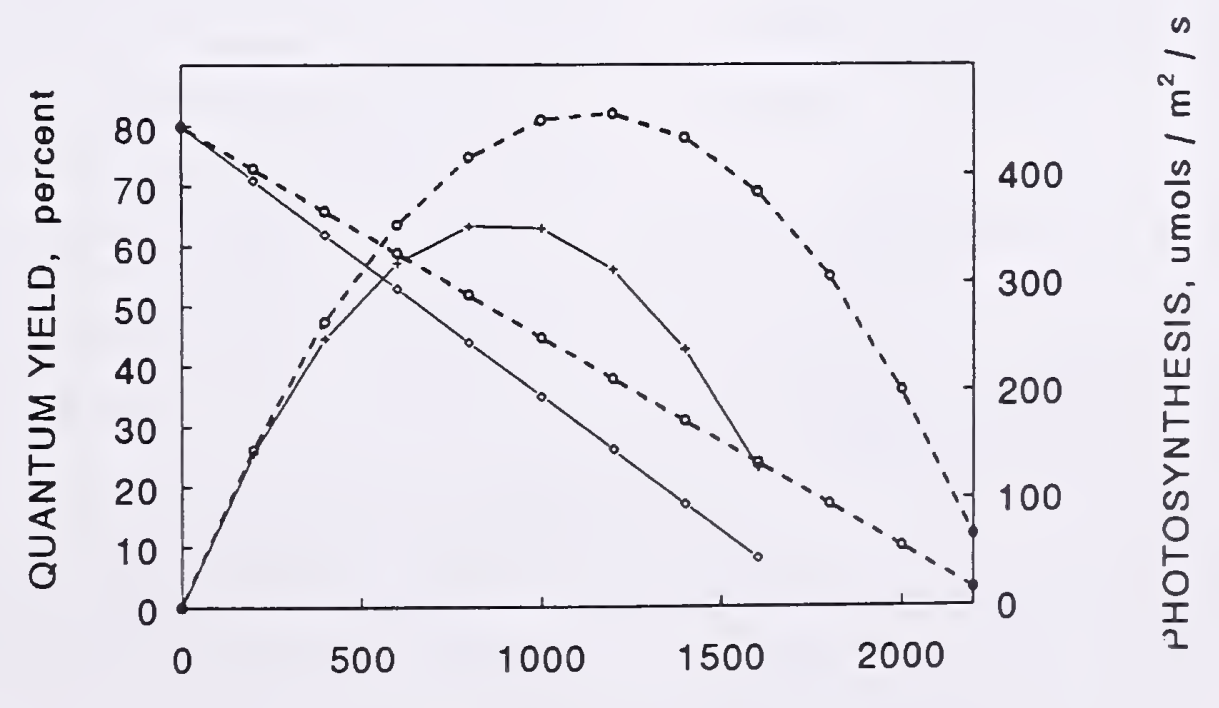

LIGHT INTENSITY, umols $/ \mathrm{m}^{2} / \mathrm{s}$

Figure 1. Theoretical quantum yield (straight lines) and photosynthesis (curved lines) for efficient (broken line) and less efficient (solid line) conifer populations.
At the end of blackout, control seedlings had a greater quantum yield (24 Jun). However in a very short time, blackout treated stock had a greater quantum yield and this held until the end of the nursery phase (20 Jul). 30 minutes after planting there was no difference between treatments (Jul 20). However by 22 July the $14 \mathrm{~h}$ treatment had the greatest quantum yield and this was the case on July 28. Again, short day nursery treatment appears to promote Ps. 
In two different seasons with three different seedlots, short day treatment promoted Ps in the nursery. Planting did not affect the promoted Ps observed in the nursery for seedlot 30664 in 1994. Blackout did not appear to affect $R d$ but when it did it decreased it. The apparent overall result of blackout is to control seedling height, promote Ps and possibly reduce Rd. This provides needed carbohydrates for accelerated developmental processes and plug filling after blackout treatment.
Krasowski, M.J., T. Letchford \& A.M. Eastham. 1993. Growth of short-day treated spruce seedlings planted throughout British Columbia. FRDA Res. Rep 209. BC Forest Service, Victoria, BC.

Odlum, K.D. \& S.J. Colombo. 1988. Short day exposure to induce budset prolongs shoot growth the following year. -In Proc. W. For. Nurs. Assoc., 1988 August 8-11, Vernon, BC, T.D. Landis (ed.), pp. $57-$ 59. USDA-For. Serv. Gen. Tech. Rep. RM-167, Ft. Collins, CO.

\section{REFERENCES:}

Hawkins, C.D.B. \& D.A. Draper. 1991. Effects of blackout on British Columbia spruce seedlots at Red Rock research Station. FRDA Res. Rep 170. BC Forest Service, Victoria, BC.

Hawkins, C.D.B. \& B.D. Hooge. 1988. Blackout and post planting bud phenology in SxS spruce seedlings. -In Proc. W. For. Nurs. Assoc., 1988 August 8-11, Vernon, BC, T.D. Landis (ed.), pp. 5456. USDA-For. Serv. Gen. Tech. Rep. RM-167, Ft. Collins, CO. 


\section{Grading Specifications of Ponderosa Pine Seedlings at Lucky Peak Nursery ${ }^{1}$}

\section{John Sloan ${ }^{2}$}

\section{INTRODUCTION}

Grading of bareroot planting stock is a necessary step in the process of reforestation. At Lucky Peak Nursery near Boise, Idaho, much effort and expense is expended on grading and counting seedlings each year at lifting time before the trees are packaged and shipped. The purpose is to screen out damaged and deformed seedlings or trees too small to survive harsh Intermountain planting conditions. Grading standards can be somewhat arbitrary at times because data on which to base them is not available.

The next step in the grading process takes place on the Ranger District. In preparation for planting, the wrapping crew discards any seedlings they feel do not meet their standards and the specifications are not necessarily those used at the nursery. Grading may also be done by the tree planters who ultimately decide whether a seedling will be planted. Finally, it is the planting site that culls out all of the seedlings unequipped to survive where they are planted. It is this last culling process that we attempt to mimic in all the grading we do.

\section{IMPORTANCE}

Nursery managers and foresters need better information on which to base grading specifications. It is likely that the process of bareroot seedling grading could be streamlined a bit. For example, grading at the nursery could be skipped altogether. The trees would be packed immediately after lifting to reduce expense and eliminate one more time the seedlings would be handled. The field forester can then assume full responsibility for grading the stock and reduce the cost per seedling.

The cost of grading is high in both labor and loss of trees which may be capable of sur- vival and growth in the field. Seedlings are often discarded on the basis of morphological characteristics which may not be indicative of field performance.

Also, we do not know the effects of culling all small seedlings on the future forest genetic makeup. If it is possible to reduce the amount of culling, we might better maintain the genetic diversity of a seed source.

\section{OBJECTIVES}

1) To determine which kinds of damage to the root system reduce ponderosa pine seedling survival and growth in the field.

2) To determine how well a random sample of ungraded ponderosa pine seedlings (bedrun) will perform after outplanting.

3) To provide data on which to base ponderosa pine grading specifications.

'Sloan, J. 1994. Grading Specifications of Ponderosa Pine Seedlings at Lucky Peak Nursery. IN: Landis, T.D.; Dumroese, R.K., tech. coords. National Proceedings, Forest and Conservation Nursery Associations. Gen. Tech. Rep. RM-257. Fort Collins, CO: U.S. Department of Agriculture, Forest Service, Rocky Mountain Forest and Range Experiment Station: $271-273$.

${ }^{2}$ U.S. Forest Service Intermountain Research Station Boise, ID 


\section{METHODS}

A ponderosa pine lot from 4500 feet elevation on the Boise National Forest was lifted at Lucky Peak Nursery and transported to the cooler. From those seedlings, a sample of ungraded trees (bedrun) were set aside as a treatment. The remaining trees were graded to the following minimum standards: 3 in. height, $3 \mathrm{~mm}$ caliper, and 10 in. root.

We selected seven different treatments for root growth potential tests and outplanting:

1) Control, good trees of average size and with good root systems.

2) Bedrun, sample of ungraded seedlings, variable size and root conditions.
3) Large, bigger than average seedlings with calipers in the 8-12 $\mathrm{mm}$ range.

4) Stripped, similar to controls but fine roots stripped during the lifting process.

5) Split Taproot, similar to controls but taproot split near the bottom near an intersection and torn up the root 4-5 $\mathrm{cm}$.

6) Scraped, similar to controls but scarred on the root collar about .5 by $1.0 \mathrm{~cm}$ in size, going through the cambium and into the wood.

7) Lost Roots, seedlings which have lost $1 / 4$ to $1 / 3$ of their root systems.
Seedlings were stored at $34^{\circ} \mathrm{F}$ from lifting in mid March until planting in mid May. They were planted in auger holes on 2-ft hand made scalps in a Douglasfir/Elk sedge habitat type on the Boise National Forest. We followed standards established by the U.S. Forest Service Intermountain Region.

\section{RESULTS}

There was little difference in average caliper between treatments except for the large treatment which had a greater caliper. The top and root volume of the large seedlings was also much greater than the rest. Although the Stripped and Lost Roots seedlings did not have many fine roots, their root volumes were not diminished much (figure 1).

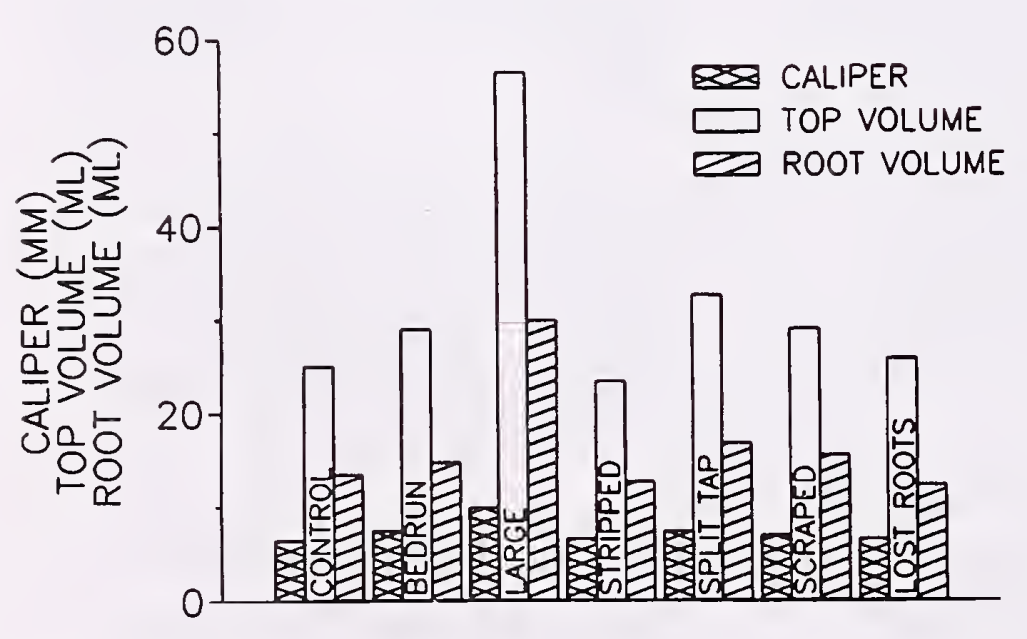

Figure 1. Mean size of seedlings in seven different treatments. The bars in each group depict average ponderosa pine caliper (in $\mathrm{mm}$ ), top volume (in $\mathrm{ml}$ ), and root volume (in $\mathrm{ml}$ ). respectively. The large treatment was larger than the others in all three catagories.

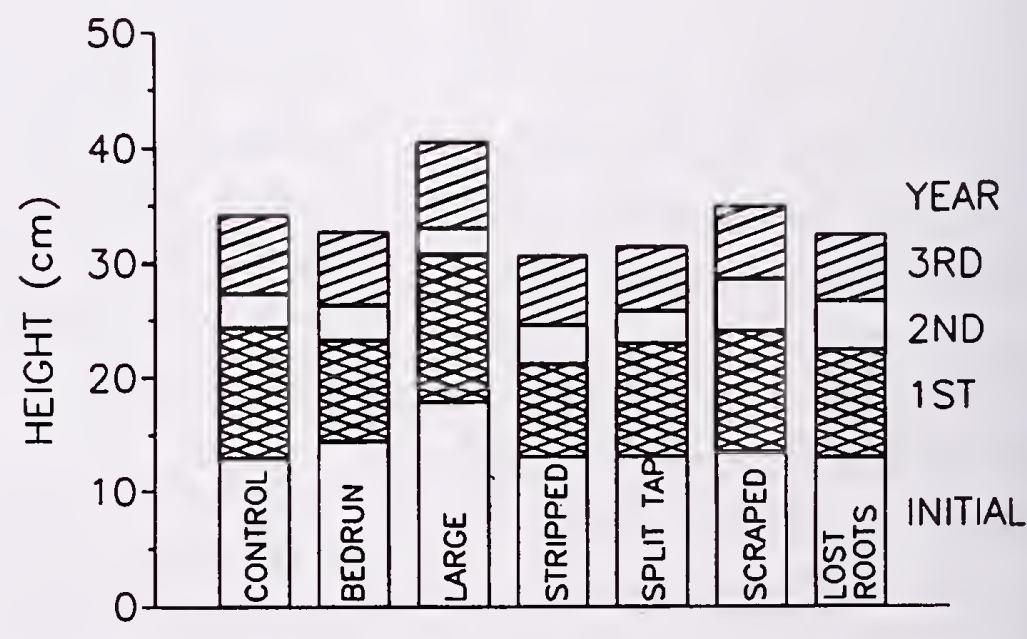

Figure 2. Mean seedling heights of seven different treatments planted on the Boise National Forest. Bars show the ponderosa pine height growth for three growing seasons after outplanting. 
Treatments had little effect on first-year seedling heights. Rather, initial height seems to be more important in determining the height after one growing season (figure 2).

Eighty-three percent of the seedlings survived a late planting and a very dry summer. Root growth potential (figure 3 ) and survival (figure 4) both showed that incidental damage to the root system was not detrimental to seedling establishment. The Split Taproot and Scraped treatments performed as well as the Control treatment.

Large seedlings can be successful if they are planted well and the root systems are large enough to support the top.

Bedrun seedling survival was 5 percent less than the Control. This will vary with each seedlot and could also depend on the sample selected. Culling of high risk seedlings should be done at some stage in the process.

Loss of fine roots reduces the likelihood of seedling survival considerably. The Lost Roots treatment produced a lower root growth potential and survival than the Control. The seedlings on which the fine roots had been Stripped away showed the lowest root growth potential and survival of all the treatments.

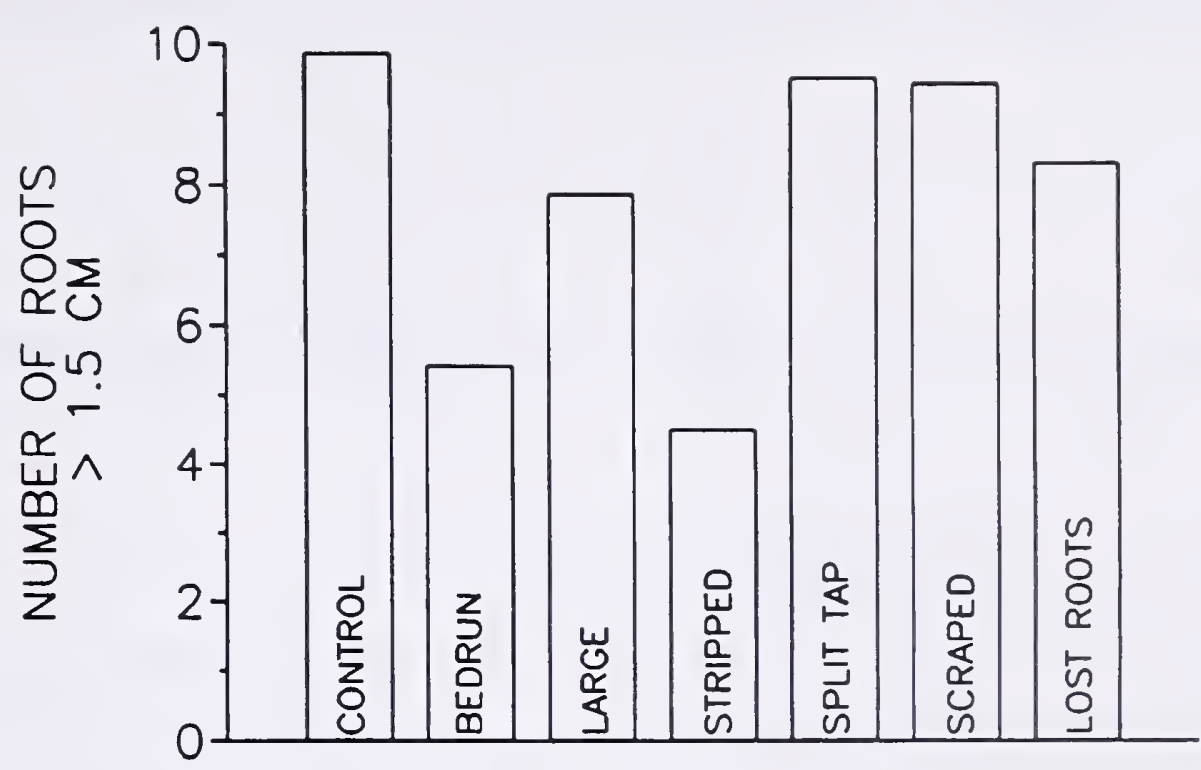

Figure 3. Mean root growth potential for seven different treatments. Bars depict the average number of new ponderosa pine roots greater than $1.5 \mathrm{~cm}$ after a 14 day test.

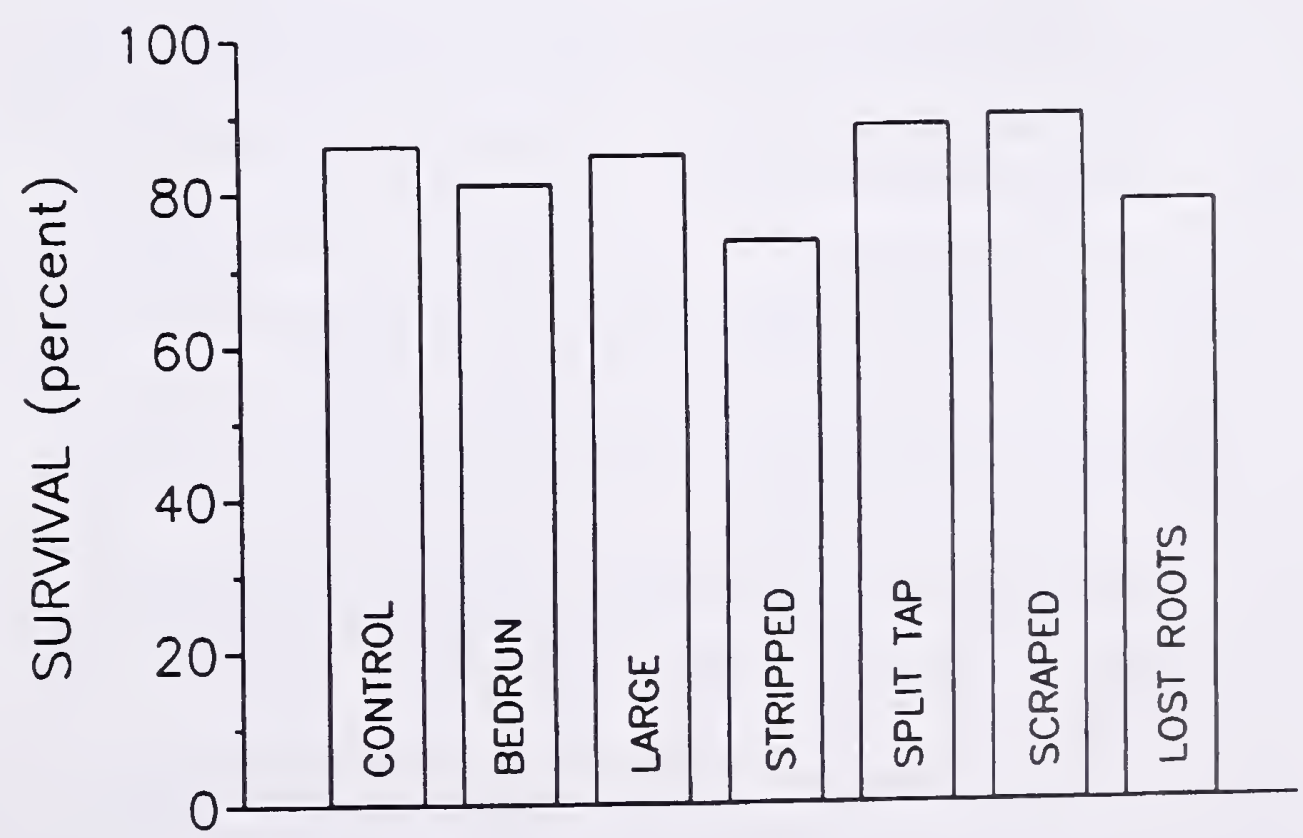

Figure 4. Mean first-year seedling survival of seven different treatments. Ponderosa pine seedlings were planted on the Boise National Forest. 


\title{
Propagation of Juniperus for Conservation Planting ${ }^{1}$
}

\author{
Bert Cregg 2 , Scott Lee ${ }^{3}$,Ted Hovland², Clark Fleege ${ }^{4}$, and John Gleason ${ }^{4}$
}

\begin{abstract}
Current nursery practices in the Great Plains often fail to produce acceptable crops of Rocky Mountain juniper and eastern redcedar. Research and anecdotal evidence from other regions of the country have suggested alternatives to the current practice of-fall sowing seed and covering the beds with clear plastic and shade-frame. In this study, we compared seed germination under several alternatives to the conventional clear plastic treatment. We also compared seed germination among five seed sources of Rocky Mountain juniper and one source of eastern redcedar. In general, the clear plastic resulted in the highest rates of seed germination and germination was higher for eastern redcedar than for any of the Rocky Mountain juniper sources. The increased germination under the clear plastic appears to be related to better heat and moisture retention under the plastic than the alternative treatments.
\end{abstract}

\section{INTRODUCTION}

Historically, Rocky Mountain juniper (Juniperus scopulorum Sarg.) and eastern redcedar (Juniperus virginiana L.) have been difficult to propagate from seed in forest nurseries. Consistently low and variable germination rates, winter injury, genetic variability, and a lack of understanding of seed dormancy have contributed to this dilemma (Rietveld 1989, VanHaverbeke and Comer 1985). Presently there is widespread interest in conservation tree plantings in the
Great Plains and Intermountain regions. As interest demand has increased, the demand for Juniperus planting stock has increased concomitantly as juniper and redcedar play an integral role in many conservation plantings. Because of their tight crown form and tolerance to a wide range of site conditions, Juniperus species are highly valued for windbreaks, living snowfences, wildlife cover, and mine reclamation. However, due to the difficulties in propagating eastern redcedar and Rocky Mountain juniper from seed, conservation nurseries are not always able to meet the demand for seedlings. If, as expected, the trend in conservation tree planting continues to increase these deficits will likely become more common.

The fundamental problem with producing consistent crops of Rocky Mountain juniper and eastern redcedar seedlings is that overcoming seed dormancy is often difficult. Juniperus seed have both seed-coat and embryo dormancy. Over the years, nursery managers have devel-

\footnotetext{
${ }^{1}$ Cregg, B.; Lee, S.; Hovland, T.; Fleege, C.; Gleason, J. 1994. Propagation of Juniperus for Conservation Planting. IN: Landis, T.D.; Dumroese, R.K., tech. coords. National Proceedings, Forest and Conservation Nursery Associations. Gen. Tech. Rep. RM-257. Fort Collins, CO: U.S. Department of Agriculture, Forest Service, Rocky Mountain Forest and Range Experiment Station: 274-278.

¿USDA Forest Service, Rocky Mountain Forest and Range Experiment Station, Center for Semiarid Agroforestry, Lincoln, NE 68583-0822.
}

${ }^{3}$ Department of Forestry, Fisheries, and Wildlife, University of Nebraska, Lincoln, NE 68583-0814.

${ }^{4}$ USDA Forest Service, Bessey Tree Nursery, Halsey, NE 69142. 
oped a number of techniques to overcome seed dormancy and produce a stand of seedlings. At the USDA Forest Service Bessey Tree Nursery the traditional practice has been to fall-sow the seed and then cover the nursery bed with clear plastic and shadeframe. While this practice has generally produced reliable crops of eastern redcedar, the results with Rocky Mountain juniper have been inconsistent. Furthermore, laying plastic and shade-frame is labor-intensive and increasing concerns with plastic disposal threaten to make the cost of this practice prohibitive. A number of products and practices recently have been shown to be effective mulches in other regions. These include sowing cover crops,
Hydromulch $^{\circledR}$, latex ground cover, and frost fabrics (Stauder 1994, Wichman 1994, Racey 1987). In order to evaluate the potential of these materials and practices as an alternative to clear plastic, we conducted the following trial at the Bessey nursery in 1993 and 1994.

\section{MATERIALS AND METHODS}

We established the field trial in the late summer of 1993. The trial was installed as a split-plot design with three replications. The seed-bed treatment was the main plot effect and seed source was the sub-plot effect. We sowed 144 seeds from one of six seedlots in each sub-plot. The seed-bed treatments are listed in
Table 1 and seedlots are listed in Table 2. We sowed the seed using a progeny seed sower developed by the USDA Forest Service Missoula Technology Development Center (Herzberg 1991). The seed-bed treatments were installed immediately after sowing the seed. Soil temperature at $5 \mathrm{~cm}$ was monitored on each plot in one replicate with an automatic data recorder (Note: due to equipment malfunctions, only temperature data from November - February is presented here). We measured soil moisture in the upper $15 \mathrm{~cm}$ of soil in mid-March and mid-May, 1994 using a Time Domain Reflectometry soil moisture gauge (TRASE model $6050 \mathrm{X1}$, Soil Moisture Equipment, Inc. Santa Barbara, CA). Soil mois-

Table 1. Cover treatments applied to nursery beds in Juniperus trials at USDA Forest Service Bessey Nursery, Halsey, Nebraska Winter, 1994.

Treatment

Clear plastic

$V^{2}$ isqueen ${ }^{(2)}$

(Ethyl Visqueen Film Products, Dallas, TX)

Agrolock ${ }^{(}$

(Swift Adhesives Division,

Reichold Chemicals, Downers Grove, IL)

N-sulate ${ }^{\circledR}$

(DeWitt Company, Fort Collins, CO)

Ramie fibre mat

Hydromulch ${ }^{\circledR}$

(Centron Fiber Corp., Wellsville, KS)

Oat cover
Description

Conventional nursery practice, clear plastic laid over seed-bed after fall sowing and covered with shade frame

Opaque, perforated white plastic, laid over seed-bed after sowing

White latex ground cover applied immediately after sowing

White fabric ground cover

Brown ground cover made of natural fibers

Green slurry made from recycled paper

Oats sown as cover crop Immediately after sowing Juniperus seed 
Table 2. Eastern redcedar (ERC) and Rocky Mountain juniper (RMJ) seed used for seed-bed trials at USDA Forest Service Bessey nursery, Halsey, Nebraska, Winter, 1994.

\begin{tabular}{llll}
\hline $\begin{array}{l}\text { Seedlot } \\
\text { Number }\end{array}$ & $\begin{array}{l}\text { Location or } \\
\text { Seed zone }\end{array}$ & $\begin{array}{l}\text { Year } \\
\text { Collected }\end{array}$ & $\begin{array}{l}\text { Seed } \\
\text { provided by: }\end{array}$ \\
ERC & Anselmo-Merna, NE & 1987 & \\
RMJ-1 & Saguaches, CO & 1992 & USDA Forest Service Bessey Nursery \\
RMJ-2 & Colorado State Nursery \\
RMJ-3 & Wastane, CO & 1988 & Colorado State Nursery \\
RMJ-4 & Creighton-Wall, SD & 1988 & USDA Forest Service Bessey Nursery \\
RMJ-5 & Wasta, SD & 1983 & Big Sioux Nursery South Dakota \\
& & 1988 & USDA Forest Service Bessey Nursery \\
& & & \\
\hline
\end{tabular}

ture was measured at three locations within each seed-bed (main plot) treatment. We tested for seed-bed treatment effects by analysis of variance using a randomized block model. We counted the total number of seedlings that emerged in each plot on June 14, 1994. For statistical analyses, germination percentage data were transformed using a square root transformation (Steel and Torrie 1960). Seed-bed treatment and seed source effects on germina- tion were tested by analysis variance using a split-plot model.

\section{RESULTS}

Both seed source and seedbed treatment had a significant effect on seed germination in the field (Table 3). The eastern redcedar seed had higher germination rates than any of the Rocky Mountain juniper seed lots. Seed source RMJ-4 (SD) had the highest germination percentage of the Rocky Mountain juniper seed lots.

Seed germination was low under all treatments. The low overall germination was at least partially attributable to the sowing technique. Although the progeny seeder was useful in sowing exact numbers of seed, it did not sow the seed as deep as the operational sower. The range of germination observed varied from $5.5 \%$ under the clear plastic

Table 3. Germination percentage of Juniperus seedlots under various mulch treatments at Bessey Nursery, Halsey, Nebraska, 1994.

\begin{tabular}{llllllll}
\hline & & \multicolumn{7}{c}{ Seedlot } & \\
\cline { 3 - 6 } $\begin{array}{l}\text { Mulch } \\
\text { treatment }\end{array}$ & ERC-1 & RMJ-1 & RMJ-2 & RMJ-3 & RMJ-4 & RMJ-5 & mean \\
\hline Clear plastic & 18.3 & 3.0 & 1.9 & 3.7 & 13.2 & 2.3 & $5.47 \mathrm{x}$ \\
Visqueen & 0.9 & 0.5 & 0.9 & 0.7 & 0.7 & 0.9 & $0.49 \mathrm{y}$ \\
Ramie Fibre Mat & 1.4 & 0.7 & 1.6 & 0.9 & 0.7 & 0 & $0.41 \mathrm{y}$ \\
Hydromulch & 0 & 0.7 & 0.2 & 0.2 & 0.9 & 0 & $0.11 \mathrm{y}$ \\
Oat Cover & 0.2 & 0 & 0.5 & 0.2 & 0.2 & 0.2 & $0.02 \mathrm{y}$ \\
N-sulate & 0.2 & 0.5 & 0 & 0 & 0.2 & 0 & $0 \mathrm{y}$ \\
Agrolock & 0 & 0 & 0 & 0 & 0 & 0 & \\
mean & $0.92 \mathrm{a}$ & $0.26 \mathrm{bc}$ & $0.28 \mathrm{bc}$ & $0.34 \mathrm{abc}$ & $0.75 \mathrm{ab}$ & $0.13 \mathrm{c}$ & \\
\end{tabular}

NOTE: Means followed by the same letter are not significantly different at 0.05 level. Means separated by Tukey's Studentized range test. 
to $0 \%$ under the Agrolock ${ }^{\circledR}$ treatment (Fig. 1). The increase in germination associated with the clear plastic appears to be related to increased soil moisture and soil temperature. On the March evaluation date soil moisture was highest under the clear plastic and lowest beneath the Hydromulch (Table 4). The clear plastic also resulted in the highest mean soil temperature as compared to the other treatments (Fig. 2).

\section{CONCLUSION}

Although alternative mulches have been effective in other nursery situations, the results here do not suggest that they will improve the production of fall sown juniper or redcedar over clear plastic. However, we will continue to explore alternative cultural practices to laying clear

Table 4. Seed-bed soil moisture under various mulch treatments at Bessey Nursery, Halsey, Nebraska, 1994.

\begin{tabular}{|c|c|c|}
\hline \multirow{2}{*}{$\begin{array}{l}\text { Mulch } \\
\text { treatment }\end{array}$} & \multicolumn{2}{|c|}{ Measurement date } \\
\hline & March & May \\
\hline Clear plastic & $7.05 a$ & $12.43 a$ \\
\hline Oat Cover & $6.51 a$ & $12.21 \mathrm{a}$ \\
\hline $\mathrm{N}$-sulate & $6.39 a b$ & $11.84 a$ \\
\hline Visqueen & $6.23 a b$ & $11.44 a$ \\
\hline Fallow & $6.19 a b$ & $12.11 \mathrm{a}$ \\
\hline Ramie Fibre mat & $6.06 a b$ & $11.21 \mathrm{a}$ \\
\hline Agrolock & $5.22 b c$ & $10.80 a$ \\
\hline Hydromulch & $4.78 \mathrm{c}$ & $10.76 \mathrm{a}$ \\
\hline mean & 6.05 & 11.61 \\
\hline
\end{tabular}

NOTE: Means followed by the same letter are not significantly different at 0.05 level. Means separated by Tukey's Studentized range test.

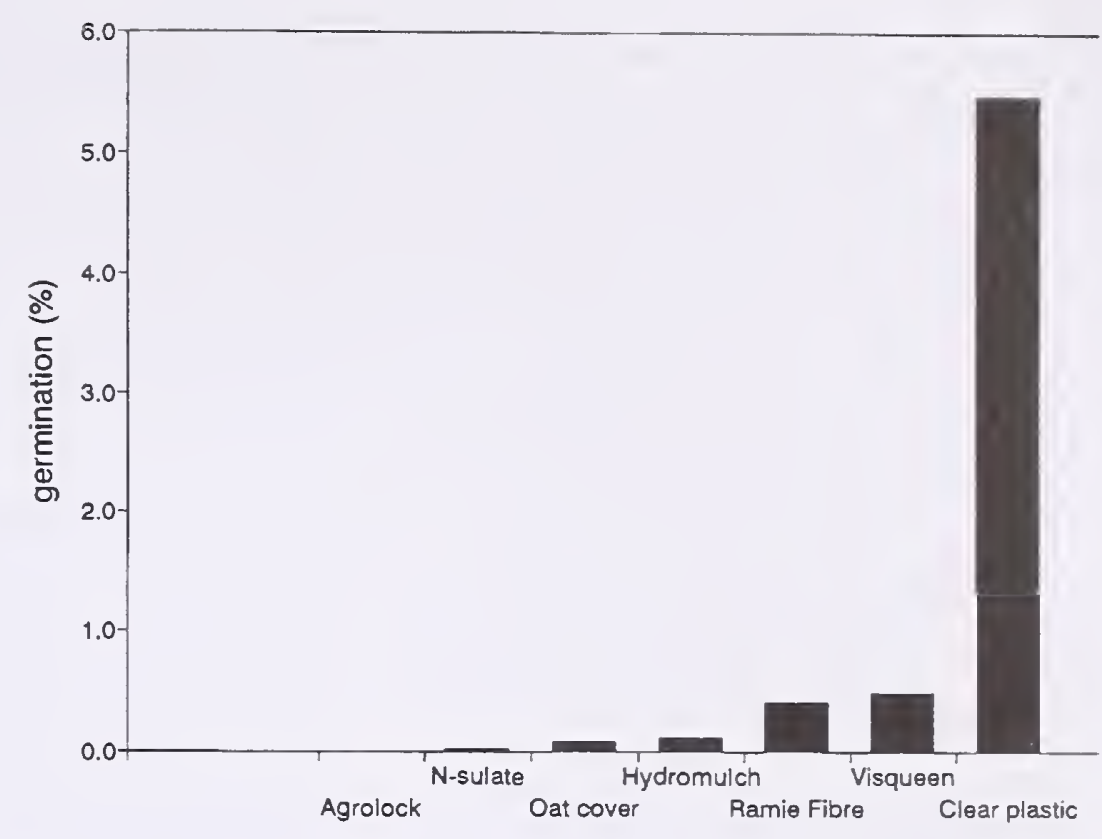

Figure 1. Germination of eastern redcedar and Rocky Mountain juniper seeds under various seed-bed treatments. All seedlots combined. Bessey Nursery, Halsey, NE. 1994.

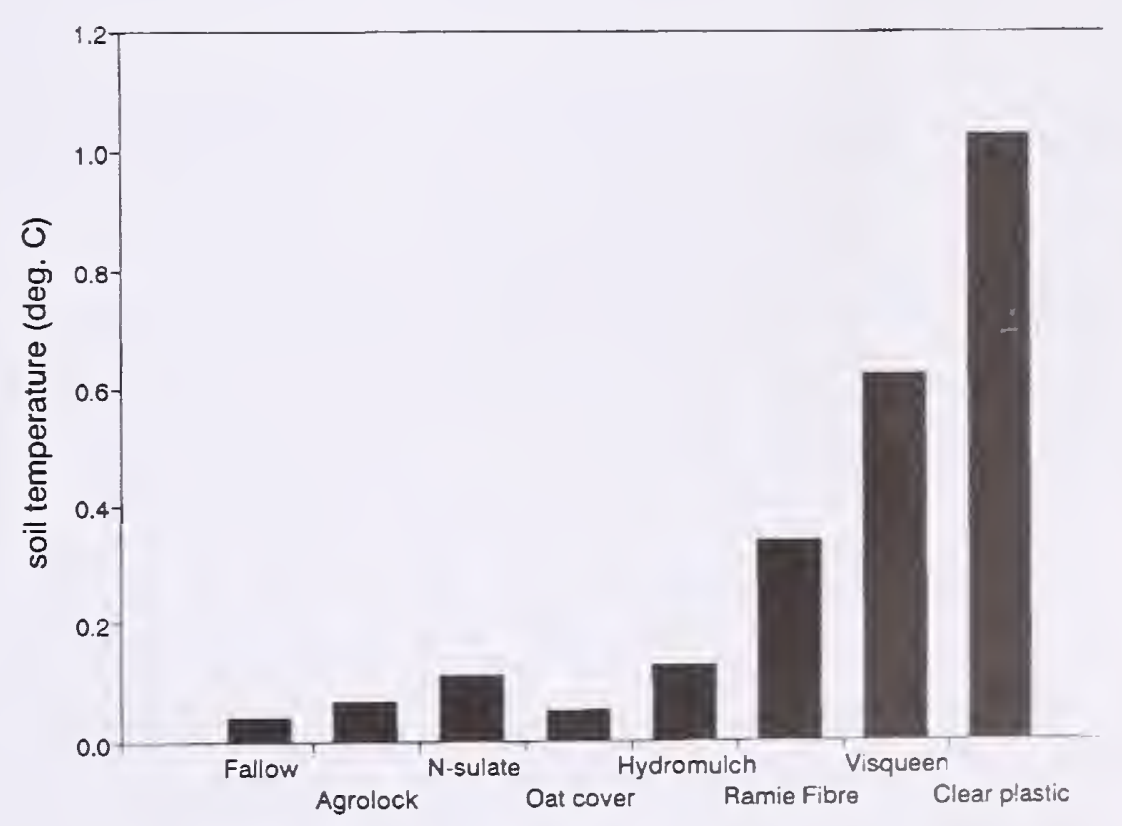

Figure 2. Mean soil temperatures under various seed-bed treatments. Bessey Nursery, Halsey, NE. November, 1993 - March, 1994. 
plastic. One possible alternative practice is to place the seed in long stratification regimes (i.e. 90-120 day warm-moist plus 90120 days cool moist) and then spring sow the seed. This approach was successful for eastern redcedar in a preliminary trial at the Bessey nursery and we will evaluate its application to Rocky Mountain juniper in the spring of 1995.

\section{ACKNOWLEDGEMENTS}

Support for this research was provided by the Intermountain Conservation Nursery Association, The International Arid Lands Consortium, and the USDA Forest Service Rocky Mountain Station Challenge Cost-share Program. The authors thank Randy Moench, Colorado State Nursery and Blaine Martien, Big Sioux Nursery, South Dakota for donating seed for this study.

\section{LITERATURE CITED}

Herzberg, D. 1991. The progeny seeder. Tree Planters' Notes, Summer, 19919-12.

Racey, G.D. 1987. An evaluation of sprayable latex mulches in some forestry applications. Forest Research Report No. 115, Ministry of Natural Resources, Ontario Tree Improvement and Forest Biomass Institute, Maple, Ontario, CANADA. 9 pp.
Rietveld, W.J. 1989. Variable seed dormancy in Rocky Mountain juniper. USDA Forest Service, Rocky Mountain Forest and Range Experiment Station, General Technical Report RM-184, 60-64.

Stauder, A.F. 1994. The use of green overwinter mulch in the Illinois state nursery program. IN: USDA Forest Service, Rocky Mountain Forest and Range Experiment Station, General Technical Report RM-243. T.D. Landis, ed. 5152.

Steel, R.G.D. and Torrie, J.H. 1960. Principles and Procedures of Statistics, McGrawHill Book Co. Inc. New York. $481 \mathrm{pp}$.

VanHaverbeke, D. and Comer, C.W. 1985. Effects of treatment and seed source on germination of eastern redcedar seed. USDA Forest Service, Rocky Mountain Forest and Range Experiment Station, Research Paper RM$265.7 \mathrm{pp}$.

Wichman, J. 1994. Use of wheat as a living mulch to replace hydromulch for fall sown seedbeds. IN: USDA Forest Service, Rocky Mountain Forest and Range Experiment Station, General Technical Report RM-243. T.D. Landis, ed. 55-56. 


\section{Cleaning Hardwood and Shrub Seed ${ }^{1}$}

\section{Robert P. Karrfalt ${ }^{2}$}

Cleaning hardwood and shrub seed can be viewed as having four phases: post harvest storage, extraction, basic cleaning and upgrading. This paper gives a brief descirption of each phase and equipment that has been found to do the work. Equipment vendors are also listed.

Post harvest storage is concerned with maintaining good viability between collection in the field and extraction. Fruits which are dry at maturity need only to be kept dry and out of the heat. Fruits which are moist at maturity need to be kept moist and prevented from heating and fermentation. Examples of this type of species would be acorns and any fleshy fruits.

Extraction is removing the seed from the fruit. This is often a necessary step for efficient sowing in the nursery and for obtaining high germination. Seeds in fleshy fruits can be separated from the pulp in a slowly turning grinder or in a macerator. It is often helpful to soak fleshy fruits for 3 to 7 days to soften the fruit. This must be done with running water or the water must be changed daily to prevent fermentation. Dry fruits of many species have been successfully prepared for cleaning using a brush machine to remove dry fruits walls and wings or to singularize seeds which are born in clusters.

The basic cleaning phase is the removal of the larger amounts of trash. The extraction process often can leave a significant amount of fine or coarse trash. Usually air-screen machines, screen machines, aspirators, or blowers are used for this step. The air is used to remove light trash of the same dimensions as the seed while the screens can be used to separate particles that are larger or smaller than the seed.

The upgrading involves the final removal of troublesome trash such as sticks and stones and the removal of empty seed or improperly formed seed. The machines that are of great value here are precision aspirators or blowers and specific gravity tables for the removal of improperly formed and empty seed and the indent cylinder for removing sticks and stems. The aspirators, blowers, and specific gravity tables remove the empty and improperly formed seed because they weigh less than the good seed. Stones can be removed with the gravity table because they are heavier than the seed. Finally sticks can be removed with the indent cylinder because they are longer than the seed.

Detailed explanation of how this equipment works can be obtained from the author or from the equipment vendors. Vendor addresses and the equipment they supply are given in the following. The equipment is listed first with the vendor code number. These vendors are not endorsed by the author but are familiar to him. Other suitable vendors may be found by the reader.

\footnotetext{
'Karrfalt, R.P. 1994. Cleaning Hardwood and Shrub Seed. IN: Landis, T.D.; Dumroese, R.K., tech. coords. National Proceedings, Forest and Conservation Nursery Associations. Gen. Tech. Rep. RM-257. Fort Collins, CO: U.S. Department of Agriculture, Forest Service, Rocky Mountain Forest and Range Experiment Station: 279-280.
} 


\section{Equipment}

Brush machines

Macerators

Aspirators or blowers

Air-screen machines

Specific gravity tables

Indent cylinders

1. Bouldin-Lawson

Rt 10, Box 208

McMinnville, TN 37110

615-668-4090

2. Carter-Day

500 73rd Ave., N.E.

Minneapolis, MN 55432

612-571-1000

3. C.S. Bell Co.

P.O. Box 291

Tiffin, Ohio 44883

419-448-0791

Fax: 419-448-1203

4. Melvin R. Dybvig

4025 Rio Vista

Milwaukie, OR 97222

503-659-0718

5. Hendrickson Enterprises 4050 N.E. Minnesota Ave.

Corvallis, Oregon 97330

503-757-8019

\section{$\underline{\text { Vendor Codes }}$}

5,9

1,4

$2,5,8,9$

$5,8,9$

$7,8,9$

$2,6,9$

6. Ideal Grain and Seed Company

85 2nd Avenue SE

New Brighton, MN 55112

612-636-7901

7. Oliver Mfg. Co.

P.O. Box 512

Rocky Ford, CO 81067

303-254-6371

8. South Pine, Inc.

P.O. Box 530127

Birmingham, AL 35253

205-879-1099

9. Westrup, Inc.

1400 Preston Road

Suite 400

Plano, Texas 75093

214-985-7991

Fax: 214-985-7887 


\title{
Improving Conifer Seedling Quality with CONFER ${ }^{\circledR 1}$
}

\author{
D. Bradley Smith, Eric Lloyd and Greg O'Neill²
}

Abstract-CONFER ${ }^{\circledR}$, a potent plant growth regulator containing the active ingredient paclobutrazol, was evaluated as a replacement for dormancy inducing treatments for container grown conifer seedlings. CONFER provided effective short term control of stem height growth of European larch, white spruce and lodgepole pine while allowing stem and root growth. At rates of 1.0 to $2.5 \mathrm{~kg}$ a.i. $/ 1000 \mathrm{~m}^{2}$, root growth of white spruce was stimulated both while in the container and after outplanting. Rates of 0.5 to $5.0 \mathrm{~kg} \mathrm{a.i./}$ $1000 \mathrm{~m}^{2}$ stimulated root growth of lodgepole pine seedlings both in the containers and after outplanting.

\section{INTRODUCTION}

CONFER $^{\circledast}$ contains paclobutrazol, a potent plant growth regulator. When applied as a high volume broadcast spray, CONFER is taken up by the roots and is translocated acropetally in the xylem tissue to sites of action within the seedling.

CONFER is currently under review by Agriculture Canada for registration as a greenhouse application on container grown conifer seedlings. CONFER application results in a number of changes in seedling morphology. Effects include inhibition of stem elongation, stimulation of bud initiation, increase in stem diameter, increase in waxiness of needles and promotion of root egress. The inhibiting effect of CONFER on stem elongation is eliminated once seedlings have passed through a cold dormancy period.

CONFER treated seedlings have shown increased tolerance to moisture and temperature stress. Roots of treated seedlings have increased starch content. The overall result of treatment with CONFER is improved seedling quality.

\section{OBJECTIVES}

1. Evaluate CONFER as a replacement for blackout and other dormancy inducing treatments on a range of conifer species.

2. Measure the short term effects of CONFER on height and caliper growth and on root and shoot dry weights.
3. Measure the short term effects of CONFER on root egress after planting.

\section{METHODS}

Container grown conifer seedlings were treated with a range of rates of CONFER using a $\mathrm{CO}_{2}$ pressurized small scale boom sprayer. Rates of application ranged from 0.5 to $5.0 \mathrm{~kg}$ a.i. $/ 1000 \mathrm{~m}^{2}$. Individual plots consisted of single styroblocks or trays with each treatment replicated four times at each experiment location. Treatments were randomized within each block with blocks identified by plot number only.

Experiments were conducted in cooperation with conifer seedling growers in B.C., Ontario and New Brunswick.

'Smith. D.B.; Lloyd, E.; O'Neill, G. 1994. Improving Conifer Seedling Quality with CONFER ${ }^{\circledR}$. IN: Landis, T.D.; Dumroese, R.K., tech. coords. National Proceedings, Forest and Conservation Nursery Associations. Gen. Tech. Rep. RM-257. Fort Collins, CO: U.S. Department of Agriculture. Foresi Service, Rocky Mountain Foresi and Range Experiment Station: 281-284.

2Zeneca Agro, Box 9910, Stoney Creek, Ontario, CANADA, L8G $3 Z 1$. 
Species tested include white spruce, lodgepole pine and European larch.

Height and stem caliper of ten preselected seedlings per plot were measured prespray and at four and eight weeks after treatment. Root egress was assessed by planting seedlings in six inch pots for four weeks under ideal growing conditions. Root growth was assessed using Burdett's scale where:

$$
\begin{aligned}
& 0=\text { no white roots } \\
& 1=\text { white roots }<1 \mathrm{~cm} \\
& 2=1-3 \text { white roots }>1 \mathrm{~cm} \\
& 3=4-10 \text { white roots }>1 \mathrm{~cm} \\
& 4=11-30 \text { white roots }>1 \mathrm{~cm} \\
& 5=31-100 \text { white roots }>1 \mathrm{~cm} \\
& 6=>100 \text { white roots }>1 \mathrm{~cm}
\end{aligned}
$$

Root and shoot samples were collected at eight weeks after treatment and again after outplanting and dried at 70 degrees Celsius.

\section{RESULTS}

\section{European Larch}

CONFER provided significant control of European larch height growth while allowing continued stem caliper growth (Figure 1).

\section{White Spruce}

CONFER provided control of height growth of white spruce compared to the greenhouse control however height growth was equal to that of the blackout control (Figure 2). Stem caliper growth of white spruce was slightly reduced by all but the highest rate of CONFER com-

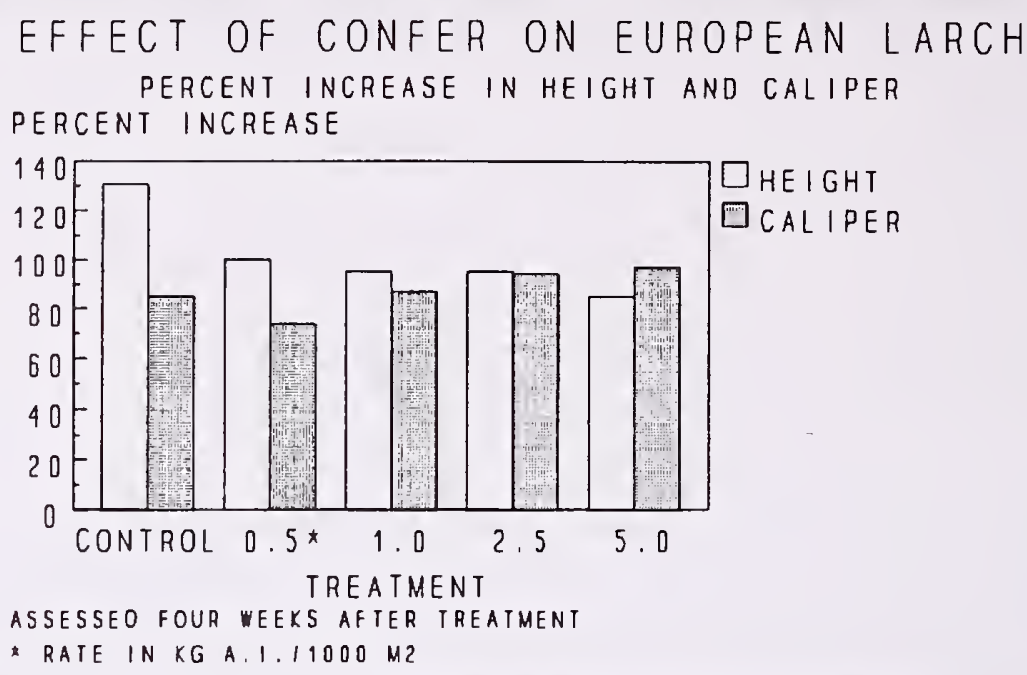

Figure 1. Effect of CONFER on European larch height and caliper growth.

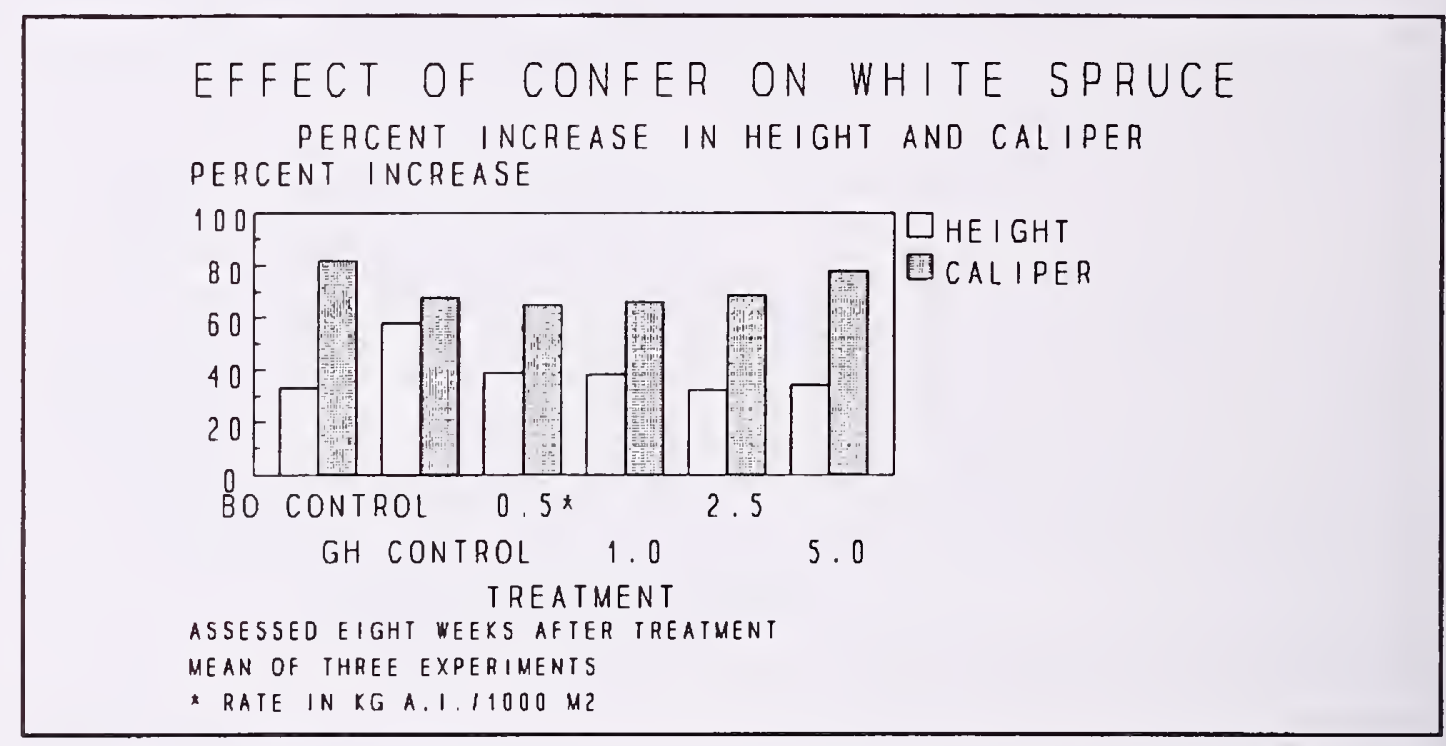

Figure 2. Effect of CONFER on white spruce height and stem caliper growth.

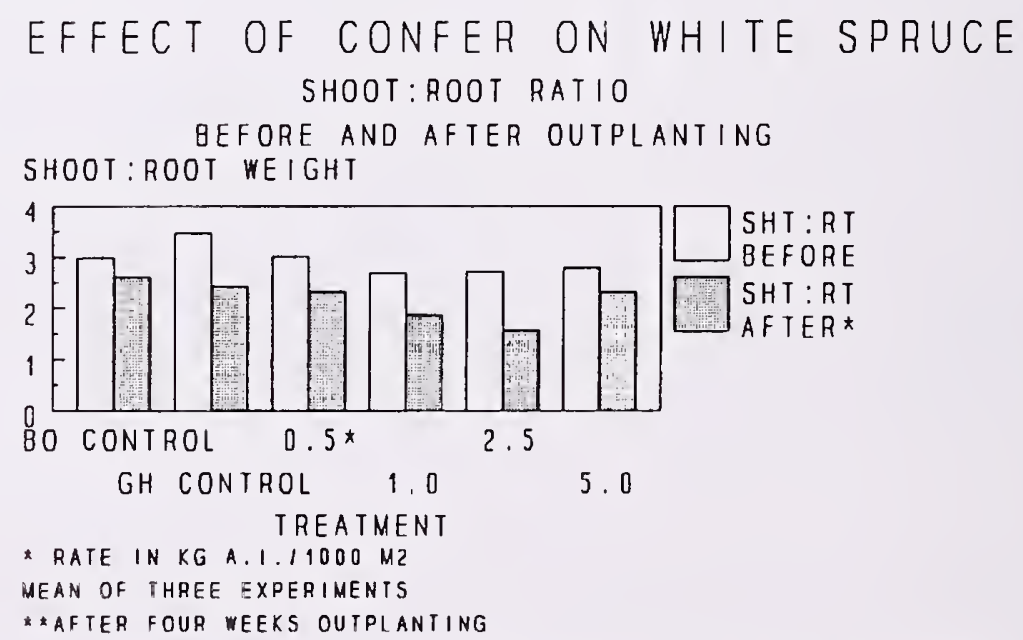

Figure 3. Effect of CONFER on white spruce shoot:root dry weight. 
pared to the blackout control however was equal to that of the greenhouse control.

Shoot to root biomass was improved by CONFER treatment at rates of 1.0 to $2.5 \mathrm{~kg}$ a.i. $/ 1000$ $\mathrm{m}^{2}$. The most pronounced effect was observed after four weeks outplanting (Figure 3). Root egress as measured using Burdett's scale was improved with all CONFER treatments compared to the blackout control, however, the greatest improvements were recorded at rates of 1.0 to $2.5 \mathrm{~kg}$ a.i. $/ 1000 \mathrm{~m}^{2}$ (Figures 4 and 8 ).

\section{Lodgepole Pine}

Shoot growth of lodgepole pine at eight weeks after treatment was reduced with CONFER at all rates of application while stem caliper growth was unaffected compared to the operational control (Figure 5). Shoot to root biomass was improved in favour of root biomass at both eight weeks after treatment and after four weeks outplanting at all rates of application (Figure 6).

Root egress as assessed using the Burdett's scale after four weeks outplanting was improved by all rates of CONFER compared to the untreated control (Figures 7 and 9).

\section{OBSERVATIONS}

Seedlings treated with CONFER were in most cases observed to be darker blue-green

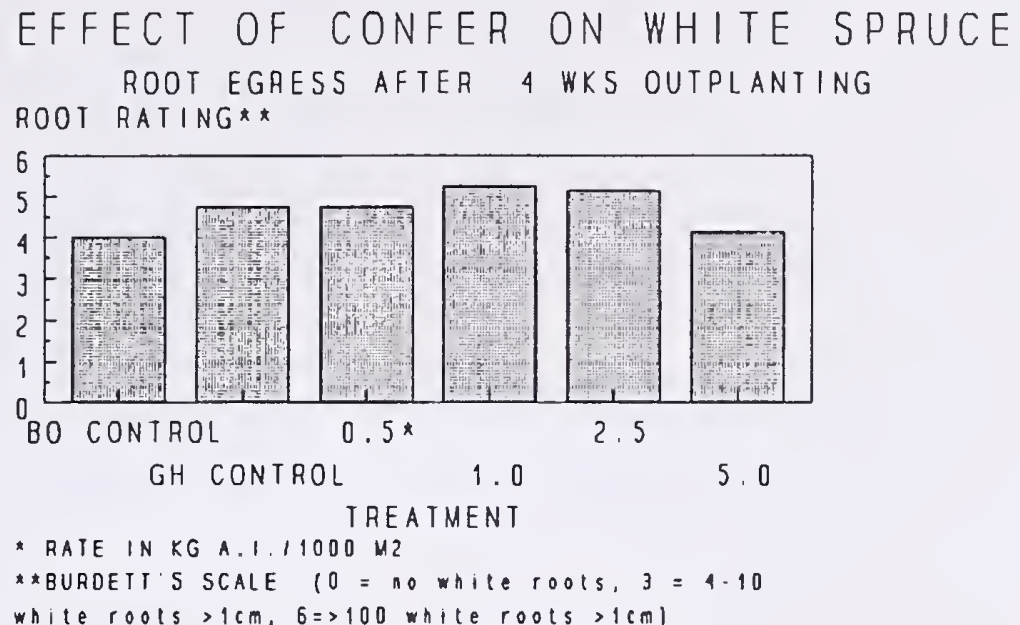

Figure 4. Effect of CONFER on white spruce root egress.

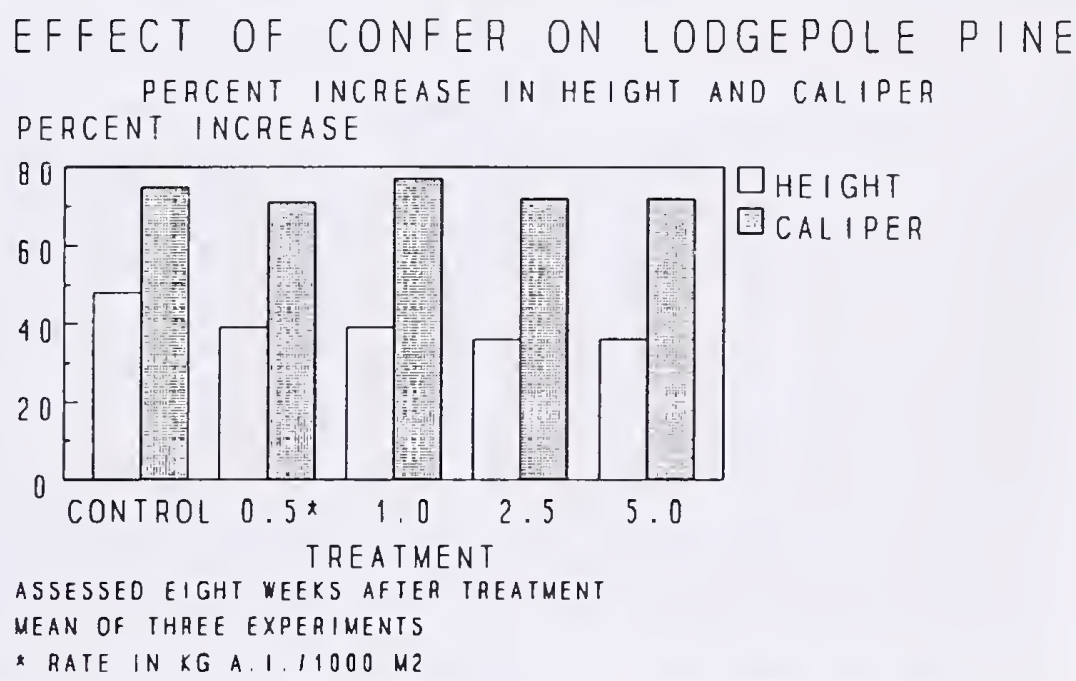

Figure 5. Effect of CONFER on lodgepole pine height and stem caliper growth.

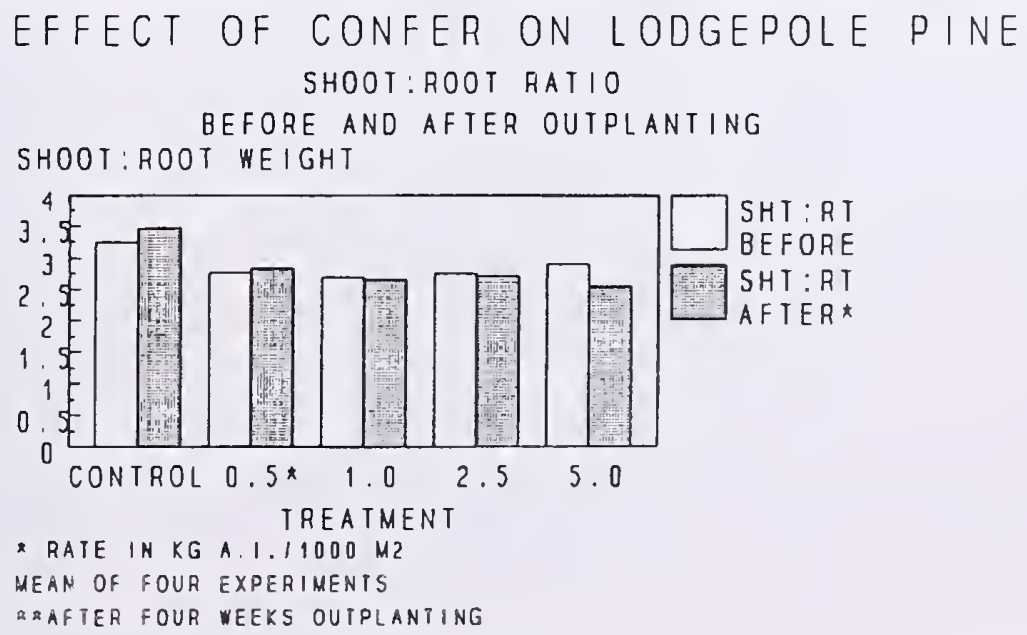

Figure 6. Effect of CONFER on lodgepole pine shoot:root dry weight. 
than operational control seedlings which may indicate greater waxiness of needles.

Lateral root branching was increased in CONFER treated seedlings, especially at rates of 1.0 to $2.5 \mathrm{~kg}$ a.i. $/ 1000 \mathrm{~m}^{2}$. Root growth was initially inhibited at the highest rate of application $\left(5.0 \mathrm{~kg}\right.$ a.i. $/ 1000 \mathrm{~m}^{2}$ ) however was stimulated over a longer period of time, especially after outplanting. In some cases thickened roots were observed, especially at the higher rates of application.

Seedlings treated with CONFER used less water and wilted less when blocks became dry.

Dormancy, defined as the cessation of shoot growth and bud initiation, was induced in all species within four to eight weeks of application. Moving seedlings outdoors accelerated the cessation of shoot growth and bud initiation in all species.

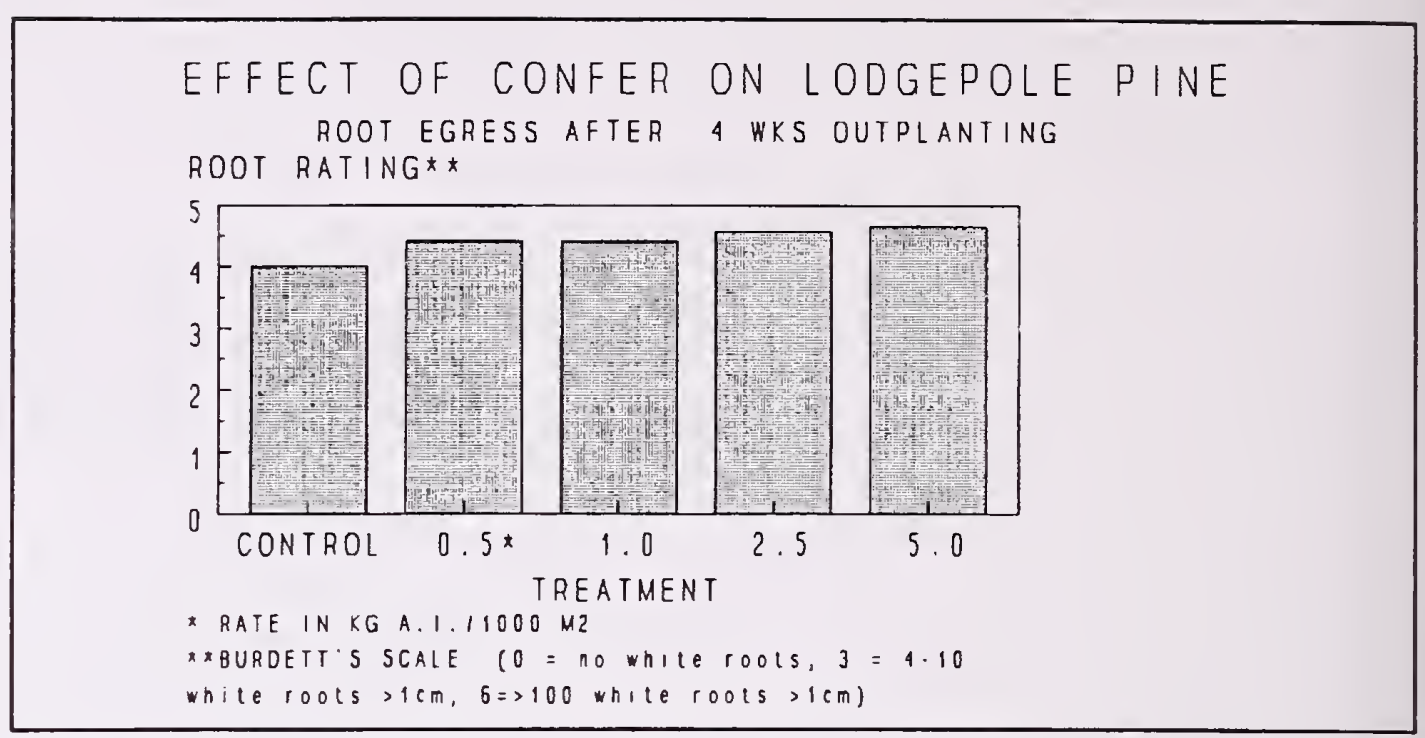

Figure 7. Effect of CONFER on lodgepole pine root egress after outplanting.

\section{CONCLUSIONS}

CONFER provided control of height growth for a period of eight weeks while allowing root and stem caliper growth of European larch, white spruce and lodgepole pine.

Shoot to root biomass of seedlings treated with CONFER was improved in favour of root growth both in the container and after outplanting for four weeks. Root egress was stimulated in both white spruce and lodgepole pine after four weeks outplanting. The optimum rates for root egress in white spruce were 1.0 to $2.5 \mathrm{~kg}$ a.i. $/ 1000 \mathrm{~m}^{2}$ while in lodgepole pine the optimum rates were 2.5 to $5.0 \mathrm{~kg}$ a.i./1000 $\mathrm{m}^{2}$.

CONFER treatment resulted in better balanced seedlings with improved root growth potential compared to seedlings produced using conventional methods. CONFER treated seedlings should establish better at the planting site and reach free to grow status earlier than seedlings produced by conventional means.

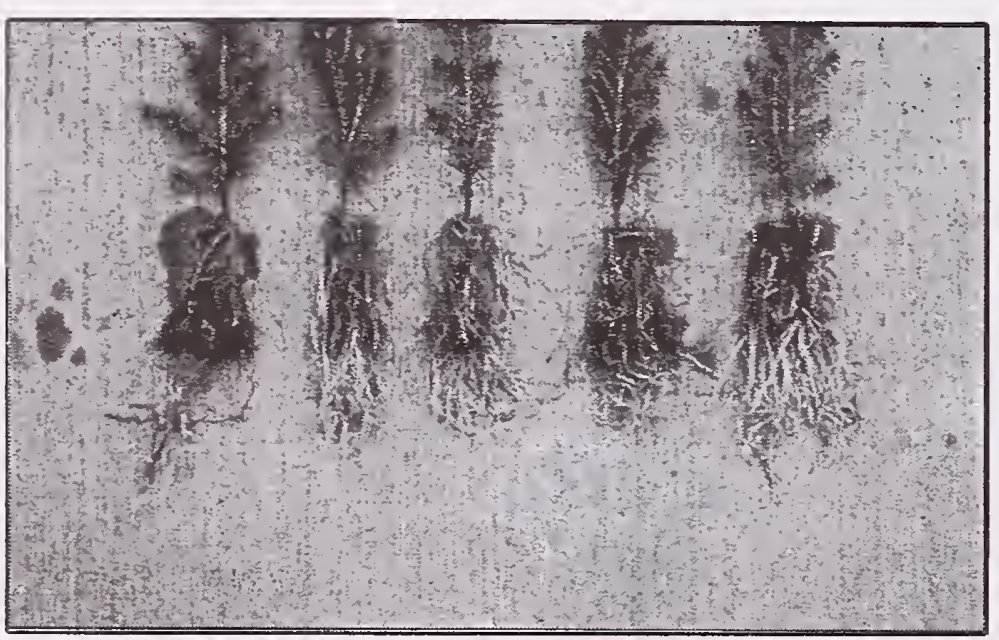

Figure 8. Effect of CONFER on root egress of white spruce. (left to right; blackout, 0.5, 1.0, 2.5 \& $5.0 \mathrm{~kg} / 1000 \mathrm{~m}^{2)}$.

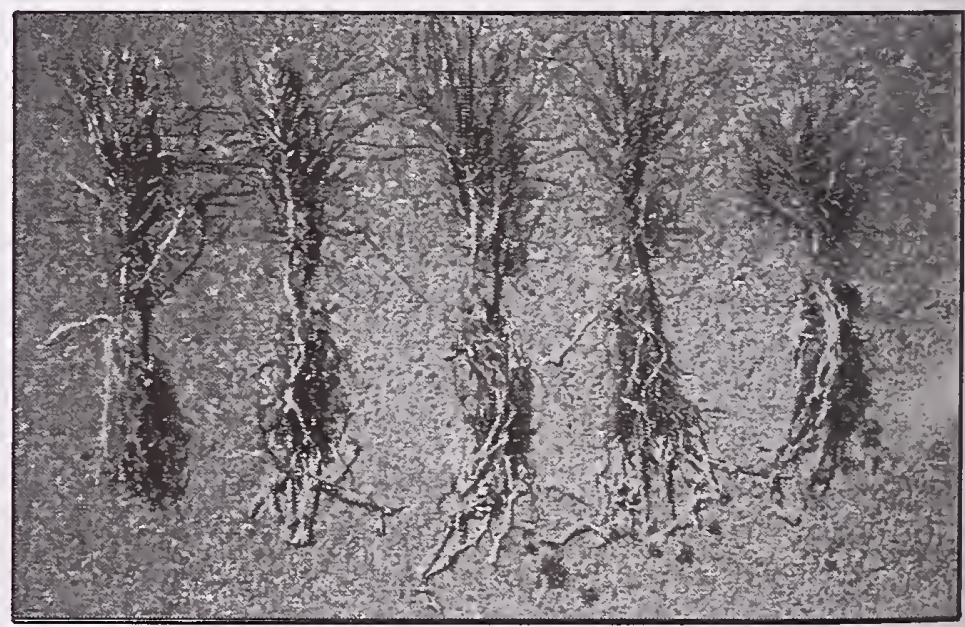

Figure 9. Effect of CONFER on root egress of lodgepole pine. (left to right; control, $0.5,1.0,2.5 \& 5.0$ $\mathrm{kg} / 1000 \mathrm{~m}^{2)}$. 


\section{Business Meetings}

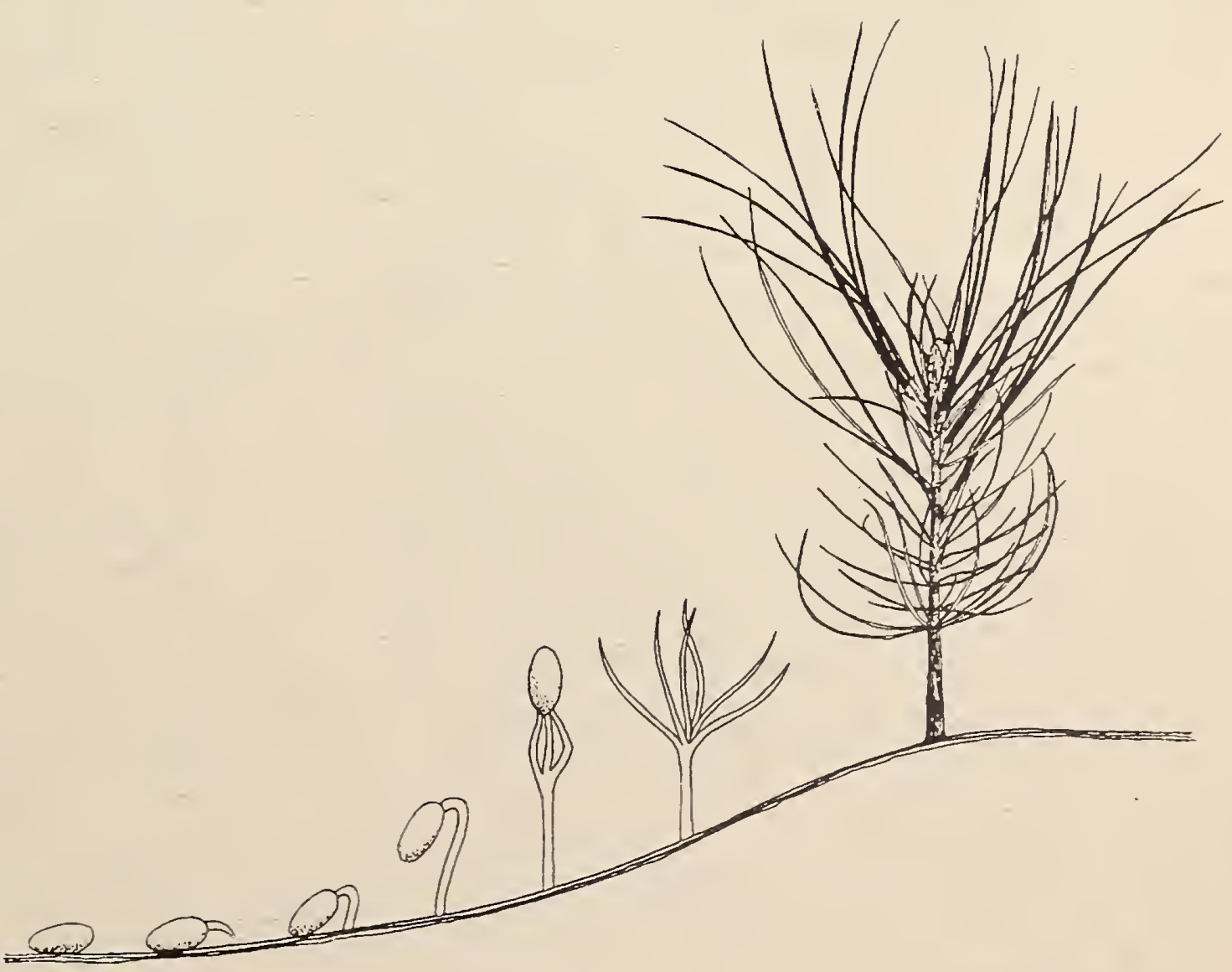





\section{Western Forest and Conservation Nursery Association: Minutes from 1994 Business Meeting}

The business meeting was called to order by Tom Landis at approximately 12:30 PM on Thursday, August 18.

\section{Old Business}

1. Minutes from the Previous Meeting. The minutes from the 1993 ICNA meeting in St. Louis, $\mathrm{MO}$ are published in the Proceedings from that meeting. The minutes were approved by a voice vote.

There was no other old business, and so the floor was opened to new business.

\section{New Business}

1. Proposal to form a single western nursery association. Tom Landis discussed the current situation where there are two informal nursery associations in the Western States. The Western Forest Nursery Council was one of the original groups of the Western Forestry and Conservation Association. Its members come mainly from the West Coast and the group met on even-numbered years. The Intermountain Conservation Nursery Association members come from the Great Plains and Intermountain areas and meet separately on odd-numbered years, and jointly with the Western Forest Nursery Council on even-numbered years.

At the 1992 business meeting of the Western Forest Nursery Council at Fallen Leaf Lake, CA, the group voted to explore the possibility of combining of Western Forest Nursery Council and Intermountain Conservation Nursery Association into a single organization. The "Western Forest and Conservation Nursery Association" would consist of two groups: the West Coast Section. which meets on even-numbered years, and the
Intermountain Section, which would meet on oddnumbered years. This is the same meeting schedule for the two existing organizations.

Tom Landis mentioned that he had presented this proposal to the business meeting at the 1993 Intermountain Conservation Nursery Association meeting in St. Louis, MO. The proposal passed unanimously, and the group recommended that the proposal would be put to a final vote at this meeting.

A discussion followed on the merits of a single association:

1. The current system of 2 organizations and the meeting schedule is very confusing, especially for the Proceedings where the name changes from year to year.

2. One western organization would mesh well with the Western Council of State Foresters, who are our primary political contact and source of financial support.

3. Association with a Parent Organization - In earlier discussions, several State Foresters expressed tentative approval of the establishment of a more formal nursery association but wanted it to be under the auspices of another parent forestry organization. Following up on this suggestion, Tom Landis contacted Richard Zabel from the Western Forestry and Conservation Association who had previously been associated with the Western Forest Nursery Council. Richard indicated that they would indeed be interested in re-establishing such a partnership.

The group concluded that this was a good idea, and then passed the motion unanimously. So, from 
this day forward, the Western Forest and Conservation Nursery Association will replace the previous groups. The charter follows the minutes.

\section{National Proceedings of all Forest and} Conservation Nursery Groups. Tom reported that the USDA Forest Service has agreed to publish an annual proceedings for all forest nursery association in a single volume. The National Proceedings would be published as a General Technical Report by the Rocky Mountain Forest and Range Experiment Station, who have published the western proceedings for the past decade. Each nursery organization would have their Proceedings in a separate section, and a joint Table of Contents would contain the entire listing. The proposal will really have no real impact on the Western Proceedings but will allow WFCNA members easier access to article from other areas of the country.

The Northeastern and Southern Forest Nursery Associations both approved this proposal at their business meetings this last July. The consensus of the group as that this was a good idea, and they voted unanimously to approve the National Proceedings.

3. Location of Future Meetings. Tom Landis reported the following meeting schedule:

1995 - The meeting will be held at the Ramada Inn in Kearney, NE on August 8-10, 1995. The meeting will be hosted by nursery manager Clark Fleege and his staff of the USDA Forest Service Bessey Nursery in Halsey, NE. Bessey Nursery was established in 1903 and is the oldest Forest Service nursery in the US, and we will be touring the nursery and historical outplantings in the Sand Hills area. Possible meeting themes include "Approaching a century of Great Plains Nursery Production" or "Learning from the Past to Meet the Challenges of the Future"
1996 - Tom Landis suggested a meeting in the Portland, OR area so that the Association would have the benefit of attending the Far West Show of the Oregon Association of Nurserymen. They typically meet at the Convention Center during the last week in August. Due to the expected impact of that group, the Association may need to consider meeting across the river in Vancouver, WA. Possible field trips include the Weyerhaeuser Mima Nursery and also local ornamental nurseries to see their latest technology. A possible theme is "Expanding our Horticultural Horizons".

1997 - The meeting will be hosted by the USDA Forest Service, Lucky Peak Nursery in Boise, ID during August 17-21. The host will be Dick Thatcher and his staff, and the meeting will include a visit to the nursery. A possible theme would be "The Role of Nurseries in Fire Rehabilitation and Forest Health".

There was no more new business and so the meeting was officially closed at 1:15 p.m.

\section{CHARTER: \\ WESTERN FOREST AND CONSERVATION NURSERY ASSOCIATION}

\section{Mission Statement}

The Western Forest and Conservation Nursery Association (WFCNA) is an organization of public and private nurseries from the Western United States whose focus is the production of seedlings for conservation and forestry plantings. Members include both bareroot and container nurseries, technical specialists, and researchers. The Association provides a mechanism to share information and technologies, identify common needs among nurseries, and manage our natural resources for future generations. 


\section{Goals}

1) Encourage greater emphasis on woody and herbaceous plant production for a wide range of forestry and conservation purposes: reforestation, resource protection, forest health. ecological restoration, biodiversity enhancement, wildlife habitat improvement. soil conservation, improvement of water quality. gene conservation, and agroforestry plantings.

2) Share state-of-the-art nursery practices.

3) Coordinate and facilitate applied nursery research.

4) Facilitate communication and resource sharing among nurseries.

5) Promote improved communication between nurseries and customers.

6) Serve as advocate of forest and conservation nursery managers in professional and political forums.

\section{Membership}

The WFCNA is open to all nursery personnel who are interested in the propagation of plants for forestry and conservation purposes. The organization is specifically defined by this function, rather than by any geographical boundaries. Nursery personnel who attend the annual meeting and pay the registration fee have voting privileges at that business meeting.

\section{Organization and Operations}

To provide direction and continuity, the WFCNA will be represented by a Board of Directors that is made up of nursery personnel. The Board of Directors consists of two positions (chair, vice-chair). who serve two-year terms. The chair will be the host of the next meeting and the vicechair will be the host of the succeeding meeting.
The vice-chair becomes the chair after two years, and a new vice-chair is determined by the location of the next meeting. Ex-officio members include the Western Nursery Specialist, and the Director of the Center of Semiarid Agroforestry at the Rocky Mountain Forest and Range Experiment Station at Lincoln.

All official business of the WFCNA will take place at the annual meeting, which will be held at a member nursery. The location of the meetings will be established on a rotating basis, and announced two years in advance. The meeting will be held on a Tuesday, Wednesday, and Thursday in August, and consist of two days, or the equivalent, of presentations and workshops, combined with field trips to nurseries and outplanting sites. The Board of Directors will meet on the Monday afternoon preceding the meeting to formulate resolutions to put before the general membership at the business meeting. They will meet again on the following Friday morning to act on the resolutions.

The goals of the WFCNA will be promoted by two separate, but related programs: applied research and technology transfer projects. Applied Research refers to projects in which existing techniques from horticulture or other related fields will be modified and adapted to the conditions at member nurseries. No attempt will be made to do basic research where new information is created. Technology Transfer projects will involve organizing workshops and training sessions to inform members of existing technical information.

\section{Applied Research Projects}

One of the key aspects of the WFCNA is to promote applied research projects among member nurseries that will increase seedling quality and outplanting success. Selection criteria for these projects will include:

* Widespread application to member nurseries

* High probablility of success

* Immediate usefuiness

* Must translate into outplanting success 
The exact mechanism for initiating these applied research projects still needs to be developed, especially ways to procure funding. The possibility of establishing a Research Coordinator will be investigated. The Coordinator would be appointed by the Board of Directors and would be responsible for surveying member nurseries to identify research needs, and report these needs to the Board. Acting upon the recommendations of the Board, the Research Coordinator would implement the research programs at participating member nurseries. The Research Coordinator would also provide problem solving services and site-specific research to member nurseries on a fee basis.

\section{Technology Transfer Projects}

Technology transfer needs and priorities will be determined by common consensus of the member nurseries. Because it is difficult for members to obtain approval to travel to separate training sessions, special "focus topics" will be scheduled at the regular nursery meetings. The Western Nursery Specialist and the Director of the Semiarid Agroforestry Center will assist in planning and implementing these projects.

\section{Political and Fiscal Support}

The WFCNA will not exist as a separate entity, but will operate as a subcommittee of the Western Forestry and Conservation Organization, which is headquartered in Portland, OR. In addition, a political liaison with the Western Association of State Foresters is desirable. The WFCNA will attempt to secure representation through a State Forester who would serve as an advocate. The WFCNA also maintains a technical liaison with the Center for Semiarid Agroforestry in Lincoln, NE, and the Western Nursery Specialist of the USDA Forest Service will also serve as technical advisor and political advocate.

Annual meeting costs will be covered by meeting registration fees and by fees paid by commercial exhibitors. A checking account will be established under the auspices of the Western Forestry and Conservation Association which will insure proper accounting and tax-free status. The vicechair will serve as treasurer of this account and make a financial report at the annual meeting. Carryover funds from the previous year's meeting will function as a reserve fund to cover mailings, room deposits, and other expenses associated with setting up the next meeting. If the account exceeds $\$ 2,500$, the money will be used to defray registration costs of the next meeting.

\section{LANDIS RECEIVES RECOGNITION}

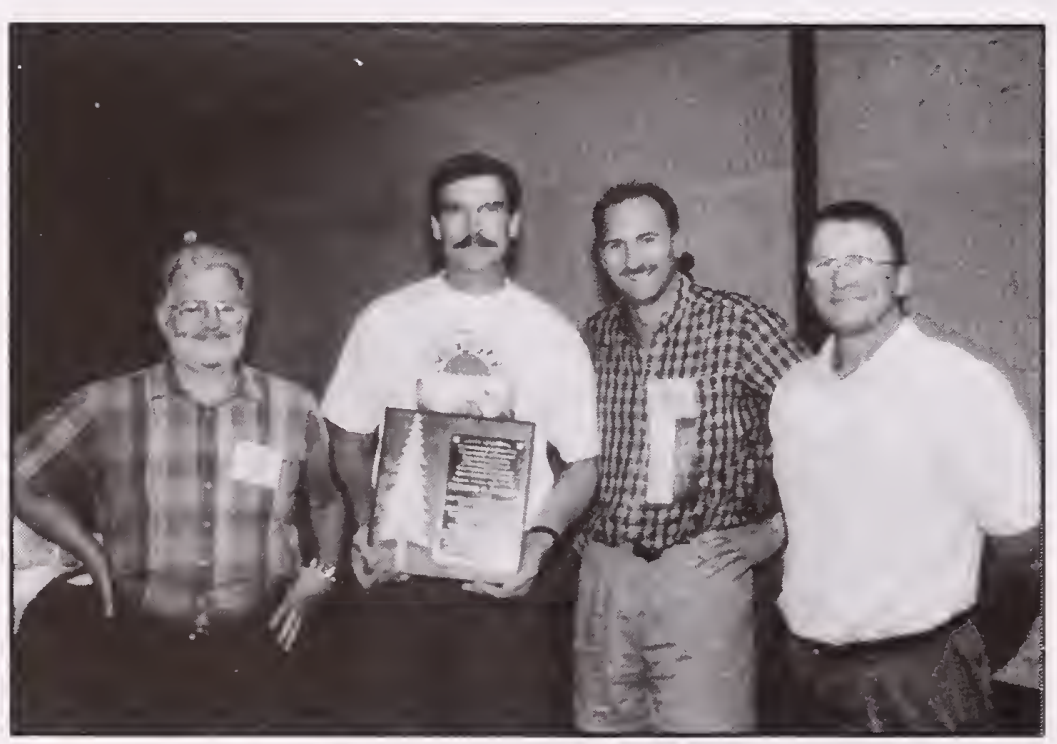

At the joint meeting of the Western Forest Nursery Association and Forest Nursery Association of British Columbia, Tom Landis was recognized for his outstanding service to US and Canadian nurseries. Tom received a wooden plaque with gold inscriptions on a marble-green backing set next to a hand-carved evergreen tree. He was also given a gift certificate to Recreational Equipment Incorporated. Pictured left to right are Ralph Huber, President of the FNABC; Tom Landis; Kas Dumroese, Chair of the joint WFNA/FNABC meeting; Dave Wenny. President of the WFNA. 
List of Participants

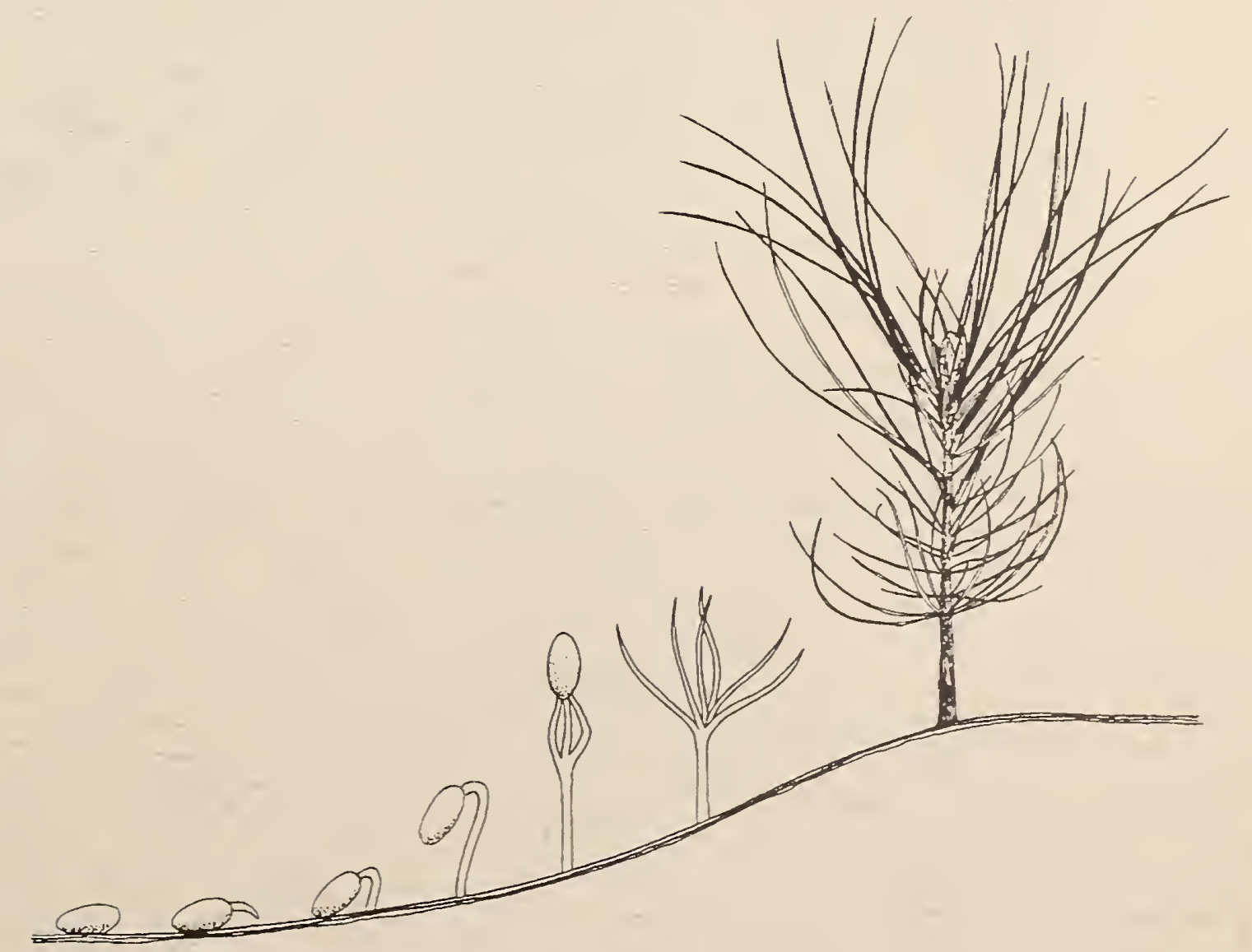





\section{Southern and Northeastern Association Forest Nursery Associations Meeting}

\section{PARTICIPANTS}

ALBAN-SNYDER. TINA

REFORESTATION SPECIALIST

DEPT. OF ENVIRONMENTAL RESOURCES

P.O. BOX 8552

HARRISBURG.PA $17105-8552$

717-787-4777

ALLISON. ALVIN C.

RETIRED

WEST VIRGINIA DIVISION OF FORESTRY

709 CHURCHILL DRIVE

CHARLESTON.WV 25314-1742

304-346-5697

ANDERSON. THOMAS A

NURSERYMAN

GEORGIA-PACIFIC CORPORATION

1444 SHUBUTA-EUCUTTA RD.

SHUBUTA.MS 39360

601-687-5766

ANTHONY, JOHN

NURSERY RESEARCHER

WEYERHAEUSER

RT. 2 BOX 339

IVASHINGTON.NC 27889

919-946-7718

ARMINTROUT, DAVID

ARMINTROUT'S NURSERY

1156 LINCOLN RD.

ALLEGAN.MI 49010

616-673-6627

BABB. TOM

CREW LEADER

UNION CAMP CORPORATION

15277 PLANK RD.

COURTLAND,VA 23837

804-653-2406
BAILEY, JAMES

FOREST GENETICIST

DEPT. OF ENVIRONMENTAL RESOURCES

P.O. BOX 8552

HARRISBURG,PA $17105-8552$

917-787-4777

BARBER. MARTY

REFORESTATION SUPERVISOR

FLORIDA DIVISION OF FORESTRY

3125 CONNER BLVD.

TALLAHASSEE,FL 32399-1650

904-488-7616

BARBOUR, JILL

GERMINATION SPECIALIST

NATIONAL TREE SEED LABORATORY

RT.1 BOX 182B

DRY BRANCH,GA 31210

$912-751-3553$

BARHAM, RICK

MANAGER-TEXAS NURSERY

INTERNATIONAL PAPER

RT.1 BOX 314 A

BULLARD,TX 75757

903-825-6101

BARNARD, DR. E. L.

FOREST PATHOLOGIST

FDACS/FLORIDA DIVISION OF FORESTR

P.O. BOX 147100

GAINESVILLE,FL 32614-7100

904-372-3505

BARNETT, JIM

RES. FORESTER

USDA-FS SOUTHERN FOREST EXP. STN.

2500 SHREVEPORT HWY.

PINEVILLE.LA 71360

318-473-7213 
BARRICK, WAYNE

NURSERY SUPERVISOR

KIRBY FOREST INDUSTRIES, INC.

RT.6 BOX 63611

WINNSBORO,TX 75494

903-629-3262

BATHRICK, CHARLES M.

NURSERY ADMINISTRATOR

OHIO DIVISION OF FORESTRY

5880 MEMORY RD.

ZANESVILLE,OH 43701

614-453-9472

BELFLOWER, WAYNE

NURSERY COORDINATOR

GEORGIA FORESTRY COMMISSION

RT.1 BOX 40

BYROMVILLE,GA 31007

912-268-7308

BELLIN, ERIC

PRESIDENT

TALL PINES FOREST NURSERY

430 REFOREST WAY

CROSS,SC 29436

803-753-3341

BENNETT, PAUL PRESIDENT

BAERTSCHI OF AMERICA, INC.

P.O. BOX 1099

GATLINBURG,TN 37738

615-428-3961

BOECKMAN, BILL

WEYERHAEUSER

BOOKER, SHARON

CONTAINER NURSERY COORDINATOR

N.C. DEPT. E.H. \& N.R., FOREST SERV

762 CLARIDGE NURSERY RD.

GOLDSBORO,NC 27530

919-731-7988

BORKENHAGEN, JOHN

NURSERY SUPERVISOR

WI. D.N.R. RT. 8 BOX 8213

HAYWARD.WI 54843

715-634-2717
BOSCH, LEONARD W.

PRESIDENT

BOSCH NURSERY, INC.

RT.2 BOX 142A

JONESBORO,LA 71251

318-259-9484

BOSCH, TED W.

VICE PRESIDENT

BOSCH NURSERY, INC.

RT.2 BOX 142A

JONESBORO,LA 71251

318-259-9484

BOWER, RALPH

MANAGER NURSERY/TREE IMPR.

MACMILLAN BLOEDEL INC.

P.O. BOX 336

PINE HILL,AL 36769

BRADLEY, CHRIS

SALES REPRESENTATIVE

EAGLE PRODUCTS, INC.

P.O. DRAWER 6536

HIGH POINT,NC 27262

800-877-3245

BRANAN, JOHN R.

CHIEF FORESTER

GEORGIA FORESTRY COMMISSION

BOX 819

MACON,GA 31298

912-751-3520

BROOKS, RHETT

NURSERYMAN

ST. JOSEPH LAND \& DEVELOPMENT CO.

RT.1 BOX 70

LAMONT,FL 32336

904-997-3736

CAMPBELL, SAM

NURSERY MANA GER

SCOTT PAPER COMPANY

29650 COMSTOCK RD.

ELBERTA,AL 36530

205-986-5210 
CANTRELL, STEVE

NURSERY SUPERVISOR

SC FORESTRY COMMISSION

P.O. BOX 116

TRENTON,SC 29847

803-275-3578

CAREY, WILLIAM A.

RESEARCH

AUBURN UNIVERSITY

$108 \mathrm{M}$. WHITE SMITH

AUBURN,AL 36849-5418

208-844-4998

CHANDLER, LAURIE A.

TECHNICAL SER VICE FORESTER

CHESAPEAKE FOREST PRODUCTS CO.

BOX 311

WEST POINT,VA 23181

804-843-5130

COADY, KATHIE E.

SALES REPRESENTATIVE

GROWTH PRODUCTS

223 CHURCH ROAD

MEDFORD.NJ 08055

914-428-1316

CONN, JOHN P.

SENIOR NURSERY MANAGER

CHAMPION INTERNATIONAL CORP.

2341 REDMOND MILL ROAD

SWANSEA,SC 29160

803-568-2436

COOP, NEWTON

NURSERY SUPERINTENDENT

KENTUCKY DIV. OF FORESTRY

438 TREE NURSERY RD.

WEST LIBERTY,KY 41472

606-743-3511

CORDELL, CHARLES E.

VICE-PRESIDENT OPERATIONS

MYCORR TECH. INC.

48 CEDAR MTN. RD.

ASHEVILLE,NC 28803

704-298-6379
CRAM, MICHELLE

PLANT PATHOLOGIST

USDA FOREST SERVICE

200 WEA VER BLVD.

ASHEVILLE,NC 28802

704-257-4316

CROOK, JOHN

VICE PRESIDENT

FULTON ENTERPRISES

108 WALTER DA VIS DR.

BIRMINGHAM,AL 35209

205-942-7504

CROSS, ROBERT E.

NURSERY MANAGER

INTERNATIONAL FOREST SEED CO.

P.O. BOX 1477

STATESBORO,GA 30459

912-587-5402

CUBANSKI, MARTIN

NURSERY MANAGER

CT. DIVISION OF FORESTRY

190 SHELDON RD.

VOLUNTOWN,CT 06384

203-376-2513

CURTIS, DOUGLAS

MARKETING MANGER

HENDRIX \& DAIL, INC.

P.O. BOX 648

GREENVILLE,NC 27835

919-758-4263

DAVEY, CHARLES

PROFESSOR

NC STATE UNIVERSITY

FORESTRY DEPT.

RALEIGH,NC 27695-8008

919-515-7787

DAVIS, JEAN

QUALITY SUPER VISOR

WEYERHAEUSER REGENERATION CTR.

HC 64 BOX 230

FT. TOWSON,OK 74735

405-873-2277 
DAY, ALEX

NURSERY OPERATIONS MANAGER

DEPT. OF ENVIRONMENTAL RESOURCES

R.R. 1 BOX 127-B

SPRING MILLS.PA 16875

814-364-1006

DeHART, DANIEL B.

NURSERY FORESTER

NEW HAMPSHIRE STATE NURSERY

405 D.W. HWY.

BOSCAWEN,NH 03303

603-796-2323

DELANEY, JOHN ERIC

VICE PRESIDENT

LOUISIANA FOREST SEED CO., INC.

303 FORESTRY RD.

LECOMPTE,LA 71346

318-443-5026

DELANEY, DERWOOD

PRESIDENT

LOUISIANA FOREST SEED CO., INC.

303 FORESTRY ROAD

LECOMPTE,LA 71346

318-443-5026

DIERAUF, TOM

CHIEF FOREST RESEARCH

VIRGINIA DEPARTMENT OF FORESTRY

BOX 3758

CHARLOTTESVILLE,VA 22903

804-977-6555

DOUBERLY, JOSEPH E.

NURSERY SUPERVISOR

GEORGIA-PACIFIC

1689 NURSERY RD.

JESUP,GA 31545

912-427-4871

DUNN, JOHNNY

NURSERY SUPERVISOR

TENNESSEE DIVISION OF FORESTRY

P.O. BOX 306

DELANO,TN 37325

615-263-1626
DUROCHER, JACQUES

PRESIDENT

ENERGIE VERTE, INC. 1465 RIVIERE ROUGE NORD QUEBEC,CANADA

514-537-3715

DUROCHER, CLAIRE

ENERGIE VERTE, INC.

1465 RIVIERE ROUGE NORD

QUEBEC,CANADA

514-537-3715

ELLIS, DA VID G.

GROWING OPERATINS MANAGER

KNUD NIELSEN COMPANY, INC.

P.O. BOX 746

EVERGREEN,AL 36401

205-578-2900

ENSMINGER, PAUL

NURSERY MANAGER

STATE OF TENNESSEE

P.O. BOX 306

DELANO,TN 37325

615-263-1626

ESTES, LARRY W. FORESTRY ASSISTANT SR.

VIRGINIA DEPT. OF FORESTRY

P.O. BOX 160

CRIMORA,VA 24431

703-363-5732

FORMY-DUVAL, JACK

MANAGER FOREST PRODUCTIVITY

FEDERAL PAPER BOARD

P.O. BOX 1007

LUMBERTON,NC 28359

910-739-7596

FOSTER, LARRY

NURSERY \& SEED ORCHARD SUPER.

INTERNATIONAL PAPER

264 CO. RD. 888

SELMA,AL 36701 
FOX, D. JOE

AREA FORESTER

TEXAS FOREST SERVICE

P.O. BOX 1327

HENDERSON,TX 75653

903-657-0511

FRANCIS, BRUCE

MANAGER

WEYERHAEUSER REGENERATION CTR.

HC 64 BOX 230

FT. TOWSON,OK 74735

405-873-2277

FRATELLO, GUY SAN

SECTION CHIEF

SC FORESTRY COMMISSION

RT2 BOX 99-19

GASTON,SC 29053

803-796-6076

FRAZIER, THOMAS

FORESTRY ASSISTANT SR.

VIRGINIA DEPT. OF FORESTRY

P.O. BOX 160

CRIMORA,VA 24431

703-363-5732

FURMAN, CHRIS

REGIONAL MANAGER

HENDRIX \& DAIL, INC.

2150 COMMERCIAL DRIVE

FRANKFORT,KY 40601

800-999-1262

GANDY, ROBERT

RG-PRODUCTION MANAGER

INTERNATIONAL FOREST SEED CO.

P.O. BOX 490

ODENVILLE,AL 35120

205-629-6461

GARMAN, R. WAYNE

NURSERY SUPERVISOR

VIRGINIA DEPT. OF FORESTRY

P.O. BOX 160

CRIMORA,VA 24431

703-363-7000
GARRETT, RICHARD

NURSERY MANAGER

MD. DNR - BUCKINGHAM NURSERY

7549 RAILROAD AVE.

HARMANS,MD 21077

410-859-7730

GATCH, CALVIN F.

SALES MANAGER

CASCADE FORESTRY

22033 FILLMORE RD.

CASCADE,IA 52033

319-852-3042

GERWIG, DA VE

TREE IMPROVEMENT LEADER

WESTVACO

P.O. BOX 1950

SUMMER VILLE,SC 29483

803-556-8391

GILBERT, JAMES A.

SUPERVISOR FORESTRY TECHICIAN

US FOREST SERVICE

368 ASHE NURSERY RD.

BROOKLYN,MS 39425

601-584-8488

GILLY, STEVEN

NURSERY MANAGER

FLORIDA DIVISION OF FORESTRY

RT.3 BOX 441

CHIEFLAND,FL 32626

904-493-6096

GJERSTAD, DEAN

PROFESSOR

AUBURN UNIVERSITY

AUBURN,AL 36849

205-844-1020

GRAMLING, CHUCK

NURSERY MANAGER

USDA FOREST SER VICE

368 ASHE NURSERY RD.

BROOKLYN,MS 39425

601-584-8488 
GREBASCH, JERRY

NURSERY FORESTER

IOWA DEPT. OF NATURAL RESOURCES

2404 SOUTH DUFF AVENUE

AMES,IA 50010

515-233-1161

GRIFFIN, MICHAEL T.

FORESTER MANAGER

VIRGINIA DEPARTMENT OF FORESTRY

P.O. BOX Q

CHARLOTTESVILLE,VA 22903

804-977-5193

GROESCHL, DAVID A.

REGENERATION MANAGER

RAYONIER INC.-GLENNVILLE REG. CNTR.

RT.2 BOX 1975

GLENNVILLE,GA 30427

912-654-4065

HAM, SUSAN H.

NURSERY SUPERINTENDENT

LOUISIANA DEPT. OF AGR. \& FORESTY

P.O. BOX 935

DeRIDDER,LA 70634

318-463-5509

HARBIN, MICHAEL C.

REFORESTATION COORD.

CHESAPEAKE FOREST PRODUCTS CO.

BOX 311

WEST POINT,VA 23181

804-843-5652

HARRIS, H. GRADY

PROGRAM HEAD

N.C. DIVISION OF FOREST RESOURCES

P.O. BOX 27687

RALEIGH,NC 27611-7687

919-733-2162

HARRIS, LISA A.

NURSERY MANAGER

MISSISSIPPI FORESTRY COMMISSION

1063 BUCKATUNNA MT.ZION RD.

WAYNESBORO,MS 39367

601-735-9512
HARTLEY, BARRY L SEEDLING COORDINATOR

GEORGIA PACIFIC

P.O. BOX 158

E. PALATKA,FL 32131

904-328-2796

HAWK, SELBY

NURSERY TREE IMP. FORESTER

N.C. DIVISION OF FORESTRY

701 SANFORD DR.

MORGANTON,NC 28655

704-438-6270

HEATER, JAMES M.

OWNER

SILVER MOUNTAIN EQUIPMENT

4672 DRIFT CREEK RD. SE

SUBLIMITY,OR 97385

503-769-7127

HENDERSHOT, ROGER

NURSERY MANAGER/ADMINISTRATION

OHIO DNR MARIETTA NURSERY

P.O. BOX 428

RENO,OH 45773

614-373-6574

HENDRIX, R.D.

TECHNICAL FORESTER - SALES

INTERNATIONAL FOREST SEED CO.

P.O. BOX 490

ODENVILLE,AL 35120

205-629-6461

HERBST, ROY

HERBST WHOLESALE TREE SEED

307 NUMBER NINE RD.

FLETCHER,NC 28732

704-628-4709

HICKAM, FLOYD

NURSERY MANAGER

ARKANSAS FORESTRY COMMISSION

1402 HIGHWAY 391 NORTH

NORTH LITTLE ROCK,AR 72117

501-945-3345 
HILL, RUSSELL B.

REGIONAL MANAGER

HENDRIX AND DAIL, INC.

P.O. BOX 965

TIFTON,GA 31794

800-872-0644

HILL, TOM

NURSERY MANAGER

WILSON STATE NURSERY

BOSCOBEL,WI 53805

608-375-4123

HINSON, KIRK

VICE-PRESIDENT

SOUTHERN SEED COMPANY, INC.

P.O. BOX 340

BALDWIN,GA 30511

706-778-4542

HINSON, STANLEY VICE-PRESIDENT SOUTHERN SEED COMPANY, INC.

P.O. BOX 340

BALDWIN,GA 30511

706-778-4542

HIXSON, DONALD L.

FORESTRY ASSISTANT SR.

VIRGINIA DEPT. OF FORESTRY

11301 POCAHONTAS TRAIL

PROVIDENCE FORGE,VA 23140

804-966-2201

HORTON, RICK

NURSERY MANAGER

INTERNATIONAL PAPER

RT.2 BOX 24

BLUFF CITY,AR 71722

501-685-2562

HORVATH, DA VID

CONSERVATION RESOURCE MGR-3

ILLINOIS DEPT CONSERVATION

R.R. 1, BOX 235

TOPEKA,IL 61567

309-535-2185
HOUSEMAN, DONALD D.

NURSERY MANAGER

UNION STATE NURSERY

RT.1 BOX 1331

JONESBORO,IL 62952

618-833-6125

HUFFMAN, GREG

NURSERY MANAGER

FORESTRY SERVICE

RT. 1 BOX 44

WASHINGTON,OK 73093

405-288-2385

ISAACS, BILL

PRESIDENT

SOUTHPINE, INC.

P.O. BOX 530127

BIRMINGHAM,AL 35253

205-879-1099

JACOBSON, MARSHALL

REFORESTATION SECTION LEADER

INTERNATIONAL PAPER

RT.1 BOX 421

BAINBRIDGE,GA 31717

912-246-3642

JENKINS, RONALD S.

NURSERY SUPERVISOR

VIRGINIA DEPT. OF FORESTRY

11301 POCAHONTAS TRAIL

PROVIDENCE FORGE, VA 23140

804-966-2201

JENNINGS, ROBERT

NURSERY SUPERVISOR

N.C. DIVISION OF FORESTRY

P.O. BOX 70

CROSSNORE,NC 28616

704-733-5236

JOHNSON, GARY

BOTANIST

US FOREST SER VICE

RT.1 BOX 182-B

DRY BRANCH,GA 31020

912-751-3555 
JOHNSON, RICHARD

SUPERINTENDENT

MICHIGAN DNR, WYMAN STATE NURSERY

RT. 2 BOX 2004

MANISTIQUE,MI 49854

906-341-2518

JONES, RANDALL BUSINESS MANAGER GRIFFIN CORPORATION

HC 51 BOX $122 \mathrm{H}$

GRAFORD,TX 76449-9612

817-779-2186

KARRFALT, BOB

LABORATORY DIRECTOR

US FOREST SERVICE/TREE SEED LAB.

RT.1 BOX 182 b

DRY BRANCH,GA 31020-9696

912-751-3552

KELLISON, BOB

PROFESSOR

NORTH CAROLINA STATE UNIVERSITY

BOX 8008

RALEIGH,NC 27695

919-515-5314

KERNAN, MICHAEL

PRODUCTION SCIENTIST

MYCORR TECH INC.

440 WILLIAM PITT WAY

PITTSBURG,PA 15238

412-826-5488

LAFLAMME, DENIS

ENERIE VERTE, INC.

1465 RIVIERE ROUGE NORD

QUEBEC,CA

514-537-3715

LAFRAMBOISE, ROY

NURSERY MANAGER

NORTH DAKOTA FOREST SERVICE

HC 2 BOX 13

TOWNER,ND 58788

701-537-5636

LANDIS, TOM D.

WESTERN NURSERY SPECIALIST

USDA - FOREST SERVICE, CF

P.O. BOX 3623

PORTLAND,OR 97208

506-326-6231
LANTZ, CLARK

NURSERY/TREE IMP. SPECIALIST

USDA FOREST SERVICE

1720 PEACHTREE RD. NW

ATLANTA,GA 30367

404-347-3554

LAWYER, JOHN N.

PRESIDENT

LAWYER NURSERY, INC.

950 HIGHWAY 200 WEST

PLAINS,MT 59859

406-826-3881

LEGGINS, CLYDE

NURSERY SUPERVISOR

N.C. DIVISION OF FORESTY

701 SANFORD DR.

MORGANTON,NC 28655

704-438-6270

LILLEY, VICTOR

REDDICK FUMIGANTS, INC.

P.O. BOX 391

WILLIAMSTON,NC 27892

800-358-8837

LITTLE, WAYNE

NURSERY MANAGER

PACKAGING CORPORATION OF AMERICA

RT.2 BOX 30-A

VINA,AL 35593

205-356-9700

LOVELACE, ROB

PRESIDENT

LOVELACE SEEDS, INC.

BROWNS MILL ROAD

ELSBERRY,MO 63343

314-898-2103

LOWDERMILK, RICHARD

FORESTRY ASSISTANT SR.

VIRGINIA DEPT. OF FORESTRY

19127 SANDY HILL

COURTLAND,VA 23837

804-834-2855 
LOWERTS, GEORGE A.

RESEARCH FORESTER

UNION CAMP CORPORATION

P.O. BOX 345

HAGON,GA 31405

$912739-4613$

MANGOLD, ROB

NURSERY SPECIALIST

USDA FOREST SER VICE

P.O. BOX 96090

WASHINGTON,DC 20090

202-205-1379

MARTY, TRENT

FOREST GENETICIST

WISCONSIN DEPT. OF NATURAL RESOURCE

BOX 7921

MADISON,WI 53707

608-266-7891

MASSIE, WILLIAM E.

REGENERATION FORESTER

MISSISSIPPI FORESTRY COMMISSION

P.O. BOX 468

LUMBERTON,MA 39455

601-796-8892

MATHERNE, CHARLES

REFORESTATION CHIEF

LA. DEPT. OF AGRICULTURE \& FORESTRY

P.O. BOX 1628

BATON ROUGE,LA 70821-1628

504-925-4515

MAUL, S TEPHEN B.

VICE-PRESIDENT PRODUCTION

MYCORR TECH INC.

440 WILLIAM PITT WAY

PITTSBURG,PA 15238

412-826-5488

MAYNOR, MAXIE

NURSERY FORESTER

FEDERAL PAPER BOARD

P.O. BOX 1007

LUMBERTON,NC 28359

910-739-7596
McBEE, WAYNE L.

SUPERINTENDENT OF NURSERIES

VIRGINIA DEPT. OF FORESTRY

P.O. BOX 3758

CHARLOTTESVILLE,VA 22903

804-977-6555

McCARTHY, BILL

ASST. NURSERY MANAGER

CASCADE FORESTRY NURSERY

22033 FILLMORE RD.

CASCADE,IA 52033

319-852-3042

McCOLLUM, GUY T.

FORESTRY TECHNICIAN

TENNESSEE DIVISION OF FORESTRY

P.O. BOX 120

PINSON,TN 38366

901-988-5221

McCORKLE, ROBBIE

NURSERY MANAGER

INTERNATIONAL FOREST SEED CO.

P.O. BOX 539

BUENA VISTA,GA 31803

912-649-6625

McCOY, WES

AGRIBUSINESS MANAGER

SWIFT ADHESIVES

P.O. BOX 600

RTP,NC 27709-3582

919-990-7500

McCURDY, DA VID K.

NURSERY SUPERINTENDENT

CLEMENTS STATE TREE NURSERY

101 ALLISON DRIVE

P.O. BOX 8

WEST COLUMBIA,WV 25287

304-675-1820

McNABB, KEN

ASSOCIATE PROFESSOR

AUBURN UNIVERSITY

SCHOOL OF FORESTRY

AUBURN UNIVERSITY,AL 36849-5418

205-844-1044 
McRAE, JOHN B.

JM-TECHNICAL FORESTER-SALES

INTERNATIONAL FOREST SEED CO.

P.O. BOX 490

ODENVILLE,AL 35120

205-629-6461

MILLER, HORACE N.

CROP QUALITY SUPERVISOR

WEYERHAEUSER CO.

RT.2 BOX 339-A

WASHINGTON,NC 27889

919-975-5831

MILLER, LARRY G.MGR.

TREE IMPROVE. \& RESEARCH

TEMPLE-INLAND FOREST PRODUCTS CORP.

229 N. BOWIE ST.

JASPER,TX 75951

409-384-3434

MITCHELL, DR. MARY

PROJECT SCIENTIST

DIVISION OF FORESTRY

P.O. BOX 147100

GAINESVILLE,FL 32614-7100

904-372-3505

MOORHEAD, DAVE

FOREST REGENERATION SPECIALIST

GEORGIA UNIVERS. SCHOOL OF FORESTRY

P.O. BOX 1209

TIFTON,GA 31793

912-386-3418

MURRAY, ALLAN FORESTER II

ARKANSAS FORESTRY COMMISSION

1402 HIGHWAY 391 NORTH

NORTH LITTLE ROCK,AR 72117

501-945-3345

NELSON, GARY

INTERNATIONAL PAPER

5530 HIGHWAY $38 \mathrm{~S}$

BLENHEIM,SC 29516

803-528-3203

NISLEY, REBECCA G.

MANAGING EDITOR

TREE PLANTERS' NOTES (USDA F S)

51 MILL POND ROAD

HAMDEN,CT 06514

203-773-2478
NORRIS, CHARLES

SALES REPRESENTATIVE

HAMILTON HYBAR, INC.

4123 CAROLINA AVE.

RICHMOND,VA 23222

804-321-6390

NORRIS, WILSON L.

NURSERY SUPERVISOR

N.C. DEPT. E.H. \& N.R., FOREST SERV

762 CLARIDGE NURSERY RD.

GOLDSBORO,NC 27530

919-731-7988

NORTON, LARRY

NURSERY SUPERINTENDENT

KENTUCKY DIVISION OF FORESTRY

P.O. BOX 97

GILBERTSVILLE,KY 42044

502-362-8331

OLIVER, TRACY

GROWTH PRODUCTS LTD.

15 HOME STREET

WHITE PLAINS,NY 10606

914-428-1316

OVERTON, RON

REGENERATION SPECIALIST

USDA FOREST SER VICE, S \& PF

1992 FOLWELL AVENUE

ST. PAUL,MN 55108

612-649-5241

PARMAR, RAJBIR S.

RESEARCH ENGINEER

UNIVERSITY OF GEORGIA

DRIFTMIER ENGINEERING CNTR.

ATHENS,GA 30602-4435

706-542-8842

PARROTT, JOHN M.

NURSERY SUPERVISOR

UNION CAMP CORPORATION

RT. 1 BOX 244

UNION SPRINGS,AL 36089

PATTERSON, ROBERT L.

MYCORR TECH INC.

440 WILLIAM PITT WAY

PITTSBURGH,PA 15238

412-826-5488 
PEASLEE, ALAN

NURSERY SUPERINTENDENT

NEW JERSEY BUREAU OF FOREST MGMT.

370 EAST VETERAMS HWY.

JACKSON,NJ 08527

908-928-0029

PENNINGTON, WILLIE

MARKET MANAGER

BASF CORPORATION

P.O. BOX 13528

RESEARCH TRIANGLE,NC 27709

919-361-5372

PICKENS, BILL

N.C. DEPT. E.H. \& N.R., FOREST SERV

762 CLARIDGE NURSERY RD.

GOLDSBORO,NC 27530

919-731-7988

PINCKNEY, P.J. "PAT"

SALES REPRESENTATIVE

UNION CAMP - BAG DIVISION

801 SUMMER LANE

PRATTVILLE,AL 36066

205-361-8880

POKORNY, JILL

PLANT PATHOLOGIST

USDA FOREST SERVICE

1992 FOLWELL AVE.

ST. PAUL,MN 55108

612-649-5247

PRINCE, FRED

37069 CHARTER OAKS BLVD.

CLINTON TOWNSHIP,MI 48036

810-463-9058

PRYOR, WILLIAM L.

NURSERY SUPERVISOR

UNION CAMP CORPORATION

P.O. BOX 56

BELLVILLE,GA 30414

912-739-4721

RAMSEY, RON

NURSERY TECHNOLOGIST

WEYERHAEUSER COMPANY

169 WEYERHAEUSER RD.

AIKEN,SC 29801

803-649-0489
REDDICK, MARK

PRESIDENT

REDDICK FUMIGANTS, INC.

P.O. BOX 391

WILLIAMSTON,NC 27892

800-358-8837

REIER, PAUL M.

FORESTRY ASSISTANT SR.

VIRGINIA DEPT. OF FORESTRY

11301 POCAHONTAS TRAIL

PROVIDENCE FORGE,VA 23140

804-966-2201

RENTZ, RANDY

NURSERY SUPERINTENDENT

LOUISIANA DEPT. OF AGRI. \& FORESTRY

P.O. BOX 1388

COLUMBIA,LA 71418

318-649-7463

RICE, FRED

GREENHOUSE MANAGER

MEAD PAPER CORPORATION

P.O. BOX 1008

ESCANABA,MI 49829

906-786-1660

RIVERS, JESSE L.

FORESTRY ASSISTANT SR.

VIRGINIA DEPT. OF FORESTRY

19127 SANDY HILL RD.

COURTLAND, VA 23837

804-834-2855

ROWAN, JIM

NURSERY CONSULTANT

1090 IVYWOOD DR.

ATHENS,GA 30606

706-549-2519

RYE, DALE

NURSERY SUPERVISOR

CONTAINER CORPORATION OF AMERICA

P.O. BOX 129

ARCHER,FL 32618

904-495-2660 
SCHAEFER, GARY M.

NURSERY MANAGER

MISSISSIPPI FORESTRY COMMISSION

RT.3 BOX 41

WINONA,MS 38967

601-283-1456

SCHERDER, MIKE

SALES MANAGER

HAMILTON HYBAR, INC.

4123 CAROLINA AVE.

RICHMOND,VA 23222

804-321-6390

SELVIG, THOMAS PRESIDENT

SELVIG CORPORATION

10615 BEACH BLVD.

JACKSONVILLE,FL 32246

904-642-4930

SHARP, DOUG

NURSERY SUPERINTENDENT

JSC/CCA

RT. 3 BOX 128

BREWTON,AL 36426

205-867-9480

SHEAN, GERALD

SALES MANAGER

EAGLE PRODUCTS, INC.

P.O. DRAWER 6536

HIGH POINT,NC 27262

800-877-3245

SHELBURNE, DOUG

NURSERY MANAGER

INTRNATIONAL PAPER

BOX 23

BLUFF CITY,AR 71722

501-685-2562

SHERRILL, ROBERT M.

NURSERY MANAGER

TENNESSEE DIVISION OF FORESTRY

P.O. BOX 120

PINSON,TN 38366 901-988-5221

SHOCKLEY, WILLIAM L.

FORESTRY ASSISTANT SR.

VIRGINIA DEPT. OF FORESTRY

11301 POCAHONTAS TRAIL

PROVIDENCE FORGE,VA 23140

804-966-2201
SIMMS, DEWEY A. "TONY"

NURSERY OPERATIONS MANAGER

TEXAS FOREST SERVICE

P.O. BOX 617

ALTO,TX 75925-0617

409-858-4202

SKROCH, WALTER

BASF

P.O. BOX 13528

RTP,NC 27709

919-361-5300

SOLAN, JOHN

ASSOCIATE FORESTER

NYS DEPT. ENVIRONMENTAL CONSERV.

431 RT. $50 \mathrm{~S}$

SARATOGA SPRINGS,NY 12866

518-581-1439

SOSSAMAN, ED

NURSERY OPERATIONS MANAGER

WEYERHAEUSER CO.

169 WEYERHAEUSER ROAD

AIKEN,SC 29801

803-649-0489

SOUTH, DA VID

PROFESSOR

AUBURN UNIVERSITY

SCHOOL OF FORESTRY

AUBURN UNIVERSITY,AL 36849

205-844-1022

SPARKMAN, DAVID

MANAGER NURSERY \& GENETICS

FEDERAL PAPER BOARD

P.O. BOX 1007

LUMBERTON,NC 28359

910-739-7596

STALLARD, DWIGHT H. NURSERY SUPERVISOR VIRGINIA DEPT. OF FORESTRY 19127 SANDY HILL RD. COURTLAND,VA 23837

804-834-2855 
STAUDER, ALBERT

NURSERY SUPERINTENDENT

INTERNATIONAL PAPER

RT. 1 BOX 314-A

BULLARD,TX 75757

903-825-6101

STEWART, W.T.

NURSERY SUPER VISOR

TEMPLE-INLAND FOREST PRODUCTS CORP.

229 N. BOWIE ST.

JASPER, TX 75951

409-384-6164

STONE, JAKE M.

SUPERINTENDENT SEEDLING PROD.

UNION CAMP CORPORATION

18229 EPPES DRIVE

CAPRON,VA 23851

804-658-4184

STORANDT, JIM

NURSERY SUPERINTENDENT

WISCONSIN D.N.R. 711 NEPCO LAKE RD

WISCONSIN RAPIDS, WI 54494

715-424-3700

STORMS, JAMES G.PLANT MANAGER

J.E. LOVE CO.

309 CALIFORNIA BOX 188

GARFIELD, WA 99130

509-635-1321

STRINGFIELD, DON

NURSERYMAN

WESTVACO CORPORATION

P.O. BOX 1950

SUMMERVILLE,SC 29484

803-556-8391

STUEWE, ERIC

PRESIDENT

STUEWE AND SONS, INC.

2290 S.E. KIGER ISLAND DR.

CORVALLIS,OR 97333-9461

503-757-7798
TANAKA, YASUOMI

FOREST NURSERY ECOLOGIST

WEYERHAEUSER COMPANY

505 N. PEARL ST.

CENTRALIA, WA 98531

206-330-1733

THIGPEN, DENNY

NURSERY SUPERINTENDENT

GEORGIA FORESTRY COMMISSION

HC 01 BOX 217

REIDSVILLE,GA 30453

912-557-6821

THOMPSON, JAN

RESEARCH ASSOCIATE

DEPT FORESTRY, IOWA STATE UNIVERSITY

251 BESSEY HALL, I. S. U.

AMES,IA 50011

515-294-5708

THOMPSON, G. W.

NURSERY SUPER VISOR

RA YONIER, INC. GRC

RT.2 BOX 1975

GLENNVILLE,GA 30427

912-654-4065

TROBAUGH, JOHN

REGIONAL RESEARCH COORDINATOR

GEORGIA-PACIFIC

100 WISCONSIN RIVER DRIVE

PORT EDWARDS, WI 54469

715-887-5115

TRULL, STACY

VICE PRESIDENT

BAERTSCHI OF AMERICA, INC.

P.O. BOX 1099

GATLINBURG,TN 37738

615-436-2008

UBINAS, RUBEN

FOREST NURSERY COORDINATOR

DEPT. OF NATURAL RESOURCES BOX 5887

SAN JUAN,PR 00906

809-724-3584 
VAN VALKENBURGH, DOUG

AREA FORESTER

GEORGIA PACIFIC CORPORATION

116 MACK QUEEN DR.

BRUNSWICK,GA 31525

912-262-9728

VANDE LINDE, FRANK

RESEARCH FORESTER (RETIRED)

609 NORWICH ST.

BRUNSWICK,GA 31520

912-265-0415

VANKUS, VICTOR

BOTANIST

USDA FOREST SER VICE

RT. 1 BOX 182-B

DRY BRANCH,GA 31020

912-751-3555

VanSICKLE, CRAIG ALAN

NURSERY SITE SUPERVISOR

MINNESOTA DNR FORESTRY

RR 2 BOX 210

AKELEY,MN 56433

218-652-2385

VERMILLION, TOM

TREE IMP./SEEDLING MANAGER

CAVENHAM FOREST INDUSTRIES DIV.

59444 HWY. 10

BOGALUSA,LA 70427

504-732-6750

WALKER, LUCY

MANAGER

GHW WEYERHAEUSER NURSERY

RT.2 BOX 339

WASHINGTON,NC 27889

919-946-7718

WALTER, RON

NURSERY MANAGER

DEPT. OF ENVIRONMENTAL RESOURCES

R.R.1 BOX 127

SPRING MILLS,PA 16875

814-364-1006
WARREN, FRED

DIRECTOR MARDETING

MYCORR TECH INC.

440 WILLIAM PITT WAY

PITTSBURG,PA 15238

412-826-5488

WHALEN, PATRICK T.

SENIOR FORESTER

NYS DEPT. ENVIRONMENTAL CONSERV.

432 RT. $50 \mathrm{~S}$.

SARATOGA SPRINGS,NY 12866

518-581-1439

WHITFIELD, JAMES

PRESIDENT

R.A. WHITFIELD MFG. CO.

P.O. BOX 188

MABLETON,GA 30059

404-948-1212

WICHMAN, JIM

NURSERY MANAGER

INDIANA DIVISION OF FORESTRY

2782 W. CO. RD. 540 S

VALLONIA,IN 47281

812-358-3621

WILKINS, WILLIAM P.

REFORESTATION FORESTER

TENNESSEE DIVISION OF FORESTRY

P.O. BOX 40627 MELROSE STATION

NASHVILLE,TN 37204

615-360-0738

WILLIFORD, MIKE

NURSERY SUPERINTENDENT

BOWATER INC.,SOUTHERN DIV.WUODLANDS

11306 HWY. $411 \mathrm{~S}$.

CHATSWORTH,GA 30705

706-334-2422

WILSON, PHILIP

NURSERY FORESTER

ALABAMA FORESTRY COMMISSION

RT.3 BOX 322

ATMORE,AL 36502

205-368-4854 
WIMER. GERALD

DISTRICT FORESTER

WEST VA. DIVISON OF FORESTRY

P.O. BOX 189

MILTON,WV 25541

304-562-9664

WOODY. KENNETH D.

NURSERY MANAGER

INTERNATIONAL PAPER

5594 HWY. 38 SOUTH

BLENHEIM.SC 29516

803-528-3203
WORLEY, LERAY

NURSERY TECHNICIAN

N.C. DIVISION OF FOREST RESOURCES

2411 OLD HWY. 70 WEST

CLAYTON,NC 27520

919-553-6178

YODER, BILL

NURSERYMAN

MISSOURI DEPT. OF CONSERVATION

RT.2 BOX 465

LICKING,MO 65542

314-674-3229

\section{EXHIBITORS}

Derwood Delany or

John Delany

Louisiana Forest Seed Co., Inc.

303 Forestry Road

Lecompte, LA 71346

Eric Stuewe

Stuewe and Sons, Inc.

2290 S.E. Kiger Island Drive

Corvallis, OR 97333

Charles E. Cordell

Mycorr Tech, Inc.

48 Cedar Mountain Road

Asheville, NC 28803

John Crook

Fulton Enterprises

108 Walter Davis Drive

Birmingham, AL 35209

Roy Herbst

Roy Herbst Seeds

307 Number Nine Road

Fletcher, NC 28732
Kirk Hinson

Southern Seed Company, Inc.

P.O. Box 340

Baldwin, GA 30511

Bill Isaacs

Southpine, Inc.

P.O. Box 230127

John N. Lawyer

Lawyer Nursery, Inc.

950 Highway 200 West

Plains, MT 59859

Pat Pinckney

Union Camp Bag Division

801 Summer Lane

Prattville, AL 36066

Robert Gandy

International Forest Seed Co.

P.O. Box 490

Odenville, AL 35120 
Paul Bennett

Baertshi of America, Inc.

P.O. Box 1099

Gatlinburg, TN 37738

Jacques Durocher

Energie Verte, Inc.

1465 Riviere Rouge Nord

Quebec, CA

Chris Furman

Hendrix \& Dail, Inc.

2150 Commercial Drive

Frankfort, KY 40601

Tracy Oliver

Growth Products, LTD

15 Home Street

White Plains, NY
Willie Pennington

BASF Corporation

P.O. Box 13528

Research Triangle, NC 27709

Gerald Shean

Eagle Products, Inc.

P.O. Drawer 6536

High Point, NC 27262

James Whitfield

R.A. Whitfield Mfg.Co.

P.O. Box 188

Mableton, GA 30059

\section{CONTIBUTORS}

A. L. Bradley

Waverly Drugs, Inc.

Waverly, Va.

Elmon Gray

Grayland Company

Waverly, Va.

John P. Pearson

Van Cleef Auto Parts

Waverly, Va.

The Williamsburg Outlet Mall

Lightfoot, Va.

The Williamsburg Pottery

Lightfoot, Va.

W. Carroll McLawhorn

Hendrix and Dail, Inc.

Greenville, N.C.
Mr. \& Mrs. Frank Keeter

Southside Grocery, Inc.

Waverly, Va.

Michael Leggett

Nansemond Ford Tractors, Inc.

Suffolk, Va.

G. Page Clarke, Jr.

Grizzard Auto Parts, Inc.

Waverly, Va.

Gurney B. Cowling

Cowling Brothers, Inc.

Waverly, Va.

Marvin K. Warthan

Presson \& Warthan, Inc.

Waverly, Va. 
Robin B. Scarborough

Ann's Dress Shoppe

Waverly, Va.

The Old Dominion Opry

Williamsburg, Va.

Edwin G. Goodrich

Plantation Peanuts of Wakefield

Wakefield, Va.

James E. Laine

Wakefield Peanut Company

Wakefield, Va.

R. M. Felts, Jr.

R. M. Felts Packing Company

Ivor, Va.

S. Wallace Edwards, Jr.

S. Wallace Edwards \& Sons, Inc.

Surry, Va.

Floyd L. Forrest, Jr.

Wakefield Equipment Company

Wakefield, Va.

Vince A. Petraglia

The Candle Factory Restaurant

Williamsburg, Va.

Edward G. Michalek

Southside Ford Tractor, Inc.

Petersburg, Va.

Harold L. Olinger

Virginia Department of Forestry

Charlottesville, Va.

Davis M. Gerwig

Westvaco

Timberlands Division

Charleston Heights, SC
Glenda Parrish/Charles Finley

Virginia Forestry Association

Richmond, Va.

Aurelia Seward

Sussex Galleries

Waverly, Va.

Tracy Adams

Evelynton Plantation

Charles City, Va.

Tom Garrett

Wakefield's IGA Supermarket

Wakefield, Va.

Drew Haynie

The Williamsburg Winery

Williamsburg, Va.

James M. Heater

Silver Mountain Equipment

Sublimity, Oregon

Derwood Delaney, John Delaney

Louisiana Forest Seed Co., Inc.

Lecompte, La.

Pat Pinckney

Union Camp - Bag Division

Prattville, Al.

Mike Stevens

The Surrey House Restaurant

Surry, Va.

Corning Revere Factory Store

Waynesboro, Va.

Virginia Metalcrafters, Inc.

Waynesboro, Va.

Linda Patrick

Lyndurst, Va. 
Lisa Geiman

Waynesboro, Va.

Tim Knicely

Mt. Sidney, Va.

Shreckhise Nursery

Grottoes, Va.

Maslow Wood Products

Powhatan, Va.

Bud Bussell's

Powhatan. Va.

Union Camp Corporation

Capron, Va.

Wes McCoy

Swift Adhesives

North Carolina

Bubber Duke

Russell Daniel Irrigation Co. LTD

Havana, FL / Athens, GA

Tom Mills

Tree Pro

West Lafayette, Indiana

Debbie Garter

Bank of Southside

Stony Creek, Va.

Debra O’Neil-Mastaler

Busch Gardens

Williamsburg, Va.

Sheila Butkus

Trellis Restaurant

Williamsburg, Va.
Virginia Diner

Wakefield, Va.

Augusta Forestry Center

Virginia Department of Forestry

Crimora, Va.

Fire Management Branch

Virginia Department of Forestry

Charlottesville, Va.

Historic Michie Tavern

Charlottesville, Va.

State Farm Insurance Co.

Charlottesville, Va.

J. E. Love, Company

Garfield, Wa.

International Forest Seed Co.

Odenville, Al.

BASF Corporation

North Carolina

Ms. Melissa St. Pierre

Williamsburg, Virginia's Great Entertainer

Williamsburg, Va.

Little Debbie Corporation

Stuarts Draft, Va.

F. W. Schumacher Co., Inc.

Sandwich, Ma. 


\section{Western Forest Nursery Association and the Forest Nursery Association of British Columbia Meeting}

\section{PARTICIPANTS}

Helen Atthowe

Bitterroot Native Growers

445 Quast Lane

Corvallis, Montana 59828

Jorge Avila

K \& C Silviculture Farms Ltd.

Box 459

Oliver, British Columbia V0H 1T0

CANADA

Dave Bainbridge

San Diego State University

Biology Department

San Diego, California 92182

Ruth Ball

Highway 21 Tree Farm

22556 Twp Rd 511

Sherwood Park, Alberta T8C 1H1

CANADA

Mishtu Banerjee

Scientificals Consulting

309-7297 Moffatt Rd.

Richmond, British Columbia V6Y 3E4

CANADA

Alice Barackman

IFA Nurseries, Inc.

1887 N. Holly Street

Canby, Oregon 97013

Jill Barbour

USDA Forest Service

National Tree Seed Laboratory

Rt. 1 Box 182B

Dry Branch, Georgia 31020-9696
Neil Barker

Pine Ridge Forest Nursery

P.O. Box 750

Smoky Lake, Alberta T0A 3C0

CANADA

Rolf Barten

Zeneca Agro

Uhland str. 15

61250 Usingen

GERMANY

John Bartok

University of Connecticut

NRME Dept, U-87

Storrs, Connecticut 06269-4087

Kay Beall

USDA-FS, Boise National Forest

Lucky Peak Nursery

HC 33 Box 1085

Boise, Idaho 83706

Wendy Bechner

Western Forest Systems, Inc.

1509 Ripon

Lewiston, Idaho 83501

Jane Belanger

Weyerhaeuser Research Center

505 N. Pearl

Centralia, Washington 98531

John Bennett

Plum Creek Forest Nursery

Box 188

Pablo, Montana 59855 
Brad Binges

University of Victoria

Department of Biology

P.O. Box 1700

Victoria, British Columbia V8W 2Y2

CANADA

Rob Bowden

B.C. Ministry of Forests

990 - Fort Street

Victoria, British Columbia V8W 3E7

CANADA

Kay Brady

Montana State Tree Nursery

Montana Dept. of State Lands

2705 Spurgin Road

Missoula, Montana 59801

Russ Braham

Pine Ridge Forest Nursery

P.O. Box 750

Smoky Lake, Alberta T0A 3C0

CANADA

Drew Brazier

B.C. Forest Service

Nursery Services

3-31 Bastion Square

Victoria, British Columbia V8W 3E7

CANADA

\section{Brian Bressan}

IFA Nurseries, Inc.

135 Old Nisqually Cut Off Rd.

Nisqually, Washington 98513

Jim Bryan

Weyerhaeuser Co.

7935 HW12 S.W.

Rochester, Washington 98579

Cheryl Bumgarner

Quinault Indian Nation

P.O. Box 189

Taholah, Washington 98587
Ian Cairns

Cowichan Lake Research Station

Box 335

Mesachie Lake, British Columbia V0R 2N0

CANADA

Dorothy Chapman

Weyerhaeuser Research Center

505 N. Pearl Street

Centralia, Washington 98531

John Chase

USDA-FS, Boise National Forest

Lucky Peak Nursery

HC33 Box 1085

Boise, Idaho 83706

Mike Clee

Bulldog Bag Ltd.

2651 No. 5 Road

Richmond, British Columbia V6X 2S8

CANADA

Bill Closson

USDA Forest Service, Genetic Resource Ctr.

2741 Cramer Lane

Chico, California 95928

Steve Colombo

Ontario Forest Research Institute

Ministry of Natural Resources

Box 969

1235 Queen Street East

Sault Ste. Marie, Ontario P6A 5N5

CANADA

Tom Corse

Bureau of Indian Affairs

P.O. Box A

Pablo, Montana 59855

Barry Court

Pine Ridge Forest Nursery

P.O. Box 750

Smoky Lake, Alberta T0A 3C0

CANADA 
Kim Creasey

Ministry of Natural Resources

Ontario Tree Seed Plant

P.O. Box 70

Angus, Ontario L0M 1B0

CANADA

Bert Cregg

USDA Forest Service

Center for Semiarid Agroforestry

East Campus - UNL

Lincoln. Nebraska 68583-0822

Tim Crockett

Washington DNR-Webster Forest Nursery

P.O. Box 47017

Olympia, Washington 98504-7017

Ken Curtis

State of Washington DNR

Webster Forest Nursery

P.O. Box 47017

Olympia, Washington 98504-7017

John Dennis

Natural Resources Canada

Canadian Forest Service

Pacific Forestry Centre

506 West Burnside Rd.

Victoria, British Columbia V3Z 1M5

CANADA

Dan Dolata

USDA-FS Lucky Peak Nursery

HC33 Box 1085

Boise, Idaho 83706

Mike Driscoll

Hood Canal Nurseries

P.O. Box 36

Port Gamble, Washington 98364

Ed Drummond

Green Tree Northwest

6200 Brooklake Rd. N.E.

Brooks, Oregon 97305
Kas Dumroese

Forest Research Nursery

University of Idaho

Moscow, Idaho 83844-1137

Raynald Durocher

Energie Verte Inc.

1465 Riviere Rouge Nord

Quebec, CANADA J0Z 2R0

John Edson

Forest Research Nursery

University of Idaho

Moscow, Idaho 83844-1137

Vic Elniski

Highway 21 Tree Farm

22556 TWP Rd. 511

Sherwood Park, Alberta T8C 1H1

CANADA

Paul Ensminger

State of Tennessee. Div. of Forestry

P.O. Box 306

Delano. Tennessee 37325

Bill Fangen

State of Washington DNR

Webster Forest Nursery

P.O. Box 47017

Olympia, Washington 98504-7017

Terry Finnerty

University of Idaho

Sandpoint Research \& Extension Center

2105 N Boyer

Sandpoint, Idaho 83864

Terry Garren

Bureau of Land Management

Horning Seed Orchard

27005 S. Sheckly Rd.

Colton, Oregon 97017 
Linda Geer

Forest Research Nursery

University of Idaho

Moscow, Idaho 83844-1137

Dave Gerdes

Silvaseed Company

P.O. Box 118

317 James Street

Roy, Washington 98580-0118

Ben Gibson

Bitterroot Native Growers

445 Quast Lane

Corvallis, Montana 59828

Lauchlan Glen

Reid Collins Nurseries

2396 272nd St.

Aldergrove, British Columbia V8W 2T9

CANADA

DeDe Grant

Potlatch Corporation

805 Mill Road

P.O. Box 1016

Lewiston, Idaho 83501

Steve Grossnickle

The Forest Biotechnology Centre

3650 Wesbrook Mall

Vancouver, British Columbia V6S 2L2

CANADA

Diane Haase

Nursery Technology Cooperative

Dept. of Forest Science

Oregon State University

FSL-020

Corvallis, Oregon 97330
Cindy Haddow

B.C. Forest Service

Nursery Services

3-31 Bastion Square

Victoria, British Columbia V8W 3E7

CANADA

Mark Haller

Kansas State \& Extension Forestry

Kansas State University

2610 Claflin Road

Manhattan, Kansas 66502

John Harrington

New Mexico State University

Mora Research Center

P.O. Box 359

Mora, New Mexico 87732

Lynne Hartman

USDA Forest Service

Genetic Resource Center

2741 Cramer Lane

Chico, California 95928

Ron Haverlandt

Cavenham Forest Industries

33671 S. Dickey Prairie Rd.

Molalla, Oregon 97038-9601

Chris Hawkins

B.C. Forest Service

Red Rock Research Station

RR \#7 RMD \#6

Prince George, British Columbia V2N 2J5

CANADA

Tom Helson

Northwood Pulp \& Timber Ltd.

Box 9000

Prince George, British Columbia V2L 4W2

CANADA 
Dave Henneman

Bureau of Land Management

P.O. Box 2965

Portland, Oregon 97208

Diane Hildebrand

USDA Forest Service, Region 6

P.O. Box 3623

Portland, Oregon 97208

Gary Hileman

USDA-FS. Boise National Forest

Lucky Peak Nursery

HC33 Box 1085

Boise. Idaho 83706

Jolyon Hodgson

Pelton Reforestation Ltd.

12930 - 203rd Street

Maple Ridge, British Columbia V3Z 1A1

CANADA

Suzanne Hostetter

Weyerhaeuser Research Center

505 N. Pearl St.

Centralia, Washington 98531

Jan Howe

Bureau of Land Management

Horning Seed Orchard

27005 S. Sheckley Rd.

Colton, Oregon 97017

Ralph Huber

B.C. Forest Service

Nursery Services

3-31 Bastion Square

Victoria, British Columbia V8W 3E7

CANADA

Kathy Hutton

Plants of the Wild

P.O. Box 866

Tekoa, Washington 99033
Bob James

USDA Forest Service

3815 Schreiber Way

Coeur d'Alene, Idaho 83814-8363

Tammy Jebb

Bureau of Land Management

Sprague Seed Orchard

1980 Russell Road

Merlin. Oregon 97527

Gary Johnson

USDA Forest Service

National Tree Seed Laboratory

Rt. 1 Box 182B

Dry Branch, Georgia 31020-9696

Bob Karrfalt

USDA Forest Service

National Tree Seed Laboratory

Rt. 1 Box 182B

Dry Branch, Georgia 31020-9696

Dick Karsky

USDA Forest Service

MTDC - Fort Missoula

Missoula, Montana 59801

Steven Kloetzel

Bitterroot Native Growers

445 Quast Lane

Corvallis, Montana 59828

Raphael Klumpp

Institute of Silviculture

Universitaet fuer Bodenkultur

Peter-Jordan-Str. 70

A-1190 Vienna

Austria

Harvey Koester

Bureau of Land Management

3040 Biddle Rd.

Medford, Oregon 97504 
Glenn Kranzler

Oklahoma State University

Biosystems \& Agricultural Engineering

Stillwater, Oklahoma 74078-0497

Bill Krelle

Calif. Dept. of Forestry \& Fire Protection

6640 Steiffen Road

Magalia, California 95954

Jim Kusisto

B.C. Forest Service

Skimikin Nursery

R.R. \#1, Site 13

Tappen, British Columbia V0E 2X0

CANADA

Denis Laflamme

Energie Verte Inc.

St. Andre Est, Quebec J0Z 2P0

CANADA

Pete Laird

USDA Forest Service

Timber, Cooperative Forestry \& Pest Mgmt.

P.O. Box 5895

Missoula, Montana 59801

Jack Lajoie

USDA Forest Service

J.H. Stone Nursery

2606 Old Stage Road

Central Point, Oregon 97502

Tom Landis

USDA Forest Service

Cooperative Forestry

P.O. Box 3623

Portland, Oregon 97208-3623

Denis Lavender

Emeritus Professor of Forest Science

3925 Fairhaven Dr. S.W.

Corvallis, Oregon 97333-1431
Scott Lee

Forestry Fisheries \& Wildlife

University of Nebraska Lincoln

Center for Semiarid Agroforestry

East Campus-UNL

Lincoln, Nebraska 68583-0822

Annette Leege-Brusven

Forest Research Nursery, University of Idaho

Moscow, Idaho 83844-1137

Stephen Leong

Westgro Sales

7333 Progress Way

Delta, British Columbia V4G 1E7

CANADA

Laurie Lippitt

L.A. Moran Reforestation Center

California Dept. Forestry \& Fire Protection

P.O. Box 1590

Davis, California 95617

Eric Lloyd

Zeneca Agro

400 Jones Road

Box 9910

Stoney Creek, Ontario L9C 3Z1

CANADA

Ruth M'Gonigle

Bitterroot Native Growers

445 Quast Lane

Corvallis, Montana 59828

Richard Marchand

Colville Confederated Tribes

P.O. Box 150

Colville Indian Agency

Nespelem, Washington 99155

Mario Martin

IFA Nurseries, Inc.

463 Eadon Rd.

Toledo, Washington 98591 
Rod Massey

Industrial Forestry Service Ltd.

1595 5th Avenue

Prince George, British Columbia V2L 3L9

CANADA

Kathy Mattson

Potlatch Corporation

805 Mill Road

P.O. Box 1016

Lewiston, Idaho 83501

Bryon McCarthy

Beaver Plastics Ltd

12150 - 160 Street

Edmonton, Alberta T5V $1 \mathrm{H} 5$

CANADA

Sharon McFadden

Potlatch Corporation

805 Mill Road

P.O. Box 1016

Lewiston, Idaho 83501

Bob Merrell

B.C. Forest Service

Green Timbers Nursery

14255 - 96 Ave.

Surrey, British Columbia V3V $7 Z 2$

CANADA

Carol Miller

Native Plants Nursery

Joshua Tree National Monument

Twenty-nine Palms, California 92277

Randy Moench

Colorado State Forest Service Nursery

CSU - Foothills Campus, Bldg. 1060

Fort Collins, Colorado 80523

Mark Montville

Plum Creek Forest Nursery

P.O. Box 188

Pablo, Montana 59855
Sue Morrison

Forest Research Nursery

University of Idaho

Moscow, Idaho 83843-1137

Joe Myers

Coeur d'Alene Nursery

USDA- FS, Idaho Panhandle National Forest

3600 Nursery Rd.

Coeur d'Alene, Idaho 83814

Al Nanka

Canadian Forest Service

Northern Forestry Centre

5320-122 St.

Edmonton, Alberta T6H 3S5

CANADA

Betty Norlander

USDA Forest Service

3600 Nursery Rd.

Coeur d'Alene, Idaho 83814

Debbie Page-Dumroese

USDA Forest Service

Forestry Sciences Laboratory

1221 S. Main

Moscow, Idaho 83843

Tom Paro

Confederated Salish \& Kootenai Tribes

Box 235

Ronan, Montana 59864

Steve Pelton

Pelton Reforestation Ltd.

12930 - 203rd Street

Maple Ridge, British Columbia V3Z 1A1

CANADA

Chris Peterson

Blandin Paper Co.

P.O. Box 407

Grand Rapids, Minnesota 55744 
Joni Peterson

Bitterroot Native Growers

445 Quast Lane

Corvallis, Montana 59828

Michael Peterson

Applied Forest Science Ltd

4417 Bennett Road

R.R. \#1

Victoria, British Columbia V9B 5T7

CANADA

Jim Plampin

Quinault Indian Nation

P.O. Box 189

Taholah, Washington 98587

Ron Powell

$\mathrm{K} \& \mathrm{C}$ Silviculture Farms Ltd.

Box 459

Oliver, British Columbia V0H 1 T0

CANADA

Kenneth Quick

Forest Research Nursery

University of Idaho

Moscow, Idaho 83844-1137

Tony Ramirez

IFA Nurseries, Inc.

463 Eadon Rd.

Toledo, Washington 98591

Nita Rauch

USFS - Bend Pine Nursery

63095 Deschutes Market Road

Bend, Oregon 97701

Richard Regan

Oregon State University

North Willamette Research \& Extension Center

15210 NE Miley Road

Aurora, Oregon 97002
Fernando Rey

Pelton Reforestation Ltd.

12930 - 203rd Street

Maple Ridge, British Columbia V3Z 1A1

CANADA

Mike Rigney

Oklahoma State University

Biosystems and Agricultural Engineering Dept.

$215 \mathrm{Ag}$. Hall

Stillwater, Oklahoma 74078

Lee Riley

USDA Forest Service

Dorena Tree Improvement Center

34963 Shoreview Rd.

Cottage Grove, Oregon 97424

Victoria Rockwell

USDA Forest Service

Portland, Oregon 97208

Dennis Rodocker

Nebraska National Forest

Bessey Nursery

P.O. Box 38

Halsey, Nebraska 69142

Jane Rogers

Native Plants Nursery

Joshua Tree National Monument

Twenty-nine Palms, California 92277

Jim Rosenberry

Nebraska National Forest

Bessey Nursery

P.O. Box 38

Halsey, Nebraska 69142

Don Roubos

Zeneca Agro

35296 McKinley Place

Abbotsford, British Columbia V3G 1B3

CANADA 
Victor Sahakian

Monrovia Nursery Co.

13455 S.E. Lafaytte Hwy.

Dayton, Oregon 97114

Chris Santana

Monrovia Nursery Co.

13455 S.E. Lafaytte Hwy.

Dayton, Oregon 97114

Janice Schaefer

Western Forest Systems, Inc.

1509 Ripon

Lewiston, Idaho 83501

Richard M Schaefer III

Western Forest Systems, Inc.

1509 Ripon

Lewiston, Idaho 83501

Marla Schwartz

North Woods Nursery Inc.

P.O. Box 149

Elk River, Idaho 83827-0149

George Shikaze

Vancouver Bio-Machine Systems Ltd

Unit 107

13375 - 76th Ave.

Surrey, British Columbia V3W 6J3

CANADA

David Simpson

B.C. Ministry of Forests

Kalamalka Res. Sta.

3401 Reservoir Road

Vernon, British Columbia V1B 2C7

CANADA

Ray Skochelas

Zeneca Agro

400 Jones Road

Box 9910

Stoney Creek, Ontario L9C 3Z1

CANADA
John Sloan

USDA Forest Service

Intermountain Research Station

316 E. Myrtle

Boise, Idaho 83702

Mike Smith

DNR Forest Resources

Reforestation Section

P.O. Box 47018

Olympia, Washington 98504-7018

Irwin Smith

Lustr Co-op

Lakehead University

955 Oliver Rd.

Thunder Bay, Ontario P7A 5J5

CANADA

Brad Smith

Zeneca Agro

400 Jones Road

Box 9910

Stoney Creek, Ontario L9C 3Z1

CANADA

Jeff Snyder

Lava Nursery Inc.

P.O. Box 370

Parkdale, Oregon 97041

John Stein

USDA Forest Service

800 Buchanan Street

West Building

Albany, California 94710-0011

Dale Stephens

Holiday Tree Farms Inc.

800 N.W. Cornell Ave.

Corvallis, Oregon 97330 
Wanda Stewart

USDA-FS, Boise National Forest

Lucky Peak Nursery

HC33 Box 1085

Boise, Idaho 83706

Ernst Stjernberg

Forest Engineering Research Institute of Canada 2601 East Mall

Vancouver, British Columbia V6T 1 Z4

CANADA

Hans Stoffelsma

Arbutus Grove Nursery Ltd.

9721 W. Saanich Rd.

Sidney, British Columbia V8L 3S1

CANADA

Kent Stralbiski

K \& C Silviculture Farms Ltd

RR \#1 Box 459

Oliver, British Columbia V0H 1T0

CANADA

Dawn Stubley

B.C. Forest Service

Surrey, British Columbia V3V $7 Z 2$

CANADA

Don Summers

B.C. Forest Service

Nursery Extension Services

14275 - 96 Ave.

Surrey, British Columbia V3V 7Z2

CANADA

David Swain

Pacific Regeneration Technologies Inc.

Harrop Nursery

S 20, C 44 RR \#3

Nelson, British Columbia V1L 5P6

CANADA
Henry Switzer

USDA Forest Service

Genetic Resource Center

2741. Cramer Lane

Chico, California 95928

Dick Thatcher

USDA-FS, Boise National Forest

Lucky Peak Nursery

HC33 Box 1085

Boise, Idaho 83706

Kendel Thomas

B.C. Forest Service

Nursery Services

R.R. \#7 RMD 6

Prince George, British Columbia V2N 2J5

CANADA

Gale Thompson

Weyerhaeuser

Rochester Regeneration Center

7935 Highway 12 SW

Rochester, Washington 98579

Gary Townsend

Glass Mountain Forest Nursery

P.O. Box 440

St. Helena, California 94574

Dave Trotter

B.C. Forest Service

Nursery Extension Services

14275 - 96 Ave.

Surrey, British Columbia V3V $7 Z 2$

CANADA

Tom Tucker

USDA-FS, Boise National Forest

Lucky Peak Nursery

HC33 Box 1085

Brise, Idaho 83706 
Tootie Turner

USDA-FS, Boise National Forest

Lucky Peak Nursery

HC33 Box 1085

Boise, Idaho 83706

Brenda Udy

Plants of the Wild

P.O. Box 866

Tekoa, Washington 99033

Peter Vackomies

K \& C Silviculture Farms Ltd.

Box 459

Oliver, British Columbia V0H $1 \mathrm{TO}$

CANADA

Ev Van Eerden

Pacific Regeneration Technologies Inc.

\#4-1028 Fort Street

Victoria, British Columbia V8V 3K4

CANADA

Eric Van Steenis

B.C. Forest Service

Nursery Extension Services

14275 - 96 Ave.

Surrey, British Columbia V3V 7Z2

CANADA

Victor Vaukus

Nat'l Tree Seed Laboratory, U.S. Forest Service

Rt. 1 Box 182B

Dry Branch, Georgia 31020-9696

Johan Visser

J. H. Stone Nursery, U.S. Forest Service

2606 Old Stage Rd.

Central Point, Oregon 97502

Debbie Wagner

Montana State Tree Nursery

Montana Dept. of State Lands

2705 Spurgin Rd.

Missoula, Montana 59801
Bevin Wells

B.C. Forest Service

Nursery Extension Services

14275 - 96 Ave.

Surrey, British Columbia V3V 7Z2

CANADA

Dave Wenny

Forest Research Nursery

University of Idaho

Moscow, Idaho 83844-1137

Sheri Whiting

Confederated Salish \& Kootenai Tribes

Box 235

Ronan, Montana 59864

John Wiens

Reid Collins Nurseries

2396 272nd Street

Aldergrove, British Columbia V8W 2T9

CANADA

Tony Willingdon

B.C. Forest Service, Surrey Nursery

3605 - 192 Street

Surrey, British Columbia V4P 1M5

CANADA

Farrell Wise

Westvaco Corporation, Forest Research

P.O. Box 1950

Summerville, South Carolina 29484

Barry Wood

Pine Ridge Forest Nursery

P.O. Box 750

Smoky Lake, Alberta T0A 3C0

CANADA

Cathy Wright

Alaska Plant Materials Center

Division of Agriculture

HCO2, Box 7440

Palmer, Alaska 99645 
Arne Aiking

BCC Sylviculture Systems Inc.

789 Don Mills Road, Suite 700

Toronto, Ontario M3C 3L6

CANADA

Paul Bennett

Baertschi of America, Inc.

P.O. Box 1099

Gatlinburg, TN 37738

Mark Crawford

Griffin Corporation

Rocky Ford Road

Valdosta, GA 31603

Ed Danzer and Josh Englund

Danzco

1006 - 143rd Ave. S.E.

Tenino, WA 98589

Linda Dean

Electronic Data Solutions

P.O. Box 31

Jerome, ID 83338

Bob Decker

The Old Mill Company

12011 Builford Road, Suite 102

Annapolis Junction, MD 20701

Alonzo Dupuis

Jiffy Products Ltd

P.O. Box 360

Shippagan, N.B. E0B 2P0

CANADA
Mike Gerdes

Silvaseed Company

P.O. Box 118

Roy, WA 98580-0118

John Giraud

Target Products Ltd

7550 Conrad Street

Burnaby, B.C. V5A 2H7

CANADA

Greg Henderson

Jiffy Products

111 MacDonald Ave.

Sault Ste. Marie, Ontario P6B 1H2

CANADA

Randall Jones

Griffin Corporation

10375 Richmond Ave., Suite 1215

Houston, TX 77042

Bert Klassen

Drader Manufacturing Industries Ltd 241 - 76 Avenue N.W.

Edmonton, Alberta T6P 1P2

CANADA

John Lawyer

Lawyer Nursery, Inc.

950 Highway 200 West

Plains, MT 59859-9706

Dana Main

J.M. McConkey and Company

P.O. Box 1690

Sumner, WA 98390 
Paul O'Neill and Mike Kadwell

Beaver Plastics Ltd

12150 - 160 Street

Edmonton, Alberta T5V $1 \mathrm{H} 5$

CANADA

Michelle Oliveira

Black Gold, Inc.

19308 Highway 99 E

Hubbard, OR 97068

Jim Reid

Inno-Tec

R.R. 6, Site 6, Box 9

Thunder Bay, Ontario P7C 5N5

CANADA

Brian Steele

B \& W Greenhouse Construction Ltd 26950 - 16th Ave.

Aldergrove, B.C. V4W 2S3

\section{CANADA}

Wayne Stewart

Wilbur-Ellis

E. 12001 Empire Ave.

Spokane, WA 99206

Kurt Spingath

Wilbur-Ellis

E. 12001 Empire Ave.

Spokane, WA 99206

Eric Stuewe

Stuewe and Sons Inc.

2290 S.E. Kiger Island Road

Corvallis, OR 97333
Jerry Walters

Plant Pro-Tec Inc.

24389 Racoon Way

Oak Run, CA 96069

Ralph White

Paravant Computer Systems, Inc.

780 South Apollo Blvd., Atrium One

Melbourne, FL 32901

Terry Wood

Westgro Sales

7333 Progress Way

Delta, B.C. V4G 1E7

CANADA

Al Zylstra

Growth Zone Systems

1719 Highway 99 S

Mount Vernon, WA 98273 


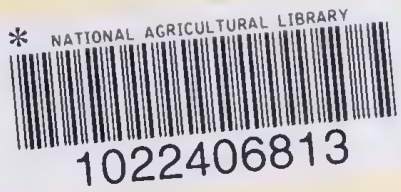




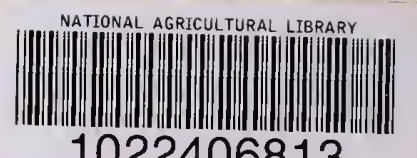

1022406813 